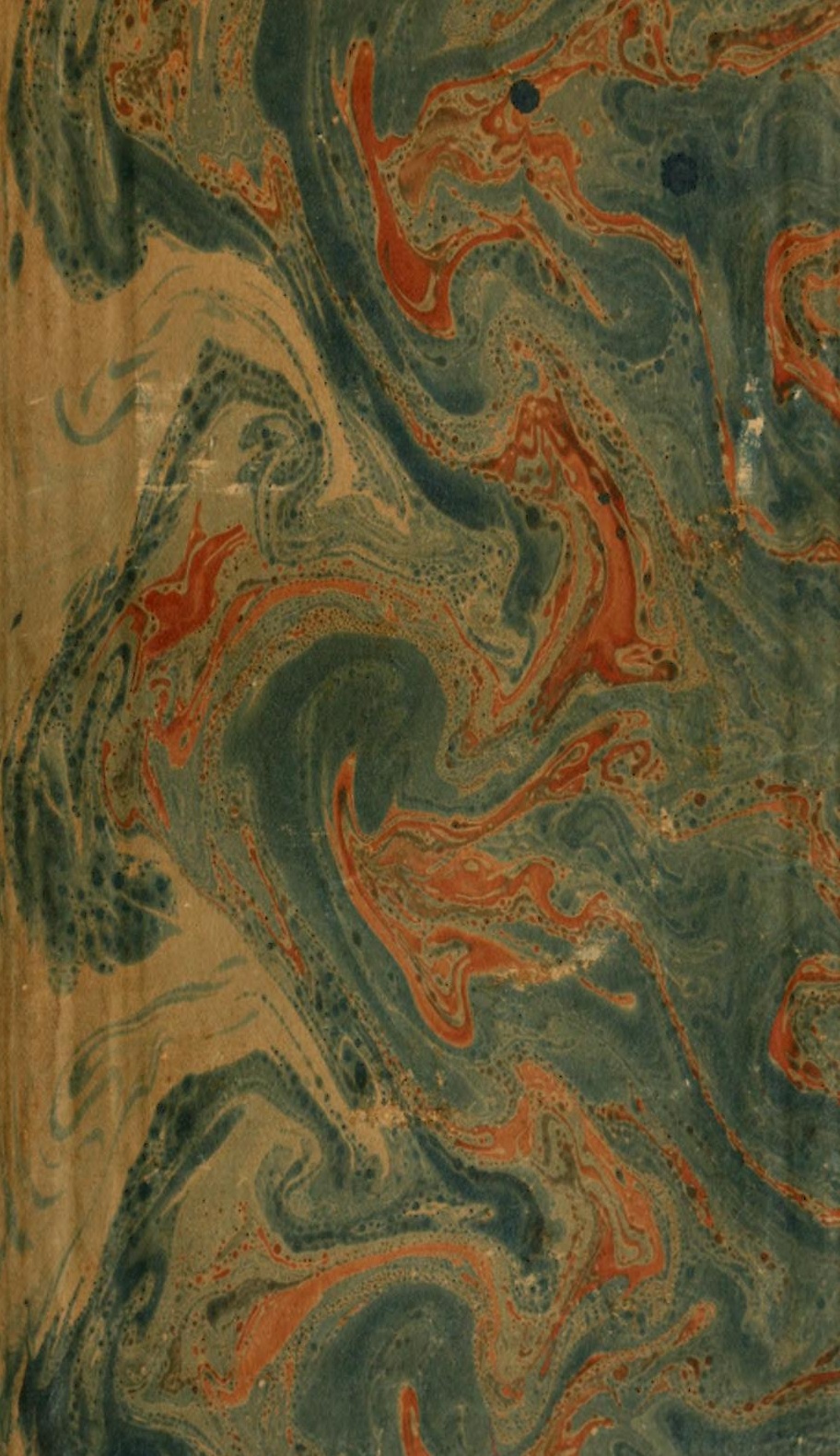




\section{Smithsonian Institution Sibraries}

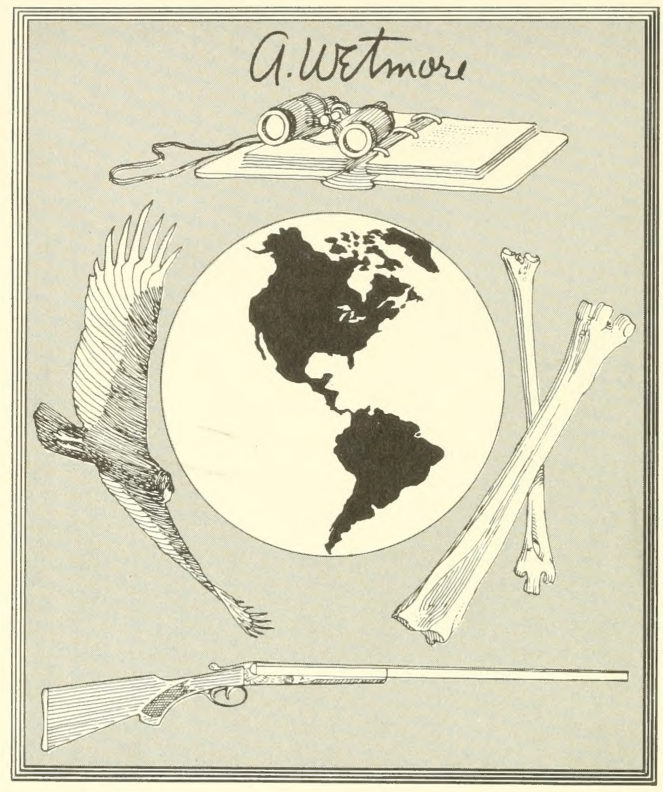

Alexander Wetmore 1946 Sixth Secretary 1953 3 




\section{LES NOMS}

\section{DES OISEAUX}

expliqués par leurs moeurs.

ESSAIS ÉTYMOLOGIOUES SUR L'ORNITHOLOGIE 




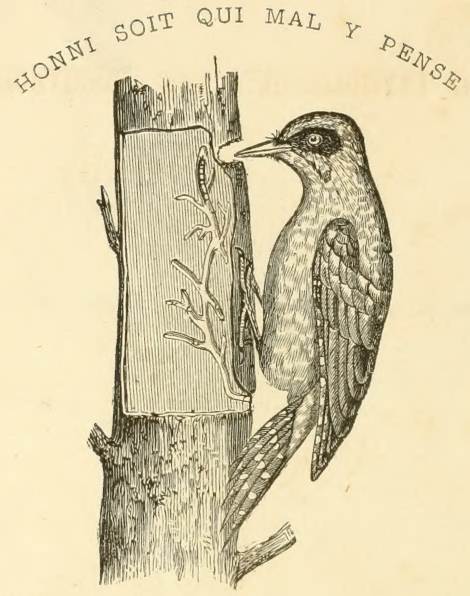

PIC-VERT A LA RECHERCHE D'UNE LARVE. 


\title{
xis NOMS
}

pres

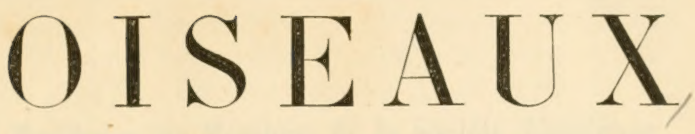

EXPLIQUES PAR LEURS MOEURS

OU

\section{ESSAIS ÉTYMOLOGIQUES SUR L'ORNITHOLOGIE}

\author{
PAR
}

L'ABBÉ VINCELOT, Michel Hon ore Chanoine honoraire, aumonier de la pension Saint-Julien, membre de la Société Lináénne de Maine-et-Loire.

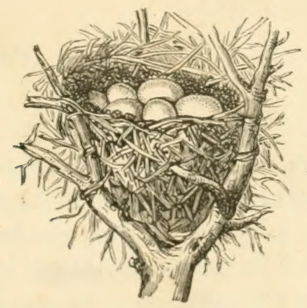

TROISIËME ÉDTTION

ENTIEREMENT REFONDDE ET ORNEE DE ORAVURES

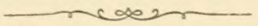

ANGERS

I MPRTMERIE P. LACHĖSE, BELLEUVRE ET DOLBEAU 13, Chaussée Saint-Pierre, 13

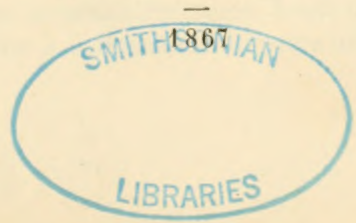





\section{A Messienrs les Hembres de la Société Limnéenne de Maine-el-Loire.}

\section{Messicurs,}

Dans mes études sur l'oriithologie, j'ai été sonvent arreti far certaines dinnminations domners aux oisean, denominations qui me paraissaient plus ou moins (ubscures; ansi ai-je pensí qu un tratsial dont le but trondrait it dimontrer que ces mots, vulgaires nu savante, somt lindes sur quelyues particularités des merurs gu du plumage des viscaux, ne serait dénú ni d’intrírt ni d'utilití. Ces notes pourront mème contribuer it rendere lis ditiments de cette scimee plus liciles of muins arides, en associant at chanem de ers noms des notions propures a raractíniser les oiseaux, of it montrer ansi l'action le lit Providence lì vù les naturalistes ne vinent trop sunten! Ifue bizarrerie ou caprice. Cest done sous lempire de entte pensie que jai entrepris le travail dont je viens

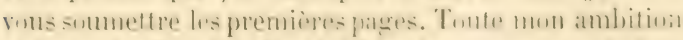

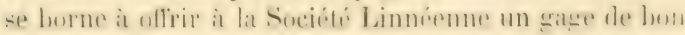


vouloir, et à indiquer une route que d'autres parcourront ensuite avec plus de science et de succès.

Dansl'espoir aussi que ce travail servira de complément à la Faune de Maine-et-Loire, je donnerai des notions sur la couleur, la forme, les dimensions des œufs et la construction des nids de chaque espèce d'oiseau. Je ferai aussi entrer dans cette nomenclature quelques faits ou quelques renseignements nouveaux pour la rendre moins sèché et plus intéressante. Quant à la classification, je suivrai celle qui a été adoptée par M. Millet, dans sa Faune de Mlaine-ct-Loire, sans que je veuille en justifier ni en attaquer les principes.

(En tête de la première edition, mars 1857.) 


\section{A MIES LECTEURS}

Les quelrues lignes qui préèdent ont éti récrites il y a plus dr huit ans. Elles expriment en toute simpliciti le hut que je me proposais, et le plan que je devais suive. Depuis cette épurue, de numelles pages sont venues sucressivement sajouter aux promières, et, jusqu'ì refte année, elles n'avaient motivé ancune contradiction ni souleré aucune tempête. Encouragé par un qrand nombre le naturalistes, je continuais lentement mon moleste fravail, quand je me suis truuvi tuat à coup en présenee d'objections qui s'ilevaient devant moi comme une barrière formirlahle. Cés ohjections ont íté suscitées par mon Mémoire sur les llouettes et sur les Mésanges, Memoire envoyi an concours d'histoire naturelle fondi par la bienseillance du Conseil greneral de Maine-elLripe . Je me suis alors demandi si ces observations

${ }^{1}$ Ce Mémoire se trouve reproduit dans ce volume, avec quelques moditieations. 
devaient m'arrêter dans la réalisation de mon travail ou me forcer à en modifier le plan. Après avoir réfléchi, j’ai pris la résolution de suivre la même route que par le passé. Mais je crois, dans l'intérêt de la vérité, devoir examiner rapidement les objections que l'on formule contre moi, en essayant d'y répondre.

On me reproche de m'appuyer sur un principe faux, en paraissant admettre que tous les noms scientifiques et vulgaires des oiseaux représentent une idée caractérisée par leur dénomination, d'être téméraire dans mes liypothèses sur les étymologies, ot de creuser ainsi un abîme dangereux.

S'il s'agissait d'un symbole de foi ou d'un principe dautorité infaillible, je m'inclinerais respectueusement devant la décision de mes juges; mais ici, je puis discuter sans m'exposer à encourir d'autre note que celle de téméraire. J'accepte volontiers cette responsabilité.

D'abord, je reconnais bien naïvement que la première accusation est fondée, et très-fondée. Oui, j’ai cru, et je crois encore que les noms des oiseaux, dans les langues savantes et dans les langues vulgaires, doivent représenter une particularité du plumage, de la nourriture, des mœurs, etc., de ces habitants de l'air. Voici le raisonnement sur lequel je croyais pouroir fonder ma convietion: Ou le nom a été donné par un savant, ou il est employé par les habitants des campagnes. Dans le premier cas, il me paraît difficile d'admettre qu'un savant ait donné à un oiseau, pour le déterminer, un nom n'ayant. aucune signification, et que cette expression, vide de sens et fruit d'un caprice que rien ne pouvait justifier, ait été admise par tous ceux qui s'occupent d'ornithologie. D'où je concluais que, si quelques noms scientifiques nous apparaissent maintenant dénués de signification, c'est qu'ils ont pu etre modifiés, dénaturés 
feut-îtee, et qu'avere de lat patienee el une épulition plus rate et plus etendue que la miemme, on fonrrait retrouver le nom frimitil modifié dans le parcours des siècles.

Dans le proces que lion m'intente, je pourrais invoquer comme témoin à décharge le mot cirlus, employi four désisner le bruant. Cette démomination, que lion sontenait stre vide de sens, ne se trouve dans aucun diclionnaire, et cependant elle rejuésente me idée juste et ditermine, d'une manière précise, l'oiseau dont il s'agit. Le mot cirlus, comme beaucoup d'autres, s'est moriffie en traversant les siècles. P'our revenir au point de dipart, je me suis appliqué à étudier avec une attention soutenue les mœurs du bruant, et j'ai cherché à trouser, en ubservant les habitudes de cet oiseau, le fil qui desait me ronduire diuns le dédale de mes investigations. Cirice au concours de quelques annis el à ma persévérance, jai ju retrouver l'acte de naissance du mot cirlus.

Cirlus me semble venir naturellement de kithotos, cillurus, d'vì, par transposition des liquides, on obtient cirrulus, et par al)réviation cirles. Or, killotios a pour racine Kellô, " se mouvoir, " et ounA, "queue, " exfrrssions qui représentent exactement l'une des habitudes du bruant. Ciet oiseau se tient très-sourent at l'oxtrimiti des branches des haies et des arbres, sur le bord des ruutes, et il duit it cette position un mourement fresque enntimur quile fait ressembler au hoche-puene. Mais la rarrine kel.tò a fourni le derivé kntous, cielus, "ìne, bourrique; "la liquider a ju se sulsstituer dans ce mot à la première des dems liquides l, et alors or: oblient cirlus, yui sisnifierait: "stupide comme un ine. Erossier comme une hourrique. " Cette upinion est corroborre pare le mot cirliscus, allongement sirlent de cirlus. Cirliscus se trouve dans les glus-aires avec la signification de "patsan, rustre." Entin, en Italie, selon 
l'autorité d'Aldrovande, le bruant est appelé matto, c'està-dire, stultus, "sot, imbécile, " et l'une des espèces du bruant porte partout le nom de fou.

Cette explication fait connaître, d'une manière trèsplausible, les habitudes du bruant, lequel paraît dénué des qualités que l'on remarque dans la plupart des oiseaux. Son air niais et stupide, la position qu'il affectionne le plus ordinairement, enfin, son chant, qui est plutôt un cri rauque, monotone et continu, lui enlève toute espèce de sympathie. En Lorraine; on appelle brouant ou bruant la crécerelle, ce qui prouve combien le chant du bruant est fatigant. Il est probable que les naturalistes ont trouvé avec raison quelque ressemblance entre le chant du bruant et le cri de l'âne. C'est peutêtre à cause de ce rapprochement que le bruant a reçu dans certains pays le nom de bréant, " oiseau qui brait comme un âne. ") Du reste, le nom qui lui est donné généralement, bruant, indique que les naturalistes ont tous été frappés du peu d'harmonie qu'offre son chant.

Quand je traiterai l'article de cet oiseau, je donnerai sur ce sujet des développements plus complets.

Maintenant, je passe à la deuxième partie du dilemme énoncé précédemment, et je crois pouvoir affirmer que si les noms vulgaires des oiseaux ont été donnés et admis par les gens de la campagne, ils représenteront, sous une forme pittoresque ou même grotesque, une idée juste, une habitude caractéristique. Le villageois, le montagnard, le marin se servent d'expressions trèsprécises pour peindre dans leur langage les oiseaux et les animaux, dont ils ont surpris les habitudes bien plus exactement que le savant qui ne les étudie que dans son cabinet. Les preuves évidentes de cette assertion se présenteront bien souvent dans le cour's de ce travail. 
Mon but étant connu, je devais travailler à l'atteindre: c'est alor's que les moyens que j'ai employés m'unt fait encourir l'accusation de tíméraire. Cette accusation, je ne puis la repousser entièrenınt; eependant voici mes moyens de justification :

Les étymologies contenues dans ce travail sont de trois sortes. Les premières offrent une complète certitude; je les ai dès lor's présentées affirmativement, sans restriction aucune. Telles sont celles de catharte, de proglosses, de latirostres, de muscicapa, de fauvette, et d'une foule d'épithètes, comme brachyote, appliquée au hibou, de percnoptère, au vautour, d'hepaticus, au coucou, de mbicola, au trayuet, de rustica, de domestica, d'urbica, de rupestris, à l'hirondelle, ete., etc. D'autres sont douteuses : j’ai rappelé les sentiments divers des principaux auteurs dont elles ont exercé lit pénétration ; j’y ai parfois ajouté mes propres conjectures, mais avec des formules indiquant une grande réserve. Telles sont les étymologies d'hirondelle, de martinet, de mésange, d'aloutte, etc.

Lorsqu'une opinion m'a paru plus probable que les autres, j'ai indiqué de quel côté j'inclinais. Dans l'incertitude, j'ai laissí, comme je derais le faire, le choix au lecteur. Enfin, j’ai conservé quelques étymologies éridemment crronies : telle est en particulier celle de nonnette, nome, tirée par Martinius de Noḱô, soùs, et celle d'hippoluis, citée par Niphus, que j’ai pris soin de rejeter. Elles servent à préciser l'état de la science étymolugique dans les derniers siecles par rapport ì l'ornithologie, it montrer lia route parcourue, et à íviter, à ceux qui voudraient s'y engager, la tentation de retomber dans les mêmes prreurs. Si au nombre des étymulogies certaines j'en ai rangí de douteuses ou de fausses, je mempresserai de profiter des abservations qui pourraient mötre faites ì cet égard. C'est ainsi que, daus 
cette seconde édition, j’ai rejeté une étymologie fausse de boarula ou boarina, et une autre d'hippolaïs. Par là je témoigne assez de la circonspection (qu'il faut, sans iucun doute, apporter dans ces sortes de recherches. Où donc est l'abîme que l'on m'accuse de creuser? Fautil renoncer à poursuivre l'application d'un principe que je persiste à croire juste, le sens réel des noms employés dans l'ornithologie, parce qu'il est ì craindre que l'on ne tombe en quelque erreur? J'espère, au contraire, avoir fait naître dans le cœur de mes jeunes lecteurs le désir d'étudier l'ornithologie de notre bel Anjou, en leur' indiquant une route non encore parcourue et tout ce qui reste à faire sous ce rapport. J'ose espérer même que je pourrai rendre à la science en général un modeste service, et j'ai poursuivi avec d'autant plus de confiance la réalisation de mon plan, que j'y avais été encouragé par de graves autorités.

Dans la visite que j'avais faite au docteur Dégland, auteur d'une sarante Ornithologie des oiseaux de l'Europe, il m'avait adressé des paroles très-propres à me fortifier dans l'exécution de mon plan : "Depuis plus de " 60 ansj'étudie l'ornithologie, - me disait le savant pro" fesseur de Lille : - j'ai consacré à cette étude tous mes " loisirs; mais si Dieu devait prolonger encore ma vie " de quelques années, j'avoue que je ne comprendrais "plus rien aux ouvrages nouveaux, et que je serais forcé " de me remettre sur les bancs; et alors quel maître de"vrais-je prendre, puisque chacun se crée une langue " et formule de nouvelles classifications? Peut-être, " ajouta-t-il en souriant, - mon âge me porte-t-il plutôt à " consolider les vieux monuments, qu'à travailler à en " construire de nouveaux. Courage! si votre travail " fait naître la pensée d'entreprendre une étude géné"rale sur l'étymologie des mots légués à l'ornithologie "par l'antiquité, peut-être sera-t-on moins tenté de les 
" changer quand on aura la preuve qu'ils renferment une "signifieation sériense. ) P'lus tard, el it diffirentes fors, II. Bailly, aussi modeste qu'instruit, auteur de l'Orni-

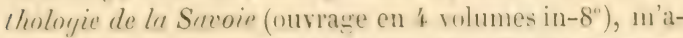
vait, le vise roix et par éerit, pressé, sollicité de pourstrive un tratail gu il regardait comme nouseau et comme intéressant. I ees nums je pourrais joindre ceux de .III. Fairmaire, Catire, Crespon et de bien d'autres. Mais je résume toutes ces auturités dans celle de . M. Muyuin-Tandon. Cesarant professeur de la Facultó de l'aris, dunt l'erudition était si profonde et si varie, avait bien voulu, dims une fuule de cirennstances, timoigner, is mon honorable ami X. Riunl de Barace et ì moi-mème, l’intérèt qüil prenait it mon travail. "J'ai reçu, - m’erivait-il, - votre brochure, maximu cum lestitin, avec une tris-grande satisfaction. "Il me pressa de ne pas me laisser arriter par les difficultís ni par les contradictions. l'our me donner une preuve de sa sympathie, il m'uffrit un tris-bel exemplaire, in-folio, de l'ourrage d'Aldrorande. "Tris-probablement, - me dit-il, - volls ne " trouverez pas cet omrage dans la hibliothequed'Angers, " et, quoiqu'il suit le seul exemplaire que je pussìde, je " vous loffre puur ruus prourer que japhrécie votre étude, " et que je disire contribuer ì vous en rendre laceom"plissement muins difficile." Il fit plus. Avant sit mort, il avait pris soin de líguer sa bienveillance pour mon travail ì un de ses meilleurs amis, en le priant de mettre à ma disposition et sa bonne monté ef son érudition.

Jo me suis peut-ître trup ítemlu sur ces létails; mais

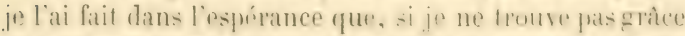
au trihumal de mes juges, je pumrat du moins junir du bénéfice des circonstances atténuantes.

lit si quelyues tem rites meme mititent ichappres, olles ne seraicht sans dutute pas lansereuses : mes jeune- 
lecteurs, sans être nulle part égarés par une affirmation absolue, les attribueraient avant tout à mon désir de les intéresser, comme ils verraient, dans l'ouvrage entier, une preuve de dévouement et de vive sympathie, une pensée de foi fondée sur la sagesse de Dieu et sur l'action de la Providence.

(Préface de la deuxième édition, 1865.) 


\section{PRÉFACE}

DE CFTTE NOUVELLE IEDITION

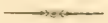

J'avais eru devoir soumettre au jugement de mes lecteurs les observations qu'on vient de lire, lorsorue je fis imprimer la deuxième édition de mes études ornithologiques. Aujourd'hui que je leur offre un volume beaucoup plus complet que ceux qui l'ont préredí, je n'ai rien a changer dans mes convictions; mats, jour me rapprocher autant qüil mótait possible de la méthode préconisée par mes contradicteurs, jessaierai iin puiser dans les langues primitives les renseignements qui me paraîtront propres à jeter un certain intérêt sur mon modeste travail.

Pour répondre au désir d'un grand nombre de me: amis, j’ai lait représenter par des vignettes les principaus types des oiseaux dont je décris les mœurs.

De plus, afin de ne pas śluigner de cette lecture les frersunnes qui ne sont pats initiés à lat langue erecque, f'ai remplacé les cartetères de cet idiome par cenx de notre langue, et j'ai représenté les mots grecs en petites lettres capilales. Cette manière dócrire le grec en fran- 


\section{$-12-$}

anis rembra plus laciles pun tout le monde les compratratisons d'une langue a l'antre, at permettra de suive sanseffont les divers changements, altreations ou accroissements que les mots ont subis puur venir jusqu a mus. Yuant anx hellinistes, j'espereque rien ne leur sera plus atisé que de retrourer le mot gree sous la figure frangraise.

Ces molifications importantes mont determine à réimprimer ausis, augmentie de renseignements nouveaux el multipliés, la première partie de mon tratsail, afiu qu'elle pût s'harmoniser avec la seconde et former aver elle un tout homogène.

Ilai 1867. 


\section{LES NOMS}

\section{DES OISEAUX}

expliqués par leurs moeurs.

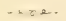

ESSAIS ETYMOLGIQUES SUR L'ORNITHOLOGIE

\section{PRENIER ORDRE. - RAPACES}

Le mot générique Rapaces vient du latin rapax, qui luimême dérive du grec manpax, " ravisseur, " dont l'une des racines est HARPÉ, "faulx de guerre, " arme terrible dont les anciens entouraient leurs chariots, pour semer la terreur et la mort dans les rangs ennemis. Cette dernière dénomination, qui indique les habitudes des rapaces, dont le bec moissonne tant de victimes, exprime si bien la pensée des naturalistes, que ceux-ci l'ont consacrée en donnant à cet ordre tout entier le nom de Faucon, falco, qui découle de falx, "faulx. »

Ce premier ordre se partage en Rapaces nocturnes ou Egoliens, et Rapaces diurnes ou Accipitrins. 


\section{PREMIERE FAMILLE.}

\section{Gapaces nocturnes ou Egoliens.}

Le premier de ces mots s'explique naturellement par le senre de vie rie ces oiseaux, qui chassent pendant le ammencement de la muit, nox, noctis, srks, xxктоs, "la nuit, " d'où l'adjectif xskténos, qui leur a fait encore donner le nom de myctérins. L'ípithète crépusculaires conviendrait mieux à ces rapaces et pourrait être plus facilement justifice; car aucun oiseau ne cliasse d'une manière régulière pendant les véritables ténèhres de la unit, mais seulement pendant les heures du crépuscule, ct prolonge ou abrége cette chasse selon les ressources qu'elle lui procure, et aussi selon les besoins de sa progíniture plus ou moins nombreuse. Pour que les rapaces nocturnes puissent s'y livrer avec plus de succès, Dicu les a doués d'une vue perçante et d'une ouïe très-fine. Cihez cux, le pavillon de l'oreille est remplacé par des plumes très-mobiles, et dès lors ils peurent fermer et ourir à volonté la conque auditive; c'est une porte, en quelque sorte, qu'ils ourrent pendant la nuit et qu'ils ferment pendant le jour. La nature floconneuse de leur's plumes permet à l'air de cireuler entre clles sans iprouver de résistance, ni oceasiommer le moindre bruit qui pourrait avertir el éloigner les mulots, les gros insectes, etc. Leurs ailes, arrondies et uniformément concaves, remplacent en quelque sorte un double parachute; elles leur procurent un vol soutenu sans aucun bruit: avec ce secours, les chouettes semblent glisser lenternent 
dans l'air au-dessus de leur proie, sans l'effrayer d'avance.

Le deuxième nom est formé d'ä̈Gs, AïGos, "bouc, chèvre, " et ouos, " tout, - tout chèvre, semblable à la chèvre. " Cette dénomination a semblé à plusieurs naturalistes être fondée sur les caractères qu'ils ont pu trouver communs aux chèvres et aux rapaces nocturnes.

Les chouettes et les chèvres ont la voix rauque, brève, désagréable; leurs yeux sont très-larges et placés en avant: ce dernier caractère est si spécial dans ces oiseaux, qu'il ne se rencontre que dans les rapaces nocturnes; eux seuls aussi ont la tête ronde. Les chouettes, comme les chèvres, ont la figure encadrée, les unes par des plumes fines et pressées, les autres par de longs poils qui leur donnent une physionomie toute particulière.

Le mot Egolien peut dériver aussi d'une particule, telle que Aï pour AEI, " toujours, 》 et GôLÉoN ou GôLÉos, "caverne " et signifierait " oiseau qui aime, qui recherche l'obscurité des cavernes (Alexandre). »

Les Egoliens se subdivisent en Chouettes et en IIiboux que l'on distingue des premières par leur's aigrettes. Celles-ci ne sont pas un simple ornement, mais un don de la Providence, qui affaiblit les rayons de la lumière en les empêchant de frapper directement les yeux très-sensibles de ces oiseaux. Ces aigrettes leur permettent ainsi de chasser un peu plus longtemps le soir et le matin, et même quelquefois pendant le jour.

Les chats-huants ou chouettes, qui se trouvent en Anjou, sont au nombre de trois.

Selon Buffon, le mot chouette dériverait de crecua, "oiseau nocturne; " la racinc pourrait en être ceccus, $c(p c a$, "aveugle, ) et ne convenir aux chouettes que pendant le jour. Je crois qu'il est plus naturel de donner au mot shonette la même étymologie qu'au mot cliathreant. 
С.

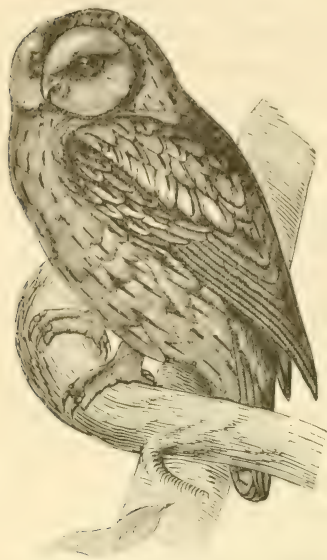

Le nom de chat est fondé sur les habiturles de cet oiseau, qui, comme les chats, vit de souris et de mulots, voit et chasse dans les ténèbres, et qui, comme eux, trouble le sommeil de l'homme par ses cris plaintifs. La physionomie de la chouette a aussi quelques traits de ressemblance avec celle du chat: L'adjectif huant, du mot " huer, crier, ") indique une habitude commune à tous les rapaces nocturnes, moyen puissant que Dieu leur a tomni pour réveiller, effrayer et tromer leur proie, et par là même la dévorer plus facilement.

Le mot scientifique strix, en gree strugs, indique lit même idée et vient de struzò, ponr тnzò, "crier.»

Xicot, cití par llénage. prétend que chat-husant ou plutòt chuhuan n'a pas cette sitymolosie, et Ménage luimime en indique l'urigine dans le mot breton caomen. Or, crouen, 't mieux caouhuan, suivant le l'. Le Pelletier, est. liait de cru ou crom, monosyllibe, "caché, ") et le hurm, "soleil, " et veut dire "caché du soleil, " ce uni est naturel ut ordinaire à ce vulatile. C'est de lia que lin a liat, dans la basse latinité, cavaumum ou carmumus, rt 'n francais clut-luent. Les Irlandais le nomment rmm-lill. Remarquons que cette explication concorde-

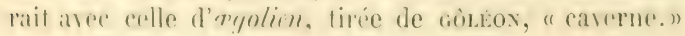


Mais, d'autre part, caouen, dans l'opinion du même savant, peut aussi bien être composé de cat, "chat, " et de chuyn, " plainte, lamentation. " "Le chat-huant, " dit-il, _ crie d'un ton lugubre, et a la tête et le naturel ( du chat. ) D'où il suit que l'orthographe ordinaire n'est pas si éloignée de la vérité que l'affirmait Nicot.

Chouette vient de caouet, participe passif de caoü, "cacher, fermer, encaver, » et qui, comme caouen. a cau, ou caou pour racine. Les Picards disent cave et cavette pour chouette.

L'on pourrait, il est vrai, faire dériver les mots chathuant ou chahuan et chouctle de la racine ch, chu, chw, imitant le chuintement de cet oiseau, d'où est venu en breton le mot chwita, " siffler, " cité par le P. Le Pelletier à l'article alouette; c'est la même étymologic que Roquefort assigne au mot chevêche, comme nous le verrons plus loin. Quelque opinion qu'on adopte à cet ígard, quand les chouettes aperçoivent leur proie, elles poussent rarement leur cri strident, mais elles fondent à l'improviste sur leurs victimes.

Hulotte dérive de ululare, "se lamenter, " et a la même signification.

L'épithète aluco, qui détermine cette chouette, peut venir de $\mathrm{A}$ et Luros, "loup, - qui ne ressemble pas au loup, " par antiphrase, figure si familière aux Grecs, ou de A ei LuKoô, "dévorer, " d'après la même pensée, ou enfin de a et Lukè, " crépuscule, - qui n'aime pas le crépuscule, qui redoute le lever du soleil. »)

Solis et occasum servans de culmine summo

Necquidquam seros exercet noctua cantus.

$$
\text { (Georg., I, v. 402.) }
$$

Et le triste hibou, le soir au haut des toits,

En longs gémissements ne traine plus sa voix.

(Detrlete.) 
En admettant l'a dans le sens augmentatif, uluco signifierait alor's a-Lukos, "qui ressemble beaucoup an loup. "

Comme les loups, en effet, les chouettes fuient la lumière; comme eux, elles vivent dans les bois et chassent fuand l'homme est endormi, avec cette différence essentielle que la chouette prend les intérêts du villageois, défend sa propriété, tandis que le loup l'attarque et l'enlève. La mythologie expliquait ainsi l'horreur que les chouettes ont pour la lumière: Nyctimène, fille d'Épopée, et suivant d'autres, de Nictée, roi des Lesbiens, ayant śté déshonorée par son père, alla cacher sa honte au fond des bois où elle fut changée en chouette par Minerve.

D'après Ducange, aluco vient de olobvxeïx, futur de ololczò, dont le radical est oLtz, et signifierait alor's "oiseau qui crie d'une manière stridente. "

D'après P'ictet, aluco ou ulucus répondrait au sanscrit "cilu " pour " ciru, " lequel mot serait composé de à intensitif et de " $r u$, "clamare, et signifierait " crier bien fort, gímir avec intensite. " Cette explication pourrait se justifier frar les habitudes des rapaces nocturnes, et s'appuyer sur le nom donné par les Grecs à l'effraic, ELÉos, ÉLÉAs, qui sont de même famille que tét́lizomaï, "gémir, se plaindre. "

Pour completer ces hypothèses, j’ajouterai aLtKE, "état d'agitation, d'inquiétude, " qui dérive de atcò, " être agité, " et pourrait représenter les préoccupations auxquelles les chouettes sont condamnées à cause de leur cécité.

La hulotte pond, vers la fin de février ou au commencement de mar's, deux œufs arrondis et blancs, de $0^{\mathrm{m}}, 042$ de longueur et $0^{\mathrm{m}}, 036 \mathrm{i}$ de diamètre. Elle les dépose sur la poussière vermoulue des arbres, dans l'intérieur desyuels elle s'est príparé un trou avec le secour's de ses 
pattes et de sun bec. Cette chonette s'arrache quelquefois les plumes du'milieu du ventre pour envelopper ses œufs, les réchauffer et préparer un nid plus agréable à ses petits. D'autres fois elle ne prend pas ce soin, et choisit un vieux nid de buse, de corneille, de pie ou d'écureuil, dont les matériaux sont tout réunis. La hulotte couve ses œufs toute la journée et une partie de la nuit,

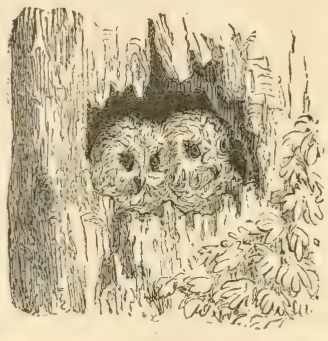
et ne chasse que le matin et le soir. Elle se livre au travail de l'incubation avec une telle persevérance et un tel dévouement, que le bruit de la hache du bûcheron, abattant l'arbre qui renferme ses œufs, ne peut la déterminer à les abandonner. Souvent elle ne sort de son nid qu'après la chute de l'arbre.

II. Courtiller, naturaliste distingué de l'Anjou, conserve dans le musíe de Saumur un nid et un œuf de hulotte qui datent de plusieurs siècles et qui offrent une particularité curieuse. Lors de la construction de l'église Saint-Pierre de Saumur, une chonette se réfugia dans un trou de boulin, et là, réunit en cercle quelques brins de paille desséchée, sur lesquels elle déposa un œuf. Les ouvriers, en faisant le ravalement, fermèrent le trou; l'humidité de la pierre et celle de la chaux nouvellement employée se déposèrent en couche légère de salpêtre sur le nid et sur l'œuf. Les parties les plus déliées s'étant évaporées insensiblement, le nid et l'œuf conservèrent une apparence calcaire qui les faisait ressembler un peu aux objets de la fontaine Sainte-Allyre, en Auvergne. Ce nid et cet cuf furent apportés à II. Courtiller par les ouvriers qui, chargés récemment 
des réparations extérieures de l'église, enlevèrent la pierre fermant le trou de boulin.

Quand l'éducation de ses petits est terminée, la hulotte fait ordinairement choix d'un domicile : c'est le' trou d'une vieille souche entourie de lierre et situće sur le bord d'un chemin creux et ombragé. Si l'atmosphère est chaude, la hulotte surt de sia retraite, se perche it l'ombre de quelque branche touffue, toujour's à la même place et le plus près possible du tronc de l'arbre, et Jit elle reste immolile pendant des journées entières. Il m'est arrivé quelquefois de rencontrer dans cette position deux hulottes à côté l'une de l'autre, faisant toutes sortes de grimaces, et prenant les preses les plus grotesques quand elles étaient troublées par le bruit des passants. Toutefois la hulotte ne sort de son domicile que lorsque la journée doit être exempte de pluie ou de vent. Elle peut servir de véritable baromètre. Souvent je l'ai consultée lursque j'étais à la campagne, et jamais ses indications ne m'ont trompé.

Ici je soumettrai à l'appréciation du lecteur une hypothèse au sujet des œufs des rapaces nocturnes. Cies œufs sont presque tous déposés dans des trous d'arbres ou dans la profondeur des vieilles masures. Leur couleur toujour's blanche, comme celle des œufs appartenant aux pies et aux martins-pêcheurs, qui nichent de la même manière, ne serait-elle pas le résultat de l'attention de la Providence? Dans les tinèbres, le blane s'aperçoit mieux que les autres couleur's, et offre ainsi ì ces oiseaux un moyen de conserver leur's œufs, en les leur faisant distinguer dès qu'ils plongent daus leurs trous, ou lorsqu'ils les changent de place pour faciliter l'incubation. Depuis l'impression de mon travail, l'opinion que je viens d'émettre a éte combattue par plusieurs naturalistes qui s'appuyaient sur l'autorité de II. Gerbe, cité par II. des 
Murs dans son Traité d'oologie, pages 186 et suiv. Voici les paroles de N. Gerbe : "Quant au blanc pur et rare" ment piqueté des œufs pondus dans des cavités qui les " mettent hors de l'atteinte de la lumière... ne pourrait" on pas arguer de ces faits que la lumière a une action " bien marquée sur les produits ovariens des oiseaux, " comme elle en a une sur les autres productions de la " nature? La fleur qui s'épanouit dans l'ombre et dans " l'obscurité n'est-elle pas pâle et étiolée comme tout ce "que le soleil ne colore pas, et les oiseaux eux-mêmes " ne sont-ils pas la preuve la plus évidente de ce fait?" Mes contradicteurs n'avaient pas eu connaissance de la nouvelle note rédigée par M. Gerbe et dans laquelle il reconnaissait plus tard le peu de solidité de son argument.

En effet, on ne peut assimiler les œufs aux plantes: celles-ci se développent, se parfument et se colorent sous l'influence salutaire de l'air et l'action du soleil; mais les œufs sortent de l'oviducte tels qu'ils doivent être et sans avoir à subir aucune modification par l'action de l'air ou de la chaleur. Une autre cause doit donc être recherchée, et, jusqu'à preuve du contraire, je préfère, it toute autre, une opinion qui me manifeste une nouvelle attention de la Providence et me donne un nouveau motif de la bénir.

Ici devrait trouver place, assez naturellement, une seconde observation. Le plus grand nombre des œufs dont la coquille est parsemée de taches portent presque tous, ou une couronne vers le gros bout, ou du moins des taches plus prononcées qu'à l'autre extrémité. L'explication de ce phénomène me semble assez simple. Le gros diamètre de l'œuf, exerçant sur les parois de l'oviducte une pression plus forte que celle qui se trouve occasionnée par le petit bout, doit dès lors déterminer assez régulièrement une secrétion sanguinolente qui, s'unissant aux taches de la coquille encore humide, ajoute des teintes 
plus prononcées, et engendre des taches plus étendues. Aussi ces nuances accidentelles disparaissent-elles au rontact de l'eau, yuand l'auf est nouvellement pondu, tandis que les taches véritables résistent ordinairement it cette épreuve.

\section{CHOUETTE CHEVECHE. - STRIX PASSERINA.}

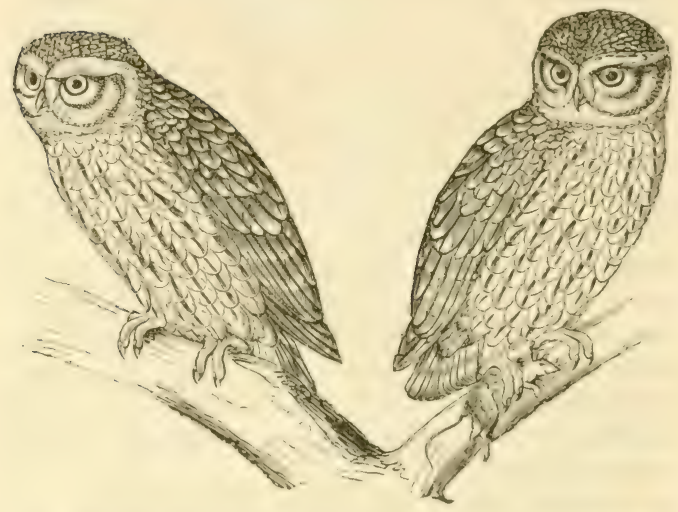

L'adjectif passerinu, "qui tient du passereau, " s'esplique naturellement par les habitudes de ce rapace. Lir chevêche se rapproche un peu lu patsisereau en ce sens que, ruyant mieux que ses congúnères, elle voltige quelquefois pendant une partie du jour, surtuut dans les champs plinti's de pommiers. Il n'en est pas de même du mut cheveche, et, jusquu à ce moment-ci, javais cru ne pouswir l'expliquer qu'en le faisant dériser du mot «chevaucher. ")

En lanconnerie, ce trime se dit de "l'oiseau śélevant 
par seccusses au-dessus du vent. ") Cette manière de voler, étant propre à la chevêche, rendrait l'étymologie plus admissible qu'elle ne le paraissait d'abord. Mais le mot AïgôLıos, par lequel Aristote distingue la chevêche des autres chouettes, a porté ma pensée ver's les chèvres, et j'ai cru trouver dès lors le véritable sens de chevêche dans ces mots : chèvre-chef " oiseau dont la tête ressemble à celle de la chèvre. " Cette explication est confirmée par le nom que les Latins donnaient à la chevêche, capriceps, "tête de chèvre. " Roquefort pense que le nom de chevêche a été donné à cette chouette, à cause de ses soufflements : " chè, chei, cheu, cheue, chiiou, ") qui ressemblent à ceux d'un homme dont la poitrine est oppressée et qui sommeille la bouche ouverte. Enfin, d'autres natu-

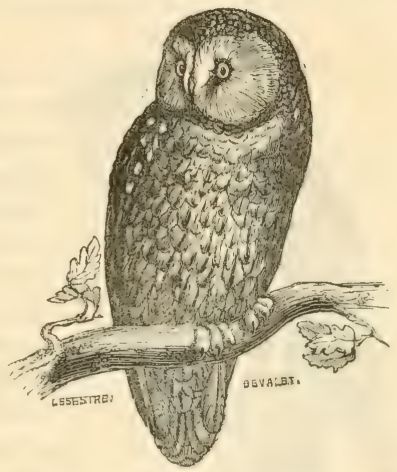
ralistes ne voient dans la dénomination chevêche que le mot chef défiguré. En effet, chevèche, chevèce, dans l'ancien français, signifiaient "tête, vêtement de tête; " de là le chevécier était un dignitaire qui avait soin du " chevet " de l'église, du fond du chœur, et dont le nom dérivait de capitiarius, capitium, caput, " tête. " Quelques auteurs la nomment mupides, "aux pieds nus, " parce que ses pieds sont moins velus que ceux des autres chouettes. Ce caractère sert à la distinguer de la chouette tengmalm, qui, destinée à vivre dans les pays froids, a les pieds couverts de plumes longues et très-pressées. 
La chereche affectionne les vergers, et e'est souvent dans le creux des arbres fruitiers, sur des débris de leuilles sèches, qu elle pond de trois à cinq weilfs blancs et arrondis, dont le srand diamètre varie de $0^{\mathrm{m}}, 031$ is ()$^{m}, 0: 34$, et le petit, de 0$)^{\mathrm{m}}, 024$ à 0,026 . Quelquefois clle dépose ses cufs dans un trou de vieux mur.

IHOUETTE EFTRAIE, VIIGAMEMENT FRESAIE. - STRIX FI.AMMEA.

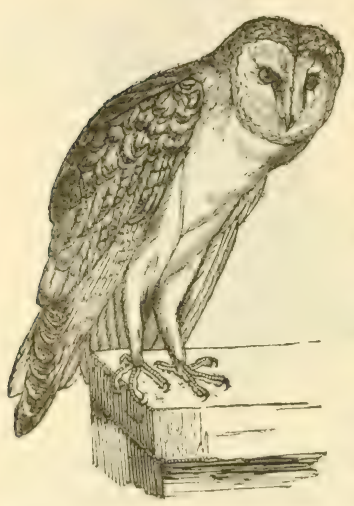

Cette chouette doit son nom aux idées d'effroi qui s'attachent à sa présence et se fondent sur' ses habitudes. D'abord elle vit plus près de nous que ses congénères : elle habite les villes, les châteaux; nous sommes plus à même d'entendre ses cris ; puis, c'est elle qui, pendant la nuit, aime à accompagner le voyageur dans les chemins creux et hoisés, à le précéder en voltigeant d'arbre en arbre, et à lui jeter de distance en distance un eri d'alarme, une espèce de qui-vive sinistre. C'est elle enfiu qui vient se réfugier dans les replis des vieilles cheminies, et qui, surprise par le jour dans sa nouvelle demeure, plonge en culbutant dans le tuyau de ces cheminées, et apparait tout ì coup au milieu du foyer, comme un oiseau de mauvais ausure. Le nom scientifigue /lammen lui a étí donni à cause de la couleur de ses flumes, d'un blane très-pur ef terminíes par une pointe d'un jaune 
un peu ardent, couleur qui la fait encore apparaître dans les nuits sombres comme un météore précurseur de tristes nouvelles.

L'effraie est appelée dans le midi de la France buceou l'holi, c'est-à-dire, " oiseau qui boit l'huile. " Cette erreur populaire a peut-être pris naissance dans quelques faits recueillis et dénaturés par l'imagination méridionale. Attirées par la lueur des lampes, les effraies ont pu venir se heurter à ces lampes, et non pas boire, mais renverser l'huile qui y était contenue ${ }^{1}$. On pense généralement que l'effraie annonce la mort, et qu'elle vient frapper aux fenêtres des personnes près de rendre le dernier soupir. Cette croyance contribue beaucoup à inspirer une vive répulsion contre la présence de l'effraie. Cependant cet oiseau ne fait que constater la décomposition du corps; il ne vient pas pour jeter un triste sort, mais il est attiré par la lumière des veilleuses et par les miasmes qui se développent sous l'action de la maladie. Son cri n'a rien alors de plus sinistre qu'à l'ordinaire; la seule différence en est qu'on l'entend quand on veille, et qu'on y reste insensible quand on dort. Aussi n'est-ce que sous l'impression d'une imagination exaltée qu'on peut reconnaître dans le cri de l'effraie le sifflement des serpents et le râle des agonisants; c'est sous l'empire de la

1 La même opinion a cours dans d'autres pays, comme on peut le voir par le fragment suivant d'un voyage dans l'Amérique du Sud :

"Quatre baies sans fenètre, deux au levant, deux au couchant " sont pratiquées dans les murs... Les grands et moyens-ducs " des environs, les effraies, les hihoux, les chouttes, les chaures" souris profitent de ces baies ourertes depuis l'anne 1791, pour " s'introduire nuitamment dans l'eglise, s'acerocher a la lampe " du chœur, en éteindre la mêche d'un coup d'aile, et pomper " avidement l'huile de lamantin qu'on y brûle. "

(Paul Marcoy, royage de l'océan Pacifique à l'océan Atlantique, dans le Tour du Monde, livraison 274). 
mìme influence qu'on a dénaturé une foule de faits ficciles à expliquer, et qui ont entouré cette chouette d'une auréole de terreur et de ripulsion. On prétend que leffraie choisit de préférence pour sa demeure les vieilles églises situées dans les cimetières; que, dans ces églises, elle affectionne d'une manière toute spéciale les murs des clochers; qu'elle sort de sa retraite au son de la cloche annonçaut l'agonie des mourants; qu'elle bat des ailes en signe de satisfaction; enfin qu'elle s'unit au chant de l'office des morts, en secouant la tête et en faisant craquer les mandibules de son bec. Tous ces griefs reposent sur desobservations mal comprises, et qu'il est facile de rétablir au véritable point de vue de l'histoire naturelle. Les effraies, comme les choucas, les martinets, les moineaux même, préfèrent les vieilles églises solitaires, etc., it tous les autres monuments pour y établir leurs demenres, par la raison toute simple qu'elles y trouvent plus facilement une très-grande quantité de trous, provenant et de la main de l'homme et du ravage des siècles; que, plus les églises sont élojenées des habitations de l'homme, plus ces viscaux y gagnent en sécurite, et enfin que les églises situćes près des cimetières jouissent encore d'un isolement plus complet que les autres. Mais dans ces églises, les endroits les plus favrrables au síjour de l'effraie sont incontestablement les clochers, parce que ce rapace a besoin, comme la hulotte, de ressentir l'influence de l'air et même celle de la chaleur; qu'il ne pent rester toujours dans son trou, et que, d'un autre côté, se mettre sur les bords d'un refuge exposé it lil vue des passants, ce serait lévoiler sa présence et compromettre sa vie. Dans les clochers, l'effraie pent, tour à tour' of sans dinger, se réfugier dans son repaire ou rester sur ses bords, sans trahir sa prísence; là aussi elle peut respirer plus it son aise et ressentir linfluence salutaire de la chaleur et de l'air. Si, lorsqu'elle occupe cette position, 
la cloche vient à se balancer dans les airs, soit pour annoncer un trépas, soit pour célébrer les joies souvent éphémères d'un nouvel hymen, soit pour s'associer à la joie des parents d'un nouveau-né, l'effraie est arrachée aux douceurs de son demi-sommeil par les vibrations de l'air que déplacent les mouvements de la cloche et par le bruit de la sonnerie, et alors elle manifeste sa surprise et son mécontentement par des signes et des grimaces caractéristiques. Le chant de l'office des morts, uni à l'ébranlement des cloches, produit sur l'effraie les mêmes effets indiqués précédemment, et dès lors s'expliquent tout naturellement ces mouvements de tête, ces craquements de bec, etc. Des sonneurs ou des sacristains ont constaté les faits sans en comprendre le motif, et leurs récits ont servi, sous le souffle d'une imagination exaltée, à composer le dossier de tous les méfaits reprochés à la chouette effraie, méfaits qui se dissipent au flambeau de la raison et d'une observation sérieuse.

Les accusations, qui pèsent sur ce rapace, rappellent à ma mémoire le préjugé qui s'attache à la visite faite par le prêtre aux personnes malades. Quelques familles éloignent le ministre dı Seigneur du lit de souffrance des parents qui leur sont chers. Leur motif est que la mort suit presque toujours cette visite: la remarque me parait d'autant plus fondée, que le prêtre n'est appelé d'ordinaire que si les malades sont près de rendre le dernier soupir, et souvent lorsqu'ils n'ont plus de connaissance. Que ces familles voient dans le prêtre un ministre de Dieu, un consolateur, un ami, et sa visite n'annoncera pas la mort, mais apportera l'espérance et la force, lorsque la maladie viendra frapper à la porte de leur demeure.

La chouette effraie, dont les œufs sont un peu plus allongés que ceux dess précédentes, pond ordinairement 
dans les excavations des vieux murs, des clochers et des chateaux, de trois à cing wufs, dont la longueur varie de ()$^{\mathrm{m}}, 033$ ì $0^{\mathrm{m}},(040)$, et le diamètre, de $0^{\mathrm{m}}, 026$ à $0^{\mathrm{m}},(130)$; lat coquille en est plus lígère et moins unie que celle des ceuts des autres argoliens: la ponte a lieu vers les premiers jours d'avril ou la fin de mars.

La deuxième section des rapaces nocturnes comprend les chouettes it aigrettes ou hiboux. Cette dernière dénomination me parait venir de hiare, "crier, " qui a formi: lis vieux mots français hier, hie, "faire jouer la hie ou demoiselle, " et de bos, "bœuf, crier comme un bœuf. " L'on dit en grec Bezô, " hurler comme un hibou (BLAs). " Le mot choisi par les Latins pour désigner cet oiseau prouve aussi qu'ils avaient été déterminés à le lui donner d'après sun eri : ils l'appelaient mycticorax, " corbeau de nuit, " à cause du croasscment dósagréable qu'il fait entendre pendant, le sommeil de l'homme.

L'Anjou possède quatre espèces de chouettes ì aigrettes.

\section{HIBOU BRACHYOTE. - STRIX BRACHYOTOS.}

Cie hibou sert de trait d'union entre les chouettes proprement dites et les chouettes à aigrettes. Son nom est ('omposé de macirss, "court, " et miss, òtos, " oreille, " parce que ses aigrettes sont peu apparentes, et ne renferment ehateune que deux, trois, quatre plumes, tandis que celles du grand-duc en comptent dix, at celles du moyenduc et duscups, six. Le brachyote suppurte plus facilement que ses concinerese, l'éelat des rayons luminem, et s'itdonne it des prérigrinations régulières. Il pond, au com- 
mencement du printemps, de trois à cinq œufs blancs, un peu oblongs et plus luisants que ceux des chouettes; cette nouvelle manière d'être convient à tous les œuf́s des différentes espèces de hibou. Ceux du brachyote ont

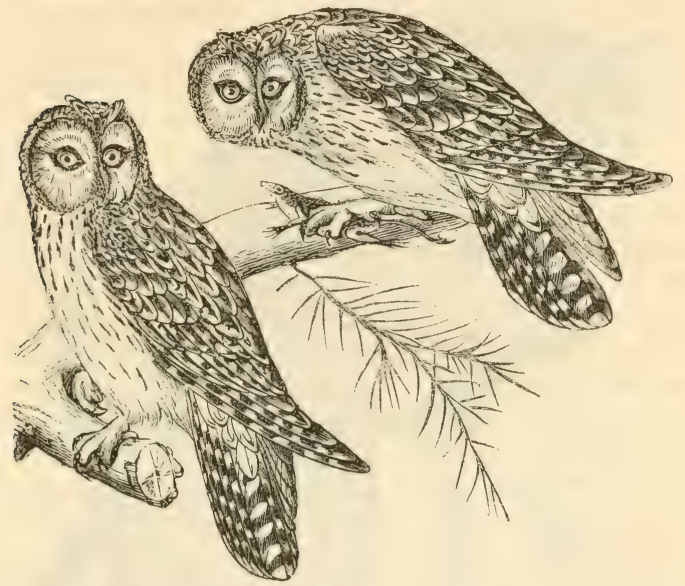

de $0^{\mathrm{m}}, 035$ à $0^{\mathrm{m}}, 037$ de longueur, et de $0^{\mathrm{m}}, 029$ à 0,031 de diamètre. Ils sont déposés à terre sur quelque éminence ou dans les marais desséchés, au milieu des herbes touffues, ou bien encore sur des pierres ou dans des nids abandonnés par les pies et par les corneilles.

\section{HIBOU GRAND-DUG. - STRIX BUBO.}

Le nom de duc donné par les Latins aux trois autres chouettes à aigrettes est fondé, s'il faut s'en rapporter à Buffon (éd. in- $4^{\circ}$, vol. 1, pag. 321), sur une erreur des Grecs. Ceux-ci ayant aperçu une fois un moyen-duc perché 
non loin d'une troupe numbreuse de cailles arrivant dians leur pays, pensìrent qu'il sprvait de guide à ces oiscaux. Leur imagination très-ardente entrevoyait dans les aigrettes de ce hibou un indice de commandement, une

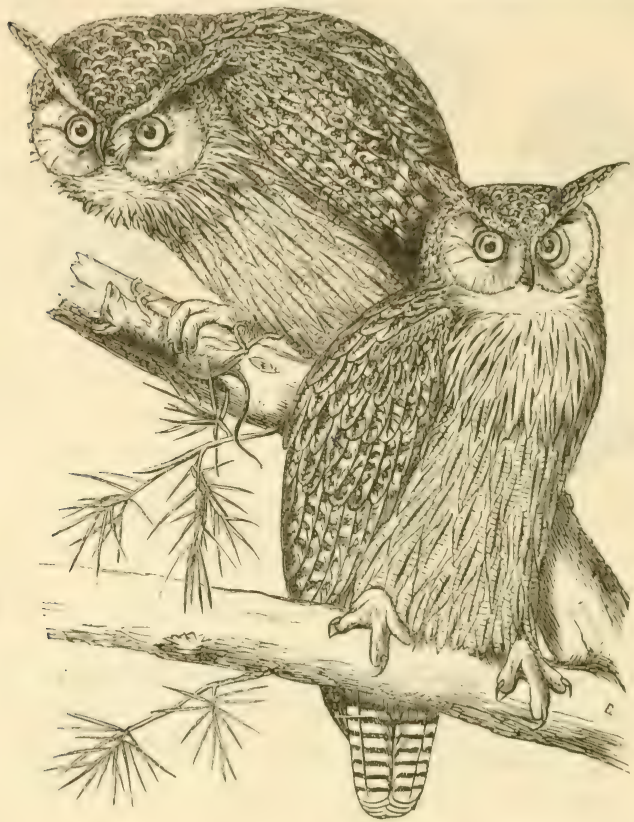

image des panaches qui flottaient sur les easques de leurs chefs, de leurs ducs (dux, ducis, traduction du mot grec ènexôx). Mais l'étymologie ne paraît pas heancoup plus certaine que le fait sur leguel on l'appuie. Quelques savants, s'autorisant du mot irlandais diucuim, qui signifie "gémir, " pensaient que la dénomination duc 
pourrait bien avoir une origine celtique, et représenter l'idée de " cri étouffé, gémissement. "

Les mots grand, moyen et petit, ajoutés à celui de duc, sont destinés à distinguer ces oiseaux d'après leurs dimensions relatives. L'épithète bubo, qui est donnée au grand-duc, dérive de bubulo, " crier d'une manière stridente, " ou butio et bos, "pousser des mugissements de taureau. » Elle se raproche beaucoup du cri du grandduc, bou-hou, bou-hou.

Le grand-duc apparaît très-rarement en Anjou, et vit ordinairement sur les sommets boisés des montagnes; là, il lutte avec énergie et même quelquefois avec succès contre les aigles. Jamais il ne refuse le combat, et des naturalistes consciencieux assurent que, lorsque l'approche de la nuit lui rend toutes ses armes, il soutient avec persévérance le choc de l'aigle royal, son ennemi acharné. Plusieurs fois il a entrainé dans sa chute son adversaire qui succombait aux blessures reçues dans le combat.

La femelle pond, dans le mois de mars ou d'avril, deux œufs blancs et arrondis, ou un peu oblongs, dont la longueur varie de $0^{\mathrm{m}}, 063 \mathrm{a} 0^{\mathrm{m}}, 063$, et le diamètre, de $0^{\mathrm{m}}, 050$ à $0^{\mathrm{m}}, 053$. Rarement ces œufs ont une teinte légère de roux, qui doit provenir de leur contact avec la poussière humide ou vermoulue, sur laquelle ils sont déposés dans le creux des arbres ou dans les anfractuosités des rochers escarpés.

\section{HIBOU MOYEN-DUC. - STRIX OTUS.}

Les noms de ce rapace dérivent des étymologies données précédemment. Cet oiseau, assez commun en Anjou, niche ordinairement dans les nids abandonnés des 
corneilles, des pies ou des ícureuils, et pond quatre ou eing ceuls blanes et un peu oblones, dont la longueur

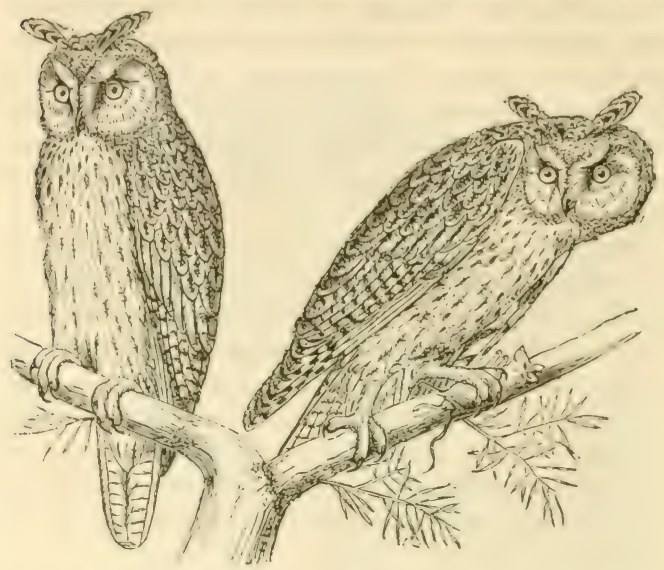

varic de $0^{\mathrm{m}}, 036$ à $0^{\mathrm{m}}, 038$, et le diamètre, de $0^{\mathrm{m}}, 030$ à $0^{\text {m.1 }}, 032$.

\section{HIBOU PETIT-DUC OU SCOPS.}

Peut-être pourrait-on hasarder l'hypothèse que scops est composé de skia, "ombre, " et ôrs, "voix, " ou de sku et òrs, ôpos, "regard: ") ces deux explications conviennent ézalement au scopss; il roit dans les ténèbres, aime ì sc cacher sous les leuilles de noyer et à faire enlendre pendant le jour un son trè-fortement siffli. Mais la véritable étymologie du mot est šôrtô, "railler, » exprimant ainsi l'impression qu'on éprouveà l'égard d'un oiscan impussible à découvrir malgrí ses cris, et dont le sifflemrnt persisérant parait ètre une raillerie provocante. 


\section{- $33-$}

Ce hibou voyage quelquefois par petites bandes, en Anjou et surtout dans le Saumurois. Il pond, vers la fin d'avril, quatre ou cing œufs blancs et presque ronds, de $0^{\mathrm{m}}, 028$ à $0^{\mathrm{m}}, 030$ de longueur, et de $0^{\mathrm{m}}, 026$ à $0^{\mathrm{m}}, 028$

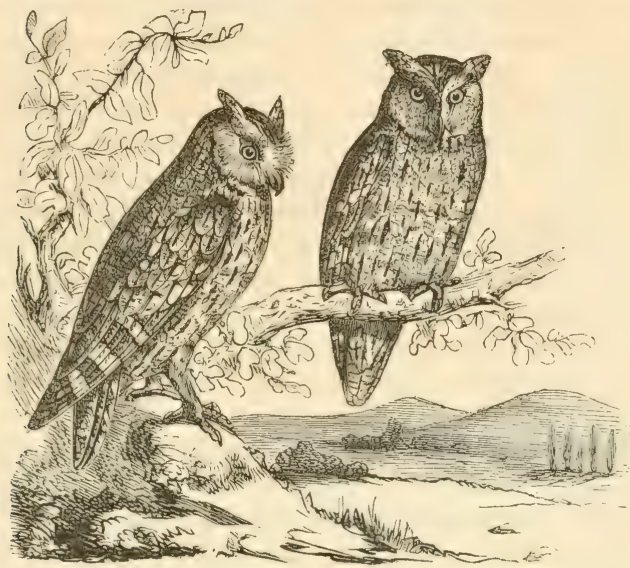

de diamètre. Quelques-uns de ces œufs ont une couleur d'un jaune foncé, qu'on doit attribuer à leur séjour' dans le creux humide des arbres auxquels ils sont confiés.

Tous les rapaces nocturnes dont nous venons d'énumérer les noms se réfugient régulièrement pendant le jour dans les trous des arbres, sous le feuillage épais des forêts ou dans les crevasses des murs des vieux édifices. Leur but est de se soustraire ainsi à l'action de la lumière qui fatigue leurs yeux : ceux-ci, pourvus d'une double paupière, sont cependant incapables de recevoir des rayons trop vifs, à cause d'une extrême sensibilité de la vue, qui tient sans doute augrand épanouissement dunerf 
optigue. Aussi, ruand, par une cause queleonque, ils sont fiorés d'abandonner leur réduit, d'interrompre leur sommeil et de s'exposer à l'éclat d'une lumière vive, ils se liverent alor's à une série de grimaces et de joses bizarres qui les rendent un sujet de risée pour tous les autres oiseaux. C'e qui contribue encore à donner aux rapaces nocturnes une physionomie ridicule, c'est l'absence du cou, remplacé chez tous les oiseaux de ee genre par une espèce de pivot sur lequel la tête repose et peut tourner en tous sens, comme une toupie sur son point d'appui. Les autres oiseaux, n'ayant rien it craindre d'un ennemi à moitié endormi et b́bloui par l'excès de la lumière, l'attaquent avec acharnement. Mais malheur aux assaillants quand le crépuscule arriıe avant la fin du combat! car les ròles changent, et souvent plusieurs des agresseurs paient de leur vie une attaque dictée par la lâcheté.

L'homme a su profiter de cette frarticularité pour attirer et prendre les oiseaux, soit en se servant de chouettes captives, soit en contrefaisant la voix de ces dernières. Les gros oiseaux viennent plus facilement au cri du moven-duc, ei les petits, ì la voix de la hulotte. C'est aussi eette chasse, nommée pipée, qui avait fait appeler chevêche un ancien jeu de cartes, dans lequel celui qui litisait la chouette luttait contre plusieurs adversaires.

Je termine ce travail sur les rapaces nocturnes en joisnant ma roix à celle de tous ceux qui ont étudié les mours de ces oiscaux, pour ríclamer contre lingratitude des villageois qui poursuivent ì outrance et dítruisent, par tous les moyens possibles, des auxiliaires dont ils devraient, dans l'intérèt de l'agriculture, favoriser la propagation.

Ces rapaces sunt, en effet, les vrais amis des cultivitterurs, et, pendint que ceux-ci se repusent des latigues du jour, les chourettes sortent de lears retraites pour 


\section{$-35-$}

veiller à la conservation des semences, objet de tant de soins et de soucis. Elles parcourent les champs, dévorent les souris, les mulots, les taupes, les gros insectes, et ne demandent pour toute récompense qu'un asile dans le trou d'un vieil arbre. Là, elles se réunissent quelquefois en grand nombre pour se réchauffer pendant l'hiver, et font entendre des cris sourds et prolongés qui effraient les habitants de la campagne et constituent le seul grief qu'on puisse reprocher à ces utiles serviteurs. Les anciens avaient plus justement apprécié les services rendus par les nyctérins en consacrant la chouette à Minerve, personnification de la guerre unie à la vigilance et à la sagesse. Chaque année, les naturalistes peuvent constater, d'une manière bien évidente, quels secours les rapaces nocturnes apportent à l'agriculture. Quand le froid se fait sentir et qu'une couche épaisse de neige s'étend comme un linceul sur les contrées scandinaves, des myriades de rats et de mulots descendent de ces régions glacées, et s'avancent en légions innombrables vers les contríes du centre de l'Europe. Comme les anciennes troupes des hommes du Nord, elles sèmeraient partout sur leur passage la ruine et la dévastation, si cette terrible émigration n'était arrêtée dans son cours par un adversaire redoutable. Cet adversaire est le hibou brachyote, dont les bandes nombreuses se pressent à la poursuite des mulots et des rats scandinares, et en immolent des quantités considérables.

Que de fois, quand je revenais avec mes élèves de faire quelque course, ne me suis-je pas arrêté, sur les bords des fossés, dans les vastes prairies d'Ecouflant, pour jouir d'un spectacle très-curieux et qui se reproduit chaque année, surtout pendant les mois de juin et de juillet! A peine les faucheurs ont-ils quitté le lieu de leurs travaux, qu'un petit cri se fait entendre, et bientôt un certain nombre de peupliers semblent surmontés 
d'un panache mobile, se diveloppant et se resserrant tour ì teur. C'e sont des chouettes chevêches qui ont occupé leurs postes d'observation, et dont les ailes s'ouvrent et se referment selon les ondulations imprimées aux arbres par le souffle du vent. De temps en temps ce panache se détache de l'arbre, et se dirige, sans bruit et avec une grande rapidití, vers quelque point de la prairie. On dirait un flocon de neige emporté par une brise légère. C'est une chevêche fondant sur quelque mulot ou sur quelque gros insecte qu'elle a aperçu du haut de son observatoire.

Quand le travail des faucheurs est terminé, et que les faneur's ont formé, dans ces immenses prairies, les meules de foin, les chouettes chevêches abandonnent la cime des peupliers pour se rapprocher du théatre de leurs investigations. L'on peut alors voir un très-grand nombre de ces meules surmontées d'un point brunt̂tre, qui tour ì tour semble décrire une circonférence sur le haut de la meule ou rester immobile comme une sentinelle sous les armes. C'est toujours la chevêche accomplissant la mission que la Providence lui a confiée.

Ajoutons que les Grees attribuaient à la chouette la connaissance de l'avenir. Les monnaies d'Athènes portaient d'un côté la tête de Minerve, et de l'autre une chouette; de là l'usage, chez les Athiniens, de donner quelquefois le nom de chouette, gidurs, graukos, à leur monnaie.

Peut-être faudrait-il encore rattacher à cet usage l'explieation de ce dicton populaire : "e'est chouette, ce n'est pas chouette, " pour dire "c'est précieux, ce ne l'est pas, " expression qui reviendrait à peu près à celle-ci : "c'est le P'érou, ce n'est pas le P'érou, "pour dire que les objets ont une grande ou une petite valeur, selon qu'ils se rapprochent plus ou moins de l'or. 


\section{DEUXIÈME FAMILLE DES RAPACES.}

\section{Hapaces diurmes ou ceipitrins.}

L'adjectif diurnes, dont la racine est dies, " jour, " convient parfaitement aux rapaces qui ne fuient pas la lumière pour se livrer à la chasse; il en est de même du mot accipitrins, dérivé d'accipiter, " oiseau de proie, voleur. " D'après Littré, accipere est formé de ad, "à, ) et cipere pour capere, "prendre, " et signifie "recevoir. " Des mêmes racines s'est formé acceptare, "accepter. " Mais le mot accipiter, " oiseau de proie " et "voleur," ajoute aux radicaux primitifs une signification nouvelle. C'est en effet une singulière manière d'interpréter l'acceptation que de lui faire représenter l'acte de celui qui s'empare de quelque chose, non-seulement sans la volonté, mais encore contrairement à la volonté du propriétaire. IIélas! il faut bien en convenir, à notre époque de progrès, le nombre des accipitrins, dans le sens de Littré, va toujours croissant.

D'accipiter dérive probablement le verbe douteux accipitro, " mettre en pièces, ") comme les accipitriens, et indiquant d'une manière énergique le caractère distinctif des oiseaux qu'il détermine. A moins que l'on n'aime mieux donner pour racine à accipitro, ad caput ire, "'se jeter à la tête de ceux que l'on attaque. " Accipitrin et faucon exprimeraient ainsi une même idée.

Cependant les savants versés dans les langues primitives croient qu'accipiter aurait pour racine âcupatra, signifiant (aile rapide, ) étymologie qui aurait l'avantage de peindre le vol des oiseaux de proie, le plus rapide de tous, et viendrait confirmer l'opinion de Benfey, qui donne à ıÉTos, " aigle, " les racines sanscrites " ari, " " air, 
vonl, " "t "yut, " ire, " aller, - rapide comme le vent. "

Le premier genre de cette famille eomprend les Vautours, auxgnels appartiennent les Cathartes.

\section{PIREMIFIR GEVIR E. - VAUTOUIR.}

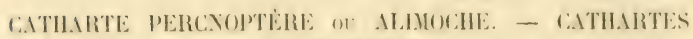
PERCNOPTERUS.

Un jeune catharte mâle a séjourné pendant quelque temps dans l'arrondissement de Beaupreau, et a 'té tué le 19 cotubre 18\%4. Il fait partie du cabinet de .I. Ciuillou, de Cholet, où je l'ai vu en septembre 18:3̈. Ln autre eatharte est resté deux jours, en janvier $183 \%$, ì rôder autour d'un établissement d'engrais animal, à deux likilumètres de Cholet, et a été poursuivi par MI. de Beauroys, notaire, et IIoudet, docteur-médecin.

Mais avant d'inserire le catharte dans la Faune de Maine-et-Loire, il me semble nécessaire de développer un principe propre à résoudre une question débattue depuis quelque temps. Composer la Faune ornithologique d'un pays, c'est faire le catalogue complet des viseaux qui s'y rencontrent, décrire leurs mour's, les variations 'fu'ils subissent dans leur plumage, selon l'âge, le sexe et. la mue; c'est indiquer sils sont sédentaires, de passage accidentel ou rígulier. Quand on attribue à chaque visean la manière d'être qui lui convient, on est dans le vai; l'erreur ne se produit que lursque l'auteur citablit de nouvelles espèces qui n’existent pas réellement, lur'squ'il donne comme sédentaires des espèces qui ne sunt. yue de passage, ou enfin lorsque, confundant des espèces différentes, il constate la prísence d'oiseatux qui nont jamais visiti la contrie. Ces principes ont citi admis par Linnie, Buffon, Cusier, Temmink, Dégland, pour l'ornithologie europienne; ils ont servi it chasser 
toutes les collections des musées. N'admettre, comme apppartenant à la Faune de l'Europe, que les oiseaux qui s'y propagent, ce serait bouleverser tous les musées et en exclure plus de la moitié des sujets qui les composent maintenant. MII. Crespon, Bailly, Millet et tous les auteurs ont adopté les mêmes principes pour l'ornithologie particulière; modifier cette marche générale, ce serait supprimer au moins un des volumes de la Faune de Maine-et-Loire, et rendre inutile toute espèce de supplément. Je crois donc que dire d'un oiseau qu'il a visité un pays, lorsqu'il y a été tué dans l'état de liberté, c'est enregistrer un fait vrai, et fournir un renseignement précieux pour des recherches subséquentes. De nouvelles preuves viennent justifier et fortifier les assertions précédentes. Ainsi le martin-roselin, dont l'apparition était regardée comme un fait très-rare, a été tué cette année sur plusieurs points de notre département, à des époques différentes : en juin $185 \%$, par MM. de Monfrière, et en septembre, par $\mathbf{l l}$. Charles, vétérinaire à Cholet.

J'admets donc le catharte comme oiseau de passage accidentel.

Ce rapace appartient aux vautours, dont le nom latin, vullur, désignait, d'après Sénèque, ceux qui vivaient d'héritages, expression très-juste pour déterminer des oiseaux lâches qui sc nourrissent de cadavres, héritage que leur lègue la mort. Leur cou, long et dénude en partie ou en totalité, a procuré aux vautours le nom de mudicolles, et leur permet de plonger plus facilement la tête dans les cadavres pour en dévorer les intestins. Quelques auteurs écrivent mudicoles, expression signifiant alor's " oiseau qui aime, qui recherche le nu, les corps nus, les cadavres. ")

Chez tous les vautours, l'œsophage est pourvu d'un renflement ou jabot qui fait saillie à la base du col et retombe sur la poitrine comme une besace trop chargée. 
Très-souvent les vautours absorhent plus de nourriture que ne peut en contenir le grand réservoir dont la P'rovidence les a gratifiés dans l'intérêt de la salubriti des pays qu'ils habitent. Dès lors ils s'envolent péniblement loin des lieux que leur voracite a purifiés, et vomissent sur des rochers escarpés une partie de la nourriture entassie dans leur prodigieux jabot. Cette voracité extrême

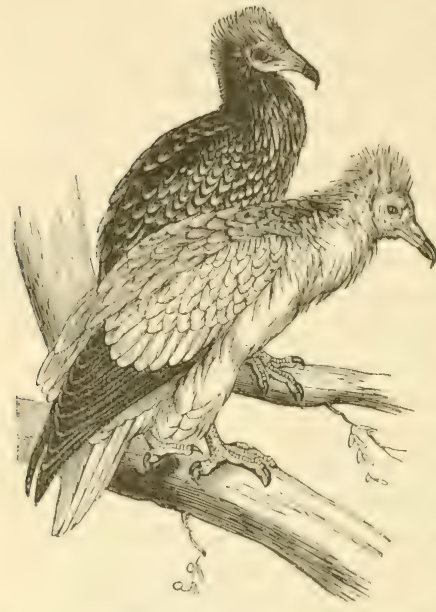
est la cause de la perte des condors et des vautours. En Amérique surtout, les habitants tendent des piéges ì ces oiseaux en accumulant, dans des endroits isolés, un grand nombre de cadavres d'animaux. Les condors se réunisserit pour assouvir leur faim insatiable, et les naturels profitent du demi-sommeil forcé qu'une digestion pénible impose

ì ces oisenux, pour les tuer ì coups de bâton.

Le num de catharte, кaтmä̈rô, "purger," indique les habitudes de ces oiseaux et les services fu'ils rendent dans les pays où la chaleur et la malpropreté des habitants s'unissent pour rendre le climat peu salubre. Les eathartes sont très-nombreux à Constantinuple et en Eigyite, où autrefois ils étaient connus sous le nom de "poules de Pharam net réputés sacrés. Dans ces pays, chacque jour, les cathartes délivrent les villes des immondices qui ? 
séjourneraient longtemps sans leur concours. En Amérique, ils rendent les mêmes services et sont sous la protection des lois.

Pour pouvoir remplir la mission qui leur a été confiée, la Providence a doué ces oiseaux d'un odorat très-développé et qui, d'après Duméril et plusieurs autres naturalistes, leur permet de découvrir les cadavres à une distance de plus de cinquante kilomètres. La salive purulente qui suinte perpétuellement des larges narines des vautours, en répandant une odeur fétide, jouerait-elle un certain rôle dans l'odorat extraordinaire dont ils sont doués? Quand, pendant l'hiver de $185 \%$, le froid et les privations moissonnaient les chevaux des alliés en Crimée et menaçaient d'engendrer des maladies pestilentielles, les cathartes, attirés par les émanations des cadavres, se réunissaient par centaines, s'abattaient tous les soirs sur le camp cornme un nuage épais, et ne laissaient le lendemain matin que des os blanchis et desséchés. Gérard a souvent constaté des faits de cette nature dans le cours de ses chasses en Algérie. "Lorsque je " désire, écrit-il, conserver, comme appât, un des bœufs " égorgés la veille par le lion, je le couvre de plusieurs " couches épaisses de branches, afin de le dérober le plus " possible à la vue et à l'odorat des vautours et des ea"thartes; les bœufs qui n'ont pas été soumis à ces "précautions ne m'offrent le soir qu'un squelette en" tièrement dénudé et fouillé en quelque sorte avec le " scalpel. "

L'adjectif percnoptère, de perknos, " noirâtre, moucheté de noir, " et de PTÉnox, " aile, " indique que les grandes pennes des ailes sont noires, tandis que le plumage général des adultes est d'un blanc jaune, varié de brun et de roussâtre. Le plumage des jeunes diffère essentiellement de celui des adultes; il est d'un brun noirâtre strié de taches roussâtres qui s'harmonisent sans se confondre. 
Le plumage de cet oiseau devient de plus en phus blane ì mesure qu'il vieillit.

Lat plupart des naturalistes modernes donnent au caltharte fe nom de Véoplirom, en mémoire des infortunes du fils de Tymandre, changé en vautour par Jupiter. Le mot alimoche, qui servait à le désigner ordinairement, paraît abandonné des savants modernes. De tous les noms du catharte, celui d'ulimoche est cependant le plus convenable. Composé de a et de cuoses, "faim, " et Écnô, " avoir, " et signifiant " très-affamé, " il représente très-exactement les habitudes d'un oiseau qui est assez vorace pour accepter, comme nourriture, les immondices et les cadavres en putréfaction.

D'après l'opinion des érudits, dans les langues primitives, le mot vultur aurait la même signification représenterait l'idée «d'une faim insatiable. n Tout en respectant l'autorité de ces sarants, je crois devoir relater ici une étymologie indiquée par Aldrovande et qui me paraît ne pas manquer d'intérêt. Je profiterai en même temps de cette circonstance pour rectifier une interprétation que j'ai indiquée précédemment.

En effet, j'ai dit que le mot vultur, employé par Sínèque et par les auteurs de l'antiquité à représenter les personnes qui vivaient d'héritages aux dépens même de la justice, avait été choisi avec raison pour déterminer l'ignoble oiseau qui ne vivait, le plus souvent, que des héritages légués par la mort. Cette interprétation, en apparence plausible, me praraît, à la réflexion, manquer de base solide; car ce nom de vultur a íté donné ì ces gens méprisables, justement parce que leur conduite rapprelait celle des vautours. La question reste done fout entière it rísoulre, et quelle est alor's l'étrmolugie du mot rultur? Ciràce au secours et ì la vaste érudition d . Mdrurande, je crois punvoir l'indiquer d'une manière assez pricise. Le savant prolesseur de Bologne dit que cultur dérive de 
volatu tardo, "d'un vol pénible, " comme si de ces mots on eût fait volitardus, "oiseau dont le vol est lourd, pénible, difficile, " dans le même sens que outarde vient de avis tarda, " oiseau gros, pesant. "

Cette explication peint d'une manière exacte le vol du vautour, qui est difficile en tout temps, mais surtout lorsqu'il s'est rassasié avec excès, selon son habitude.

Quand le vautour n'est pas sur un point culminant d'où il puisse facilement s'élancer dans l'espace, il a peine à prendre son essor; il court volontiers devant son enncmi, et ce n'est que la nécessité ou la crainte du danger qui le force à recourir aux ressources de ses ailes trèslongues et très-puissantes. Dans ce sens, volitardus serait encore une expression très-juste, d'autant plus que les anciens naturalistes, frappés de cette particularité, le désignaient par l'épithète quadrupes, "semblable aux quadrupèdes. $n$

Le vautour fait entendre en volant un bruit assez vif : on dirait les ailes d'un moulin qui, dans leur mécanisme, éprouvent un certain frottement, ou un fainéant qui ne met ses bras en mouvement que parce qu'il y est lorcé, etqui lutte péniblement contre un défaut d'habitude.

Les Latins appelaient vulturnus le même vent que les Grecs nommaient ecros. C'est le vent qui souffle de l'est en hiver; il présage la pluie et est accompagné d'un sifflement assez prononcé qui, peut-être, lui avait valu ce nonı de vulturne, "quoniam altè resonat, - dit Aldrovande, "- parce qui il fait un grand bruit." Un fleuve, une montagne, une ville de la Campanie portaient aussi le nom de Volturnee, et sont encore aujourd'hui désignés par le mot Voltumo. Cette dernière expression fait connaître encore plus ividemment que volare, "voler," entre dans la composition de vultur; du reste, d'après Pline, le vautour était appelé indifféremment vultur et voltur. Etaitce à cause de la mollesse et des excès auxquels se livraient 
les habitants de Capoue, que les Romains avaient appelé cette ville Volturno? Toutes ces explications du mot vultur prouvent que les Romains araient été frappés trè:vivement des habitudes du vautour, qui se gorge de nourriture et s'abantonne à ure somnolence paresseuse, résultat de sa gourmandise. Les montagnes dont le sommet était dénudé leur paraissaient devoir être assimilées au vautour, dont le cou long et dépourvu de plumes se termine par une tête aplatie et à laquelle des yeux sans éclat contribuent à donner une physionomie hideuse. Les Romains consultaient beaucoup le vol du vautour; ils pensaient que ces oiseaux prédisaient l'avenir. lls avaient été entraînés à cette erreur parce que le rautour, itant doué d'un odorat très-fin, dirigeait son vol vers les endroits oủ gisaient des cadarres, particularité que les anciens n'expliquaient que par la connaissance de l'avenir. Les augures assuraient aussi que les vautours planaient pendant trois jours sur les champs et sur tous les lieux où la mort devait moissonner des victimes.

Le mot volitardus pourrait être pris dans une autre acception, et signifier "oiseau qui vole tardivement, lentement. ") Cette interprétation se justifierait facilement. Tous les oiseaux qui, en fauconnerie, sont appelés nobles, se choisissent un arrondissement de chasse, parce que, dans un cercle assez restreint, ils peuvent, par leur courage et leur adresse, pourvoir à leur's besoins et à ceux de leurs petits; ils ne chilssent que le matin et le soir, et pendant quelques heures seulement. Il n'en est pas ainsi du vautour : il est condamné à voler jusqu'à ce qu'il trouse des rictimes immolíes par la mort; pour lui, il n'y a pas d'arrondissement de chasse; il doit aller là vì la mort a frappé ses coups, tantòt près, tantòt très-loin. Il y a entre l'oiseau nuble et le vautour la même différence qu'entre l'vuvrier et le mendiant : l'un sait où, par son travail, il trouvera le pain nécessaire à si famille; 
l'autre l'attend de la charité publique, et, dès lors, il devient errant, vagabond, jusqu'à ce qu'une main charitable s'ouvre pour lui faire l'aumône, et, si cette aulmône est insuffisante, il doit recommencer ses pérégrinations continuelles. Que serait-ce, s'il devait, comme le vautour, recueillir de quoi assouvir une avidité insatiable! Le vautour est done un mendiant de la pire espèce, un bohême, et même moins qu'un bohême, car il ne peut se rassasier que des immondices entassées, préparées par la mort et par la putréfaction. Aussi les anciens, qui supposaient que Jupiter avait envoyé un aigle pour accomplir son œuvre de vengeance et dévorer le cœur et le foie du malheureux Prométhée, n'ont-ils pas tardé à remplacer l'oiseau qui porte la foudre par celui qui, consacré à Mlars et à Junon, symbolisait le carnage et la jalousie. Les Grees avaient peint les vautours par une expression très-énergique : ils les appelaient tapious EMPSychous, "sépulcres vivants. "

Le catharte est le plus petit et le plus sale de tous les vautours. Méfiant et rusé, il vit principalement de cadavres et d'immondices, et quelquefois de tétras, de rats et de taupes. Il niche dans des endroits inaccessibles, pose son aire dans les crevasses des rochers. Cette aire, formée de petites branches, est garnie de mousse et défendue sur le bord par des épines. La femelle pond, dans les mois de mai ou de juin, un ou deux œufs dont la longueur et le diamètre varient beaucoup ainsi que la forme et la couleur. Ils ont ordinairement $0^{\mathrm{m}}, 064$ de longueur et $0^{\mathrm{m}}, 052$ de diamètre. La plupart sont d'un blanc sale pointillé de rougeâtre ou de violet pâle. Quelquefois les taches forment une couronne ou une calotte vers le gros bout; d'autres fois, le rouge est d'une couleur si prononcée qu'il couvre entièrement la coquille et la fait ressembler aux œufs de Päques. Quelques-ıns enfin sont moitié rouges et moitié blancs. 


\section{$-46-$}

Plusicurs fois, dans le cours do ce travail, j'aurai l'oecasion de comparer les nuances de certains oufs à celles des ceufs que l'on distribue aux enfants et même à de grandes personnes, dans les jours qui précèdent la solennití de Pìques, et que, pour cette raison, on appelle mu/s de Padpues. Peut-être ne sera-t-il pas sans intérêt de rappeler ici l'origine de cette coutume et les circonstanees qui l'ont modifiće rlans le cours des siècles.

L'historien Alius Lampridius dit que, le jour de la naissance de .lare-Aurèle Sévère, une des poules de lit mère de ce prince avait pondu un œuf dont la coquille itait couverte presque entièremeut de taches rougeâtres. Cette princesse fut frappée de cette particularité, et elle s'empressa d'aller en demander la signification à un devin renommé. Celui-ci, après aroir examiné la coquille de l'œuf, répondit que cette nuance annonşait que l'enfant nouveau-né serait 1 m jour empereur des Romains. Pour ne pas exposer son fils à des persícutions. la mère garda son secret jusqu'en 22.4, année dans laquelle Marc-Aurèle fut proclamé empereur. Depuis ce moment, les Romains contractìent l'habitude de s'uffrir des aufs dont la corquille était revêtue de différentes couleurs, comme souhait d'une bonne fortune.

Les chrítiens sanctifièrent cette coutume, et y attachèrent une pensée de foi. En distribuant des oufs dans le temps pascal, ils se souhaitaient mutuellement une royauté, celle de triompher de leurs penchants, et, it l'exemple de Jísus-Christ, de régner sur le monde et sur le péché, en mourant à eux-mèmes, par la pratique de lat mortification. Servire Den reynare est (I alCor. I, (1). Les oufs de P'aques avaient done pour but de rapproler a ceus auxquels ils étaient ufferts que, comme MarcAurile, ils étaient appelís à régner et que, dè lors, ils deraient s'y préparer. L'est sous l'empire de cette pensie que les moines de l'ancienne abbaye de Saint-A ubin 
d'Angers avaient contracté l'habitude de faire servir sur leur table, pendant la semaine sainte, des cufs entourés de feuilles de tanaisie (tanacetum vulgare), plante amère de la famille des Composées, et qui se trouve en grande quantité sur les rives de la Loire. Ciette plante rappelait aux religieux, comme autrefois les laitues amères aux Israélites, qu’ils devaient penser à célébrer la Pâque, par la pénitence et par la mortification. Les mêmes œufs étaient servis à tous les repas de la semaine sainte, et les moines devaient se contenter de les voir en mettant à profit l'enseignement qu'ils annonçaient.

Le jour de Pâques, à la cathédrale d'Angers, deux ecclésiastiques, sous le nom de corbeilliers, se rendaient après Natines à la sacristie, prenaient l'amict sur la tête, la barrette sur l'amict, se revêtaient de l'aube, des gants brodés, de la ceinture et de la dalmatique blanches, puis, sans manipule et sans étole, ils se dirigeaient vers le tombeau. Là, chacun d'eux prenait un bassin sur lequel reposait un œuf d'autruche couvert d'étoffe blanche, puis se rendait au trône de l'évêque. Le plus âgé des deux s'approchait de l'oreille droite de l'évêque, et, en lui présentant le bassin contenant l'œuf d'autruche, disait tout bas, d'un air mystérieux : "Surrexit Domimus, Allehiia! Le Seigneur est ressuscité, Allehuia! „) L'évêque répondait : "Deo gratias, Alleluia! Grices à Dieu. Alleluia! » Le deuxième corbeillier faisait la même chose du côté gauche. Puis, chacun d'eux parcourait tous les rangs des ecclésiastiques, l'un à droite, l'autre à gauche, en commençant par les plus dignes, répétant les mêmes paroles et recevant la même réponse. Les œufs étaient ensuite reportés à la sacristie sur les bassins. Ces œufs faisaient partie du trésor de la cathédrale d'Angers. Voici ce qu'on lit dans un inventaire des religieux de cette église, écrit au xvı" siècle: "Il y a en outre dans le grand reliquaire deux œufs d'autruche soutenus par 
des chaînes d'argent. Le jour de Pâtques il faut mettre les deux ouf's d'autruche sur l'autel de Saint-René avec les deux gases. ")

Dans les inventaires des siècles précédents on trouve ces paroles: "Item, deux œufs d'autruche qui servent a donner les œufs de Pasques. ״

C'est it la coutume précédente que fiat allusion Urbain lenard, l'un des auteurs des Nuëls angevins :

\author{
La joie est angélique \\ A P'ique d'ouir \\ Cloches, orgues, musique; \\ Les Marie venir \\ Chereher dans le sépulcre \\ Jésus qui n’est plus là, \\ Puis portant oufs d'autruche, \\ On chante Alleluia.
}

(Page 28, édition de 1780).

Cies œufs annonçaient la royaute de Jésus-Christ, le commencement de son règne londé sur sa résurrection. L'wuf de l'autruche avait paru symboliser plus qu'aucun autre la résurrection spontanée de Jísus-Christ, puisque, abanảinné à lui-mème, il éclôt sous linfluence seulc. lu elimat brûlant des déserts. Le petit, pour sortir vivant de la coquille qui le retient captif, n'at besoin dn secour's ni de son père ni de sa mère, mais il sort triomphant par sa propre puissance. Dans un certain nombre d'églises, on remarque des exufs diautruche suspendus ilevant l'autel principal, comme souvenir de la résurrection de Jésus-Christ, base et fondement de la religion catholique. Dans quelques autres, les wufs d'autruche remplacent le gland placé ordinairement au-dessous de la lampe qui brûle jour et nuit devant le Saint-Sacrement, touchant symbole de ces paroles : "Christus surrexit, jum non moritur n..... "Le Christ est ressuscite; 
il ne meurt plus, et il répand la lumière, l'onction et la force maintenant et dans les siècles des siècles. ”

\section{DEUXIËME GENRE. - FAUCON.}

Le deuxième genre des Accipitrins comprend les faucons proprement dits.

L'étude de ces oiseaux présente de graves difficultés, parce qu'il existe de grandes variations dans leur plumage et dans leurs proportions selon l'âge, le sexe et la mue. Ces variations ont trompé beaucoup de naturalistes qui ont multiplié les espèces avec d'autant plus de facilité que les faucons, par leur vol hardi et rapide, par l'escarpement des lieux où ils se réfugient ordinairement, laissent à peine aux naturalistes le temps d'étudier leurs mœurs. Quelques remarques préliminaires pourront aider à distinguer et à classer les faucons.

Les jeunes ressemblent presque toujours à la femelle qui est beaucoup plus grosse que le mâle : tous les faucons ont des taches assez prononcées sur les plumes du ventre; ces taches s'effacent avec l'âge et disparaissent presque entièrement chez les vieux sujets. Lorsque les adultes portent les taches dans le sens horizontal, les jeunes les ont dans le sens perpendiculaire. Les jeunes enfin sont toujours plus fauves que les vieux; c'est cette particularité qui a fait donner aux premiers le nom de faucons sors, saures, vieux mot qui signifie " de couleur jaune, " comme on le voit par le mot hareng-saur.

Les faucons sont, de tous les rapaces, ceux dont le courage est le plus franc et le plus grand relativement ì leur taille. Ils fondent presque tous perpendiculairement sur leur proie, sans reculer devant aucun ennemi. Leur courage les avait fait remarguer des chevaliers du moyen âge, juges compétents en bravoure et même en témérité. Ceux-ci avaient utilisé les instincts des faucons 
en les soumettant it une ćducation longue et pénible qui les rendait aptes à une chasse dont le produit revenait ì leurs maîtres. L'art d'élever le faucon prit bientôt de grandes proportions, et constitua la fauconnerie, étude it laquelle s'adonnèrent les seigneurs et les vilains, pendant une longue série d'années. L'amour de la fauconnerie devint si vif que les seigneurs et les rois de France se livrèrent à cet amusement, même en Palestine, pendant les Croisades. Ces expéditions nous rappellent un fait curieux transmis par un historien de ces temps de ferveur chevaleresque : "Parmi les faucons du roi de "France, il s'en trouvait un de couleur blanche et d'une " espèce rare. Le roi aimait beaucoup cet oiseau, pt cet " oiseau aimait le roi de même. Ce faucon s'itant ́́chappé, " alla se percher sur les remparts de Ptolémaïs; toute "l'armée ehrétienne fut en mouvement pour rattraper "l'oiseau fugitif. Comme il fut pris par les musulmans " et porté à Saladin, Philippe envoya un ambassadeur au " sultan pour le racheter, et fit offrir une somme d'or " qui eût suffi à la rançon de plusieurs gutuerrier's chré" tiens."

Je crois devoir relater ici un autre fait que j'ai lu avec intérêt dans plusieur's revues. J'en laisse la responsabilité au rédacteur; mais, quand même cet épisode ne serait qu'une fiction, il prouverait que ceux qui l'ont composée étaient convaincus, avec raison, que les fancons sont susceptibles d'une éducation prompte et certaine :

"Devant Síbastopol, dans la journée du 4 novembre, an plus fort du bombardement, notre armée fit une perte regrettable : il ne s'agissait pourtant que d'un faucon, mais il faisait les délices des gardes des tranchíes, par l'amusant spectacle qu il leur donnait chaque jour.

"Il avait été amené en Crimée par un zonave, qui le tenait d'un chef arabe : les grands seigneurs algériens 


\section{$-51-$}

ont presque tous un goût très-prononcé pour la chasse au vol. Le zouave ne pouvant plus lancer son faucon contre le gibier, plus rare en Crimée qu'en Afrique, dressa l'oiseau à fondre sur un mannequin russe, coiffé d'une casquette, puis il l'habitua à rapporter cette casquette dans ses serres.

"Quand la nouvelle éducation du faucon fut terminée, il l'emporta avec lui dans les tranchées et le lança. L'oiseau prit son vol, aperçut des Russes couchés dans leurs embuscades, fondit sur l'un d'eux, enleva sa casquette et revint à tire d'aile, apportant son butin à son maître.

" On cria bravo sur toute la ligne des parallèles; les Russes étaient stupéfaits.

"Le faucon fut lancé une seconde fois; les sentinelles ennemies lui envoyèrent une volée de balles, qui se perdirent inutilement.

" L'oiseau s'enleva à une grande hauteur, et nos adversaires purent croire qu'il s'était envolé pour toujour's; ils se recouchèrent derrière leurs abris; soudain une sorte de pelote noire sembla se détacher du ciel, tomba avec une surprenante rapidité sur une embuscade, et décoiffa de nouveau une sentinelle.

“Les bravos redoublèrent dans nos lignes; les Russes étaient furieux.

“ Plusieurs officiers envoyèrent chercher des fusils de chasse à Sébastopol; ils attendirent le retour du fau:con. L'oiseau ne tarda pas à s'abattre sur un factionnaire, après avoir plané pendant quelque temps.

"Les chasseurs, qui le guettaient, tirèrent; ils le manquèrent; l'un d'eux envoya même une charge de plomb dans le dos d'un soldat qui, stupéfait de recevoir une blessure par derrière, et ahuri par la douleur, se mit à courir vers nos tranchées, où il fut reçu avec tous les igards dus au courage malheureux. Le faucon con- 
tinuait níanmoins le cours de ses exploits; toute lit garnison était accourue derrière les remparts, chacun suivait anxieusement du regard les péripéties de cette chasse aux casquettes.

" Lorsque l'oiseau partait de nos lignes, les assiégés purtaient aussitôt la main à leur coiffure; mais le faucon savait si bien choisir son temps, qu'il prenait toujours quelqu'un des assiégés en défaut.

"Les Russes commençaient à s'implatienter vivement de se voir à la merci du faucon : un oiseau bravant vingt mille hommes, il y avait de quoi exaspérer une armée! Les rires de nos troupiers surtout outraient les Russes; ils envoyaient des volées de mitraille sur les points où ces rires éclataient. Un incident grotesque mit le comble ì la fureur de l'ennemi.

" Un général chargé de visiter les batteries parut avec son état-major; le faucon remarqua ce groupe qui se détachait du reste des troupes; il trouva sans doute la casquette du général plus belle que les autres; il la lui enleva. Il y eut dans l'armée ennemie un cri d'indignation générale; cette clameur stridente dérouta probabilement le faucon. $\mathrm{Au}$ lieu de revenir vers nos tranchées, il alla placer la casquette sur un grand mât de signaux, puis se percha sur les cordages; on lui envoya plus de mille balies. Effrayé par les sifflements des projectiles, il parut hésiter un instant; il prit son vol, laissa la coiffure du général à la cime du mât et revint vers nous à tire d'aile. Aussitôt un Russe s'élança vers le mât et grimpa jusqu'au sommet pour rapporter la casquette du général; malheureusement pour ce paurre diable, les franes-tireurs tenaient à prolonger la plaisanterie; le Russe fut atteint par leur's balles arant d'ètre arrivé an but.

"Plusicur's des marins ditachés au service des balteries renouvelèrent sans snceis cetle tentative dangereuse; 
il fallut laisser la casquette où elle était. Nos soldats se mirent alors à chanter ce fameux refrain :

"As-tu vu la casquette au père Bugeaud;

“ Si tu ne l'as pas vue, la voilà !...

"Les clairons accompagnaient.

"Nos soldats savent au besoin improviser des couplets. Un composa une complainte qui fit le pendant de celle du paletot noisette de Menschikoff. On la rédigea au crayon, on la roula autour d'une balle, et les arantpostes la lancèrent aux Russes. Ils avaient les paroles, et ils eurent le loisir d'entendre l'air. On chanta jusqu'au soir, le tout semé de coups de fusil et de coups de canon.

" La chasse au faucon avait trop égayé l'armée pour ne pas recommencer souvent; on n'imagine pas à quel point en était arrivée la rage de la garnison. Chaque jour on ajoutait de nouveaux couplets à la complainte; on exposait au-dessus des parapets les casquettes enlevées par l'oiseau, comme les sauvages exposent dans leurs camps les chevelures de ceux qu'ils ont scalpés.

"Enfin ces scènes décapitantes eurent un dénoûment tragique.

"Dans la journée du 4 novembre, le faucon fut sans doute rencontré par un boulet pendant qu'il s'élevait en l'air. Un bout d'aile tombé dans la tranchée nous annonça ce malheur.

" Les Russes furent ainsi délivrés de leur persécuteur.

"Il y a tout lieu de croire qu'ils ne pleurèrent pas sur son trépas ${ }^{1} \cdot \|$

Les faucons volent avec une rapidité extraordinaire; ils doivent cette puissance de vol à la conformation de leurs ailes. La deuxième remige est beaucoup plus longue que la première et que la troisième, particularité qui donne à leurs ailes la forme d'une faulx et leur a

${ }^{1}$ Louis Noir, Souvenirs de l'expédition de Crimée. 
mériti, selon quelyues auteur's, le nom de "faucheurs, " fulcrli. Tous les oiseaux de ce genre, bien différents, en cela, des hommes, deviennent plus heaux à mosure yu'ils vieillissent; tous donnent à leurs maîtres des preuves multipliées d'un attachement sincère et d'une fidélité inaltérable.

Les faucons les plus propres à la chasse sont le gerfault, le pèlerin, le hobereau et l'émerillon. Tous ont le bec échancré de chaque cêté en torme de dent, disposition d'une grande utilité pour lépecer leurs victimes, et qui sert en même temps à les distinguer des autres oiseaux de proie. Les faucons présentent une singularité qui n’a pu être expliquée, jusqu’à ce moment-ci, d'une manière satisfaisante, et qui se retrouve aussi chez les autres rapaces, mais avec un caractère moins prononcé. Lat femelle est beaucnup plus grosse que le mâle, éest jourquoi un certain nombre de ces accipitrins ont reçu le nom de tiercelets, parce gue la différence entre le mâle et la femelle est souvent du tiers de la grosseur totale. Deux raisons me paraissent justifier cette disposition : la grosseur des femelles peut être attribuée au cocum qui est double chez elles et simple dans les mîles ', un plutiot à l'attention de la Providence qui a diparti plus de force à la femelle. Elle est presque seule chargéc de pourvoir à la nourriture de ses petits, et elle ne pent la leur procurer que par des courses pénilbles et des combats incessints. Cette supériorité de courage et de force dans la femelle est confirmée par l'llistoire de la Fancomerie. Le mâle était consacré à prendre less pertrix, les geais, les merles, les alouettes, et lit femelle destince à la chasse du lièrre, du milan et même de la grue.

Cing de ces futucons habitent ou visitent l'Anjon.

I Le cacum est une branche des intestins placie entre l'intestin grèle et le colon. 

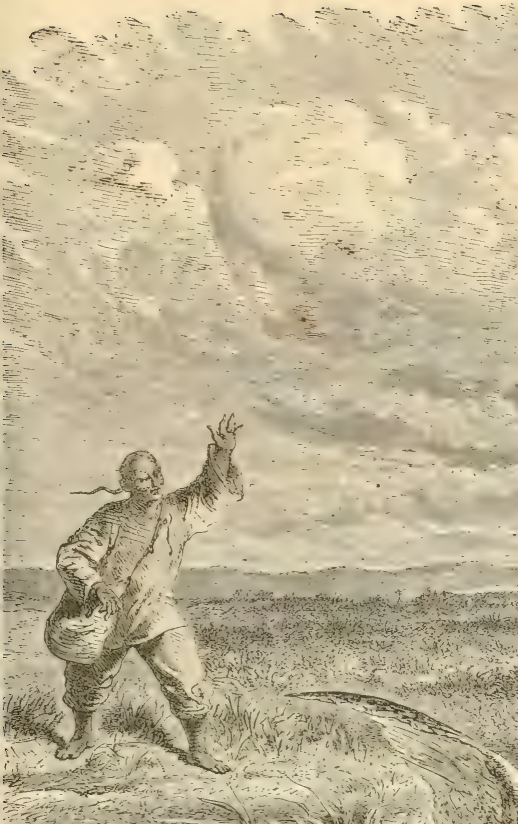

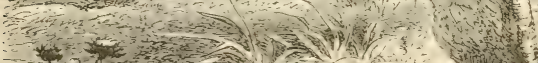

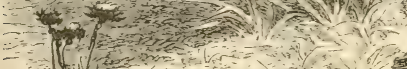

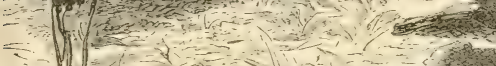

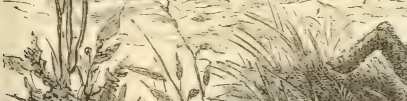

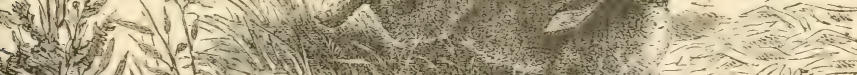

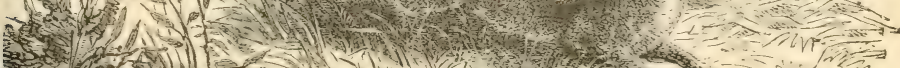

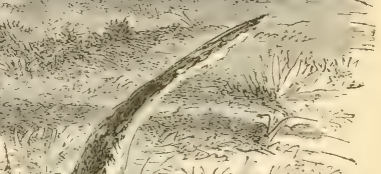
135)

4. (4)

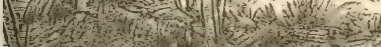
Pen

La chasse du lièvre, au faucon, dirigée par un habitant du Céleste-Empire. 



\section{FAUCON PÉLERIN. - FALCO PEREGRINUS.}

Ce bel oiseau qui, chaque année, traverse deux fois l'Anjou, en immolant bon nombre de victimes, doit son nom ì son amour et à son besoin des excursions, des pérégrinations, de peregrinare, "voyager, " mot qui dérive lui-

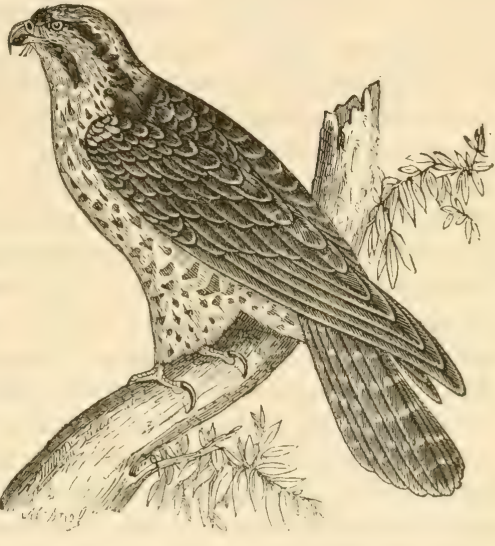
même de peragros, "à travers les champs. ) Cette dernière étymologie fait connaître exactement la manière de chasser de ce faucon, qui vole en rasant la surface des champs arec une grande rapidité, pour faire lever et pour saisir les oiseaux cachés dans l'herbe et derrière les mottes de terre. Le faucon pèlerin pond, sur une aire plate formée de petites branches recouvertes de racines et de mousse, trois ou cinq œufs un peu arrondis, d'un rouge de brique plus ou moins rif, sur lequel on aperçoit des taches de brun qui forment en quelque sorte une deuxième couche irrégulière plus foncée que la première. Ces œufs pourraient être confondus avec ceux de la buse bondrée, mais ils sont généralement plus gros, et ont des caractères communs à ceux de tous les faucons. La coquille est plus légère que celle des autres rapaces, puis elle est blanche à l'intérieur, tandis que celle des buses est d'un vert plus 
on moins foncé. Les cuf́s du laucon pùterin ont ordi-

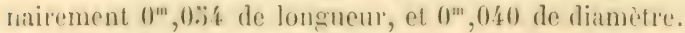
L'aire de ce rapace est confire aux anfractunsités des rocher's, ou aux buissons touffus qui se trouvent sur le versant des montagnes exposíes au midi. Le faucon pèlerin, comme tous les oiseaux dont quelques couples nichent indifféremment dans les forêts ou sur les montitgnes, varie dans le temps de sa ponte. Ceus qui choisissent les rochers escarpés pour y ilever leurs petits pondent presque un mois plus tard que ceux qui nichent diuns les forêts. Les couples qui se reproduisent dans les Pyrénées ont des œufs dès le mois de férrier. Le vol du pòlerin est si puissant qu'il visite chaque année presique foutes les contrées de l'Europe. Mlusieurs foris, depuis 18:30, quelques-uns de ces rapaces se sont arrêtés sur la tour de la Trinité et sur les flèches de la cathédrale, pour y sijjourner pendant plusieurs jours. De ces points culminants, ils se précipitaient sur les piceons qui rultigeaient autour des maisons de la rille, les enlevaient avec la rapidité de l'éclair, et les mangeaient après les avmr plumés à loisir, malgré les eris des curieus, témoins de ce spectacle.

\section{FAUCON HOBEREAU. - FALCO SUBBUTEO.}

L'épithète donnée à ce rapace peut venir du vieux mot français holber, "royager souvent, gèner ses voisins, ou de hobel, "oiseau de proie du genre milan, ") d'où "hoberean, " petit milan. Ce fiucon chasse sourent, et sun voisinage est peu agréable à bien des viseaux. C'est lui qui avait ilonné son nom aux petits scigneurs du moyen âge, dísignís sous le nom de hobereaux, parre qu'ils étaient les tyrans de leurs voisins ou de leurs serfs. Quclques anleurs pensent que l'on avait appelé ainsi les seigneurs yui, n'ayant pas les ressources nécessaires pour créer 
une fauconnerie complète, se bornaient à élever quelques hobereaux qu'ils portaient sur le poing. Subbuteo signifie "sous-buse, " nom donné autrefois à un certain nombre de rapaces, mal classés, mal déterminés. Était-ce parce que ces oiseaux sont inférieurs à la buse par les dimensions de leur taille et par la puissance de leur voix ? Quoi qu'il en soit, le hobereau l'emporte sur la buse par l'énergie et le courage. Il paraît ne pas connaitre et ne pas craindre l'effet des armes à feu. Quand il aperçoit un chasseur accompagné de son chien, il le suit ou le précède, saisit le gibier que le chien a fait lever, soit avant qu'il ait été tiré, soit après, et souvent il presse avec une telle ardeur la proie qui a été lancée, que le chasseur abat d'un même coup de fusil le hobereau et sa victime. Ce faucon, que l'on confond quelquefois avec l'émerillon, s'en distingue par des proportions plus fortes, une moustache plus prononcée, des ailes plus longues et la couleu' des plumes du ventre, qui sont blanchâtres chez le hobereau et de couleur fauve chez l'émerillon. Le hobereau pond, dans le mois de mai, quatre ou cinq œufs d'un blanc sale pointillé de rouge et de petites taches noirâtres ou olivâtres qui forment quelquefois une couronne vers le gros bout. Ces œufs sont un peu plus oblongs que ceux des autres faucons, et ont ordinairement $0^{\mathrm{m}}, 033$ de longueur, et $0^{\mathrm{m}}, 027$ de diamètre. L'aire de ce rapace est construite comme celle du pèlerin; mais il la confie it la cime des arbres les plus élevés. Quelques-uns de ces nids ont été trouvés en Anjou, et j’ai reçu, cette année, des œufs de hobereau dénichés dans la forêt de Brissac.

\section{FAUCON ÉMERILLON. - FALCO ESALON.}

Le mot émerillon vient de l'italien smerylione, en ajoutant un $e$ devant, comme dans "espérance" de spe- 
rmza, et dans "épervier, " espervier, de sparvarius. Etant. formé d'une particule et d'un nom qui sionifie "merle, " il ferait connaître que ce faucon "chasse les merles. ) Dans cette hypothèse, le mot émerillon conviendrait encore beacoup mieux à l'épervier que lesgens de la campagne appellent, dans leur languc expressive, fesse-merle. Le faucon hobereau est désignó en italien par le mot smerlo, qui a la même signnification. Le mot savant peut dériver de Aeї, aï, " toujours, ) et salecò, "agiter, ) dont la racine salos, " agitation des flots, " indique d'une manière expressive les mouvements incessants etrapides de ce rapace. Mais la véritable racine est aїтнaLos, " noirci par le feu, » dont le principeest aїтıò, "brûler. ) Cette dénomination convient ì l'ímerillon sous ce double rapport. Il est très-ardent à la chasse. Il brûle, il dérore sa proie; quant à son plumage, d'un jaune noirâtre, il semble avoir été noirci par la fumée. Dans plusieurs ornithologies, on le nomme rochier et lithofulco, "faucon des rochers, " parce qu'il aime à construire son aire dans les fentes des rochers des régions froides et boisées du nord de la Russie. L'émerillon, à cause de sa lígèreté et de ses formes gracieuses, était recherché des jeunes pages et des dames qui accompagnaient les seigneurs dans leurs chasses. Ce petit rapace a un vol très-rapide, et l'on cite un fait trèsremarquable de sa puissance. Un émerillon appartenant it Ilenri II s'emporta après une caneptière dans une chasse aux environs de Paris, et fut pris le lendemain dins l'île de Malte, où il fut reconnu à l'anneau royal qu'il portait au tarse. La femelle de cette espèce n'est gutuere plus grosse que le mâle; elle pond ver's le mois de mai, dans un nid suspendu à la cime des arbres, cinq ou six cufs moins gros que ceux du hobereau, plus ronds, d'un rouge pâle parsemé de taches d'une couleur plus foncée. 
FAUCON a PIEDS ROUGES, KOBEZ. - FALCO RUFIPES.

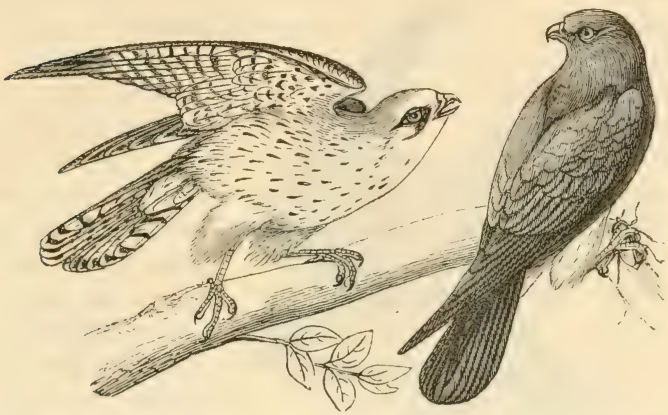

Ce faucon, un des plus petits et un des plus gracieux du genre, doit son nom à la couleur des pieds du mâle (rufus pes, "pied rouge»). L'adjectif vespertinus, "faucon du soir, ") sous lequel il est classé dans plusieurs musées, peut lui avoir été donné à cause de la couleur des plumes du mâle, qui sont d'un noir pâle et sombre comme les premières ténèbres de la nuit, ou à cause de son habitude de rechercher les endroits les plus obscurs des forêts pour se cacher sous le feuillage et pour y guetter sa proie.

Cet oiseau niche dans le nord de la Russie et dépose, dans une aire placée à l'extrémité des arbres, trois ou cinq œufs un peu plus petits que ceux de l'émerillon, et dont le fond plus blanc est parsemé de petits points rouges. L'épithète de kobez ou kober, sous laquelle ce rapace est connu généralement, est le nom populaire qui lui est donné en Russie où il est très-commun. Ce faucon visite très-rarement l'Anjou; il vit plutôt d'insectes que d'oiseaux. 


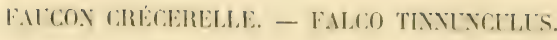

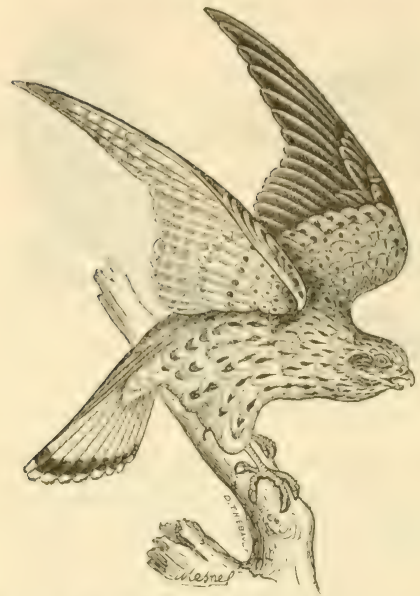

Le nom de crécerelle vient de KRÉкô, « retentir, faire du bruit, ) et désigne le rapace dont la voix a quelque chose de strident et de répété, assez semblable au son de l'instrument qui, dans les communautés, remplace les cloches, aux jours de deuil. Timmunculus peut être dérivé de TrNassô, " darder, agiter, ") et de oxkos, uncus, "crochet.) Cette étymologie serait alors fondée sur une habitude particulière à ce faucon qui, pour chasser sa proie, s'élive à des hauteurs prodigieuses, et se suntient en l'air sans changer de place, en agitant ses ailes et ses serres avec une grande rapiditi, jusqu'à ee qu'il ait aperçu une victime. Alor's il se laisse tomber avec la rapidité de la flèche, pour se relever perpendiculairement, en emportant sa proie dans ses serres.

Ce faucon, sous le double rapport du bee et des serres, est le moins bien armé de tous les faucuns proprement dits. Aussi, sous le rène de Louis XIII, l'avait-on, un peu par mépris, dressé à la chasse de la chativesouris. Enfin timmenculus vient peut-être de timmulus, qui signitie "rendant un son clair et aigu » comme celui des métaux, de limnio, "rendre un son clair, métilligue." 
C'est donc avec raison que par l'instrument nommé crécerelle on peut remplacer les cloches. Dès-lors ce mot pourrait s'appliquer à la crécerelle, parce qu'elle fait entendre un cri perçant et clair : vocem reddit tenuem et tinnulam. Ce rapace, autrefois très-commun en Anjou, est devenu rare à cause de la guerre acharnée qu'on lui fait. Il niche ordinairement dans les vieilles masures, surtout lorsque l'ouverture des crevasses est dérobée aux regards par des festons de lierre; quelquefois il choisit un vieux nid abandonné par les pies ou par les corneilles. Souvent un couple revient plusieurs années de suite dans le même nid. Ainsi, depuis trois ans, un couple de crécerelles a établi son domicile au sommet de la tour Saint-Aubin, à Angers, et à chaque printemps, pendant quelques mois, lorsque les petits sont assez forts pour essayer leur vol, on peut jouir du spectacle intéressant de l'éducation de ces jeunes rapaces. Le père et la mère les accompagnent dans leur vol, les excitent et les modèrent tour à tour, leur apprennent à poursuivre et ì saisir leurs victimes. Un cri très-accentué et très-différent se fait entendre selon que les petits ont atteint ou manqué la proie qu'ils poursuivaient. C'est une marque de satisfaction ou un reproche qui s'échappe d'une manière stridente du gosier du père ou de la mère. Dans leurs premières courses à travers les régions de l'air, les petits sont accompagnés de l'un et de l'autre. Ceux-ci voltigent autour d'eux, les soutenant en quelque sorte de leurs ailes. Bien des fois j'ai vu le père ou la mère diriger, par ses cris et par son vol, vers les bancs de fer qui entourent le sommet de la vieille tour Saint-Aubin, le petit qui paraissait fatigué et que ses parents jugeaient avoir besoin de repos.

Les œufs de la crécerelle, au nombre de cinq à sept, sont déposés sur des débris de racines, de mousse ou de feuilles desséchées, et ont $0^{\mathrm{m}}, 033$ de longueur, et $0^{\mathrm{m}}, 026$ 
de diamètre. Leur couleur est d'un rouge plus ou moins foncé, et striée de taches d'un brun rougeâtre. Les œuls des jeunes femelles sont moins chargés de taches, et d'une couleur plus pîle que ceux des vieilles. Quelquesuns sont blancs, d'autres couleur isabelle.

La crécerelle vit moins solitaire que ses congénères, et il n'est pas rare de voir quatre ou cinq couples composer, en quelque sorte, une petite société dont les membres vivent en bonne intelligence et se soutiennent mutuellement dans leurs chasses et ì l'approche du danger.

\section{TROISMÈME GENRE. - AMGLE.}

Le troisième genre des rapaces diurnes comprend les Aigles, qui se distinguent des autres oiseaux de proie par leur tête aplatie et par leur bec droit, dont la mandibule supérieure est plus longue que l'infírieure et trèsrecourbée à son extrémité. Les aigles tiennent le premier rang, parmi les rapaces, par leur force musculaire, par leur énergie et par la puissance de leurs serres. Ils vivent tous de proie vivante, dédaignent les insultes des oiseaux plus petits qu'eux, et enlèvent dans leur's serres les victimes qu'ils ont choisies, pour les dépecer sur les rochers escarpés. Quand leur proie est trop pesante, ils la mangent sur place, en abandonnant les débris aux autres oiseaux. Quelquefois du haut des airs, ils la laissent retomber sur les montagnes, afin de la briser et de l'emporter' ensuite avec plus de facilité. Ce moyen, ils l'emploient surtout pour rompre la carrapace des tortues dont la chair est pour eux un mets de prédilection, et c'est à cette habitude des aigles qu'a été dùe la mort d'Eschỵle. Ce poète, plus connu par ses tragédies que par le courage qu'il avait manifesté dans les combats de Marathon, de Salamine et de Platée, avait consulté, dans sa jennesse, un 
célèbre devin qui lui avait annoncé que la chute d'une maison serait la cause de sa mort. Afin d'éloigner autant que possible cet instant fatal, Eschyle évitait de séjourner dans les habitations et surtout d'y dormir. Une fois qu'étendu sur l'herbe, le poète se livrait aux douceurs du sommeil, un aigle, qui enlevait dans ses serres une pesante tortue, crut reconnaître, dans la tête entièrement dénudée d'Eschyle, la pointe d'un rocher, et laissa tomber d'une hauteur prodigieuse, sur le front du dormeur, la carapace de sa proie. Le choc fut si violent que le crâne d'Eschyle fut entièrement brisé, et ce fut ainsi que, vers l'an 436 avant J.-C., s'accomplit la prédiction du devin.

Tous les avantages dont les aigles sont doués ont été remarqués, non-seulement par les naturalistes, mais encore par les guerriers et par les monarques. Les uns et les autres se sont plus à prendre l'aigle comme le symbole de leur courage et de leur puissance, et à placer son effigie au-dessus des drapeaux qui devaient conduire les soldats au combat et à la victoire. Une particularité conservée dans l'histoire, et fondée sur une observation ornithologique, explique pourquoi les Polonais ont adopté pour enseigne un aigle blanc. Les aigles, comme les faucons, les milans, les chouettes, etc., quand ils sortent de l'œuf, sont revêtus d'un duvet soyeux et parfaitement blanc; ce duvet disparaît avec l'âge pour être remplacé par un plumage plus ou moins fauve. Lochus, premier roi de Pologne, trouva, lorsqu'il jeta les fondements de sa première ville, une aire contenant un petit aiglon courert d'un très-beau duvet blanc. Pour conserver le souvenir: de cet événement, dans lequel il voyait un présage de la grandeur de son nouveau royaume, ce prince adopta comme emblème l'aigle blanc, qu'il représenta par un aigle d'argent.

L'aire des aigles est composée de perches de $4^{\mathrm{m}}, 50$ ì 
2 metres de longueur, recouvertes de plusicurs couches de ratrines et de mousse grossière. Ces perches sont appuyées par leurs extrémités sur les rochers, tans un lieu sec et inaccessible. Le nid n'est abrité que par l'avancement des parties supérieures du rocher. Quelques-uns de ces rapaces nichent ì la cime des arbres, dans les buissons touffus suspendus aux flanes escarpés des montagnes, ou enfin au milieu des roseaux des marais impriaticables. Une aire sert au même couple pendant un grand nombre d'années. C'est dans ces nids que les femelles pondent un, deux ou trois œufs, et une scule fois par an. Cinq, sept et même dix jours s'écoulent entre la ponte de chacun de ces œufs. Le plus souvent un seul est fécond. La P'rovidence a limité le nombre de ces terribles rapaces, dans leur intérêt et dans celui de la propagation des autres oiseaux. Plus nombreux, les aigles exerceraient trop de ravages, et ne pourraient se procurer asse/ de victimes pour leur subsistance. Ordinairement, quand deux œufs se sont trouvés féconds, on n'aperçoit qu'un seul aiglon vivant; l'autre a été tué par le mâle et est étendu sans vie sur le bord du nid. Ce n'est pas un motif de froide cruauté qui a poussi. l'aigle à immuler son petit, mais la difficulté dans laquelle il s'était trouvi de pouvoir suffire à en nourrir plusieurs, sans se livrer a une chasse continuelle et très-pénible. Le véritable motif de cet acte odieux est donc un sentiment d'éguïsme. Les aiglons restent, en effet, dans leur nid jusqu'à ce qu'ils soient assez forts puur virre de leur propre chasse, et plusieurs faits, arrivís dans les Alpes et les Pyrénées, ont démontri la srande quantité de victimes que ces jeunes rapaces absorbent. Des familles entières ont vécu, pendant trois ou quatre semaines, des plus belles pièces de gibier qu'un montagnard hardi allait chaque jurr, au moyen d'une corde nouée, chercher dans l'aire de ces infatigables chasseurs. Quand l'aiglon abandonne 
son nid, la femelle l'accompagne, pendant quelque temps, pour le protéger, et bientôt elle rejoint le mâle, afin de chasser avec lui, après avoir toutefois éloigné son petit, même pai la force. Tous deux ne laissent aucun autre aigle chasser dans le canton qu'ils ont choisi. L'un se tient dans un lieu élevé, tandis que l'autre bat la campagne. Presque toujours, dans leurs courses, ils partent et reviennent à la même heure, parcourant la même route: on a pu constater cette habitude dans les deux couples de balbuzards qui ont séjourné cette année, pendant plusieur's mois, dans l'espace compris entre Bouchemaine et Ecouflant, théâtre de leur pêche abondante. Une vieille femelle, appartenant à un de ces couples, a été tuée par M. Garin. C'est cette habitude qui permet aux chasseur's de se placer en embuscade et de les faire tomber sous leurs balles. Les aigles chassent le plus souvent le matin et le soir, et se reposent pendant le milieu du jour. Ils s'élèvent à des hauteur's prodigieuses sans être gênés par les rayons du soleil, dont ils supportent l'éclat au moyen d'une deuxième paupière transparente qu'ils abaissent ou relèvent à volonté. Cette puissance de vol, et cette facilité des aigles à braver les rayons du soleil, ont donné lieu à toutes les fables de la mythologie et procuré à ces rapaces l'honneur d'être consacrés à Jupiter, et de porter ses foudres; l'un d'eux, le balbuzard, a même été appelé Pandion, de Pás, " tout, " Dlos, "de Jupiter, orné de tous les dons de Jupiter. " Ce nom rappelle aussi les malheurs du roi d'Athènes, dont les filles, Progné et Philomèle, furent métamorphosées en hirondelle et en rossignol.

Les aigles vivent très-longtemps et blanchissent en vieillissant. Les maladies ou une longue diète produisent sur leur plumage le même résultat. Les aigles, comme tous les rapaces qui mangent des mammifères et des oiseaux, sont pourvus d'une poche analogue au jabot des 
pigeons; en terme de fauconnerie, cette poche s'appelait la mulette.

Chez les aigles, la femelle commande toujours, et le mîle obeit arec une soumission qui semblerait prouser qu'il reconnaît son infériorité. Dans les circonstances difficiles, la femelle vient en aide au male; mais ordinairement elle jouit du spectacle des combats et des courses de celui-ci, et n'abandonne son observatuire que pour partager le fruit de la chasse.

Sir espèces d'aigles se sont montrées en Injou.

\section{AIGLE BONELLI. - FALCO BONELLI.}

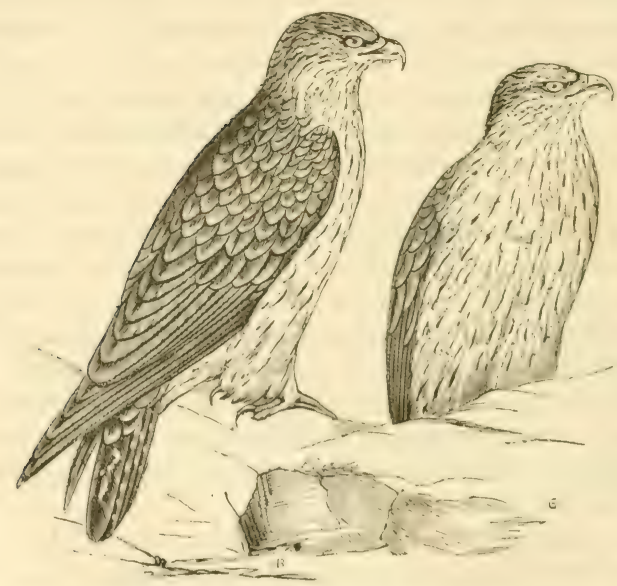

Le mot aigle est la traduction du mot látin aquilu, qui lui-mème peut être considiré comme un adjectif ajouté at aris ou it fulco. Dans cette hypothèse, il signifierait, 
d'après son sens ordinaire, "faucon brun," aquilus, et selon Robert Estienne, "faucon noir et mélangé de blane, " définition la plus exacte qui puisse s'appliquer ì tous ces rapaces.

II. Littré dit que certains auteurs font dériver aquila du sanscrit açu équivalant à ôcus, "rapide. ) Dès lors le mot aigle signifierait « oiseau rapide par excellence. » S'il en était ainsi, cette dénomination conviendrait bien mieux aux véritables faucons qu'aux aigles proprement dits. Le même auteur ajoute, avec raison, que les expressions aquilus, "noirâtre, " et aquilo, "vent du nord, " ne paraissent pas sans analogie avec aquila. En effet, aquilo, "vent du nord, " exprimerait non-seulement la ( rapidité, " mais la "désolation, ) en un mot l'idée de " tourmente. " L'épithète uquila indiquerait done que l'oiseau qui porte ce nom passe "rapidement, " comme le vent du nord, et que comme lui sa présence apporte la "désolation. " Quant à l'adjectif aquilus, " noirâtre, " que j'avais indiqué déjà comme pouvant être la racine d'aquila, je serais d'autant plus porté à lui donner la préférence sur toutes les autres étymologies, que cette hypothèse me paraît justifiée par un mot consacré dans la langue de la fauconnerie. On appelle, en effet, aiglure l'ensemble des taches rousses dont le plumage des oiseaux est parsemé. Enfin, pour compléter ces renseignements, je rapporterai l'opinion de Court de Gébelin, qui me semble aussi être assez plausible. Selon cet auteur " aquila vient de ac, "pointu," et al, " oiseau, " et signifie mot à mot " oiseau pointu, au bec crochu, ") figure de l'aigle si remarquable, qu'on a nommé aquilin tout ce qui est long, pointu et recourbé!» (Tom. VI, page 10.)

L'aigle Bonelli porte le nom d'un savant professeur piémontais connu par d'importantes découvertes. Il a été décrit pour la première fois par le chevalier de la Mar- 
mora. Celui-ci l'avait tuí dans les montagnes de la Sitrdatigne. Cet accipitrin se distingue des autres aigles par la couleur des plumes du ventre, d'une couleur de rouille strice de petites taches noirâtres en forme de larmes, jar la petitesse de son bec, par la force de ses serres et enfin piar la longueur de son tarse couvert, jusqu'aux doigts, l'un poil fin. Le plumage du ventre blanchit à mesure que l'oiseau devient plus adulte. Les taches diminuent de grandeur et s'effacent, à la lonsue, presque entièrement. Le Bonelli habite quelques contrées méridionales de l'Europe; un jeune mâle de cette espèce a été tué en Anjou, dans la forêt de .I. le comte Wralsh de Serrant. Cet aigle suspend son aire aux crevasses des rochers, jond un ou deux cufs de $0^{\mathrm{m}}, 06(3:)$ à $0^{\mathrm{m}}, 070$ de longueur. ut $0^{\mathrm{m}}, 0: \mathrm{i} 2$ à $0^{\mathrm{m}}, 0: 3 \mathrm{n}$ de diamètre; ils sunt ordinairement d'un blanc sale strié de petits points rougeâtres et imferceptibles, ou d'un brun rougeâtre plus ou moins pâle. avec des taches effacées et formant des marbrures ou the deuxième couche irrígulière et plus foncée. La première description convient seule aux véritables wuls de l'aigle Bonelli. La seconde détermine ceux du nexins, trop souvent confondus avec les œuls de son congénire.

l'et aigle est encore appelé souvent fasciata, ou " it quene barrée, " parce que sa quene est marquée endessous de neuf à dix bandes transversales.

\section{AIGLE CRIARI), - FALCO NEVIUS.}

Cet aigle doit son nom vulgaire aux cris plaintifs qu'il pousie pendant ses chasises et mime quand il est perché. Les épithètes plamy", clomina, constatent la même habiturle. On l'appelle aussi muturia, à cause de sa prédilection pour la chasse aux canards, anates. Les noms 
srientifiques navius, maculatus, font allusion ì son pluınage d'un brun obscur et marqueté sur les jambes et, sous les ailes de taches blanches. Il a aussi sous la gorge une grande zône blanchâtre. Cet aigle voyage quelquefois par bandes de quatre à six individus. Sa présence a été constatée plusieurs fois en Anjou, pendant l'hiver. Il suit les bandes de canards ou d'oies sauvages, qui lui fournissent une copieuse nourriture. Cet aigle pond, vers

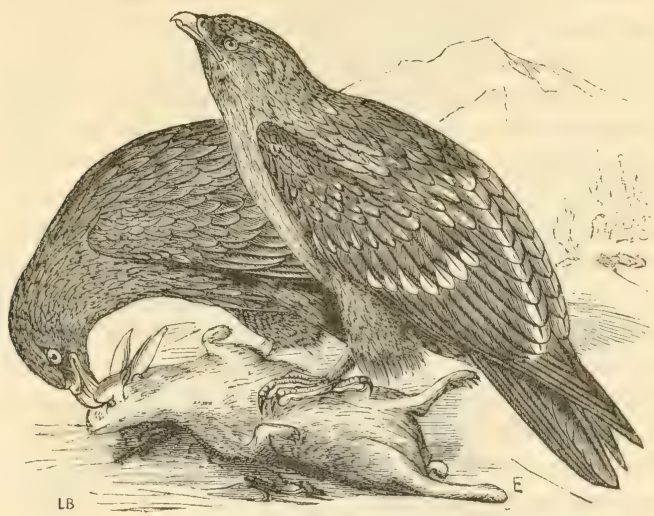

la fin d'avril, deux ou trois œufs qui varient beaucoup quant à la grosseur, la couleur et l'abondance des taches ou des raies. Ils ont le plus souvent $0^{\mathrm{m}}, 064$ de longueur, et $0^{\mathrm{m}}, 056$ de diamètre. Quelques-uns sont d'un blanc sale et tacheté de gris, de violet ou de jaune effacé; d'autres ressemblent à ceux de la buse ordinaire, mais sont plus gros et portent des taches plus foncées qui forment une couronne vers le gros bout. La couleur verdâtre de l'intérieur de la coquille, commune aux buses et aux aigles, ne peut servir à les distinguer. D'après les 
iludes des naturalistes modernes, on distingue maintenaut l'aigle criard, Fulco clanga, et l'aigle tachetí, Fulcu nuvius. Ce dernier est plus petit que le précédent.

\section{AIGLE BOTTÉ. - FALCO PENNATUS.}

Cet aigle, très-petit et très-gracieux, doit ses deux noms it ses tarses emplumés jusqu'aux doigts. Plusieurs conples ont habité l'Anjou et niché à la cime de la forêt de Bangé et de celle d'Ombrée, près Combrée. Ce rapace a souvent étí pris pour la buse pattue; mais en dehors des signes caractéristiques des aigles, il s'en distingue encore par un bouquet de plumes blanches it l'insertion des ailes et par la couleur brune de sa queue : celle de la buse pattue est blanche. Les æufs de l'aigle botté ont $0^{\mathrm{m}}, 0: 36$ de longueur, et $0^{\mathrm{m}}, 042$ de diamètre. Leur couleur est d'un blane sale, sur lequel se remarqueut quelquefois des taches irrégulières et presque effacées, d'un vert ou d'un jaune très-pâle. Quelques-uns sont parsemés de taches violettes et fondues dans la nuance blanchitte de la cogquille. Ils diffèrent de ceux de l'autour et de la buse commune par le grain de la coquille, qui est couverte de petites aspérités.

\section{AIGLE PYGARGUE. - AOUILA ALBICILLA.}

Quelques naturalistes ont voulu síparer les pyeareues des aigles proprement dits; mais leur opinion na pats ití adoptée généralement. Cependant les prgargues se distinguent des aigles purs, par leur's jambes nues, par leur bee hlane ou jaune, et par les lieux qu'ils fréquentent ordinairement. Ils n habitent ni les lieux déserts, ni les hautes montagnes. Le nom de pygargue est formi de 
PIGHE, "fesse, et par extension queue, " et angHt, "blanche, » nom qui lui convient très-bien, parce que cet aigle a les plumes de la queue d'un blanc pur, quandil estadulte. Onl'appelle albicilla, de album, «blanc, ) et cilium, "cil,»

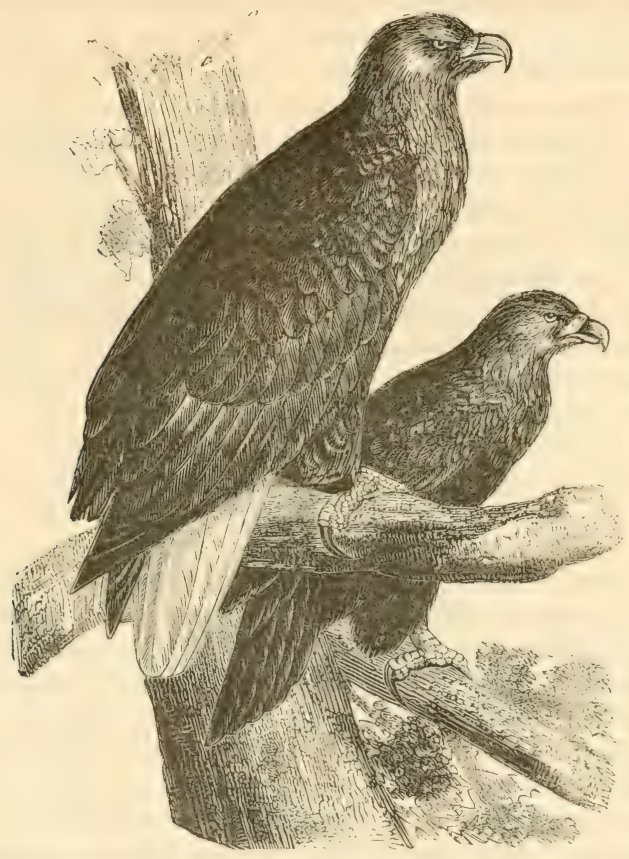

venant lui-même de cilleo ou cillo, " mouroir, agiter " (кELLô, "mouvoir arec vitesse "). Ses cils sont, en effet, d'un blane très-prononcé. Buffon le nomme aussi orfraie, ossi fraga, "qui brise les os, " pour indiquer la puissance de son bec. Les anciens le désignaient sous le nom 


\section{$-7.4-$}

te himmlarin, de himmlus, "faon," parce qu'ils pensaient que cet aigle est assez fort pour attaquer les jeune's daims et les jeunes chevreuils. Le pygargue se précipite avec une telle rapidité sur les phoques, qu'il devient souvent la victime de sa voracité. Ses serres se trouvent engagées dans la peau des phoques qui le noient en entraînant au fond de la mer ce terrible adversaire. Cet accipitrin parait en Maine-et-Loire de temps en temps; il y vit principalement de poissons et de canards. Ses œufs, d'un blane sale, sont quelquefois parsemés de taches de rouille plus ou moins prononcíes; la coquille en est assez. lisse, particularité qui les distingue de ceux du Jean-le-Blane, auxquels ils ressemblent souvent pour la grosseur et même pour la forme, mais qui sont couverts de petites aspéritís. Ils ont $0^{\mathrm{m}}, 068$ de longueur, et $0^{\mathrm{m}},(0 . \mathrm{j} 4$ de diamètre. Le prgargue niche, dans le mois de mars, sur les arbres des iles du Volga.

AIGLE BALBUZARD. - AQUILA HALIETA.

Le mot bulbusard est composé de deux mots anglais, buld-buzzard: bald, "chauve, " et buzzard, " aigle, oiseau de proie chauve. n Cette dénomination est fundée sur quelques caractères de ce rapace. Il a la tête très-aplatie et recouverte de petites plumes effilées et blanchittres, à nervures noires et bordées, selon l'âge des sujets, d'un blanc roussâtre. Ces plumes représentent une aigrette, une petite perruque blanche replice sur un fond noirit-

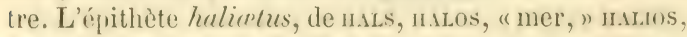
" marin, " et séros, "aigle, " indique les habitudes de cet oisean, qui vit presque exelusivement de gros poissons. Il les saisit en se précipitant dans l'eau avec une telle rapidité, que ses serres et la moitié de son rorps y pinètrent ordinairement. Ses pieds, couverts de fortes écailles, 
servent à retenir sa proic dans l'eau en l'empêchant de glisser entre ses serres. Il vit aussi d'oiseaux aquatiques. On l'appelle quelquefois fuvialis, parce qu'il aime it suivre le cours des fleuves dans ses chasses. Les ailes du balbuzard sont très-longues et son vol est très-rapide. Il visite assez régulièrement l'Anjou, accompagnant dans leur's migrations les oies et les canards sauvages. Le

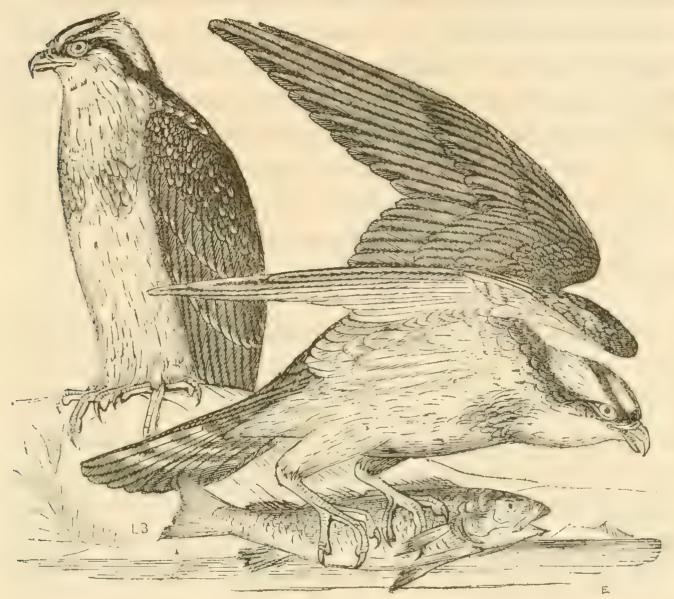

balbuzard se tient souvent ì l'embouchure des fleuves, et là il déploie une énergie continuelle en pêchant les poissons qui abandonnent la mer pour remonter les cour's d'eau douce. Malheureusement, un rapace plus puissant le surveille : c'est le pygargue. Chaque fois que le balbuzard a saisi une proie importante, le pygargue se précipite sur lui et le force à lui céder le fruit de sa chasse. Le balbuzard ne se prête pas facilement à cette spoliation, et, le plus souvent, il ne se reconnaît tributaire de 
son ennemi (qu'apres un combat terrible et prolongé. Comme beaucoup d'hommes, il aime mieux cependant renoricer à sit propricíté que de sacrifier sa vie, surtout quand il s'est convaincu que toute nouvelle lutte est impossible. Il niche dans des marais imprénétrables ou sur les rochers voisins de la mer, ou enfin à la cime des arbres plantés sur les bords du Volga. Sies cufs, au nombre de trois à quatre, ont $0^{\mathrm{m}}, 0 \% \mathrm{~B} 6$ de longurur, et (1) ${ }^{\text {ma }}, 042$ de diamètre; ils sont d'un blanc jaunâtre, par'semés de taches roussitres dont le centre est plus foncé que les bords; ces taches forment souvent une seconde couche presque compacte; d'autres fois elles sont rares et se réunissent en couronne vers le gros bout; enfin quelques-uns de ces œufs ne portent aucune tache, et leur coquille semble veloutíe ou couverte d'une couche de lait.

AIGLLE JEAN-LE-BLANG - AOTILA BRACHYTDLTTLA. GALLICA.

Ce rapace, ainsi que le précédent, a été longtemps éloigné du genre des aigles, dont il n'a pas toute la grâce ni l'énergie. Cependant il en posside les caractères généraus, et dès lors il doit rester dans cette catégorie, afin de ne pas multiplier les divisions qui ne servent fu'à entraver l'étude de l'ornithologie. De face, il ressemble à l'aigle, et de còté, à la buse; son cou est trìscourt, et sa tête très-épaisse. Il doit son nom vulgraire de Jerm-le-bline aux gens de la campagne, dont il visite souvent la basse-cour, et qui l'appelèrent Maitre-Jeun, parce qu'il venait exercer sans leur consentement les Aroits de grand seigneur, et choisir à son gré les plus belles pieces parmi leurs volailles. Puis, comme MaitreJean avait le rentre fauve et de couleur blanchitre, il fut désicmé sous le nom de dean-le-blanc. Son nom scientifique lrachydactyla, de mucurs, "court, " et incrivos. 
" doigt," indique que ses doigts sont beaucoup plus courts que ceux des autres aigles. L'épithète gallica fait connaître que cet aigle est commun en France. Il vit de volailles, de lézards et de serpents; aussi ses doigts sont-ils couverts de fortes écailles, comme préservatif contre les reptiles qu'il dévore. Cet aigle, dont chaque année quelques couples nichent en Anjou, pond un ou deux œufs d'une grosseur presque démesurée, affectant ordinairement la forme ronde; ils sont d'un gris blanchâtre sur lequel se trouvent quelquefois des taches d'un jaune sale presque effacé. La longueur ordinaire de ces œufs est $0^{\mathrm{m}}, 068$, et leur diamètre $0^{\mathrm{m}}, 056$.

\section{QUATRABME GENRE. - AUTOUR.}

La quatrième division des rapaces diurnes comprend les Autours. Plusieurs naturalistes ne renferment dans ce genre que l'autour proprement dit; quelques-uns y font entrer aussi l'épervier.

L'autour se distingue des autres rapaces par son bec, quii n'est pas échancré comme celui des faucons, ni crochu comme celui des aigles; par la petitesse de ses ailes, qui ne couvrent que les deux tiers de sa queue; enfin par quelques raies parallèles dans le sens de la longueur de cette queue. La tête de l'autour est grosse et aplatie en avant. Tous ces caractères conviennent à l'épervier, qui a la queue coupée carrément, tandis que celle de l'autour est arrondie; les tarses de l'épervier sont aussi beaucoup plus longs que ceux de l'autour.

\section{AUTOUR. - ASTUR PALUMBARIUS.}

Le nom d'autour semblerait attacher à cet oiseau une idée de ruse, qui serait confirmée par le mot latin astur, si toutefois l'on admettait que cette expression dérivât de 
"s/us, " rusé, " dont la racine primilive est AsT", "ville, finesse; " itymologie londée sur l'opinion des anciens yui pensaient que les habitants des villes itaient plus dípourvus de simplicité que ceux de la campagne. Cetle explication s'appuierait alors sur le caractère de l'autour, moins courageux, mais aussi adroit que les faucons. Ce

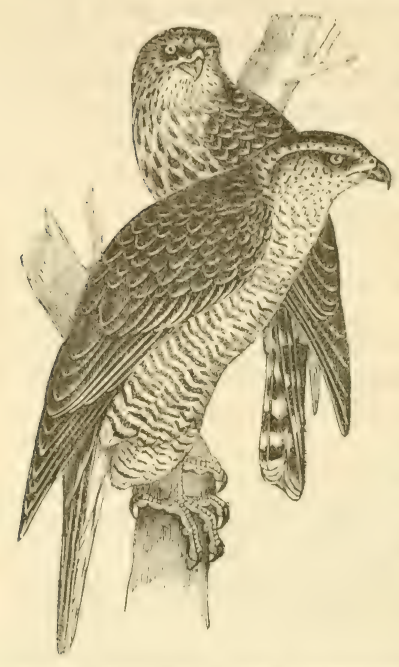

rapace se tient en embuscade sur la lisière des bois ou sur une motte de terre, le long des haies; c'est de lìt qu'il poursuit ses victimes par un rol toujours oblique et cependant assez vif. Souvent il rase la terre en décrivant des circuits autour des champs dans lesquels il espère découvrir une proie. Quand il l'aperçoit, il l'attaque rarement de front.

Mais autour dérive plus probablement, toutefois, de astur, asturius, asterius, mots employés par I'line pour désigner ce rapace. Cette dernière dénomination asterias. "étoilé, p peint d'une manière frapprante l'autour', sur lequel semblent briller des " étoiles» que forment en se croisant les raies de son plumage. (Quelques-uns puensent. que l'adjectif asterius indique seulement que cet oiseau vient des Asturies, où il est très-commun. L'adjectil

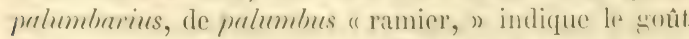
de l'autour pour les pigenss qu'il parait chasser dre pré- 
férence aux autres oiseaux. La beauté de ce rapace l'avait fait rechercher pour la chasse; mais il ne fut jamais classé dans la catégorie des oiseaux nobles. Il fut mème généralement délaissé à cause de son caractère sanguinaire, qui le porte à tuer les oiseaux renfermés avec lui. L'éducation de cet accipitrin, pour la chasse, avait donné lieu à l'autourserie, qui constituait la fauconnerie des petits seigneurs et des simples particuliers. Aujourd'hui encore on se sert en Perse de l'autour pour chasser la gazelle; cet oiseau arrête ses victimes en leur crevant les yeux. Pour le former à ce moyen perfide de s'emparer des gazelles, on l'habitue à chercher sa nourriture dans l'orbite des yeux d'une gazelle empaillée.

L'autour est sédentaire en Anjou; il établit son nid dans les forêts, à une lıauteur moyenne. C'e nid plat, assez solide, mais peu façonné, est composé de petites branches, de feuilles desséchúes et de mousse. Il contient ordinairement trois ou quatre œufs d'un blane pâle et d'une légère teinte bleuâtre; ils peuvent être facilement confondus avec ceux du héron cendré. Ces œufs ont $0^{\text {ma }}, 0 \oiiint^{2}$ de longueur, et $0^{\mathrm{m}}, 040$ de diamètre.

AUTOUR ou FALCON ÉPERVIER. - FALCO SPARVARIUS, NISUS.

L'adjectif épervier dérive du vieux mot sparvarius, qui signifie "oiseau de rapine, " et c'est encore sous ce nom qu'il est désigné dans un grand nombre de musées et de catalogues. Les auteurs ont trouvé un rapport entre la dénomination sparvarius et SPAÏrô, ASPAÏrô, signifiant " trembler, palpiter, s'agiter. " Cee caractère se rapproche des habitudes de l'épervier, mais convient bien plus au faucon crécerelle. Son nom scientifique nisus est le même qui désignait l'épervier dans la langue latine. Il a 
liomni matière ì une lígende mythologique. Nisus, roi de Mrgare, avait un cheveu d'or aurguel élait attachéc la conservation de son royaume. Scylla, sa fille, éprise de Alnos, eoupa ce cheveu d'or et livra sa patrie et son père sans défense. Les dieux irrités changèrent Scylla en alouette et Nisus en épervier. Sous cette forme, le malheureux pìre poursuit sans cesse sa fille pour assouvir sa vengeance.

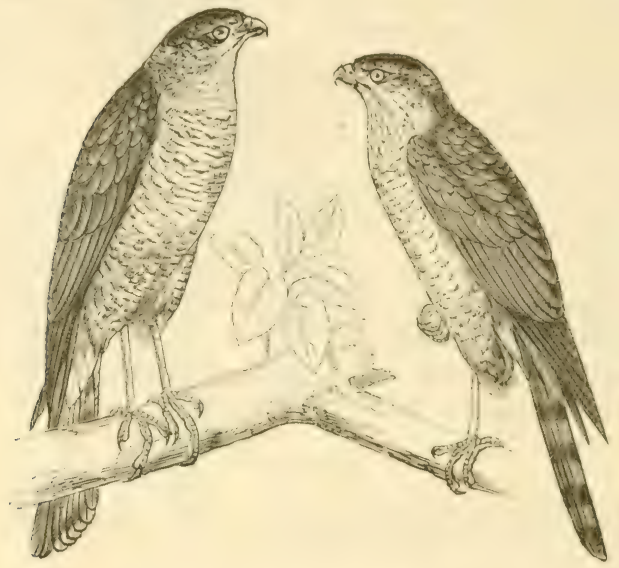

L'épervier confie à la cime les arbres un nid construit d'une manière grossière comme celui de l'autour; assez. souvent il pond dans les nids abandomnis, de pie ou de corneille, eing ou six ceul's arrondis, longs de ()$^{\mathrm{m}}, 1140$, of de $0^{\mathrm{m}}$, (1):32 de diametre. Ils ont le find blanehatre ou blenitre, parsemé de taches d'un rouge noir. Les uns sont presque entierement enurerts de ces taches; d'antres en ont très-pen: queliques-uns sunt d'un blane fiâle et uniforme; rnfin on remarque, sur certains de ces 
œufs, des taches très-fortes, en forme de couronne, vers le gros bout; chez d'autres, ces taches paraissent en zig-zag.

Les anciens attachaient à l'épervier des idées mystérieuses; ils pensaient que c'était lui qui engendrait le coucou. Ils supposaient aussi que ce faucon avait l'habitude, pendant la saison rigoureuse de l'hiver, de capturer, chaque soir, un moineau frane, et de le presser sur sa poitrine jusqu'au lendemain matin. L'épervier lui rendait alors la liberté, pour le récompenser de l'avoir préservé du froid, en lui servant, pour ainsi dire, de bouillotte.

\section{crvquikine gevire. - MLAN.}

Les Milans forment le cinquième genre de l'ordre des Accipitrins. Ils ont pour signes caractéristiques : un bec très-faible, crochu dès la base; les tarses emplumés audessous du genou; les ailes étroites et très-longues, et la queue fourchue.

\section{MILAN ROYAL. - FALCO MILVUS, REGALIS.}

Milan est la traduction de miluus pour milvus, qui signifie " oiseau de proie,) et selon Plaute, " voleur de bas étage.» Cette signification convient parfaitement au milan. Ce rapace est vorace, insatiable, vivant de tout, dévorant les insectes, les reptiles, les mammifères, les oiseaux sans défense, et toute espèce d'animal en putréfaction. II se précipite sur tout, vole tout, pourvu qu'il n'y ait pas le moindre danger à courir. A la vue du plus petit rapace, il abandonne sa proie et s'éloigne avec la rapidité de la flèche. C'est grâce à cette puissance de vol et à sa vue très-perçante que le milan échappe à ses nombreux ennemis. Quoiqu'il ne pèse qu'un kilogramme, il a plus 
d'un mètre cincuante centimètres d'envergure. A la crainte du premier danger, il s'élève bien au-dessus de ses adver:aires, et, ì une hauteur de quatre lilomètres, il listinguc les plus petits oiseaux et les reptiles cachés sous

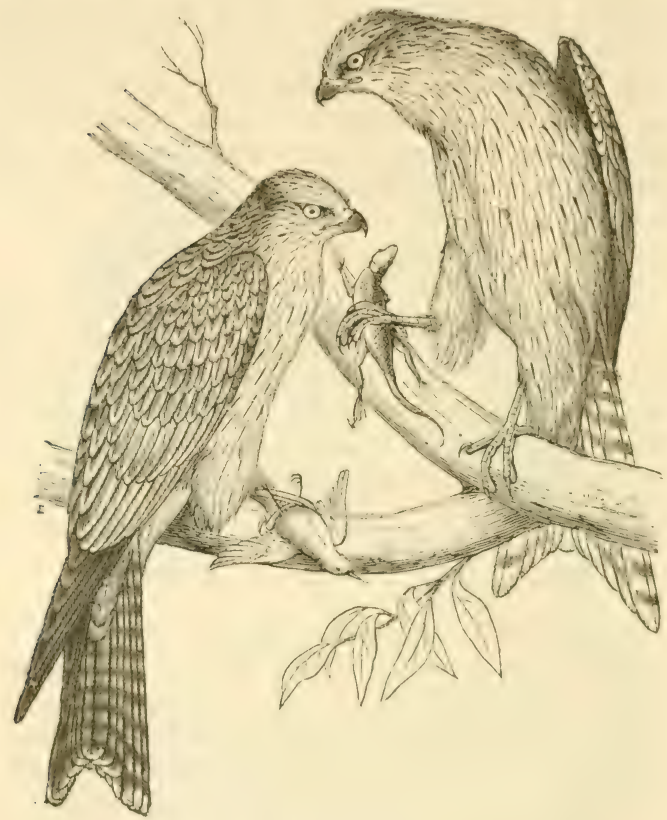

I'herbe des prairies. Il tumbe sur sa proie avec la rapidité de la foudre, pour fuir ensuite avec la mème vitesse. Le milan ne chasse prìs des fermes que le matin, et, dìs que In danger peut apparaître, il s'éloigne pour continuer ses courses loin de la demeure des hommes. Dans les tempss 
de la fauconnerie, il servait aux délassements de nos rois; c'est ce privilége qui lui a mérité le surnom de royal. Les princes aimaient à assister à des luttes entre les oiseaux de proie, et le milan était toujours choisi pour figurer dans le combat, à cause de la beauté de son vol. Ce don que la Providence lui a départi avec tant de générosité, servait à prolonger le combat et à le rendre plus intéressant; mais le milan succombait toujours sous les serres du plus petit faucon et même de l'épervier. Le milan royal passe sa vie dans l'air; il semble y glisser en conservant ses ailes immobiles et en se servant de sa large queue comme d'un gouvernail. On a vu dans la grâce de son vol l'origine de son nom : Milvus quod de molli volatu dicitur ${ }^{~}$. Selon quelques auteurs, le nom du milan était fondé sur une croyance populaire qui accordait à cet oiseau une très-longue vie, une existence de " mille ans. ")

D'autres auteurs font dériver milvus de mirlus, mirle. "Mirle est species accipitris. - Nirle est une espèce d'aiglen (Ducange). Ce nom désignait done une espèce d'accipitrin; il aurait pour racine primitive un mot de la langue sanscrite : " mri, mri,» signifiant " tuer" et qui serait lui-même la racine de miles, "soldat. " Je ne puis suivre ces érudits dans toutes leurs savantes transformations, et ici, comme en beaucoup d'autres passages, je me borne à indiquer des idées générales. Ainsi donc, selon cette hypothèse, le mot milvus indiquerait que l'oiseau qui le porte serait un "combattant; " cela est vrai, mais en tout cas, ce n'est pas un guerrier bien brave, car il n'accepte le combat que lorsqu'il n'y a pas de danger. Cependant si l'on admet que le mot vullur, "vautour, " représente aussi

\footnotetext{
1 Mathias Martinius, dans son Étymoloyie, cité par Ménage, au mot Milan.
} 
l'idie d'un combattant, on peut, sans trop se compromettre, attribuer au milan le rôle de soldat.

Ce qui pourrait fortifier l'hypothèse précédente, c'est l'expression uктाN, uктіxos, employée par les Grecs pour désigner le vautour et le milan, expression qui semble dériver de ктеїхô, signifiant "tuer, immoler, " et rentrer dès lors dans le sens de miles, "soldat."

Le milan est sédentaire en Anjou. Il construit son nit it la cime des arbres. Cette aire est grossièrement façonnée; dans les pays de montagne, il la confie aux buissons suspendus aux flanes des rochers. Les œufs, dont le nombre varie de trois ì quatre, sont ordinairement oblongs, d'un blanc sale, et portent à une des extrémités unr couronne de petits points noirs plus ou moins multipliés. Quelquefois ces œufs ont un côté beaucoup plus pointu que l'autre et portent des taches noirâtres ou violettes qui ressemblent à des gouttes étendues avec le doigt. Leur Ingueur moyenne est tle $0^{\mathrm{m}}, 0: 36$, leur diamètre de $0^{\mathrm{m}}, 1142.2$. Ils se distinguent de ceux des buses ordinaires par leurs dimensions régulièrement plus petites et par la nature de leurs taches.

\section{MILAN NOIR, PARASITE. - FALCO ATER.}

Ce milan doit son premier nom à lia couleur de ses plumes; le deuxième, dérivé de para, "proche, " et siros, "blé, — qui vit aux dépens des roisins, " est une dénomination qui pourrait convenir à heaucoup d'autres. Des études récentes ont démontrí que le rapace connu ordinairement sous le nom de milan noir ou parasite enstitue deux espèces distinctes. Le milan noir a le bee noir et la queue peu fourchue. Le parasite a le bee jaune; sa queue est longue et fourchue; son doigt externe dépasse de beancoup le milieu du doigt médian. 
Enfin son plumage est d'une couleur plus claire en dessus, et plus rousse en dessous, que celui du milan noir. Aristote appelait ce dernier italien, parce qu'il est trèscommun en Italie. Plus petit et plus courageux que le milan royal, le milan noir préfère le poisson à toute autre nourriture. Il détruit beaucoup de serpents, et choisit ordinairement pour lieu de résidence les bois situés près des étangs. C'est à la cime de ces bois qu'il construit son nid, comme son congénère. Quelquefois il profite d'une aire abandonnée pour s'y établir. Son vol est moins élevé que celui du milan royal. Ses œufs, au nombre de deux ou trois, ont $0^{\mathrm{m}}, 05$ de longueur et $0^{\mathrm{m}}, 04$ de diamètre; quelques-uns sont d'un blanc jaunâtre sans aucune tache ; d'autres d'un blanc bleuâtre avec des taches plus ou moins nombreuses, mais cependant toujours plus multipliées que sur les œufs du milan royal.

\section{SQXIÈME GENRE. - BUSE.}

Le sixième genre des Accipitrins comprend les Buses, que l'on reconnaît à leur cou très-court, à leur tête large, it leur corps trapu, à leurs tarses forts et très-peu allongés. Ces oiseaux ont la vue peu étendue, défaut qui, joint à leur manière d'être, les a fait regarder comme peu intelligents, et a converti leur nom en une épithète peu flatteuse. Les buses ne saisissent presque jamais leur proie à tire d'ailes; elles se tiennent immobiles sur un sillon ou sur une branche d'arbre, pendant des journées entières, jusqu'ì ce qu'elles aperçoivent une proie facile sur laquelle elles se précipitent avec rapidité.

La Faune de Maine-et-Loire comprend trois espèces de ces rapaces. 
BISEE BONDRÉL. - FALCO APIVORIS.

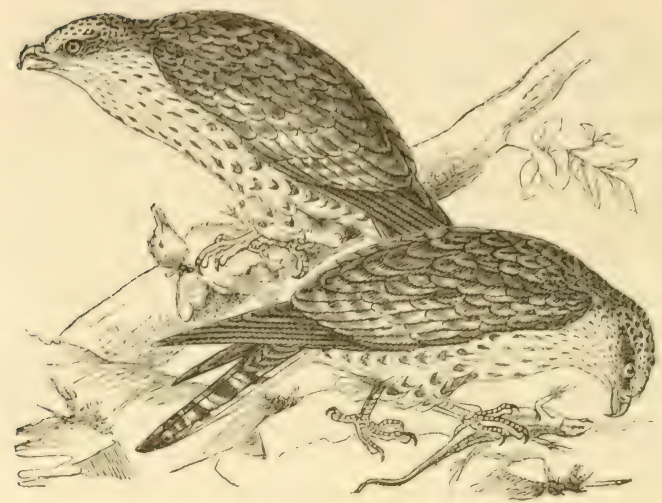

Le nom de buse vient de buten, lution, qui dérive luimême de BLzô, "crier, " et convient ì ces accipitrins dont la voix est forte et désagréable. L'épithète bomdrée a ju paraître, à quelques naturalistes, fondée sur une habitude propre à cette buse. Elle saute de branche en branche, de sillon en sillon, comme la pie, sans se servir de ses ailes; elle piéte et court comme les oiseaux de basse-cour; elle se tient dans le voisinage de l'eau el foursuit les reptiles ou les insectes qui fuient devant elle. Le môme mot peut dériver aussi de ponderala, qui sisnilie "lourde, pesante, " parce que ce rapace devient excessivement gras pendant l'hiver. lette dernière explication, qui s'appuie sur l'autorité de Mínage et sur relle de Le Duchat, me semble ittre la seule víritable. Ponderatu a pour racine pomelus, qui signifie "poids, pesanteur. ") Aussi les gens de la campagne, excellents ubservateurs, appellent-ils bondrées tous les gros oiscaus 
de proie, sans distinction. Ils appliquent cette même expression aux personnes dont le poids parait être considérable. Cette pesanteur est un moyen puissant que la Providence a mis à la disposition de ce rapace pour lui procurer une nourriture abondante dans toutes les saisons de l'année. En effet, la bondrée, après avoir multiplié ses recherches dans les terrains humides ou détrempés par la pluie, s'arrête, regarde autour d'elle, et s'empare des insectes que la secousse imprimée par son poids à la terre force à quitter leur repaire. Elle imite les pêcheurs qui, ponr avoir des lombrics destinés à amorcer leurs lignes, b́banlent la terre, et attendent ensuite le résultat de la secousse communiquée autour d'eux. Par ce stratagème, la bondrée se procure en tout temps, et surtout en hiver, une proie suffisante qui, sans cela, lui échapperait souvent à cause de la faiblesse de sia vue. L'adjectif apivorus, "mangeur d'abeilles, » indique que cette buse aime beaucoup les abeilles et surtout les guêpes et les chrysalides qui lui servent à nourrir ses petits. Elle se distingue de ses congénères par sa tête moins grosse et d'un gris cendré qui tourne au bleuâtre. La buse bondrée présente de très-belles variétés dont quelques-unes pourraient être confondues avec l'aigle botté. Un signe certain auquel on peut toujours la reconnaître, c'est le bouquet de petites plumes fines qui remplit, chez cette buse, l'espace compris entre l'œil et la base du bec, et qui n'existe jamais chez les aigles, ni chez les autres buses. Dans les forêts, elle fait un nid avec quelques morceaux de bois, recouverts de racines, de feuilles desséchées ou de mousse grossière. Quelquefois elle pond dans un vieux nid, de corneille ou de pie, deux ou trois œufs un peu arrondis, parsemés de taches rouges si multipliées, qu'elles se fondent ensemble pour présenter une couleur uniforme et pour voiler entièrement le blanc sale de la coquille sur laquelle elles sont 
ifendues. Cies wul's ressemblent ì ceux que les enfants appellent, daus notre pays, wufs de Pôtques. Quelquesuns sont d'un blanc d'ivoire, mouchetís de larges taches d'un rouge de brique. D'autres ont une couleur chocolat, uniforme, paraissant formée de deux couches, dont la première est plus foncie que la seconde. Enfin, on en truave dont le fond de la coquille est d'un blane jaune, strié de petits points rouges qui se réunissent quelquefois vers le gros bout pour former une espèce de calotte. Les uns sont entièrement ronds, d'autres ublongs ou pirilormes. Ils ont $0^{\mathrm{m}}, 0.31$ de longueur, et $0^{\mathrm{m}}, 0$, 22 de diamètre.

BUSE COMMUNE OU VARIABLE. - FALCO OU BUTEO VARIABILIS.

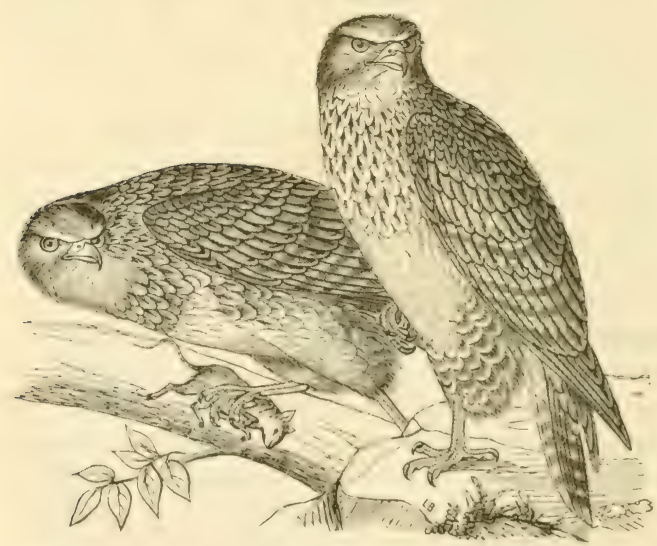

Cette buse a donné lieu à hien des erreurs dans la rlassification des oiseaux, ì cause de la particularité à larjurlle elle doit son nom. Tous les sujets de cette espèce 
varient de couleur; ils vont du noir au blanc, en présentant toutes les nuances intermédiaires. Des naturalistes, qui avaient pris plaisir à réunir des buses, en offraient une collection de quarante-cinq à cinquante, sur lesquelles on n'en trouvait pas deux de même couleur ni de même grosseur. Celle-ci est appelée commune, parce qu'elle est bien plus répandue que les deux autres espèces; elle porte aussi le nom de buse à poitrine barrée, à cause des taches qui semblent former sur sa poitrine des raies assez régulières.

La buse variable niche comme la précédente. Ses œufs, au nombre de deux ou de trois, sont oblongs, d'un blanc sale avec des taches, d'un gris brun ou jaunatre, plus ou moins nombreuses vers le gros bout. Leur longueur est de $0^{\mathrm{m}}, 0522$, et leur diamètre de $0^{\mathrm{m}}, 042$.

\section{BUSE PATTUE. - FALCO OU BUTEO LAGOPUS.}

Les deux adjectifs qui désignent cette buse indiquent son caractère distinctif : pattue et lagopède, "à pieds gros, emplumés, velus comme ceux du lièvre ; " de Lagiôs, "lièvre, " et poûs, ponos, "pied de lièvre, pied velu. " Cet oiseau a, en effet, les pieds emplumés jusqu'aux doigts. Il vit ordinairement dans les forêts du Nord, et pond deux ou trois œufs de la même grosseur que ceux de la buse commune, mais dont le fond est strié de taches d'un brun pâle ou violet, semblables à des gouttes effácées. D'autres sont un peu plus petits, et ne portent pas de taches. Cette buse est moins grosse et plus féroce que ses congénères, et n'a pas leur patience pour attendre sa proie. Elle fréquente le bord des rivières et des marais, où elle détruit une grande quantité de serpents, de mulots, de grenouilles et de taupes.

Un des spectacles les plus curieux que présente l'étude 
de I'histoire naturelle, c'est la chasse donnce aux buses par les corneilles, les pies et les geais. Quand ces oiseaus ont découvert une buse et reconnu exactement l'arbre sur lerquel elle se tient en sentinelle, ils poussent un cri d'alarme et de rappel. Bientôt les pies, les geais et principalement toutes les corneilles du canton se réunissent. Chacun de ces oiseaux mêle sa voix au concert formidable qui se fait entendre et semble vouloir crier plus

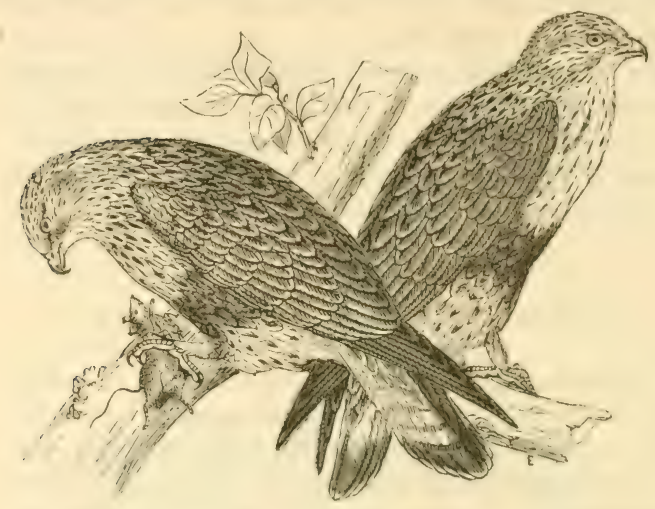

for' que tous les autres. La buse résiste quelquefuis arec un calme imperturbable à ce véritable charivari. Mais enhardies par les dédains de la buse, les corneilles s'approchent encore davantage de leur ennemie, et finissent presque toujours, à force d'insultes, par la déterminer à s'envoler. Dans ce moment solennel, les corneilles accompagnent la buse, et s'élèvent à des hauteurs prodigieuses en dícrivant autour du rapace des cercles multipliés, essayant ainsi en quelque sorte de l'étourdir. Lat buse s'evile du lieu qu'elle avait choisi four arrondissement de chasse, et les corneilles alors se retirent, de rinant 
sans doute que, dans le nouveau canton où s'établira la buse, d'autres corneilles auront soin de la faire déloger à Jeur tour.

La buse se prend facilement au piége appâté avec des débris de viande recouverts de plumes. L'habitude où elle est de se tenir toujour's sur la même branche facilite encore le travail du trappeur. Il suffit de placer le piége ì terre, au-dessous de la branche sur laquelle se repose la buse, et souvent, quelques minutes après l'opération, l'oiseau se trouve victime de sa témérité. Si le terrain est un peu découvert, et que les corneilles puissent apercevoir la captive, elles s'abattent en grand nombre et exécutent autour d'elle des danses frénétiques, accompagnées de cris de fureur ou de satisfaction. Chacune veut insulter à l'ennemi vaincu, et cependant, par prudence, chacune se tient à une distance respectueuse. En vain la buse se renverse sur le dos et, avec son bec et ses serres, semble défier tout cet essaim de lâches combattants; les efforts inutiles que fait la pauvre prisonnière pour se venger, le poids des piéges qui rend tous ses mouvements plus pénibles, hâtent le moment de sa mort. N'ayant plus rien à craindre, les corneilles s'approchent, insultent au cadavre, puis se dispersent. Il m'a été donné de conternpler ce spectacle, grâce à la bienveillante amitié de M. Raoul de Baracé.

Depuis plusieurs années, mon honorable ami a capturé à Valoncourt, près le Lion-d Angers, un certain nombre de buses, variété blanchâtre. Ces buses lui ont paru constituer une race dont les mœurs diffèrent de celles des buses ordinaires. Elles voyagent par couple; car, après avoir capturé le mâle, la femelle se laisse prendre facilement. Le faits'est répété pendant quatre années consécutives. L'ette variété paraît plus timide que ses congénères; elle vole près de terre; son vol est court et ses pauses sont très-rapprochées, comme celles d'un semi- 
nocturne. Le màle est beaucoup plus petit, plus blanc of plus effili que la femelle. Cette race affectionne les arbores touffus, où elle peut déguiser sa présence. Elle se perche volontiers sur les basses branches des pommiers peu ilevés; elle semble craindre le jour. Doit-elle cette modifieation de ses habitudes à la blancheur de son plumage, Ifui lit rend plus visible que ses congénères ou cherchet-elle a compenser par la prudence les disavantages que lui donue sa couleur spéciale?

\section{SEPTIEIL GENRE. - IBUSAIB.}

Les busards forment le septième et dernier genre des rapaces diurnes. Ils s'éloignent des buses par leurs proportions beaucoup plus petites et plus sveltes, par la longueur de leurs ailes et par celle de leurs tarses entierement nus, par leur tête petite et leur cou assez dégagí. Leur nom peut dériver du mot anglais buzzard, qui désigne oiseau de proie, ou être an diminutif de buse, ou enfin signifier "buse ardente, courageuse. " Cette dernière étymologie ferait connaître le caractère de ces accipitrins, dont le courage est très-grand et l'ardeur incessante. Ils ne craignent pas de combattre et même d'attaquer les autres oiseaux de proie. Autant les buses paraissent pesantes et stupides, autant les husards ont de légèreté et de gràce. Leur vol autour des buissons et à travers les champs at quelque chose de celui de l'hirondelle ot de la mouette ; dans leurs chasses, ils paraissent prendre plaisir ì se balancer, en imprimant ì leur's ailes un mouvement de bascule presque continuel.

La Faune de l'A njou compte trois busards. 
BLSARD DES ILARAIS OE: HARPAYE. - FALCO RLFLS ou CIRCUS RUFUS.

Le premier de ces noms a été donné à ce busard à cause des lieux qu'il affectionne. Il chasse sur les bords des étangs, des marais, où il vit d'oiseaux aquatiques, de grenouilles et de poissons. L'adjectif harpaye, du mot harper, haRpazeïx, " ravir, " haRPAGHE, " croc, instrument qui saisit fortement, qui enlève, " peint très-bien l'énergie de cet oiseau, vrai fléau des foulques et des poules d'eau. Le mot générique circus s'applique à tous les busards, et rappelle un caractère spécial de ces accipitrins : le cercle ou demi-collier de plumes serrées qu'ils portent tous d'une manière plus ou moins sensible et qui s'étend du menton aux oreilles. L'épithète rufus, "roux," représente la couleur des plumes de ce rapace, désigné aussi par les arjectifs arriginosus, "couleur de rouille," et suisse, du nom du pays où il se trouve en grande quantité. Les changements multipliés que ce busard subit dans les nuances de son plumage, selon l'âge et le sexe des individus, avaient engagé quelques naturalistes à multiplier des espèces abandonnées généralement, comme n'étant pas fondées sur des caractères positifs.

Le harpaye fait son nid d'une manière grossière, dans les jones des marais ou sur une petite éminence voisine de l'eau. Il y pond de trois à cinq œufs d'un blane bleuâtre pâle, ordinairement sans taches; quand ces taches existent, elles semblent formées par une seconde couche irrégulière, plus foncée que la première. Ces œufs ont de $0^{\mathrm{m}}, 048$ à $0^{\mathrm{m}}, 0 \% 0$ de longueur, et de $0^{\mathrm{m}}, 036$ à $0^{\text {mi }}, 038$ de diamètre. Tous ont une des extrémités plus grosse que l'autre. 
BLSARI SAINT-MARTIN. - FALCO OF CIRCIS CYANELS.

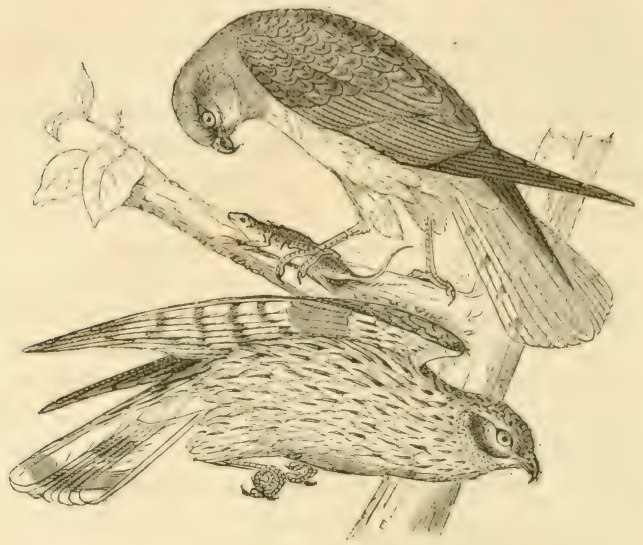

Ce busard doit son nom à l'époque à laquelle il a cité observé à son passage en France, en automne à "la Saint-Martin. " L'adjectif cyaneus, "bleu gris, ") indique la couleur du plumage de cet riseau. Le SainıMartin est plus petit que le précédent, et porte une collerette formée de plumes fines, pressées, et de couleur d'un gris bleu pâle. Il niche à terre dans les jones et dans les bois marécageux, pond quatre ou cinq œufs semblables à ceux du busard harpaye, mais un peu plus petits; quelques-uns sont parsemés d'un noir ou d'un l'oux foncé, et ressemblent à de gros œufs d'épervier. J'ai reģu de la Buhème et de la Ilongrie des wufs de busard SaintMartin dont la coquille était revêtue de taches très-larges, irrégulières et d'une couleur foncie. Ce sont ces types que des marchands essaient de vendre aux jeunes col- 
lecteurs comme étant des œufs de l'Elanion Blac (falco ou elanus melanopterus); ils ont $0^{\mathrm{m}}, 046$ de longueur, et $0^{\mathrm{m}}, 036$ de diamètre.

BISARD MONTAGU, - FALCO CIRGUS or CIRANELS.

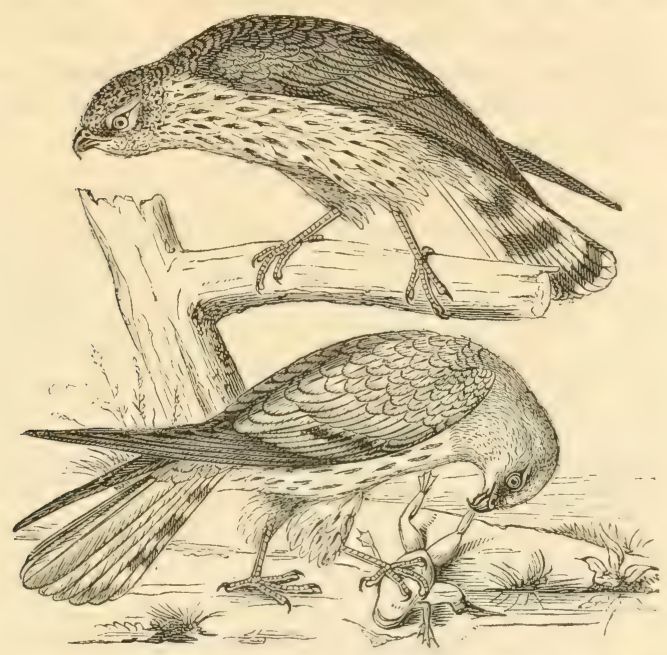

Le Montagu porte le nom du savant naturaliste anglais qui le premicr fit connaître, d'une manière précise, les caractères établissant une distinction entre le SaintMartin et celui-ci. L'épithète cineraceus, "cendré," constate la couleur du plumage de cet accipitrin. Le Montagu est plus petit que les deux précédents; il se distingue du Saint-Martin par les ailes qui, dans celui-ci, couvrent la queue, tandis que dans le Montagu elles ne s'étendent qu'aux deux tier's. Les plumes des flancs et 


\section{$-96-$}

de l'abdomen du Montagu sont blanchâtres, et portent des traits d'un roux de rouille. Ce rapace niche dans les bois ou dans les landes, et pond quatre ou cind cufs semblables à ceux du Saint-Martin, mais plus petits et un peu moins allongés. Cependant ils n'offrent pas les mêmes variétís que ceux du précédent. Quelques-uns seulement sont pointillís de petites taches d'un noir pâle et presque effacé. Ils ont $\left(0^{\mathrm{m}}, 036\right.$ de longueur, et ()$^{\mathrm{m}}, 032$ de diamètre. Ainsi les reuf́s des trois espèces de busards ne diffèrent que par leur grosseur, qui varie selon les proportions de l'oiseau.

Les vingt-neuf rapaces que je viens d'énumérer, et dont treize seulement sont sédentaires, forment la quinzième partie des oiseaux de la Faune de l'Anjou. C'ette proportion est la même que celle qui existe dans l'ornithologie ginćrale. Les carnassiers composent, au contraire, le tiersdes mammiferes. Mais afin de rétablir l'íguilibre, les oiseaux l'emportent de beaucoup en nombre sur les quadrupèdes dans la chasse sur l'eau. Lì, on trouve une multitude d'oiseaux qui suppléent aux quadrupèdes, que leur nature tient éloignés des rivières. Tous les oiseaux de cette dernière catégorie saisissent leurs nombreuses victimes avec un bec crochu et quel(qurfois dentelé. Ainsi la Providence a tout coordonné de manière à ce que les espèces pussent se propager sans dépasser de sages limites.

\section{$-\infty$ \\ DEUXIEIIE ORDRE. - GRIHPEURS.}

Les maturalistes ont rumi sous le nom de Girimpeurs, nom-seulement les oiseaux dont la vie est consacrie a srimper le long des arbers pour chercher lent nourri- 
ture, mais encore ceux qui sont organisés de manière ì pouvoir se cramponner à l'écorce des arbres, le temps suffisant pour y saisir leur proie.

Les grimpeurs se distinguent des autres oiseaux par leurs doigts dont deux sont placés en avant et deux en arrière; le quatrième est versatile.

\section{PREMIERE FAMILLE.}

\section{Les Cuculides.}

Le nom donné à cette première famille est la traduction de cuculus, mot formé dans les trois langues par l'imitation du chant des giseaux qui la composent : KorkUx, cuculus, " coucou.»)

Les coucous appartiennent aux grimpeurs par leurs doigts dont les deux en avant sont réunis et les deux en arrière séparés. Ils s'éloignent des pies et du torcol par la langue qui n'est pas extensible.

\section{COUCOU GRIS. - GUGULUS CANORUS.}

L'épithète donnée à ce coucou est fondée sur les nuances de son plumage, et l'adjectif canorus sur le " cri retentissant " qu'il se plaît à répéter dans les bois au commencement du printemps.

Les coucous, ainsi que les pics et les oiseaux qui ne se nourrissent pas des biens de la terre, sont condamnés à être solitaires, moins par inclination que par nécessité. Ils vivent d'insectes et surtout de chenilles velues, qu'ils saisissent en se cramponnant aux arbres et mêrne quelquefois aux pierres recouvertes de mousse ou de petites plantes rampantes. Ils avalent leur proie avec une grancie 
voracité, et rejettent, après la déglutition, la peau des chenilles roulće en pelotes. Les coucous pratiquent la polygamie. Les mâles sont beaucoup plus nombreux que les femelles. Celles-ci pondent de quatre à six œufs dans les nids des insectivores. Quand ceos nids sunt en rase campitgne, comme ceux des pipits, des alouettes, du proyer, etc., et que la mère se trouve sur les œufs, la femeile du coucou décrit plusieurs circonférences, à l'exemple des rapaces, et finit par effrayer la couveuse et par l'éloigner pendant quelque temps. Libre alors de ses mouvements, elle s'établit sur le nid, pond et s'enfuit, après avoir mangé un œuf de l'oiseau auquel elle abandonne les soucis de sa propre maternité. Quand l'ouverture du nid est défendue par des ronces et que la femelle du coucou ne peut en approcher facilement, elle pond à terre, saisit l'œuf dans son bee, et va le díposer ensuite dans le berceau qu'elle a choisi. La femelle du coucou ne pond que dans les nids dont les œufs ne sont pas encore couvés. Est-ce pour s'assurer de leur état qu'elle mange un de ces œufs? Est-ce pour tromper plus facilement la paurre mère? Cette dernière hypothèse paraît plus admissible que la première. On a constaté, en effet, que deux œufs avaient disparu dans des nids de rouge-gorge, de pipit, de proyer, etc., dans lesquels la femelle du coucou en avait pondu le même nombre. L'œuf déposé par le coucou est couvé avec soin par l'oiseau auquel il a été confié. Celui-ci ignore que son nid renferme l'ennemi de ses petits. En effet, si l'œuf du coucou íclòt le premier, le petit jette hor's du nid les autres œufs; s'il ne voit le jour qu'après les petits de la véritable mère, il ne tarde pas it les étouffer par ses mouvements brusques dans un nid beaucoup trop étroit pour le contenir. Resté seul, il devient pour son père et sa mère adoptifs la cause d'un travail prínible par suite de son extrême voracité. Qurlquefois même il ćtoulfe, dans son large gosier, le 
rouge-gorge qui a porté trop imprudemment dans l'intérieur du bec du coucou l'insecte capturé pour la nourriture de cet ingrat. Devenu un peu grand, le jeune coucou tombe naturellement du nid; ses parents nourriciers veillent à ses besoins pendant quelque temps, et bientôt il vit de sa propre chasse en saisissant dans les buissons les insectes et les vermisseaux. Plus tard, il mangera des hannetons, puis de jeunes grenouilles et surtout les œufs et les petits nouvellement éclos. Ce dernier grief explique l'énergie et l'acharnement avec lesquels les coucous sont repoussés par tous les oiseaux dont ils visitent les couvées. La femelle du coucou met un intervalle de cinq à sept jours entre la ponte de chacun de ses œufs. Ceux-ci sont très-petits par rapport à la grosseur de l'oiseau. Ils ont de $0^{\mathrm{m}}, 021$ à $0^{\mathrm{m}}, 023$ de longueur, et de $0^{\mathrm{m}}, 014$ à $0^{\mathrm{m}}, 016$ de diamètre. Ces œufs varient beaucoup de teinte et de couleur, depuis le blanc verdâtre jusqu'au bleuâtre clair; ils sont parsemés de raies très-légères ou de petits points bruns, noirs, gris cendrés, violets. Quelques-uns ressemblent aux œufs du bruant-proyer, d'autres à ceux des alouettes cochevis et calandre. La Providence semble avoir permis cette variété, afin que la temelle du coucou pût tromper plus facilement les mères auxquelles elle confie ses œufs, en modifiant leurs couleurs selon les nids dans lesquels elle les dépose. Je ne veux pas faire de ces différences de couleurs un principe général; je constate simplement des faits nombreux parvenus à ma connaissance. Les œufs de coucous trouvés dans les nids d'accenteur mouchet et dans ceux d'accenteur pégot sont assez fréquemment d'une couleur bleue, semblables à ceux que contenait le nid dans lequel ils ont été déposés par la femelle du coucou, tandis que d'autres qui ont été recueillis dans le nid de la rubiette tithys étaient blanes; de plus, ceux que l'on prend dans les nids de bergeronnette, d'alouette, 
de rouge-gorge, etc., se rapprochent beaucoup de la couleur des œul's de ces différents oiseaux. Pour ces variétís si multipliées, qui ne se rencontrent dans les œufs d'aucun autre oiseau, doit-on adinettre l'influence du climat et celle de la nourriture? ou bien plutôt une preuve nouvelle de l'attention de la Providence ? En effet, le coucou, après avoir pondu ses œufs, ne choisirait-il pats d'abord, par un instinct admirable, le nid des insectivores dont la nourriture est la seule qui convienne au jeune coucou, et ne chercherait-il pas dans ces nids des (eufs de même couleur avant d'aller y déposer les siens? Cette dernière précaution ne serait-elle pas alors un nouveau moyen de tromper la pauvre mère, à laquelle la femelle du coucou confie l'incubation de ses cufs? Cette hypothèse pourrait d'autant mieux être admise, qu'il paraît être démontré, par des observations nouvelles et multipliées, que la femelle du coucou pond effectivement à terre, et qu'elle transporte ses œufs très-facilement et pendant un temps assez long dans une poche dépendant de son gosier. Il a été constaté sur plusieurs femelles qu'ayant été tuées, les convulsions de la mort les forçaient de rejeter l'œuf qu'elles avaient confié à cette poche secrète.

Cette habitude de pondre dans les nids étrangers est peut-être fondée sur l'instinct de la femelle, qui dérobe ses œufs et ses petits à la voracité de leur père. Les Grecs auraient dû consacrer la femelle à Cybèle, et le mâle ì Saturne. Quelques naturalistes pensent que cette particularité vient de l'incapacité de la femelle à couver ses œufs, à cause de son extrême maigreur, devenue proverbiale. Cette excessive maigreur dépend elle-même de la ıracité de cet oiseau et du choix de ses aliments trèspeu nourrissants, qui exigent l'absorption d'une grande quantités d'insectes et un travail desintestins très-pénible. Ceus-ei, en effet, regoivent beatucoup et conservent 


\section{$-101-$}

peu. Enfin, le temps mis entre la ponte de chaque wuf serait un motif très-suffisant pour démontrer que la femelle ne peut couver ses œufs sans s'exposer à un travail d'incubation et d'éducation au-dessus de ses forces. Cet intervalle de temps est peut-être encore le résultat du travail fatigant de la digestion.

La polygamie, qui brise les liens de la véritable famille parmi les hommes, ne serait-elle pas aussi le vrai motif pour lequel la femelle du coucou abandonne à des étrangers l'éducation de ses petits?

\section{COUCOU ROUX. - CUCULUS HEPATICUS.}

Le plumage de cet oiseau est déterminé par les adjectifs roux et hepaticus. Celui-ci dérive de HEेpatikos, dont la racine est hèpar, "foie, couleur jaune brun. ” Cette couleur constitue-t-elle une variété, une espèce ? Est-elle simplement le résultat de la mue?

Le coucou roux ne saurait être une variété; car une variété qui se perpétue toujours de la même manière, avec des teintes si différentes du type primitif, ressemble bien à une espèce. L'opinion de ceux qui admettaient que le coucou roux était le mâle ou la femelle du coucou cendré, n'est pas fondée; car l'expérience a prouvé que les mâles et des femelles se trouvent dans les sujets des deux nuances. J'ai pu constater de nouveau cette vérité sur un certain nombre de coucous, que M. de Baracé avait eu la bienveillance de m'adresser cette année. Ceux qui pensent que le coucou roux est le coucou gris dans ses premières années, assuraient que les uns émigraient vers le nord, les autres vers le sud, et qu'on ne trouve pas les uns et les autres dans la même localité, suivant la règle des oiseaux voyageurs dont les vieux et les jeunes visitent rarement les mêmes pays. Ce dernier sentiment 
ne peut plus être soutenu sérieusement. Chaque annéc, en Anjou et, dans tous lespays de l'Europe, on rencontre les coucous émigrant ensemble avec les deux plumagres très-distincts, et, à l'état alulte. Malgré ces preuves, Latham et .I. Millet sont presque les seuls à soutenir que le coucou roux est une race distincte du coucou gris. Je pense que eette question doit encore être étudiée, et rqu'on peut fortifier la dernière opinion en faisant remarquer que, si la différence du plumage était le résultat de la mue, on devrait trouver des traces du passage d'une couleur à l'autre; que cette mue ne peut pas s'opérer instantanément, et que les partisans de l'opinion contraire devraient montrer des sujets roux n'ayant pas encore revêtu la livrée complète d'arlulte. On ne voit ces sujets ni dans les musces, ni dans les collections particulières, et cependant ils derraient être très-communs à cause du grand nombre de coucous qui existent dans toutes les contrées de l'univers. Enfin, comment expliquer la grande disproportion constante entre les dimensions des coucous gris et celles des coucous roux ? surtout, lorsque ginniralement, dans les oiseaux, les petits atteignent à la fiu de l'année la taille des adultes. Non-seulement cette variété du coucou, mais l'espèce elle-mème a toujours été enveloppée des voiles du mystère. Pendant bien des siècles, les anciens ont pensé que le coucou se transformait en épervier. Peut-être étaient-ils portés à admettre cette métamorphose par la disparition des cuculides, que rien ne semblait expliquer, et par les formes, les pieds et le bec de ces oiseaux qui les assimilaient un peu aux rapaces. Plus tard, les naturalistes erurent que les coucous, après s'être beaucoup) engraissés pendant l'automne, se livraient dans le ereux d'un vieil arbre à un sommeil prolongó, dont ils ne sortaient que vers les premiers jours du printemps.

Une espèce de coucou, le coucon indicaleur, rend de 
véritables services aux habitants de l'Amérique méridionale en leur faisant connaître, par son cri, les parties des forêts où se trouvent les nids des abeilles sauvages.

Depuis l'impression de la première édition de ces Essais, plusieurs personnes m'ont demandé sur quels faits pouvait reposer la croyance populaire qui admet que l'on aura de l'argent toutel'année, quand on en porte sur soi-même au moment où l'on entend, pour la première fois de l'année, le chant si accentué du coucou. Cette croyance est certainement fondée sur quelques observations qui n'ont pas échappé à la sagacité ordinaire des habitants de la campagne; ces observations, quelles sont-elles? Je l'ignore; mais je crois pouvoir relater ici une croyance qui s'y rapporte. Les anciens observaient avec une grande attention le temps de l'apparition et de la disparition du coucou en Italie. Ils attachaient des idées superstiticuses à tous les actes de cet oiseau. Les vignerons qui n'avaient point achevé de tailler leurs vignes avant son arrivée, étaient regardés comme des paresseux et devenaient l'objet de lá risée publique. Les passants, qui les voyaient en retard, leur reprochaient leur paresse en répétant le cri du coucou, et leur prédisaient qu'ils retireraient peu de bénéfice de leurs vignes à cause de leur négligence.

\section{DEUXIEME FAMILLE.}

\section{Les Proglosses.}

La dénomination de proglosses, pro, " en arant, » et GLôssa, "langue, " indique le caractère spécial de cette famille, dont tous les individus ont une langue trèslongue et extensible. 


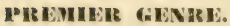

\section{I.E TORCOL. - IUNX TORQUILLA.}

Funx de mxx, magos, signifiait chez les frees, "la bergeronnette, le torcol " et "les sortiliges. " Torguilla peut avoir pour racine torques ou torquis, "collier," et yumx torquilla signifierait alors le " torcol à collier," dénomination très-exacte. Le nom français indique les singulières habitudes de cet oiseau qui tourne la tête, le col d'une manière bizarre. Ce grimpeur met sa queue de côté, en érentail, donne à son corps les ondulations d'un reptile, et paraìt éprouver les convulsions d'un ipileptique. Aussi inspire-t-il une telle frayeur à la plupart de ceux qui le prennent dans des filets, qu'ils aiment mieux lui rendre la liberté que de le saisir. Ces mouvements si extraordinaires, conséquence d'un système nerveux très-développé, sont attribués à un sentiment le crainte ou de surprise que ressent le torcol. Ils sont aussi un moyen dont se sert cet oiseau, d'un naturel très-paresseux, pour éloigner et effrayer ses ennemis. Les anciens le consultaient dans leurs augures, et s'en servaient pour jeter des sortiléges. Pendant très-longtemps, le torcol a été rangé parmi les oiseaux mỵstérieux; une croyance populaire le resrardait comme le mâle ou li femelle du coucou. Tout en lui contribue à le placer dans une catégorie exceptionnelle : par son cri, il ressemble à l'épervier et à la crécerelle; par son plumage, à la vipère. Aussi les Anglais l'appellent-ils " l'viseau-vipère. » Enfin il se plaît à faire le ventriloque au fond des arbres creux dans lesquels il se réfugie; puis il sort de si? retraite ténébreuse pour s'assurer de l'effet gu'il a produit sur ses auditeurs, et continue sa représentation par des poses et des contorsions qui en font un viritable saltimbanque, et un saltimbanque bruyant et tapageur. 
Le torcol appartient aux grimpeurs par ses doigts, diffère du coucou par sa langue, et des pics par sa queue. Sa langue, qui est extensible et cylindrique, lui sert à saisir les fourmis et les petits insectes. On le voit souvent cramponné aux branches sèches, sur lesquelles il paraît plutôt se reposer que chercher sa nourriture. Il parcourt les arbres, sans grimper à la manière des pics, et s'arrête aux cavités naturelles pour y plonger sa langue. Le torcol pond dans les trous des arbres, et choisit ceux dont l'ouverture est très-étroite. La femelle dépose de cinq à sept œufs sur la poussière vermoulue, dans laquelle elle a préparé un creux avec le secours de son bec et de ses doigts. Ces œufs sont d'un blanc brillant, caractère qui sert à les distinguer de ceux de la fauvette rouge-queue, auxquels ils ressemblent par la forme et la grosseur. Ils sont ordinairement arrondis, quelquefois pointus et ont de $0^{\mathrm{m}}, 018$ à $0^{\mathrm{m}}, 020$ de longueur, et de $0^{\mathrm{m}}, 013$ à $0^{\mathrm{m}} 013$ de diamètre. Lorsqu'on plonge le bras ou un bâton dans le nid du torcol, la mère, si elle s'y trouve enfermée, pousse immédiatement des sifflements si violents, qu'on a peine à se défendre d'un sentiment de crainte. Le plus souvent les dénicheurs s'éloignent de l'arbre, croyant s'être trompés et avoir à lutter contre un essaim de vipères.

\section{DEUXIEME GENIRE. - LES PICS.}

Ce nom rappelle encore une famille d'oiseaux victimes de l'ingratitude des hommes. Les pics ont reçu du Ciel une laborieuse mission. Dieu les a condamnés à ne vivre qu'au prix d'un travail incessant, dont le but est l'avantage réel des propriétaires. IIs doivent pareourir les bois, les vergers, monter le long des arbres en tous sens, sonder tous les trous, visiter toutes les fissures, inspecter toutes les écorces, les enlever même, si cela est néces- 
saire, pour y saisir et y tuer les insectes et les vers ronseurs. Afin de lui faciliter ce laheur pénible, Dieu a donné au pic deux doigts en avant et deux en arrière, armés d'ongles très-forts et arqués, des pieds courts et musculaires, un bec carré à sa base, cannelé dans sa longueur, aplati à la pointe; ce bee repose sur un cou raccourei, pourvu de muscles vigoureux et soutenant un crâne très-fortement constitué. Sa langue est très-lon-

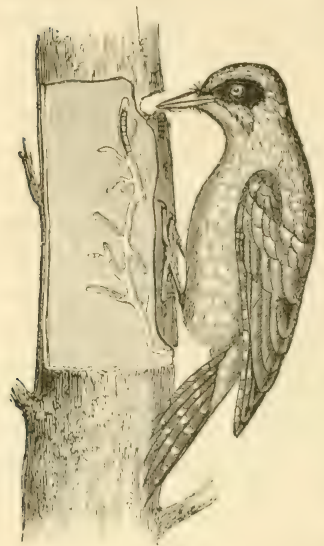
gue, effilée, arrondie, terminée par une pointe osseuse et par quelques petits crochets; elle servira à percer les insectes et à les retirer ensuite. Deux glandes y déversent une espèce de liqueur visqueuse, sur laquelle les fourmis viendronts'attacher. Enfin, sa queue est formée de dix pennes tronquées, raides, d'inégale longueur, composant une espèce de $m i$ séricorde, sur laquelle le pic s'appuiera et se reposera en gravissant les arbres, en perçant et fouillant les écorces. Armé de ces dons de la

Providence, le pic, comme tous les ouvriers condamnés ì un travail pénible et peu lueratif, commence sa journée dès que le jour paraît; il visite tous les trones et les branches des arbres; il scrute tous les trous: plonge sa langue sous toutes les écorces, sonde toutes les plaies; si l'arbre rend un son qui trahisse la présence d'un ver rongeur, le pic s'arrête, perce l'arbre, et va chercher jusque dans son repaire l'insecte destructeur. Le médecin, qui laboure arec le fer et le feu les membres de l'homme 
pour conjurer le développement du mal, est-il coupable? rend-il un service? La réponse à cette double question condamnera ou justifiera l'oiseau consacré à Mars. Les anciens avaient vu, dans la vie des pics, l'image d'un combat perpétuel; dans l'énergie des coups de bec de eet oiseau et dans son adresse à atteindre et à percer ses victimes, quelque ressemblance avec la puissance du dieu des batailles. L'apparition de cet oiseau était regardée comme un heureux présage. Aussi, lorsque les Sabins étaient en marche pour aller fonder la colonie d'Asculum, furent-ils agréablement surpris en voyant un pic-vert venir se reposer sur leur étendarả. Pour consacrer ce souvenir, ils nommèrent Picenum la contrée de l'Italie dont Asculum devint le chef-lieu.

Quand les pics sont dominés par des sentiments de crainte ou de colère, ils relèvent les plumes de leur tête. Cette particularité a fait croire à quelques naturalistes que ces oiseaux avaient une huppe. Malgré le rude labeur auquel ils sont condamnés, ils conservent une gaieté qui ne paraît jamais se démentir; ils sont l'image fidèle de l'homme acceptant généreusement la loi du travail.

M. Servaux, chef du bureau des travaux historiques au ministère de l'Instruction publique, donne, dans une lettre à M. Mulsant, président de la Société Linnéenne de Lyon, une preuve bien touchante de l'empressement avec lequel les pics se viennent en aide les uns aux autres. Voici cette lettre :

“ Un article que j’ai lu dans les Annales de la Société "Linnéenne de Maine-ct-Loire ( $2^{\circ}$ année, 1856 ), m’a " rappelé que je vous avais promis, lors de votre dernier " voyage à Paris, de vous faire part d'une observation " très-curieuse que j'avais faite, l'année dernière, sur " un couple de pics de la forêt de Montmorency.

" A la fin de l'hiver, j'avais remarqué, dans une 
"grande propriété de Montmorency (Teine-ct-(lise), "deux pics (le plus commun, le Picus viridis), qui " avaient commencé ì creuser leur nid dans un orme, "à quatre mètres environ du sol. Vers le milieu de mai. " pensant, a vec juste raison, qu'ils devaient avoir des œuls, "j’appliquai une échelle et montai le long de l'arbre; "mais impossible d'introduire mon bras dans l'ouver" ture : l'arbre était trop épais, et le trou ítait prolonol " de cinquante centimètres environ. J'essayai, mais en " vain, et pendant plus d'une demi-heure, d'arriver aux "œuls, soit à l'aide d'une branche enduite de glu, soit " avec une cuillère en étain recourbée... Enfin, lassé de " mes tentatives infructueuses, je me dicidai ì boucher " l'entrée du nid, avec cette espérance que, peut-être "pressée de pondre, la femelle déposerait ses œufs, " ainsi que je l'ai observé plusieurs fois, dans un trou " d'arbre des environs.

"Je ne m'occupais plus des pies et ne pensais déjà "plus à eux, lorsque le soir, vers quatre heures, passant " dans cette même allée, j'entendis frapper à coups re"doublés sur l'orme que j'avais quitté le matin... Je " m'avançai avec précaution et j'aperçus, cramponné à " l'arbre et frappant sans interruption, juste à la hau" teur du fond du nid, c'est-ì-dire à cinquante centi"mètres plus bas que l'ouverture, un pic qui, tout "préoccupé de son opération, ne me vit pas et me laissa " approcher jusqu'au pied de l'arbre; il s'envola alors, " et grand fut mon étonnement, lorsque jentendis con"tinuer, mais intérieurement, dans l'arbre, le même " bruit que j'avais entendu au dehors.... Evidemment " j’avais enfermé la femelle dans le nid, sans m’en dou"ter, et la paurre bête, conchée sur sa courée, n'avait "pas donni signe de vie le matin, lors de mes tentatives " pour lui enlever ses œufs.

"I'appliquai de nouveau l'échelle enntre l'arbre et 
" je collai mon oreille à l'endroit où les coups de bec " arrivaient sans arrêt et avec une précipitation qui " indiquait le désir de liberté que devait éprouver la "prisonnière; je fis du bruit, elle s'arrêta, mais un "instant après elle recommença de plus belle. De son " côté, le mâle n'était pas resté inactif, je vous assure; « car l'écorce de l'arbre était fortement entamée sur une " largeur de cinq à six centimètres et sur une profon" deur de plus de deux centimètres. Inutile d'ajouter' "que ce commencement de trou correspondait juste à " celui que la femelle commençait à l'intérieur.

" La captivité forcée, que j'avais imposée bien invo" lontairement à la pauvre femelle, avait duré assez long" temps, et, après m'être bien assuré du fait que je viens " de vous raconter, je retirai la pierre que j'avais mise "le matin pour boucher l'entrée du nid; la femelle " s'élança immédiatement, mais je la saisis au passage " pour l'examiner avec attention; elle était, comme vous " devez le penser, extrêmement farouche, très-agitée, "les plumes hérissées, le bec tout couvert de sciure de " bois, et, lorsque je la lâchai, elle poussa deux ou " trois cris en s'envolant... Etait-ce la peur que je " venais encore de lui causer, ou plutôt la joie de la " liberté?

" En quittant la maison, je fis part au jardinier de ce "qui venait de m'arriver; il me plaisanta beaucoup, me "disant que c'était impossible, attendu que, dans la " journée, à plusieurs reprises, il avait vu les deux piss " qui frappaient l'orme à l'extérieur, et qui étaient tel"lement occupés à leur travail qu'ils le continuaient " malgré sa présence, ne s'envolant qu'au moment où il " allait les toucher... Je m'expliquai alors l'énorme trou "fait en si peu de temps et qui, bien probablement, " n'aurait pas tardé à offrir une sortie à la prisonnière. "Pour rendre la liberté à sa femelle, le pic mâle avait 
" eu recours à l'obligeance d'un camarade, de son frère " peut-être.

" Cette histoire est vraie en tous points; l'expérience, " au besuin, pourrait être renouvelée. Je crois que cette " observation n'a pas encore été faite; peut-être pourrait" elle intéresser les personnes qui s'occupent d'oologie "et d'ornithologie '." )

L'Anjou possède cinq espèces de pics.

\section{PIC-VERT. - PICUS VIRIDIS.}

Le nom donné au deuxième genre de la famille des proglosses, en français et en latin, est fondé sur l'emploi de leur bec qui leur sert de pic pour perforer les arbres et trouver leur nourriture. L'adjectif vert indique la couleur dominante des plumes de la première espèce de ce genre.

Picus nous rappelle aussi des souvenirs mythologiques. Picus, fils de Saturne, père de Faune et aïeul du roi Latium, méprisa l'amour de la magicienne Circé pour épouser Canente. Circé, vivement irritée du dédain de co jeune prince, le changea en pic-vert $\%$. Picus devint

1 Extrait des Anmales de la Societé Linnéemne de Lyon, tome VII, 1860.

${ }^{2}$ Picus equum domitor, quem capta cupidine conjux, Aureì percussum virgì versumque venenis, Fecit avem Circe sparsitque coloribus alas.

$$
\text { Virgile (Eneid., liv. vir). }
$$

Picus, amateur de chevaux, le mème à qui Circé, dans son ardente jalousie, versa un breuvage magique et qu'elle transforma, d'un coup de sa baguette d'or, en un oiseau revètu de couleurs éclatantes.

Tum bis ad occasum, bis se convertit ad ortum, Ter juvenem baculo tetigit, tria carmina dixit. Ille fugit, sese solito velocius ipse 
un des dieux champêtres et présida aux augures. L'infortunée Canente fut entièrement consumée par le chagrin : il ne resta d'elle que le souvenir de son malheur. Les anciens aimaient beaucoup à consulter le vol du pic-vert, et ce fut avec plaisir qu'ils le virent, en grimpant à l'arbre qui protégeait le berceau de Remus et de Romulus pendant que la louve les allaitait, prédire la grandeur future des deux fils du dieu auquel il était consacré. Mlaintenant encore, les modifications du cri du pic-vert annoncent aux habitants de la campagne les variations de la température. C'est pour cette raison qu'il est appelé le " procureur, le pourvoyeur des moulins, le meunier. » Les Anglais le nomment "l'oiseau de pluie.»

Une vieille légende scandinave expliquait autrement les pérégrinations continuelles, la vie pénible des pics, leurs cris annonçant la pluie, enfin la calotte rouge dont leur tête est ornée. Le pic était, au point de vue des hommes du Nord, un juif-errant, un coupable expiant un grand crime. Voici, en abrégé, cette légende née

Currere miratus pennas in corpore vidit;

Seque novam subito Latiis accedere silvis

Indignatus avem, duro fera robora rostro

Figit et iratus longis dat vulnera ramis.

Purpureum chlamydis pennæ traxère colorem;

Fibula quod fuerat vestemque momorderat aurum

Pluma fit et fulvo cervix præcingitur auro.

En achevant ces mots, Circé se tourne deux fois vers l'occideni et deux fois vers l'orient; de sa baguette elle touche trois fois le jeune prince et profère trois fois tles paroles magiques. Il fuit, surpris de courir aree plus de vitesse; il roit des plumes naitre sur tous ses membres. Nouvel oiseau, il s'élance indigné dans les forèts du Latium; il déchire de son bee le flane des vieux chènes et, dans sa rage, il blesse leurs longs rameaux. La pourpre dont sa chlamyde ctait colorée se reproduit sur ses ailes; l'or de son agrafe rehausse d'un vif éclat son plumage et son cou. (Ovide, Met., 1. XIV.) 
dans les forêts de la Norwíge où les pies sont très-nombreux.

Une vieille femme, nommée fiertrude, avait l'habilude de se coiffer d'un béret rouge, et surtout de rendre la vie si pénible à son mari, que celui-ci, dans sa naïveté, assurait qu'il ne consentirait jamais à aller dans le paradis si sa femme devait s'y trouver. Le brave homme pensait que le cours de sa vie, passée avec une telle mégère, devait lui faire préférer l'enfer même ì des joies, quelles qu'elles fussent, si elles devaient être empoisonnées par la présence de Gertrude.

Un jour, un paurre se présente ì la porte du logis, demandant un verre d'eau pour désaltérer son gosier brûlí par les fatigues d'une longue marche. Gertrude l'éloigne avec brutalité, le menace de son balai et joint les injures au manque de charité. Ce paurre était JésusChrist. "Puisque, " lui dit le divin Saureur, "tu n'as " pas voulu donner au pauvre le verre d'eau recommandé " par l'Évangile, tu seras condamnée à errer continuel" lement et à gagner ta vie dans des courses incessantes; " ta lingue sera toujours brûlée par une soif insatiable, " et, pour que tout l'univers te reconnaisse et soit ins" truit de ta faute et de ta punition, tu porteras sur ta " tête ton béret rouge, et tu annonceras par un cri plaintif "l'eau que tu réclameras en vain pour assouvir ta soif." Ces paroles furent suivies immidiatement de la métamorphose de la mère Gertrude en pic-rert, et, depuis ce moment, elle expie et sa dureté envers les paurres et toutes les tracasseries dont elle a accablé son paurre homme. Débarrassé de sa femme, celui-ci a pu envisager le paradis comme un lieu de réritable repos, digne de ses désirs et de ses espérances.

Le pic-rert grimpe le long des arbres, en décrivant une suite de spirales tonjours de bas en haut. Quand il ne trouve rien dans ses pénibles investigations, il des- 
cend à terre, et se couche immobile devant une fourmilière au milieu de laquelle il plonge sa langue. Il la retire ensuite, toutes les fois qu'elle est chargée de fourmis prises à la glu qui l'humecte sans cesse. Quand le soleil ne favorise pas cette chasse et que les fourmis sont engourdies par le froid, il renverse de fond en comble la fourmilière, et fait une véritable razzia sur ces insectes et sur leurs œufs. Dans les régions glaciales, où les insectes et les vers manquent au pic pendant l'hiver, cet oiseau réunit des provisions dans le cours de l'été, et confie au creux des arbres des graines sèches, des noix, des noisettes qu'il retrouvera aux jours de disette. Pour briser les noix, il les place dans un

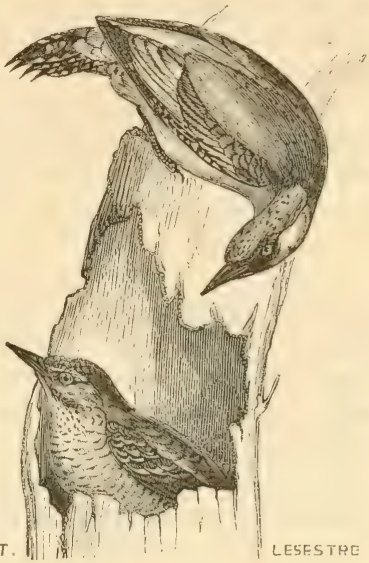
petit trou, où il les maintient avec ses doigts pendant qu'il frappe avec son bec. Dans notre département, qui offre au pic-vert des ressources suffisantes en tout temps, cet oiseau fait peu ou point de provisions. Quclquefois on aperçoit le pic, après avoir frappé quelques coups de bec dans un arbre, tourner avec rapidité du côté opposí, non pour voir s'il a percé l'arbre, mais pour saisir les insectes que le contre-coup a chassés de leur retraite. Il ne fait cette visite que lorsqu'il a reconnu, au son rendu par l'arbre, que celui-ci recèle quelque 
cavité. Cet oiseau passe les nuits dans un trou d'arbre ou de muraille où il se retire chaque soir, de très-bonne heure. (On voit à Chaloché, à l'angle du bâtiment principal de l'ancien monastère, un trou qui a servi de chambre à coucher au même pic pendant plusieurs anníes. Cet oiseau, qui offre dans son plumage une des plus belles varistés connues, a été tuí par un garde, malgré la défense de M. Gaignard de la Ranloue, et se trouve maintenant dans le cabinet de II. Rauul de Baracé.

Pour se dérober au plomb des chasseurs, le pic tourne autour de l'arbre, et se tient toujours du còté opposé à son adversaire. Si, par crainte ou de lui-même, il se dirige vers d'autres arbres, son vol est toujours saccadé et accompagné d'un cri plaintif.

Le pic-vert ereuse son nid ordinairement dans les trous des arbres, rarement dans les branches; dans ce dernier cas, l'ouverture est toujours tournée vers la terre, afin que la pluie n'y puisse pénétrer, et que l'entrée soit plus facilement dírobée aux petits rongeurs qui courent sur les branches.

Ici se présente naturellement le grief le plus sérieux qu'allighent les adversaires des pics, en objectant les ravages que ces oiseaux exercent dans les forêts pour préparer un nid à leurs petits. Ce reproche, quelque grave qu'il paraisse, peut encore être combattu victoriensement. D'abord les pics ne sont pas si nombreux que l'admet l'imagination de quelques bons propriétaires. P'uis, ce nid ne se prépare qu'une fois chaque année, et encore sert-il plusicur's années au même couple. Enfin, l'arbre choisi par les pics est presque toujours rongé intírieurement par les vers et les insectes. Quand, au moment de la nidification, le pic a trouvé dans ses courses un arbre dont la cavité lui a été révélée par les coups de son ber, il se met à l'ourage, et bientòt il parvient ì 


\section{$-115-$}

gagner l'intéricur, qui lui offre un asile pour ses petits et un salaire pour prix de ses travaux. Son premier soin est de dévorer les vers rongeur's. Quel est son crime? Celui d'avoir mis à jour un cancer intérieur, et d'en avoir arrêté les progrès en détruisant le mal dans son principe. Si l'arbre n'est pas gâté, le pic abandonne son travail ; car, autrement, comment parviendrait-il à creuser un nid perpendiculaire avec les ressources d'un trou qui ne laisse au corps qu'une faible partie de l'usage de ses mouvements? Enfin, quand il serait démontré, d'une manière positive, que le pic-vert perfore quelquefois des arbres sains el vigoureux, serait-il pour cela même condamnable? Les services qu'il rend, en détruisant des myriades de vers rongeur's, ne méritent-ils pas un salaire? L'assureur, qui prélève une dîme comme récompense de ses services, peut-il être condamné?

Le mâle se distingue de la femelle par les taches rouges de ses moustaches. Les œufs du pic-vert sont oblongs, d'un blanc lustré et le plus souvent piriformes; leur nombre varie de cinq à sept. Leur longueur moyenne est de $0^{\text {m }}, 030$, et leur diamètre de $0^{\mathrm{m}}, 020$. La femelle, lorsqu'elle est surprise sur ses œufs, fait entendre le même sifflement que le torcol. Quand les petits sortent ru nid, ils se plaisent à décrire des cercles autour du trou qui les a vus naître; ils se livrent à de joyeux ébats; mais à l'approche du premier danger, ils disparaissent dans les profondeurs de la demeure préparíe par la sollicitude de leurs parents.

PIC-CENDRÉ. - PICUS CANUS.

L'épithète française, donnée à ce pic, est, comme l'épithète latine, fondée sur la nuance de son plumage. Le pie-cendré est un peu plus petit que le pic-vert; sa tête 
et son cou sont d'un cendré pâle. Quelques taches noires longitudinales accompagnent le rouge cramoisi qui se trouve sur le sommet de sa tète, et servent à le distinguer du pic-vert. La femelle n'a pas de rouge sur l'occiput, et les moustaches du mìle en sont aussi dépourvues. Le pic-cendré, rare en Europe, creuse son uid dans les arbres; ses habitudes sont les mêmes que celles du précédent. Il pond de cinq à sept œufs, un peu moins gros que ceux de son congénère, inais plus allongés en proportion de leur diamètre qui est de $0^{\mathrm{m}}, 016$ is $0^{\mathrm{m}}, 017$; leur longueur ordinaire est de $0^{\mathrm{m}}, 028$.

L'explication donnée précédemment, sur l'étrmologie du mot canus appliqué au pic-cendré, a besoin d'être complétée.

Telle qu'elle a été exposée, elie pourrait ne pas paraître exacte. Le mot cumus signifie blanchir en vieillissant, et dès lors grisunner, selon l'expression vulgaire. Or, grisomer, c'est devenir gris, cendré, si l'on reut, et, dans cette acception, l'épithète camus conviendrait à ce pic qui, très-souvent, est appelé pic à tète grise, et cela avec d'autant plus de raison, que ce caractère sert à le distinguer véritablement de tous les autres pics.

La femelle du pic-cendré a la tète entièrement dépourvue de plumes rouges, et elle est ainsi privée du béret de la mère fiertrude. Quant au màle, il a seulement le front d'un rouge cramoisi, et les joues et l'occiput d'un cendré clair parsemé de quelques plumes noires longitudinales, comme s'il voulait exprimer la tristesse. qu'il ressent d'êcire dépouillé de la perruque d'apparat portée par le pic-rert, le pic-noir, le pic-leuconote, le pic-épeichette, ete. On dirait qu'il n'a conservé que quelques débris de la chevelure éblunissante du paurre prince Picus.

D'après Gimelin, les Tuaguses de la Navaäa Tanguska (peuples nonades qui habitent une partie du gouverne- 
ment d'Iéniséisk, en Sibérie) attribuent certaines vertus à la chair de cet oiseau. Ils la font rôtir, la pilent et y mêlent de la graisse, quelle qu'elle soit, excepté celle de l'ours. Ils enduisent ensuite, avec ce mélange, les flèches dont ils se servent à la chasse. Un animal atteint d'une de ces flèches succombe toujours, disent-ils, sous le coup qui le frappe.

PIC-ÉPEICHE. - PICISS MAJOR, PICLS VARIT'S MAJOR.

La dénomination épeiche est composée, selon quelques naturalistes, de deux mots allemands, elster et specht, qui signifient " pic varié. " Le nom latin varius indique le même sens; major fait connaître les dimensions de cet oiseau comparé aux deux suivants, qui sont aussi des pics variés. Il est plus probable cependant que cette épithète vient de spica, comme épervier de sparvarius. Le mot spica a été formé du verbe spicare qui signifie "piquer," et indique le moyen dont se servent les pics pour trouver leur nourriture et établir leur nid.

L'épeiche vit comme les pics précédents; cependant son vol est plus facile que celui du pic-vert : il poursuit et saisit au vol les insectes. Il se tient de préférence dans les vergers; il a l'habitude de frapper à coups précipités et très-riolents l'extrémité des branches sèches qu'il rencontre dans ses courses. Ce grimpeur, dont le plumage est composé de noir profond, de blanc pur, de rouge très-vif, niche dans les trous naturels, ou dans les nids abandonnés du pic-vert. Rarement l'épeiche creuse un nid; dès-lors il devrait trouver grâce aux yeux des propriétaires. L'épeiche pond cinq ou six œufs, dont la longueur moyenne est de $0^{\mathrm{m}}, 024$, et le diamètre de $0^{\mathrm{m}}, 018$. La forme des œufs de ce pic est la même que ceux des deux précédents; cependant ils sont généralement un peu plus arrondis. Le mâle seul a du rouge cramoisi sur 
l'uceiput. On constate d'une manière rígulière deux variétrís dans cette espèce; l'une est beaucoup p'us forte que l'autre.

Un habile chasseur de notre département, .11. Charles IIuart, a eu la bienveillance de me communiquer quelques renseignements sur un épeiche conservé en eaptivité pendant quinze mois. Cet oiseau avait été diniché dans un trone d'arbre près la Tour-Bouton, au commencement du mois de mai 1863. Confié à une femme, qui aime à élever les oiseaux avec une soilicitude vraiment maternelle, il put triompher de toutes les difficultés qui semblaient s'opposer à son éducation. On lui présenta d'abord du biscuit trempé dans du lait doux. Au bout de juinze jours, il sortait dı petit panier qui lui servait de nid, et venait de lui-mème becqueter les biscuits e! les fraises qu'on lai présentait. Il s'essatyait à poursuivre les petits insectes et les araignées qu'il trouvait dans l'appartement. Trois mois après, il voltigeait sur le plat contenant la soupe destinée au chat de la maison, et là, sans aucune crainte, il partageait la nourriture avec l'hôte favori de sa maîtresse. Enfin, il se fimiliarisa au point de venir prendre sa nourriture dans la bouche de la personne qui l'avait élevé, se plaisant à la piquer légèrement à la figure, en témoignage d'amitié et de reconnaissance. Ciet épeiche mangeait de tout, excepté des graines; il aimait les pois verts et surtout la viande. Sourent il venait se reposer sur la tête de sa maîtresse et y passait des heures entières. Il semblait très-accessible à des sentiments de jalousie. Lorsqu'une perruche habitant le même appartement paraissait rechercher les bonnes frrices de sa maîtresse, l'épeiche s'approchait de la cage de sa rivale, s'appuyait à terre sur ses deux ailes, lançait de vigomeux coups de bec, et forçait ainsi son adversaire aul silence et à la retraite. Un trone darbre perforé avait śtí placé dans sa cage prour lui servir de nid. L'u- 
peiche avait dédaigné le trou qui avait été pratiqué par ld main de l'ouvrier pour s'en creuser un autre. Il semblait rejeter le travail de l'homme, comme étant moins approprié à son usage. Il se livrait constamment à un travail fatigant; il coupait les pailles de toutes les chaises, et, dans ce labeur continuel, son bec semblait s'émousser pour repousser bientôt avec une nouvelle force. M. Huart a pu, plusieurs fois, prendre cet oiscau, le placer dans son paletot et circuler ainsi en ville, sans que l'épeiche cherchât à fuir cette captivité qu'il paraissait affectionner. Après quinze mois de séjour dans le même appartement, il disparut sans qu'on ait pu connaître quel avait été son sort.

PIC MAR. - PICUS MEDIUS.

Le nom de mar est une abréviation de "Mars, " auquel le pic était consacré, comme Ovide l'a consigné dáns ses vers. On lui donne indifféremment l'épithète martius ou medius. Ce dernier adjectif indique qu'il tient le ("milieu ) pour les dimensions entre l'épeiche et l'épeichette, nommée picus minor. Le pic mar ou moyen épeiche est rare dans tous les pays. Ses

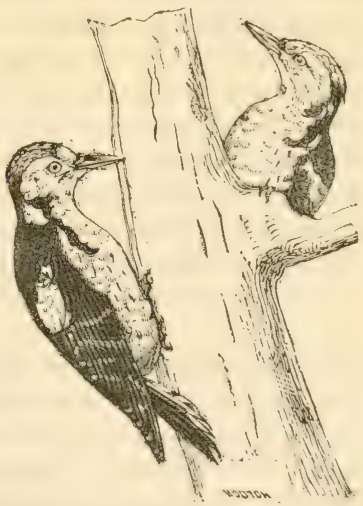
couleurs sont moins vives que celles de l'épeiche. Il visite comme celui-ci les troncs et les branches des arbres en tous sens, monte et descend en décrivant des spirales. 
Ce pie pond de trois it cing ceufs, dans un trou naturel, ou dans un vieux nid abandonni par ses congénères, ou dans une branche qu'il a perforée. Ses aul's ont $0^{\mathrm{m}},(1) 22$ de longueur, et ()$^{\mathrm{m}}, 016$ de diamètre. La femelle ressemble au mìle, mais les plumes rouges de sa tête sont moins développées et d'une couleur moins vive.

PIC: EPLICHETTE or PETTT ÉPEICHE. - PICIS MINOR.

Les différents noms donnés à ce pic sont fondés sur sa taille : il est le plus petit de la famille. L'épeichette vit de ver's, de chenilles, d'insectes, de petites baies, et, comme clle peut trouver sa nourriture beaucoup plus facilement Iue les autres pies, on la voit assez souvent en société : nouvelle preuve que la solitude, à laquelle se condamnent les grands pics, provient de la difficulté qu'ils éprourent is se procurer une proie suffisante pour vivre. L'épeichette pond, quelquefois dans un vieux nid de mésange, de sitelle, ou dans une cavite naturelle, quatre ou cinq œufs semblables à ceux des autres pics. D'autres fois, elle perfore une vieille branche vermoulue, pour y déposer ses œufs. Leur longueur moyenne est de $0^{\mathrm{m}}$, 018 , et leur diamètre de $0^{\mathrm{m}}, 014$. La femelle n'a pas de rouge sur la tête qui est entièrement noire.

Ici se termine l'ordre des grimpeurs comprenant, pour l'Injou, sept espèces, qui toutes travaillent incessamment ì préserver les arbres des ravages des insectes et des ver's rongeurs, et dont deux, le pic-rert et le piecendre, perforent les arbres pour chercher leur nourriture ou préparer leur nid; les autres attaquent quelquefois les branches vermoulues, mais le plus sourent se servent de vieux nids abandonnés. 
Avant de passer au troisième ordre des oiseaux de la Faune de Maine-et-Loire, je ne puis résister au désir de raconter un fait qui corrobore mon opinion favorable aux pics, et combat les reproches de prétendus méfaits qu'on impute aux grimpeurs avec trop de partialité et d'injustice.

Un de mes amis, grand amateur d'histoire naturelle, loin de partager mon sentiment sur cette famille de proscrits, prenait plaisir à recueillir toutes les observations propres à augmenter la liste des ravages attribués aux pics. Ainsi que l'un de ses parents, il se montrait disposé à mettre à prix, dans toute l'étendue de ses propriétés, les langues des proglosses. Combien d'autres cependant, plus nuisibles et plus dangereuses que cellesci, ne sont pas punies avec le même acharnement! Comme ce parent, il eût désiré recevoir de temps en temps une petite boite pleine de langues de grimpeurs. Cette boîte était expédiée d'une manière très-régulière, et une prime pour chaque langue était accordée à l'heureux chasseur qui exécutait un ordre dont, pour lui, l'importance se mesurait sur les bénéfices qu'il en retirait. Après un séjour assez long à la campagne, pendant lequel le mandat d'exterminer tous les pics avait été renouvelé aux gardes et aux fermiers avec une ferveur toujours croissante, mon ami vint me trouver, pressé en même temps par un sentiment de joie et de tristesse. 11 s'agissait de m'annoncer, d'un côté, une perte qu'il venait d'éprouver, et de l'autre, une nouvelle preuve péremptoire justifiant sa haine contre les pics. Un des plus beaux arbres de sa campagne, un chêne magnifique végétait depuis plusieurs années; des branches et une partie de l'écorce s'étaient détachées du trone; l'arbre paraissait languir et devoir bientôt se dessécher entièrement. Les pics de toute la contrée semblaient s'être donné rendezvous pour le percer dans tous les sens. Quelques per- 
somnes étaient portées ì reconnaître dans ce fait une croiside organisfe par la vengeance; j'y trouvai au contraire un acte de générosité exercé envers un persécuteur. Inon ami pensait que l'arbre périssait parce que les pies l'avaient perforí; je croyais au contraire qu'ils le sondaient dans tous les sens pour lui renir en aide et protéger son existence. Le ehêne est condamné et abattu, le trone scié en plusieurs billes. Le charpentier, partageant les idées du propriétaire, et convaincu que l'arbre n'était défectueux que dans les endroits oì les pies l'avaient perforé, avait payé le chêne un prix assez élevé : nouveau service rendu à mon ami par les grimpeurs. On remarqua bientôt que, sous l'écorce dont une partie avait disparu, existait une fissure pénétrant dans l'intérieur de l'arbre et offrant des ramifications irrégulières, tantôt étroites, tantôt larges et se prolongeant dans la plus grande partie du trone pour se terminer par une déchirure complétement déguisée. L'eau avait pénétré dans cette plaie et corrompu insensiblement les parties roisines, et, dès lors, une quantité considérable de ver's rongeurs s'y étaient installés. Là, ils avaient étahli leur quartier général, d'où ils sortaient fríquemment pour exercer de terribles ravages. C'était à ces ennemis du chêne que les pies avaient déclaré une guerre acharnée, et non à leur persécuteur, dont ils défendaient la propriété avec une persévérance payée par une noire ingratitude. Il fut constaté que le dépérissement de l'arbre devait être attribué à la foudre, qui avait plusieurs fois frappé le chêne et exercé quelques-uns de ces effets si bizarres et si capricieux, mais qui lui sont cependant si habituels, et dont les eonséequences n'avaient pas été visibles immédiatement.

Cette fois encore, dans le procès intenti aux pies, la déposition du témoin à chargèe, non-senlement était anéanlie, mais tumruait à la justification complète des aceusés. 
La défense des buses, que je n'ai présentée que d'une manière superficielle, serait encore plus facile à soutenir que celle des grimpeurs. Il me paraît, en effet, très-aisé de prouver aux propriétaires qui déclarent une guerre implacable à ces rapaces, que leur acharnement n'est pas fondé. Les dógâts que peuvent exercer les buses sont bien loin de pouvoir être comparés aux services que ces oiseaux rendent à l'agriculture, en détruisant tous les petits mammifères et les gros insectes qui dévorent les semences. Depuis de longues années, M. Deloche, conscrvateur du musée d'Angers, a préparé et monté plus de cent cinquante buses; toutes, sans exception, contenaient dans leur intérieur des débris de rats, de mulots, de taupes, des pelotes composées de courtilières et de grillons, et jamais aucune trace de gibier. IIon intention n'est pas de soutenir que les buses n'attaquent et ne mangent jamais de gibier : ce serait avancer une opinion fausse; mais je me borne à constater que ce dernier grief n'est pas aussi fréquent qu'on le croit ordinairement, et qu'il doit s'effacer en présence des services habituels rendus aux propriétés par ces rapaces, surtout au commencement de l'hiver. C'est, en effet, ver's cette époque, que les buses se livrent à des pérégrinations continuelles, lorsque les semences ont le plus besoin d'être préservées des ravages exercés par une multitude de petits rongeurs et d'insectes nuisibles.

Ici se terminait la défense que j'avais présentée successivement en faveur des chouettes, des pics et des buses. Depuis la première édition de mes Essais étymologiques, j'ai reçu des encouragements d'un grand nombre de naturalistes français et étrangers : tous approuvaient mon opinion; quelques-uns même me reprochaient d'avoir fait peut-être trop de concessions aux préjugés vulgaires, et de n'avoir pas défendu avec assez d'énergie mes clients de prédilection. Malheureusement cette opi- 
niou n'était pas celle des chasseurs et des propriétaires, et, de leur part, il m'a fallu soutenir des attaques très-vives et très-persévirantes. Leurs assertions m'ont déterminé à étudier encore davantage les mœurs des oiseaux que j’avais pris sous ma protection; les discussions que jai soutenues n'ont fait que me fortifier lans ma conviction précédente, et, pour preuve, je crois devoir ajouter quelques ditails nouveaux à mon premier plaidoyer.

Des naturalistes consciencieux se sont livrés à un travail rúitiré pour constater le nombre de mulots, de souris, etc., que pouvait dévorer par année un couple de chouettes hulottes. Les plus modérés en ont porté le nombre à dix par jour, cinq pour chaque rapace nocturne, sans compter ceux qui étaient nécessaires pour nourrir leurs petits pendant un certain nombre de semaines. En retranchant même quelques-unes des victimes du total de ces appréciations, on obtiendra plus de trois mille rongeurs détruits par chaque couple de hulotte. Cette assertion est de beaucoup au-dessous de la vérité; mais en l'adoptant même comme base de raisonnement, on est forcé de reconnaître les immenses services rendus par ces rapaces à l'agriculture. Si quelquefois les rongeurs sont rares et que les chouettes attaquent les merles, les perdrix, voire même les lapins, est-ce une raison pour méconnaître leur concours nécessaire? Lhomme, en les poursuivant, fait preuve d'une noire ingratitude et d'un sauvage égoïsme; il oublie les services réels et précieux de serviteurs dévoués pour ne considérer que de misérables peccadilles. Si l'on adoptait ce principe par rapport. ¿ lui-même, que de gens qui devraient être poursuivis, sans avoir mème les faits à dícharge apportés en faveur des choucttes! Ln de mes amis, possesseur d'une jolie habitation aux environs d'Angers, se laisait un véritable plaisir d'offrir aux visiteurs de sa maison de campagne les magnifiques fruits qu'il y recueillait, et surtout de 
belles cerises précoces. Mais voici qu'une année, cerises, prunes, etc., sont dévorées par un ennemi invisible. Après beaucoup de recherches, on constate que les ravages sont dus à la présence du loir lérot (myoxus vitela). Quelques individus de cette espèce parcouraient pendant la nuit, avec une grande agilité et une rare audace, les espaliers et les branches des arbres fruitiers, et en dévoraient tous les fruits. D'où venait leur confiance toute nouvelle? De la faute du propriétaire. En effet, un couple de chouettes hulottes habitait depuis plusieurs années le trou d'un vieux mur de la chapelle, et, chaque soir, elles sortaient de leur retraite pour manger les rongeurs et préserver les fruits. Le propriétaire avait fait fusiller ces rapaces nocturnes, croyant obéir à une pensée salutaire, et il reconnaissait, trop tard et à ses dépens, combien il s'était trompé. Aussi me demandait-il, avec un vif désir de réparer sa faute, comment il fallait faire pour rapatrier dans son domaine d'autres chouettes hulottes !...

L'expérience a si clairement démontré aux gens de la campagne les services que les chouettes rendent à l'agriculture, que, lorsqu'ils s'aperȩoivent des ravages exercés par les mulots, etc., dans leur's récoltes, ils s'empressent de fixer à terre, en les courbant, des branches flexibles, afin que les chouettes puissent s'y reposer pendant la nuit et veiller stir les semences confiées à leur garde, en se fixant sur l'observatoire préparé à cette intention.

Je passe à la deuxième série d'accusés; mais, en ce qui concerne les buses, je n'ai rien à ajouter, si ce n'est que tous les naturalistes que j'ai consultés et qui s'occupent de taxidermie, m'ont assuré, de vive voix et par écrit, que les centaines de buses qu'ils étaient appelés à préparer n'offraient dans leur estomac que des débris de taupes, de mulots, etc., et surtout des pelotes composées de grillons et de gros coléoptères. D'où il suit que, si telle 
est la nourriture ordinaire des buses, les délits qu'on leur reproche ue reposent que sur de's faits accidentels et ne peuvent constiturer un péché d'habitude. Dìs lor's, ces fautes doivent être facilement pardonnées, surtout lorsque l'on constate les véritables services que les buses rendent, en accomplissant pendant le jour l'œuvre salutaire que les chouettes accumplissent pendant la nuit.

J'arrive aux pies, les plus condamnés des trois espèces reconnues coupables, et en fareur desquels on repousse toute espèce de circonstances atténuantes. Cependant il est avéré que ces infortunís oiscaux ont trouré des défenseurs bien dévoués dans tous les auteurs qui ont ritudié sérieusement leurs habitudes. Tous ont reconnu que les pies avaient reçu de Dieu une mission pénible à remplir, soit qu'on les considérât dans les forêts vierges de l'Amérique, soit qu'on les suivît dans les autres contríes de l'univers. C'est en partie à la guerre acharníe qu'on leur fait, que l'on doit, dans certaines localités, la multiplication effrayante des ver's et des insectes rongeurs, dont la présence devient de plus en plus un véritable fléau.

Un de mes honorables amis, adversaire ardent des pics, a vu avec peine, cette annće, un des beaux peupliers de son avenue se briser sous le souffle d'un vent violent. L'arbre s'étuit rompu à l'endroit où un pic-vert avait fixé son domicile depuis plusieurs années. P'our convainere mes clients de fautes graves et anéantir toute excuse en leur faveur, mon ami fit scier une partie du peuplier et apporter le corps du délit. Il fut constaté que le pic-vert avait creusé dans toute l'épaisseur de l'arbre un trou de 60 à 70 centim. de profondeur. Il devenait évident que l'arbre ne devait pas résister au souffle d'un vent impétueux, et que, dès lors, le pic-vert était véritablement la cause du désastre qu'avait subi mon honorable ami. J'admettrai même, et sans conteste, que le troti arait été 
creusé dans un arbre sain et vigourcux. Je fais toutes les concessions possibles aux réquisitoires de mes adversaires, afin que je ne paraisse pas vouloir faire acquitter mes clients en dissimulant une partie de leurs torts. Il me reste à présenter quelques considérations en leur faveur sur le fait en question.

Le pic est un grimpeur : comme tel, il ne se perche pas; mais aussi, pour passer la nuit et pour se reposer, il lui faut un domicile; ce domicile, il en choisit l'emplacement, et, au lieu de l'attendre, comme beaucoup d'oiseaux, du ravage exclusif des ans ou du labeur d'autres espèces, il le prépare ordinairement dans un arbre vermoulu, qu'il creuse au prix d'un travail opiniâtre. Une fois le domicile creusé, le pic sent la nécessité de l'agrandir ì mesure que la famille s'augmente, et, dans cette espèce, comme aux àges primitifs, la famille est nombreuse. Pour lui, son domicile est son véritable cercle; il lui faut done de la place pour plusieurs générations. Après des courses longues et très-pénibles, il ne demande qu'au foyer domestique repos et délassement; comme tous ceux qui travaillent et qui souffrent et dont le cœur est pur, il aime les épanchements de la famille. Ce nid, ce développement successif sont les conséquences naturelles de sa vocation et de son esprit de famille ; l'attaquer, ce serait attaquer la Providence elle-même. Ce nid cause quelquefois un tort réel, j'en conviens; mais ce tort n'est-il pas largement compensé par les services incontestables que le pic rend à l'agriculture, en détruisant des myriades de vers, d'insectes et de fourmis? Si les ravages qu'il exerce dépasse les limites qne je viens d'indiquer, à qui la faute? Si l'on respectait le domicile du pic, que de dégâts on éviterait! Là il élèverait ses petits, et, pendant bien des années, ceux-ci ne chercheraient pas ailleurs une nouvelle habitation.

Les propriétaires traquent, poursuivent le malheureux 
pie, le forcent ì perforer beaucoup d'arbres, afin de se soustraire, ainsi que sa famille, it la haine de ses ennemis. On le contraint à fuir un nid commencé, pour chercher ailleurs un nouveau gîte qu'il abandonnera encore, et on le détermine ainsi à multiplier des ravages qu'on éviterait en le laissant accomplir tranquillement sa mission providentielle. En Amérique, dans les forêts vierges, où les pics sont si nombreux, les dégâts sont beaucoup mioins multipliées que dans nos contrées, parce que ces grimpeurs ne sont pas forcés, par la guerre implacable des hommes, ì changer aussi souvent de domicile. - "Quoi! ") me disail mon honorable ami, dans un mouvement sublime d'indignation, " vos misérables pics pullulent; j'en ai tué vingt-sept sur les bords du même nid! " L'accusation prouvait tout simplement que vingtsept membres de cette famille proscrite se réfugiaient dans le même domicile et vivaient heureux sous le même toit! Exemple bien rare et bien incompris de nos jours!

Je termine ici mon long plaidoyer en faveur des pies: puissent ces quelques pages diminuer l'acharnement de lia guerre cruelle qu'on leur fait, et leur obtenir un peu plus de tranquillité, afin qu'ils puissent accomplir la mission qu'ils ont reçue de Dieu! L'homme lui-même se procurera aussi un avantage réel, et ne donnera plus lieu ì des récriminations dont lui seul nultiplie les causes. En terminant cette défense, je m'appuierai sur l'autorité de mon honorable ami, M. Aimé d'Andigné-Legris, qui m’a affirmé plusieurs fois que les gardes généraux de la forêt de Baugé ne faisaient pas poursuivre les pies, parce qu'ils étaient convaincus que, loin d'être nuisibles, ils ćtaient plutòt utiles aux arbres qui leur itaient confiés.

Chez les Romains, les augures attachaient une grande importince à toutes les circonstances qui se rattachaient aux pics. Ainsi Pline nous apprend (qu'un pie, étant venu se reposer sur la tête du préteur (dilius Tubéro, tandis 
que ce magistrat était assis sur son tribunal, dans la place publique, se laissa prendre à la main. Aussitôt, grande fut la rumeur dans toute la ville de Rome. Les devins, consultés sur ce prodige, répondirent que l'empire était menacé d'une ruine entière si l'on rendait la liberté au pic, et le préteur, de mort prochaine si l'on retenait captif l'oiseau grimpeur. Sous l'influence d'un véritable dévouement à la patrie, Tubéro, à l'instant même, met le pic en pièces et en jette les plumes au vent. Peu de jours après, ajoute l'historien, le préteur périssait, réalisant ainsi la prédiction des augures. Si pareil événement devait arriver de nos jours, je prierais mes honorables contradicteurs d'avoir moins de dévoliement à la patrie que le préteur Tubéro, et je pense que leurs intérêts et ceux de mes clients seraient cependant sauvegardés, sans que la chose publique fût en danger.

Je voulais, je devais même, terminer ici un plaidoyer peut-être déjà beaucoup trop long; mais je ne puis résister au désir de relater un épisode dont j'ai été récemment le témoin, j'allais presque dire, la victime. Vers la fin du mois d'août 1866, une aimable hospitalité m'était offerte, à la campagne, non loin de M..... L'habitation, situće près de plusieurs allées de beaux peupliers, était une antique et simple maison patrimoniale. Depuis quelques années, elle avait subi l'influence du temps, et des fissures s'étaient développées dans les murs extérieur's. Les propriétaires avaient remarqué qu'un certain nombre de pics, paraissant aroir élu domicile dans les peupliers qui encadrent le domaine, venaient tour à tour se cramponner le long de la maison, près des lézardes, et là, sous l'effort puissant de leur's coups de bec, les murs semblaient se déchirer encore davantage. Un nouveau grief se dressait contre mes infortunés clients : non-seulement on les accusait de perforer les arbres, de causer de graves ravages dans les futaies; mais des apparences plau- 
sibles venaient encore les ranger parmi les associés de la bande noire, les démolisseurs des vieux manoirs. Pour faire disparaitre cette nouvelle accusation, j'exposai ma conviction, que les pics travaillaient simplement it capturer les insectes, les fourmis qui se réfugiaient dans les fentes des murs. Mon plaidoyer fut favorablement accueilli, mais sans porter dans l'esprit de mes auditeurs une conviction profonde. On m'installe avee une bienveillance patriarcale dans une chambre qui se trouvait au-dessus du théâtre des démolitions exercées par les pics. Bientòt je m'aperçois que quelques fourmis avaient pénétrí dans mon appartement à travers le mur, le papier et même les lambris. N'arant pas de benzine, je combats, avec le phosphore d'allumettes chimiques, avec l'eau de Cologne, etc., les insectes envahisseurs. P'uis je me livre au repos; le lendemain je renouvelle mes moyens de défense, et je me croyais maître de la position. Malheureusement, le troisiène jour, au moment du dîner, l'alarme est donnée, chacun quitte sa place et se dirige vers ma chambre. Là se livrait un véritable combat dont je conserverai, toute ma vie, le souvenir. Tout le ban et l'arrière-ban du personnel de la maison était armé de balais et d'instruments de mainte espèce, et luttait arec une grande énergie cuntre des myriades de fourmis; le carreau avait disparu sous lit couche fpaisse de leurs légions innombrables. Des milliers de fourmis, s'attaquant aree une rage incroỵable aux jambes des combattants et des combattantes, forcèrent tout le monde à battre en retraite. Les chambres voisines, l'escalier, étaient inondés par le fléau qui se déreloppait sans cesse. On ferma alors rapidement portes et fenêtres, et un mit le feu à de longues traînées de poudre de soufre. l'uis, après une heure de repos, on si rendit sur le lieu du combat, et on balaya des milliers de cutlarres de fuurmis asphysióes. Je renuuvelai l'air; jeus 
recours à tous les moyens possibles pour faire disparaître, du moins en partie, l'odeur de l'acide formique et de l'acide sulfureux, et je repris possession de ma chambre. Je croyais que la lutte était finie; mais après la trêve de la nuit, elle recommença le lendemain avec une telle fureur, que cette fois les fourmis restèrent maîtresses de la place, et que je me vis, bien à regret, obligé d'aller coucher dans une autre chambre. Avant de m'endormir, je songeai à mes chers clients, et je me fortifiai dans cette opinion que, s’ils eussent pu pénétrer dans les fissures de la maison ou du moins glisser dans tous les replis des lézardes leur langue longue et visqueuse, ils eussent évité au vénérable propriétaire, et à ses hôtes, quelques soucis et certaines préoccupations. Dens ce cas, comme dans les autres, les pies travaillaient non pas dans un but de destruction inutile et qui serait certainement une injure à la Providence, mais bien dans l'intírêt. de l'homme, qui se confondait avec l'avantage propre de mes protégés. Puisse cette défense, que je soumets à mes lecteurs, être favorablement accueillie par tous ceux qui entourent de leur sympathie les êtres en butte à un travail pénible, à la souffrance et à la calumnie!

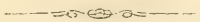

\section{TroIsIĖNe ORIDRE. - PASSEREAUX ${ }^{1}$.}

Le troisième ordre des oiseaux porte dans la Faune de Naine-et-Loire le nom de passereaux; d'autres auteurs lui ont donné celui de sylvains. La première déno-

1 Je rèpète ce que j'ai dit: je n'ai nullement l'intention de composer une Fame; mon but est simplentent d'expliquer, par 
mination me parait plus convenable que la seconde, en ce sens qu'elle est plus génírale, et qu’elle s'applique mieux aux nombreuses familles renfermées dans cet ordre.

Le mot pussereau, comme le latin passerulus (I'line), est un diminutif de passer, eris. Il a la même racine que passus, " jas, " l'où est venu le verbe de la basse latinité passare, "passer, " signifiant " aller d'un endroit dans un autre, "s sans s'y fixer longtemps, et reprisentant d'une manière expressive les habitudes des oiseau dísignés par le mot passer. Presque tous les passereaux ímigrent selon les saisons, et ront demander à de nouveaux climats la nourriture que d'autres leur refusent. I'endant leur' síjour même dans les pays qu'ils habitent, ils aiment, par goût et par nécessité, à en parcourir les différents sites. Les bois, les plaines, les buissons, les bords des rivières sont tour à tour témoins de leurs excursions rapides et multipliées.

\section{PREMIERE FAMLLE.}

\section{Fatirostres.}

La première famille de l'ordre des passereaux a reçu le nom de latirostres, de lutum, "large, " et rostrum, "bee. ") Iieu, selon le dessein de sia providence, a procuré à ces oiseaux, dans les dimensions de leur large bec, un moyen puissant et sûr de saisir les insectes ailés qui leur servent de nourriture.

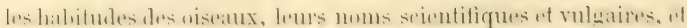
de montrer l'action de la Providence lit ou les naturalistes ne voient trop souvent (que bizarrerie ou caprice. 


\section{PIEUIIER GENIBE.}

ENGOULEVENT ORDINAIRE. - CAPRIMII,GIS EIROPELS.

L'engoulevent est un oiseau semi-nocturne. Pendant le jour, il se tient régulièrement à terre, au milieu des taillis et des bois de sapins. Si quelque cause le force à voler pendant le jour, la lumière fatigue ses yeux trop sensibles, et, dès lors, son vol est saccadé et incertain. On le voit chercher un refuge sur les arbres, contre lesquels il semble se heurter. N'ayant pas, comme les oiseaux de nuit, les moyens de se soustraire à ses ennemis en se cachant dans les cavités des arbres ou des vieux murs, il deviendrait facilement la victime des chasseurs ou des oiseaux de proie, si la Providence ne lui avait pas donné en compensation un instinct particulier.

L'engoulevent est, avec le scops, le scul oiseau de l'Europe qui se perche parallèlement à la longueur des branches. Sa couleur se marie très-bien avec celle de l'écorce des arbres; il se confond ainsi avec la branche qui lui sert d'appui, et se dérobe aux regards les plus clairvoyants. Quand le soleil disparaît et que le crépuscule lui succède, l'engoulevent s'élance dans les airs et développe toutes les ressources de son vol puissant. Il décrit des cercles en tous sens autour des arbres, qu'il enveloppe d'une série de spirales dont le diamètre se rétrécit et s'élargit tour à tour. Son vol tient alors de celui de l'hirondelle et de celui de la chouette. Comme la première, l'engoulevent se joue dans l'air, et glisse à la surface de la terre avec une grâce et une facilité remarquables. Comme la seconde, il semble soutenu par ses plumes fines et pressées, et, quand il ne chasse pas, il vole sans faire le moindre bruit. Lorsque cet oiseau poursuit les insectes, pendant les quelques heures du crépuscule, il ouvre un 
ber d'une grandeur dímesurée et garni à sa base dequelques puils longs et raides. Ceux-ci concourent à diriger les insectes daus le gosier de l'engoulevent, et il ne le referme que lorsqu'il est tapissé de victimes. Pour que ces dernières ne puissent sortir de cette prison, une fois (qu'elles y sont entrées, iout lintérieur du bec est enduit d'une couche de glu naturelle que l'oiseau renouvelle selon ses besoins. En volant arec une grande vitesse et le bec ouvert, l'engoulevent produit un bourdonnement sourd qui augmente ou diminue avec la rapidité du vol. L'air, étant alor's vivement déplacé, vient s'engouffrer dans le large gosier de cet oiseau, et produit le même eflet que dans le corps d'une tompie, dunt le ronflement est en ripport avec la puissance de rotation qu'on lui imprime. C'est ì rette manière de voler que ce passereau duit son nom d'engoulevent. Quelques instants avant de commencer la chasse, le mâle fait entendre un bruit très-sonore et semblable à celui d'un rouet à filer; il répète le même bruit pendant les moments de repos qu'il prend au milieu de ses excursions crépusculaires. De temps en temps, il interrompt son vol pour se laisser tomber a terre avec la rapidité d'une balle, et y saisir les bousiers et d'autres coléoptères qu'i! a aperçus dans sa course, malgré la rapidité avec laquelle il l'accomplit.

Cet oiseau rend des services réels à l'agriculture en détruisant des myriades de hannetons et de larves de toute espèce, pendant le temps que tous les autres insectivores se livient au sommeil. L'engoulevent poursuit pendant la nuit l'wuvre si utile de destruction commencée par les hirondelles pendant le jour. Pline le désigne sous le nom de fur nocturnus, "le voleur nocturne. " Cette expression, prise dans le sens le chasseur, est juste; mais elle serait complétement fausse, si on y attachait une idée de culpabilité.

Les fipithètes ordinaire et enropéen, ajoutées au nom 


\section{$-135-$}

de l'engoulevent, indiquent que cette espèce est la plus commune. Partout elle est répandue, et cependant nulle part elle ne se trouve en grand nombre. Cette même dénomination sert aussi à la distinguer de l'engoulevent à collier roux qui habite l'Afrique et se montre dans quelques contrées de l'Europe.

Le nom scientifique caprimulgus dérive de caprea, " chèvre, " et de mulgeo, "téter, " et signifie dès lors: " oiseau qui tette les chèvres. " Cette hypothèse n'est nullement fondée, et ne peut s'expliquer que parce que l'engoulevent, se tenant à terre et étendu sur le ventre pendant le jour, a été nommé par les habitants des campagnes crapaud-volant. Ils l'ont comparé au crapaud, à cause de son cri et de son large bec. Dès lors, on lui a attribué l'habitude prétendue du crapaud, celle de téter les chèvres, et ce préjugé est venu s'abriter sous la protection du nom pompeux adopté par la science. L'engoulevent aime à séjourner dans les parcs des brebis et des chèvres, où il trouve, sous les excréments de ces animaux, de nombreux coléoptères. Le choix de ce domicile a contribué encore à favoriser l'erreur populaire, et a propagé, sans la justifier, l'épithète de tette-chière.

L'engoulevent habite le plus souvent les terrains sablonneux et plantés de sapins; il aime de préférence la lisière des bois. C'est là qu'il trouve une nourriture abondante, et qu'il peut très-facilement élever ses petits. La femelle, beaucoup plus grosse que le mâle, ne fait aucun nid, dépose à terre deux œufs oblongs dont le diamètre varie de $0^{\mathrm{m}}, 020 \mathrm{à} 0^{\mathrm{m}}, 022$, et la longueur de $0^{\mathrm{m}}, 030$ à $0^{\mathrm{m}}, 032$. Leur couleur est d'un blanc marbré et couvert de taches brunes et cendrées. Des naturalistes prétendent que lorsque la femelle craint des dangers pour ses œufs, clle les roule ou les transporte même dans son bec en des endroits où elle pense jouir de plus de sécurité. Quelquefois on trouve trois œufs dans le même nid; mais 
ce cas rst très-rare. Il s'est cependant présenté cette année à Bagneux, près de Saumur.

Tous les ans, plusicurs comples d'engoulevents viennent se reproduire dans la propriété de $\mathrm{NI}^{\mathrm{m}}$. Boguais, au milieu des taillis encadrés par les bouquets de sapins situés sur les bords de l'ritang Saint-Nicolas. C'est lit que, pendant les mois de juin et de juillet, on peut, vers le concher du soleil, être témoin du vol, de la chasse et du bruit si curieux de l'engoulevent.

\section{DEUXIÈE GENRE.}

MLATINET DE MIRAILLES. - CYPSELIS MURARIIS.

Le martinet est, de tous les oiseaux visitant l'Europe, celui qui arrive le plus tard et qui part le plus tòt. En cela le martinet ne suit pas un caprice, mais l'instinct donné par la Providence, qui lui indique le temps et le lieu où il trouvera en plus grande quantité les insectes nécessaires à sa nourriture. Chaque année, il avance ou retarde son arrivée et son départ, selun les variations de la température.

Plus hirondelle que les hirondelles mêmes, le martinet est compris dans le même genre par le plus grand nombre des naturalistes, et porte le nom d'hirundo apus, qui, dérivé de $\mathrm{A}$ et de pous, pouos, signifie hirondelle « privée de pieds, de tarses. "C Cette particularité est un des caractìres les plus remarquables du martinet. En effet, malgré ses ailes longues et puissintes, cet oiseau ne peut se dérober à ses ennemis dès qu'il se pose à terre. La nullité de ses tarses ne lui permet pas de prendre son essor; aussi évite-t-il avec le plus grand soin de se reposer sur un terrain non accidentí. Dans les air's, il rèrgne jar la ficilité et la rapidité de son vol, et il échappe par 
cette puissance à tous les oiseaux de proie. Afin d'obvier aux inconvénients qui résultent de cette privation de tarses, Dieu a doué le martinet d'une vue très-perçante. Dès lors, il distingue de très-loin et an milieu de sa course rapide les plus petits insectes fixés sur les rochers ou le long des murailles, sans être obligé de s'arrêter en parcourant les lieux qui lui fournissent sa nourriture.

De plus, le martinet a les quatre doigts dirigés vers l'avant. Ce désavantage est compensé par l'usage de ses doigts, qui constituent ainsi une espèce de griffe avec laquelle l'oiseau se cramponne facilement aux aspérités des rochers, et se maintient dans cette position difficile assez longtemps pour y chercher et pour y saisir sa proie. Cette griffe lui sert aussi de peigne pour se débarrasser de la vermine qui le dévore. Aucun oiseau n’en étant aussi couvert que le martinet, Dieu devait, dans son infinie Providence, donner à ce latirostre un moyen de combattre cette ennemie.

Pour compléter son œuvre, Dieu a pourvu l'aile des jeunes martinets d'une espèce de crochet, comme celle des chauves-souris : c'est avec cette ressource qu'ils se meuvent dans leur nid. Ce crochet disparaît quand les martinets abandonnent le séjour qui les a vus naître, puisqu'il devient inutile. Les martinets restent dans le nid beaucoup plus longtemps que les autres oiseaux, par la raison que, lorsqu'ils le quittent, ils doirent être assez forts pour se soutenir dans les airs par un vol prolongé, le repos sur la terre leur étant en quelque sorte interdit. Lorsque le père et la mère d'une couvée de jeunes martinets pensent que leur progéniture peut se lancer dans les airs, ils s'unissent à d'autres parents et amis; et tous, par leurs cris incessants autour du nid, viennent provoquer les petits à affronter un élément inconnu; tous unissent leurs voix pour démontrer aux jeunes royageurs aériens qu'aucun danger ne les menace. 
Quand les petits, cédant à ces sollicitations si pressantes, se précipitent hors de leur nid, ils sont entourés de toute une phalange de martinets qui, en volant autour d'eux, paraissent vouloir les soutenir dans l'air, les encourager et les initier à la chasse des insectes. Les cris si vifs et si stridents qui se font entendre dans cette circonstance, paraissent être des arclamations poussées à l'instant où les jeunes martinets saisissent leur première proie : ce sont les chants de joic des parents cidébrant les premières victoires de leurs enfants.

Le martinet doit peut-être son nom ì son vol. Ses ailes frappent l'air et les murailles avec la rapidité de l'instrument mû par la vapeur et par les chutes d'eau. La dénomination de martelet, "petit marteau, " sous laquclle il est compris dans l'Encyclopédie i'histoire naturelle semble favoriser cette explication. Elle me paraît d'autant plus fondée, que le martinet, en martelant les murailles avec ses longues ailes, se propose un but sérieux et caractéristique, celui de faire envoler les insectes qui y sont attachés, afin de les saisir ensuite plus facilement dans leur vol ou dans leur chute. Nous pouvons constater cette habitude dans les mois de juin et juillet. Lorsque la température est élevée et le ciel serein, nous loyons les martinets se réunir en troupes nombreuses, voler avec une grande rapidité, en poussant des cris stridents et parcourir tous les immenses contours de notre vieux château si riche en souvenirs. Ces cris sont destinés à effrayer les insectes, à les faire sortir de leurs retraites, ou du moins à les déterminer à changer de place pour se cacher, et dès lor's à les livrer plus sùrement ì leurs ennemis en les rendant plus visibles. Les martinets baissent et álèvent tour it tour leur vol; ils semblent se proposer de balayer avec leurs ailes toutes les parois de cette antique ct magnifique forteresse.

Une idée de percussion semble naturellement attachée 
au nom du martinet. Serait-elle un souvenir pénible de l'enfance? Ne serait-elle pas fondée sur un trait caractéristique et tout particulier au martinet? Quand cet oiseau est à terre, pour parvenir à s'envoler il réagit d'une manière pénible sur le sol avec ses pattes, en étendant ses ailes et en les battant avec violence l'une contre l'autre.

Le mot martinet vient peut-être encore de Mars et de tinnio, " annoncer par ses cris le combat, la mort, " ou de Mars, Martis, et de neo, "filer, tresser le trépas, la guerre. ") Ces deux étymologies pourraient s'adapter aux habitudes de ce latirostre. Il répand la mort parmi les insectes, et son passage est annoncé par un cri de guerre strident. Dans toutes les sinuosités de son vol, il paraît encore, en passant et repassant au milieu des insectes qu'il immole, former un tissu, comme la navette lancée avec une grande rapidité dans des sens contraires. J'abandonne volontiers aux érudits la tâche de donner une solution à ce problème. Quoi qu'il en soit, ces hypothèses, même un peu téméraires, ont l'avantage de faire connaître les habitudes du martinet qui, le matin, promène la mort parmi les insectes voltigeant sur les prairies, et, le soir, poursuit, dans les régions les plus élevées et avec la rapidité de l'éclair, les insectes de haut vol.

Le bec du martinet est triangulaire, et il sécrète une humeur visqueuse sur laquelle viennent se coller les victimes qu'il saisit en volant. Quand ce latirostre a des petits et que son bec est rempli d'insectes, il passe devant son nid un grand nombre de fois, et s'élance ensuite dans le trou qui y conduit, avec la vitesse de la balle. C'est à cette habitude de nicher dans les murailles qu'il doit son épithète murarius et son nom scientifique cypselus, de KYPSÉLĖ dont la racine кYPÈ signifie " ravité. » Le martinet se retire dans les trous des murailles, des clochers, des bords escarpés des rivières, pendant le milieu du jour, 
car il ne chasse ordinairement que le matin et le soir. C'est dans ces carités qu'il fait assez grossièrement son nid avec les balayures des rues. La petitesse des tarses du martinet ne lui permettant que très-difficilement de saisir lui-même ces débris à terre, il devient évident qu'il doit recourir à la ruse pour se les procurer. En effet, il pille les nids des moineaux dont il mange les oufs et s'y établit ensuite quand il croit pouroir s'y maintenir. Ilais le plus souvent il est immolé par les propriétaires du nid, qui percent à coups de bec la tête du ravisseur. Cette habitude du martinet me parait expliquer l'opinion de Ménage qui pense que le mot martinet est un diminutif du mot Martin, nom d'homme, comme perroquet dérive du mot Perrot, Pierre; sansonnet, de Samson, etc. Car alors martinet signifierait "petit Martin, petit maître, petil père Martin, » individu qui ne se gêne pas avec ses voisins, qui s'installe chez eux volontiers, sans leur permission, et qui s'y conduit en maître, malgré leurs légitimes réclamations et leur opposition énergique.

Pendant longtemps, on a ignoré où le martinet passait la nuit: il paraît démontré que généralement cet oiseau se retire dans les clochers, et qu'il se livre au sommeil, en s'appuyant sur les poutres de ces édifices. Lit encore, il déloge le moineau, et cherche à lui ravir une demeure que celui-ci affectionne.

Quelquefois ce latirostre dépose sur des brins de paille l'humeur visqueuse quui tapisse son gosier; dès lors ces débris se trouvent liés entre eux, et forment un tout qui, en se durcissant, présente l'aspeet des nids provenant de la fontaine Sainte-Allyre, en Auvergne. Le martinet enlève aussi la mousse qui recuurre les trones d'arbres, en s'y accrochant à la manière des pics. C'est la grande difficulté gu'f́prouve cet oiseau ì saisir à terre les matéritux nícessaires pour la construction de son nid, qui a fait 
naître la pensée de prendre les martinets à la ligne. En Grèce et dans les îles de l'Archipel, où ces latirostres sont très-nombreux, les enfants montent dans les clochers ou sur les terrasses élevées, et laissent voltiger une ligne dont l'hameçon est déguisé sous un morceau de coton ou d'étoffe. Le martinet saisit en volant cet appât, et se prend à l'hameçon. Un pêcheur exercé peut capturer deux ou trois douzaines de ces oiseaux, par soirée, dans le temps de la nidification. Les martinets sont recherchés dans ces pays par les gastronomes, comme un mets délicat.

Le martinet pond trois ou quatre œufs blancs, oblongs, dont la longueur varie de $0^{\mathrm{m}}, 023 \mathrm{à} 0^{\mathrm{m}}, 026$, et le diamètre de $0^{\mathrm{m}}, 016$ à $0^{\mathrm{m}}, 018$.

\section{TROISIEME GENIRE 1.}

HIRONDELLE DE CHEMINÉE. - IIRUNDO RUSTICA, DOMESTICA.

Tous les oiseaux compris dans le genre Hirondelle sont doués d'une grande puissance de vol. Le faucon se précipite avec plus de rapidité que l'hirondelle; mais celleci glisse avec plus de facilité dans l'air, où elle poursuit

${ }^{1}$ Comme précédemment, je vais continuer à énoncer quelques hypothèses sur les étymologies des noms des oiseaux. Parcourant une route inexplorée jusqu'à ce jour, je ne puis suivre aucum guide reconnu par la science; mais si je m’égare, et si dans ce travail, je m’éloigne de la vérité, j'espère du moins n’ètre pas condamné, car l'hérésie ornithologique, comme l'hérésie religriense, suppose l’opiniàtreté dans la défense de ses erreurs. Or, je renonce d'avance à toutes celles qui seront signalées par les maîtres de la science. Les meurs des oiseaux m'engageront peut-ètre aussi quelquefois à faire de petites excursions sur le domaine de la philosophie et de la morale ; mais je pense trouver, dans l'exemple du bon Lafontaine et dans le caractere dont je suis revêtu, une justification à ces digressions. 


\section{$-142-$}

les insectes en jetant un petit cri et en ouvrant un large bee, tantòt dans les régions les plus rilevées de l'atmosphère et tantôt en rasant la surface de l'eau. Cette facilité de vol et cette habitude d'ourrir à chaque instant le bee pour happer les insectes me semblent indiquer l'itymologie du mot himmdo. Il dériverait alors de hiare, " bîiller, pousser un son avec effort, ") et de undo, " ondoyer, " et signifierait " oiseau qui bâille, qui ouvre

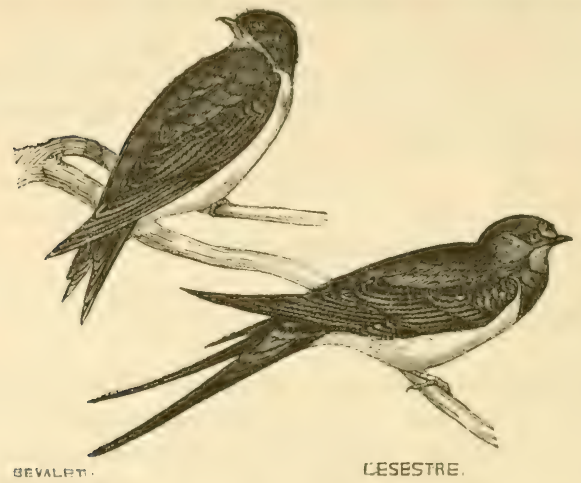

le bec en ondoyant dans l'air. ") Le deuxième verbe caractérise d’une manière expressive la grâce du vol de l'hirondelle si bien décrit par Buffon, et le premier s'appuie sur les habitudes de cet oiseau et sur l'autorité d'Illiger. Celui-ci, dans son Cours d'histoire naturelle, désigne les hirondelles par l'épithète hiantes, les "bâilleuses " et, par extension, les " criardes. " Peut-être pourrait-on hasarder l'étymologie suivante : hiure et unda, "oiseau qui ouvre le bee en effleurant l'onde: "quoiqu'un peu timéraire, cette étymologie aurait l'avantage de laire connaitre une partictilarité de la vie des hirondelles; en cflet, daus leur vol rapide, elles rasent la surface de l'eau, 
ouvrent le bec pour boire sans ralentir leur course, ou pour humecter la terre destinée à la construction de leur nid; enfin, elles aiment à se plonger dans l'eau à plusieurs reprises, en jetant un petit cri de satisfaction, dans le but de noyer les insectes nombreux s'attachant à leurs plumes et les tourmentant sans cesse. Cette habitude avait engagé les Égyptiens à se servir, dans leurs hiéroglyphes, de l'hirondelle pour représenter la déesse Isis, inconsolable de la mort d'Osiris et cherchant sans cesse son cadavre sur les flots.

Gessner prétend que le mot hirundo vient de hcerundo, "quia hirundo nidum componit tignis adhcerentem - parce que l'hirondelle attache son nid aux poutres de la maison; " haerere signifiant " être attaché. " Ainsi, d'après cet auteur, le nom d'hirondelle aurait été donné à cet oiseau, parce qu'il construit un nid «adhérent» aux poutres, aux linteaux des croisées. Scaliger fait dériver hirundo de crÉLıôn, d'où hichndo et hirundo. La racine de cாÉLıoôs serait-elle alors chéLrs, "lyre " et Eïnos, " forme? " Dans cette supposition, cette étymologie s'appliquerait à la queue des hirondelles représentant assez exactement une lyre et fournissant l'un des caractères les plus distinctifs de ces oiseaux, celui qui sert à les classer. Cetle forme a été assez remarquée pour devenir un terme de comparaison employé dans les arts et même dans les fortifications, où queue d'aronde signifie des " travaux représentant une queue d'hirondelle," ou une "lyre. " Quelques auteurs trouvent une racine du mot hirondelle dans Éreîn signifiant " gazouiller, parler, " étymologie qui se rapprocherait de celle que j'ai avancée. Enfin la vieille dénomination de l'hirondelle, aronde. nous présenterait un nouvel ordre d'idées : elle viendrait de Éar, printemps, d'où Éarinos, "printanier, » et signifierait alors " oiseau du printemps, qui, par son arrivée, annonce le retour du printemps. » 
Sur le printemps de ma jeunesse folle Je ressemblois l'arondelle qui volle Puis cha, puis lì. L'àge me conduisoit Sans peur, sans soing, où le cœur me disoit.

\section{(MAROT).}

Le nom de la chélidoine viendrait fortifier cette dernière opinion et servir de trait d'union entre cuécıbôx et aronde. Les anciens avaient en effet donné à la chélidoine le même nom qu'à l'hirondelle, parce que cette plante fleurit au printemps, à l'époque de l'arrivée des hírondelles, et aussi parce qu'ils pensaient que cet oiseau suérissait, avec le suc de la plante ainsi appelée, les yeux malades de ses petits. De plus, Curtius admet que hirundo est le même mot que le grec cuéLıuôs : hir-undo, CHÉL-I1ôx; pour cela il suppose un ancien mot grec chérexnòn. Complétant l'étymologie des deux mots, Corssen les rattache au radical sanscrit " har, ghar, prendre, " qui a fait le grec cuem, " la main " considérée comme "organe pour prendre, " et le latin archäque hir, " la main. " Dans cette hypothèse, l'hirondelle serait " la preneuse » (de mouches). (Littré.)

Partout l'arrivée des hirondelles est accueillie arec plaisir, car elle annonce le retour du printemps. En Espagne, une légende populaire, répétée dans tous les foyers, donne un autre motif de cette bienvenue. La voici : "Pourquoi l'hirondelle est-elle un oiseau aimé et respecté, accueilli en signe de bonheur? C'est que ce fut une hirondelle qui alla arracher les épines dans le front saignant du Christ. ")

Les mèmes légendes expliquent ainsi le chant étouflé du hibou et son éloignement pour la lumière. Le hibou était autrefois un des oiseaux qui chantaient le mieux. Il se trouva présent lorsque le Sieigneur expira, et, depuis ce moment, il fuit la lumière témoin d'un si grand crime, et il ne fait plus entendre que son cri plaintif et 
étouffé, où le peuple andaloux croit distinguer encore le mot Cruz, cruz (croix, croix). J'ai cru devoir laisser dans cette nouvelle édition toutes les hypothèses que j'avais énumérées précédemment. Je me borne à y ajouter celle que j'ai trouvée dans les Aryas primitifs, et qui pourrait même prêter un certain appui à quelques-unes des miennes. Adolphe Pictet voit, dans créL, le sanscrit " hari, air, vent, " et dans bon, le sanscrit "dâna, qui fend, qui coupe, " ou mieux encore "dan, » de la racine de même forme avec le sens du latin caedere, "frapper " et même "tuer. " D'après le même auteur, hirundo et dès lors hirondelle serait analogue à chÉLIDox, mais non pas identique. Ainsi, selon l'autorité de ce savant, les différents mots consacrés à désigner l'hirondelle signifieraient "oiseau qui fend, qui coupe l'air. » On pourrait même en déduire ce sens, " oiseau qui tue dans l'air. " Dès lor's ces expressions représenteraient les habitudes caractéristiques des latirostres, et pourraient, jusqu'à un certain point, rendre moins téméraires les étymologies que j'avais exposées, avec une grande réserve, pour les mots martinet et hirondelle.

Les ressources du vol des hirondelles auraient dû résoudre plus tôt la question de leur immersion annuelle. Pendant plusieurs siècles on a cru que ces oiseaux ne pouvaient pas franchir les mers pour demander à d'autres climats la nourriture et l'hospitalité pendant l'hiver. On admettait qu'ils se retiraient dans des cavernes, où ils passaient la saison des frimas, attachés aux parois des murs à la manière des chauves-souris. Des naturalistes ont même soutenu que les hirondelles se précipitaient dans les puits ou dans les marais pour s'ensevelir sous la vase ou le sable et ressusciter au printemps. Cette opinion, contraire aux principes les plus élémentaires de l'organisation des oiseaux, était tellement répandue, que Buffon a consacré près d'un demi-volume à la réfuter : 
si les cailles peuvent franchir la Méditerranée avec leur wol peu soutenu, ce passage ne doit pas être un obstacle sérieux pour les hirondelles. On a constaté, depuis un certain nombre d'années, que ces oiseaux se trouvent pendant l'hiver par troupes innombrables au caip de Bonne-Espérance et dans les autres régions du midi de l'Afrique : circonstance qui explique l'absence des hirondelles au nord de cette même contrée.

L'hirondelle de cheminée a reçu les épithètes de "domestique, de villageoise, de campagnarde, ") domestica, rustica. La première de ces expressions nous reporte i des temps bien éloignés de nous, à des mœur's, hélas! qui n'existent presque plus que comme des souvenirs. Cet adjectif me semble renfermer le sens de deux mots grees, Dòma, " maison " dont la racine est ఎÉมô, signifiant "fonder, bâtir, demeurer, " et estia, "foyer, banquet, " et associer ainsi des idées bien touchantes. Dans le temps des mœurs patriarcales, cette expression domesticus, a, "serviteur, domestique, " fut emplovée pour désigner ceux qui, appelés au banquet et au foyer de la famille, étaient considérés comme des membres de cette même famille, dont ils devaient partager les traraux, les joies et les douleurs. C'était à eux que l'on confiait les missions les plus délicates, comme la Bible nous en offre des exemples si multipliés et si attachants. Les domestiques, les serviteurs étaient pour le maitre d'autres lui-même; ils recevaient l'enfant naissant pour lui prodiguer les caresses les plus tendres, les soins les plus intelligents et les plus persévérants; sans ambition, ils n’aspiraient, après aroir élevé plusieurs générations et s'être dépensés en soins et en travaux continuels, qu ì rendre le dernier soupir dans la maison et au sein d'une famille qu'ils regardaient et aimaient comme la leur. Maintenant que le cours des siècles, l゙indépendance des mcur's et le progrès des idées sceptiques ont renver'sé et 
détruit le banquet et le foyer domestiques, ces derniers mots sont vides de sens. Ils ne rappellent plus ces réunions intimes, ces épanchements du cœur, ces causeries dans lesquelles plusieurs générations, maîtres et servitcurs, puisaient tour à tour enseignement, espérance et gaieté, respect et douce confiance, et où les traditions de foi, de loyauté et d'honneur se transmettaient pures et intactes. Dès lors que chacun semble fuir le foyer domestique comme pour échapper à un ennui ou à un remords, et cherche à s'étourdir dans ces réunions, décorées peut-être par un esprit malin du nom de cercles (sans principe et sans fin), le mot domesticus, domestica, a perdu sa véritable signification. Aujourd'hui il sert malheureusement trop souvent à désigner ceux qui, comme les passereaux, ne se fixent nulle part, voyagent de maison en maison au gré de leurs caprices, emportant ou laissant tour à tour de tristes souvenirs de leur passage éphémère sous le toit qui leur a donné l'hospitalité. IIéritière des vieilles traditions, l'hirondelle de cheminée est véritablement domestique, dans la bonne acception du mot. Elle vient se reposer au foyer de la maison; elle s'y fixe, y établit son nid, et y élève ses petits avec une tendre sollicitude. L'année suivante, le même foyer la verra revenir; si le nid est demeuré intact, elle s'y installe immédiatement comme dans sa propriété; s'il est détruit, elle le rétablit. L'hirondelle ne quittera la maison de son choix que si elle y est contrainte par la force, et, dans ce cas mème, son dernier chant, en s'éloignant, sera un adieu d'amour et de reconnaissance, et jamais un cri de haine. Plus tard les jeunes viendront continuer la chaîne de la tradition, et le même nid verra s'élever bien des générations successives. Chaque année, le retour sera annoncé aux habitants de la maison par une série de petits cris, expression de la joie et de la confiance, cris dans lesquels une 
naïve tradition croit distinguer ces paroles : "Le bon homme, qui ćtait lit l'annie dernière, vit-il encore? ah! vit-il encore? "), et le moment du départ sera aussi salué par des signes non équivoques de regret et de sympathie. Les cris que les hirondelles font entendre ì leur arrivée et à leur départ sont peut-être, pour elles, l'expression de sentiments analogues à ceux que nous éprourons lorsque, après une longue absence, nous retrouvons les lieux qui nous ont vus naitre, ou lorsqu'il s'agit de quitter le toit paternel pour entreprendre un lointain et périlleux voyage. Les auteurs d'histoire naturelle viennent corroborer l'opinion que j'ai émise, lorsqu'ils disent que le nom domestica a été donné à cette hirondelle parce qu'elle est plus familière (de la famille) que les autres, et paraît aimer et rechercher la société de l'homme.

L'épithète rustica fait connaitre que cet viseau est plus commun à la campagne que dans les villes. Est-ce parce che là il retrouve encore, malgré le naufrage des mœurs et des saines traditions, plus facilement le foyer et le banquet domestiques? Indépendamment de cette hypothèse, peut-être toute gratuite, mais qui sourit ì ceux dont l'intelligence et le cœur cherchent ì saisir, partout où ils les entrevoient, quelques pensées consolantes pour s'y reposer, l'hirondelle domestique troure à la campagne plus facilement que dans le sein des villes, des cheminées privíes de feu et où elle puisse, sans danger, établir son nid. Ce motif est le seul que tous les naturalistes aient donné pour expliquer la présence de l'hirondelle domestique dans les campagnes, tandis qu'elle s'éloigne de plus en plus du séjour des villes. Cette raison ne me paraît pas péremptoire, et, pour la fortifier et la completer, je soumets à mes lecteurs les hypothèses suivantes. Les cheminćes étant à la campagne beaucoup plus larges que dans les villes où leur 
diamètre se rétrécit de jour en jour, ne contribuent-elles pas ainsi par leurs dimensions à préserver plus facilement les hirondelles de l'incommodité de la fumée? En sccond lieu, les cheminées des campagnes, étant trèsrarement ramonées, n'offrent-elles pas encore en ce point un précieux avantage aux hirondelles, en leur donnant, par les aspérités dont les murs sont revêtus, plus de facilité pour fixer leur nid, et surtout en conservant pendant de longues années le travail fait précédemment? Enfin, l'extrémité des cheminées de campagne n'est pas restreinte par des appareils plus ou moins étroits; elle procure à l'hirondelle plus d'espace pour ses évolutions et concentre moins la colonne de fumée.

Le nid de cette hirondelle est façonné avec de la terre détrempée et mélangée à du foin; il reçoit ordinairement une forme sphérique, excepté du côté par lequel il tient au mur de la cheminée. Souvent ce nid est établi sur celui de l'année précédente, et il n'est pas rare d'en trouver trois ou quatre superposés. L'intérieur garni de plumes et de débris de toute espèce contient le plus souvent quatre ou cinq œufs d'un blanc parsemé de taches d'un rouge noir. Leur longueur varie de $0^{\mathrm{m}}, 018 \mathrm{à} 0^{\mathrm{m}}, 020$, et leur diamètre de $0^{\mathrm{m}}, 012$ à $0^{\mathrm{m}}, 014$.

La première ponte est suivie régulièrement d'une seconde dont les œufs dépassent rarement le nombre trois.

L'hirondelle de cheminée justifie encore les noms qui lui ont été donnés, par les soins et la tendresse avec lesquels elle élève ses petits. Quand ils commencent à voler, elle les précède en leur présentant de la nourriture, comme une bonne mère s'éloigne de son enfant, en lui offrant des friandises pour l'engager à essayer ses premiers pas. Plusieurs se sont précipitées dans les flammes qui dévoraient les maisons auxquelles étaient confiés leurs petits, aimant mieux se donner la mort que de se séparer des objets de leur tendresse. On a su tirer profit 
de ces sentiments affectueux de l'hirondelle, et des mères enlevées à leurs petits ont été envoyíes à de grandes distances; rendues alors à la liberté, elles revenaient bientòt sur leurs nids, et, messagères rapides, rapportaient le billet confié à leur tarse.

L'hirondelle, qui retrace les mœurs patriarcales, élève chaque année plusieurs couvées; les petits de la première couvée viennent en aide à leurs parents pour nourrir leurs jeunes frères, et paraissent tout joyeux de voir se multiplier leur famille.

Non-seulement l'hirondelle de cheminée entoure sess petits d'une tendresse et d'une sollicitude qui ne se démentent en aucune circonstance, mais elle accomplit sans cesse une mission de charité en faveur de tous les oiseaux sans défense. Par ses cris, elle les avertit de l'approche des rapaces, qu'clle poursuit de ses clameur: sans avoir rien à redouter de leur colère.

On lit dans le mémoire de M. le docteur Mabille sur la vie et les ouvrages de notre compatriote Bernicr, un passage, extrait de la Philosophie de ce célèbre voyageur, Iui offre, dans une touchante et naïre peinture, une nouvelle preuve de la sollicitude avec laquelle l'hirondelle veille sur ses petits. Voici ce passage : " Il me souvient, "-dit Bernier, - de ce que me promenant un jour le "long d'un chemin, j'aperçus sur la branche d'un saule " assez bas, trois petites hirondelles nouvellement sorties " du nid, qui ne s'envolèrent pas quoique je passasse " tout proche. Retournant sur mes pas et repassant pour " la troisième fois par-dlessous la branche, j'étendis la "main comme pour les prendre, mais deux grandes " hirondelles étant survenues sur ces entrefaites et ayant " gazouillé je ne sais quoi, les petits s'envolèrent aussitòt. "Ce qui me fit juger premièrement que ces srandes " hirondelles itaient le père et la mère qui en les que"rellant les araient avertis de me fuir comme un de 
" leurs ennemis, en second lieu que la plupart des ani" maux ne nous fuient que parce qu'ils ont reçu quelques " dommages de nous. "

Je terminerai l'exposé des mœurs de l'hirondelle de cheminée par une de ses habitudes les plus touchantes. Quand un des deux membres de l'union conjugale a succombé, celui qui survit ne contracte pas un nouvel hymen, mais il manifeste, par l'observance d'un veuvage permanent, la vivacité de ses regrets et de sa douleur. Quelquefois même il franchit des distances immenses pour revoir encore une fois le lieu témoin de son bonheur, le nid où s'élevèrent ses petits et près duquel périt l'objet de son amour et de ses regrets. C'est là aussi qu'il fixe son séjour, en attendant la mort qui seule peut mettre un terme à son affliction sincère.

\section{HIRONDELLE DE CROISÉE. - HIRUNDO URBICA.}

Les différents noms donnés à cette hirondelle indiquent qu'elle préfère la ville à la campagne et choisit souvent les croisées pour y fixer son nid. Celui-ci est composé avec la terre que les lombrics rejettent après en aroir extrait les sucs, et à laquelle ils communiquent une certaine viscosité. Ici se manifestent encore les preuves de l'admirable instinct que Dieu, dans les desseins de sa providence, a donné à ces oiseaux pour qu'ils atteignent le but qu'il s'est proposé en les créant. Cette terre, en effet, est préférée à toute autre par la raison qu'elle se lie plus facilement. Mais comme elle se trouve en plus grande quantité lorsqu'il tombe de la pluie, il est donc important de profiter de cette circonstance. Que feront les hirondelles? Un certain nombre se réuniront, mettront leurs efforts en commun, et les nids se façonneront simultanément pour plusieur's ménages. On profite 
des matériaux précieux, et la petite société épargne ì chacun une perte de temps et des fatigues inutiles. Quelques-unes, désirant se servir du travail des autres sans se lasser elles-mêmes, comme cela arrive hélas! trop souvent parmi les hommes, viennent chercher la terre au nid que l'on construit, afin d'éviter un parcours beaucoup plus long. Peut-être aussi celles-ci ont-elles été reléguées de la suciété de leurs congénères, et sont-elles

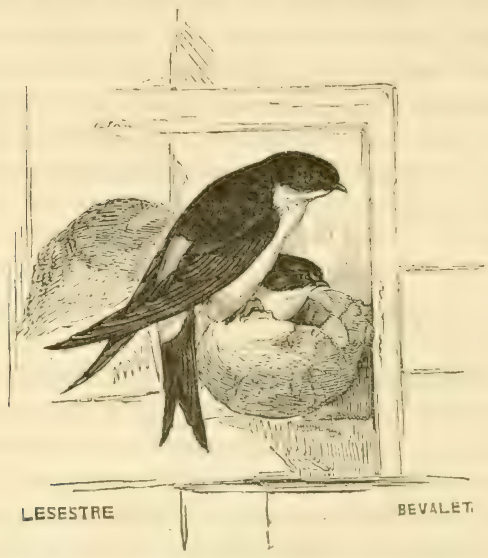

des prétendants malheureux. Dès lors, si la vengeance était le mobile de leur conduite, les hommes auraient-ils bien le droit de les blamer?

C'est arec un véritable intérêt que j'ai suivi et étudié les moyens que ces hirondelles emploient afin d'achever leur nid et de donner à leur travail toute la perfection possible. Pendant que plusieurs ouvriers infatigables apportent des matériaux pour l'édifice en construction, la future mère se réserve le soin de polir la terre détrempué, et de faire disparaître toutes les aspérités qui 


\section{$-153-$}

pourraient gêner la couveuse et blesser les petits. Elle tourne et retourne sur elle-même dans tous les sens, et par ce stratagème et avec le frottement de ses plumes, elle rend très-lisse l'intérieur du nid formé de terre encore humide. Quant à l'ouverture qui conduit dans ce petit chef-d'œuvre de patience, elle en fera disparaître jusqu'aux plus petites inégalités, en promenant, sur les bords, les plumes soyeuses de son cou.

Ces nids adhèrent à une croisée ou à un mur, ont une forme cylindrique, et ne présentent en haut qu'une petite ouverture par laquelle l'hirondelle pénètre en se diminuant de volume. L'exiguité de cette entrée empêche les autres oiseaux de s'y introduire, et permet aux propriétaires de défendre plus facilement leur domicile. Cependant quelquefois les moineaux s'y introduisent; mais très-souvent, dans ce cas, le domicile qu'ils ont violé devient leur tombeau; les hirondelles s'empressent de fermer avec de la maçonnerie l'ouverture du nid, et l'intrus périt de faim, victime de sa témérité.

Les hirondelles recherchent surtout les grands murs et les rochers peu éloignés des rivières, pour y accoler leurs nids. A Lyon, la façade de l'hôpital situé sur le quai de la Saône, est couverte de rangs innombrables de ces nids formant plusieurs guirlandes suspendues les unes au-dessus des autres.

L'hirondelle de croisée, plus sauvage que la précédente, arrive dans nos contrées quelques semaines avant sa congénère. Elle chasse les insectes sur le bord des eaux, qu'elle effleure quelquefois pour y tremper la terre destinée à son nid.

Dans son vol, elle frappe de ses ailes les moucherons fixés aux parois des murailles, afin de les en détacher et de les saisir ensuite au vol. L'hirondelle de croisée chasse le bec fermé, et, toutes les fois qu'elle aperçoit une proie, elle la saisit en faisant claquer son bec. 
Comme l'hirondelle de cheminée, elle rend de vrais services à l'homme en purgeant l'air d'une multitude d'insectes nuisibles ou gênants. Ces services sont d'autant plus réels, que la faim qui dévore ses petits parait plus insatiable, si l'on en juge par leur's cris. P'eu d'oiseaux appellent leur parents et réclament leur nourriture arec un bruit plus continuel et plus accentué que la progéniture de l'hirondelle de croisée; c'est à cette habitude que fait allusion le prophète Isaĩe, 38 : "Sicut pullus himundinis sic clamabo; je crierai vers vous, ô mon Dieu, avec la même instance que le petit de l'hirondelle, vers sa mère. ") Elle fait deux pontes, la première de quatre à six cufs et la seconde de trois à quatre; ils sont d'un blanc lustré, sans tache et un peu piriformes. Leur longueur est de $0^{\mathrm{m}}, 016$ à $0^{\mathrm{m}}, 018$, et leur diamètre de $0^{\mathrm{m}}, 011$ à $0^{\mathrm{m}}, 013$.

Quand les hirondelles de croisée ou de cheminée doivent émigrer, elles se réunissent en grand nombre. Quelques-unes, plus âgées ou plus expérimentées, semblent avoir reçu la mission d'avertir les autres que le moment propice pour le départ est arrivé; pendant quelques jours on les voit parcourir les diverses parties d'une ville ou d'une campagne, faire entendre un petit cri très-vif qui ressemble à un cri d'impatience, venir et revenir bien des fois sur leurs pas; on dirait des chefs s'empressant de réunir leurs soldats pour une expédition lointaine. $\Lambda$ la voix de ces hirondelles, leurs compagnes se réunissent sur un arbre ou sur un édifice élevé, et lì, par de petits cris multipliés, marquent les différents sentiments qu'elles éprouvent au moment d'entreprendre un royage long et quelquefois périlleux. A Angers, le lieu du rendez-yous est ordinairement le toit si vaste et si ćlevé du Musée. Pendant plusieurs jours, elles se livrent à des exercices préparatoires et simulent un départ général; les chefs trouvent ainsi le moyen de reconnaitre 


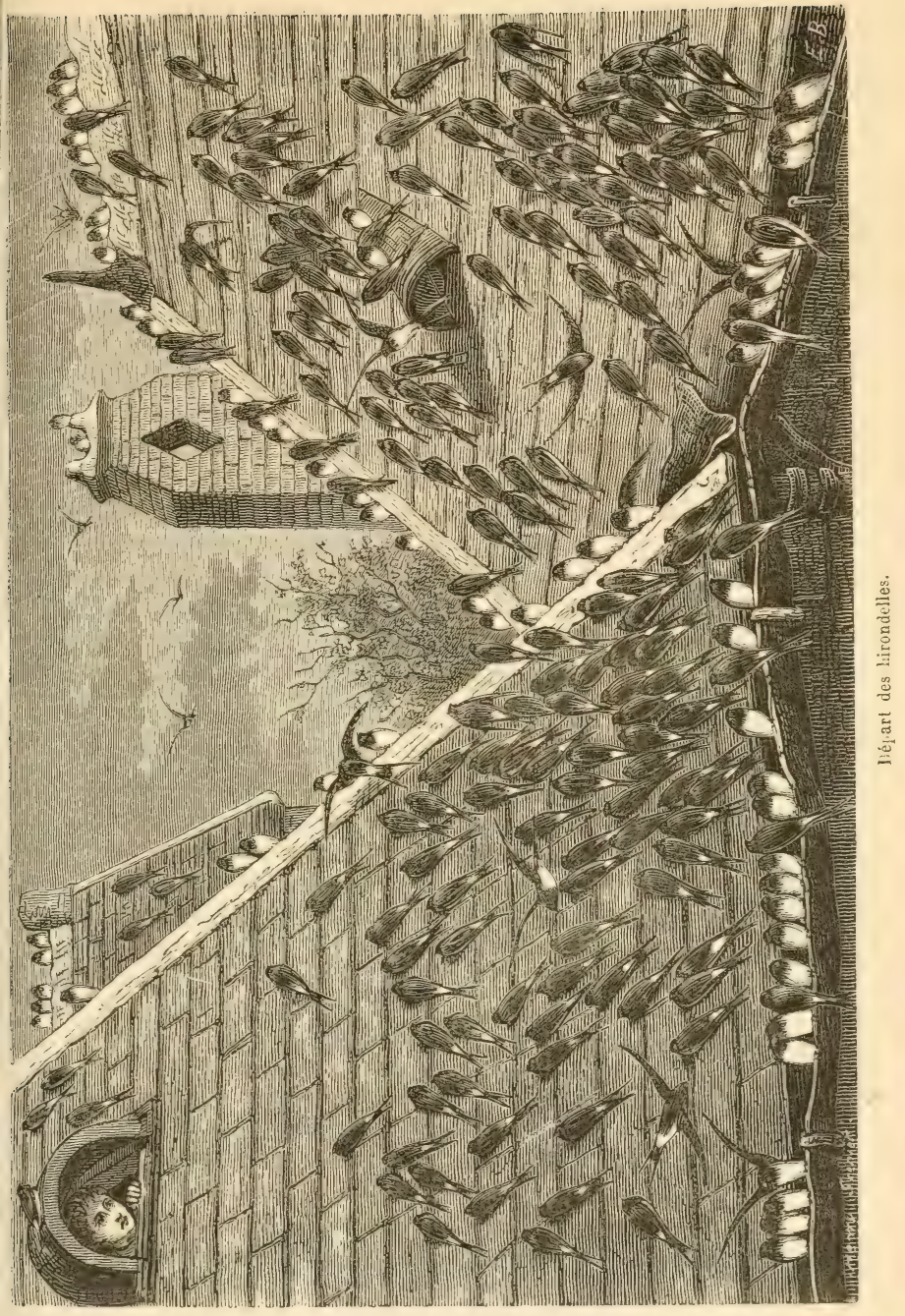



celles qui, par leur énergie et par la puissance de leur vol, pourront être placées en première ligne, et celles qu'il faudra mettre au centre et qui auront besoin d'être soutenues et encouragées.

Après plusieurs jours d'attente et de préparatifs, quand les chefs croient être certains que toutes les hirondelles ont été averties et que toutes les dispositions sont prises, on eutend un cri général qui paraît être un assentiment unanime. On dirait une de ces anciennes assemblées parlementaires tumultueuses, acclamant un vote d'où dépend le bien-être d'un grand peuple. A ces cris succède un silence général, et toute la colonie part avec la rapidité de la flèche, au commencement de la nuit, selon le mot d'ordre donné par les chefs, afin d'échapper' plus facilement aux oiseaux de proie, et d'éviter l'action énervante du soleil et de la chaleur. C'est ce voyage exécuté pendant la nuit qui a contribué à jeter tant d'incertitude sur l'émigration des hirondelles.

On connaît les vers charmants de $\mathrm{L}$. Racine décrivant le départ de ces oiseaux voyageurs :

Ceux qui, de nos hivers redoutant le courroux,

Vont se réfugier dans des climats plus doux,

$\mathrm{Ne}$ laisseront jamais la saison rigoureuse

Surprendre parmi nous leur troupe paresseuse.

Dans un sage conseil par le chef assemblé

Du départ général le grand jour est réglé ;

Il arrive, tout part: le plus jeune peut-être

Demande, en regardant les lieux qui l'ont vu naître,

Quand viendra ce printemps par qui tant d'exilés

Dans les champs paternels se verront rappelés.

(La Religion, chant $\mathrm{I}^{\mathrm{er}}$ ).

D'après Martial, aucune hirondelle ne pouvait manquer à ce départ, sans être punie comme coupable de trahison.

Hibernos peterent solito quum more recessus

Atthides, in nidis una remansit avis. 


\section{$-158-$}

Deprendere nefas ad tempora verna reverse,

Et profugam volucres diripuere suse.

Serò dedit ponas : diseerpi noxia mater

Debuerat; sed tunc, rqum laceravit Itym.

" A l'éproque où les hirondelles gagnaient, selon leur usage, leur's retraites d'hiver, une d'elles resta dans sou nid. Ses compagnes, de retour à l'approche du printemps, découvrirent la trahison, et mirent en pièces lat transfuge. ()n la punit trop tard; cette mère coupabs avait mérité ee supplice, mais alor's surtout qu'elle déchira le malheureux Itys. »)

Martial, Epig., livre V, Ep. 67. (Traduction de Panckouke.)

IIIRONDELLE IJE RIVAGE. - HIRUNDO RIPARIA.

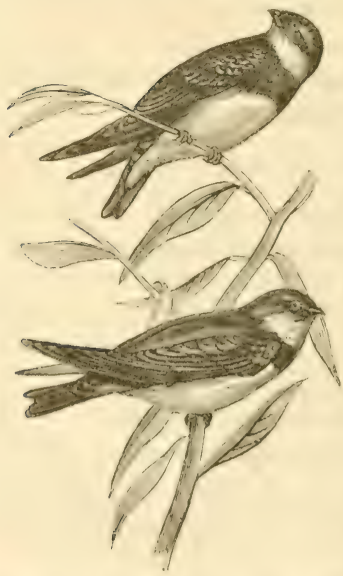

Cette hirondelle, plus petite que les espèces précédentes, est aussi plus vive et plus pétulante dans la chasse qu'elle fait aux insectes. Elle doit son nom aux lieux qu'elle habite et dans lesquels elle se reproduit. Elle ne quitte guère les bords des rivières et des fleuves, et établit son nid dans les trous des rats d'eau. Quand elle n'en trouve pas de convenables, elle cherche des terrains friables, et choisit ordinairement ceux qui sont escarpís ou coupés a pie par des éboulements. Elle creuse arver rapidité un trou de $0^{\text {ma }}, ; 0$ de profindeur. L'ouver- 
ture en est étroite pour opposer un obstacle à l'introduction des ennemis de la petite famille, et afin de pouvoir être défendue au besoin avec plus de facilité. Le boyau qui y conduit est sourent en zig-zag, et présente ainsi un nouveau moyen de sûreté. L'extrémité au contraire se développe, et offre une excavation plus spacieuse et plus commode pour les différents mouvements de la couveuse. Quelquefois plusieurs trous, après avoir serpenté pendant 60 ou 80 centimètres dans des directions différentes, viennent se réunir à un carrefour commun qui sert alors à l'éducation de plusieurs familles. Dans le mois de mai 1865 , j’ai trouvé deux trous semblables à ceux que je viens de décrire, sur les bords de la Sarthe, près de Morannes, dans une excursion que j'ai faite avec mes jeunes amis Eugène Lelong, Guillaume Bodinier et Louis Manceau. Aussi, ce n'est qu'avec le concours persévérant et énergique de ceux-ci que j’ai pu pénétrer jusqu'à l'endroit où les hirondelles avaient établi leur nid, et encore, pour remporter cette victoire, mes jeunes naturalistes, dirigés par leur chef intrépide, Eugène Lelong, ont-ils dû pendant des heures entières employer tous les moyens stratégiques des mineurs, sans se laisser arrêter par aucune difficulté. Le nid qui en tapisse le fond est garni de paille, de duvet, de plumes, etc:, et contient cinq ou six œufs blancs, piriformes très-fragiles, et même transparents. Ils ont ordinairement $0^{\mathrm{m}}, 017$ de longueur, et $0^{\mathrm{m}}, 012$ de diamètre.

L'hirondelle de rivage ne fait qu'une couvée; pour dissimuler la véritable entrée de son nid, elle s'y précipite de plein vol et sans ralentir la rapidité de sa course. Au moyen de ses ongles longs et crochus, elle peut se fixer aux bords de son nid, aux flanes des rochers ou des rives escarpées, jusqu'à ce qu'elle ait saisi la proie qu'elle y a aperçue. 


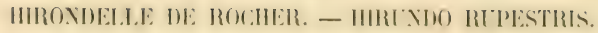

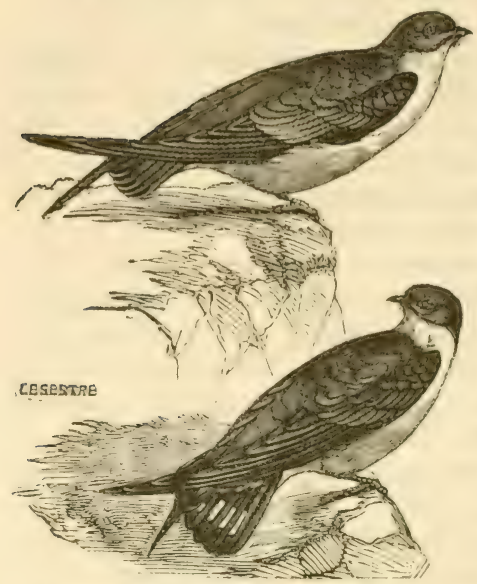

L'hirondelle de rocher vient rarementen Anjou, elle habite les pays de montagnes. C'est là qu'elle fait son nid de la même manière que sa compagne de cheminée, avec cette diflérence toutefois qu'elle l'appuie le long des rochers, et qu'elle emploie quelques petits morceaux de gravier pour lier la terre, à la place du foin et de la paille. La femelle ne fait qu'une ponte. Les œufs, au nombre de cinq ou six, sont d'un blane pointillé de bruin ; leur longueur ordinaire est de $0^{\mathrm{m}}, 020$, et leur diamètre de $0^{\mathrm{w}}, 01^{\prime}$. Ils se distinguent de ceux de l'hirondelle de cheminée par des proportions ordinairement plus fortes, et surtout par des taches plus larges et d'une couleur plus foncée.

Cette espèce montre moins de tendresse pour ses petits que ses congénères. Peut-être faut-il attribuer cette disposition aux lieux qu'elle habite. Offrant peu de dangers et fournissant plus de ressources, ils exigent moins de précautions.

Je termine ces notions par quelques renseignements propres à faire distinguer les quatre espèces d'hirondelles. 
Le manteau de l'hirondelle de cheminée est d'un noir ì reflets bleuâtres, le dessous du corps blanchâtre, avec une légère teinte aurore. Les mâles ont les couleurs plus vives que les femelles.

La gorge et le croupion de l'hirondelle de fenêtre sont d'un beau blanc. Ce dernier caractère lui a fait donner le nom de cul-blanc. Le reste du corps est d'un noir lustré.

Le collier et le manteau de l'hirondelle de rivage sont d'un gris de souris; les autres parties, d'un blanc pâle. Cette espèce est beaucoup plus petite que ses congénères. Le mâle affecte une couleur plus sombre que la femelle, et sa gorge reflète une teinte jaunâtre. L'hirondelle de rocher, la plus grosse des quatre espèces qui se montrent en Anjou, a toutes les plumes d'un gris bordé de roux.

\section{QUATR:ĖHE GENRE. - GOBE-MOUCHES (MUSCICAP.E).}

Les gobe-mouches complètent la famille des latirostres. La Faune de Maine-et-Loire comprend trois espèces de ces oiseaux. Dans les pays chauds, où les insectes sont très-multipliés et très-incommodes, les gobe-mouches se trouvent en grand nombre, et la force de ces auxiliaires de l'homme croît en proportion avec celle de ses ennemis. Ils ne viennent dans notre département que pendant l'été, lorsque leur présence est utile et nécessaire aux hommes et même aux troupeaux, qu'ils délivrent des insectes qui les poursuivent ou les persécutent en plein air. Les gobe-mouches ont le bec comprimé à la base, presque triangulaire, et garni de poils longs et durs, caractère que l'on retrouve chez presque tous les oiseaux qui vivent d'insectes ailés. Ces latirostres sont solitaires et querelleurs; ils doivent leur nom aux petites mouches qui composent leur nourriture ordinaire. Pour les saisir, ils se tiennent souvent à l'extrémité des arbres, d'où ils s'é- 


\section{$-162-$}

lancent sur leur proie, quand celle-ci passe à leur portée. Ils voltigent aussi de branche en branche, et descendent jusqu'à terre, selon que les variations de l'atmosphère engagent les insectes à se tenir dans des endroits plus ou moins élevés. Les gobes-mouches recherchent les bois frais, les promenades publiques et les lieux dans lesquels viennent paître les troupeaux. Le plus souvent ils saisissent les mouches au vol, pour les manger ensuite sur la branche d'où ils se sont élancés. Presque tous les mouvements des gobe-mouches sont accompagnés d'un balancement des pennes de la queue, habitude qui leur imprime une physionomie toute particulière, et qui a contribué à faire de leur nom une épithète peu flatteuse.

\section{GOBE-MOUCHES GRIS. - MUSCICAPA GRISOLA.}

La dénomination française donnée à cet oiseau a entièrement la même signification que le nom latin sous lequel il est désigné. La première indique la nourriture, muscas capere, "prendre les mouches, " et la seconde, la couleur de cet oiseau.

Le gobe-mouches gris est commun dans notre département, pendant l'été. Il fait un nid assez grossier, qu'il appuie sur quelques inégalités du tronc des arbres. D'autres fois, il le place sur des ceps de vigne. Ce nid contient ordinairement quatre ou cinq œufs d'un fond blanc ou jaune pâle, couvert de taches roussâtres; leur grand diamètre est de $0^{\mathrm{m}}, 018$, et le petit de $0^{\mathrm{m}}, 014$.

\section{(iOBE-MOUCHES A COLLIER BL.ANC. - MUSCICAPA ALBICOLIIS.}

L'épithète à collier blanc sert à distinguer ce gobemouches du précédent. Ses habitudes sont presque les mêmes. Plus vil' que le gobe-monehes gris, mais aussi 
stupide, il se tient ordinairement plus près de la terre; il niche assez souvent dans les trous des sitelles, des torcols, des mésanges, et il aime à profiter du travail des autres. Ses œufs, au nombre de quatre ou cinq, sont d'un bleu pâle ou d'un vert sale; leurs dimensions ordinaires sont $0^{\mathrm{m}}, 019$ et $0^{\mathrm{m}}, 013$.

\section{GOBE-MOUCHES BEG-FIGUE. - MUSCICAPA LUGTUOSA.}

Le mot luctuosa qui signifie "sombre, couleur de deuil, » indique la particularité distinctive du plumage de cette espèce. Ce gobe-mouches, moins défiant encore que ses congénères, recherche les insectes, et les mouvements nécessaires, auxquelsil se livre pour les capturer, ont fait croire qu'il becquetait les figues. Mais cette opinion ne peut s'expliquer que par des cas isolés, qui constituent plutôt une exception qu'une règle générale.

Le bec-figue niche comme le précèdent. Ses œufs, ordinairement au nombre de quatre ou cinq, ont souvent une forme oblongue et sont d'un bleu verdâtre peu prononcé. Leur longueur est de $0^{\mathrm{w}}, 017$, et leur diamèire de $0^{\mathrm{m}}, 012$.

Les deux dernières espèces sont beaucoup plus rares, dans notre département, que le gobe-mouches gris. Elles ne font que le traverser à différentes époques de l'année, sans s'y arrêter pour nicher.

\section{Dentirostres.}

La deuxième famille de l'ordre des Passereaux comprend les Dentirostres. Ceux-ci doivent leur nom ì l'échancrure de leur bec, caractère qui les rapproche des rapaces. Le mot dentirostre est composé de dens, dentis, 
" dent, " et de rostrum, "bec, ") et signifie dès lor's "bec avec des dents, bec denté."

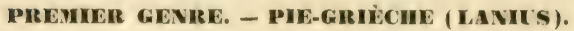

Je donnerai l'étymologie du mot pie, quand il s'agira de la véritable pie, corvus pica, et je me bornerai à expliquer maintenant l'épithète donnée au premier genre des dentirostres.

La dénomination grièche vient de gresca "grecque: " plle a été attribuée à ces oiseaux pour indiquer le pays vù ces passereaux sont très-communs, et pour peindre exactement les mœurs des pies-grièches.

Ortie grieche, perdrix grièche signifient ortie grecque, perdrix grecque. Autrefois, les Français appelaient les cailles des grièches, parce que ces oiseaux paraissaient venir des provinces de la Grèce.

Dans notre langue, l'épithète grec, grecque conserve les significations attachées au mot grecor, grepcari, "laire le Grec, " c'est-à-dire "être hautain, persécuteur' et de mauraise foi, tendre des pieges aux faibles, etc. ") Dès lor's, on a donné ce nom aux personnes en qui l'on supposait des habitudes désagréables, un caractère sans pitié, une tendance à des querelles incessantes jointe souvent à un bavardage fatigant. En un mot, l'épithète pie-grièche est restéc parmi nous comme une véritable injure. Toutes les mauvaises acceptions de cet adjectif conviennent entièrement au premier genre des dentirostres. Quoique petites et armées de doigts peu redoutables, les pies-grièches luttent contre tous les rapaces, non-seulement pour se défendre, mais encore pour éloigner les oiseaux de proie, quand elles jugent que ceux-ci ne se tiennent pas à une distance assez considerable des lieux où elles ont fixé leur séjour. Cihaque 


\section{$-165-$}

couple, à l'imitation des aigles, se choisit un arrondissement de chasse, sur lequel il veut régner en véritable despote.

Le vol des pies-grièches sert de transition entre le vol des pies et celui des oiseaux de proie; il procède par une série de courbes figurant des festons et des guirlandes.

Les pies-grièches mettent en fuite les corneilles, les crécerelles, et elles soutiennent même avec avantage le combat contre les milans et contre les buses. Elles poursuivent les petits oiseaux, les jeunes levrauts, leur crèvent la tête avec le bec, ou les étranglent avec les ongles. Leur audace est telle, que, dans les pays où l'on tend des piéges aux oiseaux de passage, elles s'élancent au milieu des filets pour tuer et pour saisir les appeaux, même lor'sque ces derniers sont des chouettes chevêches. Elles immolent aussi des souris, des mulots et d'autres petits mammifères. Elles rendent de vrais services, en détruisant des myriades de capricornes qui font des trous aux peupliers et qui occasionnent ainsi aux arbres des fistules propres à les faire périr.

Le mot latin lanius signifie " bourreau, boucher. " Il peint d'une manière très-expressive les mœurs des piesgrièches. Comme les bourreaux, elles font un grand nombre de victimes, et insultent en outre au malheur de celles-ci par leurs cris stridents et railleurs; elles semblent vouloir couvrir leur voix et étouffer leurs plaintes. Non-seulement les dentirostres tuent les oiseaux et les insectes, en quantité suffisante pour assouvir leur appétit vorace; mais elles pourvoient encore à l'avenir, en faisant des réserves abondantes. Les pies-grièches enfilent alor's une série de gros coléoptères dans les épines des buissons élevés et touffus, et semblent imiter ainsi les bouchers, en faisant en quelque sorte l'étalage des victimes qu'elles ont immolées. 
Ciependant ces oiscaux, qui sout perpétuellement en querelle avec tous ceux qui les entourent, prennent un soin affectueux de leurs petits, qu'ils nourrissent et défendent arec une tendresse et un courage extraordinaires. Lorsque ceux-ci sont sortis du nid, ils restent avec leur jère et leur mère, et forment une espèce de société, dont les membres ne se séparent qu'à l'approche du printemps suivant. Pendant les premières semaines qui suivent leur sortie du nid, les jeunes pies-grièches rousses et écorcheurs se tiennent à l'extrémité des branches des haies situées sur le bord des routes. Elles regardent d'un air très-niais les voyageurs, et semblent ne pas comprendre le danger auquel elles s'exposent. Il m'est arrivé d'en tuer plusieurs avec l'extrémité de ma canne, sans qu'elles aient cherché à se dérober à la mort.

Quatre espèces de pies-grièches apparaissent et nichent en Anjou.

PIE-GRIĖCIE GRISE. - LANIUS EXCUBITOR.

Cette pie-grièche, la plus grosse des quatre espèces, est rare dans notre département. Elle se montre plus particulièrement dans le Saumurois, où elle niche en petit nombre. L'épithète grise désigne la couleur de son plumage; et le mot excubitor, "sentinelle, " retrace une de ses habitudes les plus singulières. Cict oiseau aime, en effet, à se tenir à la pointe des branche: isolíes rt les plus élevées des haies ou des arbres, à y faire sentinelle, jusqu'à ce qu'il apergive une proie, sur laquelle il seprécipite pour l'immoler; après quoi il reprend sa première position. De temps en temps, il pousse une espèce de eri, de qui vive, pour effrayer et pour faire sortir de leur retraite les gros insectes et les petits oiseaux. (Wuelques auteurs ont affirmé que le lout que se proposait la pie-grièche en oceupant la position d'une sentinelle ì 
l'extrémité des arbres les plus élevés était d'avertir les oiseaux, ses voisins, de l'approche du faucon et des autres rapaces.

La pie-grièche grise mange rarement sur place la victime qu'elle a immolée. Elle la dépèce à terre, et l'emporte ensuite, pour la dévorer plus à son aise, à l'extrémité des arbres ou des buissons.

Elle construit, sur la branche fourchue d'un arbre élevé, son nid qui est ordinairement composé de mousse desséchée, encadré d'herbes longues et fines, et tapissé à l'intérieur de grossiers débris de laine.

Ses œufs, au nombre de quatre à six, affectent bien des formes: les uns sont piriformes; d'autres oblongs, ou présentant une très-légère différence dans le diamètre des deux extrémités. Le fond de la coquille est le plus souvent d'une coulcur fauve; quelques-uns de ces œufs sont pointillés uniformément de taches d'un gris noir; d'autres sont parsemés de taches plus épaisses et fondues, en quelque sorte, avec la nuance de la coquille. Leurlongueur varie de $0^{\mathrm{m}}, 025$ à $0^{\mathrm{m}}, 028$, et leur diamètre de $0^{\mathrm{m}}, 016$ à $0^{\mathrm{m}}, 019$.

PIE-GRIÉCHE: A POITRINE ROSE. - LANIUS MINOR.

Les noms de cette pie-grièche, bien plus répandue en Anjou que les précédentes, sont fondés sur la couleur des plumes de sa poitrine, et sur la proportion de sa taille, inférieure à celle de la pie-grièche grise. Très-souvent aussi on l'appelle pie-grièche d'Italie, parce qu'elle se tient presque toujours dans les peupliers d'Italie, auxquels elle confie ordinairement son nid. Celui-ci est formé de petites racines entrelacées; l'intérieur en est garni de mousse, de laine et, quelquefois, de plantes odoriférantes. Cette pie-grièche, moins défiante et plus sociable que la grise, s'éloigne peu des habitations de 
Thomme pour construire son nid. Il renferme de cinq it six cuf's un jeu oblongs, d'un vert clair et blanchâtre, parsomé de petites taches brunes ou de couleur olive. Leur longueur est de $0^{\mathrm{m}}, 024$ à $0^{\mathrm{m}}, 027$, et leur diamètre de $0^{\mathrm{m}}, 016$ à $0^{\mathrm{m}}, 017$.

\section{PIE-GRIECHE ROUSSE. - LANIUS RUTILUS.}

L'épithète latine et l'épithète française font cunnaître la couleur du plumage de cette espèce, plus petite encore que les précédentes. La pie-grièche rousse imite et contrefait, comme triutes ses congénères, le cri ou le chant des oiseaux dans le voisinage desquels elle vit. Elle a même souvent recours à une ruse plus perfide encore: elle fait entendre le cri du père ou de la mère, afin de surprendre plus facilement les petits qui se réunissent et s'approchent, croyant qu'on leur apporte la becquée. Cette faculté lui fournit un moyen de tendre des piéges, d'attirer, de tromper et de multiplier ses victimes. Elle justifie encore ainsi le nom énergique qui a été donné à tous ces dentirostres. Le nid du lanius rutilus est fait avee plus de soin que celui de ses congénères. Formé de petites racines lices entre elles avee art, il est garni à l'intérieur de crin, de laine et de brins d'herbe très-fins. Il est établi dans les haies touffues; souvent aussi je l'ai trouvé dans les osiers, sur les bords de la Loire. Les œufs, au nombre de quatre à six, sont d'un vert trèspâle, presque blanchâtre, parsemé de taches brunes et presque effacées.

La pie-grièche rontsse manifeste, envers ses petits, une tendresse encore plus grande que ne font les autres piesgrièches. La persévérance qu'elle met ì couver ses œufs est telle, que la femelle se laisse facilement prendre à la main, plutòt que d'abandonner son nid. Le grand dia- 
mètre de ses œufs varie de $0^{\mathrm{m}}, 020 \mathrm{à} 0^{\mathrm{m}}, 023$, et le petit de $0^{\mathrm{m}}, 014$ à $0^{\mathrm{m}}, 016$.

PIE-GRIÉCHE ÉCORCHEUR. - LANIUS COLLLRIO.

L'écorcheur se plaît à briser la tête de ses victimes et à les dépouiller, lorsque celles-ci sont de petits oiseaux. Cette opération n'est pas, comme on pourrait le croire, un acte de cruauté inutile, mais une nécessité fondée sur la conformation des pies-grièches. Elles ne sont pas douées, comme le plus grand nombre des oiseaux carnivores ou piscivores, de la faculté de vomir en pelote la peau et les os ou les arêtes de leurs victimes: dès lors, pour se rendre la digestion possible, elles prennent la précaution de dépouiller et de préparer leur proie.

Le nom scientifique collurio peint d'une manière trèsexpressive cette habitude. Les Grecs appelaient cette piegrièche kolluriôx, Kordluôs, dont la racine est korus, " casque, " et LEïoô, " broyer. " Maintenant encore, on đonne aux pies-grièches, et à l'écorcheur surtout, le nom de picquoys, vieux mot français signifiant "pic," outil dont on se servait en guise de hache. Cette dénomination indique que ces oiseaux usent de leur bec, comme d'un pic ou d'une hache, pour briser la tête de leurs victimes. L'écorcheur est la plus petite des pies-grièches de l'Europe; il niche dans les buissons épais et touffus, et même dans les ajoncs. Son nid, à l'extérieur, est composé comme celui de ses congénères; mais, à l'intérieur, il est ordinairement garni de matières plus molles et mieux choisies. Les œufs, au nombre de cinq à six, varient beaucoup de forme et de couleur. Les uns sont ronds, d'autres oblongs, quelques-uns piriformes; tous portent vers le gros bout une couronne formée de petits points pressés ou de taches rougeâtres assez régulières. La couleur de la coquille est ordinairement d'un blane roux; 
la nuance en est plus ou moins foncie, et, quelquefois, clle a une teinte orange. Elle revêt anssi un brillant que ne présentent pas les œufs des autres espèces de piessrièches. Ceux de l'écorcheur ont de $0^{\mathrm{m}}, 020$ à $0^{\mathrm{m}}, 024$ de longueur, et de $0^{\mathrm{m}}, 014$ à $\left.^{\mathrm{m}}\right)^{\mathrm{m}}, 016$ de diamètre.

\section{DECXİUE GENRE. - MERLE (MERULA TLIBDS).}

Le mot merle désigne un genre assez nombreux. Six espèces de merles habitent ou visitent l'Anjou. Le principe de ce nom est merula, dont la racine me semble être merus, "pur, sans tache," pour indiquer que le plumage de cet oiseau est d'une seule couleur et sans aucun mélange. Merus signifie aussi solitaire, et cette dénomination a été donnée au merle quia vaga et solitaria pascitur, "il ragabonde, et il mange toujour's seul." En effet, ces oiseaux ne se réunissent jamais, comme les corneilles, les pies, ete., pour chercher leur nourriture; et, lorsque plusieurs merles se trouvent dans le même champ, chacun d'eux s'éloigne de ses congénères, et semble craindre de partager avec les autres la proie qu'il peut découvrir. Cette habitude rentre dans le caractère lu merle, qui est d'une défiance excessive, ce que l'on est trop souvent porté à prendre pour de la ruse. La racine du mot merle ne serait-elle pas aussi merum, "vin pur?" désignation qui rappellerait le goût prononcé que manifeste, pour les raisins, un certain nombre des oiseaux du genre merle? Et ce qui me parait encore plus évident, merle n'en dériverait-il pas par l'intermédiaire de merella, merellum? En effet, d'après Ducange, " merellit vel merellum vinum est tenue, vinum et aqquâ mixtum. Merella ou merellum est un petit vin, du vin mêlé avec de l'eau. ") Ainsi, en s'appuyant sur de nombreux textes, l'auteur cité précédemment démontre que le mot 
merella désigne un " vir faible, mélangé d'eau, " celui que les élèves aiment à appeler abondance. La pensée reste identique : c'est le jus du raisin, et par conséquent le raisin qui aurait fait donner au genre merle la dénomination sous laquelle il est connu. Quant au substantif ou à l'adjectif turdus, c'est le mot primitif employé par les Romains pour désigner, d'une manière particulière, les grives, et dont on a étendu la signification à tous les oiseaux de ce genre. Peut-être pourrait-on en trouver la racine dans les noms des Turduni ou Turdetani, peuples d'Espagne. Ce qui semblerait fortifier cette étymologie, c'est le grand nombre de grives qui se trouvent en Espagne, et l'habitude des peuples de cette contrée d'engraisser ces oiseaux, pour les manger ou pour les vendre aux Romains : nam Turdetani et populi sunt qui turdos saginant et vendunt et qui turdorum avide sunt (Lexicon Forcellini). Enfin le nom d'iliacus donné au merle mauvis, parce que ce passereau se trouve en grand nombre aux environs d'llion, viendrait encore corrohorer mon hypothèse, en prouvant qu'on donnait autrefois aux oiseaux le nom du pays qu'ils habitaient.

Ducange affirme que les plus habiles pêcheurs désignent indifféremment un certain poisson par les mots turdus et merula. "Turdus est species piscis quem peritiores piscatores merle vocant, non distinguentes turdum a meruld. "Il n'est donc pas impossible que turdus et merula étant synonymes, soit qu'ils déterminent un poisson, soit qu'ils déterminent un oiseau, ne doivent avoir la même signification, et dès lors la même origine.

Turdus ne serait-il alors qu'une abréviation de turgidus signifiant " enflé, gonflé? " En appliquant cette signification aux effets d'un goût trop vif pour le vin, pour la gourmandise, le problème serait résolu, et l'on expliquerait facilement les locutions populaires : souil comme une grive; gras comme un merlan en octobre. 
Aux hypothèses précédentes, qui se trouvaient énumérées dans la première édition de ces Etudes, je crois pouvoir en ajouter quelques autres.

Les Grees nommaient la grive, iLlas, ildas, mot qui probablement aura donné naissance à iliacus. Or, d'après quelques savants, mL.as serait une corruption de chillas, dont la racine pourrait être cimLoô et cHeïLoô, signifiant " repaitre, engraisser, " et se rapprochant dès lors du sens de turgidus.

Adolphe Pictet (t. I, pag. 481) pense que turdus pourrait bien être pour tursdus ou trusdus, dont la racine sanscrite "tras") se traduit par timere, "craindre. " Ainsi le mot turdus représenterait l'idée de crainte et pourrait se remplacer par "l'oiseau timide, craintif. ") Cette explication rentre parfaitement dans le caractère du merle et surtout de la grive, et a de plus l'avantage d'indiquer peut-être la racine de draine, "traie," qui ne serait qu'une forme corrompue d'un mot primitif; si le véritable caractère de la timidité, de la crainte, est de fuir et de crier, la draine est assurément l'oiseau timide par excellence. Le mot tras, dans le sanscrit, signifie " crier. ")

\section{MIERLE DRAINE. - TURDUS VISCIVORUS.}

L'épithètedraine peut-elle avoir pour racine deux mots grecs : uris, " chêne, " et aïxos, "parole, " d Ȧ̀m ou aò, " souffler, " désignant ainsi une habitude caractéristique de ce merle, qui fait entendre un chant dur et sifflé en fuyant d'arbre en arbre? Dériverait-clle de snä̈ex, une des formes de la eonjugaison de muraskò, "fuir, " peignant avec énergie la vie de la druine, qui s'écoule en fuites incessantes, toujours accompagnées diun certain cri d'inquiétude?

Dans le midi de la France, draie signifie chenin, et 


\section{$-173-$}

s'adrayer indique l'action d'un homme qui travaille ì s'habituer à parcourir rapidement une longue route.

Peut-être, à la pensée d'une opération qui prend depuis quelque temps des proportions colossales en France, serait-il permis de trouver dans le mot draine un rapport éloigné avec le drainage, dont la racine anglaise to drain veut dire "épuiser, dessécher. " Le merle draine vit d'insectes et de vers; il aime à chercher ces derniers dans la terre détrempée par la pluie. Quand l'eau est tombée en abondance, et qu'elle a pénétré profondément le sol, on aperçoit des troupes de draines creusant avec leur bec et avec leurs pieds de petits sillons. Leur but est de trouver plus facilement les vers, et de faciliter ainsi l'écoulement de l'eau qui les gêne dans ce moment, après avoir été cependant la cause de l'abondance de leur récolte.

Le nom de draine, ou drenne, n'est peut-être aussi qu'un mot qui retrace le chant saccadé de cet oiseau, dre, dre, trre, trre, d'oùil a reçu les épithètes vulgaires de traie et de criarde.

L'adjectif viscivorus retrace encore une des habitudes de la draine, celle de manger le gui du chêne et des autres arbres, de viscum, "gui, " et vorare, "manger, dévorer. ")

Cet oiseau fixe ordinairement son nid à la bifurcation des grosses branches des arbres, à une hauteur moyenne. Il paraît rechercher, de préférence à tous les autres, les arbres fruitiers, probablement parce que l'extérieur de son nid, se mariant mieux avec la couleur de ces arbres, échappe plus facilement aux yeux de ses ennemis. En effet, ce nid, dont les dimerisions sont très-grandes et contribuent ainsi à le trahir, est composé à l'extérieur de racines et de petites branches entrelacées, mélangées et revêtues de lichens blanes, qui couvrent ordinairement en grande quantité l'écorce des arbres fruitiers. Le fond 
en est garni te mousse ou d'herbes et de racines fines. Le nombre des eufs est de quatre it sis; ils varient beancoup de grosseur et de couleur. Le plus souvent le fond de la coguille est d'un roux parsemí de taches d'un violet terne et presque effacé. Quelques-uns revêtent une conleur uniformiment verdatre, et offrent quelques ressemblances avec certains œufs d'étourneau. Leur longueur est de $0^{\mathrm{min}}, 02: 3$ ì $0^{\mathrm{m}}, 032$, et leur diamètre de $0^{\mathrm{m}}, 018$ à $0^{\mathrm{m}}, 022$.

MERLE LITORNE. - TURDUS PILARIS.

Ce merle, plus petit que le précédent, apparaît dans les différentes contrées de l'Europe par bandes nombreuses, pendant l'automne ou pendant l'hiver; il se retire ensuite au sein des forèts des régions du Nord, dans lesquelles il se reproduit. Sa chair est jugée bien inférieure à celle des autres merles; elle est imprégnée d'une amertume assez prononcée, provenant, selon toute probabilité, de quelques espèces de baies qui composent en partie sa nourriture. C'est dans cette particularité que se trouve sans doute l'étymologie de son nom, urtos, "vil, petit," et orNis, " oiseau, - oiseau de peu de valeur. "

L'épithète pilaris, "poilu, " indique que la litorne a autour du bec des poils plus longs que ceux des autres grives. Ce merle voyage en troupes innombrables, et occasionne des ravages considérables dans les propriétés sur lesquelles il s'arrête. 11 mange arec une gourmandise, une avidité devenie proverbiale. Pour assouvir son appétit insatiable, il abat encore plus de fruits qu'il n'en dévore. Son nom ne dériverait-il pas alors de pilo, pilare, " voler, ravager?" et le mot litome ne s'expliquerait-il pas dans le mème sens, par antiphrase? car Lrros signifie aussi frugal.

Le merle litorne appuie sur les branches ou sur le trone 
des arbres un nid ayant quelque ressemblance avec celui de la draine. Ses œufs, au nombre de quatre à six, sont le plus souvent d'une couleur verte, parsemés de petits points roux, bruns ou noirâtres, et régulièrement plus gros et moins pointus que ceux du merle noir. Leur longueur varie de $0^{\mathrm{m}}, 02 \mathrm{y}^{\mathrm{a}} 0^{\mathrm{m}}, 030$, et leur diamètre de $0^{\mathrm{m}}, 018$ à $0^{\mathrm{m}}, 022$.

\section{MERLE GRIVE. - TURDUS MUSICUS.}

L'épithète grive me semble avoir été donnée à ce merle parce qu'il aime à fréquenter les vignes, à manger les raisins, à se griser. En effet le mot se griser vient du mot latin grecari, signifiant " faire le grec, se livrer à l'ivrognerie, à une gaieté bruyante, exploiter les autres, en s'emparant, avec une adresse plus ou moins grande, de ce qui leur appartient, etc. ") Les mots grec et gris étaient synonymes dans le moyen âge, comme il est facile de s'en convaincre par ces expressions du vieux roman d'Alexandre : Il fut bien escouté d'Alexandre et des Gris. D'où le mot gris n'indiquait pas seulement la couleur désignée par ce nom, mais encore une conduite semblable à celle des Grecs, et, pour représenter les habitudes de ceux qui se livraient aux excès du vin et à toutes les tristes conséquences de l'ivresse, on pouvait dire indifféremment: qu'ils faisaient les grecs ou les gris. Du mot gris, on a formé, selon Génin, griu et le féminin griue, et enfin grive. Villehardoin appelle la Grèce, la Griève.

L'adjectif grivois donné aux soldats ou aux personnes qui se livrent à une joie folle, fruit de l'ivresse, vient encore corroborer cette opinion.

L'habitude du merle grive, de manger des raisins avec une avidité insatiable, justifierait alors complétement la signification de l'épithète qui lui a été donnée. Grivelée 
signifiait autrefois petile volerie. Enfin le proverbe populaire, "soül comme une grive, " sanctionne encore la justesse de cette étymologie, et s'appuie lui-même sur les faits recueillis par les chasseurs. Ceux-ci ont constaté, dans les grives, une véritable irresse, manifestée dans leur vol et dans l'ensemble de leurs mourements, pendant leur séjour dans les vignes. M. Littrí n'adopte pas l'étymologie indiquée par Giénin, et il croit que le mot gris, dans le sens d'ivresse, n'est que l'expression d'une plaisanterie, employée pour indiquer l'état entre le blanc et le noir, et, figurément, entre la raison et l'ivresse.

Quant à l'epithète musicus, "musicien, " elle a été donnée au merle grive à cause de son chant, le plus agréable de tous ceux des oiseaux de ce genre. Le merle et la grive sont deux des plus délicieux chantres de la campagne. Leur voix pénétrante et fortement accentuée s'étend à plusieurs kilomètres de distance. Les notes de leur chant, ordinairement sur un diapason fort ćlevé, tranchent par leur intensité sur toutes les autres voix, et forment comme la haute-contre du concert harmonicux que les oiseaux nous donnent au printemps en fêtant, par un hymne d'amour, l'œurre de la création qui sans cesse se renouvelle.

Cependant la grive a, dans ses notes, quelque chose de bien supérieur au merle, dont le chant est plutôt sifflé que chanté. Le rossignol, avec les incroyables ressources de son gosier, n'a rien d'aussi sonore que le zip, zip ou trhit, trhit de la grive. Les diverse's parties du chant de la grive ne se répètent pas d'une manière régulière; elles paraissent plutôt résulter de l'inspiration du moment. Peut-être pourrait-on admettre l'hypothèse que le nom de grive a été donné a cet viseau par onomatopée et far corruption de sun chant "tri-tri," ou "yri-gri. " Le merle grive chante principalement, lorsque le temps est frais et mème froid; il semblerait que, plus la tempera- 
ture s'abaisse, plus son gosier acquiert d'élasticité et de puissance. L'air plus dense transmet aussi son chant avec plus de netteté, et ce chant est si attrayant que, quand une grive se fait entendre, on se sent porté à s'arrêter pour en jouir. Ses phrases ne se touchent pas; elles laissent entre elles quelques secondes d'intervalle, partieularité qui dispose encore à prêter l'oreille avec plus d'attention.

Le merle grive niche dans notre département; il établit son nid dans les taillis, dans les buissons épais, ou sur les arbres peu élevés. Presque chaque année, plusieurs couples se reproduisent dans les taillis appartenant à M. de Boguais, et situés derrière la chapelle des Martyrs, auprès d'Angers; c'est là qu'on peut facilement étudier les mœurs de cette grive et jouir de la beauté de son chant. Le nid de cet oiseau est composé de terre gâchée ; à l'extérieur il est revêtu de mousse et d'herbes fines. Les œufs, au nombre de quatre à six, reposent sur la terre nue; ils sont d'une belle couleur bleu de ciel, avec des taches rondes, d'un noir foncé, plus ou moins larges, répandues sur toute la coquille et formant quelquefois une couronne vers le gros bout. Ces œufs sont ordinairement beaucoup plus ronds que ceux des autres oiseaux de ce genre; ils ont de $0^{\mathrm{m}}, 025 \mathrm{a} 0^{\mathrm{m}}, 028$ de longueur, et de $0^{\mathrm{m}}, 019$ à $0^{\mathrm{m}}, 022$ de diamètre.

\section{MERLE MAUVIS. - TURDUS ILIACUS.}

Le nom scientifique iliacus indique que ce merle venait des côtes d'Asie, des environs d'llion, où il séjournait en si grand nombre, qu'il semblait en quelque sorte y avoir acquis le droit de cité (Iliacus). Quant au mot mauvis, il dérive de mala-avis, et signifie "oiseau malfaisant, 》 désignation justifiée par les ravages qu'il exerce dans les vignes où il s'arrête pour assouvir sa faim insa- 


\section{$-178-$}

tiable. Ducange traduit mauvis par malvitius, et Génin l'interpròte par le mot français malvis, "mauvais visage." La pensére resterait la même, car ce mot indiquerait que le manivis est semblable à ces êtres d'un "visage sinistre, ") que l'on craint de voir, à cause de leurs nombreux méfaits.

Le merle mauvis établit son nid dans les buissons. Ses cufs, au nombre de quatre à six, sont d'un bleu verlâtre, parsemés de petits points noirs. La coquille en est généralement plus luisante que dans les autres espèces de merles. Ces œuls, ilont le grand diamètre est de $0^{\mathrm{m}}, 023$ et le petit de $0^{\mathrm{m}}, 018$, sont déposés dans un nirl façonné avec des herbes grossières et de la mousse.

Le mauvis niche en grande quantité aux environs de Dantzig; presque partont ailleurs, il ne fait que passer, sans s'y reproduire.

\section{MERLE A PLASTRON. - TURDUS TORQUATUS.}

Les noms donnés à ce merle, dans les différentes langues, ont le même sens, et sont fondés sur le plustron blanc qui décore sa poitrine. Ce plastron est plus ou moins étendu, selon l'âge de l'oiseau; il est toujours moins prononcé chez la femelle que chez le mâle. Chaque année, le merle à plastron visite notre département, et un certain nombre de couples s'y arrêtent pour nicher. Placé à une petite élévation de terre, au milieu ou au pied des buissons, appliqué sur le tronc des arbres, le nid de cet viseau est formé de feuilles sèches, de racines et le mousses liées ensemble par de la terre argileuse. L'intérieur est garni de mousse ou de foin. Les aufs, d'un vert bleu, sont par'semis de taches d'un brun rougeatre, formant quelquefois une couronne ver's le gros bout. Les taches sont régulièrement moins numbreuses, mais p̣lus longues que celles des aufs du merle noir. Ils ont beau- 
coup de ressemblance avec quelques variétés de ces derniers; cependant leurs dimensions sont presque toujour's plus fortes. Ils pourraient aussi se confondre avec de gros œufs oblongs du merle draine. Leur longueur varie de $0^{\mathrm{m}}, 026$ à $0^{\mathrm{m}}, 030$, et leur diamètre de $0^{\mathrm{m}}, 019$ à $0^{\mathrm{m}}, 022$.

\section{MERLE NOIR. - TURDUS MERULA.}

Les épithètes données à ce merle s'expliquent d'ellesmêmes, et sont fondées sur son plumage sans mélange et plus noir encore que celui du corbeau. Le merle noir, le plus commun des oiseaux de ce genre, est sédentaire en Anjou. Il établit son nid tantôt à terre, sur les talus des fossés, habitude qui lui a fait donner le nom de merle terrier; tantôt au pied des buissons épais, sur la tête des arbres émondés, le long des vieilles souches entourées de lierre. Ces nids, dont quelques-uns sont bien façonnés, présentent des dimensions assez considérables; ils sont composés de racines, de feuilles desséchées, de monsse, de foin, et revêtus quelquefois à l'extérieur de terre argileuse. Les œufs, au nombre de quatre ì six, présentent un grand nombre de variétés, bien différentes les unes des autres. Quelques-uns sont ronds, d'autres oblongs, piriformes, etc. Leur couleur se nuance du vert très-foncé au jaune d'ocre. Tous sont pointillés de brun clair ou jaunâtre. Quelquefois, les points sont si petits et si multipliés, qu'ils semblent composer le fond de la coquille et y former une seconde couche, qui recouvre la première. linfin, quelques-uns présentent une couronne vers le gros bout, ou une large tache en forme de calotte. Leur grand diamètre est de $0^{\mathrm{m}}, 025 \mathrm{à} 0^{\mathrm{m}}, 032$, et le petit de $0^{\mathrm{m}}, 016$ à $0^{\mathrm{m}}, 022$.

Le merle noir a une antipathie extrême pour le renard; c'est lui qui souvent, du haut des arbres, indique 
aux chasseurs la retraite de cet animal, ru'il accompagne et poursuit de ses eris pendant plus d'un kilomètre de distance. Il annonce de même l'approche de l'oiseau de proie.

En géníral, la chair du merle est bien moins recherchée que celle de la grive. Cependant le merle à plastron tué pendant les vendanges fournit un mets qui le cède ì peine à la caille. Dans le midi de la France, la chair des merles de la Corse, à cause des baies odoriférantes dunt ils se nourrissent, est très-estimée des gastronomes.

\section{THOISIẺNE GENRE.}

LE GRAND-JASETR DE BOHEME. - BOMBTCILLA GARRITA.

Le yrand-jaseur doit son nom au gazouillement qu'il se plaît ì faire entendre, et qui le distingue des oiseaux qui chantent ou qui parlent. L'adjectif grand sert à le séparer du jaseur d'Amérique, auquel il ressemble sous plusieur's rapports, mais dont il s'éloigne par des proportions plus grandes. Errant et ragabond, cet oiseau n'a pas de patrie connue; comme les bohémiens, il semble suivre dans ses migrations continuelles plutòt un caprice qu'un besoin. Partout on le trouve, et toujours de passage. A certaines epoques, il apparaît par bandes nombreuses dans quelques contrées, pour ne plus revenir qu à des époques éloignées et irrégulières.

Le grand-jaseur n'habite pas la Bohême; il ne vient dans cette province que d'une manière accidentelle, et le nom de bohéme n'aurait été, d'après certains auteurs, ajouté au sien que parce que les Autrichiens, en voyant autrefois des bantes innombrables de jaseurs s'abattre sur leur pays du còted des frontières de la Bohème, avaient jensí que cette région était la véritable patrie du bombycilla. Cette explication, fondie sur la désignation 
" originaire de Bohême, " n'est pas la véritable. L'épithète bohemicus, "bohême, bohémien, " rend d'une manière plus exacte, plus dramatique, les habitudes de cet oiseau. Le jaseur est, dans toute la force du terme, un vrai bohême; manière d'indiquer immédiatement que, dans les habitudes de cet oiseau, il y a quelque chose d'extraordinaire, de désordonné, de vagabond. C'est pour cela qu'il ne porte ni le nom de migratorins, ni celui de viator, ni celui de peregrinus, mais celui de bohemicus. En effet, les premiers adjectifs indiquent bien l'idée d'un voyage, mais d'un voyage déterminé, à heure fixe, accompli après des préparatifs sérieux et avec des ressources convenables. Or il n'en est pas ainsi des migrations du jaseur : elles sont essentiellement baroques, éventuelles, incertaines; elles représentent un voyage en zigzag, sans but, sans raison plausible, et ne peuvent mieux être résumées que par ce mot bolieme. Cet adjectif convient encore parfaitement au costume et à la livrée de l'oiseau. C'est, par le fait, un plumage très-original, orné de galons d'or sur les ailes et sur la queue, terne et sans éclat sur le reste du corps. Sa huppe, qu'il relève assez souvent d'une manière grotesque, ressemble au diadème d'un roi de théâtre. Le mot bohême convient au jaseur à cause de son plumage, qui en fait un véritable histrion, et l'assimile à ces bouffons, à ces baladins, dont le costume est un mélange disparate de soie et de bure.

Le mot garmla signifie " jaseur, » et l'adjectif bombycivora, de bombyx, bombycis, "ver à soie, " et vorare, "dévorer, " indique que "les vers à soie " sont recherchés de cet oiseau. Peut-être trouverait-on dans ce goût particulier le motif des migrations incessantes du grandjaseur.

Cet oiseau est aussi désigné très-souvent par le mot bombycilla, dont l'étymologie doit être bombyx, " soie " et cilium, "cil. " Alors cette épithète indiquerait une 
particularité propre an srand-jaseur, dont les narines sont cachées sous de petites plumes soyeuses dirigies en avant. Ces plumes se relèvent en forme de panache, et viennent ombrager ses yeux.

Jusqu'ì ce moment-ci (août 18:8), les ornithologistes français n'avaient, sur le lieu, le temps et le mode de nidifieation du srand jaseur, que des renseignements laux ou très-incomplets. Un naturaliste de l'Allemagne, II. II.Ferd. Moeschler, que j'avais prié de vouloir bien faire exícuter des recherches sur cette question par ses currespondants du nord de l'Europe, vient de m'adresser six œuf's du grand-jaseur et quelques détails obtenus après plusieurs années d'investigations incessantes et ¡uinibles. Grâce à la persevérance et à la bienveillance de mon correspondant et ami, je puis donner, sur le nid et les cufs du bombycilla garrula, des notions détaillées et précises.

Les grands-jaseur's se réunissent en troupes assez considérables dans la Laponie, vers la fin du printemps. Dès le commencement de juin, le mâle et la femelle travaillent à lit construction de leur nid. Ils choisissent de préférence les pins, les sapins et les bouleaux les plus élevés. Ce nid est appuyé ordinairement à la bifurcation de plusieur's brariches. Le diamètre en est d'environ $0^{\mathrm{m}}, 14$, et l'épaisseur sur les bords de $0^{\mathrm{m}}, 03$. La base et la partic exterieure sont composées de petites branches sèches de sapin ou d'autres arbres des rigions boréales. Les vides entre ces branches sont remplis par des mousses, telles que le brynm et l'hypmum, ainsi que les feuilles aciculaires des pins et les flocuns du cuton des arbres. La coupe du nid a $0^{\mathrm{m}}, 03$ de profondeur; elle est formée presque exclusivement de filaments trèsdéliés de l'usnée burlue ou chevelue (usnen burbutn), espèce de lichen qui eroît ordinairement sur le trone des vieux arbres, d'vù il pend en masses tilamenteuses 
plus ou moins longues et plus ou moins touffues. L'intérieur du nid est garni de tiges fines de gramen mêlées à des plumes de lagopède, ou à celles du grandjaseur lui-même. Par sa forme et par les matières qui le composent, ce nid se rapproche de celui du casse-noix. La ponte du jaseur a lieu ordinairement vers la fin de juin ; elle varie de quatre à six œufs. Ceux-ci ont de $0^{\mathrm{m}}, 022$ à $0^{\mathrm{m}}, 024$ de longueur, et de $0^{\mathrm{m}}, 016$ à $0^{\mathrm{m}}, 018$ de diamètre. Le fond de la coquille est d'un blanc bleuâtre ou d'un gris perle pâle, moucheté de taches rondes ou un peu oblongues d'un noir assez foncé, surtout vers le centre, ou enfin d'un bleu gris pâle. Ces taches sont répandues régulièrement sur toute l'étendue de la coquille. Quelques-unes ayant les mêmes formes, mais une couleur plus pâle que les premières, semblent presque effacées ou fondues dans la teinte primitive de l'œuf. Elles représentent en quelque sorte une seconde couche plus foncée, mais incomplète et ne couvrant qu'irrégulièrement une partie de la coquille. Les œufs du grand-jaseur affectent ordinairement une forme assez aliongée et un peu piriforme. Moins gros et moins ventrus que les œufs du gros-bec ordinaire (Fringilla coccolliraustes), et d'une teinte plus vive, ils en diffèrent encore par leurs taches petites et presque rondes, tandis que celles des œufs du gros-bee sont formées, assez ordinairement, de larges points étendus en zigzag.

\section{QUATRIÈME GENRE.}

\section{LE LORIOT. - ORIOLUS GALBULA.}

Le loriot est un des oiseaux les plus beaux qui visitent notre continent. Il habite le nord de l'Afrique et, chaque année, il se répand dans les contrées méridionales de l'Europe pour s'y reproduire. Le loriot doit, selon quel- 
quos auteurs, son num à son cri : ourion, ouriou, que l'on traduit trop facilement par celui de louriou, louriot, loriot. Cependant la vérilable étymologie de ce nom me semble se trouver dans son nom latin oriolus, dérivé dui grec cumònòx, dont la racine chlòros signifie "jaune," et désigne la belle couleur qui éclate sur la plus grande partie du plumage du mâle adulte. Scaligrer le dérive d'anreolus, allongement d'aureus, "doré. ») Cette opinion est partagée par Génin, qui pense que loriot est la contraction de l'article le et du substantif auriouz, dérivant d'mureolus et signifiant "couleur d'or, doré. ) Loriot résumerait done ces deux mots, et pourrait être remplacé far cette expression : le doré ou l'oiseau couleur d'or.

Pour justifier son opinion, Génin cite les passages suivants des anciens auteurs :

Ce fut en mai, que la rose est fleurie;

L'auriouz chante, et li mauvis s'escrie...

(Gérard de Viane, v. 3293).

Et parmi les genz plaisséis, Russignous, merles et mauvis, Geais, oriouz, treie et calandre, etc.

(Chron. des ducs de Normandie, 11, pag. 133).

Là sist li empereres sur un cuisin vaillant, La plume est d'oriol, la teie d'escarimant.

Lit était assis l'empereur sur un coussin précieux de plumes de loriot, avec une taie d'écarlate.

(Voyage de Charlemagne ì Jérusalem, p. 12). (Géxis, Récréations philologiques, p. 101).

Quant à l'épithète galbula, "verdìtre, " elle peint la couleur de la femelle et celle des petits; ear, par une coïncidence touchante, les petits, dans presque toutes le: especes, ressemblent par leur plumage, arant la mue, à 
leur mère, dont la sollicitude veille avec tant d'empressement sur les premiers instants de leur vie.

Le lorict choisit la bifurcation des petites branches, à l'extrémité des arbres les plus élevés, pour y établir son nid. Celui-ci est composé de brins de foin ou de paille artistement entrelacés; il est assujetti aux deux branches par des galons, des fils, des rubans, des filaments de chanvre, quelquefois même par des chaînes de montre, des lacets recueillis sur les grandes routes. Ces tissus s'enroulent plusicurs fois autour des branches, et pénètrent dans le nid, dont ils lient fortement les différentes parties entre elles. L'intérieur est garni de laine, de crin, du duvet des fleurs et même, quelquefois, de papier fin. Ce nid présente un gracicux tableau lorsque, semblable à un hamac, il subit les ondulations du vent, pendant que la femelle couve ses œufs et que le mâle, dont la couleur jaune contraste avec la verdure du feuillage, se tient perché sur une branche voisine et varie de la manière la plus douce possible son chant sifflé. Les œufs, au nombre de quatre à six, sont d'un blanc brillant, parsemé de taches noires et d'un brun rougeâtre. Lor'squ'ils sont nouvellement pondus, la coquille paraît transparente et d'une belle couleur rose. Leur grand diamètre varie de $0^{\mathrm{m}}, 027$ à $0^{\mathrm{m}}, 030$, et le petit de $0^{\mathrm{m}}, 018$ à $0^{\mathrm{m}}, 022$.

Le loriot arrive très-tard en Anjou, vers le mois d'avril, et repart dans les derniers jours d'août. Il ne séjourne dans notre pays que pendant la saison des cerises, qui composent presque exclusivement sa nourriture. Les gens de la campagne prétendent que, dans son chant, il répète ces paroles : "Je suis le compère Loriot, qui mange les cerises et laisse les noyaux, ") ou bien celles-ci : "Quand cerises sont en saison, je dis confiteor Deo. ")

Martial dit que cet oiseau, d'un caractère ordinaire- 
ment très-défiant, se laisse prendre aux filets ì l'époque où le raisin commence à mûrir :

Galbula decipitur calamis et retibus ales

Turget alluc viridi quum rudis uva mero.

Le loriot se proml aux gluaux et aux filets, alors que commence a grossir le raisin encore vert. (Mantal, liv, xil, Epig. 58.)

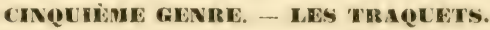

LE TRAQUET hotTEUX. - SAXICOLA OENANTHE.

Le genre traquet comprend des oiseaux brillants de couleurs, et remarquables par la grâce et la rapidité de leurs mouvements. Quatre espèces visitent l'Anjou, et trois s'y reproduisent. Ces oiseaux doivent leur nom français au mouvement continuel de leurs ailes et de leur queue, qui les a fait comparer an traquet des moulins, que le vent, la vapeur ou l'eau agitent d'une manière incessante.

L'épithète molteux retrace l'histuire entière du traquet désigné par ce nom. Il se tient, en effet, dans les terrains dont les sillons n'ont pas encore reçu la dernière laçon, cherche les petits insectes qui s'y réfugient, roltige de motte en motte, et tour à tour paraît sur leur point culminant, ou se dérobe à la vue du chasseur en se cachant derrière leur épaisseur. C'est encore sous "les mottes " qu'il niche et élève ses petits. Le mot saxicolu fait connaître les lieux que les traquets fréquentent; il lérive de saxum, "rocher, " et colo, " labiter, " et signifie dès lors " oiseau qui aime, recherche et habite les rochers. ")

L'adjectif ananthe vient compléter encore ces renseignements précis et y ajouter un caractère noureau. Ce mot dérive, en effet, d'ö̈xè, "vigne, " et axtuos, "fleur. " Les traquets, par leurs mourements sracieux 
et rapides, par la beauté de leur plamage, embellissent et vivifient les vignobles, dont la culture et l'aspect sont ordinairement plus sombres et moins animés que ceux des terres ensemencées.

Le traquet motteux se pratique un nid sous les mottes ou sous les pierres; là, il réunit des débris de paille, de mousse, de crin, y mêle quelques plumes, et pond quatre ou cinq œufs un peu obtus, d'un bleu pâle et régulièrement sans aucune tache. Grand diamètre de $0^{\mathrm{m}}, 018$ à $0^{\mathrm{m}}, 022$; petit de $0^{\mathrm{m}}, 012 \grave{a} 0^{\mathrm{m}}, 015$.

\section{TRAQUET TARIER. - SAXICOLA RUBETRA.}

Ce traquet se montre dans toutes les contrées tempérées de l'Europe; il aime les prairies, le bord des cours d'eaux, des marais; il recherche aussi les terrains incultes, les landes, etc.; on le voit à chaque instant à l'extrémité des bruyères ou des herbes les plus élevées, toujours en mouvement, agitant les ailes et la queue, comme s'il devait reprendre immédiatement son vol. Ce balancement me semble cependant lui être plutôt commandé par la nécessité, comme s’il était destiné à lui fournir le moyen de se maintenir en équilibre dans une position très-difficile.

Ce charmant petit oiseau doit peut-être le nom de tarier à son habitude de nicher "à terre," habitude qui l'a fait nommer terrasson. Plus probablement pourraiton, en admettant le mot dans toute son acception, en fonder l'explication sur l'extrême facilité de cet oiseau à pénétrer, avec la même promptitude que la tarière pénètre partout, dans les herbes touffues, pour s'y soustraire aux regards de ses ennemis, et y tronver sa nourriture.

Le nom scientifique rubetra signifie, d'après quelques 
naturalistes, " oiseau rougeatre, " et s'expliquerait par le "rouge bai ") de la poitrine du tarier. Mais je pense que la racine véritable pourrait bien être rulus, " buisson, ronces, mûres, ) et que dès lor's ce nom indiquerait que le tarier se plaît dans les ronces et qu'il aime les mùres. Cette étymologie se trouve fortifíe par le nom grec ватıs, appliqué au tarier, et qui dérive lui-même de Batos, signifiant "ronce, mûre. " Quant à la terminaison / $r a$, ne pourrait-elle pas venir de tero, "piller, broyer, se frayer un passage? " Dès lor's cet adjectil se traduirait ainsi : "oiseau qui pille, qui mange des mûres, " ou yui, comme une tarière, "se fait un passage au milieu des ronces. " Virgile a dit : Terere iter, "se frayer un chemin. " Cette dernière explication viendrait fortifier celle que j'avais précédemment énoncée.

Le tarier fait le plus souvent son nid dans les prairies. Il le construit très-simplement au pied d'une touffe épaisse d'herbe; l'extérieur est composé de quelques brins de foin desséchés; l'intérieur est garni de laine, d'aigrettes de chardon et de duvet des plantes. La femelle y dépose quatre ou cinq œufs d'un bleu vert très-prononcé, parsemé de points d'un brun roux plus ou moins foncé et répandus surtout vers le gros bout; quelquesuns de ces œufs ne portent aucune tache; les uns sont entièrement ronds, les autres oblongs. Leur grand diamètre est de $0^{\mathrm{m}}, 016$ à $0^{\mathrm{m}}, 018$, et le petit de $0^{\mathrm{m}}, 012$ à $0^{\mathrm{m}}, 014$.

TRAQUET PATRE. - SAXICOLA RUBICOLA.

Le traquet paitre est le véritable ornement des pays fu'il habite; il y répand la vie par ses courses incessantes et par la grâre de ses mouvements. Toujours agité, il s'ilève en imprimant à son vol de petites secousses, et retombe en tournant sur lui-même, justifiant 
ainsi son nom de traquet. Ce saxicole aime les terrains arides, les landes, les bruyères, les contrées solitaires et sauvages; là, il devient le compagnon assidu du berger. Il égaie le jeune pâtre dans ses longues heures de solitude et d'ennui, par son cri et par la légèreté avec laquelle il aime à se reposer et à se balancer sur les tiges les plus élevées, les plus isolées et les plus flexibles des buissons et des herbes. Dans une heureuse pensée, pour l'identifier davantage encore au jeune pâtre dont il est le compagnon et l'ami assidu, on les a désignés tous les deux par le même nom. Souvent le traquet pâtre se plaît à suivre la charrue qui trace les sillons, à saisir les petits vers que le soc amène à la surface. Quelquefois même il se pose sur la bêche du travailleur pour s'emparer des insectes qui s'y sont attachés.

L'épithète rubicola dérive de rubus, "mûre, " et colo, "habiter, ") et indique que le traquet pâtre recherche les ronces et les buissons.

Peut-être l'étymologie la plus vraie, si toutefois cette dénomination était de date récente et de formation irrégulière, serait-elle rubus, rubi, et color, " oiseau couleur de mûre, de couleur noire; " elle serait alors fondée sur les nuances du plumage de ce traquet, qui le font désigner partoat sous le nom de petit charbonnier.

Le pâtre chasse les mouches et les insectes au vol; à terre, il poursuit les sauterelles avec une grande agilité.

Le nid du rubicole, placé à terre, dans les champs en friche ou au pied d'un buisson, et souvent sur les bords des fossés le long de routes solitaires, est composé, en dehors, de foin, de filaments d'herbes sèches, et garni, en dedans, de crin, de laine, de plumes. Dans mes courses, avec mes jeunes amis Daniel Mlétivier et Eugène Lelong, je l'ai trouvé fréquemment sur les talus des fossés profonds qui serpentent dans les vastes landes de Bécon. Revêtant la forme d'une petite coupe aplatie, ce nid se 
confond par ses nuances avec la couleur du terrain auquel il est confić. Dissimulé dans une excaration dont il ne dépasse pas les bords, il est le plus sourent abrité par une touffe d'herbe ou par un petit arbuste qui en prortége l'ouverture, tout en la dérobant à la vue des passants, à l'action du soleil et aux inconvénients de la pluie. Il contient quatre ou cinq œufs d'un vert très-pâle et un peu gris, parsemé de petits points roussattres formant assez souvent une couronne ver's le gros hout. Le coucou y dépose fréquemment un œuf.

Le grand diamètre varie de $0^{\mathrm{m}}, 044$ à $0^{\mathrm{m}}, 016$, et le petit de $0^{\mathrm{m}}, 012$ à $0^{\mathrm{m}}, 014$.

\section{TRAQUET OREILLARD. - SAXICOLA AURITA.}

Chaque annće ce traquet passe en Anjou pour se rendre dans des contrées où il doit se reproduire. Il offre deux races très-distinctes, dont l'une est beaucoup plus grosse que l'autre, et doit son nom d'oreillard, auritus, à la bande noire qui de chaque côté du bee s'étend derrière les oreilles en passant sous les yeux. Ce saxicole aime les contrées chaudes, et recherche, de preférence à tous les autres lieux, les collines, les montagnes les plus élevées et les terrains arides.

L'oreillard niche à terre sous des mottes, des pierres ou dans les trous des vieux murs situés près de terre. Son nid n'est pas façonné avec soin; il est composé it l'extérieur de foin, d'herbe fine, et à l'intérieur, de laine, de mousse et de plumes. Les œufs, dont le nombre varie de quatre à ciny, sont d'un bleu verdâtre pointillé, surtout vers le gros bout, de petites taches d'un nuir rougeatre formant une couronne. Leur grand diamètre est. de $0^{\mathrm{m}}, 018$ ì $\left(0^{\mathrm{m}}, 020\right.$, et le petit, de $0^{\mathrm{m}}, 014 \mathrm{à} 0^{\mathrm{m}}, 016$.

La chair des traquets, comme celle de tous les oiseaux a pieds noirs, est très-recherchée par les gastronomes. 


\section{SIXIËUE GENRE. - LES FAUVETTES.}

Les Fauvettes forment un genre très-nombreux. Dixneuf espèces habitent ou visitent chaque année notre département. Vives, agiles, gracieuses, elles embellissent de leur présence et charment par leur chant les taillis, les buissons, les vergers, les bords des rivieres et les roseaux des marais. Aucun site ne leur est étranger; aucune localité n'est privée du plaisir de les voir et de les entendre. Les unes semblent avoir pour tâche de distraire dans leurs travaux les bergers et les moissonneurs; d'autres, de charmer les pêcheurs et d'animer, par leur chant et par la rapidité de leurs mouvements, les bords isolés et solitaires des rivières. Quelques-unes s'associent aux travaux des bûcherons, et ne les abandonnent pas même pendant les journées sombres et froides de l'hiver. Quand toute la nature semble morte ou endormie, les fauvettes viennent apporter à ces travailleurs l'image du mouvement, de l'espérance et de la vie. Dieu, qui a été si généreux dans les avantages variés qu'il a prodigués à ces chantres de nos bois et de nos campagnes, semblerait avoir oublié de parer leur plumage. Il est obscur et terne, et je pense que c'est à cette couleur sombre qu'ils doivent le nom de fauvettes. Belon le fait dériver de fovea, "petite fosse, " parce qu'il prétend que les fauvettes ont été ainsi désignées à cause de leur habitude d'entrer dans les fossettes et les murailles. Cette étymologie, qui me paraît fausse, n'a pas même l'avantage de s'appuyer sur les mœurs des fauvettes. A l'exception d'une ou deux espèces, toutes les autres nichent à ciel ouvert, et aucune ne passe sa vie dans les trous des murailles, pas même pour y chercher sa nourriture ou son repos. 
PALVETTE ROISSEROLE. - SHLYIA TIRDOIDES.

Cette fauvette, la plus grande de toutes celles qui sont conmues en Europe, doit son nom au brun roux et uniforme qui couvre sa queue et toutes les parties supérieures du corps. Les deux épithètes turdoüdes et turdoüde indiquent que la rousserole ressemble à la grive, de tarïus, "grive, " et Eünos, "ressemblance. " Cette expression est peut-être simplement un diminutif de turclus, et signifierait alors "petite grive. ) Ce qui fortifierait cette dernière opinion, c'est que la rousserole a été classie pendant très-longtemps parmi les grives.

Le nom générique de sylvia, que l'on a donni à toutes les faurettes, vient certainement par l'intermédiaire de sylva, de xruos, dérivé lui-même de nrLè, " bois, broussailles, taillis, " et indique ainsi une partie des lieux que ces passereaux habitent.

La rousserole vient chaque année dans nos contrées, en très-grand nombre, animer les bords des rivières ou des marais plantís de roseaux. Elle grimpe avec rapiäité et avec srâce le long des tiges des joncs, pour y saisir les insectes. Elle poursuit aussi au rol les libellules qu'elle aperçoit. Son cri saccadé, cara, cra, cara, auquel elle drit son nom vulgaire, trahit souvent sa présence. Cependant, malgré cette indication précise, la rousserole est dilficile à découvrir à cause de son habileté à se cacher et à se glisser derrière les roseaux et les herbes épaisses auquelles elle reste suspendue très-facilement. P'our composer son nid, elle choisit quatre ou cinq roseaux assez rapprochés, les réunit par des filaments de plantes aquatiques, qu'elle enroule bien des lois autour des jones pour former une espèce de bourse grossière. Ce nid a quelquelois une hauteur de près de deux décimètres, et semble aroir été ainsi labriqué pour arracher aux dangers de 
l'inondation des œufs ou des petits de la fauvette. Il ressemble alor's à plusieurs nids superposés. L'intérieur en est garni de débris fins et déliés de feuilles de roseaux; il contient ordinairement quatre ou cing œufs dont le fónd blanc verdâtre ou bleuâtre est parsemé de points ou de taches noires ou brunes qui forment quelquefois une couronne vers le gros bout. Ces œufs sont un peu piriformes, et le plus grand nombre sont oblongs; plusieurs seraient confondus facilement avec des œufs de moineau, dont ils ne diffèrent souvent que par leurs taches plus larges et une couleur plus foncée et plus bleuâtre. Leur grand diamètre varie

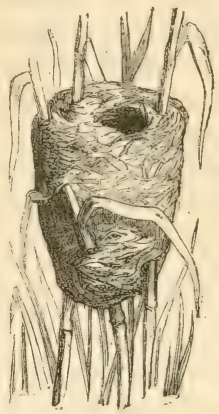
de $0^{\mathrm{m}}, 020$ à $0^{\mathrm{m}}, 023$, et le petit de $0^{\mathrm{m}}, 017$ à $0^{\mathrm{m}}, 019$.

Les gens de la campagne nomment la fauvette rousserole paisse des marais, parce que, par la couleur de son plumage, elle ressemble entièrement au moineau. Dans leur langage expressif, ils l'appellent encore la racasse, à cause du chant rauque et assourdissant, cra, cra, cara, cara, que cette fauvette fait entendre le jour et même la nuit. C'est ce chani qui indique très-souvent l'endroit où se trouve le nid de la rousserole. Un jour que, de concert avec M. Aristide Olivier, je visitais en bateau les différentes parties de la Fosse-de-Sorges, notre attention fut éveillée par le chant d'une rousserole; plus saccadé encore et plus fatigant que celui de ses congénères, il révélait une préoccupation très-vive. Nous nous dirigeâmes vers l'endroit d'où elle faisait entendre ses cris, et nous trouvâmes un nid contenant cinq œufs; soutenu par quelques joncs auxquels il était assujetti, il se trouvait à deux décimètres au-dessus de l'eau. En nous approchant pour l'examiner en détail, nous fùmes très- 
étonnés d'en trouver un second lié aux mêmes roseaux et plongeant it deux centimètres environ dans l'eau. Il renfermait quatre œufs. Une crue subite l'avait submergé, et la pauvre mère, ne voulant pas abandonner entièrement l'espoir de sa jeune famille, avait construit un second nid au-dessus du premier pour veiller sur les deux en même temps. C'était la crainte d'un deuxième malheur, que lui faisait redouter notre présence, qui donnait à son chant cette expression saisissante de mélancolie et d'angoisse.

\section{FAUVETTE EFFARVATE, - SYLVIA ARUNDINACEA.}

Cette fauvette, une des plus babillardes et des plus agiles de l'Europe, a un caractère peu sociable. Elle éloigne du lieu qu'elle a choisi pour nicher, non-seulement les oiseaux étrangers à son espèce, mais encore ses congénères. Elle semble avoir recour's à un bruit assourdissant pour arriver à ses fins. L'effarvate grimpe sans cesse avec une grande agilité le long des roseaux, pour y saisir les insectes qui y adhèrent; elle redescend, remonte avec une grâce et une rapidité remarquables, s'arrête à l'extrémité des tiges, y reste un instant en observation, puis s'élance avec la vitesse de l'éclair pour saisir au vol un insecte ou une libellule, et continuer ensuite le même exercice. Tous ses mouvements ont, par leur rapidité, une apparence d'irritation et de colère. Dès lors, son nom effarvate ou effervete pourrait dériver de efferven, signifiant "s'échauffer, s'animer. " Quant à l'épithète arundinacea, "des roseaux, " elle indique les lieux dans lesquels cette fauvette vit et se reproduit.

L'effarvate, comme la rousserole, établit son nid dans les roseaux, qu'elle reunit au moyen de filaments de plantes aquatiques. Ce nid est construit arec plus de soin 
que celui de sa congénère; l'extérieur est composé d'herbes et de feuilles entrelacées, et l'intérieur est garni de plusieurs couches de pelures sèches de roseaux trèsfines, très-déliées et très-molles. Il ressemble exactement, pour la forme, à ces petits paniers d'osier qui servent, en Anjou, à faire les crémets.

Vers le milieu du mois de juin 1865 , en parcourant les bords de la Sarthe, près de Morannes, avec mes jeunes amis Lugène Lelong, Guillaume Bodinier et Louis Manceau, je découvris un nid d'effarvate dont la construction me parut faite encore avec plus d'art que les autres. Ce gracieux travail reposait sur les branches entrelacées d'une forte tige de mauve. Les larges feuilles de la plante ondulaient au-dessus du nid, et semblaient destinées à préserver la mère et ses petits des ardeurs du soleil et des inconvénients de la pluie. Les fleurs de la mauve s'épanouissaient, comme une couronne au-dessus d'un riant berceau. Des touffes nombreuses et serrées de roseaux formaient, autour de la demeure de la future famille, un rideau de verdure, et complétaient ainsi les charmes de ce séjour privilégié. Là, nous eûmes une lutte à soutenir; d'un còté, nous désiriuns augmenter les richesses de nos collections et emporter le nid et les œufs; de l'autre, il nous répugnait de ne pas laisser la pauvre mère jouir des fruits du pénible travail qu'elle s'était imposé pour construire ce petit chef-d'œuvre, et aussi de briser les douces espérances qu'elle y avait confiées. Le sentiment de la générosité triompha; ct nous nous éloignâmes, en faisant des vœux pour que le nid échappât aux regards de tous les ennemis de la petite famille.

Les œufs, au nombre de quatre ou cinq, varient beaucoup de couleur. Les uns sont d'un vert brun uniforme, ou parsemés de taches, d'une nuance plus foncée, qui s'harmonisent avec la première teinte. Le plus souvent, le fond de la coqquille est d'un blanc sale ou verdâtre, sur 
lequel se trouvent des taches brunes plus ou moins nombreuses et parsemées irrégulièrement. Les œufs se rapprochent, par leur couleur, de guelques-uns de ceux de la rousserole, dont l'effarvate n'est, en quelque sorte, qu'une variété plus petite.

Guand les eaux s'élèvent à une certaine hauleur, et que l'effarvate craint de voir sa jeune famille submergée, elle abandonne les roseaux, et établit son nid dans les haies voisines des rivières ou des marais; clle le pose à la bifurcation de plusieur's petites branches, qu'elle unit de la même manière que les roseaux. J'ai trouxé de jolis nids d'effarvate, non loin de l'étang Saint-Nicolas; ils étaient fixés à de petites branches d'aubépine.

Cette fauvette niche aussi, assez souvent, parmi les grandes herbes qui croissent dans les îles et sur les bords de la Loire.

Le grand diamètre de ses œufs est de $0^{\mathrm{m}}, 016$ a $0^{\mathrm{m}}, 018$, et le petit de $0,{ }^{\mathrm{m}}, 014$ à $0^{\mathrm{m}}, 017$.

F.LVETTE VERDEROLLE. - SILVIA P.ILISTRIS.

La verderolle se rapproche beaucoup de l'effarvate; mais elle s'en éloigne, cependant, par ses pieds " verdâtres») et par les parties supérieures de son plumage légèrement nuancées de la même couleur. C'est ce qui la distingue des autres faurettes, et lui a fait donner le nom qu'elle porte.

Le véritable chant de lat verderolle est aussi très-diffírent de celui de l'effarvate. Néanmoins, eile contrefait assez souvent la voix de sa congénère, ainsi que colle du traquet motteux et des autres oiseaux, près desquels elle séjourne.

L'epithète palustris indique que ce passereau aime et habite les " marais. " Cette fauvette niche, ainsi que les précedentes, daus notre département, mais en plus 
petit nombre. Son nid sphérique est placé près de terre, dans les herbes élevées et dans les lieux humides. Formé à l'extérieur de tiges d'herbes fines et desséchées, il est garni en dedans de crin, de filaments très-déliés et du duvet des plantes. Il contient de quatre à six œufs d'un gris cendré, parsemé de táches brunes un peu verdâtres, arec d'autres qui ne diffèrent de la couleur de la coquille que par une nuance plus foncée.

Leur longueur est de $0^{\mathrm{m}}, 018$ à $0^{\mathrm{m}}, 020$, et leur diamètre de $0^{\mathrm{m}}, 012$ à $0^{\mathrm{m}}, 014$.

\section{FAUVETTE PHRAGMITE. - SYLVIA PHRAgMITIS.}

Cette fauvette ressemble à la suivante par sa taille, par ses habitudes, et même par son plumage. Elle en diffère par sa gorge, qui est presque blanche, et par ses flancs qui ne portent aucune tache. On la distingue assez facilement de sa congénère, par les nuances de l'ensemble de son plumage, qui est plus sombre et beaucoup moins jaune.

Les deux noms de cet oiseau ont la même signification; ils viennent de phragmitès, signifiant " oiseau qui vit dans les haies, les roseaux, etc., ") dénomination qui n’ajoute rien de spécial au nom de cette fauvette, et qui pourrait convenir à beaucoup d'autres.

La phragmite se reproduit en Anjou. Son nid a la forme d'un petit panier; il est souvent fixé à quelques roseaux, et le plus souvent à des tiges d'herbe ou même de blé, sur-

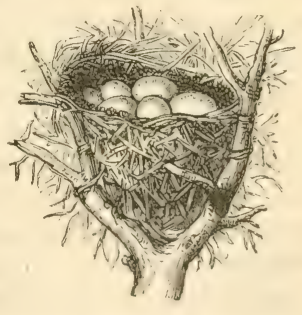
tout quand l'inondation éloigne cette fauvette des bords des rivières. Ce nid est composé de brins d'herbes 
souples ot dóliés entrelacés avec art; l'intérieur est matelassé avec les mêmes éléments, mais plus fins et plus mous. La femelle y pond quatre ou cinq cuf's d'un jaune pâle et uniforme. Quelques-uns cependant sont d'un jaune verdâtre, revêtu d'une seconde couche non régulière et plus nuancée que la première, qu'elle laisse entrevoir. Quelquefois aussi, on remarque vers le gros bout un ou deux filets noirs très-déliés et serpentant en zig-zag.

Le grand diamètre est de $0^{\mathrm{m}}, 016 \mathrm{a} 0^{\mathrm{m}}, 018$, et le petit de $0^{\mathrm{m}}, 012$ à $0^{\mathrm{m}}, 014$.

\section{FAUVETTE $\Lambda Q U A T I Q U E .-$ SYLVIA AQUATICA.}

L'aquatique aime les lieux " marécageux et humides; elle vit sur le bord des caux, ") auxquelles elle doit son nom. Sa nourriture consiste en ver's, en petits limaçons, en insectes qu'elle saisit à terre ou en grimpant en travers, le long des osier's et des tiges d'herbe, qu'elle fouille en tous sens. Elle redescend la tête en bas, et remonte aussitòt pour redescendre encore, rappelant par ses halbitudes et par la rapidité de ses mourements, sur les bords des rivières, la vie active des mísanges dans les vergers. L'aquatique se distingue de la phragmite, spécialement par la bande d'un blanc roux qui sillonne sa tête, et par les taches de même couleur répandues au centre des plumes qui garnissent ses flancs et sa poitrine.

L'acquatique fait un nid semblable à celui de la phragmite. L'intérieur est peut-être composé de matières plus molles et plus délicates. Il renferme quatre ou cinq œufs d'un gris verdître aree de très-petits points olivâtres; ils ressemblent à quelques variétés de la fauvette grisette, mais ils sont beaucoup plus petits; quelques-uns se rapprochent aussi, par la couleur et les taches, de certains auls de la bergeronnette printanière. Les marchands ont 
abusé de ces ressemblances, et le plus grand nombre des œufs vendus par eux, sous le nom de la fauvette aquatique, n'appartiennent pas à cette espèce.

Le grand diamètre est de $0^{\mathrm{m}}, 016$ à $0^{\mathrm{m}}, 017$, et le petit de $0^{\mathrm{m}}, 011$ à $0^{\mathrm{m}}, 013$.

\section{FAUVETTE LOCUSTELLE. - SILVIA LOCUSTELLA.}

La locustelle est beaucoup plus commune en Anjou et dans les autres départements, qu'on ne le pense ordinairement. Les habitudes de cette fauvette servent à la dérober aux recherches des chasseurs et de ses ennemis. Elle se tient habituellement cachée à terre, la plus grande partie de la journée, dans les herbes et dans les endroits humides. Elle ne s'envole pas quand on approche; mais elle court avec rapidité comme le râle de genêt, et déconcerte ainsi ceux qui la poursuivent. De toutes les fauvettes, la locustelle est la seule qui puisse marcher, privilége dont elle se sert avec avantage. Elle doit encore un moyen d'échapper à ceux qui la poursuivent à la particularité de mœurs qui l'a fait dénommer locustelle, " petite sauterelle. ) En effet, cette fauvette fait entendre un cri semblable à celui de la cigale ou de la sauterelle, locusta, et, comme cette dernière, elle continue ce bruit pendant très-longtemps. Les habitants des campagnes la désignent sous le nom de longue haleine, à cause de ce chant prolongé qui contribue à tromper le chasseur, en lui faisant confondre la locustelle avec les cigales. Enfin, elle niche plus tard que les autres fauvettes, et le plus souvent dans les plantes fourragères et dans les champs de haricots, ce qui rend presque toujours vaines les recherches des dénicheurs; car, lorsque le moment de pénétrer dans ces cultures est arrivé, les petits sont envolés. Son nid repose assez souvent à terre. Il est ormé d'herbes entrelacées, et garni intérieurement du 


\section{$-200-$}

luvet des plantes ou de paille très-fine et bien souple. Les cufs, au nombre de quatre ou cing, sont d'un gris rose quelquefois uniforme, émaillé le plus souvent de petits points de mème nuance, mais plus foncé; quelquelois ces points varient du jaunâtre au rougeâtre.

Le grand diamètre est de $0^{\mathrm{m}}, 016$ à $0^{\mathrm{m}}, 018$, et le petit de $0^{\mathrm{m}}, 012$ à $0^{\mathrm{m}}, 013$.

Ici se termine la première subdivision des fauvettes, admise par un certain nombre de naturalistes et désignie sous le nom commun de calamoherpes, peignant très-bien les habitudes générales de ces fauvettes. Cette dénomination dérive de kalamos, "roseau, herbe, " et Herpô, "ramper, glisser, grimper, " et signifie alor's viseaux qui "se glissent entre les roseaux, qui grimpent le long des tiges. " Cette dernière habitude est tout à fait caractéristique; car les calamoherpes non-seulement parcourent les roseaux dans tous les sens avec une grande agilité, mais encore ils effectuent ces évolutions en s'élerant de côté. Leur corps forme arec les roseaux un angle qui rarie de l'aigu au droit, selon que l'oiseau a besoin l'en modifier l'inclinaison, pour capturer sa proie ou pour se dérober à ses ennemis.

Les fauvettes comprises dans la deuxième subdivision portent le nom de mubiettes, parce que toutes les espèces groupées sous cette désignation ont quelque partie de leur plumage de couleur " rougeâtre. )

\section{FAUVETTE PIT-CHOU. - SYLVIA PROVINCIALIS.}

Le pit-chou doit, selon quelques auteurs, son nom aux petites dimensions de sa taille. D'après Buffon et plusieurs naturalistes, cette dínomination signifierait en provençal, " petit, menu. " Elle serait alors très-bien 


\section{$-201-$}

attribuée à un oiseau qui est l'un des plus petits de l'Europe. Des ornithologistes avaient pensé, au contraire, faire dériver ce nom d'une habitude de cette fauvette, habitude qui convient à beaucoup d'autres oiseaux. Le pitchou se plaît à parcourir les terrains plantés de choux, et visite les feuilles dans tous les sens pour y saisir les insectes qui s'y trouvent attachés. Dès-lors, il picote, non les choux, mais la proie qu'il poursuit. Dans la langue provençale, le verbe pita veut dire " ramasser, avec le hec, sa nourriture grain à grain. ") On dit d'un avare : c'est un " pite dardenne. " Dardenne est l'ancienne pièce de deux liards. L'avare est done un homme qui ramasse une à une les pièces de deux liards, comme un oiseau recueille son grain. Pit-chou signifierait done un passereau qui récolte sa nourriture " grain à grain, petit à petit, sur les choux. ")

Quelques écrivains avaient même soutenu que cette fauvette se cachait sous les feuilles des choux, pendant la nuit, afin d'éviterr les attaques des chauves-souris trèsfriandes de sa chair. Cette hypothèse ne peut être almise, par la raison que la chauve-souris, du moins celle de notre pays, ne vit pas d'oiseaux, mais d'insectes.

L'épithète provincialis indique que le pit-chou est très-multiplié dans la Provence, qui paraît être sa patrie. Cette fauvette se montre en Anjou, mais en petit nombre; quelques couples y sont même sédentaires et s'y reproduisent.

J'ai rencontré le pit-chou dans les taillis formés de brosses (chêne tauzin - quercus toza) plantés sur les bords de l'étang Saint-Nicolas. Le nid, placé dans les buissons à peu d'élévation de terre, est composé à l'extérieur de gramen, et garni à l'intérieur de crin ou de matière cotonneuse. Il renferme quatre ou cinq œufs, dont le fond de la coquille est d'un brun grisâtre, parsemé de points bruns ou d'un jaune sale et pâle, avec des taches 
eflicrées rougeatres, brunes ou rousses, formant quelquefinis par leur rapprochement une espèce de calotte. Les coufs peuvent facilement être confondus avec les petites variétís de la passerinette, ou même de la grisette. Leur grand diamètre est de $0^{\text {m }}, 016$ ì $0^{\mathrm{m}}, 018$, et le petit. de $0^{\mathrm{m}}, 012$ à $0^{\mathrm{m}}, 014$.

\section{FALVETTE ROLGE-GORGE. - SYLVIA RLBECILA.}

Cette fauvette, la plus répandue de toutes et la seule quui soit sédentaire en Anjou, est presque méprisée dans toutes les contrées qu'elle habite. Le nom populaire qui lui est donné dans plusieurs campagnes vient ajouter encore au ridicule attaché ì sa triste existence. On l'appelle la gadille. Cette dénomination cependant, comme le nom commun et le nom scientifique du rouge-yorge, est fondée sur le plastron "rouge » qui courre sa poitrine en remontant jusqu'à " la gorge. " En effet, d'après Ménage, gadille dérive de rubiadilla, rubjadilla, jadillu, gadilla; dès lors, la racine, dont la terminaison seule aurait prévalu, serait rubia, "rouge; ") ce qui expliquerait pourquoi gadille est synonyme de roupie. Belon dit qu'on appelle le rouge-gorge la roupie ou la gadille, parce qu'on voit cet oiseau venir aux villes et aux villages lorsque " les roupies » pendent au nez des personnes; ce qui signifierait que ces oiseaux voltigent même pendant les plus grands froids, qui font "rougir" le nez des villageois.

Le rouge-gorge vit de petits insectes et de vermisseaux (qu'il cherche dans les buissons. Peu défiant, il se laisse facilement approcher. Dans les pipées, il est ordinairement une des premières victimes qui viennent se prendre aux gluaux. Sa pose, ses manières, tout en lui semble dire à l'homme qu'il réclame une indulgence, hélas ! trop souvent refusée. Malgré l'ingratitude qui le poursuit sans 
cesse, le rouge-gorge reste ami de l'homme, et s'attache aux pas du bûcheron, dans les forêts solitaires. Par son chant plaintif, il paraît s'associer à ses labeur's, et, quand tout est mort autour de lui, cet oiseau est encore pour le bûcheron une image de la vie. Il vient becqueter le pain du travailleur, se poser sur l'instrument de ses fatigues, et semble lui demander à faire partie de la famille. Souvent aussi le villageois voit le rouge-gorge se percher sur l'arbre voisin de la chaumière, et égayer par son petit chant le repas du soir composé d'un pain trempé de sueurs. Il s'arrête longtemps sur le toit rustique, et continue son ramage jusqu'à ce que l'heure du repos ait sonné pour la famille fatiguée. Afin de s'identifier davantage encore à la vie de labeur des gens de la campagne, il est de tous les oiseaux celui qui se réveille et chante le plus tôt, qui s'endort et chante le plus tard. C'est à lui, et non au moineau, que doivent se rapporter ces paroles: Sicut passer solitarius in tecto. — "Comme le passereau solitaire sur les toits. " Dans la saison des frimats, le rouge-gorge se pose sur les maisons, sur les croisées et réclame l'hospitalité au foyer domestique. Si l'accueil fait à sa demande lui paraît favorable, ce passereau s'enhardit, s'arrête quelques instants sur la porte entreouverte, et pénètre à l'intérieur de la maison pour recueillir quelques miettes de pain; c'est un indigent qui a confiance dans la générosité de l'homme, et dont l'espérance ne devrait pas être trompée. Ce qu'il demande est si peu de chose! Son cri est si plaintif, sa confiance si naïve ! Puis lui-même est souvent si généreux, si hospitalier! Que de fois il couve l'œuf que la femelle du coucou a déposé dans son nid, et comme il entoure de soins celui qui doit le payer d'ingratitude !

Une vieille légende bretonne raconte que le rougegorge accompagna Jésus-Christ sur le Calvaire, chercha it le consoler par son chant, et détacha une épine de lis. 
couronne du divin Rédempteur pour aduncir, autant qu'il le pouvait, ses soufrances. Afin de récompenser sa courageuse sympathie, Dieu laissa, sur la poitrine du rouge-gorge, l'empreinte d'une goutle de son sang divin, et cet oiseau reçut alors la mission de s'attacher aux pas de ceux qui travaillent et qui souffrent, pour continuer ainsi son rôle d'ami et de consolateur.

Un poète malheureux a traduit dans quelques beaux vers la croyance naïse de la vieille Armorique; mais il lui a enlevé une partie de son doux parfum :

Lorsque de ses douleurs le blond fils de Marie Mourant réjouissait Sion et Samarie,

Ilérode, Pilate et l'enfer;

Son agonie émut d'une pitié profonde

Les angez dans le ciel, les femmes en ce monde,

Et les petits oiseaux dans l'air.

Et sur le Golgotha, noir de peuple infidèle, Quand les vautours, à grand bruit d'aile,

Flairant la mort, volaient en rond :

Sortant d'un bois en fleur au pied de la colline,

Une fauvette pèlerine

Pour consoler Jésus se posa sur son front.

Oubliant pour la eroix son doux nid sur la branche,

Elle chantait, pleurait et piétinait en vain,

Et de son bec pieux mordait l'épine-blanche,

Vermeille, hélas! du sang divin;

Et l'ironique diadème

Pesait plus douloureux au front du moribond, Et Jésus, souriant d'un sourire suprème, Dit i la fauvette : $\Lambda$ quoi bon?...

A quoi bon te rougir aux blessures divines?

Aux clous du saint gibet, à quoi bon t'écorcher?

Il est, petit oiseau, des maux et des épines

Que du front et du cœur on ne peut arracher.

La tempête qui m'environne

Jette au vent ta plume et ta voix,

Et ton stérile eflort au poids de ma couronne,

Sans mème l'effeuiller, ajoute un nouveau poids. 


\section{$-205-$}

La fauvette comprit, et, déployant son aile,

Au perchoir épineux déchirée à moitié,

Dans son nid que bercait la branche maternelle

Courut ensevelir ses chants et sa pitié.

Bien des fois aussi le rouge-gorge s'est empressé de venir au secours des voyageurs égarés dans les forêts. Quand le jour disparaît et que le chasseur ou le pèlerin ne savent plus quels sentiers suivre pour regagner leurs demeures, le rouge-gorge voltige autour d'eux, dissipe leurs préoccupations et leur tristesse par son chant sympathique, et, en les précédant, leur indique la route qu'il a si souvent parcourue lorsqu'il accompagnait chaque fois le bûcheron fatigué regagnant le foyer domestique. 0 rouge-gorge, si justement nommé la fauvette du Cialvaire, continue ta noble mission et sois béni des hommes comme tu l'as été par un Dieu mourant!

Le nid du rouge-gorge est le plus souvent posé à terre dans les trous des vieux murs. Il est composé presque toujours d'un lit de feuilles desséchées sur lequel repose une espèce de coupe aplatie formée de mousse, de bourre et de crins entrelacés. Il contient de cinq à six œufs dont la grosseur, la forme et les couleurs varient beaucoup. Souvent ils sont d'un roux uniforme parsemé de points imperceptibles et de couleur de brique. Quelques-uns portent sur un fond d'un blanc sale de larges taches roussâtres réunies en plus grand nornbre vers le gros bout. D'autres sont d'un blanc mat strié de points noiratres formant une couronne, et ressemblent à de petits œufs de la pie-grièche écorcheur.

Le rouge-gorge élève ses petits avec une tendresse remarquable; le mâle partage avec la femelle le soin de l'incubation. Les membres d'une famille malheureuse ne doivent-ils pas s'entr'aider ?

Le grand diamètre des œufs est de $0^{\mathrm{m}}, 017$ à $0^{\mathrm{m}}, 020$, et le petit de $0^{\mathrm{m}}, 014$ à $0^{\mathrm{m}}, 016$. 
FAUVETTE GORGE-BLEUE. - SYLVIA SUECICA.

Cet oiseau, l'un des plus brillants de l'Europe, rappelle par ses couleurs vives et nuancées ceux des tropiques. Il doit son nom au magnifique bleu azuré qui couvre sa poitrine et sa gorge. Ce plastron se développe avec l'âge de l'oiseau, et encadre une tache d'un blanc pur et éclatant. Une bande d'un noir mat règne au-dessous du bleu, et lait encore ressortir d'une manière plus sensible les autres couleurs.

L'épithète suecica, "suidoise, " indique que cette lauvette est très-commune en Suède. Quelques naturalistes ont distingué deux espèces de gorge-bleue, l'une nommée suecica, et l'autre cyanecula, le cyaneus, "bleu cúleste. ") Selon l'opinion la plus probable, ce sont deux variétés de la même espèce, et dont les légères différences peuvent dépendre du climat habité par cette fauvette.

La gorge-bleue se reproduit, chaque année, en Injou. On la trouve dans les osiers et dans les arbustes qui croissent sur le bord des rivières; principalement au-dessus et au-dessous des Ponis-de-Cé, dans les oseraies qui bordent la Loire, et dans les marais de la Baumette. Elle - est difficile à trouver, parce que, se taisant la plus grande partie de la journée, elle se trahit dès lors très-rarement jar son chant. Puis elle reste à terre dans les grandes herbes ou dans les fourrés. Son nid composé, en dehor's, d'herbes sèches, de mousse et de racines déliées, est revêtu, en dedans, d'une couche de foin, de crin et de plumes. Ordinairement il est placé à terre, caché sous des racines, des branches d'osier ou des touffes d'herle. Ouelquefois, comme celui du rouge-gorge, il est confić i des excavations pratiquées dans la terre ou dans les fentes des trones des vieux arbres. Les œufs, au nombre de quatre à six, sont d'un bleu verditre, reflétant quel- 
quefois plusieurs nuances. Ils ressemblent assez à ceux du rossignol; mais ils sont plus petits et presque toujours pointus des deux bouts. Leur longueur varie de $0^{\mathrm{m}}, 016$ à $0^{\mathrm{m}}, 018$, et leur diamètre de $0^{\mathrm{m}}, 013 \mathrm{à} 0^{\mathrm{m}}, 017$.

\section{FAUVETTE ROUGE-QUEUE. — SYLYIA TITHYS.}

Cette fauvette ne fait qu'apparaître dans notre département. Elle y séjourne seulement quelques jours à l'époque de ses migrations; et encore ce passage n'a lieu que d'une manière irrégulière. Elle doit son nom vulgaire à la couleur des plumes de sa queue.

Quant à celui de tithys, je le crois assez récent et mal formé, soit du mot Trтz qui servait à désigner un petit oiseau chez les Grees, et dérivé lui-même de trтzzô, " pépier, piailler," soit de son cri tui-tui. Cette dénomination, qui convient bien à cette fauvette, la distingue aussi naturellement de ses congénères, puisqu'elle n'a ni chant ni ramage proprement dit, mais seulement un petit son flûté, composé de notes aiguës et empreintes d'un sentiment de tristesse, en rapport avec les lieux solitaires qu'elle habite.

La rouge-queue se plaît dans les terrains rocailleux dont elle visite toutes les sinuosités pour y saisir les insectes; elle parcourt aussi les bords des torrents et les terres nouvellement labourées, où elle se nourrit de vermisseaux.

Cette fauvette fait son nid dans les fentes des rochers, entre les pierres tombées des montagnes, et assez souvent sous les hangar's isolés des habitations. Composé extérieurement de feuilles desséchées ou de mousse, il est revêtu à l'intérieur de plumes, de crin ou d'autres matières molles et flexibles. Il contient de quatre à six œufs d'un blanc pur et lustré : ces œufs se rapprochent 
de ceux du torcol; mais on les distingue assez facilement de ces derniers, parce que ceux de la sylvia tithỵs sont légèrement piriformes, tandis que ceux du torcol sont presque toujours oblongs.

M. l'abbé Caire, ornithologiste éclairé et persévérant, a découvert une nouvelle espèce de fauvette tithys. La femelle ressemble à celle dont je viens de parler; mais le mâle adulte est très-différent de celui qui se montre en Anjou. Ciette faurette a reçu le nom de celui qui l'a découverte, et elle est connue sous le nom de sylvia on ruticella Carii. Les wufs de cette seconde espèce sont également d'un blane pur, mais un peu moins gros et plus ronds que ceux de la sylvia tithys. Quelques-uns sont pointillés de taches d'un brun roux.

Le grand diamètre des œuf's de la première espèce varie de $0^{\mathrm{m}}, 017$ à $0^{\mathrm{m}}, 019$, et le petit de $0^{\mathrm{m}}, 012$ ì $0^{\mathrm{mm}}, 014$.

\section{FALVETE IEE MIRALLL. - SYLVIA PHIANICIRA.}

Ce passereau, très-commun en Anjou, est désigné sous plusieurs noms, selon les habitudes que l'on considère en lui. On le nomme rossignol de murcille, parce qu'il se plait à percher sur les ruines ou sur les toits, où il fait entendre son chant très-accentué, agréable, mais mélancolique. Puis il se rapproche du rossignol, en ce que, comme lui, il ne chante que le soir et le matin. Mais il s'en éloigne, en ce qu'il se place dans des lieux élevés pour redire ses accents, tandis que son congínère, se dérobant le plus possible aux regards, recherche les endroits bas et futrrés. La fauvette de murailles est encore appelée hoche-queue, à cause du mourement qu'elle imprime, de droite à gauche, aux pennes de sa queue. Quant ì sa dénomination la plus ordinaire, elle lui a été donnée parce que cet oiseau 
aime à établir son nid dans les trous et dans les crevasses des vieux murs; enfin son nom de cul-rouge est fondé sur les nuances de sa queue, et l'épithète phonicura retrace la même idée, puisqu'elle vient de pHoïs-

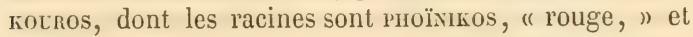
OURA, "queue. "

Cette fauvette, remarquable par la vivacité de ses mouvements, est très-répandue dans notre département et dans toute l'Europe. Elle fait son nid dans les trous des murailles ou des arbres fruitiers. Ce nid prend, dès lors, toutes les formes de l'endroit auquel il est confié, et devient tour à tour oblong, carré, triangulaire, petit ou grand, selon les dimensions des excavations qui le contiennent. Quelques-uns ont des proportions trèsconsidérables; ils sont composés de mousse, de plumes et de crin. Peu de nids offrent aux petits une couche plus molle et plus chaude. La ponte varie de quatre à six œufs d'un bleu brillant et d'un diamètre moins considérable ordinairement que celui des œufs de l'accenteur mouchet, avec lesquels ils pourraient être confondus assez facilement; cependant ces derniers sont moins allongés que ceux de la fauvette de muraille et d'une couleur plus terne.

Le grand diamètre est de $0^{\mathrm{m}}, 017 \mathrm{à} 0^{\mathrm{m}}, 020$, et le petit de $0^{\mathrm{m}}, 012$ à $0^{\mathrm{m}}, 014$.

\section{FAUVETTE ROSSIGNOL. - SYLVIA LUSCINIA.}

Le rossignol est de tous les oiseaux connus celui dont le chant est le plus varié, le plus harmonieux et le plus étendu. A lui seul il réunit toutes les ressources et toutes les beautés de la voix des autres oiseaux chanteurs. Son nom français rossignol a été formé par corruption du latin lusciniana, mot qui dérive de luscinus, employé par Plaute pour désigner cette fauvette. Luscinius ou luscinia 
est formé de lux, lucis, "jour, " on de lucus, luce, "bois, " et de canere, cecini, " chanter, " et signifie alors : " oiseau qui chante au point du jour ou dans les bois, qui canit sub lucem ou in lucis. "Le rossignol parait en effet se complaire dans son chant et fuir tout ce qui pourrait en diminuer l'éclat. C'est pour cela qu'il ne se fait entendre que le matin et le soir, lorsque tout se tait autour de lui, et qu'il peut régner en maître absolu. Il aime aussi à chanter dans les bois les plus sombres et les plus solitaires, évitant tout ce qui pourrait le distraire, tout bruit qui enlèverait à sa voix quelıue chose de son incomparable beauté. Cependant, dès que les petits du rossignol sont élevés, son chant si simple, si harmonieux, si étendu et si souvent admiré, est remplacé par un son rauque assez semblable au coassement du crapaud.

Cet oiseau vient chaque année se reproduire en Anjou. Il établit son nid à terre ou près de terre, dans les fourrés et dans les taillis les plus épais, au milieu des haies touffues, sur la pente des fossés ombragés. Ce nid, régulièrement composé de feuilles desséchées, est assez profond et pénètre en terre dans un petit creux de quelques centimètres, préparé par le rossignol pour donner plus de solidité à son travail. L'intérieur est garni de feuilles plus délicates que celles de l'enveloppe, de petites racines et de crin. Les œufs, au nombre de quatre à cinq, sont d'un brun uniforme avec quelques reflets verdâtres ou d'un brun olivâtre. La femelle seule est chargée des soins de l'incubation, et malgré la sollicitude qu'elle manifeste pour cette opération, elle abandonne son nid dès que le coucou y a déposé un œuf.

Le grand diamètre est de $0^{\mathrm{m}}, 018$ à $0^{\mathrm{m}}, 020$, et le petit de $0^{\mathrm{m}}, 013$ ì $0^{\mathrm{m}}, 01 \%$. 


\section{$-211-$}

FALVETTE PHILOMELE. - SYLVIA PHILOMELA.

La fauvette philomèle se rapproche beaucoup du rossignol; ses habitudes sont les mêmes; elle en diffère cependant par la nuance plus foncée de son plumage et par sa taille plus forte. En liberté, on la reconnaît facilement à sa voix plus vibrante encore que celle de sa congénère, et surtout à ses roulades beaucoup plus prolongées.

Son nom de philomèle, de Prilos, "ami, 》 et Mècos, " chant, " rappelle l'histoire de la fille de Pandion, roi d'Athènes. Cette malheureuse princesse ayant subi d'indignes traitements de la part de son beau-frère Térée, chercha à s'en venger. Ne pouvant dévoiler de vive voix ses infortunes, puisqu'on lui avait coupé la langue, elle retraça au fond de sa prison, sur une toile, tout ce qu'elle avait souffert. Cette toile fut envoyée à sa sœur Progné, qui, à la tête d'une troupe de Bacchantes, délivra Philomèle. Puis, par un mouvement de délire incompréhensible, Progné immole son propre fils, et, dans un grand festin, elle en sert les membres à son époux; à la fin du repas, la mère coupable jette sur la table la tête du jeune Itys, et lorsque son mari se jette sur elle pour assouvir sa fureur, il se trouve changé en épervier, Progné en hirondelle, ltys en faisan, et Philomèle en la fauvette qui porte son nom. Les habitudes de ce passereau, son éloignement pour la société des autres oiseaux et surtout pour celle de l'homme, la mélancolie de son chant semblaient, chez les païens, justifier ce récit de la mythologie. Depuis cette métamorphose, l'épervier poursuit inutilement l'hirondelle, et Philomèle échappe aussi à ses serres par l'obscurité et la solitude des lieux qu'elle habite.

Suivant l'opinion qui me semble la plus probable, 
j'admets que la fauvette philomèle se reproduit en Anjou. Son nid ressemble à celui du rossignol; ses œufs ne diffèrent de ceux de la précédente que par des dimensions un peu plus fortes et par une nuance assez souvent plus sombre. Le grand diamètre de ces œufs est de $0^{\mathrm{m}}, 020$ à $0^{\mathrm{m}}, 022$; le petit, de $0^{\mathrm{m}}, 014 \mathrm{à} 0^{\mathrm{m}}, 016$.

Ici se termine la section des rubiettes. Pour compléter la nomenclature des fauvettes, il ne reste plus qu’à parcourir la subdivision comprenant les fauvettes proprement dites.

\section{FAUVETTE ORPHÉE. - SYLVIA ORPHEA.}

Si le nom de la fauvette philomèle rappelle le souvenir de crimes atroces, celui de l'orphée ne rappelle du moins à notre esprit que les aventures d'un époux malheureux. Orphée, fils d'Apollon et de Clio, jouait admirablement de la lyre. Son épouse Eurydice, ayant été piquée par une vipère, le jour de ses noces, descendit dans le sombre séjour de Pluton. Orphée résolut d'arracher aus enfers celle qu'il aimait tendrement. La puissance de sa lyre triompha de tous les obstacles; les lois immuables de la mort furent suspendues par l'harmonie du fils d'Apollon, et Eurydice lui fut rendue. Malheureusement une condition était imposée : Orphée devait précéder Eurydice, et ne la regarder que lorsqu'il serait sorti des noirs abîmes. Déjà il franchissait le seuil de cet empire ténébreux, lorsque, cédant ì un désir bien naturel, il se retourne, voit Eurydice qui disparait et lui est enlevée pour toujours. Inconsolable de cette perte, Orphie fuit la société des hommes, et cherche dans les accents de sa lyre un soulagement ì sa douleur. Les forêts, les montagnes, les animaux se montrèrent sensibles aux charmes de son harmonie; mais elle ne put calmer le ressenti- 
timent des femmes, dont Orphée avait repoussé l'union depuis la mort d'Eurydice. Le malheureux chantre fut massacré par les Bacchantes en fureur, et sa tête, jetée dans l'Hèbre, murmurait encore le nom d'Eurydice.

Tum quoque, marmorea caput a cervice revulsum Gurgite quum medio portans Eagrius Hebrus Volveret, Eurydicen vox ipsa et frigida lingua, $\mathrm{Ah}$ ! miseram Eurydicen ! anima fugiente, vocabat, Eurydicen toto referebant flumine ripæ ${ }^{1}$.

L'Èbre roula sa tête encor toute sanglante :

Là, sa langue glacée et sa voix expirante, Jusqu'au dernier soupir formant un faible son, D'Eurydice, en flottant, murmurait le doux nom : Eurydice, ô douleur! Touchés de son supplice, Les échos répétaient : Eurydice ! Eurydice !

\section{DELILLe.}

Tel est le sommaire de la vie mythologique de celui auquel l'ornithologie a emprunté le nom qu'elle donne ì l'une des plus gracieuses fauvettes. L'orphée ressemble ì la fauvette à tête noire, ce qui l'a fait surnommer la grosse tête noire. Elle en diffère essentiellement par ses dimensions, qui sont plus fortes même que celles du rossignol. Son chant est puissant et doux, mais moins étendu que celui des deux espèces précédentes. Il respire la mélancolie et la tristesse, et fournit à cet oiseau un moyen d'échapper à la poursuite des chasseurs. L'orphée jouit de la faculté de modifier son ramage, de telle sorte que, lorsqu'on est près d'elle, son chant paraît venir de bien loin ou d'un côté tout opposé à celui qu'elle occupe. Ceux qui se guident sur ce renseignement pour capturer l'orphée se trompent toujours, et, dans cette circonstance encore, la voix de cet oiseau semble venir des entrailles de la terre ou se perdre dans ses profondeurs:

${ }^{1}$ Virgile, Géorgiques, l. IV, v. 524 et suivants. 
rapport qui n'a pas dù échapper à ceux qui ont uni par le même nom la fauvette et l'époux infortuné.

Non-seulement l'orphée traverse notre département chaque année, mais elle s'y arrête quelquefois pour s'y reproduire. Cette année, j’ai reçu de Charcé, par l'entremise de $\mathrm{Al}^{\text {He }}$ Chauveau, institutrice, un très-beau nid d'orphée, contenant cinq œufs. Ce nid, très-gros, est composé à l'extérieur de gramen, de paille et de racines, et de crin à l'intérieur. Les wufs, d'un blanc sale, sont parsemés de taches brunes ou d'un cendré jaunâtre; le centre des taches est d'une couleur plus foncée que sur lę bords, où elle semble se confondre avec les nuances de la coquille. Le nid de l'orphée est placé ordinairement sur les arbustes ou dans les haies et les buissons épais. Ses œufs mesurent, par le grand diamètre, de $0^{\mathrm{m}}, 017$ à $0^{\mathrm{m}}, 019$, et par le petit, de $0^{\mathrm{m}}, 013$ à $0^{\mathrm{m}}, 01 \%$.

\section{FATVETE A TETE NOIRE. - SILVIA ATRICAPILLA.}

Cette faurette, l'une des plus communes en Europe, doit son nom au noir profond répandu sur le dessus de sa tête. Peu craintive, elle vient animer de son chant et de son vol non-seulement les campagnes, mais encore les jardins des villes. Elle dissimule peu l'endroit qu'elle a choisi pour y construire son nid. Elle l'ítablit dans les haies, sur les bords des chemins, dans les groseilliers, les rosiers et les autres arbustes. Il est composé à l'extérieur de gramen, et garni à l'intérieur de quelques brins de crin. Arrondi en forme de coupe, il est très-peu ćpais et ordinairement transparent. Les œufs qu'il contient, au nombre de quatre à cinq, varient beaucoup en grosscur et en couleur. Régulièrement ils ont des dimensions fortes, si on les compare à la taille de l'oiseau. Les uns, presque arrondis, ont le fond de la coquille d'un blane 
sale ou roussâtre parsemé de taches brunes dont le centre est plus foncé que les bords; d'autres ont une couleur rougeâtre pointillée de noir. Quelques-uns paraissent recouverts de deux couches uniformes d'un jaune pâle et effacé, dont la seconde semble plus épaisse que la première. Enfin, on en trouve qui sont entièrement blanes. Pour cette fauvette, comme pour les autres oiseaux, cette grande variété dans les couleurs des œufs me semble provenir non-seulement de la différence d'âge des femelles, et des lieux qu'elles habitent, mais surtout de la nourriture qu'elles trouvent. En effet, les couvées successives des mêmes oiseaux présentant une grande variété de nuances dans les œufs, ce changement me semble ne pouvoir être attribué qu'à la nourriture, qui varie avec le cours de l'année.

Quelquefois il est très-difficile de distinguer les œufs de la fauvette à tête noire de ceux de la fauvette des jardins, si ce n'est par la petite différence qui existe dans leurs dimensions. Les œufs de la première sont ordinairement un peu moins longs et moins blanchâtres que ceux de la seconde.

La fauvette à tête noire fait chaque année plusieurs couvées. Elle rivalise avec le rossignol pour la fraîcheur et l'harmonie de son chant; mais s'il est aussi doux et aussi flexible, il est moins étendu. Le mâle partage avec la femelle les soucis de l'incubation; il prodigue à ses petits les soins les plus tendres, et, quand ils sont menacés par un ennemi, il cherche à l'éloigner des objets de son amour en feignant d'être blessé et de traîner l'aile. Puis, quand il pense avoir écarté le danger par cette ruse innocente, il s'envole et revient auprès de ses petits par une route détournée.

Grand diamètre des œufs de $0^{\mathrm{m}}, 017$ à $0^{\mathrm{m}}, 020$; petit, de $0^{\mathrm{m}}, 012$ à $0^{\mathrm{m}}, 014$. 
FAIVITTE DES JARIINS. - SHLWI HORTENSIS.

Cette fauvette aime à séjourner dans les jardins, hortus, horti, à y chercher sa nourriture, à s'y reproduire, habitudes qui justifient son nom. Le nid de la fauvette des jardins, composé à l'extérieur de paille et de brins d'herbe, et garni de crin à l'intérieur, se trouve ordinairement dans les massifs et dans les haies des jardins. Le crin, employé par la plupart des petits oiseaux dans la contexture de leurs nids, me paraît fournir une nouvelle preuve de l'instinct admirable que Dieu leur a donné, dans sa tendre sollicitude pour tous les êtres de la création. Cette matière, tout à la fois chaude et flexible, se trouve facilement partout; par son élasticité, elle se prête à tous les mouvements de la couveuse; avec le secour's de cette garniture intérieure, le nid se développe selon l'âge des petits qu'il renferme, reçoit et conserve cependant toujours la forme ronde, la plus commode et la plus favorable pour l'incubation.

Le nid de la fauvette des jardins contient ordinairement quatre ou cinq œufs. La coquille en est d'un blane jaunâtre parsemé de taches brunes, dont le milieu est. d'une nuance plus foncée, tandis que celle des bords semble presque effacée.

Cette fauvette recherche encore les lieux ombragés et. voisins des petits cours d'eau. Elle aime à nicher près de ses congénères, avec lesquelles elle vit en bonne harmonie. Son chant, varié et coulant, est moins éclatant que celui de la fauvette à tête noire.

Le grand diamètre de ses œufs est de $0^{\mathrm{m}}, 018$ à $0^{\mathrm{m}}, 020$, et le petit de $0^{\mathrm{m}}, 013$ à $0^{\mathrm{m}}, 014$.

FAUVETTE GRISETTE. - SYLVIA CINEREA.

La couleur cendrée de cette fiturette lui a peut-etre fail donner son nom vulgaire et son nom scientifigue. 
Et cette hypothèse me paraît d'autant plus probable, que IIénage, Pierroni, Roquefort prétendent que le mot gris, représenté dans la basse latinité par les expressions griseus, grisius, dérive, selon ces auteurs, du latin cinereus, "de couleur de cendre," ou de varius, "petitgris. " On appelle ainsi une espèce de fourrure, parce que la peau qui la compose est de couleur grise, c'est-àdire variée de différentes nuances. Cet oiseau se trouve en très-grand nombre dans toute l'Europe. Il ne paraît nullement redouter le voisinage de l'homme. Son chant moins agréable que celui de la plupart de ses congénères, plaît cependant par son excessive volubilité. Plus élancée dans ses formes qu'un certain nombre d'autres fauvettes, la grisette est aussi plus vive dans ses mouvements. Elle est sans cesse en activité; on la voit tour à tour voltiger de branche en branche ou courir de buisson en buisson, voler en pirouettant au-dessus des haies, pour y pénétrer ensuite avec agilité, et se livrer à toute sorte d'ébats qui scmblent indiquer un caractère léger et folâtre. La gaieté de la grisette, l'étourderie de ses mouvements, son chant saccadé, cette espèce de joyeuse folie qu'elle manifeste dans l'ensemble de ses habitudes, ne pourraient-ils pas faire supposer à son nom l'étymologie qui a été donnée à l'épithète grive?

La fauvette grisette fait deux, trois et même quatre couvées par an. Son nid, grossièrement façonné, est composé de petits brins de gramen et de paille; l'intérieur est quelquefois garni de flocons de laine ou du coton des plantes. Il est placé le plus souvent dans les haies peu élevées, sur le bord des routes, ou confié aux ronces qui s'étendent sur les fossés. Les œufs, au nombre de quatre ou cinq, varient beancoup en dimensions et en couleurs. Les uns sont d'un blanc sale et verdâtre parsemé de petits points ou de larges taches noirâtres toujours plus nombreuses vers le gros bout. D'autres sont 


\section{$-218$.}

tout ronds ou très-allongés. On en trouve dont la coquille, d'un blane de lait, porte vers le gros bout une courunne de petits points grisitres. Enfin, quelques-uns revetent la couleur jaunatre avec des taches brunes. Malheureusement cette grande variété donne lieu à des erreurs involontaires ou à des fraudes calculées. Beaucoup d'cuifs de la fauvette grisette circulent dans les collections et chez les marchands comme appartenant au pit-chou, à l'aquatique ou même à la passerinette.

Le grand diamètre est de $0^{\mathrm{m}}, 01: \mathrm{j}^{\mathrm{a}}$ à $0^{\mathrm{m}}, 018$, et le petit de $0^{\mathrm{m}}, 011$ à $0^{\mathrm{m}}, 014$.

\section{FAUVETTE BABILLARDE. - SYLVIA CURRUCA.}

La fauvette babillarde doit son nom à son chant peu ítendu et sans cesse répété. Cet oiseau aime les taillis et les endroits fourrés. Sans cesse en mouvement, comme les mésanges et les pouillots, il poursuit et recherche dans ses chasses continuelles les insectes et les petites mouches qu'il rencontre sur les branches ou qu'il saisit au vol. Comme la fauvette grisette, il s'élève au-dessus des buissons en tournant sur lui-même, pour y pénétrer ensuite avec la rapidité de la flèche. Dans ses évolutions, il retrace les ruses et les habitudes de l'épervier poursuivant sa proie. La babillarde enfle les plumes de sa gorge et de sa tête toutes les fois qu'elle reprend son chant monotone; cette habitude lui donne un air d'importance qui ne sied guère à sa petite taille.

L'épithète curruca, par laquelle elle est désignée dans presque tous les ouvrages dornithologie, est un mot qui n'a jamais été employé que par Juvénal, dans sa satire vi". Le sens qu'il a attaché à curruca ne peut convenir à la fauvette babillarde que parce que cette sylvie, par ses habitudes, a paru couver, avec plus de facilité encore que ses congénères, l'cuf que le coucou aime à déposer sou- 
vent dans son nid. La femelle semble alors, par une indifférence coupable, imposer au mâle la pénible fonction de pourvoir à la nourriture et à l'éducation d'un petit qui ne devrait pas faire partie de la famille.

Quelques auteurs, d'après Forcellini, pensent que curruca n'est autre chose qu'urruca. Ce mot signifierait alors "l'oiseau qui vit dans les parties inférieures des buissons et des orties, " ou plutôt encore "l'oiseau le plus infime du genre, ") ce qui rentrerait dans la pensée de Juvénal, qui est une idée de mépris. Les différentes acceptions des épithètes curruca et urruca peuvent se justifier par les habitudes de la babillarde. Elle se tient dans les taillis les plus sombres. On dirait une coupable fuyant la lumière.

Ce passereau, dont la présence a été signalée en Anjou, niche dans les buissons, dans les taillis ou sur les branches peu élevées des arbres. Son nid, compasé à l'extérieur d'herbe ou de paille desséchée, est garni à l'intérieur de crin ou de plantes molles. Il contient quatre ou cinq œufs de couleur blanche, légèrement jaunâtre, parsemés, surtout vers le gros bout, de taches rousses ou olivâtres dont le centre est beaucoup plus foncé que les bords. Ils reproduisent assez bien les nuances et la forme des œufs de la fauvette orphée; mais ils sont d'une dimension beaucoup plus petite. Leur grand diamètre est de $0^{\mathrm{m}}, 014$ à $0^{\mathrm{m}}, 016$, et le petit de $0^{\mathrm{m}}, 011$ à $0^{\mathrm{m}}, 013$.

FAUVETTE A POITRINE JALNE. - SILVIA IIPPOLAIS, OU PLUTÔT HYPOLAIS.

Augustin Niphus, cité par Aldrovande 1, prétend que cette fauvette a été nommée hippolais du mot urpus, "cheval, " parce qu'elle fait son nid dans l'œil d'un

${ }^{1}$ Liv. XVII, ch. XxxIv. 
cheval mort. Une pareille itymologie, comme le savant Bolonais le fait remarquer, est ridicule, indigne d'un homme docte, et provient de l'ignorance du grec. Il faut écrire, en effet, non hippolaïs, mais hypolais, de urpoläis ou ÉplLaïs (Aristote), dont les racines, suivant les meilleurs dictionnaires, sont HYPO, "sous, " EPI, "sur, " xas, LAAS, LaOS, LaEs, "rochers. " Ce mot indique non, d'après l'interprétation fournie par certains lexiques, que cet oiseau se tient "sous" ou "parmi les pierres et les rochers, " mais qu'il cherche " sous") ou "parmi les pierres " les insectes et les vermisseaux qui lui servent de nourriture. L'hypolaïs imite la voix, le chant, le cri de rappel de tous les oiseaux qui sont dans son roisinage, depuis la rousserole des marais jusqu'à l'hirondelle des cheminées, et depuis la pie-grièche jusqu'au moineau. Cette facilité excessive l'a fait surnommer généralement fauvette polyglotte, de poLys, "plusieurs, " et GLôtra, "langue, - oiseau qui fait entendre plusieurs chants, qui parle en quelque sorte plusieurs langues. ") En m'appuyant sur cette dernière étymologie et sur les habitudes de cette fauvette, j'avais pensé que le mot нYpolä̈s pouvait dériver de HYPo, "sens dessus dessous, " et de calis, pour lalos, "babillard, " et signifier alors fauvette "babillant ì tort et it traver's," comme il est très-facile de le constater pendant le temps de son séjour dans notre département. Mais, en me conformant davantage aux lois de l'étymolugie, je m'arrête à la première, comme à la seule véritable.

L'hypolaïs se reproduit, chaque année, en Anjou; elle recherche ordinairement les buissons touffus et les haies impénétrables pour y établir son nid. Lì, selon la méthode des rousseroles, elle réunit plusieurs branches d'aubépine, de ronce ou d'arbustes par des brins de paille ou d'herbes sèches et déliées. Elle continue ensuite son travail en dionnant a son nid une grande pro- 
fondeur. L'intérieur est garni de crin, de laine, du coton des saules et d'autres matières souples et molles. L'extérieur, assujetti par les bords à ces petites branches, est composé de plantes entrelacées avec art. La femelle y dépose quatre ou cinq œufs très-jolis, surtout lorsqu'ils sont nouvellement pondus. Leur couleur est d'un rouge lilas, ou violeté et parsemé de raies et de taches noires ou rougeâtres. Leur longueur est de $0^{\mathrm{m}}, 016$ à $0^{\mathrm{m}}, 0.99$, et leur diamètre de $0^{\mathrm{m}}, 012$ à $0^{\mathrm{m}}, 013$.

Les naturalistes ont fait un genre hypolaïs, qui comprend plusieurs espèces. L'une d'elles, l'ictérine, de ІктÉRos, " jaunisse, " me paraît venir chaque année dans notre département. Elle est d'autant plus facile à confondre avec la fauvette à poitrine jaune, qu'elle a les mêmes nuances de plumage, les mêmes habitudes que celle-ci. Les nids et les œufs des deux espèces se ressemblent entièrement. L'ictérine diffère de l'hypolaïs proprement dite par des proportions un peu plus grandes, par un bec plus court, des ailes plus longues et une queue un peu plus fourchue au centre.

Malheureusement ces fauvettes, ainsi que la plupart des oiseaux qui ne visitent l'Anjou que pour s'y reproduire, arrivent dans un temps où la chasse est interdite, pour nous quitter vers l'époque où elle est ouverte. Dès lors, il est difficile de pouvoir étudier ces oiseaux; d'autant plus que presque tous ceux qui restent plus longtemps parmi nous perdent leur voix après la nidification, et échappent à toutes les recherches en ne trahissant plus leur présence par leur chant.

Je pense que les fauvettes mélanocéphale, à lunettes, passerinette, passent chaque année dans notre département, et que même elles s'y reproduisent. Cette hypothèse devient presque une certitude, si l'on admet comme exactes les descriptions des nids et des œufs de ces oiseaux, faites par MMI. Dégland, Bailly et Crespon. 
Pour faciliter aux ornithologistes de notre Anjou la vérification de mon assertion, je vais donner quelques détails sur ces trois fauvettes et sur leur mode de nidification.

FAUYETTE MELANOCEPHALE. - SYLVLA MLLANOCEPIILLA.

Les épithètes données à cet oiseau, en latin et en français, ont la même étymologie; toutes les deux elles dérivent du gree MÉLLAs, " noire, " et KÉPIIAL̀̀, " tête, " et signifient "fauvette à tête noire. " La melanocéphale ressemble beaucoup à la sylvia atricapilla, faurette ì tête noire; ses dimensions sont inférieures à celles de sa congénère, de cinq millimètres seulement. La couleur rougeatre qui entoure ses yeux est le signe le plus caractéristique qui la sépare des autres sylvies. Elle vit et niche comme la fauvette à tête noire, et peut être ainsi facilement confondue avec cette dernière. Ses œufs, au nombre de quatre à cinq, ont $0^{\mathrm{m}}, 018$ ou $0^{\mathrm{m}}, 019$ de longueur, et $0^{\mathrm{m}}, 013$ ou $0^{\mathrm{m}}, 017$ de diamètre. D'après II. Crespon, ils sont d'une couleur blanchâtre, et parsemés de points noirâtres, en forme de couronne, vers le gros bout. Selon M. Dégland, leur teinte est d'un gris roussâtre, moucheté de petits points fauves ou d'un roux olivâtre, plus rapprochés au gros bout et peu sensibles. Cette différence peut s'expliquer par les variétés qui ont été communiquées à ces naturalistes. Quoi qu'il en soit, l'on trouve en Anjou des types se rapportant exactement aux œufs décrits par ces deux auteurs.

\section{FAIVETTE A LINETTES. - SYLVLA CONSPICILLATA.}

Cette jolie petite sylvie, dont les différents noms ont la mème signification, se distingue de la fauvette grisette par les plumes noires qu'elle porte en forine de lunettes 
autour du cercle blanc de ses yeux, par des couleurs plus pures et plus vives, et par des dimensions plus petites. Elle a ordinairement trois centimètres de moins que sa congénère, à laquelle elle ressemble par l'ensemble de ses habitudes et par son genre de nourriture. La fauvette à lunettes fait son nid avec les mêmes matériaux que la grisette; il renferme ordinairement quatre ou cinq œufs dont la longueur varie de $0^{\mathrm{m}}, 014 \mathrm{à} 0^{\mathrm{m}}, 016$, et le diamètre de $0^{\mathrm{m}}, 011$ à $0^{\mathrm{m}}, 012$. La coquille de ces œufs est blanchâtre, ou d'un blanc teint de grisaire, avec de nombreux points ou de petites taches brunes ou verdâtres, formant quelquefois une espèce de calotte vers le gros bout.

\section{FAUVETTE PASSERINETTE. - SILVIA PASSERINA.}

Le nom donné à cette fauvette est un diminutif du mot passer, " moineau, " et indique que la couleur d'une partie de son plumage se rapporte par ses nuances à celui du moineau. Le male a toutes les parties supérieures d'un cendré couleur de plomb, inclinant au bleu, et toutes les parties inférieures en général d'un roux de brique avec une légère teinte de violet. Le ventre et l'abdomen sont blanchatres; deux petits traits blancs, en forme de moustaches, partent de la base du bec et descendent de chaque côté du cou: enfin, la queue est noirâtre.

La longueur de la passerinette est de 13 centimètres. La femelle a le dessus du corps d'un cendré clair, avec une très-légère teinte olivâtre; les parties inférieures sont d'un gris roussâtre clair ou jaunâtre, le ventre blanchâtre tirant un peu au roux. La bande blanche près du bec est peu apparente.

La passerinette habite de préférence les localités montueuses couvertes de broussailles et d'arbustes. Elle 
aime beaucoup les fruits sucrés. Elle a aussi les mêmes habitudes que la grisette; elle construit, avec les mêmes matériaux et dans les mèmes endroits, un nid en forme de coupe, contenant quatre ou cinq œufs. Ceux-ci sont blanchâtres ou d'un blanc inclinant au verdâtre, avec des taches et des points tirant sur le violet pale, mêlés avec quelques autres d'un cendré roux et très-rapprochés sur le gros bout, où la couleur du fond s'aperçoit à peine. Quelques-uns sont d'un blanc cendré, avec des points d'un gris roussâtre plus nombreux vers le gros bout et se confondant avee la couleur de la coquille. Leur longueur varie de $0^{\mathrm{mm}}, 015$ à $0^{\mathrm{m}}, 016$, et leur diamètre de $0^{\mathrm{m}}, 012$ à $0^{\mathrm{m}}, 013$.

Les différences qui existent entre ces dernières sylvies sont si difficiles à saisir, qu'elles ont échappé pendant longtemps à un grand nombre de naturalistes. Maintenant encore, malgré les travaux récents et de nouvelles observations, plusieurs auteurs distingués, et parmi eux, M. Nordmann, ont soutenu que la fauvette grisette, sylvia cinerea, la passerinette, sylvia passerina, la fauvette à lunettes, sylvia conspicillata, pourraient bien ne former qu'une seule espèce, se manifestant par plusieurs variétés.

J'abandonne aux savants la solution de ce problème. Cependant je puis constater dès maintenant, quelle que soit leur décision, que l'on trouve en Anjou les différentes variétés d'œufs attribuées aux trois espèces précédentes.

\section{SEPTILUE GENRE. - POCHLOTS.}

Dans la Faune de Maine-et-Loire, aux faurettes succèdent les pouillots. Pendant très-longtemps, ces derniers ont été classés parmi les sylvies, arec lesquelles ils ont 
beaucoup de rapport. Les pouillots sont, avec les roitelets et le troglodyte, les plus petits oiseaux de l'Europe. C'est aussi aux dimensions de leur taille qu'ils doivent le nom de pouillot, formé de pullus, pusillus, "petit." Ces passereaux vivent régulièrement en société; on les rencontre, quelquefois, en troupes assez nombreuses. Sans cesse en mouvement, ils papillonnent autour des branches et des feuilles, afin d'y saisir les vers et les insectes. Aussi, le bon sens populaire les a-t-il désignés sous le nom de frétillet. Ils visitent les arbres dans tous les sens pour y trouver leur proie, et accompagnent leur chasse d'un cri vif et perçant, qui semble être souvent un cri de rappel. Quatre espèces de pouillots parcourent l'Anjou et s'y reproduisent. La cinquième espèce, le pouillot à ventre jaune, admise par M. Millet, n'est, d'après la grande majorité des naturalistes, que le pouillot fitis, jeune âge et en plumage d'automne.

\section{POUILLOT SIFFLEUR, - SYLVIA SIBILATRIX.}

Les noms du pouillot siffleur, le plus grand du genre, lui viennent de son cri de rappel, qui est aussi son cri ordinaire. Ce cri perģant ressemble à un sifftement; il est assez semblable à celui que fait entendre le bouvreuil, et sa puissance étonne de la part d'un oiseau si faible.

Le siffleur établit son nid près de terre, dans les broussailles, dans les lieux humides, sur le bord des fossés. Des feuilles de fougères desséchées, de la guinche (molinie bleuatre, molinia carulea), de la mousse en forment l'extérieur; des plumes, du crin et des matières molles en garnissent l'intérieur. Ce nid a la forme d'une grosse boule oblongue ou d'un four de campagne, selon les endroits dans lesquels il se trouve établi. Une petite ouver- 
fure y est pratiquíc du côté le moins exposí aux regards; le plus ordinairement, elle est trurníe vers le fossé. L'entrée se trouve ì peu près au milieu du nid, de manière cependant que la partie supérieure puisse s'avancer pour former toit, et préserver la mère et sa jeune famille de la pluie et de l'humidité de la rosée. Ce nid, par sa couleur et par sa position, échappe facilement aux regards; mais il se trouve malheureusement trop près de terre, pour n'itre pas souvent visité et dévasté par les lézards verts et par les couleurres. Les œufs, dont le nombre varie de cing à sept, sont un peu oblongs; la coquille en est d'un blanc plus ou moins rosé et pointillé de taches d'un brun roux et rougeâtre, plus nombreuses et plus rapprochées à mesure qu'elles s'élèvent vers le gros hout. Ces œufs se distinguent de ceux du natterer, par leur's dimensions un peu plus fortes et par le fond de la coquille toujours plus blane; enfin les taches des œufs du siffleur sont ordinairement plus larges et plus séparées les unes des autres, que celles des œuls du natterer.

Le grand diamètre des œufs du pouillot siffleur est de $0^{\mathrm{m}}, 014$ ì $0^{\mathrm{m}}, 016$, et le petit de $0^{\mathrm{m}}, 011$ ì $0^{\mathrm{m}}, 012$.

\section{POUILLOT FITIS. - SYLVIA TROCHILUS.}

La difficulté de distinguer les différentes espèces de pouillots, qui ont tous des traits de ressemblance, a forcé les naturalistes à remarquer en eux certaines particularités. qu'ils omettent d'ordinaire dans le classement des autres oiseaux. Le cri triste et mélaneolique du pouillot fitis, qui semble faire entendre ee mot: "fist-fist, " a sulfi pour que Bechstein lui donnit le nom de fitis, expression difigurée du chant du pouillot trochilus. Quant à cette dernière dénomination, elle convient à tous les pouillots; olle dérive de thocumos, dont la racine trescro, " tour- 
ner, " voltiger avec vitesse, représente le vol papillonnaut et bruyant de ces oiseaux, tournant antour des petites branches avec la même rapidité et le même bourdonnement que le fuseau sous une main exercée.

Le nid du pouillot fitis, beaucoup plus restreint dans ses dimensions que celui du précédent, est composé des

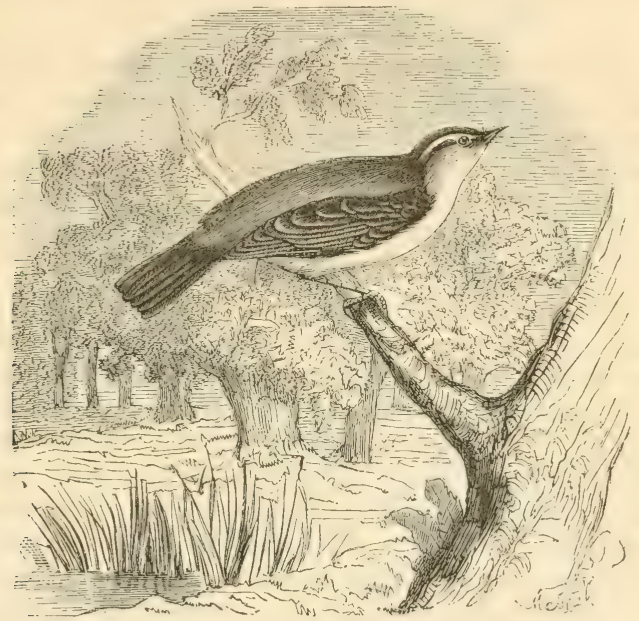

mêmes matières, et placé souvent, moins près de terre; on le trouve dans les bois ou dans les taillis, non loin des petits cours d'eau ou des fossés, suspendu à de grandes tiges de fougères. On le prendrait facilement pour le nid du rat des moissons. Il contient cinq ou six aufs, moins gros et plus allongés que ceux du siffleur, d'un fond blanchâtre disparaissant sous des petits points très-multipliés d'un rouge de brique, et recouvrant presque entièrement le fond de la coquille. Ils pourraient 
itre confondus avec quelques variétís des cufs de la mésange bleue; mais ces derniers, cependant, ne sont jamais aussi chargés de taches.

Grand diamètre de $0^{\mathrm{m}}, 01^{\mathrm{\prime}} \mathrm{t}$ à $0^{\mathrm{m}}, 01 \mathrm{~B}$; petit, de $0^{\mathrm{mm}},(110)$ à $0^{\mathrm{m}}, 012$.

\section{POUILLOT VÉLOCE. - SYLVIA RUFUS.}

Les noms de ce pouillot offrent une nouvelle preuve de la peine que l'on éprouve à saisir des nuances dans les couleurs, ou des différences dans les habitudes de ces petits oiscaux. Les noms de véloce et de mfus, "roux, " peuvent convenir à tous les pouillots, puisque tous sont. d'une agiliti remarquable, et que leur couleur faure les atrait fait classer parmi les sylvies. Pentant l'hiver, on trouve le véloce en grand nombre dans les arbustes et dans les osiers plantés sur le bord des rivières et surtout des marais ou des étangs. De l'extrémité des branches, qu'il risite en tous sens, il se précipite sur la proie qu’il aperçnit fixée aux plantes aquatiques ou entraînée par les eaux. Quand cette proie est attachée ì un dúbris ou ì un objet capable de le supporter, il s'y fixe, et dès lors s'abandonne, sur cette espèce d'esquif, au cours de l'eau, jusqu'ì ce que sa laim soit satisfaite, ou que sa patience soit vaincue. On peut constater ces habitudes du véloce près des bords de l'útang Saint-Xiculas, principalement ¿t l'endroit où l'eau décrit une courbe entre les deux bouquets de sapins. Le véloce a la faculté de modifier sa voix, et de faire croire qu'il chante bien loin du chasscur, lor'squ'il en est très-près. Ainsi, dans le mois de mai 18:.7 T' j'étais occupé avec plusieurs jeunes gens it chercher un nid de pouillot réloce dans les petits taillis situés sur la rive droite du mème étang; pendant nos investigations, le mâle resta perché à l'extrémití d'un arbre, faisant entendre un cri dinquiétude qui nous 
semblait devoir diriger nos pas. Après un certain temps consacré à des recherches inutiles, nous nous aperçûmes que nous étions les victimes du petit ventriloque. Nous ne pouvions l'entrevoir lui-même, et, lorsque nous pensions être près de le découvrir, son chant nous paraissait venir de bien loin, pour se rapprocher quand nous nous éloignions, puis recommencer sans cesse, par une ruse qui nous fatiguait sans amener aucun résultat.

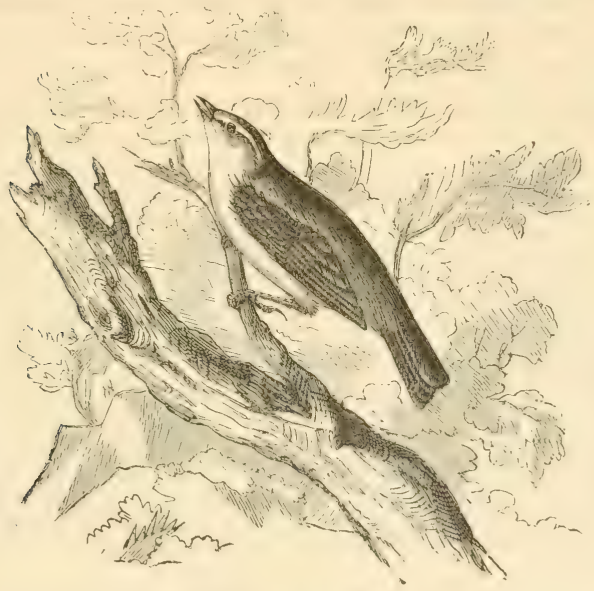

Le pouillot véloce est, en Anjou, le plus répandu des oiscaux de ce genre. Comme le siffleur, il niche très-près de terre, le long des talus des fossés et toujours du côté de la route, espérant ainsi éviter plus facilement les regards des hommes. Pour le découvrir, en effet, on est non-seulement obligé de se courber profondément, mais de descendre même dans le fossé. Cée nid, construit avec les mêmes éléments que ceux des pouillots précédents, contient de cing à sept œufs variant de formes et de 
taches. Peut-ître trouverait-on, dans ces diffirences très-sensibles, une preuve en faveur de ceux qui admettent une cinquième espèce de pouillot. Ces nuances trèsdistinctes méritent de fixer l'attention des naturalistes. Quelques nids contiennent des aufs presque ronds, dont la coquille est d'un blanc parsemé de taches noires; d'autres prísentent des œufs de forme allongie, couverts the taches plus petites et d'un rouge de brique.

Girand diamètre de $0^{\mathrm{m}}, 014$ it $0^{\mathrm{m}}, 017$; petit, de $0^{\mathrm{m}}, 011$ à $0^{\text {m }}, 013$.

\section{POILLLOT NATTERER OE BONELLL. - SILTH NATTERERI OU BONELLI.}

Ce pouillot porte indifféremment le nom de Nutterer ou celui de Bonelli. Il doit ces dénominations aux deux savants qui les premiers ont pu, par de minutieuses observations, le distinguer des autres espèces. Les habitudes de cet oiseau sont les mêmes que celles de ses congénères. Il niche comme le véloce, en préférant toutefois la lisière des bris à tous les autres lieux. Son nid renferme cinf ou six œufs, plus petits que ceux du siffleur, et tellement chargés de points rougeâtres, qu'ils paraissent se confondre et donner ì la coquille une nouvelle nuance; celle-ci semble quelquefois tirer sur le violet.

Frand diamètre de $0^{\mathrm{m}}, 011^{\mathrm{t}}$ à $0^{\mathrm{m}}, 01 \mathrm{~T}$; petit, de 0 , ${ }^{\mathrm{m}} 011$ à $0^{\mathrm{m}}, 012$.

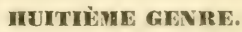

ACCENTEUR PÉGOT. - ACCENTOR ALPINUS.

Les inflexions brèves et saceadées du chant de l'accenteur ont determini les ornitholugistes it donner à cet viseau un nom qui reproduisit cette particularité : accen- 
tor, " celui qui entonne. ") Ou dirait qu'il annonce une antienne sur un ton mélancolique; c'est un chant commencé et subitement interrompu. Quant au mot pégot, il me semble pouvoir s'expliquer de deux manières. L'accenteur alpin vit sur le sommet des montagnes du midi de l'Europe, et en particulier sur celui des Alpes. Il se nourrit d'insectes et de graines, double avantage qui lui permet de séjourner, presque en tout temps, dans les mêmes pays. Cet oiseau se plaît dans les régions solitaires. Fixé sur une pierre, il s'y tient immobile pendant longtemps, regardant autour de lui, d'un air hébété, tout ce qui se fait, et ne paraissant pas redouter l'approche de l'homme, par indifférence ou par ignorance du danger. Cette habitude, cet air stupide, lui ont fait donner le nom de pégot, dérivé de pée, expression du pays de Comminges (IIaute-Gascogne), signifiant " hébété, imbécile. " La couleur noirâtre du plumage de cet oiseau pourrait peut-être faire admettre que pégol vient du vieux mot français pége, signifiant "couleur de poix, noirâtre. ") Cet accenteur niche à terre, dans les inégalités de terrain ou entre les pierres; son nid, composé de racines, de brins d'herbe et de paille, est très-solidement construit. Ces différentes matières sont tellement unies et liées, qu'elles paraissent avoir été soumises à l'action d'une presse puissante. Les bords du nid ont jusqu'à $0^{\mathrm{m}}, 05$ d'épaisseur. Il contient de quatre à six œufs bleus sans tache; leur longueur varie de $0^{\mathrm{m}}, 020$ à $0^{\mathrm{m}}, 024$, et leur diamètre de $0^{\mathrm{m}}, 015 \mathrm{\text {à }} 0^{\mathrm{m}}, 017$.

Le pégot traversel'Anjou très-rarement, etn'y séjourne jamais.

ACCENTEUR HOUCHET. - ACCENTOR MODLLARIS.

Ce congénère du pégot est sédentaire dans notre département. On le trouve partout et en grand nombre. 
II se tient dans les taillis et dans les haies fipaisses, sans cesse occupé ì recueillir quelques petites graines, à saisir des vermisseaux, des insectes et surtout des mouches, labitude qui lui a fait donner l'épithète moushet. Cet accenteur est très-lent dans ses mouvements; il sautille, d'un air stupidle et peu défiant, dans les buissons : aussi at-t-il reçu le nom expressif de traine-luisson. Son chant est bref, peu varié; il le fait suivre ou précéder de quelrfues sons plaintifs, tremblants, qu'il semble se plaire it moduler, ce qui explique sa dénomination latine modularis.

L'accenteur mouchet établit son nid dans les arbustes et dans les haies, ì environ un mètre de terre; ce nid, assez volumineux, est formé ordinairement d'une couche épaisse de mousse disposée en coupe, revêtue, à l'extérieur, de quelques brins de paille ou de petites racines, et, à l'intérieur, de crin. Il renferme quatre ou cinq œufs bleus, un peu rentrus, et se distinguant de ceux du rossignol de murailles, par une forme moins allongie et par une couleur plus pale.

Grand diamètre de $0^{\mathrm{m}}, 017$ à $0^{\mathrm{m}}, 019$; petit, de $0^{\mathrm{m}}, 012$ à $0^{\mathrm{m}}, 014$.

\section{NEUVBL̈HE GEVIE.}

\section{ROITELET IIUPPÉ. - REGULUS CRISTATUS.}

Deux fuis chaque année, notre départementest traversí par des bandes de petits oiseaux, dont le cri et le vol plaisent ì ceux qui en sont les témoins. Il parcourent, ave une vitesse et une grâce qui tiennent beaucoup de colles du papillon, les taillis et surtout les arbres verts, cherchant les petites mouches, les insectes et leurs larves. Aucune partie des arbres n'échappe à leurs inves- 
tigations multipliées; on les voit suspendus à l'extrémité même des feuilles agiiées par le vent, le corps renversé, afin d'être plus certains de ne rien oublier sur leur passage. Ces oiseaux si vifs, si gracieux, sont des habitants des Alpes qui, malgré leur faiblesse, entreprennent et exécutent de longs voyages. Les naturalistes les ont nommés roitelets, "petits rois, " à cause de leur huppe et de leur bandeau, qui semble être une couronne.

En Europe, trois espèces forment ce genre; deux seulement nous visitent. Celles-ci se distinguent entre elles par la huppe et par le triple bandeau de vives couleurs, qui embellissent encore leur petite tête. Cette particularité a servi pour former les noms vulgaires ou savants qu'ils portent. Pendant longtemps, ils ont été confondus dans une seule espèce, et c'est MI. Brehm, naturaliste saxon, qui le premier les a déterminés d'une manière précise.

Le roitelet huppé, mâle, porte sur le sommet de la tête une huppe d'un jaune orange, encadrée, sur les côtés et par devant, entre des plumes effilées, noires à l'extrémité des barbes, et d'un jaune vifàl'intéricur. Ces plumes font en quelque sorte partie de la huppe; car elles s'élèvent ou s'abaissent avec elle.

Le diadème des femelles est moins brillant que celui des mâles. Cet oiseau établit son nid dans les arbres élevés et touffus; il lui donne la forme d'une boule trèsronde, dans laquelle est pratiqué un petit trou placé en dessous, afin que l'eau n'y puisse pénétrer. Cette ouverture est ordinairement dissimulée sous un branche. Sourent il m'est arrivé d'examiner ce nid dans tous les sens, avant d'apercevoir l'ouverture qui donnait passage à la femelle. De la mousse parsemée de petits lichens, et unie par des toiles d'araignée, en compose l'extérieur; des plumes et du crin garnissent l'intérieur. Ce nid renferme de six à huit œufs d'un blanc sale ou jaunatre, et dont le gros bout est ordinairement d'une nuance uni- 
forme, mais plus linncée; on dirait une seconde conche répandue sur la jremière en forme de calotte.

Le grand diamètre est de $0^{\mathrm{m}}, 012 \mathrm{à} 0^{\mathrm{m}}, 013$, et le petit, de $0^{\mathrm{m}}, 009$ à $0^{\mathrm{m}}, 010$.

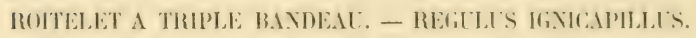

Le roitelet à triple bunden doit son nom anx différentes bandes blanches et noires qui sillonnent sa tête et encadrent sa hupps. Celle-ci est d'un orangé couleur de feu, ce qu'indique très-énergiquement l'épithète latine igni-capillus, de ignis, "feu, " et capillus, "cheveu, " - "cheveu de flamme. "Ses habitudes sont les mêmes que celles du prícédent, avec lequel il émig̨re et vit en honne harmonie. Son niel est fait de la même manière; il est placé au milieu de petites branches qui, en retombant, l'enveloppent et le cachent tout à la fois.

Ses œufs diffèrent de ceux de son congénère, par leur rouleur rose et par de petits points d'un rouge un peu efficé; leurs dimensions sont aussi un peu plus petites que dans l'espèce précédente.

Grand diamètre, de $0^{\mathrm{m}}, 011$ à $0^{\mathrm{m}}, 012$; petit, de $0^{\mathrm{m}}, 0108$ à $0^{\mathrm{m}}, 009$.

\section{DIXYÈY GENRE.}

TROGIONYTE D'ETROPL. - TROGLONOYTES VITAIARIS.

Les anciens avaient donné le nom de Troylodyles à des peuples d'Afrique dont ils connaissaient peu les habitudes précises, et qu’ils supposaient devoir vivre en sauvages, et habiter les cavernes et les bois. Selon une "pinion admise par un certain nombre d'historiens modernes, le peuple des Troglodytes n aurait jamais existe; et les anciens auraient vu des hommes là vù n'existaient 
réellement que des singes. Quoi qu'il en soit, les ornithologistes se sont apppuyés sur ces données, vraies ou fausses, pour imposer à un très-petit oiseau le nom de troglodyte, composé de TrôGLì, "trou, caverne, " et Dxô, Dxô, " entrer, habiter. " Ce passereau aime, en effet, à visiter, à parcourir les fentes, les crevasses des vieilles murailles, les trous des arbres vermoulus, pour y saisir les insectes et les vermisscaux. De plus, il choisit quelque anfractuosité de vieux mur tapissé de lierre, ou le débris d'un nid, ou même l'excavation d'un arbre, pour y établir son domicile, et y passer la nuit à l'abri du froid et de tout danger.

En Anjou, on appelle communément le troglodyte berrichot, beurichon et burrichon. Ce nom vulgaire dérive du vieux mot latin burrichus, signifiant " roux, " dont la racine est purruos ou prrkhos, « roux. ) Burrichus ou burricus est un diminutif de burrhus, ancien mot latin signifiant "roux, " témoin ce passage de Festus : "Burrum dicebant antiqui quod nunc dicimus rufum ") (cité par Ménage à l'article Bourrique). Cette dénomination, petit roux, est parfaitement justifiée par la couleur uniforme des plumes du troglodyte.

Quant au mot robertaud, petit Robert, petit maître Robert, il convient à ce petit oiseau, qui fait acte de propriétaire en se glissant partout, même dans l'intérieur des maisons, pour y manger ou pour s'y reproduire, et sans demander aucun consentement. Ce mot a, en outre, le même sens que beurichon, car Robert vient de l'allemand Rotbert, signifiant "barbe rousse, ) et peut dès lors se traduire encore ainsi : "le petit roux. "

Le courage que déploie le troglodyte en présence du danger, l'énergie avec laquelle il attaque les oiseaux beaucoup plus gros que lui, surtout lorsque sa jeune famille est menacée, l'ont peut-être aussi fait comparer aux grands guerriers de l'antiquité, et lui ont mérité le 
nom de "Roi-Rertaut. " Dans leur langage naîf et expressil, les cimpagnards auront voulu consacrer leur juste appreciation de la valeur du petit roux, et ils lui ont dérerné une couronne, comme prix de son courage. Ils inilaient en cela les liomains, qui avaient trouré une certaine analogie entre César et les troglodytes. "La veille du jour où Jules César reçut ses vingt-deux coups de poignard dans le Sénat, un troglodyte fut écharpé de lat même façon sur la place publique par une vingtaine d'autres petites bêtes, et cet événement, qui semblait un triste présage pour le nouveau roi, impressionna vivement les amis du grand homme, et les fit se douter de l'atfaire qui se machinait. " (Histoire romaine, de Michelet.)

L'imagination ne s'est pas arrêtée à comparer le truglodyte aux rois et aux empereurs; clle a supposé encore que le petit Robert avait défié l'aigle dans son vol audacieux, et que, pour triompher de son terrible adversaire, il s'itait élancé sur le dos du roi des air's. Anssi, lorsque l'oiseau de Jupiter se fut élevé à une hauteur inaccessible, il jeta un regard de dédain pour apercevoir son rival qu'il croyait encore à la surface de la terre. Mais tout it coup retentit ì ses oreilles tin chant de victoire: c'atait le roi Bertaut déployant toutes les richesses de son gosier musical pour célébrer son triomphe.

Dans quelques localités, les habitants de la campagne appellent le troglodyte le petit mussot, du mot mussure, formé, d'après Ménage, de mLo, mrssò, "se cacher, " qui lui-même a servi de racine, selon l'auturité de Scatliger, à ms, "souris. " aLs, Apo tor meï, id est abdere se in lutibula, inlutebrare se, quod sane mus facit (Scaliger, sur Ausune, $2-2-2 \bar{i}$ ); parce que, comme les souris, il se fraie un passage, avec une grande adresse et une grande rapidité, au milieu des fourrés les plus épais, et que, de plus, il se rapproche de la cuuleur de la souris 
par les nuances sombres et uniformes de son plumage.

Le troglodyte se plaît aussi dans les haies touffues, dans les lierres qui tapissent les murs ou serpentent autour des arbres. Ses mouvements sont vifs et saccadés; son chant, assez agréable, est très-étendu et très-perçant pour un si petit oiseau; ce chant ne se compose que d'une seule phrase non interrompue qui dure cinq ou six secondes. Cette particularité, très-rare chez les oiseaux, mérite d'être remarquée. Car les phrases du rossignol ne se prolongent pas au-delà de deux ou trois secondes; colles du merle noir durent trois ou quatre secondes; celles du merle grive, deux ou trois; seule, l'alonette l'emporte sur le troglodyte par un chant qui se soutient pendant l'espace de plusieurs minutes.

La queue du troglodyte est toujours relevée en éventail, et ses mouvements semblent indiquer une colère ou une irritation presque continuelle, qui imprime à tout son corps un mouvement de bascule. On le voit sans cesse paraître et disparaître derrière les branches ou les feuilles; il trompe la vigilance de tous ses ennemis par cette espèce de fuite stratégique. Dans le temps de la nidification, le mâle se tient près de son nid, surveille tous ceux qui s'en approchent, et manifeste, par le mouvement de ses plumes et par ses cris non interrompus, l'inquiétude qui l'agite. Le troglodyte établit son nid le long des arbres couverts de lierre, sous les hangars près des fermes, dans les trous des vieux murs et, quelquefois, à une petite distance de terre, entre les branches d'un arbuste ou des charmilles. Ce nid, dont les dimensions sont très-considérables, présente ordinairement la forme d'une boule oblongue; un petit trou très-rond, placé sur le côté ou vers le haut, donne passage à la couveuse. Cette ouverture est fortifiée par de petites racines qui, en assujettissant la mousse, l'empêcheut de céder sous la pression occasionnéc par l'entrée et par la sortie de la 
femelle. Le haut du nid s'avance presque toujours, afin de servir de trit et de préserver l'intérieur contre les in-

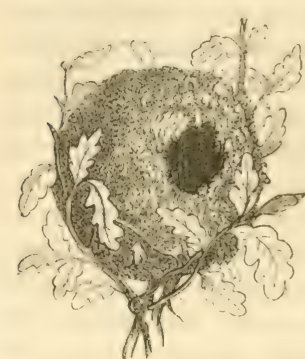
convénients de la pluie et les intempéries de la saison. Il forme ainsi une petite marquise champêtre. Des feuilles desséchées de fougère ou d'autres plantes, de la mousse liée par des racines, forment l'extérieur; le dedans est garni de plumes et de crin. Il contient de cinq à sept œufs très-gros pour les dimensions de l'oiseau. Leur forme est un peu oblongue; le fond de la coquille est d'un blane uniforme, et de couleur rose lorsque les ceufs ne sont pas vidés. Le plus souvent ils sont parsemés de points rougeâtres. Le nid du troglodyte est très-remarquable par la propreté qui y rèzne intéricurement. Le père et la mère le purgent continuellement des inscctes (qui s'y introduisent et des excréments de la petite famille.

Le grand diamètre des œufs est de $0^{\mathrm{m}}, 014$ in in $0^{\mathrm{m}}, 016$, et le petit, de $0^{\mathrm{m}}, 011$ à $0^{\mathrm{m}}, 012$.

\section{ONZIVME GENRF。}

\section{BERGERONNETTE. - MOTACILLA.}

Le genre des bergeronnettes comprenil un certiain nombre d'oiseaux intéressants par les habitudes auxquelles ils doivent leurs différents noms. Ces patssereanx ivent de vermisseanx, dinsectes, et recherchent les lieus nù ils peuvent les trouver le plus facilement. Par gaietí (c) pour saisir atu vol quelque insecte ailie, ils aiment it 
s'élancer à une petite élévation au-dessus des prairies, ì tourner sur eux-mêmes, et à retomber ensuite, pour recommencer plusieurs fois les mêmes évolutions. On les voit courir avec grâce et agilité au bord des rivières, voltiger sur les feuilles de nénuphar ou sur les roseaux inclinés. Ils se plaisent à visiter les bassins, dans lesquels s'abreuvent les troupeaux, ou qui servent de lavoirs publics : cette habitude les a fait nommer lavandières. Le mouvement imprimé sans cesse de haut en bas à leur longue queue leur a mérité l'épithète de hoche-quene ou motacilles, en latin motacilla, de moveo, (agiter, remuer," et cilleo ou cillo, mêmesens, "remue-mouvantes, " épithète, on le voit, essentiellement earactéristique. Quant au nom de bergeronnette, ils le doivent à leur habitude de suivre les cultivateurs et les bergers, et de s'attacher ì leurs pas sans craindre leurs attaques. Ils se tiennent derrière la charrue qui trace les sillons, saisissent les insectes sous les mottes renversées, ne redoutant ni les animaux ni ceux qui les dirigent. Dans les prairies, ils restent au milieu du troupeau, suivant tour à tour les bestiaux, et vivant des insectes ou des vermisseaux que les pas pesants des vaches ou des bœufs font sortir de leurs retraites. D'autres fois, ils s'attachent au dos des moutons, des porcs même, et les débarrassent des insectes qui les tourmentent. Souvent on a vu une ou deux bergeronnettes fixées sur un seul animal, le suivre dans sa course furieuse déterminée par les piqûres qu'il ressentait et dont il ne comprenait pas le motif, et ne l'abandonner que lorsque la visite générale était terminée.

Les bergeronnettes ont beaucoup de rapports les unes avec les autres; dès lurs, quelques naturalistes ont réuni plusieurs espèces en une seule; d'autres, au contraire, ont fait un grand nombre de subdivisions. On admet généralement quatre espèces, qui toutes visitent l'Anjou, et dont trois s'y reproduisent. 


\section{BERGERONNETTE GRISE. - MOTACILLA ALBA.}

La bergeronnette grise doit son nom à l'ensemble de sa couleur, d'un gris blanchître; elle niche dans notre département. Composé de mousse, de crins et de plumes, son nid est placé ordinairement dans les tas de pierres situís sur le bord des eaux. Il prend, dès lor's, la forme. du trou auruel il est confié. Pour en dissimuler l'entrée, le père et la mère y pínètrent par différents passages. Ce nid contient quatre ou cinq œufs d'un blane grisitre parsemé de petits points d'un brun noiràtre, et dont le srand diamètre est de $0^{\mathrm{m}}, 020$, et le petit de $0^{\mathrm{m}}, 01 \%$.

\section{BERGERONNETTE ICGTBRE. - MOTACILLA I.TGLRRIS.}

Quelques ornithologistes pensent que la véritable bergeronnette lugubre ne vient pas en Europe, et que celle it laquelle on a donné ce nom, ì cause des nuances plus sombres et plus foncées de son plumage, n'est qu'une variété de la grise.

Quant à la bergeronnette Yarrell, ainsi appelée du nom du savant Anglais qui l'a déterminée, elle est consiclérée par les uns comme une variété dépendant de la vieillesse du sujet, ou de l'influence du climat; d'autres auteurs l'ont érigée en espèce.

Quoi qu'il en soit, les deux bergeronnettes lugubre et Yarrell ont les mèmes habitudes que la grise. Leur nid est en tout conforme à celui de cette dernière, et leurs oufs ne diffèrent que par la rouleur' te la coquille quelquefois plus foncíe : variétés insuffizantes cependant pour servir de fondement ì une distinction d'espèces, puiscrue ces variétés se manifestent d'une manière eneore plus sensible dans les coufs de presque tous les passereaux. 
BERGERONNETTE JAUNE. - MOTACILLA BOARULA.

Cette bergeronnette se distingue des précédentes, nonsculement par les nuances de son plumage auxquelles elle doit un de ses noms, mais encore par son caractère. Ennemie de la société, elle recherche la solitude, et attaque celles de ses congénères qui se trouvent dans les lieux qu'elle parcourt. Elle accompagne son vol d'un petit cri plaintif et vibrant. Son nom paraît provenir de Boaria, ancienne désignation sous laquelle était connue la Bavière, depuis le moment où les Bö̈ens, chassés do la Bohême par les Narcomans, vinrent s'y établir. Ce nom de Boïens semble avoir été donné à tous les peuples qui s'occupaient principalement d'élever des troupeaux; dès lors, il serait assez rationnel d'en chercher l'étymologie dans la même racine que le mot grec Boûs, "bœuf.) On rencontre les Boïens de la Gaule, les Boïens d'Italie, les Boïens de la Germanie, etc. Dans le Poitou, maintenant encore, le bœuf est appelé boe, et le bouvier boier ; bouvier lui-même dérive évidemment de boviarius.

Dans Ducange boarius est pastor boum, "le pasteur des bœufs, ") et, d'après Forcellini, boarius peut se remplacer par ces mots : ad boves pertinens, "qui se rapporte aux bœufs, qui leur ressemble. " Chez les Romains, on appelait forum boarium, "le marché aux bœufs. "

D'après ces explications, l'épithète boarule, donnée à la bergeronnette jaune, semblerait indiquer, au premier coup d'œil, que cet oiseau s'attache aux pas des troupeaux, et que, comme un certain nombre de ses congénères, il cherche sa nourriture jusque sur le dos des bœufs. Mais les habitudes de la bergeronnette jaune s'opposent à cette hypothèse. Car, plus sauvage que toutes les autres espèces, elle fuit la présence de l'homme et 
des troupeaux, n'habite que les endroits solitaires, et surtout le bord des cours d'eau.

On a proposé aussi d'expliquer boarule et particulièrement boarine, en faisant dériver l'un et l'autre de soûs, " bœuf, " et runos, "peau, " pour indiquer un oiseau dont " la peau, la couleur se rapproche de celle du bœuf, ad boves pertinens. ") Dans ce sens, boarule ou boarine seraient synonymes de jaune, épithète qui désigne ordinairement cette bergeronnette. Mais il y a plus d'une objection à ce que boûs et runNos puissent être les racines de boarine et, à plus forte raison, de boarule. Ces deux mots ne sont peut-être, en définitive, que des allongements de boarius cité plus haut. Mais cela n'importe pas pour l'idée exprimée, qui reste à peu près la même.

Souvent la boarule trarerse les villes pour s'arrêter de jardin en jardin, de cour en cour, afin de visiter tous les endroits humides. On l'aperȩoit solitaire et perchée sur le toit des maisons, où elle fait entendre son cri perçant, et d'où elle semble rechercher les endroits les jlus favorables à ses investigations.

Son nid, composé à l'extérieur de brins d'herbe et de débris de plantes, est garni à l'intérieur de plumes et de crin. Placé à terre et sous des pierres, près des cour's d'eau, il contient de quatre à six œufs d'un blanc sale, roussâtre ou même isabelle. La couleur de quelques-ıns est uniforme; d'autres sont couverts d'une seconde couche presque effacée, ou de petites taches grisatres et jaunâtres. Grand diamètre de $0^{\mathrm{m}}, 018$ ì $0^{\mathrm{m}}, 020$; petit, de $0^{\mathrm{m}}, 014$ à $0^{\mathrm{m}}, 015$.

BERGERONETTE PLIYTANIERE. - MOTACHLLA FLAVA.

Cette bergeronnette, la plus sociable de tout le genre, est très-répandue en Europe. Elle arrive en srand 
nombre, dès les premiers jours du printemps, dans les pays où elle doit nicher. Elle paraît annoncer le retour de la belle saison, et c'est cette particularité qui lui a fait donner son nom français. Quant au mot flava, "jaune,» il indique que son plumage se rapproche de celui de la précédente. Elle niche à terre dans l'herbe, près des rivières, et pond le même nombre d'œufs que la boarule. La couleur de ces œufs est plus jaune, plus rousse et plus uniforme que celle des œufs de sa congénère. Grand diamètre de $0^{\mathrm{m}}, 017$ à $0^{\mathrm{m}}, 018$; petit, de $0^{\mathrm{m}}, 013$ à $0^{\mathrm{m}}, 014$.

Quelques naturalistes ont admis une bergeronnette flaveole (motacilla flaveola, " jaunâtre, ) ) qui, selon l'opinion la plus accréditíe, n'est qu'une variété de la printanière. Les œufs qu'on lui attribue sont d'un blane roussâtre ou jaunâtre uniforme, et strié de petits points bruns peu visibles.

\section{DOUZIÈTE GENIRE.}

\section{PIPIT RICHARD. - ANTIIUS RICHARDI.}

Les pipits ont été pendant très-longtemps confondus avec les alouettes, dont ils se rapprochent par quelques traits de ressemblance, mais dont ils s'éloignent par plusieurs habiludes. Ces oiseaux forment la transition naturelle entre les bergeronnettes et les alouettes. Comme les premières, ils vivent d'insectes et donnent à leur queue un mouvement de haut en bas. Comme les secondes, ils chantenten s'élevant dans les airs, et présentent des formes beaucoup moins sveltes que les motacilles. Plusieurs espèces semblent prendre plaisir à s'élancer dans les airs du haut des arbres, après s'y être reposés, pour redescendre, la tête en bas, les ailes étendues, représentant une flèche, et accompagnant ce vol irrégulier d'un chant agréable, 
mais un peu saccadé. Enfin quelques-uns se perchent très-rarement.

Leur nom générique pipit est la reproduction de leur chant, pit-pit, qu'ils répètent sans cesse, et qui semble ître en même temps un chant de joie et un cri de rappel. Leur dénomination latine anthus dérive du gree axtnos, signifiant "fleur. " Si le mot est pris au figuré, les pipits seront alors considérés comme l'ornement des lieux qu'ils habitent, par leur vol et par leurs mourements continuels. S'il est adopté selon le sens propre, il indiquera que ces passereaux vivent, en général, au milieu des terrains cultivés, et qu'ils se nourrissent de la graine des fleurs et des plantes.

Le pipit Richard, le plus gros de tout, a été dédié par M. Veillot au naturaliste de Lunéville qui l'avait signalé le premier. Comme tous ses congénères, il niche à terre; son nid se compose de petites racines et de brins de foin, ou de plantes; il renferme quatre ou cinq œufs, dont lia coquille, d'un blane gris sale, est revêtue de taches d'un noir rougeâtre.

Leur grand diamètre varie de $0^{\mathrm{m}}, 022$ à $0^{\mathrm{m}}, 028$, et le petit de $0^{\mathrm{m}}, 018$ à $0^{\mathrm{m}}, 020$.

\section{PITIT SPIONCELLE. - ANTHUS AQUATICUS.}

L'épithète spinula, qui, chez certains auteurs, sert ì désigner ce pipit, rappelle une des habitudes de ce passereau, celle de se plaire et de vivre dans les terrains plantés de buissons d'épines, spina, "épine. " C'est le même motif qui l'a fait nommer spinoletta. Le deuxième surnom aquaticus, "aquatique," nous retrase une autre habitude de cet oisean, celle de fréquenter les lieux humiles, et les bords des rivières et des marais. Quant au mot spioncelle, il dérive de spiomia, expression employée 
par Pline pour désigner" "la vigne sauvage. " Du substantif spionia on a fait l'adjectif spionicus, "qui appartient à la vigne sauvage, " d'où spioncelle. Cette qualification, indiquant un oiseau qui "vit dans la vigne sauvage," convenait d'autant mieux au pipit qu'il détermine, que ce passereau est appelé dans le midi de la France bec-figue des vignes. Les Romains le nommaient ficedula, " becfigue. ") Les gens de la campagne, très-bons observateurs, désignent le pipit spioncelle sous le nom de vinette. Ainsi se trouve réalisé, par le bon sens populaire, le désir que Martial exprimait, il y a bien des siècles, sous la forme d'une épigramme :

Cum me ficus alat, cum pascar dulcibus uvis,

Cur potius nomen non dedit uva mihi ?

Puisque je me nourris non-seulement de figues, mais aussi de raisins sucrés, pourquoi n’est-ce pas le raisin qui me donne son nom ${ }^{1}$ ?

Cependant le mot spionicus eùt dû être remplacé par un autre, pour représenter exactement les habitudes d'un oiseau qui se rapproche de la grive par le plumage, par le chant et par la nourriture, et qui, comme elle, préfère les vignes cultivées à celles qui sont sauvages. Le spioncelle manifeste une grande variabilité dans ses goûts, et c'est cette particularité qui a induit en erreur plusieurs naturalistes, et lui a valu des noms d'une signification toute différente. I quelques époques de l'année, et revêtu d'un certain plumage, on voit le spioncelle fréquenter les terrains marécageux et les bords des rivières : on le nomme alors anthus aquaticus, " le pipit des eaux. n A une autre époque, et avec une livrée différente, on l'a remarqué dans les endroits rocailleux, couverts de buissons, sur les montagnes : on lui a, par conséquent, donné la dénomination d'anthus montanus, "pipit des

${ }^{1}$ Martial, livre XIII, Épigramme 49. 
montagnes. "Ces pérónrinations dans des lieux si diffirents ne sont pas, chez les spioncelles, le résultat d'un caprice; mais elles leur sont dictíes par l'instinct raisunné qui les dirige vers les endroits où, selon les saisons, ils trouveront plus de ressources et d'abondance pour leur nourriture. Le pipit spioncelle est appelé spipolette par un certain nombre de naturalistes; et Buffon, entre autres, s'empresse d'adopter cette désignation qui a été choisie par les Florentins. Le nom de spipolette paraît dériver tout naturellement du verbe italien spipolare ${ }^{1}$, qui signifie " chanter avec caprice. " Cette expression peindrait très-bien une des habiturles de ce pipit, qui, comne celui des buissons, s'élève à une certaine hauteur pour retomber la tète en bas, en faisant la flèche et en accompagnant ses érolutions d'un chant gracieux, mais décousu. Ce chant paraît être effectivement un chant de fantaisic plus ou moins soutenu, selun la hauteur it laquelle l'oiseau s'est éleré, et dépendant ainsi des difficultés qu'il peut éprouver par la résistance de l'air ou par l'approche d'un danger. On dirait un enlant qui ne redit pas une leçon selon les principes de son maître, mais qui brode un thème selon ses dispositions et ses caprices.

Les gastronomes romains, comme ceux de nos jours, estimaient la chair du pipit spioncelle plus délicate et plus sueculente que celle des autres oiseaux.

Le spioncelle fait, à terre, dans les endroits rocailleux, un nid composé de racines et d'herbes. Il contient de quatre a six œufs ventrus, de teintes et de couleur's trèdiffirentes. Les uns sont d'un blanc sale; d'autres, d'un gris un peu violet; on en trouve de rougeâtres; tous portent des taches brunes ou noiratres, toujours plus nombreuses vers le gros bout. (Quelques-uns paraissent

1 Dictionnaire d'Alberti. 
avoir une seconde couche plus foncée que la pr'emière, et qui donne à une partie de l'œuf une teinte toute particulière.

Grand diamètre, de $0^{\mathrm{m}}, 020$ ì $0^{\mathrm{m}}, 023$; petit, de $0^{\mathrm{m}}, 013$ à $0^{\mathrm{m}}, 017$.

\section{PiPIT ROUSSELINE. - ANTHUS RUFESCENS.}

Le nom de cet oiseau, en français et en latin, est fondé sur les nuances de son plumage. Le pipit rousseline aime à s'élever à des hauteurs considérables en répétant son ramage un peu monotone, puis à se laisser tomber, la tête en bas, avec la rapidité de la flèche, dont il prend la ressemblance, en conservant ses ailes étendues sans leur imprimer aucun mouvement.

Son nid, composé de mousse, de petites racines, d'herbe et de crin, reçoit ordinairement de quatre à six œufs, dont la coquille, légèrement blanchâtre, est souvent striée de points, de taches et même de raies qui varient du violet au brun ou au roux foncé.

Le grand diamètre des œufs est de $0^{\mathrm{m}}, 020$ à $0^{\mathrm{m}}, 024$, et le petit, de $0^{\mathrm{m}}, 017$ à $0^{\mathrm{m}}, 018$.

\section{PIPIT FARLOUSE, - ANTHUS PRATENSIS.}

Le pipit farlouse est très-commun dans notre département; il est le plus petit du genre, et ressemble beaucoup au pipit des arbres. Souvent il est désigné sous le nom "d'alouette des prés, " prati alauda; ce sont ces deux derniers mots réunis et défigurés qui ont formé la dénomination farlouse, en subissant, d'après Le Duchat, les transformations suivantes : prati alauda, puis pralauda, fralauda, farloue, et enfin farlouse. L'épithète latine pratensis, "de pré,» représente la même idée. Con- 


\section{$-248-$}

trairement à l'opinion ímise par Le Duchat, je pense que farlouse est simplement une corruption de farlota, mot de l'idiome breton, signifiant "se divertir, s'amuser, s'ébattre, se livrer it une joie folâtre, n et qui, dès lors, raractíriserait très-bien les habitudes que j’ai décrites en parlant de l'épithète spipolette, donnée aux spioncelles. Le pipit farlouse vit en bandes nombreuses, se tient de préférence dans les herbes et dans tous les lieux humides et arrosés; il y poursuit les insectes et les petits

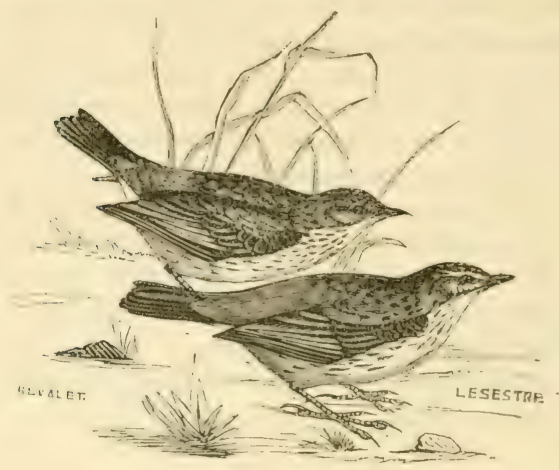

vermisseaux. On le trouve en très-grand nombre, pendant l'automne et l'hiver, dans les marais de la Baumette - et sur les bords de l'étang Saint-Xicolas; à l'approche du chasseur, il s'élève à une hauteur peu considérable, par un vol incertain et saccadé, en faisant entendre un petit cri répíté qui paraît être en même temps un cri de rappel et de mécontentement. On voit qu'il s'éloigne à regret des lieux qu'il avait choisis pour y chercher sat nourriture, et dans lesquels il revient presque immédiatement, dès qu'il aperçoit que le dlanger est passé.

Le pipit farlouse fait son nid à terre, dans les champs 
ensemencés, dans les prairies, quelquefois dans les taillis ou au pied d'un buisson. Des herbes sèches, des racines et un peu de mousse en composent l'extérieur. Les œufs, au nombre de quatre ou cinq, reposent sur une petite couche de crin et de duvet de plantes; ils varient de couleurs plus que les œufs de tous les autres oiseaux. Ils présentent toutes les formes, les couleurs et les nuances les plus variées. Chez les uns, le fond de la coquille est d'un blanc un peu enfumé; chez d'autres, il varie du blanchâtre au rougeâtre, avec des points ou des taches brunes, pourprées, violettes. Les uns sont parsemés de petits points couleur de brique; d'autres portent de larges taches brunes effacées et se fondant dans les premières teintes de la coquille. Enfin, quelques-uns sont ronds, d'autres oblongs, et un certain nombre piriformes. Souvent les couleurs de ces œufs ont un éclat si vif, qu'ils semblent avoir été recouverts d'une couche de vernis.

Leur grand diamètre est de $0^{\mathrm{m}}, 018$ à $0^{\mathrm{m}}, 022$; le petit, de $0^{\mathrm{m}}, 014$ à $0^{\mathrm{m}}, 016$.

\section{PIPIT DES ARBRES. - ANTHUS ARBOREUS.}

Ce passereau doit son nom à quelques-unes de ses habitudes. Il se perche plus facilement que ses congénères, et fréquente plus volontiers qu'eux les lieux plantés d'arbres ou parsemés de buissons. Il se distingue facilement du pipit farlouse, par un éperon beaucoup plus court que celui de son congénère; et c'est même à cette particularité qu'il doit l'avantage de pouvoir se percher. Il niche cependant à terre, comme tous les pipits. Son nid, formé d'herbe, de foin et de mousse, est garni à l'intérieur de crin et de petites racines très-déliées. Placé dans les fourrages, dans les bruyères ou dans les taillis, il contient de quatre à six œufs un peu oblongs. La co- 
quille en est souvent d'un blane grrisâtre strié de petits points bruns ou noirâtres Elle offre des traits ou des taches rougeatres ou d'un cendré violet, sur un fond blanc recouvert d'une seconde couche rougeatre. Ces œufs offrent les mêmes variétés que ceux du pipit farlouse.

Désirant obtenir des renseignements positifs sur les motifs qui pouvaient amener des modifications si essentielles dans les nuances et dans les dimensions des œufs du pipit des arbres, j'avais prié mon excellent ami, M. Raoul de Baracé, de me venir en aide. Grâce à ses soins bienveillants, j'obtins trois femelles, capturies sur leur's nids it 200 mètres de distance les unes des autres et dans le même temps. Le premier nid contenait des œufs presque ronds, petits, pointillés de gris d'une manière uniforme. Les œufs du second, beaucoup plus gros que les précédents, ressemblaient à certúines variétés de ceux de la fauvette à tête noire; ils étaient parsemés de taches rougeâtres, irrégulières, fondues dans la coquille, représentant diverses couches superposées. Enfin, le troisième nid renfermait cinq œufs : le fond de la coquille en était d'une couleur rougeatre, pointillé de petites taches de même nuance, mais un peu plus foncée et très-régulière. Ces nids ayant été trourés à la même époque, dans la même contrée, dans la même propriété, les raisons de température, de climat, de nourriture, alléguíes pour expliquer les variétis de coloration des aufs de quelques espèces de pipit, s'évanouissent, et la difficulté de la solution de ce problème subsiste dans toute sa force.

Les œufs du pipit des arbres ont le grand diamètre de $0^{\mathrm{m}}, 019$ it $0^{\mathrm{m}}, 020$, et le petit, de $0^{\mathrm{m}}, 012$ i $0^{\mathrm{m}}, 017$.

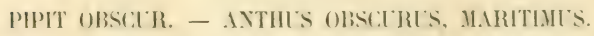

La présence du pipit obscur a été signalée en Anjou; quelques naturalistes mème ont pensé qu'il s'y était re- 
produit. La couleur sombre du plumage de cet oiseau, les lieux qu'il recherche de préférence justifient les épithètes obscur et maritime, sous lesquelles il est désigné. Il habite ordinairement le nord de l'Europe, et se répand dans des régions plus tempérées. Il se tient sur les bords de la mer, où on le rencontre en très-grand nombre, et dans les joncs et les marécages situés à l'embouchure des rivières. On le voit, par troupes assez considérables, courir sur les terrains couverts et abandonnés tour à tour par les flots de la mer, dans les marais salants. Il cherche alors, dans les terres humides et détrempées, de petits vermisseaux. Il niche à terre, souvent dans les îlots, sur les bords de la mer, dans les touffes d'herbe ou entre les rochers. Son nid, formé d'herbes desséchées, de racines et de mousse, renferme de quatre à six œufs un peu oblongs, d'un gris verdâtre, strié de petits points bruns ou noirâtres.

Leur grand diamètre est de $0^{\mathrm{m}}, 020$ à $0^{\mathrm{m}}, 022$, et le petit de $0^{\mathrm{m}}, 015$ à $0^{\mathrm{m}} 016$.

Ici se termine la deuxième famille de l'ordre des Passereaux.

\section{TROISIEME FAMILLE.}

\section{Comirostres.}

Les alouettes et les mésanges, dont je vais essayer de décrire les mœurs, en recherchant l'étymologie de leurs noms, appartiennent à la troisième famille de l'ordre des passereaux, laquelle comprend un très-grand nombre de genres et d'espèces.

Celles-ci diffèrent essentiellement entre elles, par leurs proportions et par leurs habitudes.

Afin de les désigner par un même nom, les natura- 
listes ne les ont envisagées que sous un rapport, celui du bee : dès lors ils les ont nommées comirostres, des mots latins comum, "cône, " rostrum, " bec, " parce que tous les oiseaux renfermés dans cette famille ont les deux mandibules du bee très-fortes, sans échancrure, bombées et de forme conique.

Linspection du bee de ces passereaux prouve, d'une manière évidente, qu'ils sont destinés ì vivre principalement de graines, et que Dieu leur a donné dans cet organe un moyen puissant de les concasser avec facilité.

\section{PREMIEIR GENIRE.}

\section{ALAUDE. - LES ALOUETTES.}

Les recherches auxquelles j'ai dû me livrer pour déterminer dans sa racine première l'étymologie du mot alouette, m'ont amené à conclure que personne jusqu'ici ne l'a indiquée avec une entière certitude. La question, en effet, n'est pas de savoir si aloutte est la transformation allongée de alauda, ce qui ne paraît pas douteux, mais d'où vient lui-même le mot alauda, et ce qu'il signifie; en un mot : pourquoi l'alouette porte-t-elle le nom d'aloutte?

D'abord il est facile de suivre, dans les poètes du moyen âge et de la renaissance, la formation du mot ulouette. Au treizième siècle, fiuiart disait dans sa chronique rimée :

Au matin il point que l'aloe

Sa douce chansonnette loe.

Deux siècles plus tard, Alain Chartier empruntait à notre petit oiseau cette comparaison gracieuse :

Les biens mondains, les hommes, les gloires

Qu'on aime tant, désire, prise et loue,

Ne sont qu'abus et choses transitoires

Plus tôt passant que le vol d'une aloue. 
Et Dubartas, cent ans après, employait déjà le diminutif, l'ayant emprunté peut-être au mot lodetta de la langue italienne.

La gentille alouette avec son tirelire, Tirelire, relire tirelirant tire

Vers la voute du ciel, puis son vol en ce lieu

Vire et semble nous dire : adieu, adieu, adieu !

Ainsi, alauda, aloe, aloue, alonette, telle est, du latin jusqu'à nous, l'histoire des transformations de ce mot.

Quelle est maintenant la signification d'alauda? Nous savons, par des témoignages écrits, que les Romains n'ont pas toujours employé ce mot pour désigner l'alouette. Ils la nommèrent d'abord galerita (avis galerita), ce qui signifie proprement oiseau coiffé d'un galerum ou galerus, c'est-à-dire, d'une sorte de casque en peau non préparée; voulant désigner ainsi, sans doute, le petit bouquet de plumes ou la crête qui décore la tête de l'alonette huppée. C'est aussi ce caractère extérieur qui avait frappé les Grecs, lesquels désignaient l'alouette par les mots KORYDOS, KORYDALOS, KORYDALLIS, dont la racine ronys signifie tout à la fois "casque " et " tête couverte de cheveux. ") Une preuve encore que, par galerita, les Romains avaient bien l'intention de dire " un oiseau à casque, un oiseau huppé, " c'est que le même mot servait à désigner, peut-être même longtemps auparavant, une légion, legio galerita, dont les casques étaient couverts de peaux de bêtes et terminés par une aigrette, ainsi qu'on le voit dans Pline (liv. XI, ch. 1) : " I'alouette se rend en gaulois par le mot alaud, d'où ce nom a été donné à une légion romaine qui était désignée anciennement par le mot galerita, à cause de la crête qui surmontait le casque des légionnaires. n) Marcellus Empiricus, Suétone, Grégoire de Tours, attestent également 
qu'alanda a été pris pour remplacer galerita. "Avis galerita qua gallice alunda dicitur, - la galerita que les Gaulois appellent alaud, » dit le premier, et Girégoire de Tours: "Avis corydalus, quam alaudam vocamus, - le corydalos, que nous appelons alauda. "Il y a plus, e'est que la lerjio yalerita fut remplacée aussi par la legio alcueda, ou plutôt par les alauda. Suétone (Vie de C'́sar, ch. xxiv) dit expressément que César ajouta, aux lígions ru'il avait reçues de la république, d’autres légions: levées à ses frais, et entre autres une légion de Gaulois, (ju'il organisa selon la discipline et la tenue des Romains, et qui porta le nom d'alaudce. Il paraît même, et ceci doit flatter quelque peu notre orgueil national, que ces Giaulois n'étaient pas les plus mauvais suldats de l'armée romaine : car Cicéron ne craint pas de les nommer sur le même rang que les vétérans, et, qui plus est, à leur tête : IIuc accedunt alaude ceterique veterani. - On voit venir ici les alaudes, et les autres vétérans (Philipp., 13, 2). " Comme si nous disions aujourd'hui : Les zouaves et les autres troupes d'élite.

Alauda est done un mot gaulois latinisé. Quelle en est la signification? En le substituant au mot galerita, dent le sens est précis, les Romains ont-ils voulu représenter la mème idée? Alauda est-il en gaulois la traduction de yalerita, comme galerita traduisait exactement ronrmaLos? C'est ici que l'incertitude commence; et il faut bien dire qu'elle n'est pas médiocre.

A première vue, rien de plus facile. Alunda et alouette sembleraient venir du celtique alc'houéder, alc'houede:, on allwedé, qui eux-mêmes sont formis de all et c'hneder ou hueder, que le $\mathbf{P}$. Lepelletier interprète de la manière suivante :

" All semble être, dit-il, la même chose que alli, avertissement, et ce mot pourrait bien entrer dans le nom de 
cet oiseau dont le chant avertit le laboureur du temps propre au travail.

D'a clevet au allwedez

Oreand d'en goulou dez.

ce qui veut dire : “ à écouter l'alouette, lorsqu'elle chante au point du jour. ") On a vu d'ailleurs, par les vers de Guiart, cités plus haut, et mieux encore, on sait, par le témoignage des gens de la campagne, que l'alouette chante dès le point du jour.

“ L'alouette est la fille du jour, — dit Michelet. - Dès " qu'il commence, quand l'horizon s'empourpre et que le " soleil va paraître, elle part du sillon comme une flèche " et porte au ciel l'hymne de joie! ”

Mais pour que cette explication de all pût être admise, il faudrait qu'elle fût d'autre part fortifiée par le sens de weder, qui est, dit le P. Lepelletier, le fond du composé. Or, ec'hweder, chweder, ou huëder tout seul, désignent aussi l'alouette. Et Davies, auteur cité par le P. Lepelletier, fait dériver huëder de ehuëdyz et huëdid, composé du hu, bonnet poilu, et ehediad ou hediad, volatile, ce qui voudrait dire "volatile à coiffure, " comme galerita et norydalos. Que devient alors le préfixe all, avec sa signification d'avertissement? Il me semble que nous en sommes fort éloignés.

Toutefois je dois ajouter que le P. Lepelletier ne se trouve pas lui-même tellement assuré de son explication, qu'il n'ait cru devoir en risquer une autre. "Car, dit-il, " puisque le nom breton de cet oiseau est si diversifié, " on peut en donner diverses étymologies. Uc'heder et " uhedez seraient faits d'uc'h, haut, et de hediad, que " l'on a expliqué ci-dessus. Ce petit oiseau vole et chante " fort haut. Il faut observer que le nom hediad est dérivé "de hedi, ehed, volare, voler. Hedez est proprement un 


\section{$-256-$}

" substantif qui doit signifier vol. " Ici la particule all ne serait pas déplacée, et allwedez indiquerait alors l'oiseau qui "vole en avertissant, " en " donnant un signal. $)$

Je ne rapporte ensuite que pour mémoire une autre étymologie du même P. Lepelletier, qui ferait venir all hweder de $c^{\prime} h w i t a$, "siffler, ") et c'hwiter «siffleur, " ou bien encore $\epsilon c$ 'luceder de aës, "aisément, " et du même c'hwiler, \& ce qui convient, - dit-il, - à l'alouette. " Comment? C'est ce gu'il a négligé de nous dire. Je sais que l'alouette apprend aisément à répéter les airs qu'elle entend; mais il est impossible que les vieux Celtes aient pensé à tirer le nom de l'alouette d'une particularité qu'ils n'ont pas dû découvrir tout d'abord. Or il tombe sous le sens, et ce devrait être un axiome de la science étymologique, que la langue populaire a cherché les noms des animaux dans leurs caractères, leur's qualités, leurs habitudes les plus communes et les plus faciles ì connaittre. C'est en partant de ce principe que je suis porté à donner is allweder ou ì alc'hueder la signification de " oiseau avertisseur, oiseau signal, ") dont le chant est le premier signe de l'approche du jour, et comme le premier cri de la terre à son réveil.

C'est peut-être aussi dans cet ordre d'idées gu'ii faut aller chercher l'explication d'une tradition qui ferait de l'alouette une sorte d'oiseau national chez les Gaulois. "Jules "César, - dit M. Michelet, dans son Histoire romaine," engagea it tout prix les meilleurs guerriers gaulois dans "ses légions; il en composa une légion tout entière "dont les soldats portaient une alouette sur leur casque " et qu'on appelait pour cette raison l'alauda. Sous cet " emblème tout nutional de la vigilance matinale et de la " vive gaieté, ces intrépides suldats passèrent les Alpes " en chantant et jusqu'a Pharsale poursuivirent de leurs "défis les taciturnes légions de Pompée. L'alonette gon- 
"loise conduite par l'aigle romaine prit Rome une se" conde fois."

Ce n'est là, il est vrai, qu'une tradition; mais il faut bien qu'elle ait un fond de vérité pour subsister même en l'absence de textes positifs. Qui sait? peut-être que le cri de l'alouette était, pour nos ancêtres, les héros de l'indépendance gauloise, un signe de reconnaissance et de ralliement, comme le cri de la chouette, chez les Vendéens et les Bretons, pendant les guerres de la Révolulution. De nos jours encore, les intrépides habitants de l'IIelvétie, si fiers et si jaloux de leur liberté, n'ont-ils pas introduit dans leurs hymnes guerriers le chant de l'alouette? En faisant redire à leurs fifres ce chant vif et perçant, ils semblent vouloir donner à leurs mouvements militaires la prestesse et l'élan rapide de l'alouette. N'estce pas aussi un souvenir et un symbole de leur antique indépendance? Quel oiseau d'ailleurs représente mieux que celui-ci toutes les nobles vertus d'un peuple qui lutte pour son indépendance? Cette vigilance qui n'est jamais en défaut, et qui déjoue tous les piéges de l'ennemi; cette vivacité de mouvement; ce vol infatigable de la terre au ciel et du ciel à la terre; tout enfin, jusqu'à ce chant joyeux qui ne se tait point, même en présence du péril, n'est-il point ici l'image vivante de l'espérance et de la gaieté dans les combats? Quel oiseau convenait mieux pour représenter les intrépides Gaulois devenus plus tard les joyeux et rapides fantassins de nos armées françaises?

Quoi qu'il en soit de ces hypothèses qui n'ont rien d'improbable, le nom alauda, donné à une légion gauloise, comme pour laisser aux vaincus la consolation d'un souvenir national, prouve que l'alouette avait, à un titre ou à un autre, une grande importance chez les Gaulois. Aussi je ne suis point étonné que J. Goropius-Bécan ait. basé sur cette idée l'étymologie d'alauda, qui viendrait, 
suivant lui, de all ou al, "tout, " et aut on aud, "antique, " ce qu'il explique en disant que "l'alouette était pour les Gaulois comme le premier de tous les oiseaux, et par suite le plus apprécié, l'oiseau pur cxcellence. " Malgré l'autorité d'Ilauteserre, cití par Ménage, cette étymologie de Bécan ne me paraît pas être la bonne. Il est bien évident que l'on rı'a pas dù commencer par nommer l'alouette " oiseau antique; » et, d'autre part, si le mot latin antiquus, ou plutôt anitiquissimus, a quelquefois le sens "d'apprécié, estimé, sacré, " le mot antique en français ne l'a point du tout, et probablement J. Goropius-Bécan ne s'aventurerait point à l'affirmer' non plus du celtique aut ou aud. En sorte que cette étymologie repose tout entière sur une sorte de calembourg, dont le sel s'évapore quand on fait passer en français ou en celtique le latin de J. Goropius-Bécan.

Pour en finir avec cette discussion déjà fort longue, je mentionnerai encore une opinion qui fait venir aluuda, assez capricieusement, de a laude.

Plusieurs naturalistes, entre autres Schwenclifeld et Klein, ont soutenu cette opinion.

Les alouettes, en effet, s'élèvent à des hauteur's considérables en faisant entendre un chant agréable; plus elles montent, plus elles étendent leur voix, de sorte que lorsqu'elles disparaissent à nos regards, nous les entendons encore très-distinctement. Elles redescendent ensuite en chantant, et diminuent graduellement la puissance de leur voix jusqu'à ce qu'elles se soient posées ì terre. Elles répètent cette ascension un certain nombre de fois, particulièrement le matin et le soir.

Les auteurs que nous venons de nommer ont cru que ces ascensions étaient au nombre de sept, et que les alnuettes accomplissaient ainsi le rœu du Roi-Prophète, qui demandait à célébrer les louanges du Serigneur sept fois le jour ('Ps. 118): Septies in die landem dixi tibi. Il 
leur a semblé que ces oiseaux portaient vers le ciel l'hommage de la reconnaissance des créatures, et qu'ils exprimaient en redescendant leur satisfaction d'avoir accompli un devoir imposé à tout être qui se montre sensible aux bienfaits du Créateur.

Les paysans bas-bretons attribuent au vol perpendiculaire de l'alouette un autre motif. Voici la légende que je lis dans l'ouvrage intitulé Barzaz-Breiz ${ }^{1}$ : "Les paysans bas-bretons, dans leur poétique naïveté, se figurent que les âmes montent au ciel sous la forme d'une alouette. Comme je suivais un jour de l'œil un de ces oiseaux qui s'élevait en chantant dans les airs, un vieux laboureur, qui charruait à quelques pas de moi, s'arrêta ; et s'appuyant sur les bras de son instrument aratoire, me dit : "Je parie que vous ne savez pas ce qu'elle dit? " Je l'avouai. "Eh! bien, ajouta-t-il, voici ce qu'elle chante :

\author{
Sant Per digor ann nor d'in \\ Saint Pierre ouvre la porte à moi \\ Birwiken na béc'hinn! \\ Jamais je ne pécherai! \\ Na bèc'hinn, na bèe'him! \\ Je ne pécherai, je ne pécherai!
}

Nous allons voir si on lui ouvre, dit le paysan. " Au bout de quelques minutes comme l'oiseau descendait, il s'écria : "Non, elle a trop péché; voyez-vous comme elle est de mauvaise humeur; l'entendez-vous la méchante, répéter

Péc’hinn! pée’hinn! péc'hinn! 》

Je pécherai! je péchérai! je pécherai! ”

Pour justifier leur opinion, Klein et Schwenckfeld pensèrent que le mot alaudx était composé de $a$ et de laude qui vient de laus, "louange, " ou laudare, "célébrer

${ }^{1}$ Poésies bretonnes, par Th. Hersart de la Villemarqué. 
les louanges, ") et signifiait : "oiseau qui chante et redit les louanges. " Leur opinion pourait s'appuyer aussi sur le mot allaudare, "louer beaucoup et souvent. "

P'eut-ĉtre ces atuteur's avaient-ils été portés ì admettre cette étymologie plus pieuse que réelle, en observant que les alouettes font entendre très-rarement leur véritable chant lorsqu'elles sont à terre, et qu'en redoublant l'éclat de leur voix, elles la rendent plus harmonieuse ì mesure qu'elles s'approchent du ciel. Ce qui a pu encore les fortifier dans leur opinion, e'est que l'alouette est le seul de tous les oiseaux qui chante en s'élevant perpendiculairement vers le ciel. La farlouse fait bien entendre un chant très-rif dans les airs, mais c'est toujours lorsqu'elle redescend ver's la terre; et son chant devient plus accentué à mesure que le mâle s'approche du nid de sa couveuse. Un sentiment d'amour est done le motif qui inspire ces accents. Nos deux auteurs ont cru pouvoir trouver au chant de l'alouette un motif plus délicat et presque surnaturel.

Le sens attachi au vieux mot alonser pourrait corroborer, dans une certiine mesure, l'opinion précédente, comme on a pu le remarquer dans les vers d'Alain Chartier, cités précédemment.

En effet du mot alauda on a pu former le mot aloue et le verbe alouser, signifiant tout ì la fois "louer et acquérir renom. »)

Ainsi, alouser désignait autrefois l'action de tousceux qui désiraient plaire et acquérir un renom, qui remplissaient le rôle de flatteurs. On le prenait aussi dans un autre sens : celui de se complaire en soi-même, de chercher à surpasser les autres.

Ces deux dernières acceptions conviennent ígalement à l'alouette. En eflet, soit pour dissimuler sa présence et ́́chapper ì ses conemis, soit pour attirer lis regards et comme puur acquérir du renom, l'aluuette non-seule- 
ment imite le chant des autres oiseaux lorsqu'elle est ì terre, mais elle le travaille, elle l'embellit et se permet des variantes dans lesquelles elle se complaît. Dans ce cas, elle ne donne pas la louange, elle paraît la rechercher et vouloir acquérir renom. Elle s'attache aussi avec passion aux objets qui peuvent réfléter son image; elle aime à s'y contempler; et cette funeste complaisance est

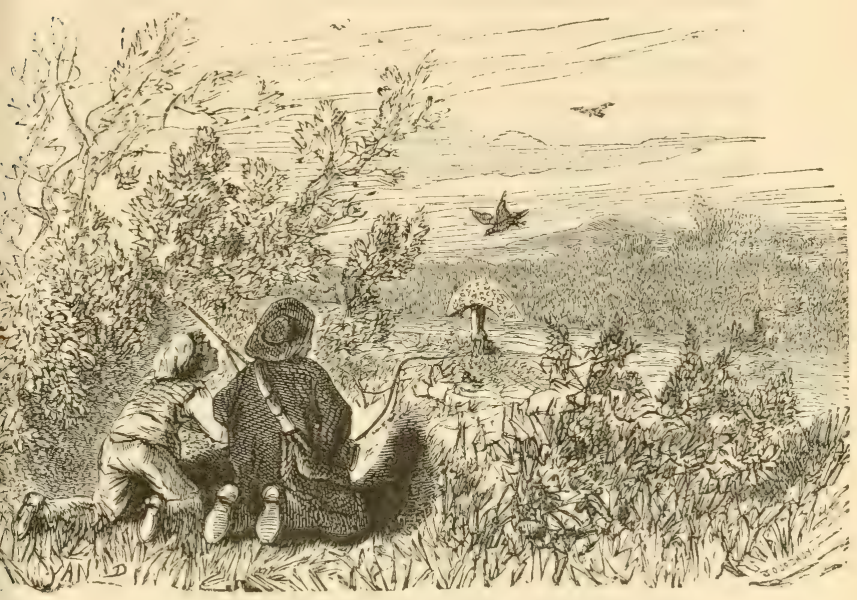

pour elle, comme pour beaucoup d'autres, la cause de sa perte. Les chasseurs, profitant de cet instinct, ont eu la pensée de placer, dans les pays où les alouettes sont abondantes, des miroirs mobiles sur un pied fixe, et de les faire mouvoir avec une corde. Les alouettes arrivent bientôt en grand nombre, voltigent autour de cet appareil en poussant un petit cri de joie, se contemplent dans toutes les subdivisions des miroirs, et finissent par se poser à terre, afin de pouvoir prolonger leur satisfaction 
plus longlemps et sans fatigue. Lì, elles trouvent lat récompense de leur vanité : le filet et la mort. Ciette rhasse se fait au lever du soleil et produit des résultats très-fructueux. Que de victimes ne ferait-elle pas, si elle était appliquée avec toutes ses conséquences à l'espèce humaine?

Les alouettes, qui recherchent avec tant de passion les miroirs, cause de leur mort, manifestent une crainte très-vive à l'approche des oiseaux de proie, et surtout de l'épervier. Pour se dérober aux serres de ce rapace, elles se précipitent dans toute espèce de piéges; toute mort leur paraît préférable à celle dont les menace le falconisus. Les anciens ont cherché à expliquer cette appréhension excessive par un fait mythologique.

Seylla, fille de Nisus, roi de Mégare, coupa à son père les cheveux d'or dont dépendait le salut de sa patrie, et livra ainsi son père et son pays à Minos qu'elle aimait éperdûment. Le malheureux père voulut punir sa fille; mais celle-ci se trouva aussitôt métamorphosie en alouette, et lui-même fut changí en épervier.

Tout le monde connaît ces beaux vers de Virgile :

Apparet liquido sublimis in aere Nisus, Et pro purpureo pœnas dat Scylla capillo :

Quâcumque illa levem fugiens secat xthera pennis, Ecce inimicus, atrox, magno stridore per auras Insequitur Nisus : qua se fert Nisus ad auras, Illa levem fugiens raptim secat æthera pennis.

(Géorgiques, livre I, v. 40'-9.)

Tantôt l'affreux Nisus, avide de vengeance, Sur sa fille à grand bruit, du haut des cieux s'élance. Scylla vole et fend l'air, Nisus vole et la suit, Scylla, plus prompte encor, se détourne et s'enfuit.

(Delille.)

Cette fable, en mème temps qu'elle faisait connaître, du point de vue de la mythologie, la cause de la crainte 
extraordinaire que ressentent les alouettes à l'approche du falco-nisus, semblait expliquer aussi, par la métamorphose de Scylla qui, de femme devenue alouette, aurait conservé quelques restes des penchants naturels au beau sexe, la complaisance avec laquelle ces oiseaux aiment à se contempler dans les miroirs. Mais ce n'est là qu'une fable. Pour se dórober à la poursuite de l'épervier, les alouettes s'élèvent perpendiculairement à des hauteurs prodigieuses, qui dépassent souvent 1,000 mètres. Comme tous les faibles et les opprimés, elles cherchent secours, espérance et consolation en s'approchant du ciel. Plus elles s'élèvent, plus leur chant revêt le caractère de la prière; elles semblent chercher un asile là où l'innocence se repose et où l'iniquité ne peut pénétrer. Cette confiance n'est pas inutile, car ces ascensions préservent souvent les alouettes de la mort. Les rapaces ne peuvent suivre leur proie dans ce vol inaccoutumé pour eux; ils sont condamnés à décrire des cercles autour des alouettes et à attendre qu'elles redescendent vers la terre. Dieu, encore, y veillera sur elles : en effet, fatiguées par ce vol hardi et continu, les alouettes retombent des hauteurs de l'air avec la vitesse d'une balle, puis elles se blottissent sous une motte de terre ou sous une touffe d'herbe. Là, leur immobilité et la nuance sombre de leur plumage, en harmonie avec le refuge qu'elles ont choisi, les dérobe aux regards de leurs persécuteurs.

Victimes des oiseaux de proie de toutes les formes, les alouettes trouvent encore un ennemi persévérant dans le coucou. En effet, il mange leurs œufs, et dépose ensuite dans le nid un œuf qui, couvé avec soin, donnera naissance à un nouveau persécuteur. Cependant, malgré toutes ces causes de destruction et les quantités incalculables d'alouettes capturées pendant la saison des neiges, ces oiseaux apparaissent en hiver, et surtout dans les pays de plaines, par légions innombrables. 
La Providence veille sur elles daus l'intérêt du pays qu'elles habitent.

Les alouettes se tiennent ordinairement à terre, et ne peuvent se percher que très-difficilement.

Elles ont trois doigts en avant et un en arrière.

Le doigt externe est soudé à la base avec le médium, et ne permet pasà l'oiseau de saisir fortement la branche ou l'appui sur lequel il voudrait se reposer.

Le doigt placé en arrière est armé d'un ongle plus long que le doigt lui-même, et très-fort.

La plupart des naturalistes n'ont vu dans cet ongle qu'un embarras, tandis qu'il est pour l'alouette un bienfait de Dieu.

D'un naturel timide et sans défiance contre ses nombreux ennemis, l'alouette ne peut pas toujour's leur échapper par son vol. Pour vivre, elle doit dissimuler si présence. Afin d'atteindre ce but, elle ne fait que trèsrarement entendre, comme je l'ai dit, son véritable chant lorsqu'elle est à terre; mais elle se plaît, au contraire, à tromper ses ennemis en contrefaisant la roix des autres oiseaux. Sa couleur uniforme et fauve se confond facilement avec les nuances des sillons ou même avec les terrains sablonneux qu'elle recherche de préfirence aus autres. Sa course au milieu de ces sillons pourrait encore la trahir, et sans son ongle elle serait souvent découverte et perdue. Aussi, toutes les fois qu'un péril se manifeste, l'alouette s'arrête, se tapit le long des mottes, même les plus irrégulières, et se tient immobile et en quelque sorte suspendue en enfonçant dans la terre son ongle qui lui sert d'appui et de miséricorde. Avec ce puissant secours, elle peut conserver longtemps une position qui, sans cela, lui serait impossible. Cet ongle est encore pour l'alouette d'une grande utilité dans ses courses à travers les terres labourées ou les sables des déserts; en augmentant considérablement la base de 


\section{$-265-$}

son pied, il lui donne beaucoup plus de solidité, et facilite les excursions pénibles et continues qu'elle doit entreprendre pour trouver sa nourriture.

Afin de réparer les pertes nombreuses que tant de périls occasionnent dans les rangs des alouettes, Dieu a doué ces oiseaux d'une grande fécondité : elles font deux, trois et même quatre couvées par an, surtout au milieu des déserts où leur présence est plus nécessaire encore que partout ailleurs; car elles y détruisent ces myriades de sauterelles qui deviennent de temps en temps de véritables fléaux.

Il serait très-curieux d'étudier et de constater si ces nuées de sauterelles, qui s'échappent de l'Afrique pour porter au loin la dévastation, la famine et la peste, ne manifestent pas leur présence après les hivers rigourcux et abondants en neige, pendant lesquels les alouettes suecombent en plus grande quantité. S'il en était ainsi, les services rendus par les alouettes seraient démontrés d'une manière plus rigoureuse et plus intéressante; et dès lors il deviendrait difficile de justifier les arrêtés qui proscrivent les alouettes sous le nom d'animaux destructeurs et nuisibles.

Avant d'étudier en particulier chaque espèce d'alouette, ce serait ici le lieu de discuter la valeur d'une remarque faite par plusieurs personnes, et notamment par François Pithou dans son Glossaire sur les Capitulaires de Charlemagne, à savoir qu'il y a un rapport marqué, quant à la forme, entre alauda et allodium; d'où Pithou n'hésite pas à donner alauda pour racine à allodium. A première vue, cette affirmation ne manque pas de vraisemblance. De même en effet qu'on trouve, en français, alleu et aleu, on dit, en latin, alodium et allodium et, chose bien remarquable, alaudium et allaudium. Les deux $l l$ n'établissent donc pas une différence importante, et, d'autre part, l'o, transition entre l'au d'alauda et 
l'ou d'ulouette, subsiste dans le mot alodetu, qui est encore empluyé pour signifier alouctle par les habitants de la Lombardie.

Dans cette hypothèse, Pithou fait dériver allodium ou alaudium de l'étymologie déjà citée de J. Goropius-Bécan, al-aud, parce que l'allodium ou l'alleu en français était une terre qui donnait toute la considération attachée à une propriété antique: "Quasi ommino antiqua sit et "hareditas aviatica; vel forsan alludere videtur ad hu"jus avicula? morem in symbolis plerumque usurpa"tum, que ut a terra sese elevans post aliquot crispante "voce versiculos decantatos felici epodo Deum laudat, " ita allodium sut terra sublimior veluti ques solum Deum "ratione dominii recognoscat superiorem. - Comme " si le mot alleu désignait la possession primordiale " tenue par héritage des aïeux; ou bien comme si l'on "voulait faire allusion aux mœurs de l'alouette qui sont " souvent employées d'une manière symbolique. Cet " oiseau, lorsqu'il s'élève de terre, fait entendre des airs " joyeux comme pour louer Dieu; de même l'alleu est " une terre élevée au-dessus des autres et qui ne recon" naît que Dieu seul pour propriétaire. " En d'autres termes, afin d'éclaircir la phrase tant soit peu embarrassée de l'auteur, l'alouette ou l'allouette, chez les Giaulois, avait été l'oiseau antique, primordinl, c'est-ì-dire supérieur à tous les autres par son vol et son chant réunis, car il est le seul qui, en chantant, s'élève ainsi dans les airs; et pareillement, l'alleu, après la conquête, aurait été la terre antique, primordinle, dont la possession l'emportait sur toutes les autres, et dont le propristaire ue relevait que de Dieu. L'on conçoit que dans cette hypothèse, si allodium ne dérive pas précisément d'alıuda, et alleu d'alouette, ces différents mots appartiennent it une souche commune, ce qui revient au même.

L'étymologie précédente soulère une objection, comme 
je l'ai dit plus haut. C'est qu'il faudrait prouver qu'en celtique l'idée d'ancien, d'antique, a emporté, comme en grec et en latin, celle de vénérable, de plus grand, de plus important, de supérieur. La chose n'est pas impossible. Quoi qu'il en soit, l'opinion de F. Pithou, relative à la communauté d'origine existant entre allodium et alouette me semblerait pouvoir être, jusqu'à un certain point, confirmée par une remarque qui m'est personnelle, et que je tire des noms Alleuds, Alaudière, donnés à quelques endroits en France.

Dans le département de Maine-et-Loire, la commune Les Alleuds est située dans une contrée où les alouettes sont en si grande quantité que, dans la discussion de la nouvelle loi suł la chasse, il a été question de faire une exception en faveur de ce pays. Il eût été permis aux habitants de prendre des alouettes dans les temps de neige, motivant ce privilége sur les pertes qu'occasionneraient aux fermiers l'application de la loi générale. Un trèsgrand nombre d'entre eux, en effet, capturent pendant l'hiver des quantités innombrables d'alouettes, dont le prix s'élève à plusieurs centaines de francs pour chaque villageois. Ici, au moins, le mot Alleuds me paraît signifier très-probablement " portion de terre habitée, recherchée par les aloucttes. ") Le mot alleu, en général, ne saurait avoir un sens aussi restreint : vient-il, toutefois, de la même racine qu'alouette comme l'a prétendu l'écrivain cité plus haut?

D'abord, il faut le dire, un certain nombre d'auteurs font dériver le mot alleu de l'allemand all, "tout, " et od, "propriété. " Si l'on admet leur étymologie, il est clair qu'il ne saurait y avoir qu'un rapport fortuit de son entre les deux mots qui nous occupent. Mais rien ne démontre qu'il faille s'en tenir à cette supposition. D'autres font venir alleu de $a$ et de loos ou los, signifiant dans l'ancienne langue allemande ("sort, partage, lot. ) Il est remar- 
quable que cette étymologie coïncide avec celle que fournit le I'. Lepelletier. - "Je terne du jurisconsulte allodium est - dit-il à l'article laut - régulièrement formé du breton alloden, "la part, la portion, le partage. " $A$ lest l'article, loden est le nom correspondant au verhe loden, lausden, laoden, dérivé de lant, laot, lot, qui signifie "part, portion, lot. " - Le mot français, le même dans les deux traductions et dérivé de l'une et de l'autre source, prouve la conformité de la racine. Cette similitude n'eùt-elle pas existé, les Francs ont nécessairement emprunté aux Gaulois une foule de locutions, et il eût été fort pussible que, voulant exprimer une propriété exempte de toute servitude, les vainqueurs se fussent servis d'un mot formé d'éléments appartenant à l'idiome des vaiacus, afin de se faire mieux comprendre de ceux-ci. A plus forte raison l'ont-ils pu faire dans le cas présent, où ils avaient l'avantage de trouver un terme d'origine identique dans leur propre langue. Alouette, maintenant, proviendraitil aussi de al-loden? Je laisse à de plus versés que moi dans la connaissance du celtique le soin de trancher cette question. A en juger par le provençal lautzo, abréviation de alauso, et par l'italien lodola, abréviation de alı́odolı, on pencherait pour l'affirmative. Ces formes nous mènent loin d'alchwedé, et surtout de huider. Pourquoi le latin aurait-il été calqué sur ce mot du dialecte breton, et non sur un mot du dialecte aquitain? Lors mème que, contrairement à l'opinion de M. Granier de Cassagnac, on soutiendrait que lodola et lauzo ${ }^{1}$ ne sont que des corruptions du latin même, il serait encore très-probable que les Celtes Aquitains fussent demeurés assez fidèles au génie de leur langue pour que la partie principale du

${ }^{1}$ Cité, ainsi que lauzetto, par M. Granier de Cassagnac, dans

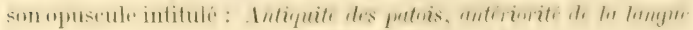
française sur le latin, p. 31-32. Paris, Dentu, éditeur. 
mot se fût le plus exactement conservée, et il paraîtrait difficile de n'y pas reconnaître une racine analogue ì laut et loden ou lawden. En admettant done, d'une part, la communauté d'origine assignée aux termes alleu et aloutte par F. Pithou, et de l'autre l'étymologie mieux fondée d'alleu fournie par le P. Lepelletier, n'y aurait-il pas quelques inductions à tirer de ce nouveau point de vue?

Si alleu veut dire la part, la portion, la propriété par excellence, que pouvait, en suivant la même idée, signifier alouette? L'oiseau spécialement attaché à la propriété? L'on allègue que l'alouette est un oiseau de passage. Il n'en est pas moins vrai qu'il s'arrête de préférence, comme j'en ai fait la remarque, dans telle ou telle localité. Les Gaulois ont-ils été, par l'abondance des alouettes, portés à croire qu'elles affectionnaient particulièrement certaines parties remarquables de leurs possessions? Les ont-ils, en quelque sorte, identifiées avec leur territoire? A supposer qu'ils eussent voulu, dès le principe, symboliser l'indépendance, la supériorité, à quelque point de vue que ce fût, de la terre aussi bien que des hommes, ils n'auraient pu choisir un oiseau qui leur en offrit de plus puissants moyens que l'alouette cochevis, " au visage de coq, " semblable par la crête à cet animal, autre emblème de la vigilance matinale comme elle, mais auquel elle est bien supérieure par' ce vol audacieux et par ce chant unique que j'ai déjà plusieurs fois caractérisés. Et c'est pourquoi, sans doute, ils ont fait de l'alouette un de leurs insignes nationaux, et, soit de leur propre mouvement, soit par l'effet des circonstances, se sont, nous l'avons dit, appelés de son nom en servant à l'étranger.

Au reste, le P. Lepelletier ouvre le champ à une tout autre explication. "Le mot latin laus, louange, peut encore,-_dit-il, - être notre lanvden, comme en hébreu eleq 
signifie partager et louer, ou complimenter, gracieuser de helles paroles, flatter. $)$ Une chose curieuse, en effet, c'est que, dans un grand nombre de langues, une parenté originelle semble avoir embrassé les mots qui exprimaient l'idée de placer, à part ou ensemble, par conséquent de diviser, de séparer ou de réunir, et ceux qui exprimaient l'idée de dire, de parler, de louer. Cela est frappant en grec : s.Écô, y signifie tout à la fois dire, parler, rassembler et coucher : d'où Locios, "discours, " et Locios, " armée, embuscade, accouchement. " Ln latin, une affinité semblable relie loqui, locutus et lucare, locus, pluriel loci; laus, par cette dernière forme, se rattache à la même racine primitive, et, comme l'a trèsbien vu le savant auteur du dictionnaire breton, se rapproche du celtique laut, loaden, comme de l'allemand loos ou los. Notre mot louer a une double signitication analogue, indiquée, dans les deux sens différents, par les mots louanye et lot. Il semble que le langage ait été considéré, dès la plus haute antiquité, comme un instrument de distinction, de distribution, que parler soit mettre chaque chose à sa place, et louer, assigner à chacun le lot, la part qui lui est due. Cette analogie si frappante dans les langues primitives serait-elle fondéc sur le souvenir de la Bible? Dixit et facta sunt. "Dieu dit, et toutes choses furent créées et occupèrent la place déterminée par la volonté du Créateur. ") Est-ce sous l'influence de cette pensée, qu'en grec et dans d'autres idiomes, la même expression a été employée pour signifier, comme je l'ai dit ci-dessus, parler et mettre au jour? Ceux qui ont crée les langues primitives ont-ils roulu refléter dans leurs expressions cette puissance de Dieu qui les avait frappés? La personnification la plus entière de la volonté et de la puissance divine, s'est appelée, d'après les desseins du Tout-Puissant, Verle, parole par excellence. Ce Verbe, cette Purole par excel- 
lence s'est nommée elle-même la Vérité : Ego sum Veritas. Ainsi d'après Dieu, la parole est et doit être l'expression, la personnification de la vérité. Parler est donc envisager chaque fait, chaque chose, chaque personne sous son véritable point de vue; c'est donc distribuer à chaque fait, à chaque chose, à chaque personne la louange et le blâme qui lui sont dûs selon les circonstances; c'est donc faire à chaque chose, à chaque être, sa véritable part, lui concéder son véritable lot. Il n'est donc pas étonnant que lawden ait signifié chez les Celtes partager et louer. Or voici, non sans vraisemblance, comment les choses ont pu se passer. Le mot alouette serait, à l'origine, dérivé de la racine lawden, prise dans le sens de louer. Alors alouctte aurait signifié oiseau qui loue, qui célèbre soit l'auteur de la lumière, soit le retour de la clarté, la naissance du jour, si l'on jugeait trop mystique l'interprétation adoptée par plusieurs modernes, et précisément fondée sur le rapprochement d'alauda et de laudare. Ou bien il aurait signifié l'oiseau qui, par l'élévation de son vol et l'ardeur de son chant, cherchait à s'attirer la louange. Le mot alleu, postérieurement, serait venu de la même racine prise dans le sens de partager. Dès lors, s'expliquerait le rapport existant, non-seulement entre alleu et alouette, mais encore entre plusieurs autres mots indiqués précédemment, et aloue, alouser, allouer, alauso, lauzetto, etc. Je donne ces conjectures sous toutes réserves. Néanmoins et dans tous les cas, je crois pouvoir maintenir que les alleuds, nom attribué à certaines localités, notamment en Anjou, ont vraisemblablement avec le mot alouette un rapport direct.

Je trouve enfio, dans une dernière hypothèse, une étymologie que je demande à présenter. Elle consisterait à faire dériver aloutte de deux anciens mots celtiques, al, "le, " et laouën, "joyeux. " Dans ce cas, 
l'alouette signifierait "l'oiseau de la gaieté," et il cût alor's très-bien convenu pour symboliser l'entrain des soldats gaulois et devenir notre emblème militaire et national.

P'our ceux qui auraient eru trouver dans la langue bretonne l'origine du mot alouette, la dernière étymologie que je viens de donner pourrait peut-être se fortifier encore par le mot dont se servent les Bretons pour désigner les pouillots, les roitelets et tous les petits oiseaux qui se font remarquer par leur agilité, par leur chant joyeux, et par leurs mouvements continuels. Ils les appellent luouënan, de laouën, "joyeux, " et an pour ezn, "volatiles, " c'est-ì-dire " joyeux oiseaux, oiseaux de la gaieté. ") Or, si une pareille expression peut être appliquíe avec raison à un oiseau, c'est surtout à l'alouette qui, à tous ces titres de la gaieté, du chant, du vol, serait parfaitement appelée " l'oiseau de la joie. "

On pourrait aussi laisser de côté la terminaison an et prendre pour racine du mot alouette, l'article al et le substantif laouën ; on obtiendrait alor's : "l'oiseau joyeux par excellence, " comme je l'ai dit, et l'on suivrait plus facilement encore la formation du mot alouette dans ses modifications successives, de allouën ou aloën en aloe, aloue et alouette.

ll est temps de clore cette discussion, dans laquelle j'ai déroulé le tableau de beaucoup d'opinions différentes. Pour faire connaître, ce qui est en moi une impression et un désir, plutôt qu'une conviction si difficile à se former, je voudrais que la science étymologique, mieux éclairée sur ce point, permît de s'attacher définitivement à l'explication la plus simple, la plus approprice de toutes au sujet, à celle que donne Court de Gébelin diuns son ouvrage du Monde primilif: Aland", "alouette, - nom "que les Romains empruntèrent des Gaulois; il fut très"expressif; lormé de al, "s'élever" et aud "chant," 
( mot à mot : « qui s'élève en chantant, ) ce qui carac" térise cet oiseau ${ }^{1}$. "

J'ai dû examiner chacune des hypothèses précédentes, ne fût-ce que pour exercer la sagacité des personnes qui aiment les problèmes d'une solution difficile. Dans un temps où les recherches historiques sont en si grand honneur, nul ne me reprochera, je l'espère, de m'être étendu sur un sujet qui n'intéresse pas uniquement la science ornithologique, mais qui se lie étroitement aussi à l'étude même de nos origines nationales.

Les alouettes ont beaucoup de traits de ressemblance avec les pipits; mais elles s'en éloignent par une taille moins élancée, par une queue courte et par une tête plate et arrondie. Ce genre renferme un grand nombre d'espèces dont quatre viennent, chaque année, se reproduire en Anjou.

ALOUETTE COCHEVIS. - ALAUDA CRISTATA.

L'alouctte cochevis, appelée en grec кorys et KorYDALos, et en latin cristata, " huppée, " doit son nom au petit bouquet de plumes étagées qui surmonte, comme une crête de coq, la tête du mâle et de la femelle, et représente assez bien un triangle, un peu comme le casque de nos sapeurs-pornpiers, en petite tenue. Le mot cochevis est composé de coche pour coq et de vis, ancien substantif qui était employé pour signifier ( visage. »

Le roman de la Rose, en parlant de Narcisse, dit :

Il vit en l'eau claire et nette

Son vis, son nez et sa bouchette.

Ainsi cochevis veut donc dire : " visage de coq, ressemblance de coq. )

Ce nom n'avait-il été donné à cette alouette qu'à cause

1 Dictionnaire étymologique de Court de Gébelin. 
de la huppe qu'elle porte? Sa ressemblanen avec le con n'était-elle pas aussi fondée sur sa vigilance et sur son chant matinal? L'alouette cocheris élève ou abaisse à volonté cette huppe, selon les impressions qu'elle éprouve. Onla trouve très-souvent sur les routes; elle cherche, dans les excréments des animaux, les grains d'avoine non digérés. A l'approche des passants, elle ne manifeste qu'une faible crainte, et, sans avoir recours au vol, elle s'éloigne d'eux en courant avec une rapidité et une grâce semblables à celles qu'on admire dans la démarche des goëlands et des mouettes. Cette grâce et cette légèreté sont un des priviléges de presque tous les oiseaux qui ne sont pas conformés pour se percher. Ne pouvant, dans leur fuite, se dérober à leurs ennemis en se reposant et en se cachant sur les branches et sous le feuillage des arbres, ils seraient condamnés à un vol continu et très-fatigant, si la Providence ne leur avait donné une ressource puissante dans leur course rapide, dont les avantages s'accroissent encore par un exercice incessant.

L'alouette cochevis se tient sur les côtés de la route pendant quelques instants pour laisser circuler les voyageurs, et revient ensuite continuer ses investigations. Si le chemin est étroit, et que l'alouette se sente encore trop près des hommes, elle voltige, se pose sur les murs ou sur quelque monticule, attend avee calme et patience l'éloignement de ses ennemis, pour reprendre ensuite sa première occupation. Cette alouette ne vit pas en troupes nombreuses, comme l'alouette des champs; mais on la trouve en petites bandes, qui semblent être la réunion des différentes générations d'une même famille. Dans ce cas, un des membres les plus âgés ou les plus expérimentés se tient ordinairement en sentinelle sur un point culminant, et fait entendre, de temps en temps, un signal, pour prévenir ses congénères de veiller avec persévérance, et de fuir quand le péril se manifeste. Alors 
tous les individus de la bande jettent un petit cri, qui semble être un signe d'obéissance à l'avertissement reçu et, en même temps, un mot d'ord̉re répété aux retardataires et aux insouciants. Dans leur fuite, ces alouettes s'élèvent à une petite hauteur par des bonds multipliés.

Leur vol saccadé et leur taille peu élancée donnent à ces oiseaux une certaine ressemblance avec les rapaces nocturnes.

Les alouettes sont des oiseaux pulvérateurs, caractère qui les rapproche des gallinacés, et explique pourquoi elles recherchent les terrains sablonneux.

Elles vivent de graines, de sauterelles et d'œufs de fourmis.

Le cochevis niche à terre; il choisit un pas de bœuf ou de cheval, et y réunit quelques brins d'herbe, sur lesquels la femelle dépose quatre ou cinq œufs.

Quelquefois il place son nid au milieu d'une touffe d'herbe ou dans les blés. Ces œufs sont d'un gris roussâtre ou jaunâtre, ou d'un cendré clair parsemé de taches ou de points bruns et roussâtres. Ils portent assez souvent une couronne vers le gros bout.

On trouve fréquemment une variété d'œufs plus gros, plus colorés et plus luisants que ceux que je viens de décrire.

Leur grand diamètre varie de $0^{\mathrm{m}}, 019$ à $0^{\mathrm{m}}, 022$, et le petit de $0^{\mathrm{m}}, 014$ à $0^{\mathrm{m}}, 017$.

ALOUETTE DES CHAMPS. - ALAUDA ARVENSIS.

L'alouette des champs recherche plus que ses congénères les terrains cultivés; c'est à cette préférence qu'elle doit ses noms.

Plus multipliée que le cochevis, l'alouette des champs présente deux variétés bien distinctes. 
Celle qui séjourne dans l'Anjou, et qui s'y reproduit, a des proportions plus grandes que celle qui arparuît dans les temps de froid ou de neige.

L'alouette des champs est douée d'une voix trèsagréable et très-étendue; elle se plaît à la faire entendre pendant qu'elle décrit dans les airs des cercles concentriques, comme ceux des rapaces qui veulent étourdir leurs victimes.

Elle s'élève à des hauteur's considérables, pour redescendre ensuite, avec la rapidité de la balle, quand elle est menacée par un oiseau de proie ou attirée par un sentiment d'amour.

Lorsqu'un de ces motifs ne la sollicite pas à accélérer son vol, elle descend lentement en étendant ses ailes. Elle semble se complaire dans cette manœuvre; on dirait un aéronaute jonissant arec délices de toutes les ressources de son parachute.

Cette alouette niche dans les herbes, dans les blés, dans les bruyères, ou entre les mottes de terre; elle prépare elle-même un petit creux en grattant la terre avec ses ongles. Elle le remplit d'herbes fines et délicées, de mousse, de racines, et y dépose de trois à cinq œufs, d'un blanc sale, nuancé de verdâtre, et parsemé d'un grand nombre de petits points noirâtres, qui forment une seconde couche plus foncée que la première.

Quelquesuns portent vers le gros bout une couronne composée d'une seconde couche de petits points. Lorsque ces œufs sont récemment vidés, ils ont une teinte générale beaucoup plus noire que celle qu'ils conservent plus tard. Leur grand diamètre rarie de $0^{\mathrm{m}}, 021$ à $0^{\mathrm{m}}, 023$, et le petit de $0^{\mathrm{m}}, 015 \mathrm{à} 0^{\mathrm{m}}, 017$.

\section{ALOUETTE LULU. - ALAUDA ARBOREA.}

La tête de l'alouette lulu est surmontie d'une huppe, qui diffère de celle du cochevis en ce que les plumes qui 
la composent ne sont pas étagées, ni terminées en pointe. Cette espèce doit son nom au chant qu'elle fait entendre quelquefois : lu lu lu lu. Cependant son véritable chant est : budu li, budu li; il est peu gracieux. Cette alouette contrefait aussi, mais d'une manière ridicule, le chant des autres oiseaux. Elle ne vit pas en bandes nombreuses comme l'alouette des champs; mais elle se réunit par petites troupes. Elle se plaît dans les lieux accidentés et incultes, dans les vignes et dans les landes. Elle se perche quelquefois, et c'est à cette habitude, tont exceptionnelle parmi les alouettes, qu'elle doit son épithète arborea, alouette "des arbres. "

L'alouette lulu s'élève moins haut que ses congénères, et dans son vol elle ne décrit pas de cercles concentriques. Elle niche à terre, dans les bruyères et dans les champs, à l'abri d'une motte ou d'une plante.

Elle réunit dans une petite cavité quelques racines ou des filaments d'herbes sèches, du crin, du coton, des plantes, et forme avec ces matériaux une coupe aplatie, sur laquelle la femelle dépose quatre ou cinq œufs d'un blane gris ou roussâtre, pointillé de gris et de brun. Quelques-uns de ces œufs portent une couronne comme ceux de la pie-grièche écorcheur. Les uns sont ronds, d'autres oblongs, d'autres ont une teinte rougeâtre avec des nuances d'un cendré pâle.

Leur grand diamètre est de $0^{\mathrm{m}}, 017$ à $0^{\mathrm{m}}, 020$, et le petit de $0^{\mathrm{m}}, 014$ à $0^{\mathrm{m}}, 017$.

ALOUETTE CALANDRELLE. - ALAUDA BRACHYDACTYLA.

Le mot calandrelle est un diminutif de celui de calandre, formé lui-même de KaLANDra, expression servant à désigner, chez les Grecs, la grosse alouette. 
Malheureusement M. Alexandre, dans son dietionnaire grec, met ì la suite du mot kalanora un $R$ suivi d'un point d'interrogation, pour indiquer que la racine de ce mot lui est inconnue; question indirecte qu'il adresse trop souvent pour la satisfaction de ceux qui recherchent le sens primitif des mots. Je me trouve done encore dans la nécessité de hasarder quelques hypothèses. Le mot kaLandios, kalaxiRa, dériverait-il de ralos, kaLe, KaLon, " beau, belle, " et de DÉnè, poétigue, pour téïra, " cou, gosier?" Alors calandre signifierait "beau cou, beau gosier? "

Cette interprétation se justifierait, dans la calandrelle, par le cercle de plumes blanches, en forme de couronne, placé des deux côtés de sa gorge, et encadrant une belle tache noire. Cette particularité a toujours frappé les populations; et en Provence, où l'on élève beaucoup de calandres, on les appelle couloussades, à cause de leur collier noir. Il est toutefois beancoup plus probable que le mot KALAXDRa, calandre, a traitaux ressources musicales de l'oiseau qui le porte. La calandre esî douée d'une voix très-étendue et très-agréable; de plus elle a le privilége de pouvoir joindre à son chant celui du chardonneret, du serin, de la linotte et de tous les oiseaux près desquels elle séjourne. En captivité, on peut lui apprendre très-facilement à imiter toute espèce de ramage; elle rend très-bien le miaulement de la chatte, le gloussement de la poule, etc. Marot (III, 33) relate, sous forme de légende, cette facilité de la calandre à imiter le chant de tous les autres oiseaux : "Incontinent que Viscontin mourut, son âme entra au corps d'une calandre ; ores qu'il est calantre devenu, il contrefait tous les oiseaux du monde. "

Dans le midi de l'Europe où elle est commune, on l'élève en grand nombre pour jouir de la variété de son chant. En Italie, on dit d'une personne qui chante très- 
bien : Elle chante comme une calandre. Ainsi, dans la patrie chérie de la musique, la calandre paraît détrôner même le rossignol ${ }^{1}$.

D'après ces considérations, plusieurs étymologistes ont donné pour origine à calandre les mots KaLôs, "bien, " et AÉïpô, "chanter. » Et si l'on voulait écrire, en adoptant l'ancienne forme grecque, chalandra, chalandre, l'étymologie, pour être différente, ne s'en rapporterait pas moins au chant de ce même oiseau. Ce serait alors CHalô, " relâcher, distendre, " mot qui s'y applique parfaitement. Car le propre de sa voix est de s'élever à une hauteur considérable, et d'en descendre ensuite par des inflexions rapides. Quelques auteurs prétendent que les anciens habitants de la Gaule appelaient les alouettes bardalis, nom qui semble appartenir à la même famille que le mot barde, par lequel on désignait ceux qui célébraient en public les hauts faits des guerriers et la gloire de la patrie. Si cette opinion était fondée, elle prouverait que, pour les Gaulois, l'alouette était le chantre par excellence. Peut-être aussi nos ancêtres avaient-ils trouvé quelque ressemblance entre le bardalis et le chant de l'alonette luhu. Je suis donc fondé à croire que les parti-

${ }^{1}$ On lit dans un ourrage italien (Lionello, par le P. Bresciani, chap. II, page 8) : "Au passage d'un golfe, une calandre harmo" nieuse s'élevait dans le ciel, droit comme une flèche; elle se " balancait dans les airs et les faisait retentir de son chant si " varié, de ses pauses, de ses passages, de ses roulades, de ses " groupes et de ses reprises : Alisa ne pouvait se rassasier de "l'entendre, de la suivre de son regard dans son ascension, et " puis, retombant conme une pierre, se relevait et recommen" cait son chant joyeux. - Je vois, disait-elle, comment au tra" vail peuvent s'unir l'hymne de louange a la gloire de Dieu et " l'action de gràces pour la miséricorde et l'amour qu'il a témoi" gnés à ses créatures. Cette calandre parcourt les airs; elle va " et rient, elle monte et descend, jamais elle ne s'arrète, jamais " elle ne suspend son cantique naturel." 
cularitís du plumage de la calandre et de la calandrelle, et surtout les habitudes musicales de ces oiseaux, semblent justifier les étymolegies que je soumets à l'appróciation des savants.

Ne pourrait-on pas prendre le mot calandre dans le même sens que l'instrument employé à imprimer les étolfes, et auxquels on donne pour racine kruminos, " cylindre, " parce qu'il est de forme ronde ? Cette acception de calandre serait alors fondée sur les différents cercles blancs et noirs qui se déroulent, en s'encadrant réciproquement, et embellissent les deux côtés du cou de la calandre et de celui de la calandrelle.

Enfin, l'habitude de ces oiseaux, de descendre des hauteurs où ils se sont élevés par une série de cercles concentriques en forme de spirale, ne servirait-elle pas encore à justifier la dernière acception donnée au mot calandre, puisqu'en effet, dans leur vol, ils semblent décrire un véritable cylindre? A l'appui de cette hypothèse, je peux invoquer le mot girolle, nom vulgaire donné à la calandre dans sa véritable patrie. Cette dénomination, adoptée généralement en Italie, dériva de girare, " tourner sur soi-même. ')

M. Littré dit que calandra vient probablement de caliendrum, bonnet, de callywtron, "ornement. " Ce qui signifierait que cet oiseau a été ainsi appelé parce qu'il porte une huppe; assertion qui ne me parait pas fondée. Car il est évident que si telle était la racine du mot calandre, il devrait s'appliquer à l'alouette huppée et non pas à sa congénère dont la tête est dépourvue* d'ornement.

Le nom scientifique brachydactyle est composé de BR.icirs, " court, " et DactrLe, "ongle; " il a été donné à la calandrelle parce que cet oiseau a le quatrième doigt armé "d'un ongle court, " exception caractéristique pour les oiseanx de ce genre. 
D'après les explications données ci-dessus, il est facile de constater les nombreux points de comparaison qui existent entre le cnq et l'alouette. C'étaient, chez les Gaulois, deux oiseaux représentant les mêmes idées, et pouvant être adoptés indifféremment pour signifier le travail matinal, la vigilance, etc.

Cette considération nouvelle me conduit à proposer encore une étymologie du mot calandre. De ce point de vue, il me semblerait dériver naturellement de кaLéô, " appeler, exciter, provoquer, " et ANÈr, ANDRos, "l'homme, " et signifier alors " oiseau qui appelle, réveille l'homme, " qui le provoque et l'excite au travail. Un autre sens pourrait encore être donné au mot calandre, en l'expliquant par une particularité des mœurs de l'oiseau. La calandre et la calandrelle courent devant les chasseurs avec une rapidité si extraordinaire, que, dans le midi de la France, où ces oiseaux sont très-communs et où l'on a pu étudier leurs mœurs d'une manière plus exacte que dans les autres contrées, on leur a donné le nom de courrentia, "coureuses. ) Par cette course si particulière et si caractéristique, ces oiseaux ne semblent-ils pas " provoquer, défier » le chasseur? N'en serait-il pas de même pour leur chant?

Comme sa congénère, la calandrelle niche à terre, dans les landes, ou sous les mottes d'un sillon. Son nid se compose d'une petite cavité tapissée d'herbes, de quelques racines, d'herbes fines, ou de brins de foin; c'est là que la femelle pond quatre ou cinq œufs un peu " allongés, d'un blanc sale et grisâtre. La coquille est parsemée de petits points roux ou gris, très-peu apparents, et confondus de manière à former une seconde couche plus foncée que la première. Quelquefois les points sont plus multipliés vers le gros bout et composent une couronne ou une espèce de calotte. On en trouve dont la teinte brune et luisante les ferait accepter facilement 
pour certaines variétés du moineau friguet ou du pipit maritime.

Leur longueur est de $0^{\mathrm{m}}, 016$ à $0^{\mathrm{m}}, 018$, et leur diamètre de $0^{\mathrm{m}}, 012$ à $0^{\mathrm{m}}, 014$.

\section{DEUXIÈME GENIRE.}

\section{IESSANGE. - PARUS.}

Les mésanges composent un genre très-nombreux et remarquable par les mœurs des oiseaux qui sont groupés sous cette dénomination.

Vives, pétulantes et sans cesse en mouvement, les mésanges parcourent les villes et les campagnes, et visitent tour à tour les toits et les arbres, dont elles fouillent toutes les sinuosités, pour y saisir les insectes et les petits vermisseaux qui se cachent sous l'écorce ou dans les fissures du bois. Pour découvrir plus facilement leur proie, les mésanges prennent toute espèce de positions ; elles décrivent des spirales autour des branches, descendent la tête en bas, et conservent assez longtemps cette dernière position afin d'arriver plus facilement au but qu'elles se proposent. Souvent, fixées sur une feuille agitée par le vent, elles n'abandonnent leur frêle appui que pour en gagner un autre tout aussi mobile. Lorsque les feuilles sont desséchées et tombées à terre, elles les retournent dans tous les sens. Enfin, quand la neige ou le givre couvrent les arbres, les mésanges cherchent les insectes engourdis par le froid jusque sous cette enveloppe glacée, qui ne peut pas même dérober les victimes à l'audacieuse persévérance de leur's ennemis.

Elles se répandent ensuite dans les villes, visitent le dessous des toits en décrivant une série de courbes allongees, passent et repassent plusieurs fois dans les mêmes endruits, et ne quittent le théâtre de leurs inves- 


\section{- $283-$}

tigations que lorsqu'elles se sont assurées que rien n'a échappé à leurs regards scrutateurs. Dans leurs courses réitérées, les mésanges font entendre un cri strident et saccadé, cri de satisfaction ou de colère tour à tour, et même de rappel, car elles voyagent presque toujours en petites troupes. Semblables à des forbans, elles sentent le besoin de s'unir pour se livrer plus facilement à leurs déprédations; pour se défendre et pour attaquer, mais en même temps, par un sentiment de défiance réciproque, elles se tiennent toujours à une certaine distance les unes des autres. Si quelqu'une de la bande est forcée de suspendre sa course, par indisposition ou par quelque blessure, ses compagnes se précipitent sur elle, l'immolent, partagent ses membres, et se disputent surtout sa cervelle.

Si les mésanges se livrent à de telles violences contre leurs congénères, à plus forte raison doivent-elles les exercer à l'égard des autres oiseaux, soit en liberté, soit en captivité. Quand elles sont renfermées dans des volières, elles brisent à coups de bec la tête de leurs compagnons d'infortune, et montrent, dans cette circonstance, toutes les faces de leur détestable caractère.

Les mésanges attaquent les chouettes et les oiseaux beaucoup plus gros qu'elles, et cherchent surtout à leur crever les yeux, pour être plus certaines d'un triomphe complet. Elles se défendent de l'homme, en se mettant sur le dos, à la manière des rapaces, et se servent alors, avec un acharnement et une intrépidité remarquables, de leurs ongles et de leur bec.

Les mésanges mordent opiniâtrement, et souvent alors on éprouve de la difficulté à leur faire lâcher prise. Elles vivent non-seulement d'insectes, mais encore de graines qu'elles brisent avec leur bec, après les avoir assujetties sous leur's doigts. Assez souvent, ces oiseaux percent, avec beaucoup d'adresse, l'enveloppe des baies ou des 
fruits, et en enlèvent le contenu, au moyen d'un trou qui ferait honneur ì un onvrier exercé. Si les mésanges rendent d'immenses services, en détruisant une grande quantité de chenilles, de larves, de vers et de petits insectes, elles exercent aussi de terribles ravages dans les verger's qu'elles parcourent, et où elles attaquent les boutons des arbres fruitiers. Elles occasionnent des pertes réelles dans les lieux habités par les abeilles, dont elles immolent un nombre considérable ; aussi les anciens appelaient-ils la mésange, avis apibus inimica, "l'oiseau ennemi des abeilles. ")

Quant aux noms scientifiques et vulgaires consacrís à désigner ces conirostres, peut-être ont-ils une commune origine. En effet, l'audace, la force, la méchanceté et la vivacité des mésanges ont dû étonner les observateurs, quels qu'ils fussent et, en particulier, les naturalistes, lorsque ceux-ci rapprochaient ces qualités des dimensions si petites de ces conirostres. Dès lors, l'attention des auteurs aurait été fixée sur la petite taille des mésanges, et leur petitesse serait devenue la base de leur nom. Ainsi, parus ne serait qu'une corruption de parvus, "petit, " comme parum l'est de parvum, comme, d'après la même idée, mésange dériverait aussi de mËios, «inférieur, plus petit. "Malheureusement l'a est long dans parus, et bref dans parum, ce qui paraît s'opposer absolument à l'adoption de cette étymologie; néanmoins elle semblerait être confirmée par le nom que les Anglais donnent aux mésanges : ils les appellent titmouses, "petites souris, petites rongeuses. ») Quant à l'autre étymologie greçue, MËîoò, elle me semblerait, au moins, plus naturelle que celle qui est adoptée par le plus grand nombre des auteurs, et qui fait dériver mésange de meseck, mot employé en Allemagne pour désigner cet oiseau.

Le père Labbe prétend que la dénomination mésange a été donnée à ces conirostres à cause du "mélange " 


\section{$-285-$}

très-varié de leurs plumes. Il appuie son opinion sur le mot mesk qui signifie "mélange, " ainsi que sur le grec miscô, et le latin misceo. Alors, cette étymologie reposerait sur les différentes bandes noires, bleues, blanches, etc., qui diversifient le plumage des mésanges, et le rendent assez agréable dans son ensemble.

Je pense que l'on pourrait encore hasarder l'étymologie suivante :

Le mot mésange ne serait-il pas composé de deux noms celtiques, mes, "beaucoup, " et angen, "cruel, inexorable, ") d'où est venue probablement la vieille dénomination française angir signifiant "tourmenter, vexer, " et le mot angoisse, toujours usité? Angen représente aussi, dans l'ancien allemand, l'idée de "presser, " de ( serrer, ) de "violenter. ) En grec angkнô a le même sens, et est probablement le principe de toutes ces locutions. En l'alliant avec MÉsos, ( milieu, ) il signifierait : "qui étrangle par le milieu; " et, d'une façon comme de l'autre, le mot mésange retracerait d'une manière exactc le caractère de ces petits tyrans.

Les mésanges se livrent à des investigations incessantes, non-seulement pour se procurer leur nourriture de chaque jour, mais aussi afin de se préparer des provisions pour l'hiver. Elles entassent des graines dans les trousdes arbres, et c'est dans ces réserves qu'elles puisent pendant les jours de disette. Malheur aux oiseaux téméraires qui voudraient recourir à ces greniers d'abondance! Car les mésanges ne pratiquent pas la vertu de charité. Dans cette circonstance, elles défendent leur propriété avec un courage qui tient de la fureur, et qui prouve qu'elles n'admettent pas, en ce qui les concerne, les idées de certains politiques trop enclins au partage du bien d'autrui.

Les plumes de leur tête se dressent comme une huppe, tandis que leurs cris métalliques décèlent l'indignation 


\section{$-286-$}

qui les"anime et qui décuple leurs forces. C'est alors qu'elles se précipitent sur leurs ennemis, se cramponnent ì leur dos, et leur ouvrent le crâne à coups de bec, à moins qu'elles ne soient forcées de succomber sous les serres d'un ennemi beaucoup plus puissant qu'elles. Dans ce eas même, le vainqueur a de la peine à se débarrasser de sa victime, dont les ongles restent profondément attachés au corps de son adversaire.

Si les mésanges défendent avec énergie leurs trésors, elles pillent sans scrupule celui des autres oiseaux, même de ceux qui sembleraient devoir leur paraître sacrés. Elles brisent les œufs qu'elles trouvent dans les nids, et attendent que la mère se soit éloignée de ses petits, pour se précipiter sur eux et les dévorer avec une avidité féroce. Cette habitude cruelle ne pourrait-elle pas fournir une autre étymologie du mot mésange? Ne sembleraitil pas formé des dénominations, ange, "messager,» et més, " mauvais? " (La particule més donne presque toujours au mot, auquel elle est jointe, une signification odieuse, exemple : més-alliance, més-estime, més-intelligence, més-aventure, etc.) Dès lor's mésange serait synonyme de messager " méchant, cruel, qui porte le ravage et la mort dans ses courses perpétuelles, qui ne respecte rien, " pas même les petits de ses congénères. Enfin, les mésanges pondent un très-grand nombre d'œufs; elles sont, de tous les oiseaux, ceux dont la fécondité est la plus grande. En français on appelle mésange une femme, mère d'une nombreuse famille. Le mot mésange ne pourrait-il pas lui-même aroir une étymologie d'accord arec cette dénomination? car anger signifie se propager, se multiplier, et més-ange représenterait exactement l'oiseau qui se multiplie beaucoup et pour le mal. De même le mot parus semblerait peut-être à quelques personnes une abréviation de partus, ce qui me reporterait à un souvenir de mes jeunes années. 
A Saumur s'élève une belle chapelle, bien chère à tous ceux qui croient et qui prient, à tous ceux qui aiment à déposer, dans les sanctuaires de la Mère de Dieu, leurs joies et leurs douleurs, leurs espérances et leurs craintes. L'église de Notre-Dame-des-Ardilliers, dont les dalles ont été mouillées par les larmes du repentir ou de la reconnaissance de bien des milliers de pèlerins, porte, autour de son dôme, cette inscription, que les bienfaits de la Mère de Dieu ont aussi gravée dans tous les cœurs catholiques:

\section{Virgini Deiparea, A la Vierge Mére de Dieu.}

Ces paroles, expression du symbole de nos pères, y furent placées dans le siècle où tous les grands génies, qui composaient l'auréole de gloire de Louis XIV, aimaient à manifester, dans leurs chefs-d'œuvre de toute nature, leur foi catholique et leur culte d'amour et de reconnaissance pour la Nlère de Dieu. La main sanglante de la Révolution respecta cette devise, tout en faisant disparaître celle qui se rapportait au grand Roi. Or, ces paroles furent traduites, il y a quelques années, par un ministre protestant de Saumur, MI. Duvivier, et mises, selon lui, à la portée des fidèles. M. Duvivier écrivit que cet exergue était un acte d'idolâtrie et signifiait : " A la Vierge, égale à Dieu. " II. Desmé de l'Isle prouva trèsfacilement à M. Duvivier, dans une petite brochure pleine de logique et de bon sens, que le ministre protestant ignorait les premiers éléments de la langue latine, et que Deipara n'a jamais signifié égale à Dieu, mais Mère de Dieu.

Parus, comme la terminaison para, semblerait donc impliquer une idée de "génération " et aurait pour racine, pario, "enfanter. " Un grand nombre des mots qui représentent, en latin ou en français, une idée d'enfantement, soit spirituel, soit naturel, commencent par 
la même syllabe par, parents, parrains, etc. Nais la prosodie vient encore s'opposer à cette hypothèse, si bien fondée cependant sur la nature des mésanges. Deux vers latins, où parus figure avec sa quantité correcte, vont peut-être nous fournir la véritable étymologie de parus, en nous montrant que c'est un mot latin formé, par onomatopée, da cri de la mésange. Elle fait entendre, en effet, une voix stridente, métallique, qui avait particulièrement fixé l'attention des anciens :

On lit dans l'auteur du petil poème intitulé Philoméle'

Parus enim quamvis per noctem tinniat omnem, At sua vox nulli jure placere potest.

" La mésange aurait beau prolonger toute la nuit ses notes aiguës, il n'est personne à qui sa roix puisse justement plaire. " La mésange semble répéter de cette roix de scie qui l'a fait appeler le serrurier : para! ou parra! d'où, en changeant la dernière syllable : parus. Ce nom serait donc fondé, d'après les anciens auteurs, sui' le cri de la mésange, lequel dans tous les pays a frappé ceux qui l'entendaient, et déchire les oreilles les moins sensibles à l'harmonie.

Quoi qu'il en soit, la fécondité des mésanges se trouve combattue par l'excès de leur audace et de leur pétulance; en effet, un très-grand nombre de ces oiseaux se laissent prendre à la pipée, et, dans ce cas, elles sont les victimes de leur caractère cruel qui les entraine à se précipiter sur les chouettes, sans se préoccuper des piéges tendus sous leur's pas. C'est ainsi que la soif du sang les fait déroger à leur défiance habituelle; car elles prennent, dans l'ensemble de leur vie, mille précautions pour Échapper à leur's ennemis. Jamais elles n'entrent dans un trou d'arbre, pour y déposer des provisions ou pour

' Cité par Aldrovande. 
y passer la nuit, sans avoir regardé plusieurs fois si leur démarche n'est pas surveillée, ni même soupçonnée.

MÉSANGE CHARBONNIERE. - PARUS MAJOR.

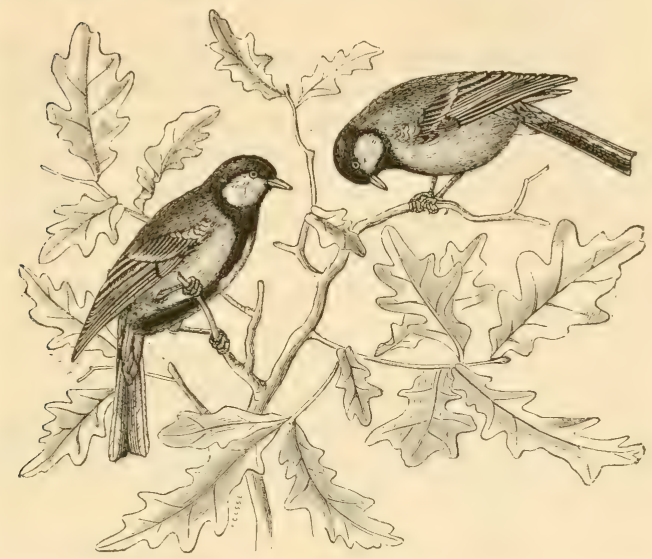

La Mésange charbonnière aime et recherche les pays plantés d'arbres fruitiers. Ceux-ci lui offrent une nourriture abondante; car les lichens qui les couvrent sont. autant de retraites favorables où se cachent les insectes, qui trouvent dans leurs replis multipliés où déposer leurs œufs et leurs larves. C'est là aussi que la présence des mésanges est utile; c'est là par conséquent que Dieu les multiplie davantage, pour qu'elles viennent en aide aux agriculteurs, en préservant les fleurs et les fruits des ravages des chenilles et des vers. L'épithète latine major indique que cette espèce est la plus grosse du genre. Quant à l'adjectif français charbonnière, il fait connaitre une particularité du plumage de cet oiseau. Une espèce 
de capuchon d'un noir brillant et lustré couvre la tête de la mésange charbonnière, et s'étend sur son cou. Enfin, un large plastron de la même couleur règne depuis le dessous du bec jusqu'aux pieds, et justifie la dénomination de charbonnière qui sert à la distinguer de ses congénères.

L'opinion de quelques auteur's, qui prétendent que cette mésange doit son nom à l'habitude qu'elle a d'établir son nid dans les huttes des charbonniers, n'est nullement fondée. En effet, la mésange recherche pour se reproduire, non les bois, mais les vergers; elle établit son nid dans les trous des arbres fruitiers, et quelquefois dans ceux des murs des enclos. Ce nid est composé de mousse, de plumes, de crins, de lichens, et prend la forme et les dimensions de l'endroit auquel il est confié. Il contient de huit à douze œufs d'un blanc rose, quand ils sont frais et non vidés. Leur coquille est parsemée de taches rousses dont les dimensions s'étendent souvent ì mesure que ces taches se rapprochent du gros bout. Le grand diamètre de ces œufs varie de $0^{\mathrm{m}}, 013 \ddot{3} \mathrm{a} 0^{\mathrm{m}}, 018$, et le petit de $0^{\mathrm{m}}, 012$ à $0^{\mathrm{m}}, 014$.

Dans le midi de la France, la grosse charbonnière a reçu le nom vulgaire de saraïé, c'est-à-dire de serrurier, à cause de son cri aigu et saccadé qui ressemble à celui que produit le fer lorsqu'il est scié avec rapidité. Ce cri, que l'on entend souvent ì l'époque du printemps, le long des routes, dans les pays ombragés, a quelque chose de triste et de sinistre.

\section{MGSANGE PETTE CHARBOYYLRE. - PARIS ATER.}

Cette mésange doit son nom latin ater à la couleur noire de son plumage, et son épithète française aux dimensions de sa taille inférieure à celle de la précédente. Moins défiante que queliues-unes de ses congénères, 
elle habite les lieux plantés de bois de sapins et d'arbres verts. Son chant n'est pas aussi fatigant ni aussi monotone que celui de la plupart des autres mésanges. Elle est encore plus pétulante et plus vive que les autres espèces de la même famille. La petite charbonnière vit en bandes peu nombreuses, dont chacune choisit un chef chargé de veiller à la sûreté commune, et d'avertir tous les autres membres à l'approche du danger. Cette mésange niche dans les trous des arbres fruitiers; ses œufs, au nombre de huit à dix, sont d'un blanc rose ou mat, selon qu'ils sont pleins ou vides; ils sont parsemés de taches d'un rouge assez vif. Le petit diamètre est de $0^{\mathrm{m}}, 010 \mathrm{à} 0^{\mathrm{m}}, 012$, et le grand de $0^{\mathrm{m}}, 013$ à $0^{\mathrm{m}}, 014$.

Chaque année, cette mésange traverse l'Anjou; mais sa présence, à l'époque de la nidification, n'a pas encore été suffisamment constatée. Aussi, l'opinion la plus commune et la mieux fondée admet-elle que, si la petite charbonnière se reproduit dans notre département, ce cas est plutôt une exception qu'une habitude.

\section{MÉSANGE Bleue. - PARUS Geruleus.}

De toutes les mésanges, celle-ci est la plus répandue; ses couleurs si vives et d'un bleu d'azur justifient les épithètes qui lui ont été assignées dans toutes les langues. Plus solitaire que ses congénères, elle vit, comme elles, d'insectes et de vers; mais quand cette nourriture lui manque, elle s'abat dans les jardins où elle exerce des dégâts considérables, en s'attaquant aux boutons des arbres fruitiers. Souvent même, elle détache le fruit qui commence à se former, et elle l'emporte dans ses greniers de réserve. Cette mésange a un appétit très-prononcé pour la chair, et, lorsqu'elle rencontre quelques cadavres de petits mammifères ou d'oiseaux, elle s'acharne sur ces débris avec une voracité et une persévérance in- 
rroyables. Iprès son passage, on ne trouve plus que des squelettes dénudés, comme si le scalpel les avait fouillís dans trus les sens. Cet oiseau grimpe avec légèreté le long des tiges des roseaux et du sorgho pour y poursuivre des insectes, et ne craint pas, dans cette chasse, de se trouver en guerre avec les rousseroles et les autres calamolierpes dont elle se fait respecter et craindre. On la vrit, même pendant l'hiver, venir, sur les grandes routes,

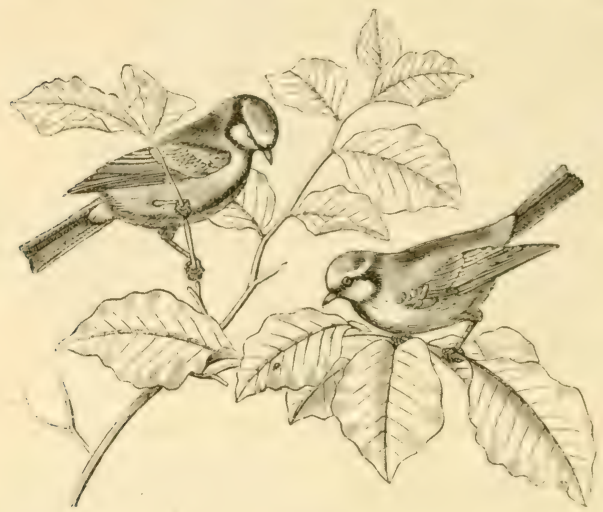

disputer avec succès aux bruants et aux moineaux les débris des graines qui se trouvent dans les excréments des chevaux.

Le nid de la misange blene, composé des mêmes matières que ceux des précidentes, est aussi confié aux trous des arbres fruitiers. Ses œufs, au nombre de sept à dix, d'un blanc mat ou couleur chair, sont parsemís de taches runges très-irrígulières et de points de mème couleur, plus abondants vers le gros bout. Le grand diamètre varie de $0^{\mathrm{m}}, 01 \mathrm{t} i \mathrm{i} 0^{\mathrm{m}}, 016$, et le petit de $0^{\mathrm{m}}, 012$ ì $0^{\mathrm{m}}, 013$. 
MÉSANGE NONNETTE. - PARUS PALUSTRIS.

La dénomination palustris, " de marais, " indique que cette mésange a les mêmes habitudes que la précédente, et qu'elle cherche souvent sa nourriture sur les tiges des herbes ou sur les roseaux des marais. Elle aime aussi à habiter les bois plantés sur lo bord des eaux, et qui lui offrent ainsi une double source de richesse. Quant à l'épithète nonnette, nonneta, elle est un diminutif de nonna, nonnce, terme de respect par lequel on désignait dans l'antiquité les aïeux et les aïeules, et qu'on donna ensuite, par déférence, aux persolnnes consacrées à Dieu, par la même raison qu'on appelle encore pères ou mères les membres de certaines congrégations. Ce mot représentait, chez les Romains, les personnes qui, avec une tendresse véritable, élevaient des enfants abandonnés. Aussi n'a-t-on pas manqué de le donner, à juste titre, à ces saintes filles, héritières de la charité de saint Vincent de Paul, qui remplacent auprès des enfants trouvés ou orphelins, des parents morts ou dénaturés.

Cette dénomination, qui a été étendue à toutes les personnes consacrées à Dieu, a, si l'on en croit certains étymologistes, pour racine, Noos, Noûs, (entendement," мó́īn, "penser, méditer, " et représente ainsi tous ceux qui appuient les œuvres de leur vie sur des pensées sérieuses. Dès lors, on trouverait moins étonnant que, dans notre siècle de légèreté et d'irréflexion, le mot nonne ne fût pas compris, et qu'il fût devenu un terme propre à jeter le ridicule sur les personnes auxquelles il est attribué. Il y a tant de gens qui fuient les pensées sérieuses, tant qui craignent de se retrouver en face d'eux-mêmes! assez semblables en cela à ceux qui ne veulent pas établir ni vérifier la balance de leurs affaires, dans l'appréhension qu'ils éprouvent de voir se dresser 
devant cux un effrayant déficit. Erreur dangereuse cependant! car un abîme qu'on ne sonde pas inspire moins de terreur, il est vrai; mais il engloutit subitement et sans retour.

Je dois dire, néanmoins, que le mot nonne dérive avec beaucoup plus de vraisemblance, soit de l'égyptien nomn, "religieux, " soit du grec Naxxa, Naxxe, " tante maternelle, » auquel se rattache également, selon toute apparence, l'italien nonno, "grand-père, " et nonna, "grand'mère; " c'est d'ailleurs, et toujours comme on le voit, une idée de vénération que ces différents termes expriment par celle d'ancienneté. Nonne correspond à " prêtre, " presbrtéros, "plus âgé, vieillard."

Maintenant, pourquoi avait-on donné ce nom à la mésange des marais?

Les naturalistes ayant remarqué que la mésange des marais avait la tête entièrement noire, ont cru y trouver une ressemblance arec les voiles qui recouvrent la tête d'un grand nombre de religieuses; elle semble, en effet, aroir une espèce de capuchon; puis l'ensemble de son plumage est plus sombre que cclui des autres mésanges ; d'où les auteurs ont appelé cette mésange, la religieuse ou la nonnette.

Elle veille aussi arec un soin tout particulier sur ses œufs, et manifeste pour ses petits une tendresse vraiment remarquable.

La mésange nonnette niche comme les précédentes. Ses œufs, au nombre de six à dix, sont régulièrement plus longs que ceux de ses congénères, et portent versle gros bout une couronne de points rougeâtres. Ces points sont ordinairement moins larges que dans les cufs décrits antérieurement.

Leur longueur varie de $0^{\mathrm{m}}, 014 \mathrm{a}$ à $0^{\mathrm{m}}, 018$, et leur diamètre de $0^{\mathrm{m}}, 010$ à $0^{\mathrm{m}}, 012$. 
MÉSANGE HUPPÉE. - PARUS CRISTATUS.

Cette mésange doit son nom à l'aigrette, crista, ou huppe qui orne sa tête et lui donne un aspect tout particulier. C'ette huppe est formée de plumes acuminées, noires et bordées d'un filet blanchâtre; elles sont étagées et réunies en pointe. De loin, ces plumes représentent une corne triangulaire, dont la base

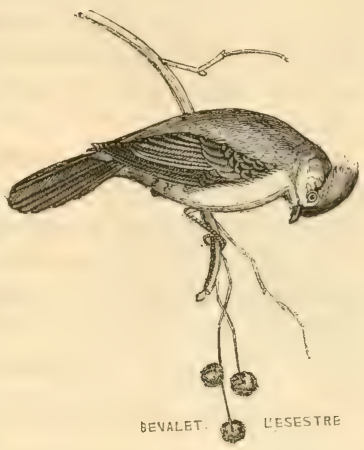
repose sur la tête de la mésange.

Celle-ci habite en grand nombre les forêts des Alpes. Pendant longtemps, les naturalistes ont pensé qu'elle ne faisait que traverser l'Anjou au moment de ses migrations. Les recherches persévérantes de M. Raoul de Baracé ont démontré que la mésange huppée s'arrête dans notre département pour s'y reproduire, et que, dans certairies localités, elle se trouve en aussi grand nombre que les autres mésanges. Aux environs du Lion-d'Angers, où elle est très-multipliée, il a été constaté que si sa présence avait été ignorée au moment de la nidification, c'est que cette espèce travaille à la construction de son nid plus tard que ses congénères : les feuilles des arbres fruitiers étant alors très-développées, la mésange huppée arrive plus facilement à dissimuler ses courses et à dérober aux regards les trous qu'elle a choisis pour élever sa petite famille. Ses œufs varient de six à dix; ils sont blanes et parsemés de grosses taches d'un rouge assez vif. 
Le caractère qui sert à le distinguer des œufs des autres mésanges, et spécialement de ceux de la grosse charbonnière, est la forme ronde qu'ils affectent souvent, et surtout les dimensions des taches réunies ordinairement vers le gros bout en forme de couronne, et qui sont beaucoup plus rondes et plus larges que dans les autres espèces.

Le grand diamètre est de $0^{\mathrm{m}}, 014 \mathrm{t}$ à $0^{\mathrm{m}}, 016$, et le petit de $0^{\mathrm{m}}, 011$ à $0^{\mathrm{m}}, 013$.

Buffon prétend que la chair de cette mésange est parfumée, à cause des graines de genévrier dont elle se nourrit dans les pays de montagnes, où elle vit en petites bandes.

\section{MÉSANGE A LONGITE QIETL. - P.IRIS CALDITIS.}

Cette mésange, la plus petite de toutes celles qui visitent l'Anjou, vole avec la rapidité et la grâce d'une flèche lancée par une main puissante et habile. Elle doit peut-ître cette vitesse à la longueur de sa queue, qui dépasse même celle de son corps, et lui imprime un mouvement accéléré et. quelquefois ondulé. Les deux noms, l'un scientifique, l'autre vulgaire, de cette mésange sont dus à la longueur de sa queue. Ce gracieux petit oiseau aime à vivre en famille, et, dans cette espèce, la famille est nombreuse, car chaque femelle pond de douze à vingt œufs. Les uns sont ronds, d'autres oblongs; quelquesuns sont tachés, d'autres parsemés de petits points rougeatres formant quelquefois une couronne vers le gros bout. Le grand diamètre est de $0^{\mathrm{m}}, 008$ ì $0^{\mathrm{m}}, 012$, et le petit de $0^{\mathrm{m}}, 00 \%$ à $0^{\mathrm{m}}, 007$. Le nid auquel sont confiés ces œufs a la forme d'une boule ovale; le haut est toujours plus large que le has. Ce nid, composi de mousse légère et de petits lichens liés entre eux par des tuiles d'araignée, est construit le long d'un arbre, arec la couleur 
duquel il se confond assez facilement. Pour dissimuler davantage à la vue leur charmant petit travail, le père et la mère choisissent ordinairement comme point d'appui la naissance d'une grosse branche. Celle-ci fortifie le travail, et contribue à tromper les regards des ennemis de la jeune famille. L'intérieur du nid est revêtu d'un véritable lit de plumes. Une ouverture très-ronde, pratiquée sur le dôme de l'édifice, donne passage à la femelle. Souvent une seconde ouverture est ménagée pour faciliter l'entrée et la sortie du mâle, qui vient apporter à sa compagne de la nourriture pendant le travail de

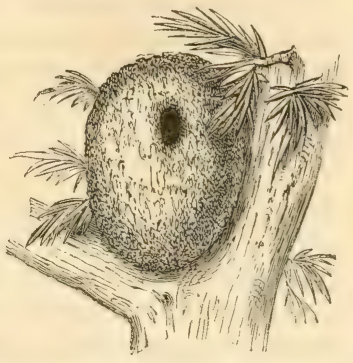
l'incubation. Cette deuxième ouverture est presque nécessitée par la longueur de la queve de cet oiseau. Les ouvertures se trouvant placées l'une vis-à-vis de l'autre, les mouvements deviennent plus faciles et la mésange à longue quene n'est point forcée de tourner sur ellemême dans une enceinte très étroite. Cette deuxième porte est fermée après l'éclosion des œufs. Le plus souvent, une seule ouverture est pratiquée dans ces nids, et la seconde ne paraît être que le travail des mésanges plus âgées, plus expérimentées, plus industrieuses ou plus coquettes. Cette mésange, comme les troglodytes, les roitelets, les pouillots et tous les petits oiseaux qui nichent en plein air et doivent élever une nombreuse famille, donne à son nid la forme ronde. La chaleur que la pauvre mère développe, au prix de bien des fatigues, se conserve plus facilement sous la voûte de ce petit four ; elle s'élève, frappe les parois intérieures du dôme construit avec tant de soin, et retombe en faisant sentir à la 
mère, aux œufs et plus tard aux petits, une douce et sa-lutaire influence!

Benedicite, omnes volucres coli, Domino! O vous tous, petits oiseaux du ciel, bénissez le Seigneur! bénissez le Seigneur qui veille sur vous avec tant de sollicitude et d'amour!

Cette mésange pourrait, aussi bien que la nonnette, être appelée palustris, car elle se trouve, surtout pendant l'hiver, presque continucllement dans les osiers et dans les arbres qui croissent sur le bord des rivières ou des étangs.

MESANGE MOLSTACHE. - PARES BIMRIICES.

La belle bande noire, veloutée et presque triangulaire qui orne la tête du mâle et s'étend en pointe des deux côtés du cou, justifie l'épithète vulgaire qui a étó donnée à cette espèce. Quant à l'adjectif biarmicus, il indiqque la contrée où cette mésange est assez multipliée, la Biarmie, actuellement nummée Permie, vaste étendue de pays comprenant les gouvernements de Vologda et d'Arkangel.

Le nid de la mésange moustache est très-artistement composé d'herbes sèches, de fleurs, de duvet et de mousse. Il ressemble à une boule ou à une bourse. Ordinairement, l'ouverture est pratiquée en dessus. Ce nid est attaché, par des filaments de plantes, au-dessus des eaux, à des roseaux ou à des branches de petits arbustes. Il renferme de cing à huit cufs ronds, d'un blanc d'ivoire, parsemé de taches d'un rouge pâle; ils portent aussi des filets de même nuance, en forme de veines, et distribués en zigzag.

Cette mésange a des mœurs très-douces; clle vit d'insectes ailés, de semences de roseaux; elle ne craint pas l'approche de l'homme, et court à terre et sur les feuilles 
de nénuphar avec la même grâce que les bergeronnettes. Autrefois ce gracieux oiseau avait fait élection de domicile dans l'étang de Rou-Marson, où chaque année il se reproduisait. Par l'éclat de son plumage et par la rapidité de ses courses continuelles, il embellissait et vivifiait ce pays solitaire; malheureusement, la guerre persévérante qui lui a été déclarée l'a forcé à quitter une contrée dont il était un des plus jolis ornements. Cependant il s'y montre encore de temps en temps, mais à des époques irrégulières.

Le Parus biarmicus vit en petites troupes; les différents membres de la même famille s'appellent par un cri métallique assez semblable au son d'une petite clochette d'argent ou au son vibrant d'une mandoline. Les gens de la campagne, dans leur langage expressif, l'ont nommé trin-trin.

Buffon prétend que, lorsque ces familles émigrent ou se livrent aux travaux de la nidification, le mâle couvre la femelle de ses ailes, pendant les moments de repos, pour la préserver ou de la fraîcheur de l'air ou des rayons brûlants du soleil.

Le grand diamètre des œufs varie de $0^{\mathrm{m}}, 016$ à $0^{\mathrm{m}}, 020$, et le petit de $0^{\mathrm{m}}, 015$ à $0 \mathrm{~m}, 017$.

\section{TROISIËUE GENIRE.}

\section{BRUANT. - EMBERIZA.}

Ici s'arrêtait la deuxième édition de mes Essais étymologiques, car les mots bruant, emberize, s'étaient présentés à moi comme le Caj des Tempêtes; et, dans la crainte de m'exposer à un naufrage certain, il m'avait semblé sage de rechercher au préalable un pilote expérimenté, avec le secours duquel le terrible passage pût 
devenir le Cap de Bonne-Espérance. Ce pilote, j’allais partout le quêtant avec persévérance, sans pouvoir le rencontrer nulle part, lorsque l'un de mes savants contradicteurs me conseilla d'avoir recours au dictionnaire de M. Littré, prétendant qu'arec ce secours, l'explication des étynologies deviendrait facile, claire, etc. J'eus la naïveté de le croire, et non-seulement je m'empressai de consulter le travail du docte membre de l'Institut, mais j'achetai même toutes les livraisons mises à lú disposition du public, afin de pouvoir profiter des lumières résumées dans cet immense répertoire.

Je me hate donc d'y chercher le mot bruant, et voici ce que je lis : "Bruant, voy. bréant. "

Je passe à l'article bréant, et je transcris l'explication ainsi conçue qui figure sous ce mot: "Bréant, nom vulgaire de l'embérize citrinelle, dite aussi verdon et verdier. C'est un oiseau jaune de la grosseur d'un moineau. ")

Le renseignement ne me parut pas satisfaisant, car ce qui m'y semble le plus clair, c'est que, d'après. .I. Littré, le bruant n'est autre chose que le bréant, que le bréant est l'emberize citrinelle et que ce conirostre est appelé verdier et verdon parce que c'est un oiseau jaune de la grosseur d'un moineau! Aussi, déconcerté par l'impénitrable obscurité de ces étymologies, je me flattais au moins de trouver au mot emberize ce que j'avais cherché inutilement aux articles bréant et bruant. Je lis : " Emberize, nom moderne du genre Bruant. Scheler le tire de l'allemand emmeriz, emberitz; cmberitz dérive lujmême de ammer, qui signifie aussi emberize. "

En présence d'un exposé si concluant, je regrettais iine le savant auteur n'eût pas composé un dictionnaire allemand, car il eût pu y consigner, à l'usag̣e des fiermains, les renseignements dont il a gratifié les Français, et ils auraient lı: "Ammer, d'où sont dérivés emmeritz, emberitz, embrilz, et le français emberize qui si- 
gnifie aussi ammer. " Et alors la question eût été complétement élucidée pour les vrais savants. Quant à moi, n'y comprenant plus rien, je fis part de ma déception à mon conseiller. Celui-ci me répondit : Si M. Littré n'a pas indiqué d'autres étymologies que celles que contient son dictionnaire, c'est qu'il n'en existe pas. Après une telle sentence, il me fallait ou admettre cette décision et renoncer à ma conviction profonde en condamnant mes principes avoués, ou m'exposer à mériter de nouveau et plus que par le passé la note de téméraire, en m'affranchissant de la tutelle que j'avais acceptée, pour un moment et avec tant de confiance. Je me résigne donc à cette nouveile censure, et cela d'autant plus volontiers que j'ai l'espérance que mes hypothèses n'auront pas du moins l'inconvénient de voiler les lumières si vives projetées par les étymologies que fournit le dictionnaire de 11 . Littré.

Pour nous tirer d'incertitude, en ce qui concerne le bruant, je vais, ami lecteur, exposer, le plus clairement qu'il me sera possible, les mœurs de cet oiseau, qui me serviront, si je ne m'abuse, à expliquer son nom. Le genre bruant comprend un très-grand nombre d'espèces qui se subdivisent en deux sections, lesquelles se distinguent par leurs doigts. Une section est composée des espèces qui se perchent facilement et ont l'ongle postérieur court et courbé; l'autre se rapproche des alouettes, et renferme les espèces qui ont un doigt armé d'un ongle long, et plus ou inoins droit. Presque tous les individus du genre bruant ont le bec armé à l'intérieur d'un tubercule osseux, variant de forme selon les espèces, et qui leur sert à concasser leur nourriture. Cette disposition spéciale les a fait classer, avec raison, par quelques auteurs, dans la famille des Fringilles. Ce mot fringille me semble avoir pour racine eff ringo, "( briser, écraser, " qui, lui-même, dérive, ainsi que plusieurs autres composés, 
de frango, ayant le meme sens. Par le radical de ce dernier verbe, l'on remonte jusqu'au grec nuÉci

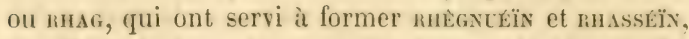
signifiant également "rompre, briser, déchirer. " Le tubercule dont est pourvu le bec du bruant est une sorte de meule, qui justifierait fort bien l'application du mot fringille, "briseur, broyeur, " meunier, si l'on veut.

Cependant, M. Millet persiste à ranger les bruants dans la famille des conirostres : il faut croire qu'il y a étí poussé par des considérations puissantes.

Les bruants ont un chant très-fatigant, que le proyer, le bruant de haies, le bruant jaune, le bruant des roseaux, etc., répètent le long des prairies, des haies ou des rivières. C'est ce bruit assourdissant qui les a fait appeler crécerelles, expression très-significative. Dans quelques pays on a comparé ce chant au cri de l'àne; c'est lui aussi qui a fait donner au bruant zizi un nom peu poétique. Bien plus, beaucoup de bruants répètent leur cri le jour et la nuit; ces oiseaux semblent partager leur existence entre deux fonctions : crier et manger, un peu comme les Romains dans les temps de décadence. Aussi avait-on profité de cette aptitude des bruants pour les engraisser et en alimenter la table des IIortensius, des Lucullus et des gastronomes, leur's successeurs. On clôturait un certain nombre de bruants dans des chambres hermétiquement fermées. Puis on éclairait ces appartements d'une manière continue au moyen de lanternes ou de lampes, et alors les bruants pouvaient manger et crier sans discontinuer : leur effigie aurait dù orner le mausolée de Sardanapale. Grâce à cet insatiable appétit, les bruants arrivent assez promptement à être, sons le nom d'ortolans, un des mets favoris des gastronomes de tous les pays et de tous les temps.

Une des espèces de bruants est disignée par Buffon et par plusieurs autres naturalistes sous le nom de la co- 
queluche. Or, d'après le dictionnaire de Bouillet, "la coqueluche est une espèce de rhume, ainsi nommé sans doute de ce que, pendant la quinte, la respiration des personnes qui en sont atteintes, devenue sonore, imite le chant du coq.» Si l'on admet cette explication, il s'ensuit que le bruant la coqueluche aurait pu mériter son nom parce qu'il se serait rapproché du coq par le chant désagréable qu'il fait entendre jour et nuit, et qui trouble le summeil des voisins.

Je ne cite cette explication de Bouillet que comme un simple renseignement; car plus tard j'en donnerai une autre qui me semble bien plus fondée.

De toutes ces observations, je pourrais, je crois, déduire déjà que le mot bruant dérive du verbe bruire, signifiant (crier d'une manière aiguë. ) Ainsi, Chateaubriand a dit : "Les serpents à sonnettes bruyaient de toutes parts.... Le vent bruit dans la forêt. ") Dès lors s'expliquerait naturellement pourquoi les gens de la campagne comparent le chant du bruant au cri de l'âne et à celui du faucon crécerelle, et pourquoi bruant et bréant sont synonymes.

Au xแI siècle, on lit dans Rone, page 8s : "Bruient li mont, et li val reson. "

Un clair ruisseau bruyant près de l'ombrage.

(MAROT.)

De plus, le mot "bruit » se rend, en langue wallon, par bruet, dans le dialecte bourguignon par bru, et dans le latin de la basse latinité par brugitus.

Selon Ménage, " broyer, réduire en poudre avec bruit, " pourrait dériver de l'ancien mot brai, boue, et signifierait alors " réduire en poussière. " Il y aurait donc dans ce nom deux idées exprimées : celle de broyer, brayer, "réduire en poussière, " et celle de bruit; deux idées qu'éveille d'ailleurs le motbraye, par lequel on dé- 
signe un instrument qui sert à broyer le lin et le chanvre, et dont le bruit monotone et agaçant peut etre comparé à celui que fait le bruant. Le chant de cet oiseau est encore assimilé avec raison par les gens de la campagne au son strident que produisent les cigales et les grosses sauterelles, lorsqu'elles frottent leurs élytres arec leurs longues pattes.

Enfin, un auteur a pensé que le bruant devait son nom au bruit qu'il fait entendre quand il s'envole; et ce bruit est en effet très-sensible, surtout dans le vol du proyer.

Quoi qu'il en soit de ces hypothèses qui me semblent assez plausibles, je crois pouvoir en avancer de plus fondées encore.

Tous les bruants, qu'ils aient l'ongle postérieur court ou long, droit ou courbé, tous vivent à terre ou dans les herbes, dans les prairies, dans les bruyères ou sur les rocher's; tuus se nourrissent de graines, de semences, de petites baies, d'insectes et de rermisseaux; ils sont omnivores. En outre, ils peuvent être facilement classís parmi les ventrus, et, comme tous les êtres de cette catégorie, ils absorbent beaueoup, pensent peu; oiseaux stupides, ils se jettent dans tous les piéges possibles, pourvu que derrière ces piéges, ils entrevoient une satisfaction de leurs appétits grossiers. Ils étuuffent aussi la roix harmonieuse des autres oiseaux par le bruit de leurs cris assourdissants. Enfin, comme conséquence de ces dispositions naturelles, les bruants virent plus près de la terre que du ciel : il leur paraît pénible de s'éloigner de cette terre; c'est près d'elle qu'ils uichent; c'est près d'elle qu'ils f́lèvent leur famille. Cette dernière particularité a dû certainement les faire séparer des véritables Fringilles; c'est là vraiment la ligne de démarcation entre les bruants et tous les autres gros-becs. Les bruants recherchent done les bruyères, les haies, les racines pour vivre et pour s'y reproduire; ce sunt lì 
les lieux qu'ils hantent, selon la vieille expression française. Or, les bruyères étaient appelés autrefois brue, et le menu bois bruaille; en breton, un pied de bruyère s'appelle brugen, et se prononce bruguenen. Le bruant serait donc l'oiseau qui " hante la brue, la bruaille, et même la brai, la boue. "

Cette explication, une fois acceptée, aurait l'immense avantage d'établir la vraie synonymie qui devrait exister entre bruant et emberize. Si, en effet, l'affirmation de MI. Toussenel était prouvée et que le mot emberize fût dérivé du grec, il pourrait avoir pour racines Éм pour ÉN,

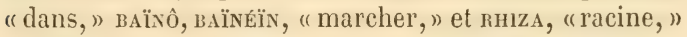
signifiant alors " oiseau qui marche parmi les racines, » et, dans un sens plus large, " oiseau qui vit au milieu des racines, au milieu des broussailles. „ Ce serait bien une dénomination essentiellement caractéristique, et qui ferait connaître une des habitudes spéciales au bruant.

Dans cette espèce, le père, la mère, les petits, tous sont doués d'un appétit dévorant; d'où il suit que, lorsque la jeune famille se développe, les parents ont peine à suffire à ses besoins. Pour simplifier alors leur travail, le père et la mère, qui ont établi leur nid à terre ou tout près de terre, peuvent, sans inconvénient pour leur's petits, les déterminer à sortir de leur berceau avant qu'ils soient capables de voler. Puis, comme la faim, chez les les bruants et chez ceux qui leur ressemblent, a une voix très-puissante, elle est facilement entendue, et elle devient très-promptement une bonne conseillère. Les petits cherchent entre les racines, dans les broussailles, dans les herbes, de petits vermisseaux; ils travaillent à se procurer une nourriture en rapport avec leur appétit, et viennent ainsi en aide à leurs parents. Chez toutes les autres espèces d'oiseaux, leз petits ne quittent le nid que lorsqu ills peurent voler, accompagner leurs parents et se dérober aux dangers qui 
les menacent. Pour les bruants, la faim l'emporte sur la crainte de la mort. Ce trait caractéristique se trourerait avec raison indiqué par la dénomination bruant on $\mathrm{cm}$ berize, en admettant toutefois les hypothèses précédentes, que je soumets ì l'appréciation de mes lecteurs.

Si ces étymologies ne sont pas d'une ividence rigoureuse, du moins paraitront-elles aussi lumineuses que d'autres, par lesquelles on fait dériver emberize du mot allemand ammer, sans en donner aucune explication.

Peut-être y aurait-il un moyen de simplifier la difficulté en écrivant hammer et non ammer. S'il en était ainsi, le mot hammer, signifiant, en allemand aussi bien qu'en anglais, " marteau, martinet, marteler, " il s'en suivrait que cette expression aurait alor's un sens trèsfondé, et qu'elle représenterait très-bien un oiseau dont le chant composé, selon les espèces, de deux ou quatre notes répétées toujours sur le même ton, ressemble assez bien ì un " marteau frappant d'une manière continue et assourdissante, ") et le mot emberize, donné au bruant, dériverait alors d'une expression qui permettrait de le traduire par celle-ci : "le frappeur, " ce qui justifierait la première de mes hypothèses.

Cette opinion me parait même d'autant plus fondée, qu'en Suisse, le bruant est appelé indifféremment $\mathrm{cm}$ meritz, embritz, emmerling, emmering, hemmerling.

Or", ce dernier mot signific aussi "bouffon, bruyant, fatigant, " ct justifierait non-seulement l'explication dans le sens de "marteau, " mais encore celle que nous avons donnée du mot cirlus. Li? mouvement de hochequeue continu qu'imprime à tout son corps le bruant l'identifierait encure, d'un autre point de vue, avec le " marteau " et le " martinet, " mis en mouvement, d'une manière régulière, par un moteur puissant, mouvement toujours accompagné d'un brait désagrrable.

Dans guelques contrées de lat France, on appelle le 
bruant roussette, ce qui prouve que les gens de la campagne ont été frappés de la nuance "rousse » ou " brune» du plumage de ces oiseaux, et qu'ils ont voulu en faire dominer le souvenir dans leur expression populaire.

Ici, comme dans bien d'autres circonstances, je ne veux pas décider quelle est la véritable étymologie du mot bruant. J'ai indiqué, en décrivant les mœurs de l'emberize, quelles pouvaient être les deux racines de cette dernière dénomination; toutes les deux me paraissent plausibles à certains points de vue. Je laisse donc à la sagacité de mes lecteurs le soin de conclure, et de voter pour l'une ou pour l'autre en toute liberté et sans crainte de blâme, avantage précieux qui ne m'a pas torjours été concédé.

Peut-être aussi, la véritable étymologie du mot bruant repose-t-elle sur une onomatopée, représentant d'une manière expressive le chant de cet oiseau, chant qui se rapproche de la syllabe " bru, bru, » répétée d'une manière assourdissante.

\section{BRUANT JAUNE. - CITRINELLA.}

Les deux épithètes jaune et citrinella, de citrinus, " couleur de citron, " ont la même signification, et rappellent la couleur dominante du plumage de cette espèce de bruant. L'emberize jaune est sédentaire en Anjou, et elle peut l'être à peu près dans tous les pays; car, grâce à son appétit très-développé et à son goût peu difficile à satisfaire, elle trouve toujour's quelque genre de nourriture pour assouvir sa faim. Les baies, les semences, les graines, les fruits, les insectes, les vermisseaux, lui fournissent tour à tour leur tribut. Quand le froid devient rigoureux et que la neige couvre la terre, on rencontre les bruants en troupes considérable sur les routes, où, mêlés aux pinsons et aux moineaux, ils cherchent 
quelques grains d'avoine dans les excréments des chevaux. C'est dans cette saison que ceux qui sont forcés d'abandonner les régions du Nord, alors couvertes de neige, se laissent prendre en grande quantité. Sur les versants des Alpes, les villageois tendent des filets ì l'une des extrémités de leurs hangars, et, lorsque les bruants jaunes s'aventurent sous ce toit inhospitalier, pour y manger les graines que l'on y a disséminécs comme un appat trompeur, les habitants poussent des cris sauvages, et les oiseaux se précipitent dans les lacets, où jls trouvent la captivité et la mort. En Belgique, on a recours ì une autre chasse appelée la $r a-$ maille. Un homme se promène, pendant une nuit obscure, le long des haies, avec ane torche allumée; les bruants voltigent aussitòt en troupes nombreuses autour de cette lumière, et là ils sont abattus par des personnes armées de rameaux épais, et qui suivent toutes les pérégrinations du porteur de torche.

Le bruant jaune se tient très-souvent à l'extrémité des nrbres, ou à la pointe la plus élevée des haies. C'est lì qu'il redit son chant de cigale, et c'est ainsi qu'il trahit la présence de son nid. Celui-ci est simplement fait à terre, sur le bord des fossés qui serpentent dansles landes, ou sur la lisière des bois taillis; façonné d'une manière assez grossière, il est composé de paille, de feuilles, de mousse, de racines, de crin, de laine, ou d'herbes très-déliées. Souvent ce nid représente une coupe entièrement enfoncée dans la terre, et dont les bords affleurent à la surface. Sa couleur, ainsi que celle de la couveuse, se confond facilement arec les nuances des terrains auxquels il est confié, et c'est cette circonstance qui contribue beaucoup à le dérober aux recherches de ses ennemis.

La femelle dépose dans ce nid de quatre à six œufs, d'un blane bleuâtre, parsemé de taches noires ou violettes, celles-ci semées en zigzag et d'une manière irrégulière. 
Presque tous les œufs de bruant ont des taches qui ressemblent à des filets tracés suivant des lignes capricieuses. Les œufs du bruant jaune se distinguent de ceux du bruant fou et de ceux du bruant zizi, parce que les filets sont plus gros que sur les œufs du premier, et que la couleur en est plus violacée que sur les œufs du second. Ils ont de $0^{\mathrm{m}}, 018$ à $0^{\mathrm{m}}, 020$ de longueur, et de $0^{\mathrm{m}}, 014$ à $0^{\mathrm{m}}, 015$ de diamètre.

Le père partage avec la mère les soins de l'incubation, quoiqu'il lui en abandonne la plus grande partie. La femelle se laisse facilement approcher et prendre sur son nid. J'ai pu, en parcourant les landes de Bécon avec mes jeunes amis Eugène Lelong et Daniel Métivier, constater l'exactitude de ces détails caractéristiques.

Schwenckfeld rapporte, en paraissant y ajouter une certaine confiance, qu'une croyance populaire admettait que le bruant jaune offrait un remède souverain contre la jaunisse; que, pour se guérir, il suffisait de considérer attentivement le bruant citrinelle, qui devenait alors plus jaune qu'auparavant, et cela à l'avantage du malade !! S'il en était ainsi, le bruant jaune eût remplacé, ct avec avantage, auprès de beaucoup de malades, l'influence salutaire des eaux de Vichy. Schwenckfeld eût pu ajouter, pour corroborer son opinion, que c'est peut-être à ce remède, si simple et si puissant, que les gens de la campagne doivent d'ignorer et la nécessité d'aller à Vichy et les causes qui y conduisent!!

BRUANT DES HAIES oU BRUANT ZIZI. - CIRLUS.

Les différents noms donnés à ce conirostre contribuent à faire connaître ses habitudes, et à le caractériser d'une manière très-exacte. Il doit la première de ses dénominations aux lieux qu'il fréquente pour vivre et pour 
se reproduire. C'est dans les haies qu'il cherche sa nourriture; c'est là qu'il établit son nid; c'est à l'extrémité des branches des buissons que se pose le mâle, et qu'il reste des heures entières, occupé à rípíter à sa couveuse un chant disagréable, que l'on a essayé de reproduire par l'épithète zizi.

Quant au mot cirlus, je l'ai déjì expliqué dans la petite préface de ces Essais étymologiques. Il térive de nintocnos, cillurus, d'où l'on a formé, par trarisposition des liquicles cirrulus, et par abréviation cirlus. Les racines de killouros sont kellò, " se mouvoir, " et ocria " queue, " expressions qui représentent exactement l'une des habitudes des bruants, et, en particulier celle du zizi et de l'embérize des roseaux. Ces oiseaux impriment à leur queue un mourement de haut en bas assez brusque et même plus saccadé que celui qui caractérise la bergeronnette ou le hoche-queue. D'un autre còté, kitilò a donné naissance au dérivé killos, cillus, "âne, " et dans ce dernier mot, la liquide " $r$ ) aura remplacé la liquide " $l$, " pour former cirlus, dont la signification naturelle sera " stupide comme un âne, " etc. Ce qui vient corroborer cette opinion, c'est le mot cirliscus, allongement évident de cirlus. Cette expression se trouve dans les glossaires, avec la signification de "rustre, paysan grossier, " etc. De plus, le bruant zizi est appelé stultus, matto, "sot, imbécile, " dans les anciens traités d'ornithologie d'Aldrovande et des autres auteurs.

Tout, dans ce conirostre, se réunit pour justifier l'épithète de mépris que les savants lui unt donnée ì juste titre. Ses formes, ses couleurs n'ont 1 ien de gracieux; son chant, ou plutôt son cri le rapproche de l'âne. La position qu'il affectionne lui imprime encore darantage un air de stupidité : il ressemble à un acrobate de bas étage, ayant peine ì se maintenir en iruilibre, et cherchant, par les mouvements saccadés de sa queue, à con- 
server son centre de gravité; à un bohémien fixéle long des routes, et poursuivant de sa voix rauque et monotone les voyageurs qui les parcourent. Comme les bohémiens aussi, il ne se pique pas de propreté : son bec est toujours terreux; aussi les Suisses l'appellent-ils emmerling, qui signifie "bouffon grossicr. " Enfin, il se jette dans toute espèce de pièges, et nous fait vérifier ainsi la justesse de l'épithète qui lui a été attribuée. A l'exemple des moutons de Panurge, auxquels on attribue un instinct irréfléchi d'imitation, il suffit qu'un bruant se précipite dans un filet, pour que tous les autres l'y suivent.

Le bruant zizi place son nid dans les haies, près de terre; grossièrement façonné, ce nid est composéà l'extérieur de mousse, d'herbes sèches, de racines chevelues; à l'intérieur, de crin, de brins d'herbes très-déliés, et quelquefois de laine et du coton des arbres. Il contient de quatre à six œufs d'un blane grisâtre parsemé de points et de raies en zig-zag, dont la couleur est brune ou noirâtre. Ils se distinguent de ceux du bruant jaune par leur forme ordinairement moins allongée, et surtout par leur teinte qui est noirâtre, tandis que celle des œufs de l'emberize jaune est violacée.

Leur grand diamètre est de $0^{\mathrm{m}}, 018$ à $0^{\mathrm{m}}, 019$, et le petit de ()$^{\mathrm{m}}, 014$ à $0^{\mathrm{m}}, 015$.

BRLANT DES ROSEALT (LA COQUELUCHE). - SCHENICLL'S.

La dénomination schueniclus a la même signification que le nom vulgaire bruant des roseanx; elle dérive de scпоїкоs, " jonc, roseau, » et indique les habitudes de ce conirostre, qui vit et se reproduit dans les grandes herbes et dans les petits roseaux situés sur le bord des rivières.

Le bruant des roseaux a un vol très-rapide et très- 
hruyant : il disparaît avec la rapidité de l'íclair, en faisant entendre une espèce de sifflement sinistre; on dirait un projectile volant pour porter la mort. Ceependant il ne sème le carnage que parmi les petits insectes qu'il rencontre en grimpant le long des herbes et des roseaux, dont les semences composent sa principale nourriture. Dans ses investigations, il est bien loin de montrer la légèreté et la grâce gui caractérisent les fauvettes des roseaux. On croirait qu'il remplit une mission pour laquelle il n'a pas été fait. Cependant il rend de vúritables services aux oiseaux qui habitent les mêmes parages que lui. Sans cesse en mouvement, l'œil toujours au guet, le bruant des roseaux semble être la sentinelle avancée du bord des rivières. Dès qu'il aperȩoit le chasseur approcher de la rive, il fait entendre un petit cri, semblable à celui du sifflet d'une locomotive, et ce cri, devenant un signal et un avertissement pour tous les oiseaux, a très-souvent privé le chasseur d'une proie dont. il se croyait assuré.

Cette habitude avait été remarquée par les Grecs; aussi les habitants de Mételin ou de l'ancienne Lesbos avaientils établi pour gardien de leur basse-cour une espèce d'ortolan nommé mitilène, et qui se rapproche beaucoup du briant des roseaux. Le mitilène place dans une cag̣e, sur une élévation dominant la basse-cour, avertissait tous les oiseaux confiés à sa surveillance, et dès qu'un faucon, un épervier, ete., paraissait an haut des airs, le gardien poussait un cri d'alarme, etfous les habitants de la bassecour se réfugiaient dans leur domicile.

Le bruant des roseaux éloigne aussi les autres oiseaux qui se trouvent dans les lieux où il s'est choisi une demeure; il piaille comme les moineaux; commecux, avant de se percher dans les roseaux où il passe la nuit, il fait un tapage capable d'étourdir les orcilles les plus aguerries. Par quelques-unes de ses habitudes, le bruant se 
rapproche donc du moineau ordinaire et du moineau friquet, avec lesquels les nuances de son plumage semblent encore le confondre. Aussi les pêcheurs l'appellentils la paisse des roseaux.

Ce conirostre a été désigné par Buffon sous le nom de coqueluche.

Qu'est-ce que la coqueluche?

Comment ce nom peut-il être appliqué au bruant des roseaux?

La coqueluche, en terme de médecine, est une maladie caractérisée par une toux violente, et qui attaque particulièrement les enfants. D'après les ouvrages spéciaux sur la matière, on aurait ainsi appelé cette toux, parce que la respiration de ceux qui en sont atteints, devient sonore et imite le chant du coq. Si l'on devait prendre le mot coqueluche dans cette acception, il est évident qu'en l'appliquant au bruant des roseaux, on aurait eu l'intention de déterminer cet oiseau par son chant fatigant et qui, comme la coqueluche, empêche les voisins de dormir'; caractère d'autant plus fondé, que le bruant des roseaux, comme le coq, fait entendre son cri pendant la nuit, surtout lorsqu'il fait clair de lune.

Le soir, lorsque les faucheurs quittent le lieu de leur's travaux, et que les derniers rayons du jour disparaissent derrière les collines, on voit de tous côtés des ombres se diriger vers les roseaux, en faisant entendre un vol et un cri bruyants; ce sont les bruants des roseaux qui filent et disparaissent dans l'ombre comme des feux follets. Ils se rendent au quartier général qu'ils ont choisi ; bientôt, à mesure que le nombre en augmente, le bruit devient plus grand; on dirait un bivouac de soldats excités par des libations copieuses, où chacın redit, sur un ton plus élevé que celui de ses compagnons de gloire, ses hauts faits et ses triomphes.

Aucun d'eux ne voulant céder à son voisin, le tapage 


\section{$-314-$}

va toujours croissant; il semble même indiquer qu'on ne se borne pas aux paroles, inais que plus d'un bruant déplace son conlière d'un poste qu'il lui enviait, et que cette victoire n'a pas été obtenue sans combat. Ce racarme assourdissant se prolonge bien avant dans la nuit. Assis sur la rive opposcie, le naturaliste cherche à comprendre toutes les péripéties de ce drame nocturne; il voudrait bien être témoin des dernières scènes; mais sa patience se fatigue, assez semblable aux policemen en face de certains meetings: dès lors que la sûreté publique n'est pas compromise, il se retire, espérant que la fatigue et le besoin de repos réduiront au silence tous ces orateurs bruyants.

Vuici, selon moi, le véritable motif qui a fait donner au bruant le nom de coqueluche.

Dans le $\mathrm{xv}^{-e}$ et le $\mathrm{xvi}$ siècle, le nom de coqueluche fut donné à une grippe très-violente, et pour laquelle les malades se couvraient la tête d'une espèce de capuchon appelé coqueluche, dérivé de cuculuccia, cucullus, d'après Ménage.

Non-seulement on désigna cette grippe du nom du capuchon, qui n'était qu'un préservatif, un renède contre la maladie, mais on l'appliqua encore à la toux convulsive des enfants.

Ce capuchon ou cette coqueluche ressemblait à la capeline ou à la frileuse dont les femmes se servent tour à tour, pendant l'ité ou pendant l'hiver, pour se garantir la tìte ou les épaules contre les atteintes de la chaleur ou du froid.

Le mot coqueluche représentait done avant tout l'idée d'un " capuchon. " Or c'est de ce point de rue qu'il a pu être appliqué au bruant des roseaux.

Cet oiseau, dont le plumage est d'une nuance pâle, a la tête, les joues, la gorge, le devant du cou d'une couleur noire très-foncée, et qui contraste d'une manière 
d'autant plus sensible avec le reste du corps, qu'elle en est séparée par un collier blanchâtre; il paraît done véritablement avoir une coqueluche. Cette particularitén'a pas échappé au regard intelligent et observateur des gens de la campagne : ils ont donné à ce bruant le nom de charbonnier, comme ils le donnent encore au traquetpattre qui, lui aussi, porte un " capuchon. " Une preuve irrésistible de la vérité de cette explication, c'est que le mâle seul est désigné sous le nom de coqueluche, parce que seul il porte le "capuchon, " la femelle étant privée de ce signe caractéristique. D'après cette dernière explication, être "la coqueluche d'une localité, » c'est y êtreen vogue, fêté, choyé, etc., en vertu du sentiment que l'on traduit par cette expression populaire, être coiffé d'une personne.

Le bruant des roseaux établit son nid près de terre, dans les grandes herbes, sur le bord des rivières, dans les petits roseaux, ou même quelquefois à terre, entre les racines des arbustes qui croissent près de l'eau. Ce nid, façonné avec des feuilles desséchées de roseaux et des filaments de plantes, se rapproche un peu, pour sa construction, de celui de la fauvette effarvate; il contient ordinairement de 4 à $气$ œufs un peu oblongs, d'un gris roux ou violacé, arec des taches brunes, le tout parsemé de petits traits en zigzag d'un brun noir, plus foncé que la teinte générale de la couleur de la coquille, et semblant y former une deuxième couche, enduite d'une sorte de vernis. Ils ont de $0^{\mathrm{m}}, 017$ à $0^{\mathrm{m}}, 019$ de longueur, et de $0^{\mathrm{m}} 013$ à $0^{\mathrm{m}}, 014$ de diamètre.

Pendant très-longtemps, on a confondu le bruant des marais avec le bruant des roseaux; les habitudes et le plumage de ces deux conirostres sont les mêrmes. Mais il est facile de distinguer cette espèce de la précédente, par ses proportions qui sont plus grandes, et surtout par son bec qui est court, gros, bombé et très-fort. 
BRUANT DES MARAIS. - PALUSTRIS.

Le bruant des marais vit et se reproduit comme son congénère près des cours d'eau; il habite de préférence les pays marécageux. Dans le mument de la nidification, cet oiseau paraît peu farouche; il se laisse facilement approcher, pour s'envoler ensuite à une petite distance, et renouveler ainsi ce stratagème, dans l'intention d'éloigner ses ennemis du berceau de sa jeune famille. Ce nid est façonné comme celui du bruant des roseaux; il est aussi placé dans les grandes herbes et dans les petits joncs; il contient de quatre à six œufs d'un blanc terne, avec des taches brunes grisâtres, parsemées de lignes de couleur noirâtre décrivant des zigzags, et une espèce de couronne vers le gros bout. Leur grand diamètre varie de $0^{\mathrm{m}}, 018$ à $0^{\mathrm{m}}, 020$, et le petit de $0^{\mathrm{m}}, 01{ }^{\prime}$ t à $0^{\mathrm{m}}, 01 \%$. Ces œufs peuvent facilement se confundre avec ceux de l'espèce précédente; le caractère qui pourrait servir davantage à les distinguer, c'est que les œufs du bruant des marais ont des dimensions un peu plus grandes que celles du bruant des roseaux.

D'après des observations récentes, ces deux espèces de bruants vivent en bonne harmonie, dans les mêmes contrées, et, selon toute probabilité, le bruant des marais, non-seulement habite l'A njou, mais encore s'y reproduit.

Le bruant des marais se joint à celui des roseaux pour passer la nuit; il contribue à augmenter le racarme de son congénère, et, dans cette espèce de charivari, on distingue assez facilement sa voix, qui est plus forte et plus brève que celle de son voisin.

Pendant le jour, on jeut le reconnaître aussi à ses mouvements beaucoup moins prestes que ceux du bruant des roseaux, et à la défiance plus grande encore qu'il manifeste à l'approche du chasseur. 
BRUANT ORTOLAN - HORTULANUS.

Le bruant ortolan tire ses différents noms de la même racine hortulanus signifiant : "qui se tient dans les jardins. " C'est de cette dénomination que s'est formé l'italien ortolano, forme primitive du mot ortolan.

Cependant, il ne faudrait pas employer ce mot dans son sens le plus restreint. Mlais, dans une acception un peu large, il signifie que l'ortolan se rapproche des lieux habités, plus que ses congénères; qu'il vient chercher sa nourriture, et qu'il se reproduit dans les jardins, mais principalement dars les vignes, qui en sont quelquefois la dépendance, surtout en Italie.

Cette espèce de bruant est très-recherchée par les gastronomes; elle est regardée comme la plus délicate de tout l'ordre des passereaux; elle s'engraisse facilement et très-promptement. Il suffit, pour en faire de véritables petites poulardes, de renfermer, pendant quelques jours, les ortolans dans des chambres obscures, éclairées par des veilleuses, et de leur donner pour nourriture du millet, qu'on a eu soin de tremper dans de l'eau bouillante. Ils se trouvent si bien de leur repas, qu'on est obligé de les tuer, pour les empêcher d'étouffer. On peut aussi les mettre dans une cage couverte entièrement de soie sombre, en laissant le jour pénétrer dans le réservoir où est placé le millet.

L'ortolan creuse quelquefois un trou à terre, dans les vignes ou près des haies; il le remplit de racines, d'herbes, de crin, de bourre, etc., et confectionne ainsi grossièrement le nid qui doit contenir sa jeune famille. Le plus souvent il le fait sur une petite élévation, le long de quelques petits arbustes, et surtout sur les ceps de vigne. Quand les chasseurs ou les chiens s'approchent de l'endroit où est établi le nid de l'ortolan, le mâle se 


\section{$-318-$}

laisse tomber ì terre en traînant l'aile; puis, lorsque par ce stratagème, il a éloignó les ennemis de sa famille, il reprend son vol, et revient près d'elle par une voie détournće, afin de tranquilliser la couveuse. Le nid contient ordinairement de quatre à cinq œufs d'un blanc mat ou rougeatre, parsemé de taches ou de raies noirâtres, de couleur violacée, qui se déroulent en zigzag tout autour de l'œuf. Le signe distinctif des œufs de l'ortolan est une forme beaucoup plus ronde que celle des autres espèces. Ils ont leur grand diamètre de $0^{\text {1n }}, 018$ à $0^{\mathrm{m}}, 020$, et le petit de $0^{\mathrm{m}}, 014$ à $0^{\mathrm{m}} 010 \%$. Le mâle s'occupe, avec beaucoup de sollicitude, d'apporter de la nourriture à la femelle, pendant le temps de l'incubation. Quand les petits sont sortis du nid, ils forment avec leurs parents une société qui persévère jusqu'à l'année suivante. Quelquefois même, plusieurs de ces familles s'unissent, pour ne plus se séparer qu'au printemps suivant. Ces habitudes d'association expliquent pourquoi les ortolans, aussi peu défiants que leur's congénères, se laissent prendre par troupes assez nombreuses.

\section{BRUANT PROYER. - MILLARIUS.}

Cette espèce, qui est la plus grosse du genre, présente aux observateur's deux races bien distinctes, dont l'une est beaucoup plus grosse que l'autre. La différence de grosseur est, du reste, le seul trait caractéristique qui fasse distinguer entre eux ces bruants dont toutes les habitudes sont les mêmes.

Le bruant proyer a été dísigné sous bien des noms différents; il est appelé le gros ortolan des marais; comme l'ortolan, il s'engraisse facilement; comme la cuqueluche, il se tient près des cour's d'eau, et, comme. le fou, il profère les prairies situées près des rivières à 
tous les autres lieux. On peut done, selon que l'on considère l'une ou l'autre de ces habitudes, modifier la dénomination du proyer.

Les anciens l'appelaient miliarius, "quia milio pinguis fit, - parce qu'il s'engraisse avec du millet. ")

Les habitants de la campagne, très-bons observateurs, le désignent sous le nom de tri-tri, expression qui n'est que la réunion des deux notes que cet oiseau répète sans cesse, et d'une manière très-fatigante, dans le temps de la nidification. Lorsque cette époque est arrivée, les proyers se réunissent en assez grand nombre sur un terrain élevé et découvert, non loin des prairies. Les mâles font alors entendre leur chant "tri-tri » avec un entrain toujours croissant; puis ils s'élèvent à une petite hautcur en continuant leur cri d'une manière encore plus vive. Pendant leur ascension, ils présentent un phénomène très-curieux : la têie droite, les pieds perpendiculaires et pendants, ils impriment à leurs ailes un mourement de trépidation très-original; ils représentent une croix, dont les deux bras subiraient un mouvement convulsif. Lorsque les mâles ont répété plusieurs fois cette ascension, ils se laissent tomber près des femelles, et, après quelques instants d'un tapage assez assourdissant, chaque couple se dirige vers les prairies, pour y faire élection d'un domicile. Ces évolutions ont pour but, sans doute, de développer tous les charmes du vol et de la voix des mâles, et de déterminer ainsi le choix des femelles; c'est une demande en mariage, sous la forme d'un concours musical. Dans leur simplicité naïve, les habitants de la campagne, non-seulement ont pensé que le bruant répétait " tri-tri, " mais ils ont cru même y reconnaître " prie, prie, je prie, je demande, " expression vive du sentiment qui l'anime, surtout à cette époque, et dès lors ils l'ont désigné sous le nom de proyer, du vieux mot français proier, "prier, fatiguer 
de ses demandes. " Cette habitude a dû frapper d'autant plus ceux qui en étaient témoins, que, lorsque le temps de la nidification est passé, le proyer renonce à son cri et à cette singulière manière de voler. Ce qui rend cette ítymologie encore flus plausible, c'est que le proyer est appelé par différents auteurs : preyer, prier, aussi bien que térits, d'après les différentes nuances de son cri (Buffon).

Le proyer établit son nid dans les prairies situées près des rivières; fixé à terre ou dans une épaisse touffe d'herbe, ce nid est composé de brins d'herbes sìches, de petites racines, de fibres des plantes; à l'intérieur, il est garni de bourre et de crin. Il offre une construction peu soignée, et contient de quatre à cinq œufs, un peu ventrus, d'un gris blanchâtre, sur lequel parait étendue une seconde couche de nuance rousse, parsemée de raies brunes, ou d'un noir gris et violacé et semées en zigzag. C'es taches sont ordinairement plus nombreuses vers le gros bout. Quelques-uns de ces œufs font exception à la forme la plus ordinaire, et sont très-allongés. Le grand diamètre varie de $0^{\mathrm{m}},\left(121 \mathrm{a}\right.$ a $0^{\mathrm{m}}, 023$, et le petit de $0^{\mathrm{m}}, 01: 3$ à $0^{\mathrm{m}}, 017$.

Quand la femelle se livre au travail de l'incubation, le mâle se tient à l'extrémité d'un arbre ou de la branche la plus élevée d'une haie, et là, placé en sentinelle, il répète, d'une manière continuc et assourdissante, son chant "tri-tri, " qu'il termine invariablement par la finale " tit-ritz! " De temps en temps, il s'élève dans les air's, ou plutôt il se laisse tomber de la place qu'il occupe, et fait ce qu'on appelle en langage vulgaire le SaintEsprit : il descend, en agitant ses ailes d'un frémissement mille fois répété, et porte la becquée à sa famille. Ce devoir accompli, il reprend sa première position, pour la quitter et la reprendre tour à tour.

Les petits sortent du nid avant de pouvoir voler; ils se répandent dans la prairie, courent et se cachent dans 
les touffes d'herbes : ce qui explique pourquoi les chiens des chasseurs les trouvent facilement au commencement de la chasse. C'est cette habitude qui trompe si souvent les dénicheurs inexpérimentés. Le chant du proyer indique que, près de lui, se trouve le berceau de sa jeune famille, puisqu'il perd sa voix lorsque ses petits sont élevés; mais souvent le nid est vide, avant que ceux-ci puissent se suffire à eux-mêmes. Alors le père et la mère leur viennent en aide, et on les voit tour à tour descendre vers quelque touffe d'herbe. Trompé par ces apparences, le jeune naturaliste se dirige avec empressement vers l'endroit qui lui semble ainsi clairement indiqué; il le scrute avec une attention persévérante, mais sans obtenir aucun résultat. S'il se cache derrière une haie épaisse pour suivre avec anxiété les évolutions de cet oiseau, le proyer lui fait parcourir bientôt les replis et les accidents de terrain de la prairie, mais presque toujours sans succès. Comment ne finirait-il pas par se croire la victime d'une mystification et des ruses calculées du proyer? Et cependant il n'en est rien. Le père et la mère suivent chaque mouvement de leurs petits qui, dispersés dans l'herbe, vont cherchant leur nourriture; il en résulte tout naturellement que le mâle et la femelle se laissent tomber tour à tour, là où se trouve leur jeune famille, et que celle-ci, n'étant jamais en repos, leur's mouvements, qui paraissent être l'effet d'une stratégic savante pour tromper leurs ennemis, ne sont, en réalité, que la preuve et le résultat de leur vigilance.

Pour compléter cette notice sur le proyer miliaire, je dois ajouter qu'il fait craquer son bec lorsqu'il prend son vol, et qu'il paraît plus ennemi de la captivité que ses congénères. Souvent il se tue, lorsqu'on le met en cage pour le faire engraisser. 
BRIANT DE PIEE OE BRTANT FOI. - CIA, PRATENSIS.

Le bruant de pré doit un de ses noms, cia, au cri qu'il fait entendre en volant, et même lorsqu'il est arrêté. Ce nom, donné au bruant ortolan, cût ité bien plus fondé, puisque son chant est " tia tia tia... tî. "

L'adjectif pratensis, "de pré, ") ne peut guère le caractériser; car il convient tout aussi exactement à plusieurs autres espèces; il en est de même de l'épithète fou, qui pourrait très-bien s'appliquer à tous les bruants, oiseaux dépourvus d'intelligence et de prudence, et qui, comme tous les gourmands, sacrifient leurs intérêts les plus chers à la satisfaction grossière d'un moment.

Cependant le bruant de pré mérite, plus qu'aucun autre membre de la famille, la dénomination de fou, parce que, plus encore que tout autre, il se précipite, avec une étourderie aveugle, dans toute espèce de piége, pourvu que son appétit y entrevoie un appât. Or, sacrifier sa vie très-légèrement, lorsque l'intérêt de la société ou l'accomplissement d'un devoir supérieur ne l'exige pas, c'est faire un véritable acte de folie. Cette dénomination est donc fondée sur la raison et le bon sens populaire. Peut-être aussi doit-il son nom à la facilité arec laquelle il s'enirre. Dans beaucoup de contrées, on répand, dans les lieux visités ordinairement par les bruants de pré, des grains de blé ou d'avoine gonflés dans l'eaude-vie. Les fous se précipitent sur cette nourriture, dont ils sont très-friauds, et bientôt ivres et tournant sur eux-mèmes, ils sont pris à la main par les chasseurs; ils méritent dunc à double titre leur dénomination; car l'ivresse est la plus coupable de toutes les folies, puisqu'elle est volontaire, et qu'elle entraìne la ruine, et de celui qui s'y abandonne, et souvent d'une famille entière. 
Le bruant fou se tient dans les haies, où il chasse les insectes et les petits vermisseaux. Comme le zizi, il imprime à sa queue un mouvement très-saccadé de bas en haut. Il niche à terre ou près de terre, sur les montagnes ou dans les prairies, au pied de petits arbustes ou au milieu d'une touffe d'herbes. Son nid est façonné d'une manière grossière, et avec les mêmes matières que les précédents; il contient de quatre à cinq œufs d'un blanc bleuâtre ou violacé, parsemé en zigzag de traits et de lignes noirâtres. Ces traits sont plus déliés que sur les œufs des autres bruants, et c'est leur caractère distinctif. Des lignes très-fines se déroulent dans tous les sens, se croisent pour former, en quelque sorte, une petite perruque recouvrant la coquille de l'œuf, en laissant toutefois entrevoir la nuance de la première couche. Ces æufs se rapprochent beaucoup de ceux du bruant jaune, par les nuances de la couleur; mais ils s'en éloignent, par leur forme plus arrondie, et surtout par les traits semés en zigzag et beaucoup plus fins que dans les autres espèces. Le grand diamètre des œufs du fou varie de $0^{\mathrm{m}}, 019$ à $0^{\mathrm{m}}, 020$ de longueur, et le petit de $0^{\mathrm{m}}, 014$ à $0^{\mathrm{m}}, 015$.

\section{BRUANT DE NEIGE. - NIVALIS.}

Le bruant de neige, dont les différentes dénominations indiquent les climats qu'il habite de préférenceà tout autre, est compris dans la deuxième section du genre Emberize. Il forme avec le bruant montain la section des Plectrophanes, de plectron, " ergot, " et pнiїNô, " briller, paraître; - oiseaux dont l'ergot apparaît, , dont l'ergot est plus long que celui des autres. Ils cussent été mieux désignés par le mot plectrophore appliqué à certains insectes, et qui signifie " porte-ergot, " de plectron, " ergot, » et puÉrô, " porter. ») Les campagnards, plus simples 
et plus énergiques dans les dénominations qu’ils cmploient, appellent ces oiseaux les éperonniers, expression très-juste et très-caractéristique.

Les bruants de neige changent de lirrée deux fois par an : pendant l'hiver, ils deviennent blanchâtres, couleur de neige, noureau motif qui justifie leurs noms. Ces oiseaux se tiennent à terre comme les alouettes; ils courent et piétinent dans les terrains couverts de neige. Ils dorment très-peu, et se mettent ì sautiller dès qu'ils aperçoivent de la lumière. Ils semblent avoir horreur des ténèbres; c'est peut-être cet instinct qui les dirige, pendant l'été, sur le sommet des hautes montagnes des régions du norl, où il n'y a pas de nuit. Le bruant de neige visite chaque année notre département, pendant l'hiver, et surtout lorsqu'un froid rigoureux et continu le force à quitter les contrées qu'il habite, et où il ne peut plus trouver de nourriture.

Il se reproduit dans les régions glaciales. Il établit ordinairement, entre les fentes des rochers, son nid, qui prend dès lors lat forme de l'emplacement auquel il est confié. Composé d'herbes fines, longues et desséchées, entremêlées de plumes de títras, ce nid est peusolidement façonné; ses bords n'ont que $0^{\mathrm{m}}, 02$ d'épaisseur, tandis que celis du bruant jaune, du bruant ortolan, ont jusqu'à $0^{\mathrm{m}}, 08$. Cette grande différence provient nécessairement de la difficulté qu'éprouve le bruant de neige à se procurer des matériaux dans les régions désolies qu'il habite. Son nid contient de quatre is cinq œufs, un peu oblongs, d'un blane blentitre, pointillé de gris, de violet, et parsemé de taches d'un brun noirâtre; ils semblent être revètus de plusieurs couches superposées, et dont la seconde a des teintes plus funcées que la première.

Le srand diamètre varie de $0^{\mathrm{m}}, 020$ a $0^{\mathrm{m}},(12 \cdot 2)$, et le petit de $0^{\mathrm{m}}, 014$ à $0^{\mathrm{m}}, 016$. 


\section{QUATRIËME GENRE.}

FRINGILLES. - FRINGILLE.

Dans la Faume de M. Millet, les fringilles succèdent aux bruants; j'ai suivi cet ordre afin de rester fidèle au principe que j'ai admis au commencement de mes essais, à savoir : de ne justifier ni critiquer les classifications de notre honorable doyen. Cependant, je dois dire que dans beaucoup d'ornithologies, les embérizes sont comprises dans la famille des fringilles, qui renferme, en effet, des espèces très-variées, ayant beaucoup de traits de ressemblance avec les bruants, mais s'en éloignant aussi par plusieurs caractères, et surtout par la manière de nicher.

Les fringilles vivent de graines et d'insectes; dès lors, ils peuvent partout trouver une nourriture facile; aussi habitent-ils toutes les contrées du globe. Cependant, quand l'hiver fait sentir ses rigueurs, et que les insectes et les graines, recouverts d'une couche épaisse de neige et sous une enveloppe glacée, ne peuvent plus procurer une nourriture suffisante aux fringilles, ces oiseaux émigrent par bandes innombrables, composées de beaucoup d'espèces, qu'un même besoin réunit, et qu'un même instinct dirige.

De tous les oiseaux, les fringilles sont, après les gallinacés ct les pigeons, les plus faciles à soumettre à la domesticité : aussi trouverons-nous parmi eux des espèces qui éveilleront facilement nos souvenirs d'enfance, et dont les mœurs nous offriront des études d'autant plus attachantes, que nous serons à même d'en vérifier les détails, et d'en constater l'exactitude.

Les fringilles sont soumis à deux mues chaque année, et les mâles ressemblent aux femelles pendant 
l'hiver; particularité qui a denné lieu à beaucoup d'erreurs, et qui nous fournira une série de remarques pleines d'intérêt.

Mais d'abord, quelle est l'étymologie du mot fringille ou fringilla?

Ce nom est celui qui désigne les pinsons : fringilla, frigilla, "pinson, oiseau qui chante en hiver, " telles sont les seules explications que nous lisons dans les glossaires. Ainsi, le pinson a donné son nom au genre tout entier; il reste donc à expliquer quelle est la signification attachée à l'expression latine déterminant le pinson. Tous les fringilles ont été classés et subdivisés d'après la forme de leurs becs; tous ont les mandibules armées pour concasser avec facilité les graines, dont ils brisent l'enveloppe avec une grande précision, afin d'en manger le contenu, après en avoir rejeté les débris. Dès lors, fringilla eût pu dériver de effrinyo composé de frango, " concasser, briser; " je l'eusse admis d'autant plus facilement, que, d'après une règle générale, tous les composés de frango changent l'a en $i$, tels que confringo, defringo, effringo, infringo, perfringn, et que tous indiquent l'idée de "rompre, briser. " Mais Festus, cité par Forcellini, prétend que fringilla est : avis, dickn quod frigore cantet et vigeat ; c'est-à-dire : " les fringilles sont ainsi nommés, paree qu'ils chantent et ont toute leur vigueur pendant la saison froide. ") En effet, loin de rester, comme beaucoup d'autres oiseaux, presque engourdis par les rigueurs du froid, les fringilles font entendre leur chant et paraissent, pendant l'hiver, aussi vifs et aussi alertes que pendant les jour's de printemps. Tel serait, d'après Festus, le principe de leur nom. "Alii putant "sono quem edit, " ajoute Forcellini; - d'autres pensent que le nom de fringilles serait une onomatopée, et retracerait, du moins en partie, le chant ou plutòt le cri saccadé du pinson, type de la famille. Enfin, 
ce nom ne pourrait-il pas encore avoir pour principe, frigulo? et fringulare, "crier comme le geai? " et surtout fringutio, "babiller, jaser, caqueter, bredouiller, faire un trémoussement, un frétillement de corpss qui marque le désir ou la joie? „) Cette dernière hypothèse aurait l'avantage de peindre, d'après nature, les habitudes de la plupart des oiseaux de cette nombreuse famille. Le verbe frigulo n'aurait-il pas lui-même pour racine frigus, malgré la différence de quantité? car le froid a pour conséquence de faire " trembler, frétiller, 》 et, dès lors, les interprétations des auteurs cités précédemment pourraient se concilier avec l'hypothèse que je propose.

Martial me vient en aide dans cette circonstance, et fortifie la supposition précédente par l'expression qu'il emploie pour désigner le pinson, laquelle se rapproche beaucoup du verbe fringulare :

Hune sturnos inopes, fringuillarumque querelas Audit et arguto passere vernat ager.

Mais nos campagnes n'entendent que le maigre étourneau, les plaintes du pinson, et le chant aigu du passereau qui fète le printemps. (Liv. IX, Épig. 55.)

Pour constater la justesse de cette remarque, et reconnaître que le chant du pinson et le frétillement du moineau ont dû frapper les naturalistes, chargés de nommer ces oiseaux, il suffit, en tout temps, de se promener sous les arbres que fréquente le pinson, et où il doit construire son nid; ou encore, d'assister au coucher des moineaux. Le cri monotone et plaintif du pinson et le tapage assourdissant du passereau ne peuvent être reproduits que par une expression stridente, et qui rappelle aussi le bruit que l'on obtient en brisant avec rapidité les graines et les corps solides. Ainsi, le mot fringilles pourrait donc représenter l'idée de "briser, " de "concasser," et celle de "chanter d'une manière peu 
agréable. „) Mais ce dernier sens ne peut convenir qu'ì quelques espèces et dans certaines parties de l'année; il serait faux, si l'on voulait l'appliquer à tous les fringilles; car cette famille renferme des chantres dont la voix est agréable, en liberté, comme en captivité.

\section{CHARDONNERET. - CARDUELIS.}

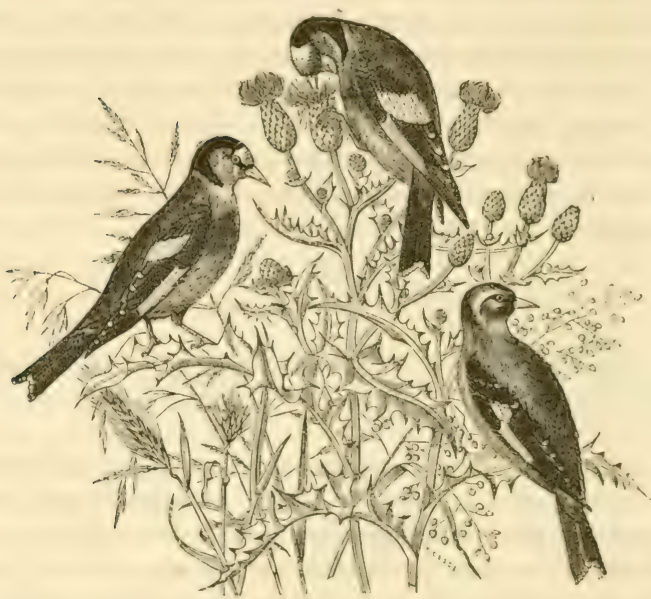

L'étymologie des noms donnès à ce gracieux fringille est facile à trouver, et, sans être condamnés à fouiller les glossaires ou à parcourir des routes dangerenses et trop fertiles en hypothèses, on peut déterminer, d'une manière précise, en français et en latin, l'origine des dénominations attribuées au chardonneret. Ces dénominations paraissent exactes, surtout quand on étudie les mœurs de cet oiseau pendant l'automne. 
Lorsque les couvées sont terminées, les chardonnerets se réunissent par familles, et quelquefois par bandes assez considérables; ils semblent alors négliger les insectes pour rechercher les graines et les semences des plantes. On les voit papillonner autour des seneçons, des plantains, et surtout des chardons en fleurs; ils se reposent avec une grâce et une légèreté remarquables sur les extrémités de ces plantes, et, comme les abeilles, ils ne s'y arrêtent qu'un instant pour continuer ailleurs leurs investigations. Dans cet examen, les chardonnerets frétillent et papillonnent, en accompagnant leurs évolutions gracieuses et rapides d'un petit cri de satisfaction ou de rappel, et d'un frémissement d'ailes tout particulier. C'est donc à son goût de prédilection pour les semences de chardons en fleurs que cet oiseau doit son nom vulgaire et son nom scientifique chardonneret, carduelis en latin, " chardon. "

Les chardonnerets sont très-estimés pour leur talent musical.

Les oiseleurs et les amateurs distinguent deux espèces de chardonnerets. Le royal est regardé comme l'espèce qui chante le mieux en captivité. On le reconnaît aux six rectrices tachetées de blanc; ces rectrices sont les trois pennes ou grandes plumes qui, de chaque côté de la queue, portent une large tache blanche presque ovoïde. Elles sont nommées rectrices, parce que la queue, ainsi composée, remplit les fonctions de gouvernail dans la navigation aérienne des oiseaux. C'est cette particularité des six rectrices qui a fait désigner le chardonneret sous le nom vulgaire de sisain ou sizain.

La seconde espèce comprend les sujets qui n'ont pas les six pennes de la queue marquées de blanc, et qui dès lors paraissent plus noirs que les autres; aussi les oiseleurs les appellent-ils charbonniers. Cette distinction, résultat de l'âge ou de la mue, n'est qu'apparente; car le 
chardonneret royal n'a quelquefois que quatre et même que deux pennes maculées de blanc. Si les chardennerets, quand ils sont revêtus de cette livrée assez pauvre, patraissent chanter moins bien que quand ils en ont ume plus brillante, on doit attribuer cette modification à l'effet de la mue qui prive, en général, tous les oiseaux des ressources de leur voix.

Non-seulement le chardonneret est recherché pour ses couleurs brillantes, pour la vivacité de son chant ou la grâce de son vol; mais il l'est encore pour la patience avec laquelle il se soumet aux rigueurs de la captisité. I'ar une contradiction qui ne s'explique pas, des enfants, de jeunes filles, de vieilles demoiselles, dont le cœur sensible aime à s'entourer d'animaux auxryuels sont prodiguies maintes caresses, et aux caprices desquels on sacrifie des largesses qui seraient si utiles à des indigents, prennent plaisir à tourmenter un des plus gracieux oiseaux de nos contrées. Pour lui, innocent, on rétablit ce que l'on a supprimé pour l'homme coupable : on le condamne ì toutes les rigueurs du bagne. Enchaîné sur un perchoir, l'infortuné chardonneret est condamné ì se procurer les graines et l'eau qui doivent lui servir de nourriture etde boisson au prix d'efforts pénihles et continus. La nourriture et l'eau sont renfermés dans de petits seaux en fer-blanc attachés à une longue châne, et, dès lnoss, le prisonnier ne peut boire et manger qu't̀ la condition de rouler et de dérouler tour à tour les chaînes de sa galère. Souvent, par une prévoyance perfide, le fund de la prison est orné d'une glace, et le paurre chardonneret s'habitue plus facilement aux rigueurs de sa position en pensant, à la vue de son image reflétée, que ses semblables sont soumis aux mêmes tortures que lui; car les souffrances fraraissent aux oiseaux, comme aux hommes, moins pénibles, quand elles sont partagées par leurs frères. Le chardonneret pardonneà ses bourreaux, et 
il égaie par ses mouvements, par sa joie et par son chant la demeure de ceux auxquels il doit une injuste détention.

En liberté, le chardonneret établit son nid dans les les arbres fruitiers et le long des petites branches des peupliers. Ce nid, qui représente une petite coupe ronde, est très-artistement fait ; composé à l'extérieur de petits lichens liés ensemble par des brins de crin et des fils d'araignée, il est garni à l'intérieur d'une couche molle et soyeuse du coton des arbres. Peu d'oiseaux de l'Europe peuvent rivaliser avec

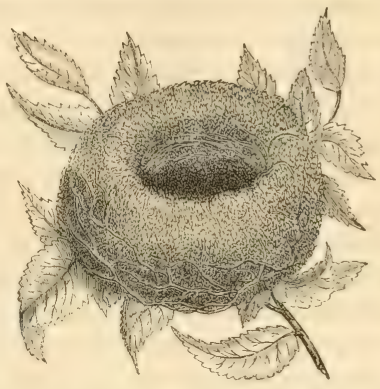
le chardonneret, et pour le fini du travail, et pour le confortable du berceau de la jeune famille. Ce chefd'œuvre renferme quatre ou cinq œufs, variant beaucoup de forme et de grosseur; les uns sont longs, les autres piriformes; les uns d'un blanc uniforme et verdâtre, les autres parsemés de points rougeâtres, ou de nuances violettes. Quelquefois enfin, on en trouve qui offrent deux couches superposées d'un blanc verdâtre. Le grand diamètre de ces œufs varie de $0^{\mathrm{m}}, 013 \mathrm{à} 0^{\mathrm{m}}, 016$, et le petit de $0^{\mathrm{m}}, 012$ à $0^{\mathrm{m}}, 013$.

Le chardonneret, comme presque tous les fringilles, fait plusieurs couvées par année.

\section{TARIN. - SPINUS.}

Le tarin traverse chaque année notre département, mais sans s'y reproduire. D'un naturel vif et joyeux, il se rapproche des mésanges et des pouillots par la rapidité 
de ses mourements et par la continuité de son cri de rappel, qui seul trahit sa présence. Ce fringille aime à visiter les arbres pour y chercher les insectes cachis sous les feuilles, et, quoigu'il préfère, comme les pouillots, se tenir sur les arbres les plus élevés et les plus touffus, comme les mésanges aussi, il descend à terre et fouille les haies et les buissons, quand il ne rencontre aucune proie dans les rigions supérieures. Pendant ses perégrinations continuelles, il parait appeler ses semblables par un cri monotone, qu'on entend de très-loin et qui se rapproche de ces syllabes: tirrly, tirrly; on croirait aussi très-facilement qu'il articule le mot : terrin, terrin, et c'est à cette remarque qu'il doit son nom vulgaire. Quant au nom scientifique spinus (prunier sauvage), il a été donné an tarin, parce que cet oiseau, qui se plaît dans les forêts, affectionne particulièrement les pruniers sauvages, surtout dans la saison de l'hiver, époque à laquelle le fruit de cet arbre lui sert de nourriture.

Quand le tarin séjourne dans notre département, il manifeste une prédilection très-rive pour les semences des aulnes. Quoique cet niseau paraisse d'un naturel plus sauvage que le chardonneret, il accepte rolontiers la captivité, et très-souvent, par ses cris, il invite ses congénères qui jouissent de la liberté à venir partager avec lui la nourriture de sa prison.

Le tarin se reproduit en captivité et se marie mème arec le serin. Il construit son nid dans les pins des Alpes, et le dissimule avee beaucoup de soin; il le confie quelquefois aux touffes de gui et aux parties les plus épaisses des arbres rerts. Ce nid se rapproche de celui du chardonneret; semblable à une petite coupe aplatie, il est composé it l'extírieur de lichens, de monsse et revitu à l'interieur de plumes, d'aigrettes et de coton des plantes. Il contient quatre ou cinq œufs, dont le grand diamètre varie de $0^{\mathrm{m}}, 014$ à $0^{\mathrm{m}}, 01 \%$, et le petit de $0^{\mathrm{m}}, 010$ 
à $0^{\mathrm{m}}, 011$. La coquille en est d'un blane bleuâtre, parsemé de taches irrégulières, de couleur rougeâtre comme de la rouille ou tirant sur le violet, mais en partie effacées.

\section{LINOTTE. - CANNABINA.}

La linotte est très-nombreuse en certaines parties de notre département; elle recherche, de préférence à toutes les autres localitís, les landes parsemées de petits arbustes et les lieux plantés de vignes.

Son nom vulgaire lui a été donné à cause de son goût pour la graine du lin. Cette étymologie me rappelle un épisode assez curieux. Il y a quelques années, un membre d'un Conseil général éprouvait une vive préoccupation au sujet d'un de ses votes. Un de ses collègues, me disait-il, lui avait demandé si la Société Linnéenne, pour laquelle le Conseil général votait chaque année une petite somme à titre d'encouragement, ne devrait point son nom aux soins qu'elle prend pour développer la culture du lin. Embarrassé par cette demande, mon interlocuteur avait répondu affirmativement, et voté comme son collègue, pensant favoriser la culture d'une plante utile. Depuis, j'ai éprouvé un scrupule, ajouta-t-il, et je vous le soumets en toute simplicité.

Je rassurai l'honorable membre du Conseil général sur la délicatesse de sa conscience, et lui procurai un motif de joie bien expansive, en lui citant, pour sa tranquillité, l'exemple du député qui votait contre la dette flotante, en pensant qu'il votait contre le budget exagéré de la marine. Du moins, mon bienveillant interlocuteur pouvait se rendre la justice que son intention était louable et éloignée de toute idée d'opposition. S'il eût connu la prédilection de la linotte pour la graine du lin, il eût voté encore avec plus d'énergie; car dans sa pen- 
sée, le secours pouvait être utile et aux hommes et aux oiseaux du ciel.

L'épithète cannabina, " de chanvre, " fait connaittre que la linotte aime ì varier sa nourriture, et qu'elle brise tour ì tour et la graine du lin et celle du chanvre.

Ce fringille, dont le plumage est très-brillant, présente beaucoup de variétés; chez un certain nombre d'individus, les nuances, ordinairement si vives et si rouges, sont remplacées par des teintes pâles et blanchâtres.

La linotte construit son nid près de terre, dans de petits arbustes épais, sur des ceps de vignes ou dans de gros ajones plantés sur le bord des fossés, des landes ou des lieux incultes. Souvent on le rencontre dans des bruyères touffues; là, il est dissimulé avec beaucoup de soin, surtout lorsqu'il est placé à l'abri de petits buissons de genévriers rabougris. Ce nid, à l'extérieur, est composé de petites racines et de mousse; à l'intérieur, il est garni de crin ou du coton des plantes: ce travail se rapproche beaucoup de celui du chardonneret; mais il est plus grossièrement façonné. Il est exécuté par la femelle seule que le mâle se contente d'égayer par son chant, pendant qu'elle ramasse et coordonne les matériaux pour le berceau de la petite famille. Il contient quatre ou cinq œufs, un peu oblongs, d'un blanc bleuâtre; les uns sont sans taches, d'autres sont parsemés de points rougeâtres, violacés ou même noirâtres. Quelques-uns laissent apercevoir des points fondus ou effacés dans les nuances de la corquille. Les plus gros se rapprochent des ceufs du verdier, et les plus petits de ceux du chardonneret. Le grand diamètre est de $0^{\mathrm{m}}, 016$ ì $0^{\mathrm{m}}, 017$, et le petit de $0^{\mathrm{m}}, 012$ à $0^{\mathrm{m}}, 013$.

Mais, lorsque le nid est achevé et que les soins de l'incubation commencent, le mâle veille arec une véritable tendresse sur la cuuveuse; il l'entoure de soins attentifs, 
et, comme le male de la colombe, il nourrit la femelle en dégorgeant dans son bec la nourriture qu'il a préparée et triturée avec soin. Plus tard, ce sera ce même moyen que le père et la mère prendront pour élever leurs petits. Quand les couvées sont terminées, les linottes se réunissent en bandes nombreuses pour passer la nuit dans les bois. Les dernières arrivées disputent aux autres les places qu'elles avaient prises, et, dès lors, commence ce tapage que nous retrouverons encore plus prononcé chez le moineau, achevant ainsi de justifier l'opinion qui donne pour racine au mot fringille le verbe fringulo, fringulare. Ces cris, accompagnés de déplacements continuels, - car chaque linotte avance et recule tour à tour, - se prolongent très-longtemps et ne cessent qu'à une heure avancée du soir. Le lendemain matin, les fringilles se partagent en bandes, dont le départ s'effectue successivement et paraît le résultat d'une décision fondée peut-être sur les observations de la veille. Chaque bande se dirige vers les lieux où elle avait laissé ou remarqué des ressources plus abondantes. Le soir, toutes les bandes reviendront se coucher dans le même bois, et renouveler le charivari des jours précédents.

On peut retrouver une partie de ces mêmes habitudes chez les freux, qui viennent se coucher, chaque soir, en si grand nombre, dans les bois d'Avrillé, vis-ì-vis la chapelle du Champ dés Martyrs.

Un vieil adage attribue à la linotte une grande variation dans les résolutions : dire à quelqu'un qu'il a une tête de linotte, c'est la même chose que de le comparer à une girouette. Cette opinion peut être fondée sur les changements brusques que l'on remarque dans la direction du vol des bandes de linottes, changements qui paraissent tellement capricieux, que rien ne peut les justifier. Une autre raison peut encore en être donnée : c'est 


\section{$-336-$}

que la tête de la linotte, ornée d'un si beau rouge lorsque l'oisean est en liberté, perd ses vives couleurs quand il est condamnó à la captivité. Le brillant de cette couleur s'efface peu à peu, et finit par disparaître presque entièrement aprè̀s la première mue. Une tête de linotte change done beaucoup de nuances et de couleurs.

\section{SIZERIN. - LIINARIA.}

Si l'on admet l'opinion des auteurs qui donnent ririssô, frigus, "froid, " pour racine au mot fringille, il est certain que le sizerin doit appartenir à cette famille, mais qu'il peut même en être regardé avec raison comme le véritable type. En effet, le sizerin se plait à habiter les parties les plus froides du globe; on le retrouve dans les contríes les plus rapprochées du pôle, au cap Nord, au Kamschatka, au Groënland : c'est là, qu'an milieu des glaces et des neiges perpétuelles, il se reproduit. Le sizerin n'abandonne ces régions hyperboréennes, que lorsqu'un froid extraordinaire le force à aller chercher dans des climats plus doux une nourriture que d'épais linceuls de glace et de neige dérobent à ses investigations.

Dès lors, ses migrations sont irrégulières, et soumises aux variations de la température. C'est cette irrégularité qui, dans les siècles passés, avait donné lieu à des fables que nous trouvons maintenant bien ridicules (Yoir Schwenclifeld, page 344). Les uns soutenaient que l'apparition des sizerins annongait la peste; d'autres, que ce n'étaient que des rats, qui se métamorphosaient en oiseaux avant l'hiver, et qui reprenaient leur forme de rats pendant le printemps. Ils prétendaient ainsi expliquer pour(̣uoi les sizerins ne paraissent jamais l'été. Cette croyance rappelle celle qui enveloppait de contes absurdes la disparition des hirondelles. 
Le sizerin est appelé la linotte des vignes et la linotte des montagnes. Ce nom ne peut lui convenir que parce que les nuances de son plumage sont les mêmes à peu près que celles de la linotte proprement dite; car toutes ses habitudes devraient le faire plus justement assimiler an tarin.

Le sizerin présente deux variétés bien distinctes, ou même deux véritables espèces; l'une, moins grosse et moins longue que l'autre, porte le nom de sizerin cabaret. Elle a les plumes du croupion roussâtres et brunes, avec une légère teinte de brun rougeâtre vers les couvertures de la queue. La dénomination de cabaret a peut-être été donnée à cette espèce, parce qu'on aura cru remarquer une certaine prédilection du sizerin pour les semences de "cabaret, " plante apétale, purgative et aromatique, qui croît sur quelques chaînes de montagnes. Cette opinion est d'autant plus probable, que la plupart d̉es noms des fringilles sont fondés sur le goût présumé de ces oiseaux pour les graines de telles ou telles plantes. Le nom scientifique du cabaret est asaret, dérivé d'asarum, autre espèce de plante, qui ne croît pas en Maine-etLoire, et même est très-rare dans tout le centre de la France.

Une autre hypothèse, tout aussi plausible que la première, pourrait donner lieu à une interprétation fondée encore sur le nom d'une plante. MM. Le Maout et Decaisne, dans leur Flore des jardins et des champs, indiquent, comme traduction vulgaire du dipsucus sylvestris, ces mots: cabaret des oiseaux. Cette expression populaire est fondée sur la nature de cette plante. Les feuilles étant très-grandes à la base, opposées les unes aux autres et soudées ensemble, forment un réservoir dans lequel se conserve l'eau pluviale. C'est cette propriété qui a fait nommer la plante dipsacus, du grec DIPSÉ, DIPSĖs, et AKos, "le remède contre la soif; ) clle ne 
se multiplie que dans les lieux incultes et arides, et devient ainsi un réservoir ménagé par la Providence, pour étancher la soif des oiseaux et surtout du sizerin cabaret.

La seconde espèce de sizerin a les plumes du croupion blanches et d'un rouge rembruni; elle est appelée sizerin boréal. Ce nom indique les lieux habités par ce fringille qui se tient encore plus près du pôle que le cabaret; il résiste aussi plus facilement aux rigueurs du froid. C'est très-probablement pour ce motif qu'il se montre beaucoup plus rarement que son congénère dans les régions tempérées; il éprouve moins que lui la nécessité d'émigrer.

Avec le sizerin, je termine la section des fringilles dégorgeur's, de ceux qui, comme les colombes, nourrissent leurs petits par voie de " dégorgement. "

Mais avant de commencer l'explication des mœurs d'un nouveau groupe, il me reste à indiquer l'éty̧mologie du nom donné au sizerin ou sizin. Cet ciseau qui, d'après Aldrovande, a beaucoup de rapport avec les chardonnerets royaux ou sizains, me semble avoir reçu le même nom, à cause des mêmes particularités de plumage. En effet, les grandes pennes du sizerin sont d'une couleur brune et bordées d'une ntiance plus claire.

Quant au nom scientifique linaria, qui dérive de linarium, "champ ensemencé de lin, " il indique que les naturalistes pensaient que ce fringille aimait à visiter les lieux consacrés à la culture du lin. Cette dénomination repose cependant plutôt sur une opinion que sur une rialité; car la linotte, comme le sizerin, se trouve souvent dans des contrées où la culture du lin n'existe même pas.

Les deux espèces de sizerins traversent l'Anjou à des époques irrégulières. Le cabaret manifeste sa prísence d'une manière beaucoup plus fréquente que le sizerin 
boréal. Lors de ces apparitions, les sizerins se trouvent mêlés aux tarins et aux linottes.

Le sizerin visite avec une grande agilité les feuilles des arbres, pour y chercher les petits insectes; dans cette investigation, il fait entendre un cri de rappel, comme les roitelets et les mésanges, et, comme ces dernières, pour accomplir avec plus de perfection sa mission, il prend toute espèce de positions, de sorte qu'aucune partie des feuilles n'échappe à ses regards. De ce qu'il se tient souvent sur les chênes, plusieurs auteurs, pour l'identifier avec l'arbre qui lui fournissait sa nourriture, l'ont nommé " la linotte du petit chêne, " linaria truncalis.

Ce fringille niche dans les forêts d'arbres verts qui couvrent les montagnes du Nord; il choisit de préférence les arbres les plus touffus et situés sur la lisière des bois. Son nid composé, à l'extérieur, de mousse, de lichens et de racines d'herbes unies par des toiles d'araignée, et, à l'intérieur, de crin et du duvet des plantes, est trèspetit et très-difficile à trouver. Ordinairement, il est dissimulé dans les replis des mousses pendantes et des rameaux épais. Il contient de quatre à cinq œufs bleuâtres parsemés de taches d'une teinte rougeâtre ou violette. On remarque quelquefois sur la coquille des raies d'un brun foncé tournant au rouge. Leur longueur varie de $0^{\mathrm{m}}, 01$ 年 à $0^{\mathrm{m}}, 015$, et leur diamètre de $0^{\mathrm{m}}, 010 \mathrm{à} 0^{\mathrm{m}}, 011$. Quelques-uns de ces œufs portent, vers le gros bout, une petite couronne formée par une seconde couche plus foncée que la première. Cette description des œufs s'applique surtout à ceux du sizerin cabaret, qui se reproduit dans quelques parties de la Suisse et de la Savoie. Quant à ceux du sizerin boréal, ils présentent les mêmes caractères, avec des nuances moins prononcées et des dimensions plus petites. 


\section{$-340-$ \\ PINSON. - FRINGILLA. - CALEBS.}

Ici commence la deuxième section des fringilles par l'oiseau qui a donné le nom à la famille. Laissant de côté la dénomination fringille expliquée précédemment, il me reste à chercher l'étymologie du mot pinson, et à dire pour quels motifs ce passereau est appelé ccelebs, " célibataire. "

Le dietionnaire de Trévoux pense que le mot pinson dérive de spinthio, expression de la basse latinité, qui elle-même a formé la dénomination pinthion, d'où viendrait le nom vulgaire donné à l'oiseau type des fringilles. Là s'est arrêtée l'explication du savant dictionnaire de Tréroux; il eût pu cependant remonter plus haut, trouver la racine de spinthio et, par conséquent, de pinson dans l'expression spixos, consacrie par les Grees à désigner le même oiseau. sprxos dérive lui-mème, par une transposition de lettres, de spizô, "gazouiller, " d'où fringille, pinson, justifierait entièrement l'interprétation des anciens, et signifierait " oiseau qui gazouille " pendant la saison du froid.

Quelques naturalistes pensent que le mot pinson a été formé du mot allemand "pincli, " qui représente assez bien un des cris de rappel de ce fringille.

D'autres, enfin, admettent que cette dénomination vulgaire est fondée sur unc habitude du pinson, qui se défend en "pinçant " jusqu'au sang les personnes qui veulent le saisir. Très-souvent, avec les mandibules de son bee, il produit le mème effet que lorsque les deux parties d'une porte enserrent les doigts. On objecte, avec raison, que cette explication pourrait s'appliquer à beaucoup d'autres oiseaux. Néammoins, il en est fort peu qui unissent, ì un caractère aussi gai que celui du pinson, un moyen anssi puissant d'éloigner leurs ennemis. La mème habitude observée chez les mésanges les 
fait appeler pinçonnières dans beaucoup de contrées.

La première de ces étymologies me paraît la plus fondée, et cependant la dernière rentre aussi davantage dans les habitudes des habitants de la campagne, qui donnent les noms d'après des observations faciles à saisir. On m'objectera, sans aucun doute, que la dénomination piusonnières, donnée aux mésanges, ne saurait venir de "pincer, " non plus que pinson, parce que ces deux mots sont écrits avec une $s$. On peut répondre à cette objection que, d'après Roquefort, pincer dérive du mot latin pinso, pinsum, pinsere, " pincer, pétrir, piler, ") etc., et que, dès lors, en donnant au mot pinson l'étymologie indiquée ci-dessus, cette expression ne ferait que se rapprocher encore davantage de la véritable racine; que de plus, le changement du $c$ en $s$ ne peut être une difficulté sérieuse. Plusieurs auteurs écrivent pinsomiières. Enfin, Perse, dans sa première satire, v. 5"8, semble justifier mon hypothèse :

'0 Jane a tergo quem nulla ciconia pensit.

“ 0 Janus que par derrière nulle cigogne ne frappe à coups de bec n, ne pince en beequetant.

Les personnes versées dans les langues primitives pensent que pinson pourrait avoir pour racine ping signiliant sonare, tinnire, "gémir, faire du bruit, " racine qui se concilierait avec le gree spinos. Benfey rapporte la dénomination pinson au sanscrit pinga, "jaune, fauve. ") Dès lors, le nom vulgaire de cet oiseau représenterait certaines nuances de son plumage.

Je passe au mot scientifique coelebs, "célibataire, " qui va fournir l'occasion naturelle de décrire les mœurs très-intéressantes du pinson.

Dans cette espèce, les femelles sont beaucoup plus nombreuses que les mâles; aussi, quand le moment de la nidification arrive, chacune d'elles se réserve le malin plaisir de choisir son époux. Les mâles déploient toutes 
les ressources de leur gosier musical et toutes les grâces de leurs personnes: c'est plus qu'un concour's d'orphéons; car, au lieu d'une médaille, les vainqueurs obtiennent une compagne.

Les vaincus parmi les pinsons font preuve de bon sens et d'un excellent caractère. Bientôt, en constatant les préoccupations auxquelles sont en proie les vainqueurs pour chereher l'endroit où s'élèvera le berceau de la famille et pour le mettre à l'abri de tout danger; la difficultó d'en réunir et d'en coordonner les matériaux; puis les soucis de la paternité, l'ingratitude et quelquefois même les mauvaises dispositions des petits, sans compter toutes les misères de l'intérieur du ménage, le défaut d'entente entre le père et la mère, que sais-je encore? les pinsons célibataires se livrent à une joie devenue proverbiale, gai comme un pinson. Dans l'espèce humaine, plus d'un membre, peut-être instruit par l'expérience, désirerait avoir conservé, malgré les humiliations d'une défaite, les douceurs et les charmes de la gaieté:

Les chefs de famille participent bien un peu à cette gaieté, mais elle est moins soutenue et moins exempte d'angoisses. De plus, pour retrouver la paix joyeuse de leur's congénères, ils ont recour's à un moyen qui justifie une seconde fois l'épithète célibataire, dunnée arec raison aux pinsons. Les naturalistes ont obsersé que, lorsque le froid excite les pinsons à chercher dans des climats plus doux la nourriture que la neige dérohe à leurs investigations, les femelles et les jeunes mâles se livrent seuls à ces voyages. Les males restent dans les pays qu'ils occupaient précédemment, et se lisrent alor's à toute la gaieté de leur caractère; on dirait presque des captifs rendus à la liberté. Les vieux mâles auraient-ils reconnu les inconvénients de voyager avec leurs épunses ou leurs filles?

Que serait-ce, si dames pinsonnes entrainaient avec 
elles tout le matériel que le développement du progrès impose maintenant de plus en plus, et si les pinsons étaient condamnés à l'enregistrement, au classement et au déclassement d'un bagage bien fait pour effrayer les plus résignés! Quoi qu iil en soit du motif qui a déterminé les mâles à se séparer des femelles, pendant les pérégrinations, je me borne à constater le fait sur lequel s'appuie la dénomination calebs donnée aux pinsons par les savants. Je dois cependant ajouter, pour la vérité pleine et entière de l'explication, que, dans les derniers temps, les naturalistes ont pensé que l'opinion précédente, prise dans sa généralité, était erronée, et que, si l'on avait admis que les femelles seules émigraient, c'est que, dans cette saison, la livrée des mâles ressemblait à celle des femelles, et que, dès lors, mâles et femelles formaient une famille revêtue d'un plumage uniforme.

Après avoir donné cette explication pour la tranquillité de ma conscience, je dis que je préfère les premières observations, à supposer qu'elles soient justes, parce qu'elles justifient l'épithète crelebs imposée aux pinsons.

Non-seulement ce fringille conserve sa gaieté dans les circonstances que je viens d'énumérer, mais encore lorsqu'une maladie, à laquelle il est sujet, vient le priver de la vue. Les hommes ayant remarqué que le chant du pinson devient plus vif, plus agréable, et sa gaieté plus soutenue encore quand il ne voit pas, ont eu la cruelle pensée, non pas de lui crever les yeux, mais de souder ses deux paupières en les labourant avec un fer chaud.

Rendus complétement aveugles par ce procédé, les pinsons peuvent vivre plusieurs années en captivité, et ne répondre à l'égoïsme barbare de leur possesseur que par des cris plus variés et plus continus. Dans quelques parties de la Belgique, chaque villageois possède au moins un pinson que l'on a ainsi privé de la vue. Les dimanches et les jours de fête, les villageois se réunis- 
sent autour d'une large table sur laquelle ils déposent leurs captifs renfermés dans leur étroite prison. Puis bientòt aprè̀s commence un véritable concours, qui donne lieu à des paris quelquefois très-élevés. Chaque Flamand, les coudes appuyés sur la table, en face d'une choppe qu'il remplit et vide tour à tour, au milieu d'une ipaisse atmosphère de fumée de tabac, garde un profond silence; on dirait de véritables gentlemen anglais livrés à toutes les émotions que font naître les péripéties d'un steeple-chase ou les succès du Derby. Tous les pinsons rivalisent d'énergie et de persévérance. Dans cette véritable lutte, leur chant, trop vif et trop fort pour être agréable ailleurs que dans la carnpagne, devient bientòt tellement bruyant, qu'il faut être assuré contre les conséquences d'une pareille harmonie pour pouvoir l'entendre même avec résignation. Les pinsons cessent leur chant successirement, à mesure qu'ils tombent épuisés, et le vainqueur est celui qui peut encore faire entendre sa voix au milieu du silence de ses congénères. Trèssouvent les vaincus et même les vainqueurs perdent la vie après de pareils concours, parce que leurs effurts ont iti: tellement exagérés, que les paures fringilles ne peurent plus retrouver leur voix. Leurs propriétaires, qui ne les conservaient que par un pur égoïsme, donnent la mort à ces paurres captifs, rictimes de leur déronement pour des ingrats. Afin de pouvoir mieux comprendre les terribles conséquences de cette lutte, il suffit de savoir que, dans ces concours, des pinsons areuglés peurent répéter, plus de huit cent fois de suite et sans aucun repos, leur phrase musicale, que les villagevis lorrains tratuisent ainsi dans leur patois: "Fi, fi les laboureux, jeirrons ben sans eux.»

Détournons-nous de ce spectacle attristant, et terminons l'étude du pinson par quelques détails sur sa nidilication. Le pinson recherche ordinairement les arbres 
fruitiers pour y construire son nid; peu de bereeaux sont plus doux, plus gracieux que celui de ce fringille. Composé à l'extéricur de pointes de lichens réunies par des toiles d'araignée, il est garni à l'intérieur de quelques brins de crin et du duvet des plantes. Appuyé ì la naissance d'une grosse branche, ce nid, qui a la forme d'une gracieuse coupe aplatie, est très bien dérobé aux regards de l'ennemi; sa couleur se marie facilement à celle de l'arbre auquel il est confié. Il est quelquefois établi dans des haies épaisses, placé à l'embranchement des tiges les plus élevées, et abrité par des touffes de houx. La femelle seule va chercher les matériaux nécessaires pour ce petit édifice. Le mâle lui aide à les coordonner, puis se contente, ensuite, d'avertir sa compagne, par des airs éclatants et saccadés, de l'appreche des importuns. Il pourvoit aussi avec une véritable sollicitude à la nourriture de la coureuse. Le pinson manifeste très-vivement alors des sentiments de jalousie; il ne permet à aucun de ses congénères d'approcher de son nid.

Lorsqu'il croit que l'on en veut à sa nichée, le mâle se laisse tomber à terre et vient au devant de l'ennemi, en feignant d'avoir les ailes brisées. Si les petits sont éclos et que la femelle puisse, sans trop d'inconvénient, abandonner sa jeune famille, elle s'empresse de se joindre au mâle. Quand, par ce stratagème, le père et la mère ont réussi à éloigner lo danger qui les menaçait, ils s'envolent rapidement, et reviennent par des voies détournées consoler ceux qui craignaient déjà d'être orphelins. Si, malgré leur stratagème, les pinsons voient l'ennomi approcher de lcur jeune famille, le mâle et la femelle poussent les petits hors de leur berceau, et souvent, à coups d'aile, parviennent à les sauver. C'est un spectacle attendrissant de les voir, dans cette circonstance, recourir à tous les moyens que peuvent inspirer l'amour et la sollicitude d'un père et d'une mère. 
Le nid du pinson eontient quatre ou cinq œufs, dont la forme, les dimensions et les nuances varient beaucoup. Les uns sont ronds, les autres piriformes. La coquille de quelques-uns est blenâtre ou d'un gris nuancé de rouge; sur cette couche apparaissent des taches noiratres quelquelois très-prononcées, d'autres fois effacées. Certains de ces œufs, au contraire, n'ont aucune tache, et la coquille en est d'un bleu pâle. Les rariétís nombreuses et trèsdifférentes qui se manifestent dans les œufs du pinson, donnent lieu à beaucoup d'erreurs volontaires ou involontaires de la part des naturalistes et des collectionneurs.

Le grand diamètre varie de $0^{\mathrm{m}}, 015 \mathrm{~s}$ à $0^{\mathrm{m}}, 018$, et le petit de $0^{\mathrm{m}}, 012$ à $0^{\mathrm{m}}, 014$.

\section{PINSON D'ARDENNES. - MONTIFRINGILLA.}

Le nom vulgaire de ce passereau ferait croire qu'il habite en grand nombre dans les forêts des Ardenncs; il n'en est rien. Ce fringille vit et se reproduit dans les régions hyperboréennes; là, il niche dans les arbres verts qui couronnent les montagnes de ces pays désolés. Cette habitude justifie la dénomination montifringilln, " fringille de montagne. " Pour lui donner une dénomination caractéristique, il faudrait l'appeler le pinson de la Scandinavie. Dans plusieurs contrées de la France il est nommó aussi ardennet, "pinson des Ardennes, " expressior qui prouve également combien est répandue l'erreur qui le fait originaire des Ardennes. Ce fringille, dont le plumage varie beaucoup, traverse chaque année l'Anjou pendant l'hiver, surtout lorsqu'un froid rigoureux le furce à quitter le Nord. Il apparaît alors par troupes innombrables, et se laisse prendre par milliers aux collets préparés pour capturer les alouettes. Quand 
il y a déjà quelques semaines qu'il a quitté les forêts boréales, sa chair devient assez agréable, parce que, dans les régions tempérées, elle perd peu à peu l'amertume qu'elle avait contractée dans le Nord, où cet oiseau se nourrit principalement de semences d'arbres à résine.

Le nid du pinson d'Ardennes, composé, à l'extérieur, de lichens et de mousse, à l'intérieur, de crin, de plumes et du coton des plantes, est confié aux parties les plus touffues des arbres verts. Il contient quatre ou cinq œufs ordinairement oblongs, d'un blanc bleuâtre pâle, parsemé de taches noirâtres. Beaucoup de ces œufs ressemblent à ceux du pinson ordinaire, et c'est cette similitude qui favorise les erreurs, involontaires ou non, de la part des marchands naturalistes. Le grand diamètre varie de $0^{\mathrm{m}}, 016$ à $0^{\mathrm{m}}, 018$, et le petit de $0^{\mathrm{m}}, 012$ à $0^{\mathrm{m}}, 014$.

Le pinson d'Ardennes manifeste un caractère hargneux, et l'on aurait peine à lui appliquer le proverbe : gai comme un pinson. Il vit en mauvaise intelligence avec les autres oiseaux, et même avec ses semblables. Dans la recherche de sa nourriture, il imite les gallinacés, et donne des coups de bec aux voisins, pour leséloigner des graines qu'il a aperçues, et pour les empêcher de s'en emparer. De plus, en parcourant les champs et les routes, les individus qui composent une même bande s'empressent de passer les uns devant les autres, et se livrent alors à une série d'évolutions, dont il est facile de se faire une jdée en voyant les bandes de moutons marcher sur les grandes routes. Enfin, le fringille de montagne fait, en se couchant, le même bruit que nous avons déjà signalé pour la linotte, et que nous retrouverons encore d'une manière plus frappante en parlant du moineau. Ce tapage crépusculaire est accompagné aussi de coups de bec distribués en grand nombre par tous les membres de la réunion; cette manière de se souhaiter 
la bonne nuit donne lieu ì une viritable mêlée, dans lacquelle chaque fringille tient à ne pas rester en retour avec ses voisins.

\section{MOINEAU. - FRINGILLA. - DOMESTICA.}

Iei je m'avance sur un terrain brûlant : quelle est l'étymologie de moineau? A rant de travailler à résoudre cette question, je vais indiquer, en quelques mots, les motifs qui ont fait appeler le moineau Pierrot ou maitre Pierre. Cet oiseau est ainsi nommé parce qu'il se met it l'aise, et qu'il vit très-facilement chez les roisins en vrai propriétaire; rien ne l'effraie; si on le chasse par la porte, il revient par la fenêtre, et tous les appareils qu'on emploie pour le mettre en fuite ne font que l'attirer davantage. I'line rapporte qu'un moineau, poursuivi par un émerillon, ne craignit pas de chercher un refuge sous less plis du vêtement de Xénocrate, où il s'établit tout à son aise. En un mot, Pierrot ou petit maitre Pierre est un personnage plus gênant que gêné.

A ce sujet, je me rappelle un fait assez curieux qui s'cst présenté en Anjou. Dans un chef-lieu de canton habite un propriétaire, qui a l'avantage de compter dans sa famille un vénérahle oncle, doté d'une très-belle fortune, et dont il est l'héritier présomptif. Comme tous les neveux prévoyants et placés dans les mêmes circonstances, notre propriétaire tenait beaucoup à satisfaire son oncle, et cherchait à lui procurer trutes les douceurs qui dipendaient de lui. Or, le respectable oncle aimaii beaucoup les primeurs, et, parmi les primeurs, les petits pois. Le neveu s'appliquait done ì cultiver ce lógume avec un soin et une persévérance qui puisaient un encouragement dans le désir bien if de recueillir plus tard un copieux héritage. 
Chaque fois que l'oncle visitait son neveu, à l'époque favorable à la culture des petits pois, l'héritier présomptif était heureux de fournir au vieillard, avec un plat abondant du légume désiré, une preuve de ses sentiments affectueux et reconnaissants. Nalheureusement, des familles de pierrots, qui n'avaient pas le même motif que le neveu de respecter les petits pois, conspiraient, depuis plusieurs années, contre lui et contre son ingénieux moyen de s'assurer un héritage. Ils mangeaient les petits pois avec une audace persistante, et l'oncle en vint à se plainùre que le plat qu'on lui servait était acheté à vil prix chez les voisins, et n'était plus le résultat d'une culture inspirée par les sentiments du cœur. Le neveu, sensible à ces reproches et plus encore à certaines craintes, résolut d'avoir recours, pour éloigner les pierrots, à tout ce que peut inventer une imagination surexcitée par le désir de s'enrichir. Il suspendit des ardoises qui s'entrechoquaient, de petits moulins, des oiseaux de proie préparés avec soin, etc. Les terribles pierrots affrontaient tout, se moquaient de tout. A ces instruments de terreur succéda l'exhibition d'une crinoline portée autrefois par la nièce. Un instant les pierrots se tinrent à l'écart, ne comprenant rien, avec raison, à un tel appareil; ils craignaient qu'il ne cachât quelque perfidie; mais bientôt ils vinrent se reposer à leur aise sur cet échantillon des produits de l'industrie américaine, et se livrèrent plus que jamais à une guerre acharnée contre les petits pois. Le neveu, que cette persécution déconcertait, commençait à perdre patience, lorsqu'une idée vint à son souvenir et ramena son espoir. Autrefois, il avait rempli de nobles fonctions dans la milice citoyenne appelée à protéger la famille, la propriété, etc., et, depuis que cette milice ne fonctionnait plus, il avait conservé avec soin son équipement complet, afin de prouver plus tard à ses enfants les immenses ser- 
vices qu'il aurait pu contribuer à rendre, si toutefois l'occasion s'en était présentée. Cé n'était done pas sans un profond regret qu'il sacrifiait le brillant uniforme; cependant, pour lui, l'héritage devait être préféré à la gloire. Le sacrifice est décidé et bientôt consommé. Un mannequin, auquel on donne autant que possible l'air martial d'un brave garde national, est revêtu du costume traditionnel, et sa tête est couronnée du shalio pyramidal, orné de la cocarde aux trois couleurs. Rien n'est oubiié; la main même est armée d'un sabre de bois. Puis le neveu, heureux de son invention, se livre de nouveau à la culture des petits pois. Il entreprend même un voyage de quelques semaines, espérant encore plus que jamais que l'héritage présumé de l'oncle pouvait lui permettre de pareilles vacances. Plein de joie et de confiance, il revient dans son domaine pour recevoir une visite de l'oncle et lui offrir le plat toujours tant désiré. Quel ne fut pas son découragement, quand il trouva son jardin entièrement dévasté! Tous les pierruts du canton semblaient avoir conspiré contre le garde national. D'abord ils s'en étaient éloignés; mais bientôt, ayant constaté qu'il n'y avait rien à en craindre et, bien plus, qu'il pouvait servir à protéger leurs familles, des couples s'étaient établis dans les différentes parties de l'uniforme, et un pierrot, plus audacieux encore que les autres, avait élevé sa jeune famille dans le shako, à l'abri de la cocarde citoyenne. L'uniforme tout entier était maculé, et prouvait que les moineaux, comme de véritables pierrots, s'étaient moqués de tout et n'avaient rien respecté. Ce fait contribue à prouver que le public, toujours malin et bon appréciateur des habitudes, a donné avee raison au moineau un nom très-caractéristique. C'est pour le même motif que beaucoup d'suteurs comparent le moineau au gamin de Paris. Le neveu, deconcerté par laudace des moineaux, a cru devoir renoncer à la culture 


\section{$-351-$}

des petits pois, et prier Dieu de lui rendre farorables les dispositions de son oncle à sa dernière heure... Que deviendra l'héritage? Est-il destiné à disparaître avec le légume privilégié? Je l'ignore. - Si ce modeste travail doit avoir les honneurs d'une nouvelle édition, peut-être pourrai-je alors faire connaître à mes bienveillants lecteurs la fin des épreuves de l'infortuné neveu.

Dans les campagnes, et souvent même dans les villes, le moineau est appelé paisse, du vieux mot latin passa, passare, "passer," qui a été aussi la racine du mot passcreau. Pour les enfants, le moineau est le passereau par excellence; c'est le plus commun de cette espèce; c'est celui que l'on élève le plus facilement, et peu de familles se sont privées du plaisir de faire l'éducation de quelques paisses venant prendre, sur la table, à l'heure du repas, une nourriture qui ne leur était pas destinée, disputant même aux chats privilégiés les mets qu'une main prévoyante leur avait préparés avec une tendresse presque maternelle.

Même en liberté, le moineau est susceptible d'une certaine familiarité. Plusieurs fois, des fenêtres du Mlusée, j'ai vu des troupes de moineaux assez nombreuses se réunir à des heures fixes, et venir sur les toits manger les graines et le pain qu'une main bienveillante aimait à leur distribuer. C'est ainsi que celle qui devait plus tard consacrer son pinceau pieux et savant à venir en aide aux orphelines, dont elle aimait à sécher les larmes et à protéger l'innocence, préludait à sa mission toute providentielle, en imitant le Seigneur, qui distribue la pâture à tous les oiseaux du ciel.

A Paris, dans le jardin des Tuileries, près des marronniers séculaires, on peut chaque jour, à des heures réglementaires, voir de vieux habitués de cette promenade jeter en l'air des miettes de pain, que des nuées de moineaux saisissent en tourbillonnant dans l'air, avec 
la même adresse et avec la même agilité que lorsqu'ils poursuivent les insectes et les papillons.

Le moineau, dont nous étudions les mœurs, et dont nous essayons d'expliquer la dénomination, est appelé moinecau franc. L'épithète ajoutée au nom indique-t-elle que cet oiseau est le véritable type du genre? Serait-ce une manière de le distinguer du moineau soulcic et du moineau friquet? Je ne le pense pas. Je crois que cette expression signifie tout naturellement que le moineau franc est ainsi appelé, parce qu'il ne dépasse pas les frontières de la France. Au delà des Pyrénées, il est remplacé par le gros-bec espagnol, et de l'autre côté des Alpes, par le gros-bec cisalpin: ces deux espèces ne sont que des variétés du moineau frane, et l'on pourrait trèsbien les appeler moineaux espagnols et moineaux italiens. Ce sont des moineaux brunis par un soleil plus chaud que celui de la France.

Quant à l'étymologie du mot moineau, quelle est-elle? Des auteurs ont prétendu que moineau dérixait de moine et signifiait petit moine.

Pour justifier cette opinion, ils s'appuyaient sur le texte cité précédemment : "Sicut passer solitarius in tecto, - Comme le passereau solitaire sur les toits." Ces paroles ne peuvent pas s'appliquer au moineau, mais à la fauvette du Calvaire, au rouge-gorge. Les mœurs du moineau s'opposent à cette interprítation : le moineau vit en bandes nombreuses; il est bien opposé ì la solitude et au silence; et, si son nom dérive de moine, c'est bien certainement à un autre point de vue.

Voici quelle serait, d'après Belon, la véritable étymologie du mot moineau. "Cet un, - dit Belon, " est nommé moineau, parce gu'il semble porter un froc " de la couleur des enfumés. " Le texte me parait assez eoncluant par sa närveté maligne. Jadmets volontiers, arec Belon, que ce passereau duit sa dénomination à la 
couleur de son plumage, qui ressemble aux nuances sombres de la robe des moines.

D'autres écrivains, dirigés par un esprit caustique, ont prétendu que le moineau avait été associé aux moines par son nom, parce que, comme ceux-ci, il vit aux dépens des autres, prélève une dîme abondante sur les biens d'autrui, piaille toujours, et est beaucoup plus nuisible qu'utile. Je rapporte ces assertions avec la fidélité de l'historien, et sans vouloir prétendre qu'elles soient en rien justifiables. J'admettrai volontiers, cependant, que le moineau peut être comparé au moine. Comme celui-ci, il rend bien des services incompris par les esprits superficiels; comme lui, il a eu l'honneur d'être proscrit dans beaucoup de pays, et, comme lui, il a été réhabilité par les écrits des hommes impartiaux et instruits. Le moine est homme, et, à ce point de rue, il peut et doit même se ressentir des misères inleérentes à l'humanité; mais l'histoire de tous les temps a inscrit les services immenses et persévérants que les moines ont rendus dans les lettres et dans les sciences. La musique, l'architecture, la peinture, l'agriculture, doivent aux moines une éternelle reconnaissance; c'est à leur vigilance continuelle, à leur travail opiniâtre qu'est due la conservation de tous les chefs-d'œurre de l'antiquité.

On les trouve établis volontairement sur la cîme des montagnes, au milieu des neiges perpétuelles, et dans les tristes réduits où sont relégués les malheurcux privés de la raison. Appuyés sur la croix, ils se vouent à consoler et à adoucir toutes les souffrances du corps et du cœur. Dans des temps de passion et d'aveuglement, ils ont été proscrits par des esprits prévenus, mais rappelés avec enpressement, lorsque le calme et la raison succédaient à la tempête et à la folie. Sous ce rapport, le moineau peut véritablement être comparé au moine; peu 
d'oiseaux ont eu des ennemis plus acharnés et des défenseurs plus dévoués.

Si l'on étudie le moineau dans l'ensemble de sa vie, c'est un des oiseaux les plus utiles; il rend des services incaleulables pendant la saison du printemps. Il est l'arlversaire le plus reduutable des hannetons, et, dès lors, il préserve les légumes, les récoltes des terribles ravages que cause la multiplication de cet insecte destructeur. En Lorraine, l'on a apprécié les services rendus à l'agriculculture par le moineau, et comme ce passereau ne trouve que très-difficilement où nicher dans les vastes plaines de cette province privée d'arbres, les habitants ont soin de placer, sur la façade de leurs maisons, deux et même trois rangs de pots destinés à donner un asile au moineau, et à faciliter sa propagation.

Le moineau fait chaque année plusieurs couvées, et il élève ses petits à l'époque où les vers et les insectes exercent le plus de ravages. Dans plusieurs rapports lus à la Société d'acclimatation et consacrés à itudier les moyens à prendre pour sauvegarder les intérêts de l'agriculture, il a été constaté, prouré que le moineau rend d'incalculables services. M. Ray ayant renfermé dans une cage une couvée de jeunes moincaux, le père et la mère continuèrent à les nourrir arec une tendre sollicitude, et, chaque jour, soixante à soixante-dix carapaces de hannetons trouvées sur les planches de la cage prouvaient l'acharnement du moineau à combattre un des adversaires les plus nuisibles à l'agriculture. Les larves des hannetons restent deux ou trois ans en terre sous le nom de vers blanes, de mans ou de tures. Parmi les hannetons immolés par les moineaux, se truuvent nécessairement. des femelles fécondées, et chacune d'elles devant déposer de vingt-cing à trente oufs, il s'ensuit que les fures détruits par une seule famille de 
moineaux, $\mathrm{y}$ compris la nourriture du père et de la mère, pendant une année, doivent se compter par centaines de mille. Quand les hannetons manquent, les moineaux dévorent des myriades de chenilles, d'insectes, de pyrales, de pucerons, de cigales, etc.

La guerre que le moineau fait aux cigales avait été remarquée déjà à une époque bien reculée; car Plutarque, dans la vie de Sylla, en donne une preuve assez curieuse. Cet auteur, pour démontier que le moineau prédit l'avenir, raconte qu'un jour que les Pères Conscrits, qu'on appellerait maintenant sénateurs, délibéraient sérieusement dans la chapelle de Bellone sur les graves affaires de la République, un moineau pénétra, sans y être invité, dans le sanctuaire des lois. Ce moineau tenait dans le bec une grosse cigale; il en laissa tomber une moitié sur les Pères Conscrits et emporta l'autre. Les Pères Conscrits suspendirent leurs délibérations et firent venir les augures; ceux-ci dérlarèrent que cet événement annonçait, d'une manière certaine, la guerre civile. Les Pères Conserits représentaient, selon l'interprétation des augures, les citoyens, les habitants des villes; le moinean personnifiait les gens de la campagne, et la cigale était la vive image de la République. D'où il suivait que les citadins et les moineaux se partageaient la cigale, ou si l'on veut la chose publique, mais peut-être pas en parties égales! L'événement prouva que, cette fois, les angures ne s'étaient pas trompés; la lutte qu'ils avaient annoncée se réalisa, et se perpétue même encore un peu de nos jours.

Enfin, le moineau consomme une grande quantité de graines de plantes nuisibles, qui auraient infesté les jardins, les vergers, les chamus. Aussi l'exemple de l'Angleterre, de la Prusse et de la IIongrie, qui avaient déclaré une guerre d'extermination aux moineaux et qui ont été obligées, dans leur propre intérêt, d'encourager 


\section{$-356-$}

ensuite la reproduction de ces oiseaux, prouve-t-il les services qu'il rend ì l'agriculture. Maequillivray, dans le fremier volume de son onvage sur les oiseaux, affirme "que les jardins polagers, aux environs de Londres, ne "pourraicut pas fournir un seul chou au marché de " cette ville sans le secours des moineaux, aux recher" ches desquels n'fichappent pas les larves des chenilles " qui, déposies tous les ans à l'état d'œuf́s sur les feuilles " et cachées à la vue de l'homme, auraient bientòt pris " tout leur dévelopjement et porté la disette au foyer des " cultivateurs de ces jardins. )

Aussi tous les membres des sociétés d'agriculture unissent-ils de plus en plus leurs voix pour recomnaitre les viritables services rendus aux récoltes par les moineaux, et pour réhabiliter des oiseaux qui n’ont pu ètre proscrits que par le citprice et lignorance. Le reproche, qu'on leur adresse, de n'habiter que près des endroits bien cultivés, pour pouroir plus facilement se livrer au pillage, nou-seulement ne fournit pas un grief contre eux, mais offre au contraire un argument en leur faveur. Si le moineau se tient près des champs ensemencís, c'est que là ses services sont plus utiles qu'ailleurs; en effet, dans les landes et dans les terrains incultes, il n'y a rien à préserver, rien à défendre. S'ils se riftugient dans les clochers, dans les créneaux des rieux chàteaux, c'est pour voir plus facilement les lieux qui réclament leur concours; de ces endroits élevés, ils apercoivent le champ de bataille sur lequel ils doivent se rendre pour combattre les ennemis des rícoltes de l'homme. ()uelques naturalistes prétendent que le moineau dépense, chatue année, quatre décalitres de blé; cette accusation n'est pas fondér, ot le serait-elle, elle n’ébranlerait pas mon upinion. Le moincau ne peut manger le blé que lorsque celui-ci n'est pas eneore récolté; or le temp̧s qui s'écuule entre l'instant wù le froment commence à mù- 
rir et celui où on le coupe, ne peut faire admettre une pareille hypothèse. Si le grief se réalisait, l'utilité et la nécessité du moineau n'en resteraient pas moins évidentes et incontestables. Le moineau serait un fidèle serviteur, un ami infatigable du cultivateur, qui ne ferait que prélever un minime salaire pour les services qu'il rend. Est-ce que l'on peut avec justice reprocher au mercenaire dévoué le pauvre morceau de pain dont il se contente?

Si chaque moineau dépense, par an, quatre décalitres de blé, et que, d'un autre côté, par la destruction qu'il fait des hannetons, des chenilles, des vers, etc., il sauvegarde d'une perte réelle des centaines de décalitres de blé et de graines, ne sera-t-il pas encore plus utile que nuisible? Si l'on ne reconnaissait comme utiles que les employés et les ouvriers qui travaillent avec conscience, sans prélever aucun salaire, et les fonctionnaires qui se dévouent à la chose publique par le seul mobile du dévouement, je crois que le nombre en serait bien imperceptible.....

Les moineaux, du moins, n'entrent pas en grève, et, maintenant, ils ne réclament rien de plus que dans les temps où les avantages du progrès n'avaient pas encore rendu nécessaire l'augmentation des salaires.

Je résume donc mon opinion, en m'appuyant sur de nombreuses et de graves autorités, sur l'expérience des siècles et sur mes propres observations, et je maintiens que le moineau est incontestablement un oiseau utile et très-utile, et que, s'il a été proscrit quelquefois, c'est parce que l'on n'avait étudié ses mœurs que sous un rapport, et non dans leurs détails.

Dieu lui-même semble avoir voulu réhabiliter, à un certain point de, vuc, le moineau, en le plaçant dans la catégorie assez restreinte des oiseaux purs. En effet, le Seigneur, dit le Lévitique (ch. xiv, v. 4), ordonne au 
lópreux, qui désire se purifier de ses sunillures, d'offrir en sacrifice deux moineaux vivants ou deux autres oiscant: purs.

Peut-être devrais-je ici relater la conduite du grand Frédirie. Ce prince possédait, daus son jardin de Pustdam, de magnifiques cerisiers qui, chaque année, produisiaient des fruits dont le monarque était très-friand. Un jour que Frécléric vit une bande de moineaux venir lui ravager ses fruits firoris, il entra dans une véritable colère royale et fit promulguer une loi, par laruelle il promettait de payer une récompeuse de six pfenning: à chatue personne qui livrerait deux têtes de moineaux. Le pfenning valant presque un centime, il s'ensuit que charque moineau était payé environ trois centimes. L'annie daus laguelle fut promulguée la loi, plus de dix mille thalers servirent à solder la prime concédée aux destrueteurs de moineatux; le thaler prussien étant de 3 fi. 73 , e'itait done un million deux cent cinciunte mille moineatix qui furent sacrifiés, dans une seule année, au caprice du grand léedérie. Les deux années suivantes, les moineau lurent poursuivis avec le mème acharnement, et leur espèce disparut de la Prusse.

Le prince croyait avoir triomphé de ses ennemis et esprérait pouroir manger les fruits de ses nombreux cerisiers. Mais, au commencement du quatrième printumps, les arbres parurent tellement couverts ile chenilles, que les fleurs, les feuilles mèmes furent dérurées arec une si audaciense persévérance, fu'il fut impossible de recueillir un seul fruit. Le roi philosophe reconnaissant qu'il s'était trompé voulut (bel exemple à suivre!) réparer lit faute qu'il avait commise, ef travailh' à conscrver, du moins, la vie il ses arbres. Pour ubtenir ce résultat, il concerla une prime de six plennings it tuns cerux qui introlluiraient daus ses Etats un eouple de moineaux. Les proscrits revinrent en grand nombre, et leur présence 
permit au monarque, non-seulement de voir ses cerisiers se couvrir de fleurs et de feuilles, mais encore de recucillir les fruits qu'il aimait tant à savourer. Puisse l'exemple du grand Frédéric servir de sujet de méditation aux persécuteurs des pics et de beaucoup d'autres oiseaux tous aussi injustement proscrits!

L'épithète domestica a déjà été longuement expliquée à l'article de l'hirondelle de cheminée; ici, cette expression peut être prise dans le même sens; mais elle sert surtout à distinguer le moineau franc du moineau soulcie et du moineau friquet, qui tous les deux fuient le voisinage de l'homme, et aiment à vivre et à se reproduire loin des habitations.

Le moineau franc niche dans les pots que l'on place au-dessus des fenctres, dans les trous des murs, dans les crevasses des terrasses qui bordent les pièces d'eau, sur les arbres des boulevards, des promenades publiques, dans les vieux nids de pie, dans les haies élevées, un peu partout; il s'accommode de tous les lieux. Son nid est grossièrement façonné, mais confortablement composé. Il représente une boule plus ou moins grosse, selon les endroits auxquels il est confié; l'extérieur est formé de paille et de filaments de plantes, de brins de papier; et l'extérieur, de morceaux d'étoffe et d'une épaisse couche de plumes, de coton, etc., offrant aux petits un berceau sphérique très-chaud et très-souple. Souvent on a reproché au moineau de s'emparer de vive force du nid des hirondelles de fenêtre, pour y établir sa demeure et profiter ainsi du travail des autres. Le grief est fondé, et il se reproduit de temps en temps. Peut-être en agissant ainsi, le moineau cherche-t-il une compensation aux torts que lui fait subir très-souvent certain membre de la famille des hirondelles. En effet, le martinet des murailles ne pouvant, à cause de la petitesse de ses tarses, se procurer facilement les matériaux nécessaires pour 
façouner son nid, pille, avec une audacieuse et persévérante effronterie, tous les nids de moineaux qu'il rencontre, emportant plumes, coton, paille, etc. En se réfugiant dans le nid d'un membre de la même famille, c'est, de la part du moineau, comme un moyen d'abriter plus facilement ses enfants sous la sauvegarde de la parenté.

Ce nid renferme de quatre à six œufs affectant toutes les formes, revêtant toutes les ruances. Les uns sont ronds, d'autres piriformes, quelques-uns entièrement oblongs comme des olives : les uns sunt parsemés de points noiratres formant plusieurs couches superposées; d'autres sont d'un blane plus ou moins clair avec une couronne vers le gros bout; d'autres ont des taches grises, cendrées, brunes, plus ou moins nombreuses, plus ou moins rapprochíes. Quelques-uns peurent être confondus avee les œufs de la rousserolle. Les variétés de ces œufs sont si multipliées, qu'elles unt donné lieu à bien des fraudes, et que les cufs du moineau frane figurent dans beaucoup de vitrines sous des noms usurpís. Indiquer les dimensions de ces œufs serait chose superflue et difficile, à cause des rariations infinies qu'elles subissent.

\section{FRIQUET. - MONTANA.}

En Anjou, le friquet est très souvent appelé la puisse des saules, parce que ce passereau se plait surtout à nicher dans les trous des vieux saules plantés sur le bord des rivières, ou dans les terrains marécageux. Dans la Loire-Inférieure, cette habitude l'a fait désigner sous le nom de saulet. Plus petit, plus vif, plus gracieux que le moineau franc, le friquet est sans cesse en mouvement; il doit son nom a l'ensemble de ses habitudes.

Selon Ménage, la dénomination friquet aurait pour racine fretillus, d'où est venu frétiller, "remuer, s'agi- 


\section{- $361-$}

ter beaucoup. ") C'est la même raison qui a fait nommer fritılla, la bergeronnette, vulgairement appelée hochequeue.

A peine le friquet est-il posé sur une branche d'arbre ou sur une plante, qu'il se tourne et retourne en tous sens avec une grande rapidité, baissant et haussant la queue sans relâche. Son vol est tellement rapide, qu'il semble bourdonner comme un sphynx.

Si le friquet frétille en tout sens et en tout temps, c'est surtout lorsqu'en compagnie des moineaux francs, il se baigne dans les lieux marécageux exposés au soleil. Les trépidations qu'il communique alors à ses ailes, les mouvements qu'il imprime à tout son corps en tournant sur ses pattes, comme sur un pivot, justifient bien exactement l'étymologie donnée au mot friquet. Puis, pour se sécher et pour se débarrasser des vermines qui les tourmentent, les friquets, ainsi que les moineaux, imitent les oiseaux pulvérateurs, et se roulent dans le sable ou sur la terre avec une grande rapidité. En Italie, le moineau friquet est nommé passa mattugia ou moineru fou. Il n'est donc pas étonnant qu'on ait donné la même épithète au bruant, qui manifestait des habitudes identiques. Il était naturel de désigner par le même mot les mêmes caractères de ces différents oiseaux.

Autrefois, on désignait par le mot friquet un enfant enjoué, vif, étourdi, et cependant gracieux.

L'épithète montana, " de montagne, montagnard, " indique que, dans certaines localités, le friquet habite les collines, les montagnes. Dans notre département, il se tient dans les lieux couverts et humides. Là, il fait une guerre acharnée aux insectes, et immole beaucoup de hannetons, de vers, d'araignées, de sauterelles, etc.; il est surtout l'ennemi particulier de la eigale qu'il poursuit, ainsi que le hanneion et le papillon, el qu'il atteint au vol avec une adresse remarquable. Moins répandu 
que le moineau franc, il est aussi moins persécuté, et il n’a pas eu, comme lui, les inconvénients de la proscription, ni les homneurs de la réliabilitation. Quand le soleil semble terminer sil carrière, et que les ombres de la nuit commencent à envelopper la tere pour l'engager itu repos, les friquets se réunissent en assez grand nombre dans les saulaies, et, avant de se livrer aux douceurs du sommeil, ils imitent les moineaux francs pendant un temps plus ou moins long; ils représentent assez bien une de nos honorables assemblées, dans les moments d'orages parlementaires, où tous les orateurs parlent en même temps, sans se comprendre. De quoi s'agit-il? Est-ce une fête de famille? Est-ce une discussion sur les préséances? ou une lutte générale dans l'intention d'occuper les positions les plus agréables et les plus commodes pour passer la nuit? J'ignore le véritable motif du bruit assourdissant que font les friquets; tout ce que je sais, c'est que le vacarme diminue peu ì peu, i mesure que les ténèbres se répandent. Les friquets se réunissent par groupes, par familles, et passent ainsi, autant qu'ils le peuvent, la nuit dans les trous des arbres vermoulus. Ces demeures, ne pouvant contenir qu'un petit nombre d'individus, fournissent peut-itre aussi un des motifs de ce bruit cripusculaire; car il doit y avoir là, comme ailleurs, beaucoup plus de prétendants que d'élus.

Le friquet établit son nid ordinairement dans les trous des vieux arbres; ce nid prend toutes les formes et se plie à loutes les dimensions des excavations auxquelles il cst confié. L'enveloppe en est grossièrement composie de paille, d'herbes, de feuilles sèches; l'intirieur est garni de laine, de crin, de plumes, de papier's, de chiffons, ete. Il contient quatre ou cinq œufs ordinairement allongís et quelquefois très-oblonis, d'autres fois tries-ronds. Le plus souvent la coquille est luisante, ou 
présente une nuance violet clair. Ces æufs offrent une multitude de variétés, de couleurs, de teintes; les uns ont un fond blanchâtre, aver une couronne de points noirâtres vers le gros bout; d'autres sont parsemés de petites taches brunes, noirâtres, très-rapprochées, el offrant, en quelque sorte, deux couches superposées. Quelques-uns de ces œufs peuvent facilement être confondus avec les œufs de la fauvette effarvate, ou avec ceux de l'alouette calandrelle et du pipit des buissons. Le grand diamètre varie de $0^{\mathrm{m}} 018$ à $0^{\mathrm{m}}, 019$, et le petit de $0^{\mathrm{m}}, 013$ à $0^{\mathrm{m}}, 014$.

\section{SOULCIE. - PETRONIA.}

Le fringille soulcie est beaucoup plus rare que les précédents. Sédentaire dans quelques parties de notre département, il recherche, de préférence à tous les autres lieux, ceux qui sont plantés de noyers.

Ce moineau doit son nom vulgaire soulcie, soucie, " semblable à la couleur de la fleur du souci, " à la belle tache d'un jaune citron que les mâles portent au-devant de leur cou, surtout à l'époque du printemps. Pendant l'automne, cette tache est beaucoup moins apparente; elle disparaît presque entièrement avec la mue ruptile. On appelle ainsi la mue, dans laquelle les oiseaux ne perdent pas leurs plumes tout entières, mais seulement l'extrímité de ces plumes. Dès lors que cette partie du plumage est revêtue de certaines nuances plus ou moins prononcées, il s'ensuit que le plumage de l'oiseau se trouve entièrement modifié par la mue ruptile.

Quant à l'épithète petronia, elle me semble avoir pour racine petro, petronis, qui signifie "bélier, paysan. " Cette dénomination ne peut se justifier que dans la deuxième acception, parce que le moineau soulcie est beaucoup plus paysan que le moineau frane, en ce sens 


\section{$-364-$}

qu'il ne s'approche jamais des villes, ni des habitations de l'homme; il recherche les endroits solitaires et les arbres touffus qui peuvent plus facilement le dérober à la vue. Les soulcies volent en troupes serrées, comme les moineaux; mais elles sont moins piailleuses, et leur vol n'est pas aussi précipité. Quelquefois même, elles paraissent voler par ondulations.

Le fringille soulcie établit son nid dans les trous naturels des arbres et surtout des noyers; la femelle, moins féconde que celle du moineau frane, ne fait ordinairement yu'une couvée. Le nid est formé comme celui des deux espèces précédentes; il contient quatre ou cing wufs d'un blanc sale ou mème roux, parsemé de pointou de taches brunes ou tirant sur le jaune. Ouelquesuns sont piriformes et pointillés comme les œufs d'alouette lılu, d'un gris uniforme. J'en ai reçu plusicur: qui portaient, vers le gros bout, une très-loelle courome de points noiràtres, ce qui aurait pu les faire confondre avec quelques varietés de l'alouette cochevis et de l'alouette des champs. Les œufs de la soulcie ont ordinairement des proportions plus fortes que ceux dumoincau franc. Le grand diamètre varie de $0^{\mathrm{m}}, 021$ à $0^{\mathrm{m}}, 022$, ef le petit de $0^{\mathrm{m}}, 01 \mathrm{~S}^{\mathrm{a}}$ à $0^{\mathrm{m}}, 016$.

\section{VERDIER. - CHLOHIS.}

Le verdier doit son nom vulgaire et sa dénomination scientifique aux nuances de son plumage qui, sans avoir une couleur bien prononcie, justifient cependant les épithètes empluyées pour disigner ce fringille. Ferdier dérive de viridis qui a la meme signification que cubins, venant, ainsi que culòios, "rert, jaune, " de chros.

Cet oiseau est confondu avec le bruant; et presuue partout on premd le bruant jaune prour le verdier, et le verdier pour le bruant. Leurs mœurs sont cependant 
bien différentes, et leur manière de nicher bien opposée.

Le motif plausible de cette erreur est la couleur jaune, tirant sur le vert, du plumage du verdier, qui le rapproche ainsi du bruant citrinelle. Je préférerais, sous toute réserve, tirer l'étymologie du mot verdier de viridarius qui servait, d'après plusieurs auteurs, à désigner un garde forestier chargé de veiller et sur les chasses et sur les bois qui lui étaient confiés. Selon Ménage, de Casseneuve et Ducange, viridarius serait formé de viride, qu'on prend absolument pour "le bois vert.) Afin de remplir' sa mission, le verdier ou le garde forestier était souvent obligé de parcourir les forêts et les bois, de s'y tenir et d'y habiter en quelque sorte. A ce point de vue, l'étymologie de verdier semblerait être bien plus vraie et bien plus caractéristique.

Cet oiseau diffère de la plupart des fringilles par sa prédilection pour les lieux isolés. Il se tient de préférence sur le bord des rivières ou des petits cours d'eau plantés d'arbres dont le feuillage est épais. Il aime à se mettre à l'ombre des rameaux touffus; il parait craindre et la trop grande lumière et la trop grande chaleur. C'est dans ces lieux solitaires qu'il établit son nid; il le construit sur la tête des arbres que l'on émonde d'une manière régulière; il choisit ceux qui l'ont été depuis deux ou trois ans, et dont les pousses souples et d'une verdure plus vive couvriront plus facilement la demeure de la future famille. D'autres fois le nid est placé le long du trone de l'arbre à quelques mètres du sol sur plusieurs branches rapprochées les unes des autres. Ce nid est composé de petites bûchettes, sur lesquelles repose une coupe artistement façonnée et formée de racines très-souples et très-déliées, entremêlées quelquefois d'herbes, de mousse et de crin.

Le verdier, dont le caractère est beaucoup plus sociable que celui du moineau, fait, comme lui, plusieurs 
courées. La femelle pond à chacune d'clles quatre ou cing mufs: allongés, d'un blane bleutitre, comme ceux de la linotte; ils sont parsemís de points ou de taches rougeatres, ou de couleur violacée et noirâtre. Ces points sont plus nombreus vers le gros bout. Les œufs de verdier varient beaucoup dans leurs dimensions; les plus petits pourraient facilement être confondus avec ceux de la linotte, et les plus gros avec ceux du bec-croisé dr:sapins. Cependant la corquille des œufs du verdier es toujours plus épaisse que celle du loxia curvirostra.

Le grand diamètre varie de $\left(0^{\mathrm{mm}}, 018\right.$ i $0^{\mathrm{m}}, 019$, et le petit de $0^{\mathrm{m}}, 012$ à $0^{\mathrm{m}}, 013$.

Le verdier élève ses petits avec une sollicitude trèsremarquable; il ne les abandonne pas même quand ils sont emmenés en captivité; car, bien qülis soient dans une étroite prison et surtout éloignés de ces ombrages et de cette verdure pour lesquels il manifeste une prédilectinn persévérante, le verdier veille sur ses petits et leur apporte une nourriture abondante, jusqu'au lioment où ils peuvent se suffire à eux-mêmes.

\section{GROS-BEC. - COCCATIIRAUSTES.}

Si l'on admet que fringille reut dire " briser, coneasser, "le gros-bee doit certainement être considiré comme le chef de la famille. Cet oiseau est doté d'un bee énorme adapté à une tête dont les dimensions contribuent à lui donner une physsinnomie exceptionnelle. La tête et le ber semblent s'être égarís en renant s'adapter sur le cou du gros-bec; ils paraissent avoir été destinés it un oiseau beaucoup plus gros. Il resiemble ainsi à ces lutteurs trapus, aux formes peu gracieuses, et qui, par l'ensemble de leur corps. annoncent qu'ils sont loin d'être destinés à des coneours d’intelligence. La phỵsionomie du gros-bec est niaise. 
Le nom scientifique de ce fringille, coccathraustes, dérive de коккоs, " graine, bourgeon, " et de thravô, " fracasser, briser, " etc.

Nous avons vu, à l'article du loriot, que cet oiseau a pour les cerises une prédilection très - sensible, et que les gens de la campagne croient qu'il dit dans son chant : Je suis le compere Loriot, Qui mange les cerises et laisse les noyanx. Ces noyaux sont recherchés avec avidité par le gros-bec, qui les brise très-facilement. Il complète ainsi l'œuvre du loriot, et efface toutes les traces des ravages causés par son confrère.

Les gros-becs voyagent par petites bandes, et, dans leur vol, ils se placent les uns à la suite des autres. Quand une de ces bandes s'arrête dans un champ de chanvre, elle y exerce de grands dommages. Lorsque tous les individus ont satisfait leur faim, l'un d'eux fait entendre un cri désagréable, semblable au bruit strident d'une lime, et tous les oiseaux de la bande répondent par un même cri, souvent accompagné d'un craquement de bec, et se dirigent vers les tiges élevées et touffues des arbres pour y passer la nuit. Le lendemain, un des membres de la famille donne le signal du réveil par un cri très-peu harmonieux, et tous le répètent en signe de consentement et de disposition à partir. En liberté, le gros-bec est sauvage et taciturne; en captivité, il est cruel, et se plaît à briser la tête et les pattes des autres oiseaux renfermés avec lui. Quand il est attaqué, il se met sur le dos comme les oiseaux de proie, fait avec sa tête le moulinet à quatre faces avec une grande rapidité, et distribue généreusement de vigoureux coups de bec. Souvent il tue les oiseaux en les pinçant cruellement et en emportant la pièce à chaque coup de bec; est-ce pour cela qu'il a été appelé pinson royal, c'est-à-dire "pinson par excellence? "

Le gros-bec vit aussi des semences des tilleuls et des 
platanes. Il recherche beaucoup les noisettes, et, pour les saisir, il s'accroche souvent par les pieds aux branches qu'il visite, et il conserve la même position jusqu'ù ce qu'il ait terminé son repas. Il est évident que, par cette halitude comme par son cri et par l'ensemble de ses mœurs, cet oiseau se rapproche de la mésange, et que, comme elle, il est peu gracieux pour ceux qui entretiennent des relations avec lui.

Le gros-bec imite le verdier; il établit son nid sur lit tête des arbres émondés ou sur un faisceau de petites loranches; le fond, composé de bûchettes, supporte une coupe formée de petites racines entrelacées avec art; rarement on y trouve du crin. Ce nid renferme quatre ou cinq œufs d'un gris cendré étendu, lavé de bleuttre, moucheté de taches d'un brun noirâtre ou olivâtre, dunt les unes se trouvent effacées dans la coquille, et les autres sont d'une nuance très-prononcie. Presque tous ces œufs ont des raies en forme de reines et qui serpentent d'une manière irrégulière. Le grand diamètre varic de (1) $\mathrm{m}, 020$ à $0^{\mathrm{m}}, 02 \%$, et le petit de $0^{\mathrm{m}}, 016$ à $0^{\mathrm{m}}, 017$. Le service le plus évident que le gros-bec rende à l'agriculture, c'est qu'il nourrit ses petits avec des insectes, des chrysalides, etc.; et, comme sa progéniture est doncée d'un appétit caractéristique, il s'ensuit que, pendant la durée de l'éducation de la jeune famille, les insectes, les vers sont immolés en très-grand nombre.

\section{GROS-BEC SERIN of CINI. - SERINUS.}

Ce fringille, l'un des plus gracieux de la famille, habite le midi de la France, et surtout les deux versants des Alpes. Il recherche les pays où règne une température chaude et assez régulière. Le cini traverse nutre patys it des époques incertaines; quelques troupes même, 
attardées par des raisons inconnues, y ont fait, très-rarement, il est vrai, élection de domicile. Par ses formes, par ses habitudes, par les teintes jaunâtres et verdâtres de sa livrée et par son chant, le cini se rapproche du tarin et du venturon; mais la dénomination de gros-bec sert à le distinguer de ces deux fringilles, qui n'ont pas, comme le serin, le bec court et bombé. Le cini vit en bonne intelligence avec tous ses congénères; d'un caractère doux et sympathique, il se plaît à charmer, par les agréments de son chant, tous les lieux qu'il fréquente, tous les êtres qui l'environnent. Dès le matin, on le voit par petites bandes, cherchant à terre des graines et des semences de plantes, surtout celles du mouron et du seneçon, et ne disputant jamais à d'autres la nourriture qui peut même lui être nécessaire. Quand la chaleur augmente, les cinis aiment à se baigner, puis à regagner les arbres touffus; et là, à l'abri d'un feuillage épais, les mâles donnent un concert de famille. Ils n'ambitionnent pas l'éclat; ils ne recherchent pas les applaudissements du public : ils semblent ne désirer qu'une chose, faire passer à tous les membres de leur famille quelques moments d'une distraction pure et agréable, et donner à leurs petits une leçon d'harmonie domestique. L'épithète serin a paru à beaucoup d'auteurs la conséquence de ces dispositions du gros-bec. "Le serin,_-dit Belon, - a pris son appellation française de l'excellence de son chant. Car tout ainsi que l'on dit que les " syrènes endorment les mariniers de leurs chansons, semblablement, pour ce que ce petit oiseau chante si doucement, il a pris le nom de serin.")

La dénomination de sirène dérive de séînên, qui a luimême pour racine sÉïra, "chaîne, " parce que les sirènes enchaînaient, pour ainsi dire, par leurs accents, les malheureux qui se laissaient captiver à cette harmonie perfide. Nicot partage l'opinion de Belon, et dit : 
"Serimus nomen habere pulatur a sirenibus, le serin est considéré comme tirant son nom des sirènes; " et il ajoute: " à cause de la douceur de son chant. "

Ménage donne lui-même une explication qui pourra satislaire les savants, en indiquant le radical prossible du mot sirene. Il affirme que le mot schir signifie en hébreu " chant dous et harmonieux, " et qu'il est le principe des mots (qui, en sree, en latin et en français, disignaient le gros-bee serin, qui signifierait "gros-bee dont la voix est agréable et symprathique. ) Cette epithète conviendrait parfaitement à ce fringille, qui sait captiver ceux qui le connaissent et l'entendent, non-seulement par les avantages de sa roix, mais encore par ceux de son caractère et de sa beauté. Je serais alors porté à croire que le mot cini a la même signification que serin, et que cette épithète n'est qu'une forme plus ou moins incomplète lérivée de cecini, parfait de cano, qui signifie "chanter."

J'eusse désiré pouvoir consulter sur ce point le dictionnaire de M. Littré; mais ce mot a échappé à l'attention du sarant professeur. Dìs lors, si je me trompe, i'aurai du moins en ma faveur une circenstance atténuante. Cette étymologie, que je donne avec une très-grande réserve, offrira l'avantage de rattacher au mot cini la pensée des mêmes habitudes retracées par l'expression serin. A cette première hypothèse j'en ajouterai une seconde, mais toutefois avec la mème prudence. Cette nourelle manière d'interpréter le mot cini s'appuierait sur les muances d'une partie des plumes de cet oiseau, qui ont déterminé les campagnards à nommer le cini "serin vert de Provence, s P'our le caractíriser encore d'une manière plus pricise, on eùt pu l'appeler le serin cendré: car une des parties les plus apparentes de ce fringille, le dus, est olivatre avec des taches noiritres et cendrées. Cette derniere couleur est très-prononcie, et contraste d'une manière vire avee les autres nuances jaunes du plumage. 
Frappés de ce contraste, les naturalistes n'auraient-ils pas voulu désigner le gros-bec cini par un mot qui fût fondé sur un signe caractéristique du plumage, "la couleur cendrée? ") et dès lors cini ne serait-il pas une forme abrégée venant comme cinereus, "cendré, " du mot cinis, "cendre? "

Quelques heures avant le coucher du soleil, les cinis quittent leur salle de concert, et redescendent chercher dans les plaines le repas du soir. Ce repas sera court et frugal, et, bientôt après, tous les membres de la même société regagneront de nouveau les arbres les plus touffus, pour y passer la nuit.

Le cini aime à placer son nid dans les orangers, les rosiers, les arbres fruitiers; ce nid est formé de petites tiges d'herbes, de pointes de lichens et de mousse unies par des toiles d'araignée. Cee charmant travail renferme quatre ou cinq œufs oblongs, de couleur blanchâtre. Ils sont parsemés de points ou de taches rougeâtres, ou noirâtres avec un mélange de rouge, dont la teinte, sur les bords, paraît effacée.

Ces œufs peurent facilement être confondus avec ceux du chardonneret. Cependant ils sont généralement plus allongés, plus petits, d'une nuance moins pronnncée. Le grand diamètre est de $0^{\mathrm{m}}, 014$, et le petit de $0^{\mathrm{m}}, 011$.

P'endant que la femelle se livre au travail de l'ineubation, le mâle se tient près d'elle avec une attention particulière, prévoit à tous ses besoins et ne néglige rien pour charmer, par la douceur et la variété de son chant, les ennuis de sa compagne. Le serin offre done, dans l'ensemble de ses habitudes, un modèle touchant de la vie de famille. Aussi son nom ne devrait-il être une épithète injurieuse que pour ceux qui s'affranchissent de plus en plus des liens qui font la véritable satisfaction du foyer domestique. 


\section{CRVQUIME GENRE. - BorvirEur.}

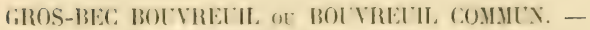
PYIRIIULA VULGAIIS.

Le bouvreuil compose à lui seul un genre dans lit fame de Maine-et-Loire. Beaucoup d'autres especes appartenant à ce genre ne visitent jamais l'Anjou. Nous pourrions teut au plus constater le passage du boncerenil ponceau, admis par quelques naturalistes comme une véritable espèce, et, par d'autres, comme étant simplement une race plus forte que celle du bourreuil commun, et qui devrait ses proportions plus grandes au pays de montagnes qu'elle habite. Mais avant de donner' quelques détails sur cette question, je dois essayer d'expliquer les noms vulgaires et scientifiques du bouvreuil. J'ouvre le dictionnaire de II. Littré et je copie textuellement l'étymologie suivante : "Bouvreuil, mot à mot, petit beuf, par une de ces comparaisons que les noms des animaus présentent non rarcment : roitelet, moineau, pierrot, etc.)

Laissant de côté la controverse à laquelle une pareille explication jourrait facilement donner lieu, je dirai que les gens de la campagne, très-bons ubservateurs, appellent le bouvreuil, bouvreux, du même nom qu'ils désignent leurs jeunes taureaux. Pourquoi ont-ils confondu sous la même dinomination un des plus jolis oiseaux de notre Faune et les jeunes taureaux, dont l'impétuosité se manifeste sourent par des actes d'une violence dangereuse? Les villageois ont envisagé le bourreuil et le jeune taureau sous un mème point de vue, celui d'une impétuosite irrégulière et quelquefois très-dangereusc; et, dans leur langage naïf, ils ont assimilé par le mème nom et le taureau et le bourreuil. Cet oiseau mange rarement les insectes; il vit principalement de sraines, de plantes, et, quand ces ressources lui font délaut, il 
attaque, avec une fougue qui tient de la colère, les boutons des arbres fruitiers, et fait alors de véritables ravages. C'est pour cette raison qu'il est souvent appelé ébourgeonneur. En quelques instants, la terre est couverte des débris que, dans sa fureur, il paraît prendre plaisir à entasser. Les campagnards ont vu dans cette habitude une certaine ressemblance avec la violence du taureau indompté, brisant tous les obstacles qui s'opposent à ses caprices ou à ses desseins. Pour fortifier cette opinion, je dois entrer dans quelques détails. Bouvreux a certainement pour racine, bos, bovis, de Bous, signifiant l'un et l'autre " bœuf ou vache. " Cette expression est remplacée dans certaines localités par le mot bouvard ou bouard, employé pour désigner un jeune taureau, mot qui pourrait dériver de bos, bovis, "bœuf, " et ardens, " violent, emporté, " et qui dès lors indiquerait, sous la forme d'une locution populaire, la même pensée que celle qui est exprimée par la science. De plus, bouvard ou bouard signifie " un marteau, " dont on se servait pour frapper les monnaies; ce marteau avait été ainsi nommé parce que, comme le bœuf, il frappait d'une manière vielente et rapide ; c'est par le même motif qu'on dit : il frappe, il crir comme un butor, c'est-à-dire "comme un bœuf. " Il me paraît done démontré que cette idée de coups violents et rapides a servi de trait d'union entre le bœuf et le gros-bec bouvreuil, et qu'elle a déterminé et les savants et les campagnards à les désigner par des expressions ayant le même principe.

Dans quelques contrées, le bouvreuil se nomme pivoine : il ressemble à la plante qui porte ce nom, par le beau rouge qui décore les plumes de son ventre et de sa poitrine. D'autres fois, il est appelé perroquet de France, à cause de la forme de son bec et de son aptitude à répéter quelques phrases, comme le véritable perroquet; enfin, à cause de la belle calotte noire qui 
couvre sa tête, il a reçu dans quelques localités le nom de prêtre et de chanoine.

Le nom scientifique pyrriuln n'est que la traduction de promortas, composé de prunhos, "rougre, couleur de feu, " et ol:cos, " entier, " et signific dès lors : "oisean d'une couleur rouge très-prononcée. " Nous retrouvons là, sous une forme savante, la dénomination populaire, "pivoine. " Quant à l'épithète vulyaris, " vulgaire, commun, " elle sert à distinguer cette espèce de quelques autres du même genre, telles que le bouvreuil cramoisi, le bouvreuil Pallas, etc., qui sont beaucoup plus rares.

Le bourreuil ponceau, reconnu par quelques naturalistes comme une espèce différente du bouvreuil commun, se trouve surtout dans les pays de montagnes, et en particulier sur les rersants des Alpes. Son chant, plus fort et plus prolongé, est un peu différent de celui de son congénère; ses tarses sont plus allongés, son bec plus gros, et toutes ses proportions sont aussi plus grandes. Enfin, au lieu d'émigrer par petites bandes comme le bouvreuil ordinaire, il voyage par couples. Ces différences sont-elles suffisantes pour déterminer deux espèces distinctes, ou ne doivent-elles servir qu'ì établir deux races, comme dans la plupart des autres espèces? J'abandonne cette solution aux savants, et je me borne, en terminant ces détails, à expliquer lépithète coccineu employée pour désigner le boureuil ponceau. Le mot coccinea signifie "écarlate " et a le mème sens que la dénomination vulgaire; et les deux noms ont été inspirés par les nuances bien vives du plumage de cet viseau.

Le bouvreuil établit son nid dans les haies, dans les buissons, dlans les rosiers; ce nid est formé à l'extérieur, de petites bûchettes, de racines lígères ef de mousse; l'intérieur est ordinairement garni de erin, entrelaci de tilaments déliés des plantes; il contient quatre ou cinq 
œufs bleuâtres, parsemés, surtout vers le gros bout, de taches assez rondes, d'une couleur noirâtre, formant une espèce de couronne. Quoique d'un caractère sauvage, le bouvreuil supporte très-bien la captivité; il s'y reproduit, et apprend à répéter le chant de ses compagnons d'infortune. Ses œufs ont de $0^{\mathrm{m}}, 017$ à $0^{\mathrm{m}}, 017.0 .3 \mathrm{de}$ longueur, et de $0^{\mathrm{m}}, 013$ à $0^{\mathrm{m}}, 014$ de diamètre.

Le bouvreuil ponceau niche de la même manière que le bouvreuil vulgaire; ses œufs présentent les mêmes nuances et les mêmes taches; seulement, les dimensions sont plus grandes, et le grand diamètre varie de $0^{\mathrm{m}}, 0185$ à $0^{\mathrm{m}}, 0195$, et le petit de $0^{\mathrm{m}}, 013: 3$ à $0^{\mathrm{m}}, 014.5$.

1I. Bailly avait eu lit complaisance de me procurel quelques œufs du bouvrenil ponceau. Je les conserve, dans ma collection, sinon comme des types d'une espèce nouvelle, du moins comme un souvenir précieux de la bienveillance du modeste et savant ornithologiste de la Savoie.

\section{SIXUÈVE GEVRE. - HEC-CROLSE.}

BEC GROISÉ DES SAPINS. - LONIA CURTIROSTIAA.

Chaque année le bec croisé des sapins abandonne les forêts des montagnes pour visiter des régions plus tempérées, et venir, dans notre pays, chercher une nourriture qu'il ne trouve plus dans son séjour ordinaire. Son passage plus ou moins régulier, dans les mois de décembre et de janvier, a donné lieu à bien des erreurs. La couleur du plumage de cet oiseau variant, selon les îges, du vert au rougeâtre, a déterminé quelques naturalistes à reconnaitre plusieurs espèces de becs-croisés des sapins, espèces qui n'existent pas réellement. La dénomination de bec-croisé donnée à ce fringille est incomplète; elle ne rend pas exactement la conforma- 
tion du bec, dont les deux mandibules non-seulement sont croisées, mais se prísentent encore à l'observateur comme étant contournées et de travers. Les inandibules de ce bec sont effectivement croisées, mais en sens inverse; elles présentent un aspect disgracieux, mais constituent un instrument très-utile pour l'oiseatu qui en est doté. Une mandibule reste fixe, et la seconde

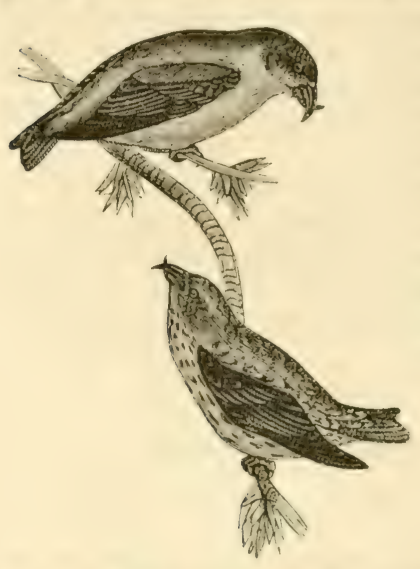
jone sur la première avec d'autant plus d'énergie, qu'elle attaque en diagonale l'objet qui lui est présenté. C'est avec ce puissant instrument que le bec-croisé recueille sa nourriture dans les forêts de sapins, dont il tranche les pommes, afin de pouvoir manger les semences qu'elles contiennent.

Ainsi se trouve justifié son nom de bec croisé des sapins. Les dénominations latines représentent la même pensée. Le mot loxia dérive de Loxos, qui signifie "oblique, " et curvirostra est composé de rostrum, "bec, " et curvum, "courbé. "

Dans l'antiquité, loxias était le surnom d'Apollon, ì cause de l'ambiguité de ses oracles.

Quoique le bec croisí vive principalement des semences des arbres verts, il mange aussi et très-rolontier's les graines de soleil, de chènevis, les pípins de pommes, et même les boutons résineux des peuplier's. Cet oiseau se montre peu craintif, très-facile ì apprivoiser et peu 
jaloux de sa liberté. Il niche, depuis le commencement de janvier jusqu'à la fin de mars, dans les forêts de sapins. Son nid repose sur quelques petites branches de mélèze; le fond est composé de bûchettes desséchées portant une coupe aplatie formée de mousse, de crin, de filaments des plantes.

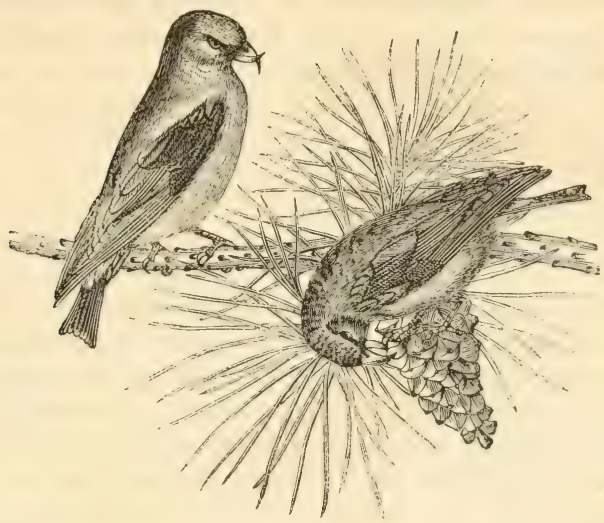

J'ai mesuré les dimensions de plusieurs de ces nids : ils avaient ordinairement $0^{\mathrm{m}}, 13$ de largeur; l'épaisseur' des bords était de $0^{\mathrm{m}}, 02$, et la profondeur de la coupe de $0^{\mathrm{m}}, 05$. Ce travail est ordinairement placé sous la protection de branches plus fortes que celles qui supportent le nid, et, en s'avançant, clles font l'office d'une marquise naturelle et préservent le nid, la couveuse et sa petite famille de l'inconvénient des variations de la température. Ce nid renferme quatre ou cinq œufs blanchâtres, teintés de violet, et parsemés de points, de raies, et quelquefois de teintes rougeâtres ou d'un brun rougeâtre, qui sont ordinairement plus prononcées vers le gros 
bout des œufs; ceux-ci, dont le grand diamètre est de $\left(0^{\mathrm{m}}, 02\right.$, et le petit de $0^{\mathrm{m}}, 01: 3$, resscmblent assez it reux du fringille verdier; mais ils sont plus gros et d'une forme moins allongée. Leur coquille surtout est beaucoup plus lígère que celle des autres fringilles. Quelques couples du bee croisé se sont arrêtés en Anjou pour s'y reproduire. Ils avaient fixé leur domicile dans le massil d'arbres verts qui se déroule devant l'entrée du grand cimetière de la ville d'Angers.

\section{SEPTIÈME GENIRE. - ETOERNEAC.}

ÉtOURneaU VUlgaire. - StuRnus velgaris.

Le nom étoumeau vulyaire n'est que la traduction des dénominations latines sturnus vulgaris, ou plutôt de sturnellus diminutif de sturmus. Là s'arrête l'étymologie donníe par M. Littré. J'y ajouterai que les habitants d'une ville de la Calabre, en Italie, portaient le nom de sturmini, "étourneaux. " - "Sturnini, incolir Sturni oppidi Calabrix, nunc Steraccio. » Le grand nombre d'étourneaux qui se trouvent dans les environs de cette ville aurait-il fait donner à ces oiseaux le même nom qu'aux habitants? hypothèse qui pourrait se justifier par les faits cités précédemment, comme l'épithète iliacus donnie au merle qui se tient aux environs de la ville d'llion. Je laisse la solution de cette question aux maitres de la science.

Court de Gébelin, dans Le monde primitif, tone VII, page 2047, classe le mot sturmus dans la mêne cittigorie que turdus, "grive, " et turgidus, "gonflé," assignant dès lor's à stumus la même racine qu'à ces dernières dénominations. Quant à l'adjectif vulyuris, " Iulgaire, " il indique que l'espèce dont il est question 
est la plus commune du genre; elle sert en même temps à la distinguer de l'étourneau unicolore, etc.

L'étourneau commun est plus ordinairement appelé sansonnet; pour justifier cette dénomination comme beaucoup d'autres, les savants se bornent à dire qu'on a donné à certains oiseaux des noms d'hommes, que l'on a modifiés un peu. Je m'incline devant de si graves autorités. Cependant je me permettrai, à titre de renseignement, de faire une simple remarque. Le mot sansonnet pourrait bien être, d'après plusieurs auteurs, une modification de l'expression chansonnet, sous laquelle cet oiseau est connu dans beaucoup de localités, expression très-caractéristique et qui conviendrait parfaitement à l'étourneau qui babille toujours. De plus ce nom ne serait que la reproduction d'une phrase qu'il répète sans cesse, " sonnez, sonnez. " On retrouverait alors pour cette dénomination la même raison qui a fait appeler la pie $\mathbf{M a r}$ got, et le corbeau Colas, à cause des mots que ces oiseaux aimentà redire souvent (Buffon, édit. in $4^{\circ}$, t. 11I, p. 176). J'aurai la témérité de soumettre encore au lecteur une autre hypothèse, quand les mœurs de ce fringille auront été expliquées.

L'étourneau vulgaire vit d'insectes, de sauterelles; il - suit la charrue du laboureur, et s'empare avec rapidité des vermisscaux qu'elle découvre. Il passe des journées entières au milieu des troupeaux de moutons, de vaches, saisissant avec beaucoup d'adresse les vermisseaux que les pieds de ces animaux font sortir de terre; souvent on le voit sur le dos des bœufs, cherchant les insectes qui se cachent sous leur poil ; et, dans cette investigation, rien ne paraît l'effrayer. Le sansonnet fait une guerre acharnée aux hannetons, à leurs larves, et surtout aux sauterelles qu'il poursuit dans la prairie en écartant les brins d'herbes avec son bec, dont il sépare les deux mandibules d'une manière exagérée et très-originale. Il im- 
mole aussi un très-grand nombre de fourmis; peut-être faut-il attribuer à ce goût particulier pour les fourmis et pour leurs œufs la saveur peu agréable de la chair de l'étourneau, laqquelle a donné lieu à ce dicton populaire : "A défaut de grives, on mange des merles et des étourneaux. ")

Les anciens pensaient que la langue de l'étourneau était vénéneuse. Etait-ce à cause de la nourriture spéciale à cet oiseau? ou bien parce que sa langue babille sans cesse à tort et à travers? Quoi qu'il en srit, dans cette espèce, les femelles se taisent, et les mâles seuls jouissent du privilége d'apprendre à parler, et certes, ils en usent largement : que serait-ce si leurs compagnes avaient la même liberté! Bien des fois, de vieilles demoiselies qui désirent pouvoir se reposer et laisser causer les autres, ou plutôt, avoir toujour's un interlocuteur, se sont empressées de me demander à quels signes elles pouvaient reconnaître les jeunes sansonnets mâles dont elles voulaient faire l'éducation.

Malgré mes renscignements, elles ont presque toujours été victimes de la fourberie des marchands quii, dans cette circonstance, n'ont que des sansonnets mâles à vendre, tandis que leurs cages cependant sont remplie: de femelles. Celles-ci se distinguent des mâles par des taches beaucoup plus nombreuses, qui parsiment le plumage du ventre, et par la couleur de leur bec qui est heaucoup moins jaune; malheureusement, ces distinetions caractéristiques ne sont guère sensibles chez les jeunes sujets.

Les étourneaux se réunissent par bandes innombrables, et, quand un oiseau de proie se rencontre sur leur passage nu les poursuit, ils se précipitent sur lui en formant un bataillon si compacte, que le rapace hat en retraite sous la puissance d'un choe qui l'étourdit et auquel il ne s'attendait pas. 
Partout le mố étourneau est une épithète peu flatteuse et plus significative encore que celle de tête de linotte. Quels sont donc les motifs qui ont pu faire attacher à cette dénomination un sens de caprice et d'étourderie? Dans leur vol, les étourneaux changent de direction subitement, décrivent des lignes en zigzag, montent, descendent, à droite, à gauche, avec une rapidité extraordinaire, et aucune raison ne parait pouvoir justifier une pareille stratégie, résultat d'un caprice bizarre. De plus, quand le plomb du chasseur a semé la mort dans les rangs d'une bande d'étourneaux, les survivants, mûs par un bon sentiment, j'aime à le croire, volent en cercle autour des victimes, et donnent ainsi le temps à leurs ennemis de tirer plusieurs coups et d'augmenter d'une manière effrayante les proportions de l'hócatombe qu'ils immolent. Dans ces circonstances, il est facile à un chasseur exercé de tuer un nombre considérable d'étourneaux; car les rangs sont si scrrés, que chaque grain de plomb frappe une victime. Enfin, quand les prairies ont été visitées par les sansonnets, et que les sauterelles et les insectes ne peuvent plus suffire à apaiser la faim de ces myriades d'oiseaux, ceux-ci s'abattent, comme un véritable ouragan, surles vignes où ils exercent des ravages considérables, moins encore par les grains dé raisin qu'ils dévorent, que par celix qu'ils abattent. Là encore, l'étourneau se conduit comme un véritable étourdi, comme un enfant gâté; il se laisse aller à tous les caprices d'un appétit de fantaisie; il choisit les grains de raisin, et, pour un qu'il mange, il en fait tomber quelquefois plusieurs douzaines. Là ne s'arrête pas sa culpabilité : il l'augmente en visitant un grand nombre de raisins, revenant à ceux qu'il avait délaissés, pour les abandonner de nouveau et donner une nouvelle preuve de son étourderie. Je pense ainsi avoir suffisamment justifié le dicton populaire : "étourdi comme un étour- 
neau, ") et je crois inutile de charger encore le dossier de maître Samson. Ce dernier grief ne serait-il pas le principe de cette dénomination populaire donnée à l'étourneau? Le souvenir des ravages que Samson se plaisait ì exercer dans les vignes des Philistins; le malin plaisir qu’il prenait à dévaster cette culture privilégiée des ennemis d'Israël, n'auraient-ils pas inspiré l'idée d'assimiler l'étourneau au terrible Samson? Ce qui me parait irrécusable, e'est que les gens de la campagne ont dù avoir un motif pour comparer l'oiseau an juge du peuple de Dieu, et que ce motif ne peut être qu'un trait de ressemblance; or celui que je viens d'indiquer me paraît assez plausible.

Je voulais terminer ici l'exposition de mes griefs contre l'étourncau. Je me vois obligé, à regret, d'ajouter encore quelques preuves pour justifier la croyance populaire, qui fait de cet oiseau le type de l'itourderie. Le sansonnet a la manie des royages et des royages en zigrag; la femelle accompagne le mâle et, comme lui, aime ì visiter tous les points du globe. Aucune difficulté ne peut arrêter le couple voyageur : on dirait un ménage anglais. Dans ses pérég rinations irrégulières, l'étourneau s'associe à toute espèce d'oiseaux, dont les mœur's et les habitudes ne lui sont guère sympathiques, et dans le commerce desquels il peut rencontrer plus d'un danger; il expose sa vie, dépense son temps, sans pouvoir justifier sa conduite par aucun motif raisonnable. Enfin, dans ces royages incompris, comme en tout autre temps, le sansonnet ne chante pas, mais babille sans cesse, et son babil est incohérent; il est composé de phrases sans liaison : on dirait de véritibles coq-ì-l'âne. Sous ce rapport, l'étourneau est done encore le type de ceux qui parlent à tort et à travers.

Un écrivain, qui a pris la difense de l'étourneau, a apporté en sa faveur une preuve qui, je crois, tourne 
contre son client. Il pensait que l'habitude qu'a le sansonnet de se retirer le soir dans les marais pour passer la nuit, suspendu le long des roseaux, était une preuve de sagesse et un moyen de se dérrber à la vue des rapaces nocturnes. Malheureusement, le soir, encore plus que le jour, le sansonnet a besoin de babiller, et, en se retirant dans les marais, il se livre à la satisfaction de cette habitude avec une espèce de frénésie, qui semble encore surexcitée par le désir, que chaque étourneau íprouve, d'occuper la meilleure place. Le tapage infernal auquel se livre la bande de sansonnets, avant de jouir du sommeil, est loin d'être un moyen de se soustraire aux regards de leurs ennemis. Ce bruit intempestif attire les rapaces, en leur révélant les lieux où se trouve une proie abondante et facile. De plus, il dirige les chasseurs et les engage à tirer vers le but indiqué, ct leurs coups moissonnent toujours un grand nombre de victimes. $\Lambda$ insi, il y a quelques années, un excellent chasseur de notre département, 11. Edgard de Baracé, tira un coup de fusil sur des roscaux qui étaient le théâtre du vacarme que j'ai signalé. Il ne voyait rien, mais il pensait, à en juger par le bruit, que les acteurs étaient nombreux; son espérance ne fut pas trompée : plusieurs douzaines d'étourneaux avaient été tués. D'autres fois, les sansonnets_viennent se percher dans les peupliers plantés le long des cour's d'eau; là, comme dans les roseaux, ils se livrent à leur tapage habituel, et trahissent, par leurs cris, le lieu de leur retraite. Cette fois encore, ils se livrent à leurs ennemis. Dans cette dernière circonstance, les chasseur's placent un vase à l'extrémité d'une perche, remplissent le vase de poudre de soufre qu'ils allument, le promènent autour des peupliers pendant quelque temps, et bientôt après, les étourneaux, suffoqués par la fumée du soufre, tombent par centaines.

Il m'est difficile de voir encore, dans cette bruyante 


\section{$-384-$}

réunion des étourneaux, une preuve de sagesse et de prévoyance.

Il est juste d'enregistrer, en fareur du sansonnet, un service qu'il rend, peut-être sans le savoir, mais fiui n'en est pas moins réel et très-sérieux, service constaté par un grand nombre de naturalistes. Dans leurs courses vagabondes, les bandes d'étourneaux, compusíes de milliers de sujets, repeuplent les cimes et les revers de l'Atlas, en y semant des graines d'oliviers et de lentisques.

Le sansonnet se reproduit dans notre département; il pond de quatre à six œufs dans les trous des arbres on dans les crevasses des vicux châteaux, et dans les nids abandonnés par les corneilles et par les écureuils. Ces (xufs, d'un bleu uniforme plus ou moins fonce', reposent sur un lit qui prend toutes les formes et les dimensions du trou auquel il est confié. Il est composé de paille, de mousse, de crin et de plumes. Le grand diamètre des œufs varie de $0^{\mathrm{m}}, 026$ à $0^{\mathrm{m}}, 027$, et le petit de $0^{\mathrm{m}}, 019$ à $0^{\mathrm{m}}, 020$. L'étourneau ne niche pas isolément; une bande plus ou moins nombreuse, selon les trous d'arbres qu'elle rencontre, se reproduit dans la même localité.

\section{HUYTIÈME GENRE. - MARTIN.}

\section{IIARTTIN ROSELIN. - PASTOR ROSEUS.}

Déjà plusieurs fois, j'ai eu l'occasion de faire remarquer qu'au mot Martin s'attachait l'idée d'une certaine autorité; et le bon Lafontaine, en dunnant cette dénomination à l'ours, au bâton, etc., a ajouté à ces deux noms un prestige tout particulier. Ici done, la même pensée a dû diriger les naturalistes, et le martin, dont je vais essayer d'expliquer les noms par ses mœur's, doit être un viseau entouré d'une certaine réputation de puissance. 


\section{$-385-$}

Cet oiseau habite, en effet, les pays où les sauterelles sont très-nombreuses et réclament, dès lors, un adversaire redoutable. Cet adversaire, c'est le martinroselin; il immole des myriades de ces terribles insectes, et accomplit sa mission providentielle avec une persévérance et une énergie dignes des plus grands éloges. Les savants modernes appellent le martin-roselin acridatherus, "chasseur de sauterelles, " de AKris, "sauterelle, » et тнѐraô, “chasser.» C'est au martin-roselin que les habitants des pays désolés par des légions innombrables de sauterelles doiventla conservation de leurs récoltes, et l'éloignement des maladies contagieuses engendrées par les cadavres putréfiés de ces insectes. Afin de mieux faire comprendre l'étendue de la mission du martin-roselin et des immenses services qu'il rend, je vais donner un petit résumé des malheurs que causent les sauterelles dans les pays qu'elles visitent.

Je laisserai de côté les détails si émouvants qui sont consignés dans les annales de l'antiquité, et ceux que les journaux de l'Algérie et de la Palestine nous ont donnés de l'apparition des sauterelles pendant l'année 1866, ainsi que sur les épouvantables ravages exercés par ces insectes, qui ne laissaient après leur passage que la désolation, la ruine, la famine et la peste. Je me bornerai-à citer quelques renseignements que je dois à la bienveillance de mon honorable ami, II. Léon de Joannis, ancien officier de la marine militaire. Plus il sera constaté que les sauterelles, par leur nombre et par leurs pérégrinations, constituent un véritable fléau, plus on devra reconnaître les services rendus par le martinroselin, qui s'oppose à la propagation de ces terribles insectes.

" J'ai assisté une fois dans ma vie, — dit M. de Joannis, "-au curieux phénomène de l'apparition des sauterelles. "Je me trouvais alor's dans la Haute-Egypte, où nous 


\section{$-386-$}

"étions allés pour enlever l'obélisque de Loug̣sor. C'était "vers le mois de mai; à la suite d'un vent brûlant, ap"parurent quelques-uns de ces insectes; puis, quelques " instants après, l'air en fut tellement obscurci, qu'on " ne peut rendre l'effet qu'ils produisaient, qu'en les com"parant à une neige épaisse tombant à gros flocons. Ce"pendant, ces sauterelles voltigeaient d'abord à une hau"teur d'un mètre à un mètre cinquante centimètres, " puis ensuite un grand nombre tombèrent à terre, " mais l'immense majorité tournoyant avee un bruit stri" dent venait frapper au visage toutes les personnes qui " s'aventuraient en dehors des habitations. Les récoltes, " dans la Ilaute-Egypte, étant faites au mois de mai, " ces sauterelles ne trouvèrent à dévorer que les feuilles " de quelques mimosas épars çà et là; aussi ne restèrent" elles pas longtemps à Lougsor et dirigèrent-elles leur " vol ver's la Basse-Egypte, l'Asie-Nineure et la Grèce. "Là, elles accomplirent l'œuvre de destruction dont "Dieu menaçait les Egyptiens au chap. $x$ de l'Exode, "v. " : " Les sauterelles courriront la surface de la " terre, en sorte qu'elle ne paraitra plus; elles mange"ront tout ce que la grêle aura épargné; car elles ron" geront toutes les herhes de la terre et tous les fruits des " arbres qui poussent dans les champs.

"On s'est étonné qu'Ilérodote, qui a beaucoup écrit " sur l'Egypte, n'ait pas signalé le fléau des sauterelles, " qui reparait d'une manière assez píriodique; mais on "pense que les serpents ailés, dont parle cet auteur, et "qui, selon lui, débouchent à certaines époques par les "gorges des montagnes pour venir ravager l'Egypte, ne " sont autres que les bandes innombrables de ces in" sectes dévastateurs. Ce qui est parfaitement démontré, " c'est que le vent contribue puissamment à l'ómigration "des sauterelles; ear, smo son secours, la faiblesse de "leur vol ne leur permettrait pas d'entreprendre les 
" voyages lointains qu'elles accomplissent, non-seule"ment sur terre, mais encore sur la mer, dont elles " traversent plusieurs centaines de kilomètres. On ignore " encore aujourd'hui quel est le motif qui rassemble en "troupe innombrable ces sauterelles et les pousse à " suivre l'impulsion du vent. La cause la plus probable "qui force ces insectes à s'abandonner à ces longues " courses semble être la nécessité de trouver une nour" riture suffisante pour leurs myriades de légions. Kirby, " dans un journal d'Amérique, raconte qu'à 200 milles " des îles Canaries, après un léger vent de nord-ouest, " un vaisseau se vit tout à coup enveloppé d'un nuage " de sauterelles qui couvrirent en un instant le pont et "les hunes.

"Lorsque, dans le mois de juin 1828, j'entrais dans " le golfe de Smyrne, sur la corvette la Pomone, je fus " étonné du ralentissement presque subit de la marche " du navire. Tous les marins cherchaient à connaître la "cause qui avait modifié tout à coup notre vitesse; des " matelots descendirent le long du bord, et il fut constaté "que nous étions au' milieu d'un bane de cadavres de " sauterelles qui avait plus d'un mètre d'épaisseur. Nous " eûmes de la peine à traverser cette couche compacte " qui remplissait tout le golfe, ct comme le vent d'imbat, " qui entre tous les jours dans le golfe, poussait les sau" terelles vers la plage encadrant la ville de chaque côté, " la mer rejeta sur le sable, en moins de vingt-quatre " heures, une couche de sauterelles ayant plus de $0^{\mathrm{m}}, 70$ " d'épaisseur. Afin d'éviter les miasmes pestilenticls qui " se dégageaient de ces cadavres en putréfaction, les au" torités de Smyrne obligèrent les habitants à enlever, "dans de nombreux chariots, ces insectes, et à les por" ter au loin dans les terres, où ils furent enfouis pour " servir d'engrais d'une nouvelle espèce.

" Le terrible fléau des sauterelles se fait aussi sentir 
" en Chine. Car, dans une lettre insérée dans les Amnales "de la Société entomologique de France (séance du " $1^{\text {er }}$ juin 1836), on affirme que, quand ces insectes n'ont "plus rien ì dévorer, ils pénètrent dans les habita" tions, où ils s'attaquent aux habits, aux bonnets, etc. "Dans l'antiquité, les peuples adressaient aux dieux des "prières spéciales pour être préservés des sauterelles, " et olfraient des sacrifices à la même intention. Des " légions de soldats étaient occupées à recueillir les sau" terelles et leurs cufs, pour les brûler ensuite, afin " d'empêcher que leur corruption n'engendrât des mala" dies contagieuses. Oresius dit effectivement que, l'an " 800 , ces insectes, rejetés à la côte par la mer, répan" dirent une odeur aussi funeste que celle qu'auraient " pu engendrer les cadavres putréfiés d'une nombreuse " armée. Barrow, voyageur anglais, rapporte qu'à la " côte sud de l'Afrique, ces insectes courrirent le sol " sur une surface de deux milles carrés, et que, poussés " par un vent violent, ils formèrent un banc de plus "d'un mètre de hauteur qui répandait une odeur insup)" portable à cinquante milles de distance.

"Dans le midi de la France, certaines localités n'ont " jamais cessé de s'imposer des dépenses pour la des" truction des sauterelles; et, dès le Xvil siècle, Marseille " consacrait, chaque année, 20,000 francs, et Arles, " $2: 3,000$, pour anéantir ces insectes. Aujourd hui en" core, on paie 0,2:3 centimes le kilogramme de saute( relles et $0,: 30$ centimes pour le même poids de leurs " œufs. On commence dans le mois de mai à recueillir " les uns et les autres. Pour accomplir cette chasse, on "se sert d'un drap de grosse toile dont les coins sont " tenus par quatre personnes, qui, dans leur marche "rapide, rasent le sol par un des còtés du drap. Les "insectes effrayés cherchent à fuir, et, en sautant, se " trouvent enveluppés dans le dran, où ils sont recueillis 
" et ensuite mis dans des sacs. Une personne exercée à " cette chasse peut récolter pour sa part six ou sept " kilogrammes d'œufs par jour, et chaque kilogramme (" renferme environ 1,600 œufs. ")

Je viens de transcrire un aperçu, déjà effrayant, des ravages des sauterelles, qui portent partout sur leur passage une épouvantable dévastation, et cependant les dimensions de ces insectes sont loin d'être en rapport avec celles dont parle Pline (chap. 29, livre X). Cet auteur prétend que, dans l'Inde, il existait de son temps des sauterelles qui n'avaient pas moins de quatre coudées de long, et dont les grandes pattes, armées de dents, servaient de scies dans le pays, pour scier le bois!

Chez tous les peuples de l'antiquité, les sauterelles portaient un nom très-caractéristique. Le mot hébreu signifiait " celui qui se multiplie; ) le sanscrit, " sauter;" le chinois, "ver qui s'avance; " le chaldẻen, "ronger." Le mot latin locusta a été, selon plusieurs auteurs, formé de loca-usta, "lieux brûlés, " et indiquait, dès lors, le pays de prédilection des sauterelles, qui se multiplient surtout dans les pays soumis à l'action brûlante du soleil; ou bien encore le résultat effroyable du passage des sauterelles, après lequel il ne reste plus que des champs noircis et rasés, comme si le feu y avait passé.

MII. Desforges-Boucher, gouverneur général, et Poivre, intendant de l'ile Naurice et de l'île de la Réuninn, voyant ces îles désolées par les sauterelles, firent venir de l'Inde quelques couples de martins-roselins qui se multiplièrent bientôt. Malheureusement, quelques propriétaires, ayant remarqué que les martins attaquaient les graines confiées à la terre et les fruits arrivés au terme de leur maturité, apportèrent, eux aussi, des preuves matérielles des ravages causés par ces oiseaux. Le poids de ces preuves fut tellement écrasant, que le gouverneur et l'intendant proscrivirent les 
ruselins. Cies oiseaux disparurent entièrement des deux îles, et les bons propriétaires étrient disposís à illuminer en signe de juie : les ennemis de leurs récoltes, de leurs fruits, les grands coupables étaient pour toujours chassés de leurs demeures! La joie ne fut pas de longue durée : les sauterelles se multiplièrent promptement; les récoltes furent dévorées; l'écorce des arbres fut iongée; et la désolation, la famine régnèrent sur l'ile Maurice et sur celle de la Réunion. Les proprićtaires, qui presque toujour's ne considèrent que le présent, et n'envisagent les questions d'histoire naturelle que sous un seul point de vue, celui de leur intrît actuel, se rendirent auprès du gouverneur général, pour lui demander de rappeler les proserits. Un navire fut envoyé dans l'Indoustan, afin de ramener une cargaison de martins-roselins; ceux-ci furent reçus en triomphe et placés sous la sauvegarde des lois. Les martins se mirent si bien à l'œurre, que, les sauterelles étant presque entièrement détruites, ils durent de nouveau attaquer les fruits et les graines pour subsister. Irais, arertis par une cruelle expérience, les habitants de ces îles se résignent facilement à subir un petit dommage qui les préserve d'un plus grand. Lit en cela je les loue; car, plus sages que Graro, ils ne pensent pas à donner à Dieu une leçon sur l'harmonie générale de la nature, ni à briser un des ammeaux de la chaîne que le Créateur a formée dans l’intérèt de l'équilibre unirersel; équilibre que Dieu seul peut comprendre, parce que seul il peut embrasser les liens qui unissent entre eux tous les etres sortis de ses mains.

Maintenant, pourquoi avoir nommé roselin le martin dont nous étudions les habitudes? Cette épithète se justifie par les nuances du plumage de l'oiseau, et c'est le mèrne motif qui l'a lait appeler roseus, "de couleur rose.)" Le mâle est surtout remarquable par la belle couleur rose qui lui courre le dos, le ventre et l'abdomen. Des 
reflets violets d'un éclat vif brillent aussi sur la huppe, le cou et la poitrine du martin-roselin.

La dénomination martin, quoique bien justifiée par les services et par les mœurs de ce fringille, est peutêtre encore moins significative que l'expression latine : Pastor roseus, "pasteur rose. " En effet, le martin accompagne les troupeaux, s'élance sur le dos des animaux pour y chercher les insectes qui se cachent sous le poil ou sous la laine, conserve cette position malgré les courses de sa monture : il paraît être le conducteur et le pasteur du troupeau.

Les martins vivent par couple l'été. Le mâle et la femelle de chaque couple sont alors constamment l'un près de l'autre, soit à terre, soit sur les arbres. En d'autres temps, ces oiseaux se réunissent $€$ n troupes, et forment de grandes volées très-serrées. Descendus dans une prairie, ils se dispersent aussitôt dans toutes les directions pour chercher leur nourriture, à la manière des étourneaux.

Les habitudes du martin-roselin nous sont seules connues, et suffisent pour donner une idée de celles des autres espèces. Voici ce que nous en apprend M. Nordmann, dans un excellent mémoire sur cet oiseau :

"Les martins-roselins, si abondants dans la Russie méridionale, y sont un vrai bienfait de la Providence, en y pourchassant continuellement, dans les grandes herbes des steppes, les sauterelles qui, y pullulant par milliers, s'en échappent parfois par grands vols et dévorent les moissons partout où elles s'abattent. Ils arrivent dans le midi de la Russie vers le commencement du printemps. Leur penchant pour la société de leurs semblables est si prononcé, que l'on n'en voit jamais de solitaires. lls forment souvent des bandes d'une multitude innombrable, surtout au moment du crépuscule, où ils 
se réunissent de toutes parts, pour chercher gîte en commun. Mais quand ils descendent dans la steppe pour y commencer leur chasse aux insectes, ils s'y dispersent, au contraire, par petites troupes, de manière que chacune en particulier puisse y faire bien à l'aise sa battue. Ils se mettent alors en marche au nilieu des herbes, séparés les uns des autres par une distance modérée, et observant strictement la même direction. Ils avancent au pas avec vitesse, en ayant cependant de temps en temps recours à leurs ailes. Pendant leur marche, ils tournent leurs tètes de tous les côtés. Lorsqu'un tertre vient leur barrer le chemin, quelques-uns y montent ensemble; arrivés en haut, ils s'arrêtent un instant et regardent dans tous les sens en relevant la hupje. Ils tiennent le cou droit, et ne le tendent en arant que si un insecte attire leur attention. Si c'est une sauterelle, ils doublent le pas, et en siutant obliquement, ils s'élancent quelquefois assez haut, de manière qu'on voit tantôt l'un, tantìt l'autre paraître au-dessus de l'herbe. Souvent les hirondelles profitent de la battue que les roselins font dans l'herbe, les précédant à une petite distance jour saisir les insectes que ceux-ci font envoler, et décelant ainsi par leur présence le passage des chasseurs. Les roselins sont très-adroits à enlever, en sautant, les insectes de dessus les brins d'herbe. Celui qui vient de faire une trouvaille pousse un cri de joie, qui attire surle-champ quelques-uns de ses compagnons, désireux de partager sa bonne fortune. Dans un pareil cas, surtout lorsqu'il s'agit d'une grosse sauterelle ou de quelque autre morceau friand, on voit souvent de petites disputes s'élever entre ces oiseaux d'ailleurs paisibles, toujours de honne humeur, gais, et d'une srande agilité. Quand leur chasse est terminée, ils se plaisent à se rassembler sur un arbre, où ils se mettent tous ensemble, célébrant sins doute la destruction profitable qu'ils viennent d'ac- 
complir. " (Catalogue raisonné des oiseaux de la Faune pontique.)

Aussi, selon le même auteur, les Arméniens et les Tartares ont-ils la plus grande vénération pour le martin-roselin, qu'ils considèrent comme un oiseau créé par la Providence pour la destruction des sauterelles. Quand ils se voient menacés d'une invasion de ces insectes, ils vont puiser, à une source qui coule au pied du mont Arara, une eau qu'ils regardent comme sacrée, et, dès que cette eau est arrivée dans leur pays, les martins y apparaissent pour commencer la destruction du fléau.

D'après le traducteur de Bechstein, le martin-roselin paraîtrait susceptible d'être apprivoisé. " Un chasseur, dit-il, - découvrit, en 1794, dans les environs de Meiningen, en Souabe, une volée de huit ou dix roselins qui allaient assez lentement du sud-ouest au nord-est, passant d'un cerisier à un autre. Il tira sur ces oiseaux; un seul tomba, mais ne fut heureusement que fort légèrement blessé, de manière qu'il ne tarda pas à en guérir parfaitement. Porté aussitôt à M. de Wachter, curé de Frickenhausen, cet ecclésiastique en prit le plus grand soin; il lui donna une cage spacieuse, et trouva que le gruau d'orge trempé de lait lui était aussi sain qu'agréable. Les bons traitements l'apprivoisèrent en peu de temps, au point que l'oiseau vint prendre dans la main les insectes qu'il lui présentait. Il chanta bientôt aussi; mais son ramage ne consistait d'abord qu'en un petit nombre de sons rauques, d'ailleurs assez bien liés; il devint dans la suite plus clair et plus soutenu. Des connaisseurs en chants d'oiseaux y trouvèrent un mélange de plusieurs ramages. Un de ces connaisseurs, qui n'avait pas encore aperçu l'oiseau et n'entendait que sa voix, croyait entendre un concert de deux étourneaux, de deux chardonnerets et peut-être d'un tarin ; et, lorsqu'il vit qu'il était seul, il ne pouvait concevoir 


\section{$-394-$}

que toute cette musique sortît du même gosier. Cet oiseau vivait encore en 1802 , et faisait le plaisir de son possesseur. ") (Manuel de l'amateur.)

Cornme l'étourneau, le martin-roselin aime les royages lointains, qu'il accomplit en bandes nombreuses; c'est un guerrier qui cherche partout des ennemis à immoler, et dont les pérégrinations sont un bienfait de la Providence de Dieu. Comme le sansonnet aussi, le roselin est d'un caractère pétulant et babille sans cesse. Cet oiseau se reproduit dans les trous des arbres et dans les creyasses des vieux murs. Son nid, composé de débris de plantes, de mousse, etc., prend la forme des cavités auxquelles il est confié; il contient quatre ou cinq œufs blanes et légèrement teintés de blentetre, un peu piriformes, ou qui, parfois, ressemblent à des œufs d'étourneau dont les nuances seraient passées.

\section{NEUVHLHE GENRE. - CORBE.}

Au martin-roselin succède un groupe bien différent de ceux qui l'ont précédé; il se trouve cependant rangé dans la famille des conirostres, à laquelle il appartient par la forme du bec, spéciale à cette nombreuse famille. Mais avant d'expliquer les mœurs des corbeaux, je dois essayer de faire connaître quelle est l'etymologie du mot affecté au genre entier.

Corbeau dérive de corvellus, diminutif de corvus, nom qui, chez les Latins, désignait le "corbeau. " Les savants font remarquer que le radical cor se retrouve dans konaks el konôxi, expressions employées, chez les firecs, pour représenter le corbeau et la corneille; il existait aussi dans l'ancien français li corlects, ou li corbaus. Ainsi, il paraît démontré que konaks, corvus, corvellus, corbeau ont une mème origine : quelle est-elle? 
Les maîtres de la science prétendent que cette origine est hébraïque, et que le principe de toutes ces dénominations est "oreb, " qui, chez les IIébreux, désignait "le corbeau, " mot qui signifie "être ténébreux, noir, obscur, " et qui convient très-bien à cet oiscau, à cause de son plumage; d'où cette locution populaire : noir comme un corbeau. En admettant cette explication, qui me semble très-plausible, corbeau aurait pour racine, dans beaucoup de langues, une expression qui pourrait se traduire par celle-ci : "le noir.» Ainsi, grâce à la langue hébraïque, il est facile de comprendre que corbeaı n'est pas un mot vide de sens; mais qu'il fait, au contraire, connaître le caractère très-prononcé du plumage de tous les oiseaux classés sous cette dénomination.

Cependant cette interprétation n'eût pas été fondée dans les temps primitifs, si toutefois on admettait le témoignage de la fable. Car, d'après les récits mythologiques, une jeune personne, Coronis, aurait été changée en corneille par la déesse Minerve, qui, pour symboliser l'innocence de sa victime, l'avait revêtue d'un plumage d'une éclatante blancheur. Malheureusement pour elle et pour d'autres, Coronis, malgré sa candeur, avait conservé l'habitude de parler, et de parler beaucoup, et même sans discrétion. Aussi $\Lambda$ pollon, pour la punir d'avoir révélé des secrets qu'elle n'eût pas dû faire connaître, changea-t-il le plumage de Coronis, qui devint noir et tel que nous le voyons aujourd'hui. Cette nouvelle métamorphose ne corrigea pas l'infortunće Coronis, et il nous est facile de constater que, sous son nouveau plumage, elle babille beaucoup et se plaît à répéter les paroles qu'elle entend. Cette habitude caractéristique, qui se joint à un amour-propre trèsprononcé, tient peut-être, selon la mythologie, à l'origine du corbeau; cette habitude a été mise en scène, sous une forme attrayante et maligne, dans la fable si célèbre 


\section{- $396-$}

de notre bon Lafontaine : Le Renard et le Corbeau.

Dans tous les temps et chez tous les peuples, le corbeau a joué un grand rôle. Etait-ce un souvenir des temps mosaïques? Voyait-on encore en lui l'oiseau chargé d'un message entre I)ieu irrité et l'homme coupable? Quoi qu'il en soit, les Romains araient consacré le corbeau ì $\Lambda$ pollon, comme prédisant l'avenir. Les augures consultaient le vol et le chant de cet oisean, et puisaient dans ses dispositions des moyens infaillibles de connaître les événements futurs. D'après Pline(livre $\mathbf{X}$, ch. $x v$ ), les Romains supposaient au corbeau un instinct naturel pour annoncer l'arenir, au moyen de soixantequatre inflexions de voix différentes, toutes distinctes el ayant chacune une signification particulière.

Lafontaine a dit :

Le corbeau sert pour le présage;

La corneille avertit des malheurs à venir.

Le corbeau, comme figure de la nuit, était consacré à Phébus, ainsi que le cygne, image du jour.

Tite-Live rapporte qu'un Romain nommé Valérius, ayant eu à soutenir un combat particulier contre un Gaulois d'une taille gigantesque, fut aidé dans cette lutte par un corbeau. A rec l'aide de cet oiseau, Valérius remporta la victoire, et, pour consacrer la mémoire de ce fait, il fut surnommé Corvinus.

La légende grecque prétend que ce fut un corbeau qui indiqua à Alexandre le Grand la route du temple mystérieux de Jupiter-Ammon.

Le corbeau est appelé vulgairement Colas, parce qu'il aime à répéter ce mot. Quelques auteurs ont, en conséquence, prétendu que l'expression kolaks avait été formée par onomatopée.

Cet oiseau apprend facilement ì parler; aussi les $R_{0}-$ mains (car en tous temps les flatteur's ont été nombreus) 
aimaient-ils à élever des corbeaux qui saluaient les empereurs : Ave, Nero! — "Salut, Néron! » Ave, Galba! — "Salut, Galba! " Mais, comme les empereurs étaient souvent détrônés et massacrés, il s'ensuivait que le salut d'aujourd'hui, fort agréé du prince, devenait, comme de notre temps, un salut coupable le lendemain. C'est ainsi que les pauvres corbeaux ont suscité quelquefois à leurs maîtres de grares difficultés, et causé même de sanglantes émeutes. Et si la longue vie que l'on attribue aux corbeaux se réalisait, du temps des Romains, à quel supplice ces pauvres oiseaux ne devaient-ils pas être condamnés, pour en venir à oublier les dieux de la veille, et à saluer ceux du jour! Combien de ces infortunés oiseaux ont payé de leur sang une erreur de mémoire! A quelle confusion et à quelles tortures ne seraient-ils pas encore exposés à notre époque!

\section{CORBEAU NOIR. - CORVUS CORAX.}

La première espèce du genre corbeau est désignée solis le nom de grand corbeau ou de corbean noir. Le motyrand s'explique par les proportions de cette espèce, beaucoup plus fortes que celles des autres. Quant à l'expression noir, elle se justifie par les nuanres du plumage, qui, dans le grand corbeau, sont encore plus foncées que dans les autres espèces. Les noms scientifiques corvus corax représentent les mêmes idées que les expressions vulgaires. Les naturalistes ont admis, les uns deux espèces, les autres deux races du grand corbeau. Pour distinguer l'une de l'autre, ils ont appelé la seconde corvus littoralis, "corbeau littoral, " parce qu'il se tient ordinairement sur des rivages déserts, où il se nourrit des débris de cadavres de toute espèce jetés aux bords des mers par les flots irrités. Ce corbeau est plus gros que 
celui qui habite nos contrées, et se trouve surtout sur les côtes des mers du nord.

Le corbean noir se reproduit en Anjon. Autrefois, il y était assez multiplié; aujourd'hui, à peine peut-on en signaler deux ou trois couples. Les nombreux méfaits qu'on lui imputait; les petits oiscaux de toute espèce, ainsi que les oufs des couveuses qu'il dévorait, lui ont suscité beaucoup d'ennemis et, dès lors, l'ont exposí à devenir l'objet d'une guerre d'extermination. Malgré tous les griefs qu'on peut lui reprocher, le grus corbeau, plus nombreux autrefois, rend, comme le catharte alimoche, de vrais services, en absorbant les cadavres en jutréfaction et les ordures qui, dans le voisinage des lieux habités, peuvent répandre des miasmes dangereux. Le corbeau noir est doué d'une grande voracití, et pour l'assouvir rien ne lui répugne; il ne réclame et ne recherche qu'une grande quantité d'aliments. Comme les vautours, il jouit d'un odorat très-développé, qui lui sert à deviner de très-loin les immondices, qu'il recherche de préférence à toute autre nourriture. Etait-ce à cause de cette manière de virre qu'il était classé parmi les animaux impurs? Cet odorat est aussi, pour lui, un moyen d'éviter le plomb du chasseur; car l'odeur de la poudre lui est révélée à de très-grandes distances. Il joint à cette faculté une excessire défiance; aussi échappe-t-i! presque toujours aux piéges qu'on lui tend. Le grand corbeau ne vit pas en troupes; on le trouve par couples, et souvent même il est solitaire.

Il établit son nid dans les excarations des rochers, sur le bord de la mer, dans les montagnes, et, assez fréquemment, sur les branches les plus ílevies des arbres des forêts. Ce nid, très-solidement construit, repose sur une couche formíe de bûchettes et d'épines qui serıent a le défendre contre ses ennemis. L'intírieur en est revêtu de terre gathée avec de la fiente d'animaux. Quel- 
quefois, mais très-rarement, on y trouve des débris de mousse, de foin ou de laine. Le même nid sert plusieurs années au couple qui l'a édifié. C'est là que la femelle dépose de trois à cinq œufs d'un vert bleuâtre ou noirâtre, sur lesquels ondulent des raies ou des taches brunes ou d'un gris pâle. Quelques-uns portent une calotte noirâtre; d'autres sont parcourus en zigzag par des veines d'un gris et d'un brun foncé, qui semblent, en s'entremêlant, former un canevas. Les dimensions de ces œufs se modifient beaucoup; j'en possède dans ma collection des exemplaires dont le grand diamètre varie de $0^{\mathrm{m}}, 04.5$ à $0^{\mathrm{m}}, 0 \%: 3$, et le petit de $0^{\mathrm{m}}, 030$ à $0 \mathrm{~m}, 03 \%$.

Le mâle manifeste une grande tendresse pour sa femelle; il partage avec elle les soucis de l'incubation.

L'opinion générale attribue au corbeau une longévité très-remarquable.

Je ne puis terminer ces observations sur le corbeau sans le justifier d'un reproche, que lui fait un de mes auteur's favoris. Le bon Lafontaine, notre inimitable fabuliste, prétend que le corbeau, voulant imiter l'aigle, embarrassa ses pieds dans la laine d'un mouton qu'il essayait d'enlever, et que, pris dans ce piége, il fut assommé par le berger. La morale de cette fable est vraie et utile; mais la fiction, sur laquelle elle repose, est entièrement dénuée de vérité et de vraisemblance. Le corbeau n'est pas armé pour enlever même les plus petits animaux; sil aime à séjourner sur le dos des bœufs, des moutons et même des porcs, ce n'est pas pour les enlever, mais pour manger les insectes qui tourmentent ces animaux. Aussi ces derniers se prêtent-ils volontiers à une visite qui les débarrasse d'hôtes importuns. Quelques auteurs ont prétendu que le corbeau, pendant l'hiver, prenait plaisir à rester sur le dos des moutons, pour se réchauffer les pieds dans la laine épaisse de leur toison. Je crois cette opinion plus ingénieuse que véritable. 


\section{$-400-$ \\ CORBEAU CORNEILLE. - CORVUS CORONE.}

Corbeau et corvus ayant été expliqués précédemment, il me reste à chercher l'étymologie de corneille et celle de coronè.

Concille dérive de cornicula, diminutif de cornix, mot employé par les Romains pour désigner l'oiseau dont nous allons étudier les mœurs. L'épithète scientifique coronè est formée du grec коnòxé, qui avait la même signification que cornix. Or, d'après les autorités citées précédemment, nous trouvons dans cornicula, comix, coronè, kurôxê, le radical cor, qui nous ramène au primitif oreb, et, dès lors, tous ces noms représentent la mìme idée, celle de noir, aver des nuances plus ou moins vitriées. Cette solution, satisfaisante pour ceux qui aiment à respirer le parfum antique de l'idiome primitif, ne doit pas m'empècher de faire quelques digressions, peut-être un peu téméraires; mais je compte sur l'indulgence de mes lecteurs; car ils comprendront qu'il est difficile de se corriger entièrement d'une vieille habitude. De plus, afin d'éviter toute erreur compromettante, je soumets mes hypothèses à leur sanction et sous toutes réserves.

Cornix désignait chez les Romains non-seulement la corneille, mais encore le petit marteau recourbé qui servait à frapper aux portes, et qui fut employé pendant bien des siècles, avant que les progrès de la civilisation n'eussent inventé tous ces moyens si ingénieux et si diversifiés d'avertir les habitants des maisons de la présence d'un visiteur. Pourquoi les Romains avaient-ils désigné la corneille et le marteau par la même dénomination? Etait-ce le marteau, était-ce la corneille qui avait prêté son nom à l'autre?

Quoi qu'il en soit, il me parait évident que les Romains avaient dû voir entre eux quelques traits de ressemblance. Les anciens avaient été frappés de la forme 
du bec de la corneille, très-souvent appelée la corbine, et cette idée se trouve reproduite dans les mots cornix et коRôNÈ, signifiant tout ce qui est " crochu, courbé." Par la forme de son bec, la corneille se rapproche déjà du marteau des portes; mais de plus, comme cette espèce de marteau subit tour à tour, quand il frappe, un mouvement prononcé d'avant et d'arrière, de même la corneille, lorsqu'elle se sert de son bec, pour frapper comme avec un marteau, imprime à son corps un mouvement analogue à celui de cet instrument et qui a donné lieu à ce proverbe populaire: " $Y$ aller de tête et de queue, comme une corneille qui abat des noix. ")

Coronè ne serait-il qu'une modification du nom de l'infortunée Coronis changée en corneille par Minerve? Cette hypothèse pourrait s'appuyer sur l'opinion des anciens, qui croyaient trouver, dans les habitudes de la corneille, quelques souvenirs de son ancien état. Coronis était une des Hyades, filles de l'Océan, et, depuis sa métamorphose, elle se plaisait à parcourir les rivages de la mer et les sables des fleuves qui lui rappelaient et sa famille et ses premières années. Là, souvent on la rencontrait seule et triste, faisant entendre un cri plaintif.

Tum cornix plenâ pluviam vocat improba voce,

Et sola in siecâ secum spatiatur arenà.

(Virgrle, Géorgiques, liv. I, v. 388-9).

Seule, errant à pas lents sur l'aride rivage,

La corneille enrouée appelle aussi l'orage.

(Delille.)

Cette solitude avait fixé avec raison l'esprit d'observation des anciens. Partout ailleurs que sur le rivage de la mer et sur les grèves des fleuves, la corneille se montre en petites bandes. Le mâle et la femelle ne se séparent pas; leur union survit à l'éducation de leurs petits, et, trèssouvent, les petits restent avec leurs parents, pour composer une société dont il est facile alors de constater 
l'existence. Mais il n'en est plus ainsi lorsque la corneille parcourt les bords des mares ou des rivières; elle se montre alors solitaire et triste. La elle se rend coupable de viritables méfaits; elle parenurt en tous sens les sables; non-sculement elle s'y repait de débris d'animaux que les flots rejettent sur les bords, ou de ver's de toute espèce qui se trourent dans la vase, mais elle brise encore les œufs de la petite hirondelle de mer et du petit pluvier à collier, œufs que ces deux charmants oiseaux abandonnent avec confiance, sans faire aucun nid, sur le gros sable des grèves.

La corneille a été accusée bien des fois, et en particulier par un agriculteur distingué de notre département, de commettre une multitude d'iniyuités. Cet écrivain reprochait à la corneille de causer des torts considérables en déterrant les grains qui commencent à germer, et en les absorbant en très-grande quantité. Cette accusation ne peut pas retomber sur la corneille; mais elle doit être imputée plutôt au corbeau freux. Cette distinction a ćté faite à l'accusateur qui, s'inspirant probablement du radical cor, appelait volontiers corbeau et corneille tous les oiseaux de ce genre qui étaient noirs. Ce serait le cas de reproduire cet axiome populaire : "Ce n'est pas l'habit qui fait le moine, ") et de n'attribuer, à chaque espèce du genre corbeau, que les torts qui lui sont propres.

La corneille peut quelquefois manger des grains de blé; mais c'est un cas tout exceptionnel, et non pas un péché d'habitude; elle vit ordinairement de vers et d'insectes qu'elle recherche dans les prairies, sur le bord des rivières et dans les sillons détrempés par la pluie. Elle se plaît aussi dans les lieux où se trouvent amoncelís des immondices et des animaux en putréfaction. Là olle se repait avec une satisfaction très-caractíristique qui proure que ce genre de nourriture est, pour clle, un aliment de prédilection. 


\section{$-403-$}

Aux environs d'Angers, on voit, en tout temps, et surtout pendant l'hiver, des bandes de corneilles séjourner dans les fossés voisins de l'abattoir, et. qui servent à l'écoulement du sang des animaux que l'on a tués; on retrouve aussi ces oiseaux sur les bords de l'étang SaintNicolas, près de l'établissement où se prépare le noir animal, et enfin, sur la route d'Avrillé, dans les dépendancesdu dépôt des vidanges de la ville. C'est dans ce dernier endroit que se rendent les amateurs qui désirent se procurer de beaux sujets pour les empailler. C'est là, plus qu'ailleurs, que les corneilles occupées à absorber des mets de leur choix, se laissent approcher facilement et deviennent victimes de leur voracité. Dans ce lieu et aux environs de l'abattoir, les corneilles noires vivent en société avec les corneilles mantelées.

Si la corneille ne cause pas de grands torts à l'agriculture, elle n'est pas exempte pour cela de tout reproche. Non-seulement elle mange les œufs qu'elle trouve sur les grèves, mais elle se nourrit de ceux qu'elle rencontre dans les champs et dans les arbres; elle dévore aussi les oiseaux nouvellement éclos, et l'opinion pub)ique l'accuse même de ne pas toujours respecter les petits levrauts. Elle joint, à tous ces mets, des fruits, des reptiles, etc., ce qui prouve que la corneille a bon appétit et bon estomac, et qu'elle aime à varier son régime.

La corneille se reproduit en grande quantité dans notre département; elle établit son nid dans des arbres assez élevés. Le fond en est composé de petites branches et d'épines, sur lesquels repose une couche épaisse de terre gâchée avec des excréments. Les bords sont quelquefois encadrés de petites racines, de mousse et de crin. Ce nid contient de quatre à cinq œufs, dont les dimensions, les formes et la couleur varient beaucoup; j'en ai trouvé dont le grand diamètre était de $0^{\mathrm{m}}, 035$ à $0^{\mathrm{m}}, 048$, et le petit de $0^{\mathrm{m}}, 02: 3$ à $0^{\mathrm{m}}, 028$. La coquille des 


\section{$-40 \%-$}

uns est verdâtre et mouchetée de noir; d'autres présentent une teinte bleuatre parsemée de points ou de taches brunes paraissant former plusieurs couches superposées; quelques-ins, enfin, ont, vers le gros bout, de nombreuses taches formant une couronne et même quelquefuis une véritable calotte. Pendant plusieur's années, mon honorable ami, II. Raoul de Baracé a fait dénicher sur les métairies de sa propriété de Valoncourt, près le Liond'Ingers, des œufs de corneille d'un bleu uniforme et sans taches. D'autres, au contraire, etaient d'une couleur bleue très-prononcée et striée de petits points noirs trèsronds. La première couche de ces œufs offrait des nuances plus ou moins foncées, et les assimilait ainsi, quant à la couleur, à ceux de l'étourneau. Ce même naturaliste avait remarqué, dans les corneilles ordinaires, deux races bien distinctes; l'une, beaucoup plus grosse et beaucoup plus saurage que l'autre. Les œufs de la première race étaient moins nombreux que ceux de la seconde : rarement ils dépassaient trois ou quatre. Cette variété semblait être comme le trait d'union entre la corneille vulgaire et le gros corbeau.

Je terminerai ces renseignements sur la corneille ordinaire, en essayant d'expliquer cette locution proverbiale : "Bayer aux corncilles. " La corneille noire, comme toutes les espèces du genre corbeau, est trèsdéfiante, ce qui ne prouve pas qu'elle soit intelligente. C'ette disposition à la áéfiance repose sur son odorat très-développé, qui l'avertit de l'approche du chasseur et l'engage, dès lor's, à s'éloigner du péril. Pour détruire ces oiseaux et s'opposer à leur multiplication trop grande, le moyen le plus simple est de dénicher leurs œufs, et même plusieurs fois chaque année, parce que tous les couples font deux, trois, et quatre pontes quand les premières ne réussissent pas. En dehors de ce moyen, des cultivateurs ont inventé un expédient assez curieux. 
Ils confectionnent, avec du papier fort ou du carton léger, des cornets, au fond desquels ils mettent un morceau de viande; puis ils enduisent les bords intérieurs du cornet, d'une épaisse couche de glu ou de colle. Les cornets ainsi préparés sont enfouis solidement en terre par le sommet, et placés dans les sillons visités par les corneilles. Celles-ci, attirées par l'odeur de la viande, arrivent en grand nombre, rôdent autour de ces cornets, impriment à leur corps un mouvement de bascule qui indique leur satisfaction : elles décrivent des ronds autour de ces appats, ouvrent un large bec en regardant d'un air niais les cornets et leur contenu; elles avancent, reculent tour à tour, et, enfin, donnent un vigoureux coup de bec pour saisir la proie. Le cornet s'adaptant à la tête des corneilles la couvre comme un capuchon et la prive de la vue; ces oiseaux cherchent alors à se débarrasser de cette coiffure d'un nouveau genre, et, ne pouvant y réussir à terre, ils s'élèvent perpendiculairement dans les airs à de grandes hauteurs, puis, vaincus par la fatigue, ils retombent avec la rapidité de la flèche et sont alors pris facilement par les agriculteurs.

Un second moyen de capturer les corneilles, est de laisser tremper, pendant quelque temps, des petits pois dans de l'eau-de-vie, puis de semer ces pois sur les terrains visités par les corneilles. Celles-ci regardent d'un air inquiet l'aliment dont l'odeur leur paraît suspecte ; mais bientôt la gourmandise l'emporte sur la défiance, et elles mangent gloutonnement le mets perfide. Quelques instants après, les corneilles, sous l'influence de l'ivresse, tournent sur elles-mêmes, ouvrent le bec comme pour se débarrasser d'un mets dont elles ressentent les funestes influences, puis, sans même essayer de fuir, se laissent prendre en regardant, d'un air niais et hébété, l'homme qui profite ainsi de sa supercherie.

C'est l'une ou l'autre de ces deux chasses qui a donné 
lieu au proverbe populaire: "Bayer aux corneilles. "

En effet, les meilleur's dictionnaires disent que bayer ou béer signifie "regarder quelque chose, la bouche ouverte, " par suite, bayer aux corncilles peindrait l'attitude des chasseur's s'amusant à regarder en l'air, la bouche béante et l'air étonné, les corneilles aveuglées ou ivres. De là l'expression figurée bayer anx comeilles, pour dire (" s'amuser à regarder en l'air niaisement. »

Peut-être devrait-on entendre cette expression dans un autre sens. La chair des corneilles n'a aucune valeur; capturer ces oiseaux est chose difficile; d'où il suit qu'essayer à les prendre, c'est perdre deux fois son temps.

Or dans Gil-Blas, Lesage dit :

"Je fus sensible à cette BalE, " c'est-à-dire, ì cette attrape, à cette tromperie.

Dès lors bayer signifierait done tendre des piéges, et bayjer aux corncilles, préparer des piéges aux corneilles, et dans un sens figuré, "perdre son temps. "

Dans la ville et dans les campagnes, la corneille est vulgairement nommée grole, yraule, graille, expressions (¡ui, signifiant " causeuse, babillarde, ) dérivent, d'après Diez, de gracula.

Quelques auteurs pensent aussi que les Provençaux et les Italiens ont donné à la corneille le nom de graille par onomatopée, et, selon tonte prubabilité, c'est de ce mot que l'on a formé le verbe grailler, signifiant "sonner du cor sur un ton enroué, "nour rappeler les chiens, et employé vulgairement pour exprimer l'action de " crier d'une manière continue et désagréable. "

CORBEAU FREUT. - CORVUS FRUGLlegus.

Me voici en présence d'un grand coupable, dont le nom éternise les méfaits; il me sera done difficile de le 
justifier de tous les griefs qu'on lui impute; mais j'espère, dans un temps, surtout, où les circonstances atténuantes sont si facilement admises, les obtenir en faveur de mon client. Je pense qu'il doit en jouir, quand ce ne serait qu'à cause de l'esprit de famille qu'il manifeste à un très-haut degré; esprit d'autant plus louable qu'il devient de plus en plus rare. Le freux, que l'on confond très-souvent avec la corneille noire, s'en distingue par' des proportions plus petites, par une taille plus élevée et surtout par son bec terreux dont la base, entièrement dénudée, offre, à ce que l'on prétend, une preuve permanente de sa culpabilité. C'est probablement à la manière d'être de son bec qu'il doit, dans certaines contrées, son nom populaire la frayonne, expression qui dérive du verbe frayer, signifiant " frotter. "

Le mot freux dérive par contraction, selon plusieurs auteurs, de l'expression scientifique frugilegus, composée de fruges, "fruits de la terre, froment, " et de lego, "choisir, ramasser, travailler. » Les deux épithètes freux et frugilegus auraient donc le même sens, et indiqueraient que le corbeau auquel elles ont été données comme signe caractéristique, vit principalement de fruits de la terre, de grains de froment. Ces dénominations, l'une savante, l'autre vulgaire, chargent dejà le dossier du freux et doivent reposer sur des faits multipliés. Ces faits, qui composent le principal chef d'accusation, ont été signalés bien des fois par les naturalistes et par les agriculteurs. Ainsi, l'honorable écrivain dont il a été question dans l'article précédent, a tué un certain nombre de freux, puis a fait l'autopsie des coupables et a trouvé dans l'estomac les preuves palpahles du délit, consistant en une espèce de bouillie composée de grains de blé à moitié germés. Si ces méfaits, dont on accuse les freux, sont généraux et bien fondés, il est difficile de les justifier' entièrement. Aussi ne me reste-t-il qu'à faire valoir en 
leur fitveur quelques considérations et surtout, je le rípète, l'esprit de famille, qui unit par des liens étroits tous les oiseaux de cette espèce.

Certains naturalistes pensent que les ravages imputés aux freux sont bien moins considérables qu'on ne le dit; ils affirment que ces oiseaux, très-souvent, ne font que couper la pointe de la tige du froment, et qu'ils facilitent ainsi un développement plus vigoureux de la racine, et, par-là même, de la plante; enfin, que le bec terreux et dénudé du freux prouve qu'il s'en sert pour chercher dans les sillons les vers et les insectes rongeur's et ennemis des récoltes, et qu'il compense ainsi largement, par les services qu'il rend a l'agriculture, les dommages qu'il peut commettre. Ces considérations, je les soumets à la bienveillance des lecteur's, dans l'intérêt des freux, mes clients, mais sans cependant vouloir en assumer la responsabilité. Quant à l'argument tiré de l'esprit de famille, je l'admets dans toute son étendue et dans ses plus larges conséquences.

Il y a quelques années, j'étais allé, arec mes honorables amis, MM. Raoul de Baracé et Deloche, conservateur du cabinet d'histoire naturelle, visiter les rives du Loir, à trois ou quatre kilomètres de Tiercé. Nous dirigeames notre excursion vers une magnifique futaie appartenant à II. de la Villeboisnet, et située près la maison de campagne de M. Langlois, cunseiller à la cour d'appel. Cette futaie, composée de cinquante ou soixante chènes séculaires, avait été choisie avec intelligence par une nombreuse colonie de freux pour y établir leurs nids. Plantée sur le bord de la rivière, le long de prairies immenses, éloignée de tout centre d'habitation, elle se trouvait dans des conditions très-avantageuses pour les freux. Nous pùmes constater la construction de plus de cent cinquante nids. Les chênes, dont les trones étaient entièrement privés de branches jusqu'à des 
hauteurs de quinze à vingt mètres, portaient à leur extrémité une très-belle tête arrondie, qui les faisait ressembler à de magnifiques orangers. C'était sur ces têtes que les freux avaient établi leurs nids. Chaque arbre en portait plusieurs, et quelques-uns même en recélaient de dix à quatorze. Ordinairement ces nids éiaient séparés les uns des autres; quelquefois cependant deux ou trois se trouvaient accolés, et paraissaient se fortifier mutuellement. Je désirais pouvoir me procurer les richesses contenues dans ces nids, et comparer les différentes variétés des œufs. Il était difficile de satisfaire à mon désir ; des naturalistes, qui m'avaient précédé, avaient été forcés de renoncer à leur entreprise, après une chute dangereuse pour l'homme qui avait essayé de parvenir au sommet des arbres. Je fus plus heureux que mes confrères, et, grâce à l'intrépidité et à l'agilité des deux jeunes Guilleux, de Tiercé, je pus faire fouiller et visiter un grand nombre de nids. J'avais remis au plus jeune des frères une longue ficelle terminée par une balle de plomb. Parvenu au sommet d'un des arbres, l'agile grimpeur laissait dérouler la ficelle, qui tombait perpendiculairement entraînée par la balle de plomb. J'attachais alors à cette ficelle un petit panicr en jones arrondis, très-profond et garni d'ouate; le panier remontait pour redescendre ensuite plein des œufs que mes ardents dénicheurs avaient recueillis. La même manœuvre se renouvelait d'arbre en arbre, et je pus constater que les œufs trouvés sur chaque arbre semblaient indiquer, par leurs dimensions et par leurs couleurs, que très-probablement les nids de chacun de ces arbres étaient construits par des freux̃ de même âge; les vieux se réunissaient ensemble, et les jeunes suivaient leur exemple; ils formaient, dans une même colonie, des groupes différents, peut-être selon les caractères.

Pour diminuer leur fatigue, mes intrépides grimpeurs 
ne descendaient pas à terre; mais, en imprimant aux branches un mouvement de balancoire, ils passaient d'un arbre dans l'autre. Les préoccupations causées par les dangers d'une pareille investigation avaient glacé de frayeur mes compagnons de voyage; tous s'étaient retirés, naturalistes et conducteurs; seul y j'itais resté, suntenu par le feu sacré de l'histoire naturelle et surtout frar ma confiance dans la Providence. Ah! si dans ce moment solennel j'avais eu arec moi mon jeune aui Eugène Lelong, il n'eût pas déserté le joste, et au besoin, pour rester fielèle ì son ardeur persévérante, il eût ranimé mon courage! Je reviens à mes jeunes dénicheurs. Leur position devenait critique; des centaines de freux les suivaient de branche en branche, les itourdissant de leurs cris tellement violents, qu'il nous était difficile de rous entendre. Je fis tirer par le fermicr quelques coups de fusil pour éloigner les plus obstinés. Les freux devinrent plus nombreux et plus acharnés; mes deux jeunes gens semblaient disparaître dans un nuage noir, dont les cercles mobiles se rapprochaient et s'éloignaient tour à tour. Pour étudier davantage encore les mœurs de ces oiseaux, je priai les frères Guilleux de jeter à terre quelques niàs. Aussitôt les clameurs devinrent encore plus grandes, et, inalgré les coups de fusil, les freux descendaient chercher les matériaux des nids qui araient été détruits et renversés sous nos yeux; toıte la colonie travaillait à les refaire immédiatement dans la place qu'ils avaient occupée : le malheur de quelques-uns était devenu le malheur de tous, et tous, sins craindre le danger, concouraient à le réparer et it eonsoler leurs frèrés infortunés. Malgré notre énergie, il nous fallut céder; le vol, les cris, étaient devenus si ítourdissants, que je donnai le signal de la retraite à mes deux dénicheurs, qui s'y conformèrent assez voluntiers. En dehors de la futaie, on apercevait deus ou trois 
arbres portant chacun un seul nid; ces nids étaient-ils habités par des coupables que la colonie avait cru devoir éloigner de son sein? Etaient-ce, au contraire, des postes d'observation confiés à des vétérans, chargés, à cause de leur longue expérience, d'avertir la colonie des dangers qui pouvaient la menacer et de jeter le cri d'alarme? Je ne puis décider ces questions; cependant je dois dire, en faveur du premier sentiment, que plusieurs coups de fusil tirés sur ces nids isolés laissèrent les freux parfaitement tranquilles; ils semblaient n'être pas intéressés à venir au secours de ceux que l'on attaquait, et, par leur impassibilité, paraissaient reconnaître la justice de l'exécution qui avait lieu.

Cet esprit de famille, chez les freux, survit à l'éducation des petits; il n'est pas fondé sur un sentiment passager, mais sur une disposition intime et permanente. Les freux continuent, après la nidification, à vivre en bandes nombreuses, et, chaque soir, ils se retirent dans les bois ou dans les futaies pour y passer la nuit; trente, quarante de ces oiseaux, et même plus, se perchent sur un arbre. Aussi, quand les rigueurs de l'hiver se font sentir et que les feuilles tombées laissent les branches apparaître dans leur triste nudité, les bandes de freux semblent revêtir ces branches d'un feuillage mobile qui, le soir, présente un aspect fantastique. Bien des fois, j'ai pu contempler ce tableau dans les bois de $\mathbf{M}^{\text {me }}$ de Bercy, près de la chapelle du Champ des Martyrs, et être témoin, le matin, dı réveil de ces oiseaux. Dès que l'aube du jour paraît, un des freux fait entendre un cri assez fort. Est-ce le signal du lever? Je n'en sais rien; mais à ce cri succèdent bientôt des clameurs qui se croisent en tous sens et qui s'élèvent de plus en plus. Peutêtre le système du vote universel est-il admis chez les freux, et le chef de la colonie consulte-t-il ses congénères 
sur la direction que l'on doit suivre, et sur les pays que l'on doit visiter? S'il en était ainsi, il paraitrait, du moins, que, même chez les freux et avec leur esprit de famille, il est difficile de s'entendre quand on demande ì chacun son opinion, surtout si on le laisse libre de l'exprimer sans contrainte. Après une demi-heure au moins de ce tapage assourdissant, le départ a lieu : les jeunes ou les vieux partent les premiers par sections; les bandes se succèdent dans différentes directions, plus ou moins nombreuses, selon les ressources présumées des lieux qu'elles doivent visiter. Quelques-uns restent après les autres : peut-être sont-ce quelques infirmes ne pouvant pas aller au loin, ou des caractères chagrins ne pensant jamais comme les autres, ou des coupables séparés de la société de leurs parents, ou plutôt des sages chargés de veiller à ce que le départ de tous s'exécute selon le vote populaire, un peu comme le commandant qui ne quitte le bivouac ou la ville, que lorsqu'il est assuré qu'aucun retardataire ne reste après lui.

Ici j'arrêterai mes renseignements sur les corbeaux freux; peut-être quelques naturalistes me reprocherontils de n'avoir pas défendu assez chaleureusement mes clients, et de n'avoir pas assez fait ressortir leur mission providentielle. Car chaque espèce d'oiseau en a une; sans cela elle n'aurait pas de raison d'exister. Cette thèse m'avait été rappelée par un savant de Paris, dans une longue lettre qu'il avait eu la bienveillance de m'adresser au sujet de mes Essais étymologiques. Il trouvait que ma défense en faveur de certains oiseaux n'était pas encore assez généreuse, et cependant, si on m'eût livré au tribunal du plus grand nombre des propriétaires, j’eusse au moins été condamné à l'exil, sans compter une amende considérable comme frais d'indemnité, et cela, à cause de mon plaidoyer'en faveur des chouettes, des buses, et 
surtout de ma sympathie pour les infortunés pics-verts. Je reconnais la sagesse de l'axiome de Lafontaine:

\section{Est bien fou du cerveau}

Qui prétend contenter tout le monde et son père.

Ici, comme précédemment, j'ai parlé d'après une étude sérieuse des mœurs des oiseaux et d'après une conviction profonde, et je continuerai d'agir de la sorte, en priant mes lecteurs de vouloir bien vérifier par euxmêmes les renseignements que je soumets à leur appréciation.

Quelques savants, repoussant l'étymologie que j'ai indiquée précédemment, font dériver le mot freux de racines anglaises et allemandes; il serait peut-être aussi naturel de voir dans ce nom une corruption du substantif "frào, fràv, " par lequel les Bas-Bretons désignent l'oiseau dont nous étudions les mœurs.

Les nids des freux ont une forme sphérique; une ouverture est ménagée sur un des côtés pour le passage de la femelle. Cette forme a l'avantage de préserver la couveuse des ardeurs du solcil et des inconvénients de la pluie, et de dérober la mère et les petits à la vue et aux attaques des oiseaux de proie. La défense İeur devient plus facile, dès lors qu'il n'y a qu'un point vulnérable à protéger. Ces nids ont des proportions considérables, qui atteignent $0^{\mathrm{m}}, 50$ de largeur et $0^{\mathrm{m}}, 25$ de hauteur. Ils sont composés de bûchettes, de racines et d'épines à l'extérieur ; cette enveloppe renferme des feuilles sèches, de la mousse grossière et enfin une coupe aplatie, réunion de deux couches, l'une composée de petites racines et l'autre de paille. Ils contiennent de quatre à cinq œufs dont le grand diamètre varie de $0^{\mathrm{m}}, 03 . \mathrm{z}$ à $0^{\mathrm{m}}, 04 \mathrm{~s}^{\circ}$, et le petit de $0^{\mathrm{m}}, 023$ à $0^{\mathrm{m}}, 036$. Les uns sont piriformes, d'autres rentrus, quelques-uns oblongs. La couleur de ces œufs se modifie beaucoup; mais généralement le 
fond de la coquille est plus gris que celui des œufs de la corneille noire; sur ce gris verlatre, plus ou moins foncé, se déroulent des lignes d'une nuance noiratre, qui s'entremêlent en formant des festons. Quelques-uns sont simplement striés de taches plus foncées que la couleur de la coquille. La difficulté qui existe pour dénicher les nids des freux, rend les œufs de ces oiseaux assez rares dans le commerce. La plupart de ceux que les naturalistes vendent appartiennent à la corneille noire. On peut cependant les reconnaitre, à leurs dimensions régulièrement plus petites, à leur couleur plus pâle et plus grise, et surtout ì la légèreté du poids de la coqquille. Ce dernier caractère tient-il au genre de nourriture des freur, moins substantielle que celle des corneilles et des corbeaux noirs? Je l'ignore; mais il est certain qu'il est très-significatif.

Il parait que la chair des jeunes freux est très-délicate; car nos bons voisins les Anglais, qui s'entendent en gastronomie, regardent comme une bonne fortune l'établissement d'une colonie de freux dans leurs propriétés. Ils la protégent contre toute attaque, et, quand ils jugent arrivé le moment favorable, ils font dénicher successirement les jeunes freux, et les mangent en guise de pigeonneaux. Les mariniers du Lcir qui peut-être, dans leur jeunesse, ont visité les bords de la Tamise, ont rapporté, à ce qu'il parait, dans notre contrie ce gout britannique; car, lorsqu'ils nariguent devant la futaie dont j'ai parlé, à une époque où les jeunes freux sont éclos, ils les font dénicher, du moins en partie, par des mousses agiles, malıré les graves dangers de l'opération ; puis ils s'en régalent avec leur's amis. Cette délicatesse de chair, qui rapproche les jeunes freux des pigeonneaux, provient très-probablement dı même genre de nourriture. 
CORNEILLE MANTELÉE. - CORVUS CORNIX.

L'article consacré à la corneille mantelée sera court, parce que les habitudes de cet oiseau n'offrent aucun caractère particulier, et qu'il m'est difficile de bien l'étudier, dès lors qu'il ne fait que visiter notre département à certaines époques de l'année et, en particulier, pendant l'hiver. Cette corneille est d'un gris cendré sur tout le corps, excepté sur la tête, sur la gorge et sur la queue, qui sont d'un beau noir. Elle doit à cette particularité l'épithète qui la distingue des autres espèces de corbeaux; car cette teinte grise semble être un léger " manteau " développé sur un fond noir. C'est elle aussi qui justifie les dénominations vulgaires données à la corneille mantelée. Dans certaines localités, elle est appelée la religieuse; dans d'autres la jacobine. Pendant le temps que la corneille mantelée séjourne dans notre département, elle manifeste les mêmes habitudes que la corneille noire, avec laquelle clle vit en bonne harmonie. Elle paraît se plaire spécialement dans les terrains humides et dans les lieux où séjournent des immondices ou des animaux en putréfaction. Cependant elle donne moins de preuves de voracité que ses congénères.

Quand la neige et la glace recouvrent la terre d'un linceul épais, qui dérobe aux investigations de la corneille mantelée et de la corneille noire leur nourriture de prédilection, ces oiseaux ont recours à la pêche. Souvent j'ai vu, près de l'abattoir, pendant l'hiver, des corneilles ordinaires, et surtout des corneilles mantelées, se balancer au-dessus des eaux de la Maine, en société des mouettes rieuses, puis s'abaisser, se laisser tomber, comme celles-ci, à la surface de la rivière, pour y saisir quelques débris de poissons et d'insectes. Dans cette circonstance, leur vol avait une facilité et une grâce qu'elles 
ne manifestent pas ordinairernent. Cependant ces oiseaux ne pouvaient se livrer longtemps à cet exercice; car les mouettes les poursuivaient avec acharnement, et les forçaient it quitter un théatre qui ue leur appartient pas.

La corneille mantelée se reproduit ordinairement dans les pays de montagnes. Elle confie son nid aux arbres élevés; il est construit comme celui de la corneille noire, et contient de quatre à cinq œufs, dont la couleur et la forme varient beaucoup; ils se rapprochent de ceux des deux espèzes précédentes, et sont ordinairement plus allongés et moins gros que ceux de la corneille ordinaire. Le grand diamètre est de $0^{\mathrm{m}}, 035$ à $0^{\mathrm{m}}, 042$, et le petit de $0^{\mathrm{m}}, 028$ à $0^{\mathrm{m}}, 032$. Leur couleur, d'un bleu verdâtre, est parsemée de taches, de raies, de points d'un brun noiratre; d'autres sont d'un vert clair, et offrent quelquefois plusieurs couches de taches plus ou moins foncées.

CORBEAU CHOLC. - CORVTS SPERMOLOGLS.

Au commencement de mes Essais étymologiques, je m'étais imposé une règle de conduite : c'était de suivre la Faune de Naine-et-Loire, sans la justifier-ni l'attaquer. Jusqu'à ce moment, j'ai été fidèle à mon principe, et j'ai adopté, sans conteste, toutes les espèces que notre vénérable doyen avait insérées dans sun ourrage. Mais je me rois à regret forcé d'agir autrement. Je me troure, en effet, obligé d'expliquer les mœurs du corbeau chouc, et de montrer qu'elles s'harmonisent avec les noms qui le désignent. Or, pour atteindre ce but, il me semble que la première chose à démontrer serait l'existence du choue, et la seconde, sa présence en Anjou. Malheureusement la plupart des naturalistes regardent l'existence du choue comme très-incertaine, et pensent que cette espèce imaginaire n'est autre chose qu'une variété du 
choucas ordinaire. Il est, dès lors, très-difficile qu'il vienne en Anjou, s'il n'existe pas. M. Dégland, dans son Ornithologie européenne, partage cette opinion et affirme que les choucs, conservés par M. Millet et examinés avec soin par M. de Lamotte, ont été reconnus par celui-ci pour être de véritables choucas (tome I, page 321). D'un autre côté, les débris de l'œuf attribué au chouc, qui se trouvaient dans le cabinet du savaut auteur de la Faune de liaine-et-Loire, pouvaient aussi bien appartenir à la corneille ordinaire, qu'à la corneille mantelée ou au freux. Je les ai étudiés avec un soin scrupuleux; ils ne présentent nullement le caractère des œuts du choucas, auquel le chouc devrait se rapporter, caractère très-prononcé, comme nous le verrons plus tard, et qui sépare d'une manière très-tranchée les œufs du choucas de tous ceux du genre corbeau. Après ces explications simples et respectueuses, il ne me reste qu'à indiquer l'étymologie des expressions spermologus et chouc.

La première est composée du grec SPERMA, "semence," et LÉGô, "recueillir; " elle indique que cet oiseau devrait se nourrir principalement de graines; dénomination vague, qui conviendrait aussi bien aux freux qu'aux choucs. Quant ì la seconde, elle aurait le même radical que chouette, dans le sens de cave, de cachette, et corbeau chouc pourrait alors être traduit par ces mots : " corbeau qui vit et se reproduit dans les trous, " explication très-juste et très-caractéristique, quand elle est appliquée au choucas.

\section{CORBEAU CHOUCAS. - CORVUS MONEDULA.}

Nous sommes ici en présence d'une réalité, et le choucas non-seulement existe, mais encore il se reproduit dans notre département. Son nom vulgaire, d'après l'explication précédente, signifie "corbeau qui se retire 
et se reproduit dans les caves, dans les trous. " Cette dénomination est très-juste, et peint, d'une manière expressive, le caractère qui sépare le choucas de toutes les autres espèces du genre corbeau. Toutes, elles construisent leurs nids sur les arbres; toutes, elles passent la nuit en plein air : le choucas, au contraire, établit son nid dans les trous des vieux édifices, et c'est dans ces trous qu'il se réfugie pour passer la nuit et pour braver l'intempérie des saisons. C'est là également qu'il élève ses petits.

Son nom scientifique moneclula signifie "monnaie, " et lui a été donné à cause de la disposition qu'il manifeste à tout recueillir, et surtout ce qui brille, ainsi que toute espèce de monnaie, disposition que nous retrouverons aussi, à un haut degré, dans les habitudes de la pie. La mythologie prétend que cet amour de l'argent, que montre le choucas, est en quelque sorte une punition de la divinité. Elle admet, en effet, que le choncas était autrefois une jeune fille, Arné, qui vendit sa patrie ì Vinos à prix d'argent, et que, pour lui faire expier son crime, les dieux la changèrent en choucas, et lui laissèrent une soif perpétuelle de l'or qui la tourmente toujours et qu'elle ne peut satisfaire.

Mutata est in avem, quæ nunc quoque diligit aurum,

Nigra pedes, nigris velata monedula pennis.

"Ell, fut changion en 110 disean qui, maintenant meme, est tout plein de l'amour de l'ox. Cóst la monedulu, dont les pieds of toutes les plumes sont enveloppés de noir. »)

(Ovide, Metamorphoses, liv. VII.)

Chaque année, un grand nombre de choucas itablissent leurs nids dans les trous de la façade de la cathidrale et dans ceux que le temps a faits au sommet de la tour Saint-Aubin. Autrefois ils nichaient dans les excavations des tours de notre magnifique citadelle fiodale; mais, de- 
puis les réparations que le génie militaire y a exécutées, les choucas ont dû chercher un autre asile. Au moment de la nidification, il est facile de voir l'activité déployée par ces oiseaux : ils transportent de la paille et des débris de toute espèce dans les cavités qu'ils ont choisies pour y élever leur future famille. Leur nid est une coupe aplatie, grossièrement façonnée et composée de brins de paille, de petites bûchettes, etc., ressemblant assez au nid des pigeons. Quand le trou est spacieux, plusieurs nids sont placés les uns auprès des autres, et composent ainsi une colonie qui rappelle celle des freux. Pendant tout le temps que dure la confection du nid, les choucas multiplient leurs voyages avec une grande rapidité, et poussent, en entrant dans leurs demeures et en en sortant, des cris qui semblent être une marque de satisfaction et un encouragement à une nouvelle activité. Chaque nid renferme cinq ou six œufs, dont la coquille est d'un blanc nuancé de bleuatre et moucheté de taches assez rondes, brunes ou noirâtres; dans le centre, elle revêt une couleur plus foncée que sur les bords. On dirait que des gouttes d'une couleur noire seraient tombées sur ces œufs, et qu'en s'étendant, les bords de ces gouttes auraient perdu une partie de leurs nuances. Le grand diamètre est de $0^{\mathrm{m}}, 032$ à $0^{\mathrm{m}}, 036$, et le petit de $0^{\mathrm{m}}, 021$ à $0^{\mathrm{m}}, 025$. Le caractère de ces œufs les distingue facilement de ceux de toutes les autres espèces du genre corbeau; aussi les naturalistes, qui admettent l'existence du chouc, devraient lui attribuer des œufs se rapprochant de ceux du choucas. Celui-ci vit pendant l'hiver assez volontairement avec les freux; il se nourrit de graines, de semences, de baies, et la dénomination spermologus lui conviendrait parfaitement.

Les choucas s'apprivoisent facilement. Aussi, chaque année, des couvreurs s'empressent-ils de visiter les trous de la cour Saint-Aubin, et de s'emparer de tous les petits 
choucas assez avancés en age pour pouvoir être élevés; puis ils les vendent aux pensionnaires du collége Mongazon. Là, chaque étudiant s'occupe seul de son protégré, et bientôt une véritable intimité s'établit entre le maitre et l'élève; celui-ci répond à la woix de son proprictaire; il le reconnait parmi tous les autres. Quand les repas sont terminés et que chaque élève, en entrant sur la cour, montre à son jeune protégé la portion qu'il a prilevée sur son dîner et qu'il lui destine, l'oiseau s'élance aussitôt du sommet des peupliers pour venir se reposer sur le bras de son maitre et lui manifester, par ses cris et le battement de ses ailes, sa joie et sa reconnaissance. Après la récréation, il reprend son poste d'observation, sans jamais déserter l'enceinte des dépendances du collége. Les jours de promenade, les choncas s'élèveront dans les airs, accompagneront les élèves, puis arrivés au but où les divisions doivent s'arrêter, ils tourbillonneront au-dessus de la tête de leurs bienfaiteur's, et bientôt chaque choucas viendra se reposer sur le bras de son maître, becqueter la nourriture qu’il lui a destince, et enfin revenir à Ilongazon, pour renouveler ainsi ces voyages aériens à chaque sortie.

Le choucas, élevé avec beaucoup de soin, peut apprendre à prononcer quelques paroles; mais sa facilité d'articuler est très-limitée.

Cette année (1866), j’ai été témoin d'un fait qui prouve avec quelle sollicitude le père et la mère veillent sur leurs petits. Ln jeune choucas, moins fort que ses frères, n'avait pu se soutenir dans les airs; les forces lui ayant fait défaut, il tomba, malgré les efforts de ses parents, dans la rue située au pied de la turr Saint-Aubin. Une petite fille s'empara de l'oiscau, et le renferma dans une cage beaucoup trop étroite pour la taille du prisonnier; puis elle plaça la cage à une croisée peu élevée au-dessus du nireau de la rue. Le père et la mère du captif se 
mirent aussitôt à voltiger autour de la maison en poussant des cris plaintifs. Les passants les effrayaient, puis les choucas redoutaient pour eux-mêmes de descendre si près de terre, et enfin aucun appui ne s'offrait à eux pour pouvoir se reposer et attendre le moment favorable qui pût leur permettre de s'élanser le long des barreaux de la cage, de s'y cramponner quelques instants et d'y glisser furtivement la nourriture préparée pour ce Benjamin de la famille. Je suivais avec attention toutes les péripéties de cepetit drame; je m'associais aux angoisses du père et de la mère, et je n'entrevoyais pour eux aucun moyen de satisfaire les désirs de leur tendresse. Une journée était presque écoulée; les cris du petit devenaient plus pressants, et les courses de ses parents plus multipliées : il m'était évident que le danger pour la vie du jeune choucas s'aggravait; il fallait donc un suprême effort pour sauver l'infortuné captif. Tout à coup, un cri de satisfaction se fait entendre; le père et la mère le répétaient avec plaisir : un point d'appui était trouvé! La coupe abandonnée d'une vieille gouttière brisée et fixée encore à la maison située vis-à-vis de la cage offrait aux parents un appui sûr et un moyen d'attendre le moment favorable, où ils pourraient apporter à leur bien-aimé prisonnier la nourriture préparée avec soin, et destinée à développer ses forces en le consolant des rigueurs de la captivité. Pendant plus de trois semaines, les parents du jeune choucas rivalisèrent de bonne volonté pour accomplir la mission que comprend le cœur d'un véritable père ou celui d'une tendre mère. Ils ne s'éloignèrent que lorsqu'ils furent parfaitement convaincus que le prisonnier pouvait se suffire à luimême. 


\section{DIXIẺME GENIRE. - PIE.}

\section{PIE COMMUNE. - GARRULA PICA.}

Dans le cours de ce petit travail, il m'est arrivé plusieurs fois de prendre, avec conviction, la défense de certains oiseaux qui étaient considérés conme nuisibles soit à l'agriculture, soit à la propagation du gibier. Ici même, je ne veux pas abandonner mon rôle de défenseur; car, persuadé que tous les viseaux ont une mission providentielle à remplir, j'admets les services dont l'importance échappe à la faiblesse de mon intelligence, et que pour apprécier il me faudrait être, comme Dieu, au sommet de la montagne d'où l'on peut embrasser d'un coup d'œil l'ensemble de la création.

Je ne puis condamner moj-même la pie; mais, pour etre impartial, je vais exposer les habitudes de cet oiseau, en laissant à chaque lecteur le soin de prononcer la condamnation ou l'acquittement, selon le degré de conviction qui résultera pour lui du tableau des méfaits reprochés, dans tous les siècles et par tous les auteurs, à la pie commune.

Cet oiseau est omnivore par excollence; son appétit est tellement développé, que, puur le satisfaire, la pie dévore tous les aliments qu'elle rencontre; e'est à cause de cette disposition gue les Latins avaient désigné, sous le nom de pica, "la faim insatiable, bizarre, dépravée, " dont sont alteintes plusicurs personnes. La pie se nourrit d'œufs, de graines, de ver's de terre, d'insectes, d'animaux vivants ou morts. On la voit fréquemment sur les grandes routes chercher dans les excríments des cheVaux les grains d'aroine qui ne sont pas digirrís. Elle se tient aussi dans les fossís voisins des abattoirs et où s'écoule le sang putréfié des victimes. Enfin, elle parcourt. avec delices et fouille dans tous les sens les immondices 
et les débris que l'on recueille dans les villes pour' les entasser en dehors des barrières. Quand ce passereau élève ses petits, il exerce de terribles ravages dans les bassescours, et il immole une si grande quantité de pirons, de poussins, que deux couvées de pies établies aux environs d'une ferme y causent des pertes assez considérables pour que l'appréciation dépasse toute croyance, si elles n'avaient pas été constatées bien des fois. Je connais des métairies dans lesquelles une seule couvée de pies, au moment de la nidification, avait tué vingt-cinq pirons et plus de trente poussins. Quand les oiseaux de basse-cour ne suffisent pas à satisfaire l'appétit des jeunes pies, les parents se mettent en quête, et bientôt ils ont trouvé des nids de perdrix, dont ils brisent les œufs ou tuent les petits. Presque toute l'année, les pies se tiennent non loin des fermes et perchées sur les arbres élevés. De là, elles surveillent les poules qui pondent dans les haies, près des berges de paille et de foin, ou sur la tête des vieilles souches, et, dès que les pondeuses se sont éloignées, la voleuse se précipite sur les œufs pour les briser et les vider avec avidité. Quand des pies aperçoivent un lièvre blessé, elles se réunissent plusieurs pour le harceler, l'étourdir par leurs cris, et parviennent presque toujours à lui crever les yeux et à le dépecer ensuite. Aucun sentiment naturel ne vicnt modérer l'énergie criminelle dont la pie est capable pour assouvir sa faim; aussi, quand la nourriture leur fait défaut, les pies se divisent entre elles, et les plus faibles sont immolées par les plus fortes; dans ce combat contre nature, les parents mangent les enfants ou sont tués par ceux-ci.

Comme faits à décharge en faveur de la pie, on peut relater que, par ses cris et par son vol, elle indique au chasseur la route que suit le renard; elle l'accompagne de huées assourdissantes qu'elle fait entendre encore à 
l'approche de l'oiseau de proie. Et aussi n'est-ce pas toujours un service désintéressé; ces cris indicateurs peuvent être les clameurs d'un voleur plus faible, voulant éloigner un voleur plus fort qui lui aurait enlevé des victimes sur lesquelles le premier aurait arrêti son choix. C'est probablement le même sentiment qui détermine la pie à se préripiter avec tant de fureur sur les gluaux, quand le cri de la chouette se fait entendre dans les pipées. Je ne puis admettre que ce soit un mutif de charité pour les autres oiseaux qui la pousse au combat; mais je crois plus facilement que, dans cette circonstance encore, la pie se laisse diriger par un vil égoïsme, qui l'engage à éloigner un ennemi, pour se livrer ensuite plus facilement et avec plus de succès à ses déprédations.

Un soir, je revenais d'une petite excursion ornithologique, lorsque, près du bourg de Gené, mes oreilles furent frappées d'un bruit si assourdissant, que je désirai en connaitre la cause. Plus j'approchais, plus les clameurs devenaient vives; je reconnaissais bien quels devaient être les auteurs d'un tel vacarme: les pies seules pouvaient revendiquer un pareil privilége; mais ce qui m'étonnait, c'était le lieu choisi pour exécuter ce concert. Les exécutants étaient à terre, et semblaient se lisrer it une danse infernale. Je m'approchai aussi près que possible, sans troubler cette étourdissante harmonie, et je me cachai derrière une vieille souche. Bientôt, je pus distinguer une chouette hulotte mangeant sur un sillon certain petit rongeur, et une vingtaine de pies se livrant, autour d'elle, pour l'effrayer, à des contorsions et à des cris, qu'il est impossible de décrire. Je tirai alor's un coup de fusil; quelques pies restèrent sur le terrain : tout rentra bientòt dans le silence, et la chouette put revenir, quelque temps après, continuer la chasse providentielle it laquelle elle consacre et ses soirs et ses nuits. 


\section{$-425-$}

La pie pourrait trouver, parmi les bœufs, les vaches, les moutons, quelques défenseurs; et cependant les services qu'elle leur rend sont encore motivés par sa gourmandise. On la voit souvent fixée sur le dos des animaux réunis dans les immenses prairies, chercher sous leur poil les insectes qui irritent ces bestiaux, et se livrer ainsi à une investigation complète et très-minutieuse. Quelquefois, quand l'insectc est très-adhérent à la pean de l'animal, la pie, pour le détacher, donne un coup assez violent, qui excite sa monture et la détermine alors à se livrer à une course plus ou moins rapide. Dans ces circonstances, la pie fait preure d'habileté en équitation ; car quelque violente que soit même la course d'un jemne taureau, jamais elle n'est désarçonnée. La pie développe alors une grâce et une adresse que pourraient même envier les premières amazones de nos cirques en renom.

Les pies se servent aussi du dos des animaux pour se livrer à une voltige que j'ai pu constater bien des fois. Quand des insectes et des papillons volent à une certaine hauteur, les pies s'élancent de sur le dos du bœuf, où elles étaient fixées, pour saisir, avec une grande adresse, les insectes au passage, et retomber ensuite, avec grâce et avec légèreté, sur leur monture.

On la voit aussi suivre le sillon tracé par la charrue du laboureur, recueillir les vers mis ì nu par cet instrument, et venir même becqueter les insectes qui adhèrent aux parois de la herse. Quand la pie parcourt les guérets pour y chercher sa nourriture, elle ne court pas comme les autres oiseaux; elle saute des deux pieds en même temps, et imprime à tout son corps un mouvement particulier qui la soulève un peu au-dessus de la terre; de cette habitude est venu le verbe piéter, "santer comme la pie. ") Cet oiseau agite aussi sa longue queue, ainsi que les bergeronnettes; on dirait un long éventail qui s'élève et s'abaisse tour à tour. 
A toutes les mauvaises qualités énumíries précédenment, la pie joint encore une disposition très-prononcée au vol et à un bavardage fatigant. Elle recueille avec empressement et se hâte de cacher les différents objets qu'elle trouve, enlevant surtout ceux qui brillent. De là on déduit généralement, mais à tort, qu'elle aime l'argent. Cette conséquence est fausse : la pie s'attache volontiers à tout ce qui brille et jette un certain éclat, sans se préoccuper si ces objets ont une véritable valeur; elle est séduite par tout ce qui produit un effet bien souvent trompeur. Cette tendance, ainsi que le bavardage continuel de la pie parlant à tort ou à travers, cuntrefaisant la roix de l'homme, le cri des animaux, et le chant des oiseaux, devait provoquer les explications de la my thologie. La fable, en effet, raconte que les neuf filles de Piérius, roi de Iacédoine, ayant défié les neuf Muses à un concours musical, furent raincues et métamorphosées en pies, pour les punir de leur témérité et de leur orgueil. Depuis ce moment elles font entendre un bavardage fatigant pour tout le monde, excepté pour elles. Trouvera-t-on dans cette fiction ancienne le principe du mot pie? Je ne le pense pas.

Roquefort affirme que le mot pie est simplement la traduction du mot pica, nom donné à cet oiseau par les anciens à cause de la forme de son bec, et peut-être à cause de l'usage qu'il en fait. Le bec de la pie ressemble effectivement ì un pic, et cet viseau sait l'utiliser comme l'instrument dont il porte le nom. C'est le mot picn qui a formé le verbe picare, "becqueter. " Picare, id est more gallinarum, victum querere, rostro appetere, " beequeter, c'est it dire chercher sa nourriture et la saisir à coups de bee, comme font les gallinacés. » Quelques auteurs donnent à pica le sens de querelle, en ajoutant même que e'est le principe du mot picarine, parce que les habitants de ce pays passent pour être assez ba- 
tailleurs. Quoi qu'il en soit, prise dans ce dernier sens, la dénomination pica, " querelleuse, " conviendrait parfaitement à la pie. Dans beaucoup de localités on l'appelle agasse, de l'anglo-saxon " aga, » dérivant d'un mot sanscrit qui signifie loqui, "parler, " d'où sont venus chez les Grees Èchos, " bruit, " Êchô, " écho. "

Margot est le nom populaire de la pie, parce que c'est la locution qu'elle répète le plus souvent et avec la plus grande facilité.

Pline (liv. X, ch. xıI ) fortifie encore, par ses assertions, l'origine mythologique de la pie. Il prétend que cet oiseau est doué d'une telle susceptibilité et d'une vainité tellement prononcée, qu'il préfère la mort à une petite humiliation, et se laisse mourir de faim lorsqu'il ne peut prononcer les paroles qu'il a entendues ou imiter la voix et le chant qui ont retenti à ses oreilles.

La pie se reproduit en Anjou, et, quand le moment de la nidification est proche, on aperçoit, dans les prairies entourées de bois, un certain nombre de ces oiseaux qui semblent se livrer à des luttes accompagnées de cris et de mouvements saccadés. Il s'agit tout simplement de contracter des unions, et les fiançailles ne sont pas précédées de combats aussi terribles qu'ils paraissent l'être. Les mâles se disputent quelquefois les femelles, mais sans acharnement; on dirait qu'ils doutent un peu des avantages de l'union qu'ils recherchent. Cependant line fois contractée, cette union se prolonge jusqu'à la fin de la vie des deux époux.

La pie établit ordinairement son nid à la cîme des arbres les plus élevés. 11 présente quelquefois des proportions très-considérables. L'intérieur offre une coupe de terre gâchée avec du fumier et revêtue de petites plantes, de racines et du coton des arbres. L'extérieur est défendu par une enveloppe de bûchettes et d'épines liées ensemble avec beaucoup d'art et constituant une défense 
sérieuse que ne peuvent vaincre facilement ni les viseaux de proie ni les autres ennemis de la pie. Une petite ouverture pour le passage de la femelle est ménagée sur

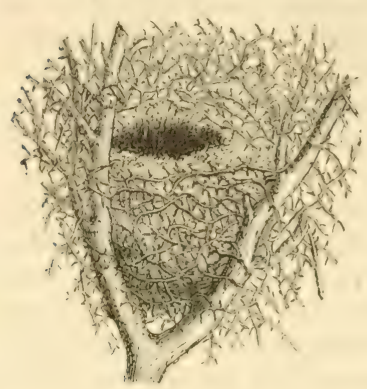

le côté le moins exposé au vent froid. J'ai vu de ces nids qui avaient avec leur enceinte extérieure fortifiée, $1^{\mathrm{m}}, 30$ de hauteur et plus d'un mètre d'épaisseur. Ce nid, dont la partie supérieure est arrondie en forme de voûte, renferme ordinairement de quatre à six œufs variant beaucoup de formes et de couleurs. La longueur est de $0^{\mathrm{m}}, 030$ à $0^{\mathrm{m}}, 034$, et le diamètre de $0^{\mathrm{m}}, 0200$ ì $0^{\mathrm{m}}, 02.2$. Ordinairement ils sont d'un vert bleuâtre plus ou moins foncé, et parsemés de points ou de taches d'une nuance brune ou cendrée. Quelques-uns ont le gros bout recouvert d'une seule tache représentant une calotte noirâtre.

Quoique la cime la plus élerée des arbres soit pour les pies le lieu où elles se plaisent à fixer le berceau de leur jeune famille, on trouve très-souvent des nids dans les haies. Ces nids ont alors des dimensions beaucoup moins grandes que celles que je viens d'indiquer; ils renferment ordinairement des cuf́s plus pâles que ceux que j'ai décrits et revêtus de taches assez larges et comme effacées. Presque partout on donne à ces pies le nom de buissomières, pour les distinguer des autres; mais si elles constituent une variété, elles ne peuvent former une espèce, car leurs mœurs sont semblables à celles de leurs congénères qui nichent dans les arbres. Cette modification à la règle générale est peut-être inspirie par lindolence ou par la faiblesse de quelques sujets qui 
établissent leurs nids dans les haies, afin d'éviter une grande partie du travail et de la fatigue que nécessite une construction à l'extrémité des arbres. Peut-être estce simplement un caprice?

Un jour qu'avec mes deux jeunes amis, Daniel Métivier et Eugène Lelong, je visitais, près de Briollay, les rives du Loir, je fis diriger le bateau vers une touffe de roseaux très-élevés, pensant y trouver quelque nid de poule d'eau ou de foulque. Ne pouvant pénétrer dans l'enceinte des joncs, je donnai un coup de bâton sur les endroits que nous ne pouvions atteindre, et tout à coup, à notre grand étonnement, une pie sortit des roseaux. Nous pensâmes d'abord qu'elle était venue commettre une de ses fautes habituelles et se livrer à quelque dévastation; mais nous fûmes bientôt détrompés quand nos recherches persévérantes nous firent découvrir un nid de pie, très-artistement construit, suspendu au-dessus de l'eau et reposant sur quelques branches d'osier. Il contenait cinq œufs.

La pie ne fait qu'une seule ponte chaque année, si toutefois la première couvée réussit. Les petits ont besoin de leurs parents pendant plus de deux mois. Tandis que la femelle se livre au travail de l'incubation, le mâle s'établit à la pointe d'un arbre très-élevé, veille avec persévérance sur la coureuse, l'avertit du danger qui se présente, et va même au-devant des ennemis pour les combattre et les éloigner par ses cris et par ses poursuites.

J'ai exposé l'étymologie des mots pie et pica. Il ne me reste plus qu'à expliquer les épithètes commune et garrula. Le premier de ces adjectifs a été donné à la pie de nos contrées, parce qu'elle est la plus répandue des oiseaux du genre, et afin de la distinguer des autres espèces, telles que la pie bleue, etc.

Quant à l'épithète garrula, signifiant “babillarde, " 
elle a été suffisamment justifiée, et je crois qu'il est inutile d'y revenir. Cette disposition de la pie à causer sans cesse et d'une manière étourdissante a donné lieu à cet arlage : Canser comme une pie. Mais si en tout temps cet oiseau fatigue par son havardage, c'est surtout le matin et le soir qu'il devient plus assourdissant. Le soir, avant de se livrer aux douceurs du sommeil, et le matin, dès l'aube du jour, les pies se réunissent à l'extrémité des peupliers ou dans les futaies, et se livrent à un tapage infernal : on dirait une réunion de brigands ivres de sang et de vin, racontant avec une joie féroce tous leurs crimes de la journée, ou s'excitant mutuellement, dès leur ríveil, par des conversations bruyantes, à continuer leur vie de déprédations.

On prétend que la pie sent la poudre de très-loin, et que c'est grâce à son odorat qu'elle échappe à la poursuite du chasseur. Cette opinion n'est pas fondée; car la pie doit son salut, non pas à son odorat, mais à sa vue pénétrante et surtout à sa vigilance excessive. Ainsi que tous les grands coupables, la pie est toujours inquiète; elle craint sans cesse la punition méritée par ses crimes incessants; comme eux aussi, elle est sans cesse sur ses gardes, et elle établit sur le théâtre de ses iniquités des sentinelles actives chargées de l'avertir à l'approche de ses ennemis. C'est le rôle que remplissent les pies que l'on apercoit à la cime des arbres les plus élevés, et qui jettent de temps en temps une espèce de cri saccarlé, rappelant le mot d'ordere répété par les soldats pendant la nuit : Garde ì vous!

Dans beaucoup de localités, les villageois pensent que le cri de la pie, lorsqu'il est plus réitéré qu'à l’ordinaire, est un présage de pluie.

Malgré tous les griefs que l'on reproche à la jie et que je viens d'énumérer, je considère cet oiseau comme pulus utile que muisible, et j'admets que les services qu'il 
rend à l'agriculture en dévorant, à cause de sa faim insatiable, des quantités infinies de vers et d'insectes, constituent une large compensation aux méfaits qui composent son dossier.

\section{ONZIÈME GENRE. - GEAI.}

\section{GEAI. - GRACULUS, GLANDARIUS.}

Me voici encore en face d'un oiseau considéré comme un grand coupable, qui, de même que la pie, aura beaucoup de peine, dans le procès qu'on lui intente, à jouir même du bénéfice des circonstances atténuantes.

Je vais décrire l'ensemble des habitudes du geai, et expliquer, autant qu'il sera possible, l'étymologie des noms donnés à cet oiseau.

Le geai est essentiellement gourmand et de plus trèsavare. Pour assouvir sa faim insatiable, tous les moyens lui sont bons, et il peut être considéré comme un des plus fervents adeptes de la politique de l'annexion, telle qu'elle est pratiquée de nos jours, c'est-à-dire aux dépens des voisins et surtout des faibles. Le geai vit de fruits, d'œufs de petits oiseaux dont il saccage les nids, d'oiseaux pris dans les lacets et les collets qu'il visite avant l'arrivée du chasseur. 11 dissèque les cadavres des animaux en putréfaction; sa roracité ne recule devant aucune espèce d'immondices. En vue de satisfaire son appétit si glouton, le geai se prépare, pour l'hiver, des greniers d'abondance. Il dépose, dans de vieux nids de pie ou d'écureuil, des noix, des pommes, des noisettes, des châtaignes, etc., qu'il transporte dans son gosier très-dilatable; mais son mets par excellence est le gland, dont il fait des amas considérables, qu'il confie au creux des arbres; c'est à cette prédilection pour le "gland " qu'il doit un de ses noms, giandarius. Son goût prononcé pour ce fruit 
lui donne un certain air de ressemblance avec le porc, dont il se rapproche encore par sal malpropreté insigne. Quelquefois les glands entassés dans le gosier du geai sont en en trop grande quantité; dès lors, la fatigue que cet oiseau éprouve en volant, les efforts qu'il fait en jetant son cri l'obligent à se débarrasser d'une partie de sa cargaison. C'est ce qui expliqque pourquoi, assez souvent dans la campagne, des glands tombent auprès du passant, lorsque des geais volent au-dessus de sa tête. C'est aussi aux provisions déposées prar ces oiseaux dans les trones des arbres que l'on peut attribuer les chênes, les noisetiers, ete., qui s'y déreloppent. Mais si le geai est prévoyant, s'il entasse des fruits de toute nature, c'est pour lui seul; réritable ventru, il ne pense qu'à lui et ne connaît nullement la charité. Si quelque confrère s'approche de sa cachette, il se précipite sur lui avec fureur, fût-il son père, sa mère, son frère, peu lui importe, et, comme il est d'un caractère très-irascible, la lutte se termine souvent par la mort de l'un des combattants. La moindre contrariété l'irrite et le plonge dans une fureur extrême. C'est cette disposition qui a contribué à faire croire qu'il tombe du mal caduc. Lorsqu'il est renfermé dans une cage, où sa volonté est combattue, il éprouve les convulsions d'un enfant terrible qui ne peut pas se satisfaire. Les efforts auxquels il se livre pour recourrer sa liberté sont tellement continus et violents, que bientòt ses plumes perdent tout leur éclat et qu'il devient alors méconnaissable.

Quand les fruits sont trop volumineux pour pouvoir être confiés au gosier du geai, celui-ci les transporte en les tenant avec ses pieds. Il met en œurre toutes les inventiuns auxquelles ont recours les gastronomes, c'estì-dire qu'il emploie tous les moyens possibles pour satisfaire sa gourmandise. C'est ainsi que pendant l'hiver, quand les fruits lui font défaut, on le voit sautiller ì 
terre, et tourner et retourner avec une grande ardeur toutes les feuilles étendues sur le sol, afin d'y découvrir les insectes qui s'étaient abrités sous ce toit protecteur. Lorsqu'il soumet les arbres à ses investigations, il ne vole ni ne grimpe comme les autres oiseaux, mais il parcourt toutes les branches par de petits bonds comme s'il montait les barreaux d'une échelle.

Pour échapper au chasseur et pour faire des victimes, le geai a recours à un stratagème bien curieux. Il contrefait la voix, le chant des hommes et des animaux; il aboie comme le chien, miaule comme le chat, bêle comme la brebis, rit comme l'homme. C'est cette facilité d'imiter les oiseaux, les animaux et l'homme que Lafontaine a voulu retracer dans sa fable du Geai paré des plumes du paon. Le geai est susceptible d'apprendre la musique; il compose lui-même des morceaux, en réunissant le chant de plusieurs espèces d'oiseaux. Cette disposition si prononcée à copier tous les autres lui sert, comme je l'ai dit, à attirer dans ses piéges les petits oiseaux, dont il contrefait les cris ou le chant, et qui, au lieu de retrouver leurs parents, tombent en présence d'un bourreau inexorable. Par elle aussi il se dérobe au danger. Ainsi, un jour que je revenais, avec quelques élèves, de visiter la fosse de Sorges, nous rencontrâmes un geai que l'un de mes jeunes Nemrods voulut tuer. Nous le poursuivîmes pendant quelque temps, mais sans résultat. Déjà nous avions renoncé à notre premier dessein, quand tout à coup nous entendîmes le miaulement d'un chat, l'aboiement d'un chien, se succédant tour à tour avec une volubilité incroyable. Comme ces cris me semblaient venir de la tête d'une vieille souche, nous ne comprenions rien à un pareil concert; nous approchâmes avec précaution pour savoir quels étaient les exécutants d'une si étonnante harmonie, quand aussitôt le geai s'envola en faisant entendre un ricanement satanique dont le souvenir ne s'est pas 
encore effacé de ma mémoire, même après de longues années.

Cétte facilité excessive, que le geai possède, d'imiter le chant, le cri de tous les animaux, serait, selon quelques auteurs, le principe du nom latin sous lequel il est désigné; et graculus ne serait qu'un mot de la basse latinité employé pour yarrulus, "babillard, " dérivant lui-rnême de garteïx, " parler, " Dorien pour gènuéĩs, " parler, " dont la racine primitive est le sanscrit " garé, " ayant la même signification que tous ses dérivés. On trouve aussi dans les glossaires : gracillo, "caqueter comme une poule, " gracito, " crier comme une oie. " Ciourt de Gébelin, s'appuyant sur ces derniers verbes, croit que graculus en découle, et que cette dénomination a été donnée au geai à cause de son chant. J'admets bien volontiers que graculus doit être synonyme de garrulus, et que l'adjectif babillard, et babillard par excellence, convient au geai.

Celui de notre pays est appelé geai ordinnire, parce que, malgré ses dispositions à contrefaire la voix et le chant de tous les êtres qui l'entourent, il est bien loin d'avoir l'aptitude de certaines espèces de sa famille et principalement du geai surnommé l'imitateur. Le geai est encore appelé graule par les riverains de la Loire, et graille, en Provence. La signification de ce mot a été donnée à l'article de la corneille noire.

Le plumage du geai a un cachet particulier. Ses ailes sont émaillées de différentes nuances de bleu et de couleurs si vives, que les élégantes de nos jours en ont orné leurs chapeaux, ou plutòt ce qui, remplaçant leur's chapeaux, ne peut que très-difficilement se représenter par une dénomination ancienne. Comme ornement, je conçois l'usage des plumes de geai; mais comme emblème, je les comprends beaucoup moins.

Sur le front du geai se trouve un bouquet de plumes bleues, noires, blanches, réunies en forme de huppe. 


\section{$-435-$}

Les mâles se distinguent des femelles par les couleurs plus vives de leur plumage, et surtout par les dimensions très-développées de leur tête. Certains auteurs pensent que l'éclat et la diversité des plumes de geai ont donné lieu à son nom vulgaire, et que gaius n'est qu'une modification de varius, " diversifié, varié. ") Telle est l'opinion de Ménage, que l'on pourrait fortifier par l'autorité de beaucoup de, naturalistes qui appellent le geai pica varia, "la pie à plumage varié. " Voici maintenant le passage du dictionnaire de Littré, se rapprochant de l'interprétation de Ménage: " GEAI, en bas latin, gaius, gaia. Diez croit que c'est le même mot que gai, adjectif. On penserait plutôt à l'adjectif dauphinois gaille, " bigarré, ") en espagnol, gayo. D'autres y ont cherché une contraction du bas-breton gegin, kegin, "geai.) Un des noms vulgaires anglais de cet oiseau est gaget. Roquefort pense que geai est une onomatopée représentant le cri naturel de cet oiseau. $)$

Je ne puis terminer cette étude sans alléguer au moins quelques faiis en faveur du coupable qui nous occupe. Son dossier est assez chargé pour que l'on puisse essayer de diminuer la gravité des méfaits qui lui sont reprochés. Le geai rend un véritable service dans les pays où les sauterelles sont un terrible fléau; car il unit ses efforts à ceux du martin-roselin pour immoler ces insectes dévastateurs. Ce service me paraît suffisant pour l'absoudre de tous les griefs qu'on iui reproche. Aussi les habitants de Lemnos lui rendaient-ils un culte public. Comme la pie, il indique, par son vol et par ses cris, la présence du renard et de l'oiseau de proie, et préserve de la mort un grand nombre de victimes.

Quoique très-méfiant et très-rusé, le geai est une des premières victimes du pipeur : il se précipite sur les gluaux avec une étourderie qui ne peut s'expliquer que par son excessive curiosité, très-souvent cause de sa 


\section{$-436-$}

perte. Une fois capturé, il attire par ses cris violents beaucoup de ses congénères, qui, j'aime à le croire, sont concluits par une louable intention et par un víritable désir de venir en aide à un confrère malheureux.

Le geai se reproduit en $A$ njou; il ne fait qu'une seule couree. Son nid, confié à la tête des vieilles souches ou aux branches des charmilles, est peu artistement fait : quelques petites racines réunies en forme de coupe aplatie constituent tout le berceau de la jeune famille. Certains auteurs prétendent que le geai le construit ainsi, afin que l'eau ne puisse pas y séjourner, et rque c'est pour la même raison qu'il est légèrement incliné sur un de ses côtés. La femelle dépose sur ce matelas un peu dur de quatre à six œufs d'un gris vert pâle, parsemé de taches et plus sourent de petits points d'un brun clair : assez fréquemment le gros bout présente une espèce de couronne formée par la réunion de petites taches plus abondantes et plus pressées que sur les autres parties de la coquille. Quelques-uns sont d'un cendré verdàtre uniforme et sans aucune tache. Le grand diamètre de ces œufs, qui sont presque toujour's un peu pointus aux deux extrémités, varie de $0^{\mathrm{m}}, 031$ à 0,032 , et le petit de $0^{\mathrm{m}}, 0: 21$ à $0^{\mathrm{m}}, 022$.

On peut reconnaître les jeunes mâles aux quelques plumes noires semées sur leur tête. Quand les petits sortent du nid, ils forment avec leurs parents une sociéti: qui persévère jusqu'au printemps suivant. Le geai abandonne son nid dès qu'il s'aperçoit qu'il a été découvert par quelque visiteur indiscret. Est-ce à cause de cette disposition, et pour n'avoir pas à renouveler un travail trop compliqué, qu'il construit avec tant de simplicité la couche sur laquelle doivent reposer ses enfants?

Dans notre département, et surtout aux environs de Saint-Florent-le-Yieil, les habitants de la eampagne admettent une ancienne légende, d'après laquelle ils croient 


\section{$-437-$}

que, tous les vendredis, les geais sont condamnés à des convulsions épileptiques, pendant lesquelles ils se frappent la tête le long des arbres. Les paysans voient, dans cette habitude du geai, un acte de la justice de Dieu, qui aurait condamné cet oiseau à un pareil châtiment, pour le punir d'avoir, par ses cris, révélé à Judas la présence de Jésus-Christ au jardin des Oliviers.

GEAI A CALOTTE MOIRE. - I.ARRLLLS MEL AYOCEPHALLS.

La dénomination rulgaire donnée à cet oiseau reproduit entièrement la même idée que le nom scientifqque.

Toutes les deux sont fondées sur une particularité qui distingue le geai à calotte noire des autres individus de la même famille. Un certain nombre de plumes longues, touffues et de couleur noire, se trouvent disposées sur la tête de ce passereau, de manière à se relever en forme de huppe quand il éprouve de rifs sentiments de satisfaction ou de colère. Le geai mélanocéphale habite le Caucase et l'Afrique, et présente même deux races assez distinctes, selon qu'elles se trouvent dans l'un ou l'autre de ces pays. Plusieurs naturalistes n'ont vu dans cet oiseau qu'une variété locale du geai ordinaire, plus petite ct d'un plumage un peu différent; modifications qui pourraient, dans cette espèce comme dans beaucoup d'autres, dépendre de l'influence du climat et de la nourriture. Quoi qu'il en soit, les mœurs du geai à calotte noire sont semblables à celles du précédent. Dès lors qu'il habite le Caucase et l'Afrique, son séjour, ou même son passage en Anjou, pourrait d'abord paraître assez extraordinaire ; mais, II. Guillou de Cholet ayant signalé la présence de ce passereau dans notre département, je laisse à ce naturaliste la responsabilité de sa découverte. Cependant, loin d'infirmer son assertion, je me sens porté à la dé- 
fendre. Le geai est essentiellement nornade; comme tous les gens pillards, il a besoin de ne pas rester trop longtemps dans les lieux témoins de ses rapines.

Le geai ordinaire parcourt l'Europe dans tous les sens. Il n'est sédentaire que dans les pays où il pense que ses provisions, unies aux larcins de chague jour, pourront satisfaire son appétit dévorant, ou dans les contrées riches en lorêts de chênes, qui lui fournissent en quantití considérable son mets privilégié. C'est encore à cette vie errante du geai que l'on doit attribuer la richesse et la diversité de son répertoire musical. A vee son talent si prononcé pour l'imitation, il copie et redit le chant et le cri des oiseaux et des animaux de tous les pays qu'il parcourt, ainsi que le patois des populations qu'il visite. Puis, non-seulement il les conserve dans leur pureté primitive, mais, en les mélangeant, il compose des variantes, de manière à déconcerter les plus intrépides virtuoses. Cependant, malgré toutes les ressources de son gosier, je fais des vœux pour que le geai mélanocéphale ne vienne plus nous visiter; qu'il reste en Afrique; qu'il y attire même et y fixe son confrère, le geai ordinaire, afin que tous deux, unissant leurs efforts et leur énergie pour combattre le terrible fléau des sauterelles, puissent prendre ainsi le moyen le plus honorable de se faire pardonner les iniquités qu'on leur attribue!

\section{DOUZIÈME GENIE. - ROLIER.}

ROLLIER ORDINAIRE. - CORACLAS GARRULA.

Cot oiseau habite l'Afrique, le Midi et les pars chauds : il ne visite notre pays que très-rarement et lursqu'un eaprice ou son amour pour les voyages l'y conduit. Mon honorable ami Rauul de Baracé a capturé, dans la commune de Sainte-Gemmes-sur-Loire, un très-beau rollier, 
qui était venu se prendre à un piége destiné à des oiseaux de proie. La présence du rollier en Anjou étant ainsi bien constatée, je dois à cet oiseau une courte mention. Le rollier est encore plus babillard que le geai et que la pie, d'où l'épithète garrula lui convient parfaitement. Au printemps, il vit d'escargots, de vers, de sauterelles, de petites grenouilles; en automne, il recherche les larves de chenilles, les baies et les fruits. Il chasse les insectes à la manière des pies-grièches, en se fixant sur des branches mortes pour attendre et capturer ses victimes au passage. Il se distingue des corbeaux par ses narines charnues, et s'en rapproche par son babil, par' sa manière de saisir sa nourriture et par son habitude de piller les nids des autres oiseaux pour en manger les œufs. De là est venu son nom coracias, de korakïas, "qui se rapproche du corbeau."

Le rollier est d'un caractère très-farouche et très-défiant; il aime à se reposer sur les arbres qui avoisinent les lacs, les marécages, et, pour appréhender plus facilement sa proie, tout en échappant lui-même à ses ennemis, il dissimule sa présence et se cache sous les feuillages les plus épais. Il ne fait pas, comme le geai et la pie, des provisions pour l'hiver, parce qu'il visite des pays qui lui offrent, selon les saisons, une nourriture abondante et variée.

En tout temps, sa chair est excellente; mais elle est surtout recherchée en automne, comme un mets délicat; c'est à cette époque que le rollier devient très-gras. Dans beaucoup d'ourrages, cet oiseau est appelé geai d'Afriqueou geai perroquet. Cette dernière dénomination indique la puissance du bec du rollier. Hais si ce dernier caractère l'assimile au corbeau et au geai, son plumage l'en éloigne, à cause de ses couleurs bleuâtres de différentes nuances et offrant un reflet métallique.

Son nom vulgaire, rollier, n'est qu'une onomatopée 
reproduisant le cri le plus ordinaire de ce passereau.

Le rollier niche dans le creux des arbres, dans les trous des vieilles murailles ou des rives sablonneuses. La femelle dépose sur une légère couche d'herbes et de mousse quatre ou cinq œufs un peu ventrus, d'un blane lustré et uniforme. Le grand diamètre est de $0^{\mathrm{m}}, 032$ à $0^{\mathrm{m}}, 034$, et le petit de $0^{\mathrm{m}}, 024$ à $0^{\mathrm{m}}, 026$.

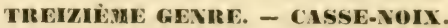

\section{IE CASSE-YOIX. - NICIFRACA CARYOCATACTES.}

Le casse-noix n'est encore, pour nous, qu'un oiseau de passage. Il choisit comme séjour de prédilection le sommet des montagnes les plus élevées et couvertes de neige, ainsi que les forêts du pin à pignons (pinus cembra). C'est dans ces régions désolées qu'il peut se livrer sans inconvénient à tonte l'énergie de son babil infatigable. D'un plumage noirâtre et moucheté de blanc, d'une forme svelte et bien proportionnée, le casse-noix est d'un aspect non dépourvu d'élégance. Cet oiseau manifeste beaucoup moins de défiance que ceux que nous venons d'étudier, probablement parce que ses ennemis sont beaucoup moins nombreux que ceux des espèces précédentes. Il vit d'insectes, qu'il saisit avec adresse, de baies et de semences des arbres. Mais sa nourriture privilégiće se compose de noix, et surtout de noisettes, qu'il dépouille de leur enveloppe ligneuse et entasse dans une espèce de poche à parois très-minces, fixée dans la partie supérieure de l'œsophage et du cou. Cette poche peut contenir de quinze à vingt noisettes, selon les dimensions des fruits. Muni de cette provision, le cassenoix ne craint pas de voyager pendant plusieurs jours. S'il rencontre des baies, des insectes, etc., il laisse intacte sa réserve; si, au contraire, la disette se fait sentir, 
il dégorge avec beaucoup d'adresse un certain nombre de noix ou de noisettes, les assujettit avec ses pieds, et les casse avec unc dextérité merveilleuse. Telle est l'origine de ses noms vulgairess ou scientifiques, ayant tous la même signification, et qui représentent le casse-noix d'après son habitude la plus caractéristique : mucifraga, de nux, nucis, " noix, ") et frango, "briser. " Le mot caryocatactes, si effrayant au premier aspect, exprime la même idée sous une forme peu poétique en apparence. Il est composé de karyon, "noix, " et de Kataktès, "qui casse, qui brise."

Le casse-noix est moins rusé que le geai et que la pie; il n'a pas recours aux stratagèmes dont se servent ces oiseaux pour faire des victimes ou pour éloigner des ennemis. Buffon a prétendu, sans motif, que le cassenoix avait été obligé d'abandonner les plaines et de se. réfugier sur le sommet des montagnes inaccessibles, à cause des dégâts immenses qu'il occasionnait dans les forêts en perforant les arbres, ravages qui avaient déchaîné contre lui la colère des propriétaires. Cette opinion n'est nullement fondée : le casse-noix ne perce pas les arbres; il ne creuse pas son nid dans le bois, comme l'a prétendu tout récemment un auteur célèbre par ses fictions mythologiques. Le casse-noix fait son nid sur les branches des arbres verts qui couronnent les pics les plus élevés des Alpes et des monts Scandinaves. Grâce à la bienveillance de mon vénérable ami, M. l'abbé Caire, et à son infatigable persévérance, j'ai pu me procurer une demi-douzaine de ces nids et les cufs qu'ils contenaient. Le casse-noix construit, dès le mois de février, le berceau de sa jeune famille. Cet édifice ressemble à un petit monticule dont le diamètre de la base, large de $0^{\mathrm{m}}, 32 \mathrm{à} 0^{\mathrm{m}}, 34$, diminue en s'élevant et se termine par une coupe aplatie et large de $0^{\mathrm{m}}, 12$. La hauteur de ces nids est ordinairement de $0^{\mathrm{m}}, 15$, et l'épaisseur du bord 


\section{$-442-$}

de $00^{\mathrm{m}}, 066$. De petites branches de mélèze, de pin, de hêtre, entremêlées de filaments d'usnée chevelue forment la base du nid. Quant à la coupe, elle est composće de brins d'herbes fines et desséchées, recouvertes de plusieurs couches de mousse et d'usnée, massées de manière ì se coordonner et à faire un tout. Ces différentes couches sont tellement foulées, qu'elles semblent former une seule substance, ou plutôt une sorte de feutre composé de plusieurs matières réunies par l'action puissante d'une presse. Ces nids sont quelquefois cachés dans des touffes de gui; ils contiennent de trois à cinq œufs, d'un blane bleuâtre, parsemé de petits points bruns plus ou moins foncés. Ils ressemblent à quelques variétés d'œufs de pie; mais la coquille en est toujours plus légère et plus lisse que celle de ces dernier's, et, sous ce rapport, elle se rapproche de la coquille des œufs du choucas. La plupart des oufs attribués aux casse-noix par les marchands naturalistes ne sont pas authentiques : la diffculté excessive de s'en procurer a contribué beaucoup ì entretenir cette fraude. Le grand diamètre est de $0^{\mathrm{m}},(036$ à $0^{\mathrm{m}}, 037$, et le petit de $0^{\mathrm{m}}, 022$ à $0^{\mathrm{m}}, 024$.

Le casse-noix se reproduisant dans les mois de février et de mars, au milieu des forêts couvertes de neige, il s'ensuit qu'il ne peut guère avoir recours aux insectes et aux fruits pour élever ses petits, et qu'il est forcé de puiser dans ses greniers de réserve. C'est alors que, le voyant entrer souvent dans le creux de vieux arbres où il a entassé des quantités considérables de noix, de noisettes, on a pensé qu'il nichait dans des excavations que lui-même avait perforíes ou du moins agrandies. Cette opinion est complétement fausse ; pour la combattre victorieusement, il suffit d'examiner le bec du casse-noix, qui n'est pas armé pour le travail, ou plutòt pour le grief qu'on lui attribue. Il est inutile d'augmenter encore le nombre des coupables, et de forcer les amis des 
pics à entreprendre la défense d'un nouveau proscrit. Le casse-noix trouve aussi dans la semence des pins une ressource précieuse, et, comme le geai, il triture et prépare dans son jabot la nourriture qu'il dégorge ensuite dans le bec de ses petits. A cause de cette habitude et de l'ensemble de son caractère, il est appelé dans beaucoup de localités, geai de montagne. Dans le temps des fruits, il fait une véritable concurrence aux écureuils, en coupant, comme ces derniers, les pommes, les poires, etc., pour en manger ensuite les pépins.

\section{QUATORZIËUE GENRE. - SITELLE.}

\section{SITELLE TORCHEPOT. - SITTA EUROPEA.}

La sitelle termine, dans la Faune de Maine-et-Loire, cette longue nomenclature d'espèces rangées sous le nom de conirostres, et qui souvent paraissent se lier entre elles, comme les grains d'un chapelet dont la chaîne est brisée. La refaire n'est pas mon intention : le labeur que je me suis imposé est déjà suffisant pour mes forces; et volontiers je laisse à d'autres le soin de coordonner et d'harmoniser toutes ces espèces, de manière à ce que chacune d'elles soit à sa véritable place, et concoure à former une gracieuse mosaïque. Nous continuerons, ami lecteur, à parcourir simplement la route qui nous a été tracée, et à recueillir, le long de notre chemin, les détails qui peuvent nous venir en aide pour relier les habitudes des oiseaux aux noms sous lesquels ils sont désignés.

Les formes de la sitelle ne sont pas gracieuses : son corps est gros et court, sa queue presque nulle; les nuances de son plumage revêtent une couleur d'un bleu cendré ; elle a trois doigts en avant et un seul en arrière; ce dernier est bien armé. La sitelle grimpe aux arbres 
dans tous les sens, de bas en haut et de haut en bas; mais elle ne descend pas jusqu'à terre. Dans ces évolutions, elle ne se sert pas de sa queue comme font les pics, pour s'appuyer et se reposer. Elle parait se plaire à décrire une série de cercles autour des arbres qu'elle visite, afin d'y saisir les insectes cachés sous les fevilles ou sous l'écorce. Son séjour favori est l'extrémité des arbres des futaies; là, elle semble plus en sûreté et plus ì son aise; c'est là aussi qu'elle répète d'une manière assez continue son cri strident, qui a quelque chose du grincement de la lime. Ce cri s'entend de trèsloin, et ne peut être confondu avec celui d'aucun autre oiseau; il est si caractéristique, qu'il est devenu le principe du nom vulgaire et du nom scientifique de la sitelle. Siтta ou sitté représentait chez les Grecs le cri dont les bergers se servaient pour réunir leurs brebis et leurs chèvres dispersées sur les montagnes. Ce cri était produit par un sifflet, qui se faisait entendre au loin. La racine de sitTa est sizò, "frémir, siffler, " signification très-juste et très-expressive.

La sitelle se reproduit en Anjou; elle choisit, pour faire son nid, un trou d'arbre qui a servi aux pics et aux mésanges; ordinairement ce trou est à quclques mètres au-dessus du sol. Quand l'ouverture parait à la sitelle trop grande pour être défendue facilement contre les visiteurs importuns, cet oiseau gâche de la terre et masonne, avec beaucoup de goùt et d'adresse, l'entrée du nid, de manière ì ne laisser qu'un petit passage parfaitement rond. Aussi les paysans l'ont appelé, à juste titre, pic-maçon. La dénomination torche-pot représente la même illée. Pour rendre son travail plus solide, la sitelle imite le maçon et mêle du gravier à la terre glaise, qui Jui sert à diminuer l'entrée de sa demeure. Deux motifs: la dirigent dans ce labeur : la délense plus aisée de sa progéniture, et un sentiment très-prononcé de jalousie 
qu'elle manifeste avec persévérance. Quand on approche du nid, et que la femelle y est renfermée, elle siffle comme le ferait une légion de vipères, afin d'éloigner ses ennemis. Si cet oiseau ne rencontre pas de trous qui lui conviennent, il perfore alors assez facilement les arbres vermoulus, et choisit de préférence les pommiers.

L'intérieur du nid est composé d'herbes, de mousse, de crins, de plumes; il renferme de quatre à six œufs blancs et mouchetés de points rouges ou rougeâtres; quelques-uns en sont parsemés d'une manière uniforme; d'autres n'en présenterit que vers le gros bout, où ils forment une espèce de couronne; enfin, on en trouve qui au lieu de points offrent des taches assez larges. Quelques-uns de ces œufs sont à peu près blancs. Ils présentent encore bien des formes; ils sont ronds ou oblongs, mais presque toujours ventrus. Le grand diamètre varie de $0^{\mathrm{m}}, 01 \mathrm{~b}^{\mathrm{a}} 0^{\mathrm{m}} 019$, et le petit de $0^{\mathrm{m}}, 011 \mathrm{à}^{\mathrm{m}}, 014$. Ils peuvent facilement être confondus avec ceux de la grosse mésange charbonnière, quoique généralement ils soient plus gros et surtout plus oblongs. Ceux qui ont une couleur jaunâtre, la doivent à leur séjour sur la poussière humide des trous auxquels ils sont confiés, surtout lorsque la couche du nid est peu épaisse.

Pendant l'hiver, la sitelle court à terre, poursuit les insectes sous les feuilles, vit même de graines, et c'est lorsgu'elle recherche ce dernier genre de nourriture qu'elle se prend aux collets. J'ai reçu plusieurs fois, de la commune de Tiercé, des sitelles capturées avec des alouettes.

Quand ils se trouvent dans une contrée où les noisettes sont abondantes, ces oiseaux exercent de grands ravages. Ils saisissent, avec une dextérité remarquable, des noisettes et même des noix, les assujettissent fortement entre deux branches, et les brisent avec leur bec. Les Anglais ont voulu peindre par une expression carac- 
téristique cette habitude de la sitelle, en lui donnant le nom de hache-noix.

La sitelle qui se reproduit en Anjou porte le nom d'enropea, "européenne, " pour la distinguer des autres sitelles, telles que la sitelle soyeuse, etc., qui ne sont pas sédentaires en Europe, quoiqu'elles la visitent cependant quelquefois.

\section{QUATRIEIE FAMILLE.}

\section{Ténuirostres.}

La famille des ténuirostres est l'avant-dernière de l'ordre des passereaux. Elle ne comprend que trois espèces, bien différentes les unes des autres. Leur véritable trait-d'union est la forme du bec, qui a déterminé le nom de témirostres. Cette expression est composcée de tenuis, tenu , "faible, délié, " et rostrum, "bec;" elle indique que les oiseaux compris sous cette dénomination ont un bee faible, en comparaison de celui des espèces précédentes, et cette faiblesse dépend surtout de la longueur, qui est peu en rapport avec les autres dimensions.

\section{Prenier GeNie. - HUPPE.}

HUPPE ORDINAIRE. - UPUPA LPOPS.

La huppe ordinaire doit son nom aux vingt-six plumes rousses bordées de noir et disposées sur deux rangs, qui forment le principal ornement de sa tête, ornement qu'elle relève et abaisse ì volonte, selon les impressions de joie, de crainte ou d'amour qu'elle ressent. Comme les étourneaux, elle la replie quand elle vole, et sa 
course aérienne semble être une série de festons qui s'enchaînent pour former une guirlande qu'elle décrit en battant des ailes. A l'époque de la nidification, elle étale les plumes de sa huppe en ramenant son bec sur sa poitrine, et semble en quelque sorte se servir de sa tête comme d'un encensoir; c'est alors que cet oiseau fait entendre un roucoulement qui se rapproche de celui du ramier.

La huppe se nourrit de sauterelles, d'insectes, de limaçons, de fourmis, etc. En Egypte, où elle est trèsnombreuse, elle apparaît lorsque les eaux du Nil se retirent et présentent un limon facile à fouiller dans tous les sens. Aussi son arrivée est-elle saluée avec joie; car elle avertit les habitants que l'époque des semences est proche. C'est pour cette raison que la huppe joue un très-grand rôle dans les hiéroglyphes.

Cet oiseau rend un véritable service à l'agriculture en détruisant un très-grand nombre de limaçons, de chenilles, de courtilières et surtout de fourmis. Il visite les fourmilières, y enfonce son long bec, élargit ainsi l'ouverture qui donne accès dans ces petites républiques, et y exerce de véritables ravages; c'est ce qui explique pourquoi sa chair est rejetée comme étant trop parfumée du goût de fourmi. La huppe est douée d'un caractère très-timide et très-solitaire, et on l'aperçoit souvent, dans les prairies, cherchant, sous les excréments des animaux, les coléoptères qui s'y sont réfugiés. Les anciens avaient attaché à la huppe des idées bien superstitieuses : ils prétendaient qu'elle connaissait les herbes propres à rendre la vue aux aveugles, que le cœur et le foie de cet oiseau guérissaient de la migraine, et que ses troupes plus ou moins considérables indiquaient, d'une manière précise, l'abondance ou la disette des vendanges.

Upupa a la même signification que le mot huppe. Quant 


\section{$-448-$}

it la dénomination ÉPops, elle est formíe de Ér et ops, " vois; " or, Er, en composition, est augmentatif : frops signifie done " cri fort, très-accentué, " dénomimination trìs-vraie et qui indique un caractère particulier it la huppe, celui de faire entendre un cri sifflé et plaintif, quand elle s'envole.

Cet oiseau se reproduit en Anjou; il choisit, pour établir son nid, les endroits humides plantés d'arbres; il le confie aux trous des vieilles souches ou des murailles qu'il remplit de mousse et d'herbes sèches unies d'une manière grossière : souvent il profite du travail de ses frédécesseurs; car la diligence n'est pas son habitude favorite. La femelle clépose sur cette couche peu gracieuse de quatre à six œufs d'un blane grisàtre qui revêtent quelquefois une teinte plus foncée, par leur contact aree la poussiere humide du creux de l'arbre. Leur grand diamètre varie de $0^{\mathrm{m}}, 023$ à $0^{\mathrm{m}}, 02: 3$, et le petit de $0^{\mathrm{m}}, 01 \%$ ì $0^{\mathrm{m}}, 017$. Quand on approche du nid, la femelle siffle de manière à effrayer les naturalistes peu expérimentés; de plus, la demcure de la jeune famille répand une odeur tellement nauséabonde, que l'opinion la plus commune admet que la couche du nid est composie de fiente de chien. Ciette croyance est entièrement erronée; l'udeur infecte que l'on sent provient des excréments des petits, mêlés aux débris des insectes qui ont servi à leur nourriture, et que le père et lit mère laissent séjourner et s'accumuler arec une négligence dont les autres oiseaux ne sont pas coupables. C'est pour peindre d'une manière très-expressive cette paresse et cette saleté de la huppe, que les gens de la campagne désignent cet oiseau sous le nom de coq puant.

La huppe vivrait facilement en captivité; mais la nourriture qui lui convient ne peut être recueillie qu'avec beaucoup de peine : dès lors cette disposition à la servitude devient inutile; elle est du reste ronforme aux de:- 
seins de la Providence qui ne peuvent être accomplis par la huppe que si elle est en liberté.

La huppe est d'un caractère très-craintif et même très-lâche; elle fuit, en manifestant toutes les angoisses d'une crainte excessive, à la vue du plus petit oiseau de proie.

\section{DEUXIÙNE GENHE. - GRHAPERAU.}

GRIMPEREAIT D'EUROPE. - CERTHIA FAMILIARIS.

L'oiseau dont je vais décrire les mœurs porte un nom latin qui a exercé longtemps ma patience, et ce n'est qu'après des recherches nombreuses et poursuivies pendant bien des années, que j'ai eu la consolation d'en découvrir l'étymologie.

Le grimpereau est d'un plumage gris-sombre. Douí d'une excessive agilité, il parcourt les arbres dans tous les sens, avec une infatigable persévérance; il décrit une série de spirales autour des branches et des trones; il sonde toutes les fissures, fouille toutes les écorces et les mousses pour se nourrir des larves, des araignées et de tous les insectes qui s'y sont réfugiés. Il commence ordinairement à grimper par le pied des arbres, comme les pics; mais il s'éloigne des habitudes de ces derniers, en ce qu'il redescend de l'extrémité jusqu'ì terre en décrivant une série de lignes courbes, et en se laissant tomber du sommet de l'arbre jusqu'au sol pour remonter plusieurs fois de suite. Cette habitude justifie son nom vulgaire, grimpereau, qui dérive du grec curmprTEÏN, signifiant " monter en s'approchant, 》 expression très-caractéristique. D'après M. Littré, on trouve dans plusieurs auteurs griper ou gripper pour grimper, et grimper pour gripper; ce savant pense donc que la racine de gripper ou griper et dès lor's de grimper serait grippen, mot hollandais qui, ainsi que l'allemand yreifen, 
signifie «saisir. " Maintenant encore, dans le Berry, frimper est employi pour "saisir avec force, " et offre le même sens que griffer, "prendre avec les griffes. " Cette étymologic est d'autant plus naturelle, que les oiseaux s'iccrochent pour monter, pour grimper. Le mot grimpereau s'écrivait autrefois grimpenhaut, expression très-juste; car, en donnant à grimper le sens de " saisir, ") cet oiseau ćtait ainsi nommé parce qu'il " saisissait sa proie en haut; " dès lor's, il fallait qu'il montut, et, selon le sens ordinaire, qu'il grimpât.

Ainsi que les pies, il se nourrit, a terre, de fourmis; comme eux aussi, il passe la nuit dans des trous d'arbres et, plus qu'eux encore, il pousse presque sans cesse, dans ses investigations, un petit cri saccadé et perçant qui s'entend de très-loin. Est-ce un cri de satisfaction, ou un moyen d'effrayer les insectes et de les faire sortir de leur repaire? est-ce le soupir du travailleur condamné à un labeur pénible, comme la plainte qui s'échappe de la poitrine des foulons? Je ne puis résoudre la question; mais je constate les faits. Cies quelques traits de ressemblance arec les pies ont diterminé Aristote à donner, mais sans raison, au grimpereau, un nom qui l'identifiait avec les pies et semblait le rendre participant de tous les méfaits si injustement reprochés à ces proscrits. Liadjectif tenuirostre, applique de nos jours an grimpereau, suffirait pour le taire absoudre de tous les griefs imagninaires qui lui ont été reprochés. Vuici le passage d'Aristote, d'après la traduction latine de Théodore Gaza, faite all xти siècle : "Est aricula quirdam, quir vocatur "certhins; audax hee est moribus et arbores accolit ef " cossis victitat, ingenio parato ad victum et voce clarà "priedita. " (Firmin Didot, śdit. in-4", vol. 1II, p. 134.) - " Il existe un petit viseau appelé certhius; d'un " caractère entreprenant, il visite les arbres, se murrit. "de wr's qui se reproduisent snus les écorces; plein 
"d'invention pour se procurer la nourriture, il est doné "d'une voix perçante. " Le mot certliius que l'on a transformé en certhia, féminin, dérive du grec кевтніоs. Dans la magnifique édition du nouveau dictionnaire grec publié par M. Firmin Didot, au mot keltwios, on lit ces paroles: "Certhius, avicula parva de quâ Aristote..... -(IIist. des animaux, liv. IX, ch. xvir.) - rerthios estle petit oiseau dont parle Aristote dans le livre neuvième de sun IIistoire des animaux. "Malheureusement aucun glossaire latin ne renferme la dénomination certhia, conservée cependant dans tous les ourrages d'ornithologie; de plus, nul dictionnaire grec n'indique la racine du mot grec кеnтноos. La difficulté était grande; mais Adolphe Pietet est venu à mon aide, et, dans son ouvrage des Aryas primitifs, il donne comme racine au mot KERTHuos, "désignant, dit-il, une espèce de pic, " le verbe кË̈ro, signifiant " couper, » et indiquant que, si кеятноo est le véritable mot employé par Aristote pour désigner le grimpereau, cet auteur a voulu, mais sans motif, l'assimiler, sous ce rapport, à la véritable famille des pies. Aussi j'admets très-rolontier's, avec Robert Constantin, cité par Aldrovande, que le copiste d'Aristote s'est trompé, et qu'il a écrit кеRтнios au lieu de kerdos, signifiant " ruse, finesse, astuce, " mot bien plus en rapport que l'expression кектніо avec les habitudes qu'Aristote attribue au grimpereau. Cet oiseau est trèsdéfiant; il est très-difficile de l'approcher et surtout de l'ajuster. Dès qu'il aperçoit le chasseur, il se crainponne du côté de l'arbre opposé à son ennemi, et, si celui - ci s'opiniâtre à le poursuivre, le grimpereau le fatignera par sa stratégie et par une série interminable de marches qui se déroulent en spirales. Le grimpereau s'appuie, comme les pies, sur sa queue qui lui sert de miséricorde et lui permet de se reposer et de continuer plus facilement le rude labeur auquel il est condamné. 
On le désigne sous le nom de yrimperenu d' Europe pour le distinguer des autres espèces exotiques. Cependant cette dénomination n'est peut-être pas entièrement exacte, si l'on admet, avec M. Bailly et avec plusieurs auteurs, que le grimpereau, étudié par mon vénérable ami, l'abbé Caire, est non-seulement une varirité ou une race, mais encore une véritable espèce. Le grimpereau désigné par les naturalistes sous le nom de certhin Costa, parce qu'il a été dédié au marquis Ciusta de lieauregard dont j'ai visité avee beaucoup d'intérêt la magnifique collection ornithologique, près de Chambéry, a été décrit par M. Gerbe, dans la Revue zoologique de France (avril 1832, p. 162).

Si l'opinion de ces savants naturalistes était admise, le grimpereau d'Europe ne serait plus le seul, et il faudrait modifier cette dénomination. Quant à l'épithète fumiliuris, "familier, de la famille, " elle indique que cet viseau, quoique très défiant, est moins saurage, moins ennemi de la société de l'homme, que ses congénères, et même que le grimpereau Custa, lequel ne se tient que dans les forèts de certaines contries couvertes de montagnes inaccessibles.

Le grimpereau se reproduit en Anjou : il réunit dans un trou d'arbre et quelquefois entre le tronc et l'écorce, it une hauteur peu considérable, de la mousse, des plumes, des herbes, du crin, du coton des arbres, et sur cette couche, qui prend les formes et les dimensions des carités auxquelles elle est confiée, la femelle pond de cinq i sept wuls. La couleur de la cuquille est d'un blanc pâle parseme de taches d'un rouge de brique; quelquefois ees taches se réunissent de manière à courrir presque entièrement l'wuf ou ì former une calotte assez prononcée. Le grand diamètre varie de $0^{\mathrm{m}}, 013$ it $0^{\mathrm{m}}, 01 . \mathrm{s}$, et le petit de $0^{\mathrm{m}}, 010$ à $0^{\mathrm{m}}, 012$.

Un certain nombre de naturalistes admettent que le 
grimpereau familier fait plusieurs pontes chaque année; je n'ai pu constater l'exactitude de cette opinion.

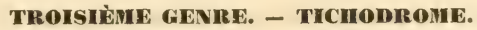

TICHODROME ÉCHELETTE. - TICIODROMA PIOENICOPTERA.

Le tableau des mœurs de ce passereau justifiera les noms sous lesquels il est désigné; car peu d'oiseaux ont été aussi bien caractérisés par leurs dénominations. Le lichodrome, appelé avec raison le grimpereau des montagnes, habite ordinairement la cime des monts escarpés. Là, il parcourt, avec une grande agilité et avec une énergie persévérante, toutes les fissures et les excavations les plus profondes des rochers pour y saisir les insectes de toute espèce qui s'y sont cachés. Dans ees investigations, il commence à gravir le théâtre de ses recherches par le pied des montagnes; il ne redescend pas comme plusieurs grimpeurs ; mais arrivé au sommet, il se laisse tomber pour retomber ensuite, et renouveler cette manœuvre plusieurs fois de suite. Jamais il ne s'appuie sur sa queue pour' se reposer; mais il grimpe, en imprimant à son corps une série de petits bonds; il semble sauter et monter à l'échelle : de là, le nom de tichodrome échelette, formé de teïchos, " mur, ") et promeus, " coureur, - oiseau qui visite les murs, et qui accomplit sa mission en paraissant monter à l'échelle. Cette dénomination est d'autant plus exacte, que le tichodrome ne visite pas simplement les montagnes, mais se livre encore ì des voyages que la rigueur de l'hiver lui rend nécessaires. Quand la neige couvre la terre de son linceul blanc, et que les insectes ont disparu sous l'action excessive du froid, le tichodrome se trouve privé de sa nourriture ordinaire et se voit condamné à des excursions luintaines, pendant lesquelles il visite toutes les façades 


\section{$-454-$}

des grands el surtout des vieux édifices; quelquefois même il pénètre dans l'intérieur des étahlissements. f'est ainsi que l'un de ces uiseaux est entrí, il y a quelques années, dans la salle du musée d'Angers et s'est glissi derrière les tableaux et les vitrines, pour y eaptures les araignées et les autres insectes, que l'œil des plus rigilants gardiens n'avait pu decouvrir pour les faire disparaître.

Assez souvent on peut, pendant l'hiver, armirer les riches couleurs dont son plumage est revêtu, lorsqu'il louille toutes les ruines de la magnifique église Toussaint. Soit pour se soutenir plus facilement en l'air, soit pour effrayer les insectes et les faire sortir de leur refuge, le tichodrome imite le papillon et agite avec une grande vivacité ses ailes, comme un sphinx : e'est alors qu'il montre le rouge si brillant qui courre les plumes de son dos, et qui ne devient visible que dans cette circonstance. C'est ce qui lui a valu le nom de phamicoptera, de phö̈xiкs, phö̈xiкos, "rouge de pourpre, " et rtïn, " aile : oiseau aux ailes rouges. ) Les montagnards l'appellent, en leur langage expressif, le papillon des montagnes. Dans les temps de froid et de disette, le tichodrome se prend a l'hameçon; il suffit, pour le capturer, de laisser voltiger le long des murailles une ligne appâtée avec un insecte.

Le tichodrome se reproduit dans les montagnes presque inaccessibles; aussi ne peut-on que très-difficilement se procurer le nid et les œufs de cet oiseau. Il ríunit, dans les fentes des rochers escarpis, de la mousse, du crin, des filaments de plantes, et en compose une coupe sulide ayant ordinairement $0^{\mathrm{m}}, 1 \mathrm{i}$ de largeur et $0^{\mathrm{m}}, 014$ de profondeur. Les borrs du nid présentent une forme arrondie de $0^{\mathrm{m}}, 0: 3$ de diametre. C.e nid renferme quatre ou cing (eufs un peu piriformes, oblongs; leur coquille, d'un blane tres-pur, est excessivement mince. Queldue- 
fois ils sont parsemés de petits points d'un rouge pâle, peu nombreux et peu apparents. Le grand diamètre de ces œulfs varie de $0^{\mathrm{m}}, 017$ à $0^{\mathrm{m}}, 019$, et le petit de $0^{\mathrm{m}}, 012$ à $0^{\mathrm{m}}, 014$.

Le tichodrome élève ses petits avec une grande sollicitude; mais lorsque ceux-ci peuvent se suffire à euxmêmes, ils se séparent de leurs parents. Est-ce à la difficulté de trouver la nourriture qui leur est nécessaire, et aux obligations de la vie nomade à laquelle ils sont condamnés, ou bien est-ce à l'influence de leur caractère, que l'on doit attribuer l'isolement dans lequel vivent les tichodromes? Je ne puis résoudre cette question, tout en pensant que le genre de vie du papillon des montagnes doit s'opposer à ce qu'il puisse se réunir en bandes; car en tout temps, le tichodrome vit et voyage solitaire.

\section{CINQUIEME FAMILLE.}

\section{Syndactyles.}

L'ordre des passereaux se termine par la famille des syndactyles, qui comprend en Anjou une seule espèce, celle du Martin-pêcheur. L'expression syndactyle peint très-exactement l'oiseau auquel elle s'applique. Syndactyle dérive de deux mots grecs, sin, "avec, " et DAKTrLos, " doigt, " et signifie "doigts unis entre eux. "

Les passereaux qui forment cette famille ont quatre doigts soudés deux à deux, deux en arant et deux en arrière, caractère qui les assimile aux pics, dont ils se rapprochent par leur queue courte, par leur tête grosse, et par leur bec très-fort. Cette disposition des doigts permet au martin-pêcheur de se percher très-facilement, et lui vient puissamment en aide pour accomplir le rôle auquel l'a assujetti la Providence. 


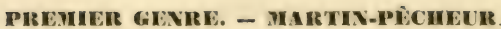

MARTIN-PECHEUR ALCYON. - ALCEDO ISPIDA.

Je n'entrerai dans aucun dítail, en ce qui concerne le mot martin. Il a déjà ité expliqué, plusieurs fois, assez longuement, pour qu'il ne soit plus nécessaire de s'y arrêter. Il suffit de parcourir les fables de notre inimitable Lafontaine pour constater que très-souvent martin est synonyme de maitre; dès lors, martin-prichentr signifie maître-pécheur, " oiseau qui excelle ̀̀ saisir le poisson. " Cette dénomination convient bien au passereau qu'elle désigne. Le martin-pècheur hal,ite le bord des rivières, des étangs, des marais, et surtout les cours d'cau ombragés par des osiers ou par de vieux arbres penchés sur les flots. Là, il se puse à l'ombre d'une branche touffue, sur quelque morceau de bois diémudí qui lui sert d'observatoire. L'œil fixé sur les eaux, il attend, avec une extrême patience, que des poissons. passent au-dessous de lui, et, dès qu il les aperçoit, il se précipite sur sa proie, qu'il capture arec une grande adresse et qu'il mange ordinairement sur quelque pierre du rivage. Sa conformation le sert merveillensement jour cette pêche. La longueur de son bec, les larges dimensions de sa tête, la petitesse de son corpis et de sa queue, la forme arrondie de ses ailes, tout concourt ì assurer au martin-pêcheur une grande facilité pour plonger. Cependant, pour accroitre encore cette puissance, il fait un bond en s'élevant un peu dans l'air, afin d'imprimer ì son corps une plus forte impulsion, imitant en cela l'action de nos jeunes cilèves lorsqu'ils s'esereent, selon leur langage expressif, is piquer une tite dans l'eau.

Quand la persivérance du martin-pêcheur n’est pas 
couronnée de succès, et que les poissons ne circulent pas au-dessous de son observatoire, cet oiseau fait entendre un cri plaintif, puis il reprend son vol en rasant l'eau, sur laquelle il semble tracer un sillon. S'il aperçoit alors quelque poisson, il s'arrête, reste suspendu dans l'air' à la même place, en agitant les ailes, comme le faucon qui semble vouloir étourdir sa victime; puis il plonge tout à coup sur la proie qu'il a choisie, et il est très-rare qu'elle échappe à son bec rapide. Quelquefois, sans plonger, il répète, de distance en distance, ce moment d'arrêt dans l'air et ce frémissement d'ailes. Cette évolution est alor's, pour lui, un simple moyen de se livrer, au-dessus de l'eau, à un véritable système d'observations. Quand cette position paraît le fatiguer, il se laisse tomber perpendiculairement jusqu'à la surface de l'eau, pour continuer ensuite son vol parallèlement à la rivière.

Ces détails suffisent pour prouver que ce passereau mérite le nom qui lui a été donné. Il me reste à expliquer les motifs qui l'ont fait appeler alcyon.

Ce mot est composé de als, "mer, " et kxôn, participe de кYEïn, " enfanter, ) et signifie alor's " oiseau qui se reproduit sur la mer. ) Cette dénomination nous vient de la mythologie. Alcyone, fille d'Eole, attristée de l'absence prolongée de son mari, qui était allé consulter l'oracle de Claros, se promenait triste et solitaire sur les bords de l'océan, espérant apercevoir, dans le lointain, le navire qui portait celui qu'elle aimait tendrement. Mais les flots irrités n'apportèrent à ses pieds que le cadavre du malheureux Céix, victime d'un naufrage. Alcyone se précipita sur ce corps inanimé, le couvrit de baisers, cherchant, mais bien inutilement, à lui rendre la chaleur et la vie. Les dieux, témoins de ces regrets si vifs et étonnés des sentiments de tendre affection qui unissaient l'homme et la femme, sentiments très-rares, ì ce qu'il paraît, même dans cet âge d'or, ne voulurent. 
pas séparer Alevone de son cher Céix : ils les changèrent tous deux en oiseaux qui portent le nom d'alcyons. Ils firent plus. Afin d'éterniser le souvenir de la paix et du calme qui rignait dans le ménage des deux époux, et de donner aux humains une leçon, hélas! trop souvent inutile, ils décidèrent que les flots de la mer resteraient calmes pendant quatorze jours, terme le plus long d'un calme parfait, même avec le secrurs des dieux! Cette période commençait sept jours avant le solstice d'hiver, et se prolongeait sept jours après. Le fait avait paru assez rare et assez extraordinaire pour que, pendant les jours alcyoniens, les procès fussent suspendus. C'est à cette éporque qque les aleyons confiaient leurs nids à la mer, et qu'Éole, dieu des rents et père d'Alerone, veillait ì ce qu'aucun souffle ne vînt mêtme rider la surface de l'onde. Plutarque, qui était parfois doué d'une excessive bonhomie, affirme avoir été témoin du calme de la mer et du travail des alcyons. Selon lui, ces oiseaux composaient à terre une espèce de radeau très-bien construit, sur lequel reposait un nid hermétiquement fermé, un peu comme une chaloupe pontée; puis, quand le travail était terminé, le père et la mère lançaient cet esquif sur la mer, pour l'y abandonner ou l'en retirer, selon qu'ils reconnaissaient qu'il pouvait ou non affronter sans danger' le contact de l'onde. Dans son admiration pour le labeur des aleyons, le bon Plutarque a oublié de nous dire de quel còte se trouvait l'ouverture, que les deux ćpoux avaient dû ménager, pour que la femelle pùt entrer dans ce petit chef-d'œurre de patience, sans cependant donner passage aux flots de la mer'. Enfin, comme les jour:

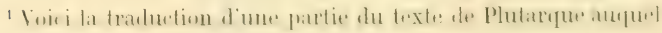
je fais allusion.

" Mais nous appelons l'abeille sage, et la célébrons comme

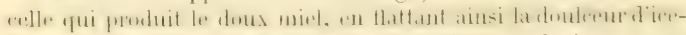
luy miel qui nous agrée et nous chatouille sur la langue, et 
alcyoniens ne dépassaient pas une quinzaine, et qu'après revenaient les tempêtes et les naufrages qui en étaient souvent la suite, il fallait que l'harmonie régnât, nonseulement dans chaque ménage, mais encore entre tous les ménages. Tous les nids devaient être prêts le même jour, et toutes les dames alcyones disposées à pondre aussi le même jour et le même nombre d'œufs.

Que les temps sont changés! Il est très-probable, pour continuer la fiction païenne, que c'est la difficulté de maintenir dans un état persévérant cette magnifique harmonie qui a fatigué la patience de Jupiter (je ne parle bien entendu que relativement aux alcyons); car de nos jours, les choses se passent d'une manière beaucoup moins poétique. Les alcyons choisissent un trou de rat d'eau, dont l'entrée est dissimulée par les racines ou nar les branches d'un vieux saule; si l'orifice est trop grand, ils le diminuent en le fermant en partie avec de

rependant nous laissons derriere la sapience et l'artifice des autres animaux tant en l'enfantement de leurs petits qu'en la nourriture d'iceulx. Comme tout premierement l'oiseau de mer que l'on nomme Alcrone, larquelle se sentant pleine, compose son nid, amassunt les arestes du poisson que l'on appelle inguille de mer, ef les entrelassant l'une parmy l'autre et tissant en long les unes avec les autres, en forme ronde et longue comme est un verueu de pescheur, et l'aiant bien diligemment lié et fortitie par lit liaison et fermeté de ces arestes, elle le va exposer au battement du flot de la mer, afin cqu'estant hattu tant hellement et pressé, la tissure de la superficie en soit plus dure et plus solide, comme il le fait, car il devient si ferme, que l'on ne sauroit fendre avec fer ni avec pierre, et qui est encore plus esmerveillable, l'ouverture et embouchure du dit nid est si proportionneement romposée à la mesure du corps de l'Alcyone que nul autre, ny plus grand, n'y plus petit oiseau n'y peult entrer, non pas la mer même, comme l'on dit, ni la moindre chose du monde. ")

(Chapitre de l'Amour et charité naturelle des péres et méres encers leurs enfants. - Traduction d'Amyot. In-fol., pag. 101. - Paris, Michel de Vascosan, 1572.) 
la terre délaycée. Ensuite ils travaillent à rendre plus commode le fond de cette retraite, qui doit servir de demeure ì la mère et ì ses petits. Par les soins du mâle et de la femelle, l'extrémité de ce réduit présente un véritable carrefour, ayant quelquefois plusieurs issues, qui viennent toutes aboutir à l'entrée principale. C'est dans ce carrefour que la femelle dépose de einq à sept œufs ronds et d'un blanc lustré, ressemblant à de petites billes d'ivoire, et dont le diamètre varie de $0^{\mathrm{m}}, 018$ i $0^{\mathrm{m}}, 022$. et le petit de $0^{\mathrm{m}}, 016$ à $0^{\mathrm{m}}, 018$. Ordinairement, ils reposent sur une couche de petites arêtes de poissons entièrement broyées, afin qu'elles soient plus molles. Des naturalistes ont prétendu que les cufs étaient déposés sur la terre nue, et que les arêtes provenaient des poissons que les martins-pêcheurs apportaient à leurs petits. Cette opinion peut être mise en doute; car ayant trouvé moi-même des arêtes dès le premier jour de la ponte, il me semble qu'elles ne peuvent être les débris de la nourriture des petits qui n'existaient pas encore. Peut-être pourrait-on cependant justifier l'opinion de ces auteurs, en admettant que ces débris provenaient de la nourriture (qu: le mâle apporte à la femelle. Dans les pays où les écrevisses sont abondantes, le martin-pêcheur s'établit. souvent, pout' se reproduire, dans les excarations que ces crustacés ont creusées.

Quelques savants ont donni au mot alcyon une étymologie différente de celle que je viens de développer. Ils font dériver alcyon de ALS, "mer, " et ksòx, "chien," et ce mot signifierait littéralement " chien de mer. " Dans ce sens, il ne devrait pas s'appliquer aumartin-pêcheur, mais au goüland, et il ne pourrait être pris que par comfaraison. Quand les ténèbres de la nuit commencent it s'étendre sur l'océan et que l’orage se prípare, les goëlands font entendre un cri sinistre, precurseur de la temprite, assez semblable a l'aloriement des chiens pen- 
dant la nuit, quand surtout ils sont sous l'empire de la crainte. Alcyon pourrait done être ainsi traduit : " oiseau dont le cri, sur la mer, ressemble à l'aboiement d'un chien. " Ce qui pourrait fortifier cette interprétation, c'est que le mot alcyon désigne moins le martinpêcheur que les mouettes et les hirondelles de mer, et même, d'après Buffon, le pétrel, oiseau de tempête. Le chien étant l'emblème de la fidélité, l'alcyon lui auraitil été aussi comparé à ce point de vue?

Ma tâche s'avance, et cependant il me reste à expliquer alcedo et ispida, noms scientifiques donnés au martin-pêcheur. D'après Court de Gébelin, alcedo aurait la même racine que le mot alcyon, et serait formé de als, ( mer, » et к xnÉï " enfanter.» Les anciens disaient indifféremment ALK Yôn et ALcydôn. De la première de ces deux expressions on a formé évidemment alcyon, et de la seconde, alcedo. Si l'on n'admet pas l'autorité de l'écrivain cité plus haut, peut-être pourrait-on accepter pour étymologie aLs "mer, " et krvos, "gloire, " et alcedo signifierait : " oiseau qui est la gloire de la mer, " sinon exclusivement par son plumage beaucoup plus brillant que celui de tous ceux qui visitent les rivages de l'océan, du moins par tous les récits fabuleux dont il a été l'objet. De plus des idées superstitieuses s'attachaient, dans tous les pays, non-seulement au martin-pêcheur vivant, mais même à sa dépouille. Son corps desséché, suspendu à un fil par le bec, servait, selon l'opinion populaire, de boussole; la mandibule supérieure du bec se tournait toujours vers l'étoile polaire; il tenait aussilieu de baromètre ou plutôt d'hygromètre, en indiquant les variations de l'atmosphère. Enfin, placé dans les meubles, sa présence éloignait les teignes et était comme un puissant vétyver. Nalgréles prog rès des lumières, ces idées fausses, du moins dans leur généralité, sont encore répandues dans les pays sauvages comme dans les régions civilisées. 
Peut-être aussi pourrait-on faire venir alcodo de as.s, " mer, " et de kithos, " soin, mariage, ") d'vù kîn:ï̀ , "prendre soin, se marier. " Alcedn signifierait alors oiseau "qui s'inquicte de l'état de la mer, qui veille sur l" mer. " ou bien oiseau "qui confie à la mer le fruit de son union. )

J'arrive an mot ispida, que l'on doit écrire hispida. Dans son acception ordinaire, hérissé, il peint exactement une des habitudes du martin-pêcheur, quand cet oiseau est en sentinelle pour attendre les poissons : il alère, à certains moments, les pltumes de sa tête, qui représentent alor's une huppe, dont les differentes parties ne seraient pas bien unies entre elles. Je pense que c'est un motif d'impatience qui détermine ce mouvement particulier des plumes. Le martin-pêcheur doit éprouver alor's le même sentiment que ressent un pêcheur passionné, quand un vent violent vient troubler la surface de l'eau, un bateau oн quelque voyageur occasionner du bruit et le priver ainsi de la proie, dont il cherchait à deriner l'approche et calculait déjà la capture plus ou moins probable. P'uis, c'est un ventre affamé qui n'admet pas, sans une vive expression de mícontentement, le jeùne prolongé auquel on le condamne malgré lui. Du reste, cette habitude est encore bien plus caractérisíe che\% quelques espèces de martins-pêcheurs; car plusieurs ont été désignés par l'épithète cristatn, "huppée."

Mais si le martin-pêcheur mérite le nom ispuida, guand il craint de voir s'échapper l'ubjet de son attente, il le justifie encore bien davantage quand le chasseur le saisit avec la main, après l'aroir blessé. Dans cette circonstance, toutes les plumes de la tête du martin-picheur sont véritablement "hérissies, " et il exprime de la sorte, par le seul moyen que lui laisse son ennemi, l’indignation que lui cause la perte de sa liberté.

Comme tous ceux qui se livrent avec persivérance à la 
pêche et à la chasse (il s'agit toujour's des oiseaux), le martin-pêcheur est excessivement jaloux. Pour lui, comme pour les grands et pour les petits seigneurs de nos jours, il y a une pêche sévèrement réservée. Les limites de sa champagne s'éloignent et se rapprochent selon les circonstances. Aucun ami, aucun parent même n'est admis au doux plaisir de capturer du poisson dans l'arrondissement que s'est choisi un couple de martins-pêcheurs. Si un imprudent s'aventure à dépasser les limites réglementaires, le mâle ou la femelle qui l'aperçoit dresse ses plumes sur sa tête, un peu comme un Péruvien, se lance sur l'audacieux violateur du territoire gardé, et le poursuit de son vol et de ses cris, jusqu'à ce qu'il ait gagné une autre champagne, dans laquelle le même accueil lui est réservé. Plusieurs fois, en royant cette poursuite et en entendant ces cris, j'étais porté à l'attribuer à quelque trouble dans le ménage; mais il n'en itait rien, car les alcyons tiennent à faire exception à la règle assez générale, si l'on en croit l'histoire de tous les temps. Quand l'un des deux époux se trouve impuissant à faire respecter l'arrondissement de pêeche, l'autre lui vient en aide, et même un couple en appelle un autre. C'est ce qui explique le vol et les cris, de trois et même de quatre martins-pêcheurs, rasant ensemble la surface de l'onde.

Cette jalouse vigilance de l'alcyon augmente encore quand il élève ses petits, auxquels il se plaît à procurer une nourriture abondante et choisie. Il leur apprend ì pêcher, à plonger, à dissimuler leur présence sous les branches touffues et sous les racines épaisses; il ne les abandonne que lorsqu'une longue expérience l'a convaincu qu'ils peuvent se suffire à eux-mêmes.

Pendant un temps assez considérable, chaque soir, les parents ramènent leur jeune famille coucher dans le trou qui les a vus naître, afin de pouvoir veiller sur eux avec plus de facilité. 
Maintenant que les martins-pêcheur's ne sont plus soumis it la règle des jours alcyoniens, ils se livrent, quand les petits se sont éloignés d'eux, aux soins d'une nouvelle couvée, qu'ils entoureront, comme la première, d'une patiente et attentive sollicitude.

J'ai pu certifier bien des fois l'exactitude des détails que je viens de donner sur les mœurs des martins-pêcheurs, lorsque je parcourais, avec mes jeunes amis, Daniel Métivier, Eugène Lelong, Guillaume Bodinier et Louis Nanceau, toutes les sinuosités du cours du Loir et de celtui de la Sarthe.

\section{QUATRIÈUE ORDRE. - PASSERIGALLES.}

Nous avons fini, non sans un rude labeur, de parcourir l'ordre des passereaux, arec ses nombreuses fitmilles si multipliées et ses genres si différents de maurs, de plumage et de proportions. Nous abordons le quatrieme ordre, qui ne comprend, pour l'Anjou, qu'une seule famille et quatre espèces. Cet ordre est désigni par M. Millet, dans sa Faume de Muine-et-Loire, sous le nom de passerigalles, expression adoptée par un très-petit nombre de naturalistes, et qui me semble cependant assez exacte. Elle signifie oiseaux "qui participent des mours des passereaux et des gallinacés" (passer-yallus); dénomination d'autant plus juste, qu'elle s'applique ì des espèces que les ornithologistes ont placées, tour it tour, dans l'ordre des passereaux ou dans celui des gallinacés. Ces savants nous semblent avoir raison, si, avec eux, nous considérons ces oiseaux sous deux points de 
vue différents. Les passerigalles se rapprochent des passereaux par leur's migrations continuelles, et, sous ce rapport, ils peuvent être considérés comme des passereaux par excellence. D'un autre côté, leurs mœurs, leur genre de nourriture, la facilité avec laquelle ils se prêten à la domesticité, les font classer parmi les gallinacés. Le mot passerigalles est donc heureux, puisqu'il est un trait d'union qui relie les deux opinions.

Peut-être serait-ce ici le moment d'indiquer, en quelques lignes, quelle est l'étymologie présumée du mot gallus, et d'insinuer, sans s'y arrêter toutefois, un nouveau rapprochement entre l'alouette et le coq. C'elui-ci a été regardé comme la souche primitive, le vrai type, le souverain des oiseaux de basse-cour; c'est lui qui leur a donné son nom. Or', l'expression gullus, d'où l'on a formé le mot gallinucé, dérive, selon les érudits, du sanscrit gal, signifiant somum edere, canere, "produire un son," et, dès lor's, gallus est l'oiseau, non-seulement qui produit un son et qui chante, mais dont le son, le chant sont remarquables. C'est de la même racine que l'antique idiome de l'Armorique avait, selon toute probabilité, emprunté le substantif liel, signifiant "voix el. bruit. " En désignant le coq sous le nom de gullus, les anciens avaient évidemment été frappès, non pas de l'agrément de la voix de cet oiseau, mais de sa puissance et surtout de son chant matinal, qui etait un véritable service rendu aux habitants des campagnes. La voix du coq était le réveille-matin, toujours régulier, placé près de la chaumière du villageois par la main providentielle de Dieu. Il méritait done, à ce titre, de donner son nom à la nombreuse famille désignée sous l'appellation de gallinacés. 


\section{PREMIERE FAMILLE.}

\section{Colombins.}

Lexpression colombin est provengale : olle dérive très-probablement de l'italien colombinu, qui lui-même a đû avoir pror grimitif le latin columba, "colombe. " Quelle est mainternant la racine de columbre? Quelques itymologistes pensent que c'est korrmas, qui, en gree. ignifie "plongeur, " M. Littré dit que "columbu vien! de kotrunos, "plongeur, " par une confusion des riseaux plongeurs et des pigeons. " II me semble que la phrase du savant anteur eût dû être plus explicite, pour que lon pùt connaître sa viritable pensée. (Juni qü il en soit du sens de cette explication incomplete, jo vais rssayer, en faisant bien commattre les habitudes des eolombins, d'exposer comment je compurends l'expression kosmuns, employée pour drésigner les colombes.

Cette famille, qui ne renferme pour l'Anjou que quatre espoices, en contient, dans la classification gínérale, plusieurs centaines, qui varient de plumage et de proportions; quelques-unes atteignent les dimensions des foules, dautres ne sont pas plus grosses qu un muineau. Certaines espèces revêtent les plus brillantes couleurs. et toutes ont des formes gracieuses. En Amérique, of surtout dans les iles de la Sonde ef en Australie, les enlombins sont trè-multipliés; leurs bandes, d'apriss le récit véridique des naturalistes et des voyageurs, compusées de centaines de milliers l’individus, ubsencissenl le ciol quand elles acemmplissent des migrations devemues indispensables par la néessite de tromer, chatpue

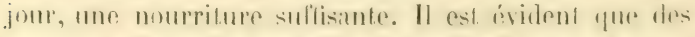

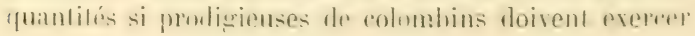


de véritables ravages dans les contrées où ils s'arrêtent, et absorber, en quelques jour's, les ressources des pays qu'ils visitent. Aussi sont-ils contraints de se livrer à des migrations incessantes. Cette habitude même a fait nommer une des colombes de l'Amérique, colombe voyageuse, columba migratoria. Quand ces troupes incalculables de colombins séjournent pendant quelque temps dans les forêts, bientòt, selon lc récit d'Audubon, plusieurs kilomètres carrés se couvrent d'une épaisse couche de guano. Ce fait, attesté par le savant naturaliste, expliquerait la formation de ces quantités considérables d'engrais que l'Amérique fournit à l'Europe.

Pour diminuer les ravages exercés par les colombins, les habitants de certaines contrées de l'Amérique et, en particulier, ceux de l'Ohio, du Kentucliy, etc., pénètrent, au moment de la nidification, vers le mois de mai, dans les immenses forêts où ces oiseaux se reproduisent; ils emportent dans leurs chariots une grande quantité de petits barils qu'ils remplissent de la graisse fondue do myriades de pigeonneaux saisis sur leurs nids, et c'est avec cette graisse qu'ils prépareront, pendant une année rntière, les aliments destinés à leurs familles. Dans le cours de ces excursions, qui durent deux ou trois semaines, les habitants se font accumpagner par de nombreux troupeaux de pores. Ceux-ci se nourrissent des restes des pigeons dont on a fait fondre li graisse. On estime ì plusieurs centaines de mille les nids qui sont capturés, charque année, sur les bords de l'Ohio. C'est dans les forêts vierges do ces contrées que l'on peut ítudier, d'une manière plus complète, les mœurs des colombins; e'cst là qu'ils s'abandonnent à tous lè jeux folâtres d'une gaieté primitive. C'est là encore qu'au sein de l'air, ils font tous les exercices auxquels se livrent les flus habiles plongeurs. C'es évolutions si gracienses, si variées, paraissent être dans la nature des colombins; 
Ieur vol rapide, qui ne le cède qu'ì colui du faucon et de l'hirondelle, seconde encore les dispositions de leur caractère. La faciliti de leur wol n'avait pas échappé au roi-prophète; aussi se plait-il à y faire allusion dans 1 . psaume LIV : "Quis debut milie pennas sicut columber? et volabo, et requiescrm. Qui est-ce qui me donnera des ailes semblables à celles de la colombe? et je prendrai mon vol, et je trouverai mon repos. " Ainsi, d'après Darid, les ailes de la colombe sont très-puissantes, puisqu'elles peuvent s'élever jusqu'ì Dieu. Quoique l’esclivage ait enlevé aux colombins captif's une partie de leur entrain naturel, nous retrouvons cependant, même parmi les espèces domestiques, quelques restes des habitudes des colombins à l'état d'indépendance. Aussi res habitudes ont-elles paru assez caractéristiques pour que l'on nommât quelques-unes de ces espèces : le culluteur, le tourneur, le plongeur, ete.

Le mot colombe, pris dans le sens de plongeur, aurait done une signification juste, dès lor's qu'il s'appliquerait au mouvement de l'oiseau dans l'air, et sous ce rappor', il n'y aurait aucune confusion.

Les anciens avaient su tirer un véritable profit de la rapidité du vol de la colombe, en dressant cet oiseau it remplir les fonctions de messager fidèle. Dans l'Orient. et surtout dans l'Arabie, la Syrie et l'Egypte, on se ser-vait autrefois des pigeons pour porter des billets dans des paýs éloignés. Les missives étaient placées sous les ailes des pigeons, et ceux-ci rapportaient la réponse à ccur qui les araient envoyés. De nos jours eneore, le Grand-Ilugol lait nourrir, en beaucoup d'endroits, des pigeous qui servent it porter les lettres d'une extrímiti de ses litats it l'autre, surtout quand une grande rapidifi: est nícessaire. Tavernier affirme que de son temps "le ronsul d'Alexandrette envoyait tous les jour's, par un pigeou, dres nourelles at .lep, en cinq heures, quoigne 
ces villes fussent éloignées de trois journées de cheval. " Les caravanes qui traversent l'Arabie se servent du ministère des pigeons, pour avertir de leur marche les chefs arabes avec lesquels elles sont en relations amicales, et pour réclamer leur concours et leur protection. Les pigeons s'acquittent avec une grande fidélité et une excessive promptitude des missions qui leur sont confiées; mais ils mettent encore une plus grande rapidité à revenir au lieu où ils ont été nourris, où ils ont laissé leurs nids, et, dès lors, à rapporter la réponse attendue. Pour avoir une idée assez précise du vol des pigeons dans les circonstances ordinaires, il suffit de savoir que des observateurs sérieux ont constaté que les ramiers employaient moins de dix minutes à traverser le détroit de Gibraltar, large de plus de vingt liilomètres, et qu'ils faisaient, dès lors, une lieue en deux minutes.

\section{PIEVIIER GEVIRE. - COLOMIBE.}

\section{PIGEON HAMIER. - COLUMBA PALUMBUS.}

Le mot colombe ayant été expliqué, il me reste à essayer d'indiquer l'étymologie des mots pigeon, ramier et palumbus, tâche assez difficile.

Quelques oiseaux sont appelés dégorgeur's, parce que, dans ces espèces, le père et la mère plongent leur bec dans celui de leurs petits pour y dégorger les graines qu'ils ont triturées et préparées avec un soin tout particulier. Les pigeons appartiennent à cette classe; mais ils ont un procédé spécial pour nourrir et élever leur's petits : ce sont ces derniers qui plongent leur bec dans celui de leurs parents, en l'agitant dans tous les sens; ils frappent ainsi contre les parois intérieures du bec du père ou de la mère, et déterminent une sorte d'irritation yui fait l'effet d'un vomitif: $\Lambda$ chaque fois que l'opération 
a lieu, la nourriture, broyie et réduite en une sorte de bouillie, sort de l'estomate des parents pour passer dens celui des petits. Ceus-ci lont alors entendre un cri tont. particulier, yu'ils accompasnent d'un mouvement demicirculaire de leur corps et d'un frémissement de leurs ailes.

D'ilprès les anciens auteurs, le pigeon devrait son num it cette action spréciale; il dériverait alor's de pipron, qui signifie "faire entendre un petit eri réitére. " On lit dans les anciens glossiares: "Punoxes, les pigeonnemux. ainsi appelés du verbe pipire, formé par imitation de lat vois des oiseaux qui n'ont encore que le duset. "

"Pipiones sumt pulli columbrrum, et est nomen formanum " proprio somo animalis. " (Iäathaens Silsaticus.)

Eit entin, "Priper, resonare, clamare, accipitrum est vel pullomen columburum, unde hic prito, "pullus columbarum. " (Jean de la Porte.)

J'admets d'autant plus volontiers l'autorití de ces auteur's, qu'il est civident qu'un très-grand nombre de nom: donnés ans oiseaux ont cité formís par onmuatopée. Dans les temps reculés, où il a fallu distinguer les oiseaus et tous les animaux par une expression qui les représentât d'une manière sensible, il fut très-naturel de choisir un nom que fuurnissait la nature, comme était, par exemple, l'imitation de leur voix et de leur chant.

L'épithète rumier a certainement pour principe le not ruméne, rumus, d'vù on a liormé raneus, rumurius.

Dans le moyen âge, rumier signifiait "ramean, leuillée, etc. »

Seguet tant la via per los ramiers

Que trabet à un fuc dos charbonniers.

Il suivit tant le chemin ì travers les fouré.

Quil trouva à un feu deux charbonniers.

(Gemand de Mossilan, fol. 47). 
Pigeon ramier a done le même sens que "pigeon qui se tient sur les branches, sur les rameaux. " Cette expression sert à mettre, entre lui et les pigeuns domestitjues, une différence essentielle. Ces dernier's ne se perchent pas; il en est de même de quelques autres espèces de colombes, même à l'état de liberté. De plus, l'épithète ramier peut indiquer que, non-seulement ce pigeon se perche wolontiers sur les branches, mais enicore y établit son nid, tandis que d'autres espèces domestiques ou sauvages se reproduisent dans des trous.

Le pigeon ramier eût pu être appelé rameur : voici pourquoi. Peu d'viseaux ont une vue aussi perçante que lui ; on ne peut l'approcher que par surprise; il aperȩoit ses ennemis à une distance très-considérable, et, pour ćloigner encore le danger, il a soin de placer des sentinelles avancíes tout autour des champs dans lesquels s'abat une troupe de ses congénères. Au premier indice de péril, les sentinelles donnent un coup d'aile très-viulent en prenant leur essor'; ce coup d'aile est répétr par chaque individu de la troupe, et le chasseur, au-dessus duquel volent ces oiseaux, entend un bruit assez semblable à celui que font les aubes d'un bateau ì vapeur quand il commence à se mettre en mouvement. Cie bruit est occasionné par ces battements d'ailes qui, déplaçant l'air brusquement, deviennent aussitôt un signal entendu au loin.

On attribue généralement au ramier un caractère trèssauvage; cette opinion n'est pas fondée. S'il s'éloigne du danger, el s'il l'ívite avec tant de promptitude, c'est que l'excessive portée de sa vue lui révèle de très-loin jusqu'ì l'apparence du péril. l'our combattre l'erreur commune, il suffit de lire les ouvrages des anciens qui constatent que le ramier s'était autrefois facilement plié à la domesticiti, et qu'il se reproduisait en captivité, et enfin de voir ce qui se patse, chaque jour, dans le jardin des Tui- 
leries, it laris. Bien des fois je m'y suis arrêté à l'ombre des marronniers sículaires, pour entempler un spectacto qui se reproduit tous les jours et aux mêmes heures. Sur la lisière ders gazons de la résidence impériale, quelques veufs ou quelques anciens célibataires civils et militaires qui ont besoin de chercher dans les itres de la nature une compensation à une famille qui leur lait défiut, se plaisent à jeter des miettes de pain aux nombreux ramiers qui peuplent le jardin des Tuileries. Ces oiseaux s'approchent, d'abord avec prudence, de leurs bienfaiteurs, puis, quand ils ont constatéque ce sont leurs rrais et vieux amis, ils s'enhardissent, voltigent autour d'eux, viennent se reposer sur leurs épaules, sur leurs bras, et hecqueter le pain dans la poche, dans les mains et mème dans la bouche de leurs assidus pourvoyeurs. Je ne connais ancune autre espèce d'oiseau qui, en liberté, manifeste une aussi grande familiarité. L'Ecriture Sainte a donc peint avec une grande vérité les dispositions des colombins, lor:qu'elle a dit: "Simplices sicut columba, - simples et confiants comme la colombe. "La confiance et la simplicité des ramiers viennent d'ètre démontrées. Mais à la simplicité, ces oiseaux joignent une srande prudence, qui se manifeste par les précautions qu'ils prennent en plaçant des sentinelles, tuutes les fois qu'ils se réunissent pour manger ou pour boire, afin d'avertir du danger leur's conginères. C'est aussi par te même motif que les bandes de ramiers ne voyagent que le matin ou le soir, afin d'éviter plus facilement les serres de l'oiseau de proie qui chasse moins ordinairement it ces heures.

D'où vient palombe, palumbus, palumbes? Je n'ai, sur ce mot, rien trouvé de bien concluant dans toutes mes recherches; j’abandonne done à l'appréciation de mes lecteurs la racine qü̈indique Court de Gribelin. Cet auteur prétend que palumbus a pour principe pal, d'vì 
est venu pala, palce, qui, comme le primitif, signifie " branche, arbre élevé, " d'où il suivrait que ramier et palombe auraient un bon degré de parenté. Je ne veux, en aucune façon, dans ce moment-ci surtout, m'y opposer, bien que la prosodie latine repousse une pareille hypothèse; et je termine cette étude par quelques petits détails sur les mœurs des pigeons ramiers. Ceux-ci, comme tous les colombins, sont pulvérateurs, c'est-ìdire qu'ils aiment à pulvériser, à réduire en poussière la terre ou le sable en se frottant le ventre contre ces matières, en tournoyant sur eux-mêmes avec un frémissement de leurs ailes, afin de se débarrasser des insectes qui les dévorent. Ainsi que tous les membres de cette nombreuse famille, ils boivent d'un seul trait et enflent leur jabot au moyen de l'eau qu'ils y accumulent, et qui leur permet de produire un son particulier appelé roucoulement.

Un des savants qui se sont occupés à trouver dans l'idiome primitif la racine des noms modernes, Kuhn, voit dans columba ou palumba la racine sanscrite " lamh" " signifiant cadere, "tomber, " et dans co ou pa une modification du préfixe " ava, " réduit à " $v a$, " et qui renforce le sens de "lamb," de sorte que ce nom signifierait "l'oiseau qui s'abat, qui tombe, qui plonge du haut des airs. " Ces hypothèses très-contestables, et très-contestées par de nombreux érudits et pour de graves raisons (voir Adolphe Pictet, t. I, p. 100, Aryas primitifs), n'ajoutent pas une grande lumière aux hypothèses qui ne sont pas fondées sur la langue-mère. Le seul avantage qu'elles semblent présenter, c'est de rattacher palumba à la même racine que columba. Enfin j'ose, mais non sans une juste défiance, indiquer une autre expression sanscrite ayant une relation avec "lamb." J'agis ainsi, pour prouver que je travaille à ma conversion ver's la véritable méthode autant qu'il m'est donné de le 
faire! Le mot s hadumba " pworrait asoir, dapres: kuhon, des liaisuns aver prolumber el. par suite avee columba ; cette expression signifie "multiturle, " et, dis lars, " oisean qui vole par troupes nombreuse's, " dísisuation tris-exacte pour les colombins ot qui indiquerait, sous ce rapport, un réritable trait d'union entre lecolombins et le's oiseaux plongeurs, tels que les canards, les oies, ete., qui vogagent, surtout dans les rígions glacées, par troupes innombrables.

de reviens aux ramiers. Ces oiseatux se reproduisent en Injou. Ils placent leur nid sur la tête des arbres cimondés, à l'ahri des feuilles de lierre; ce nid est compusé de quelques petites bûchettes peu nombreuse's, à travers tesiguelles on peut facilement apercevoir les cuff. Ceus-ci sont au nombre de deux, de forme oblongue et d'un couleur blanche. Quand its sont nouvellement pondus, ils revîtent une teinte rose. Le père et lat mère les conrent tour it tour; ces ceuls, dont le grand diamètre rst. de $0^{\mathrm{m}}, 038$, et le petit de $0^{\mathrm{m}}, 027$, domnent naissance à un mâle et à une femelle, et e'est dìs la naissance que si lorme une union qui durera autant que la vie de's époux. Souvent, pour laisser it la femelle le temps de se reposer, le mìle veut frolonger le temps pendant lequel il se dévotie à l'incubation; mais la femelle, drisirant ne par naturquer it ses devoirs de mère et d'riponse, force it coups d’aile le mâle à lui céder la place. Celui-ci, sciloienant it regret, s'ileve alors dans les airs et se laisse relumber au-dessus du nid en fuisunt le Saint-Esprit, selon l'expression populaire. Il renouvelle plusieurs loi. de suite les mêmes ivolutions, et dans cette circonslance, il justifie encore la signification du mot colombe, "plongeur." ,

Presque tous les naturalistes affirment que le's piceons ramiers un fint qu'une seule ponte. Je ne partage pats

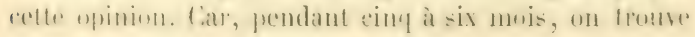


des nids de ramiers : il ne me paraît pas possible que ceux que l'on rencontre dans le mois de septembre et même dans celui d'uctobre, puissent être attribués à des ramicrs qui auraient passé le printemps et l'été sans se reproduire. De plus, si les ramiers ne faisaient qu'une couvée, il serait difficile d'expliquer leur nombre considérable, surtout lorsque leur's niảs, peu dissimulés, sont très-facilement découverts et détruits. Car les ramiers ont deux espèces d'ennemis, les martres et les corneilles, qui, toutes les deux, recherchent avec avidité les cufs de ces oiseaux ou même dévorent leurs petits.

L'homme vient encore augmenter le nombre déjà trop' considérable des adversaires des colombins; car', presque partout, les ramier's, ainsi que tous leurs congénères, sont condamnés à mort, ì cause des ravages qu'on leur impute faussement. En effet, les ramiers ne grattent pas avec leurs pieds, comme les gallinacés, pour déterrer les graines; ils ne se servent pas de leur bec, comme les corbeaux, pour arriver au même résultat : ils se contentent de recueillir les graines qui sont visibles et que la terre n'a pas recouvertes. Il est done facile de démontrer que les ravages attribués aux colombins sont très exagirés, et qu'en déclarant à ces viseaux une guerre acharnée, on enlève aux fermier's et aux petits cultivateur's une ressource considérable. Cette observation milite surtout en faveur des espèces nombreuses, qui autrefois étaient élevées dans les colombiers, et que l'on retrouve rependant encore aujourd'hui, en très-grande quantití, dans certaines parties de la France.

\section{COLOMBE COLOMBIN. - COLUMBA OENAS.}

C'ette espèce et la suivante ont, avec le pigeon ramier, un degré de parenté très-rapproché; leurs mœurs sont, dès lor's, à peu près semblables; car, chez les viseaux, 
les membres d'une minme famille ne different guère de goûts et d'habitule. Si cefte colombe porte l'épithète de colomtrin, e'est que, plus encore que les autres, elle est plongeuse. Le colombin, en eflet, comme tous ses congínères, prend son essor, non pas en suivant une lignt. droite, mais en plongeant dans l'air; on dirait un maître nageur se précipitant avec confiance au fond d'un flenve pour remonter ensuite à sa surface et s'y maintenir en dícrivant des lignes droites, mais capricieuses. Quant à l'expression scientifique anas, de oïsas, "vigne, " elle est justifiée par la couleur du poitrail du colombin et l'ensemble de son plumage qui paraît bronzé, à reflet: mítalliques, aree quelques teintes de "rouge vineux." Le colombin a la vue moins perçante que le ramier; ce qui explique pourquoi il devient, plus lacilement que lui, victime des piéges qui lui sont tendus, surtout dans les gorges des montagnes, où des baudes innombrables de colombins resteni enlacées dans des pantières. Le colombin, ainsi que tous les membres de cette intéressante famille, élève ses petits avec une solliciturle et une tendresse exemplaires. Aussi, dans le cuurs de leur vie, les petits ne seront-ils jamais aussi gras que lorsqu'ils étaient confiés aux soins de leurs parents.

Le colombin niche ordinairement dans les trones l'arbres, et c'est cette habitude qui le sépare véritableinent du ramicr. Ses ceufs, au nombre de deux, sont blanes, oblongs; ils reposent sur quelques petites buchettes grossierement réunies. Le grand diamètre est de $0^{\mathrm{m}} ; 037$, et le petit de $0^{\mathrm{m}}, 025$.

\section{COLOMBE BISET. - LIVIA.}

Cette colombe est rogardée par fous les naturalistes comme la souche de tous les pigeons domestiques. Ia surre acharmée que lui ont décharéce et les hommes et 
les oiseaux de proie a rendu cette espèce très-rare, ì l'état de liberté.

Les épithètes biset et livia ont la même signification, et sont justifiées par la couleur du plumage de cet oiseau qui est sombie, brun et d'un gris ardoisé. Livius, livia, est un mot de basse latinité signifiant, comme lividus, " ètre terne, noirâtre, plombé. » Maiaintenant encore, dans certaines localités de la campagne, on appelle une jeune fille brune une petite bisette. Un autre nom, qui est très-significatif, est celui de pigeon de roche, sous lequel le biset est assez généralement connu. Cette dernière dénomination indique le véritable caractère qui distingue le biset de ses congénères : c'est qu'il niche dans les truus des rochers sur lesquels il aime à se reposer'; car, comme les pigeons domestiques, dont il est le principe, il ne se perche jamais. C'est dans ces trous qu'il réunit quelques débris de petites bûchettes et de paille sur lesquels la femelle pond deux cufs blanes, oblongs et un peu plus renflés que ceux du colombin. Lc grand diamètre est de $0^{\mathrm{m}}, 036$, et le petit de $0^{\mathrm{m}}, 030$.

\section{PIGEON TOURTERELLE. - TURTUR.}

La tourterelle est l'un des plus gracieux oiseaux de notre pays; son vol est encore plus rapide que celui du ramier, et, comme celui de ce dernier, il est accompagné, surtout au commencement, d'un bruit d'ailes trèsprononcé. Toutes les fois que la tourterelle se perche, sa queue s'épanouit en éventail et prend une forme demicirculaire; puis elle s'abaisse pour devenir presque verticale, ce qui lui donne une physionomie très-originale. Cette habitude me semble être le résultat naturel de l'excessive rapidité du vol de la tourterelle. En eflet, ce rol se trouvant interrompu brusquement, lorsqu'elle 
bient se reposer sur une branche, le corps de la tourterelle subit une espèce de choc g̣u imprime à l'viseau un mouvement de bascule. Ce choe n'aurait pas lieu si la fourterelle ralentissiat son vol, ì mesure qu'elle approche du but qu'elle a choisi pour se percher. Cependant je crois que le véritable motif de cette tactique de la fourterelle est d'opposer à l'air le plus de résistance jossible, en dérelopplant ses ailes et sa queue, de diminuer ainsi la vitesse de son vol, et de faciliter son repos strr la branche qu'clle a choisie. Les mocurs fle cet oisean sont très-douces. Doú d'une vue trìs-pergante ot d'une excessive prudence, il échappe à ses ennemis par la vitesse de son vol et par les précautions dont il s'entoure. En effet, quand les nichées sont terminres, Ins funrterelles se réunissent en petites bandes, et, lorsyur: l'une de celles-ei vient a reporser dans un champ' pour y recueillir des graines, des insectes of meme des sauterelles, une ou plusieurs sentinelles sont placées ì les postes avancés, d'où elles s'açuiftent parfaitement. te leur missinn. A peine le chasseur a-t-il lait quelepues pas dans le terrain surveillé, que les sentinelles pronnent lrur essor en l'aceompagnant d'un bruit d'ailes assec\% virlent, ot hientit toutes les tourterelles ont suivi lems: yardiennes; le bruit quirlles font entendre dans cettr wreasion, ressemble à un véritable fru de file.

l'où jeut venir le mol cometerelle? sealiger prétend fue ent oiseau est ainsi nommé parer qu'il habite dins

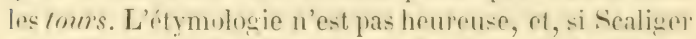
n'ritait pas mort depuis longtemps, je craindrais bien qu'au tribunal de mes juyes, il n'eut pas dans of procès le bémifice des circonstances attímmantes. Les tourterelles rhoisissent pour se reproduire une haie très-épaisse, doignép des passages ot des routes fríguentres par les fommos, ou la têfo émondre des arbres pen ćlevís; lì, sans brancoup de lravail of de rechrohes, res oiseaus 
rassemblent quelques racines ou de petites bûchettes, et c’est sur ce nid, peu artistique et peu épais, que la femelle dépose deux œufs blancs, oblongs, dont le grand diamètre est de $0^{\mathrm{m}}, 028$ et le petit de $0^{\mathrm{m}}, 022$. J'ai trouvé souvent de ces nids dans les haies touffues des îles ou des rives de la Loire, la proximité des champs dans lesquels on cultive le chanvre et le colza détermine les tourterelles à choisir res localités de préférence aux autres.

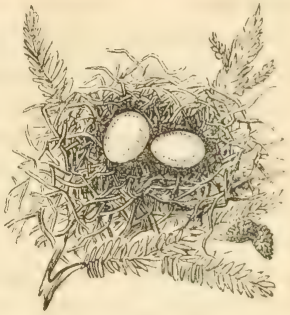

Il me souvient d'avoir découvert un de ces nids dans des conditions exceptionnelles, lorsque je sondais avec mes deux jeunes amis, Daniel Métivier et Eugène Lelong, toutes les haies qui se diroulent sur les flanes de la levée de Belle-Poule. Ce nid, plus solidement construit que ne le sont ordinairement ceux des tourterelles, avait été confié à un buisson éleví, touffu et formó de ronces trèslongues. De larges feuilles de lianes encadraient les bûchettes réunies par les tourterelles, et servaient à dérober le nid à la vue des passants et à préserver la couveuse des rayons du soleil et des atteintes de la plaie. Entrelacées avec les lonces, les lianes formaient une enceinte presque impénétrable. La pauvre mère eut bien de lit peine à sortir de cette espèce de forteresse naturelle, par une petite route sinueuse que le mâle et la femelle avaient dû frayer, non pas sans laisser fixées aux épines quelques-unes de leurs plumes. Je me sentais disposé à respecter un travail aussi remarquable; mais, comme Is dit le bon Lafontaine, le jeune âge est sans pitié, ct plus il était difficile d'atteindre le nid, plus on le désirait; car c'est ainsi qu'est formé le cour des jeunes et celui dest vieux. Après de longs efforts, quelques lambeaux d'ha- 
bils suspendus aux ronces du buisson, guelques doiṣts ensinglantés, nous avions la satisfiction de voir les deux cufs de tourterelle augmenter la récolte de la journée.

Ces détails mont un peu éloigné de la recherche de la véritable étymologie du mot tourterelle, qui dérive de turtarellı, diminutif de turtur, formé lui-même du syriaque tor, signifiant tour; tel est du moins, sous ce dernier rapport, l'opinion des savants. Je serais trèsporté à croire que l'expression turlur a été lormée pin cnomatopée, et qu'elle avait prour but de désigner la tourterelle en imitant l'acte le plus caractéristique des tourterelles, leur roucoulement empreint d'une espèce de gémissement qui n'avait pas échappé à l'ubservation du chantre des campagnes :

Nec tamen interea raucæ, tua cura, palumbes,

Nec gemere aeria cessabit turtur ab ulmo.

"Tandis que les ramiers, tes amours, ne cesseront de roncouler, et la tourterelle de gémir sur les ormes à la cime aériemne. ,

(Vinglie, Eglog., 1, v. 59.)

C'est le même motif qui arait déterminé les Grees it désigner la tourterelle par le mot Théôx, qui a pour ritcine tryzô, " roucouler. ")

Les colombes et surtunt les tourterelles avaient été classées parmi les oiseaux pur's par la loi mosaīque; elles étaient offertes à Dieu dans un grand nombre de circonstances, comme des victimes agréables. Ciette rroyanee était-elle fondée sur les mururs donees et innocentes des colombes? ou n'était-elle pas plutòt la consiqnence d'un sonvenir bibligue? La colombe apportant it Nó la branche d'olivier, signe de la réenciliation de Dieu avee les hommes, n'était-elle pas restée dans la mémoire des anciens peuples, comme une image virante qui perpútuait l'harmonie du Ciel atee lit terre? Nous lat 
retrouverons sur les bords du Jourdain, au baptême de Jésus-Cihrist; et pendant une Tongue série de siècles, la colombe, suspendue au-dessus de l'autel, a conservé dans ses flancs l'Auteur même de la véritable réconciliation de Dieu avec les hommes : touchant symbole dont la colombe de l'arche n'était qu'une pâle figure.

Je termine cette petite étude en relatant une croyance répandue généralement parmi les populations d'outreRhin. Les Allemands se plaisent à élever une grande quantité de tourterelles, moins à cause de la douceur de leurs habitudes que par un sentiment de froid égoïsme. Ces peuples sont persuadés que les tourterelles préservent leurs enfants de la terrible maladie de l'épilepsie, en assumant sur elles-mêmes le mal qui menaçait de frapper leurs maîtres. Là encore elles continucraient leur ancienne mission, et seraient destinées à être sacrifiées pour le salut des autres.

Puisqu'à tant de titres, la tourterelle est la constante et suave figure de la charité de Dieu, nous pouvous donc répéter avec confiance le pieux désir du roi-prophète et redire avec lui : Quis dabit mihi pennas sicut columber? el volabo, et requiescam? (ps. LIV). — "Qui est-cerui me donnera des ailes semblables à celles de la colombe? et je prendrai mon vol, et je trouverai mon repos dans le sein de Dieu?»

\section{CIVQUIUNE ORDRE. - GaLLINACÉS.}

L'ordre des Gallinacés, qui occupe le cinquième rang: dans la Faune de Maine-et-Loire, doit son nom au coq, gallus, mot dont j’ai indiqué précédemment l'étymologie. Cet ordre ne compte, parmi les oiseaux qui vivent à l'état. 
siuvage, qu'une senle fimille, et cette famille ne comprend elle-même que trois espèces, nu peut-être me quatrième, si l'on admet l'opinion de quelques naturalistes.

\section{$-\infty .00025$ \\ PREMIERE FAMILLE.}

\section{Tetradactyles.}

Le mot Tétradactyle est composé de tetranìs, " (quatre, ) et bucrroos, " doigt, " et signifie " oiseaux yui ont quatre doigts, " dénomination, je l'aroue, qui ne détermine guère la famille des Gallinacés, et qui peut convenir à beaucoup d'autres oiseaux.

Dans quelques ouvrages d'ornithologie, on l'applique ì une famille des Échassiers comprenant les Flamants, les Glaréoles, etc. C'est pour ce motif même que j’ai cru, peut-être un peu témérairement, devoir ranger parmi les Tétradactyles gallinacés la gglaréole à collier, dont la prísence a été signalée en Anjou. J'abandonne done la responsabilité entière de cette dénomination à l'honorable auteur de la Faune de Maine-et-Loire, ayant moimôme déjà assez d'opinions personnelles à défentre.

Mais il est facile de constater que les perdrix et les cailles appartiennent à l'ordre des Ciallinacés. En effet, comme tous les oiseaux classés sous cette dénomination, les pertrix et les cailles prélèrent la course au vol, unt les ailes et la quene courtes et arrondies, sont pulvirateurs et douŕs d'un bec tress-caractéristique. Mais, si la véritable étymologie du mot yallinacé signifie " chanter fort, se faire entendre au loin, " il est fivident que, dano cet oritre, la caille duit trouver sa place, et même itre mise au premier rang. 
pie EMIEIR GeNIRE. - PERDRIX.

\section{LA PERDRIX ROUGE. - PERDIX RUFA.}

La dénomination vulgaire et la dénomination scientifique, employées pour désigner la perdrix, ont entièrement la même signification. L'épithète rouge s'explique assez par elle-même; elle indique les nuances de plumage qui servent à distinguer cette espèce des autres membres de la même famille. Il s'agit donc seulement d'essayer quelques recherches et quelques indications sur l'étymologie du mot perdrix. Je crois que cette dénomination s'ajonte encore aux exemples, déjà si nombreux, par lesquels nous avons constaté que les anciens étaient portés à représenter les mœurs ou les qualités des animaux par une onomatopée fondée sur leurs cris ou sur leur chant. Remarquons d'abord que le mot latin perdix dérive de perdix, employé par les Grecs pour disigner cet oiseau. Pendant très-longtemps, en France, on disait perdis et non pas perdrix, comme on peut le vérifier par les vers suivants :

Assaulx mit en lieux de bataille

Entre éperviers, perdis et cailles.

(Le Roman de la Rose, fol. 122.)

Le latin est resté fidèle à l'étymologie, et le français s'en est éloigné.

Le mâle de la perdrix fait entendre différents cris; et le plus caractéristique est celui qu’il répète quand, au moment du printemps, on vient à le surprendre et à l'éloigner de celle qu'il a choisie pour contracter une union. Ce cri peut se traduire par ces mots liret ou krei. Dans les autres circonstances, le mâle répète liet, ketdin, ketdinkin. Ces cris, plus ou moins défigurés, auraient, selon l'opinion de Roquefort, donné lieu à la formation 
du mot perdrix. Le eri de la perdrix, très-acentué et jeu harmonieux, avait été remarque par les anciens. Aussi Ovide (Metam., liv. VIII, vers 2:36, ) dit que l'inventeur de la scie, dont le cri fatigue les oreilles les plus insensibles, avait eté mitamorphosé en perdrix, comme si cet oiseau eùt conservé dans son chant le son de l'instrument inventé par l'infortuné Acale. C'est aussi en souvenir de la chute terrible d'lcare, cousin d'Acale, que la perdrix, d'après Ovide, pour éviter le malheur qui a liappé un membre de sa famille, évite de se percher, vole le moins possible et établit son nid sur la terre.

Voici le texte d'Ovide :

Ilume miseri tumulo ponentem corpora nati Garrula ramosa prospexit ab ilice perdix, Et plausit pennis, testataque gaudia cantu est.

Unica tum volueris, nec visa prioribus annis, Factaque nuper avis, longum tibi, Dedale, crimen.

Namque huic tradiderat, fatorum ignara, docendam Progeniem germana suam, natalibus actis Bis puerum senis, animi ad præcepta capacis.

Ille etiam medio spinas in pisce notatas Traxit in exemplum, ferroque incidit acuto Perpetuos dentes, et serre repperit usum. Primus et ex uno duo f'errea brachia nodo Vinxit, ut aquali spatio distantibus illis Altera pars staret, pars altera duceret orbem. Dadalus invidit, sacraque ex arce Minerva Precipitem misit, lapsum mentitus. At illum, Qux favet ingeniis, excepit Pallas, avemque Reddilit, et medio velavit in aere pennis; Sed vigor ingenii quondam velocis, in alus Inque pedes abiit. Nomen, quod et ante, remansit. Non tamen hre alte volucris sua corpora tollit, Nee facit in ramis altoque eacumine nidos. Propler humum volitat, ponitque in sepibus ova, Antiquique memor metuit sublimia casus.

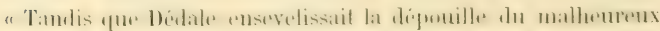
Icare, une perdrix, au bahil indiscret, cachée sous les branches 


\section{$-485-$}

fouflues de lyeuse, le voit, agite sus ailes en signe d'allégresse, et manifeste sa joie par des chants.

“ Seul de son espèce et inconnu dans les premiers âges, cet oiseau, récemment crée, devait instruire l'univers le son erime. O Dexdale, ta soeur ignorant les arrêts du destin, t'avait confié l'éducation de son fils, lorsque, à peine arrivé à sa douzième amnee, il fut capahle de recevoir tes lecons. Cet enfant examina les dards dont était hérissé le dos des poissons, il les prit pou modele, et taillant dans le fer des dents acérées, il inventa la scie. Le premier aussi il unit l'un à l'autre, par un lien commun, deux baguettes d'acier; de sorte que, toujours séparéus par la mine distance, l'ume reste immobile, l'autre décrit un cercle.

« La jalousie s'empare de Dédale : il précipite l'inventeur du haut du temple de Minerve et publie que sa chute est due au hasard; mais Pallas, favorable an génie, soutient l'enfant, le change en oiseau et le couvre de plumes au milieu des airs. Toute l'énergie de son esprit, naguẻre si actif, passe dans ses ailes et dans ses pieds; il conserve son ancien nom; toutefois, son vol est humble et il ne place plus son nid sur les branches ni à la cime des arbres; il rase les sillons, et dépose ses œufs au sein des broussailles : le souvenir de son ancienne chute lui fait craindre les lieux élevés ! »

(Ovide, Metamorphoses, liv. VIII, v. 236. Trad. Panckouke.)

L'auteur des Aryas primitifs émet une autre lıypothèse : il pense que le mot perbix a probablement la même signification que celle du mot sanscrit prdaku d'où elle dérive, et qui signifie "léopard, » et "serpent tacheté comme le léopard. » Selun Pictet, le mot perdrix représenterait donc les nuances et les taches vives et différentes qui, semées sur le plumage et surtout sur les flanes de la perdrix, la font ressembler, sous ce rapport, à la peau si variée du léopard.

Le cri dont j'ai parlé précédemment, et que le mâle répète avec une force et une persévérance assez soutenues, contribue beaucoup à trahir sa présence et à fournir au chassour le moyen de le capturer. Je n'entrerai pas dans le détail de tous les piéges plus ou moins perfectionnés qui, chaque année, servent à priver de leur liberté el 
mime à rondamner it la mort un certain nombre de perdrix. Je relaterai cependant un fait qui, loin d'être isolé, se présente dans beaneoup d'endroits. Un jeune lomme de la commune de la Meignanne, sims le secours d'aucun instrument, reproduit parfaitement avec ses lires toutes les variations des cris des perdrix qu'il s'est plu à étudier avec soin. La tête couverte de feuillage, il se place dans un fossé, et bientòt des perdrix accourent. de tous còtés à sa voix, lui becquètent la figure et ne s'íloignent que lorsqu'un examen sérieux et prolongé leur a révélé leur erreur.

Ces captures ne seraient pas préjudiciables à la propaçation de l'espèce, si elles étaient faites avec une certaine réserve et non pas inspirées par le désir effréné d'un lucre coupable. Lesmîles ítant beaucoup plus nombreux que les Pemelles, il s'ensuit que ceux qui snnt privés d'une compagne viennent troubler l'harmonie qui derrait rigner dius les ménages légitimes, livrent des combats aux époux, dispersent les matériaux du nirl, brisent les oufs et même quelquefois tuent les petits nouvellement nés. Ils ne peuvent accepter que d'autres jouissent des duuceurs d'une famille qui leur fait défaut. Cette disposition de caractère du mâle privé d'une épouse détruit chaque annie un nombre considérable de couvées, et s'opjuse beaucoup plus qu'on ne le croit au développenent de l'espèce.

Aussi les trappeurs qui, au commencement du printemps, se livreraient dans une sage mesure à la capture des mâles isolés rendraient un véritable service aux disciples de saint IIubert. Toutefois les males condamnés ì un eélibat forcé paraissent, après quelques jours d'une fureur non raisonnce, se consoler assez facilement de la position qui leur est faite; est-ce la ríflesion, est-ce une satge rxpirience, est-ce une rlairvoyante philusophie, rst-ce la considération des misères du ménage qui est le 
principe de leur résignation? Je l'ignore; mais, sans pouvoir en déterminer le motif, j'en constate les effets. Réunis en petites bandes, qu'on pourrait appeler bandes de garçons, ils mènent joyeuse vie, folâtrant et paraissant se moquer des soucis et des préoccupations de ceux que les lois de l'hymen attachent à des devoirs pénibles; ces liens ne sont cependant pas trop inflexibles; car, tandis que les femelles se livrent aux fatigues de l'incubation, les mâles abandonnent leurs épouses pour se joindre aux compagnies de célibataires, et prendre, selon l'expression populaire, quelques semaines de bon temps. Ils paraissent ne réserver leur tendresse que pour leur progéniture. Aussi, dès que les petits ont vu le jour, les mâles s'empressent de venir prendre la direction de la famille et de pourvoir, avec un dévouement de tous les instants, à la nourriture et à la défense des perdreaux. Cette union ne se brisera plus qu'à l'époque du printemps suivant. Les mâles et les femelles dont les couvées n'ont pas réussi, se mêlent aux compagnies entières pour se procurer ainsi le plaisir de vivre en famille et pour se dédommager, en voyant les enfants des autres, de ceux qu'ils ont perdus.

C'est pendant l'éducation des petits que le mâle, de concert avec la femelle, a recours à toute une série de ruses pour éloigner le chasseur, le chien ou les autres ennemis des nouveau-nés. Tour à tour, et même quelquefois ensemble, le mâle et la femelle courent derant le chasseur en traînant la patte ou l'aile, et attirent ainsi, par un stratagème innocent, loin des perdreaux, l'ennemi (qu'ils redoutaient; puis, par un vol ou une course rapide, ils reviennent consoler ceux qui déjà se croyaient orphelins. Bien des fois par jour, le mâle fait entendre un cri de rappel très-accentué, afin de réunir tous les membres de la compagnie et de les passer en revue; si quelques-uns manquent à l'appel, le mâle et la femelle 
repietent leurs accents plaintifs, ot ne cessent que lorsqu'une triste conviction leur démontre qu'il ne leur reste plus qu'à gémir sur la perte de quelque membre de la famille. Dans cette circonstance, le cri de rappel alfecte un caractère tout particulier de tristesse et d'angoisse. I In soir que je revenais de faire un pèlerinage au Champ des Martyrs, j'entendis, lorsque j'arrivais à l'endroit où la route, s'enfonçant entre les talus qui rappellent l'aspect du boeage de la vieille Vendíe, se partage en quatre chemins, le eri très-aecentui d'une perdrix. Je m'arrètai, et, pendant un assez long temps, le cri derenant de plus en plus vif et saccadé, je cherchai si je ne trouverais pas quelques petits retardataires, cause des angnisses de leur's parents. $\Lambda$ près une investigation assez. longue, j’aperegus un perdreau tapi le long d'un talus it fie, et qui luttait en vain pour gravir l'obstacle quile séfrarait de sa famille. J'aurais dû avec générosité le rendre it ses parents; mais espérant l'ílever, je l'emportai. Avant de quitter l'endroit où j'avais capturé le perdreau, je demeurai quelque temps ì la même place pour constater si les cris de rappel allaient continuer; mais ils cessèrent presque immédiatement. La raison du silence des parenis etait fondée sur celui du petit que je tenais captif dans ma main. A chaque cri du père ou de la mère, le perdreau, lorsqu'il était en liberti, répondait par un cri plaintif; ce cri ne se faisant plus entendre, les parents se taisaient, ou parce qu'ils avaient perdu tout esprir de retrouver leur enfant, ou parce qu'ils pensaient que son silence était motivé par l'imminence d'un grave dangzer, et, dès lors, ils ne voulaient pas l'augmenter encore par leurs cris, en révélant à leur ennemi qu'un membre de la famille était égaré. Après avoir fait cette observation, je méloignai avec mon jeune captif; mais, malgré mes soins, il ne put survive que quelques jours, et maintenant il fait partic de ma collection. 


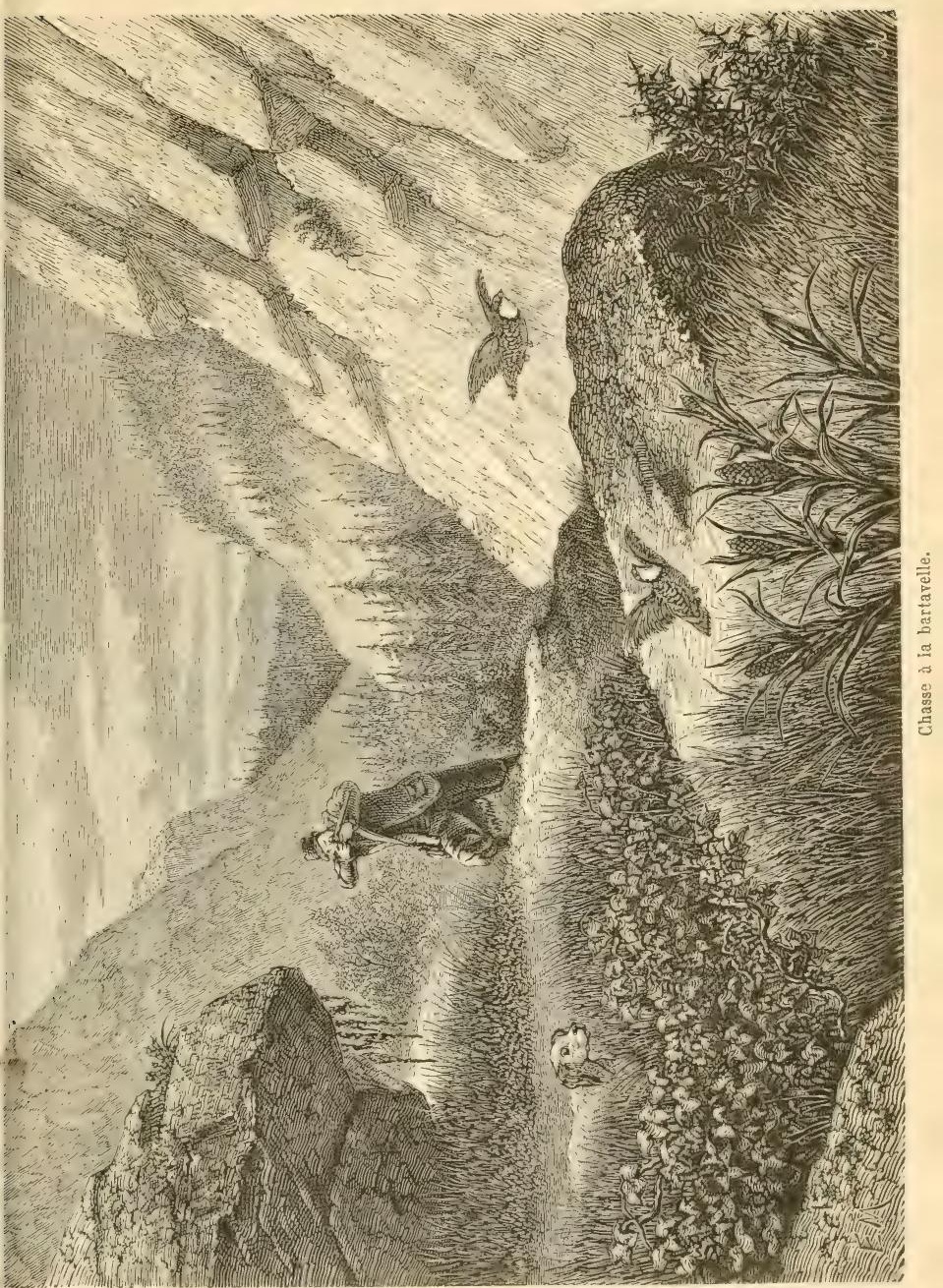



En Anjou, on trouve deux races très-distinctes de perdrix rouges, dont les proportiuns varient notablement. On appelle la plus grosse des deux races bartavelle; mais cette dénomination n'est pas fondée. Ces variétés dépendent des lieux où se fixent les perdrix, et qui leur fournissent une nourriture plus abondante et plus en harmonie avec leurs goûts. La véritable bartavelle ne se rencontre jamais en Anjou. Elle se distingue de la perdrix rouge par un collier qui ne s'égrène pas comme celui de sa congénère, mais qui se déroule autour du col comme un ruban uniforme et sans franges ; enfin, la couleur jaune du ventre de la perdrix rouge est remplacée, chez la bartavelle, par un gris ardoisé. Les proportions de la bartavelle sont aussi beaucoup plus fortes que celles de la perdrix rouge, sans toutefois atteindre celles quo Strabon attribue (liv. XV) à une perdrix que Porus, roi des Indes, offrit à l'empereur Auguste, et qui était plus grosse qu'un vautour!!! La véritable bartavelle ne se trouve qu'en petit nombre dans les localités du midi de la France; son véritable pays est la Grèce, et surtout les îles Cyclades. On l'appelle avec raison saxatilis, perdrix des rochers; elle se plaît sur les collines, dans les endroits pierreux : c'est là qu'elle échappe à ses ennemis par une ruse intelligente.

Quand elle est poursuivie par les chiens et par les chasseurs, elle s'envole pour se précipiter immédiatement dans les ravins situés au bas des collines et des montagnes, où elle se tient ordinairement; puis, pendant que le chasseur et son compagnon se fatiguent ì descendre dans le ravin pour sonder la remise, la bartavelle, par une course d'une rapidité incroyable, remonte sur le plateau d'où elle s'était envolée, et de là elle peut contempler, sans danger et avec une satisfaction maligne, toutes les marches et contremarches inutiles de ses adversaires. 
Mais avant de quitter la bartavelle, peut-être ne seraitil pais sans intérêt de ehercher l'étymologie de ce nom, que nous rencontrons sur notre route. Voiei ce que je lis dans .I. Littré : "On trouve dans le bas latin burta"vella pour vertcvella, mot du Midi, signifiant propre" ment, " chose qui se tourne " puis " clef, amneau." "Le nom de l'oiseau viendrait-il de là? "J'ai copic textuellement, intégralement, mais non pas sans une certaine satisfaction; car ce texte me fournit une justificalion de ma méthode. Il est évident que M. Littré, dans cette circonstance comme dans bien d'autres, n'est pas remonté à la langue mère, à travers les siècles et les chartes. Il s'est contenté, inalgré sa vaste érudition, d'indiquer une étymologie plus ou moins probable, que je vais essayer de mon mieux de rendre plus plausible.

La bartarelle est nommée, par Buffon et par un grand nombre de naturalistes, la perdrix grecque ou perdrix des Cyclades, par la raison que la Girèce et surtout les iles de la Crèce sont la véritable patrie de cette perdrix. Dès lors, il est facile de constater que burtavelle est une ípithète servant à désigner d'une manière plus spéciale cette espèce, et que, remplaçant la dinomination grecque, elle pourrait bien avoir yuelque trait d'union avec le nom des localités de la Grèce où la bartavelle vit en plus grand nombre. Or, les îles Cyclades étant justement la patrie favorite de la bartaselle, il s'ensuivrait que l'on aurait pu remplacer le nom de ces îles par une dénomination vulgaire et équivalente. Le mot Cyclades ayant pour racine кrkLos, "cercle, " serait l'équiralent de bartuvelle dérivant d'une expression signifiant annecu, car l'ameau est un cerele. D'où appeler cette perdrix, "la perdrix des Cyclades," ou "la bartavelle " serait identique, puisque ce serait retracer la même idtée. Cette hypothèse pourrait encore se justifier par labsence complète de la perdrix 
grise, qui ne manifeste jamais sa présence dans les îles de la Grèce.

Mais cependant l'interprétation du mot bartavelle, qui me paraît la mieux fondée et, dès lors, la seule probable, est celle qui, conservant à cette expression le sens d'anneau, indiquerait que l'on a voulu déterminer cette espèce par le ruban qui se déroule autour de son cou, non pas comme un collier égrené, tel que le porte la perdrix rouge ordinaire, mais comme une bande uniforme, caractère distinctif qui sépare les deux perdrix. Ainsi done, perdrix bartavelle signifierait, "perdrix à anneau, perdrix dont le cou semble encadré dans un anneau. "

Je reviens à la perdrix rouge : elle a un vol plus bruyant que la grise, dont elle diffère encore par un grand nombre d'habitudes. Cette perdrix ne se reproduit pas en captivité, et, tandis que sa congénère se plaît dans les lieux humides et dans les prairies, celle-ci préfère les landes et les terrains arides. En liberté, elle se cantonne plus régulièrement que la grise; puis, quand elle est poursuivie avec persévérance, elle se perche sur les branches peu élevées des arbres touffus, et là, comme dans les guérets, les différents membres de la même compagnie ne partent pas en même temps à l'approche du chien ou du chasseur, mais ils s'envolent successivement et quelquefois même assez longtemps les uns après les autres. Les perdrix rouges sont beaucoup moins sociables que les grises; elles nichent dans les haies, lc long des talus des fossés, et dans les blés ou dans les prairies artificielles. La femelle gratte la terre, prépare une légère excavation qu'elle remplit d'herbe, de petites racines et de feuilles sèches. C'est sur cette couche qu'elle pond de quatorze à dix-huit œufs obtus, dont le grand diamètre varie de $0^{\mathrm{m}}, 038$ ì $0^{\mathrm{m}}, 040$, et le petit de $0^{\mathrm{m}}, 029$ ì $0^{\mathrm{m}}, 030$. Le fond de la coyuille est d'une couleur d'ocre 
plus on moins pâle, sur laquelle appraraît une seconde rouche plus foncée ct parsemie, surtout vers le gros bout, de taches irrégulières d'un brun ou d'un roux plus ou moins prononcé. Quelques-uns de ces œufs ne présentent aucune tache; d'autres sont simplement marqués de petits points bruns.

Les vieilles perdrix entourent leurs nids de plus de précautions que les jeunes : elles semblent vouloir préserver leurs wufs des danger's que l'expérience leur it révélés, en plaçant leurs nids dans des lieux plus sulitaires et plus cachés.

Depuis près de quinze ans, les chasseurs et les naturalistes ont constaté, dans l'arrondissement de Cholet, en $\Lambda$ njou, la présence d'une perdrix, qui jusqua'à cette éporque, n'avait pas encore été étudice. Cette perdrix, qui est de la taille de la perdrix rouge ordinaire, a un plumage entièrement roux, excepté le front et la gorge qui sont noirs. On remarque aussi d'une manière rígulière, chez les vieux sujets, quelques plumes blanches au bas de l'abdomen. Cette perdrix, envoyée à la Sociétí linnéenue de Maine-et-Loire par M. Guillou, de Cholet, avait figuré à l'exposition d'Anger's en 18:38. Elle attira l'attention des visiteurs et des naturalistes, et une commission fut constituée afin d'étudier cette perdrix, et de prendre tous les renseignements nécessaires, pour déterminer si le plumage du sujet envoyé à l'exposition était le résultat de ces maladies qui occasionnent assez sonsent beaucoup de bizarreries chez les animaux et surtout chez les oiseaux, ou, enfin, s'il constituait une véritable rspèce. Pendant plusieurs années, les membres de cette commision se mirent en rapport avec les chasseurs et les naturalistes de l'arrondissement de Cholet, et ne négoligèrent rien pour recucillir tous les faits propres it risondre une question intéressant lornithologie générale et, rn particulier, celle de l'Injou. Cirìce a leurs of- 
forts persévérants, il fut constaté que la perdrix présentée par M. Guillou n'était pas un sujet isolé, mais qu'elle existait en assez grand nombre ; que six compagnies, entièrement composées de perdrix semblables à celle qui avait figuré à l'exposition, se trouvaient cantonnées dans un territoire assez restreint; enfin, que des sujets de différents âges entièrement identiques figuraient dans la collection de MII. Guillow et Baugars, dans les musées de Saumur et d'Angers, et que plusieurs douzaines de ces perdrix avaient été fournies à un certain nombre d'amateurs. Il fut démontré aussi que le vol de cette perdrix était plus rapide que celui de ses congénères; qu'elle paraissait plus sauvage que les autres espèces; que sa chair, d'une couleur jaunatre, se rapprochait, quant au goût, de celle de la pintade.

Chaque année, de nouvelles observations étaient venues confirmer les renseignements précédents, et ajouter des preuves multipliées à l'opinion de $\mathrm{M}$. Guillou, lequel avait pensé que cette perdrix, ne vivant jamais avec les perdrix rouges et les perdrix grises, et semblant au contraire les éviter, constituait une nouvelle espèce. La Commission linnéenne d'Angers erut donc pouvoir donner à cette perdrix le nom d'atro-rufa, "noire-ronge, » tout en soumettant sa décision à la sanction des savants. Plus de six ans se sont écoulés à partir du moment où la commission angevine a émis son jugement, et, depuis cette époque, la perdrix atro-rufa, "noire-rouge, " non-seulement n'a pas quitté notre département, mais elle s'y est multipliée en assez grand nombre pour qu'on la voie figurer quelquefois sur le marché de Cholet, où elle a été vendue comme gibier ordinaire. Des sujets envoyés récemment à Paris ont été étudiés avec soin, et reconnus comme constituant une race très-distincte de la perdrix rouge.

Quant aux œufs, on n'a pu, jusqu'à ce moment-ci, en 
obtenir qui fussent intacts : les dibris de quelques-uns de ces aufs, recueillis par le lermier du Con-Ṕnson (commune de Saint-Aubin, Vendée), étaient d'une conleur rougeâtre plus foncée que ceux de la perdrix rouge ordinaire.

\section{LA PIRDRIX GRISE. - PERDIX CINEREA.}

Les deux dénominations, yrise et cineren, consacréns it drsigner la perdrix grise, me somblent nawoir besoin al aucume recherche étymologique; il ne s'agit done ici que d'esquisser rapidement les mœurs de ce gallinacé. Grise et cinerea représentent en effet la mime idie : cianere se traduisant par cendrée, "couleur de cendre, " et indirfuent les muances qui dominent dans lo plumage de cette perdrix. Quant à l'épithète grise, elle ćtait, daprès Liofuefort, Ménage, Littré, ete., rendue dans l'idiome de la basse latinité par yriseus, grisius, en italien par griso, grigjo, mots qui dérivaient tous de cinereus, " cendré, couleur de cendre. " Le plumage de la perúrix -rise se marie avee les lieux quelle habite, et sert à la dípober aux regards du chien qui la poursuit. En eflet, lorsqu'clle se motte et se tapit en restant immobile le long des guérets qu'elle jarcourt, sa couleur se confond avec celle de la terre. Le mâle a le plistron orné d'un ler à cheval d'un rouge brun qui s'assombrit avec l'âge : ce signe pourrait le faire apercevoir plus litcilement; aussi le cache-t-il en marchant et surtout lorsqu'il est poursuivi. Ce fer à cheval n'est que ligèrement indiqui sur le plastron de la femelle. La perdrix grise présente, comme la perdrix rouse, deus races, l'une beaucunp plus forte que l'autre. La petite est appelie roquette : elle doit les laibles proportions de sia titlle aus licus quielle habite, et qui lui fournissent moins de ressources yue diatres contrés. La perdria grise ne st 

perche jamais; elle vit en compagnie comme sa congénère, mais elle paraît mieux obéir que celle-ci au signal que donne le chef de la famille. Quand la compagnie est pressée par le chasseur ou par les chiens, tous les membres s'envolent ensemble, et il n'y a pas de retardataires comme parmi les perdrix rouges. La perdrix grise est aussi plus sociable; elle s'accoutume mieux en captivité et elle s'y reproduit. Ainsi que sa congénère, elle a une frayeur extrême de l'oiseau de proie, et, dès qu'elle aperçoit au haut des airs un point noir indiquant la présence de son ennemi, elle cherche à se cacher partout où elle peut; elle se réfugie même dans les trous de lapin, et se laisse volontairement prendre par la main de l'homme pour échapper aux serres d'un rapace. La perdrix grise prépare avec ses pieds une petite excavation dans les prairies naturelles ou artificielles; elle y réunit quelques brins d'herbe, et dépose sur cette couche grossière quinze, vingt et même quelquefois vingt-quatre œufs; la femelle prend soin de les placer de manière à ce qu'ils tapissent tout l'intérieur du nid en formant plusieurs rangs circulaires disposés par étage, afin de pouvoir leur communiquer à tous plus facilement la chaleur qui doit les laire éclore. La perdrix grise apporte dans le travail pénible de l'incubation une persévérance et un dévouement bien remarquables : rien ne peut l'arracher à son labeur maternel, ni le bruit, ni la faim, ni la présence de ses ennemis; elle se laisse dévorer sur ses œufs ou même immoler par l'instrument du faucheur. Aussi les Egyptiens en avaient-ils fait, dans leurs hiéroglyphes, l'emblème de l'amour' maternel et celui de la fícondité. Les auds de la perdrix grise sont piriformes, d'une couleur unie et d'un jaune şris pâle; le grand diamètre varie de $0^{\mathrm{m}}, 033$ à $0^{\mathrm{m}}, 034$, et le petit de $0^{\mathrm{m}}, 024$ ì $0^{\mathrm{m}}, 02 \%$. J'en possède quelques-uns qui présentent cette particularité, que le petit bout en est d'une couleur bleue asse\% vive. 
La perdrix grise, malgré sa multiplication rapide, disparait insensiblement de nos contries, ainsi que lat perdrix rouge. Cette diminution tient it plusieurs causes. La première de toutes est la guerre acharnée que lont aux nids de ces oiseaux les fermier's, depuis la promulgation des lois sur la chasse. Par un raisonnement fiux, ils prétendent qu'ils ne doivent pas nourrir à leurs depens un gibier qui profitera exclusivement à ceux qui ont non-seulement un permis de chasse, mais encore le droit d'en user.

D'autres motifs sont la grande disproportion qui existe entre le nombre des mâles et celui des femelles, puis le mouillage des semences du froment que l'on trempe dins du sulfate de cuivre (couperose bleue), et qui empoisonne beaucoup de perdrix avides de cette semence. Les prairies artificielles contribuent aussi puissanment à diminuer le nombre des perdrix, par la raison que tontes celles qui établissent leurs nids dans ces prairies roient leurs couvées détruites, puisque l'herbe est coupée orlinairement avant que les perdreaur ne soient íclos. Enfin un des ennemis les plus redoutables des perdrix est le chat, qui exerce de plus en plus dans les campagnes le rôle d'un braconnier consommí. On pourrat ajouter ì toutes ces causes l'irrégularité des saisons, depuis un certain nombre d'années. Cétte irrégularité est un véritable fléau pour les perdrix. Les années trop chaudes leur sont contraires, et beaucoup de jeunes perdreaux se brisent les pattes en courant dans des terrains déchirés par les crevasses occasionnées par une chaleur continue. D'un autre cìté, les années trop pluvieuses privent les perdrix de leur principale nourriture, des fourmis et surtout de leurs coufs, qui ne se multiplient que sous l'influence salutaire du soleil.

Liouverture souvent trop prématuríe de la chasse est aussi une cause de l'inconvénient que je signale, puis- 
qu'au moment où les disciples de saint Hubert descendent sur le champ de bataille, leurs ennemis sont trop faibles pour pouvoir défendre leur vie par un vol régulier. P'eut-être devrait-on, pour fixer l'ourerture de la chasse, se rappeler ce vieil adage de nos pères :

A la Saint-Remy (1 ${ }^{\mathrm{er}}$ novembre)

Les perdreaux sont perdrix.

\section{LA CAILLE. - COTURNIX.}

Au commencement d'un de ses plus gracieux chefsd'œuvre, l'inimitable Lafontaine s'exprime ainsi :

Nous devons l'apologue à l'ancienne Grèce ;

Mais ce chaimp ne se peut tellement moissonner,

Que les derniers venus n'y trouvent à glaner, etc.

En parcourant tout ce que les anciens auteurs grees, latins, etc., ont écrit sur la caille, je me suis rappelé naturellement ces vers, et j'y ai puisé un encouragement. J'espère donc, même après la longue série d'hypothèses de toute espèce entassées par tant d'écrivains anciens et modernes, pouvoir encore, sans être trop présomptueux, ajouter quelques observations nouvelles à celles qui ont déjà été faites sur le nom et sur les mœurs de la caille.

Quelle est l'étymologie des dénominations caille et coturnix?

Je vais essayer de dérouler, au moins en partie, les théories si multipliées émises sur cette question, et de rattacher aux mœurs de la caille les différentes opinions des savants, en y joignant toutefois les miennes, avec une respectueuse défiance.

La caille a une physionomie tout exceptionnelle; son plumage est formé de plumes courtes et soyeuses, d'une couleur jaune pâle et presque uniforme sous le ventre, nuancées d'un gris nuirâtre sur le dos, et terminées par 
des points d'un jaune assez vif et tranchant sur les autres teintes.

L'ensemble du plumage n'est pas brillant, mais d'une richesse qui revit une certaine coquetterie. Pour avoir obtemu un pareil effet avec des nuances si peu variées et si sombres, il fallait le pinceau de Dieu. Un auteur avait itó frappé de l'aspect du plumage de la caille, et, en la voyant courir rapidement, il avait cru que les plumes du dus, s'harmonisant comme des couches mobiles: et superposées, représentaient assez bien les écailles qui ondulent sur le corps des reptiles. Dès lors il avait pensé et même osé écrire que cette particularité du plumage de la caille arait éé le principe de son nom, et que celui-ci n'était qu'une abréviation du mot écaille.

L'auteur de cette hypothèse est Iluet, cité par Mńnage. Le défendre serait inutile, le condamner peu charitable; car, avant de jeter la première pierre aus autres, il faut seruter sa propre conscience, et se demanier si quelquelois on n'a pas été soi-même un peu aventureus dans ses itymologies. Paix done à mon infortuné prédécesseur! Son hypothèse même ne sera pas sans profit pour nous : elle servira à nous rappeler d'une manière plus positive les différentes nuances du plumage de la caille. Puis cet oiseau n'est-il pas désigné sous le nom de perdrix coturnix, ou de perdrix caille? Ce dernier mot n'est done qu'un complément de l'idée représentée par perdrix; or, si cette dénomination dérive du sanscrit et signifie serpent tacheté comme le léopard, l'hypothèse mise en avant par II uet est. loin d'ètre vide de sens.

Continuons à explorer le vaste champ qui se développe: a nos regards, et nous pourrons y moissonner bien des découvertes.

Selon Ménage, caille dérive de l'italien quaglia, auquel Ferrari donne pour racine un viaux mot latin, qua- 
quila, désignant chez les anciens l'oiseau qui nous occupe en ce moment-ci. Ménage, de son côté, avait eru qu'il avait pour principe ortsgs, désignant la caille chez les Grecs. Voici les transformations au moyen desquelles il justifiait son opinion : orTygs, oRTYGmon, artigalius, artigalia, calia, culia, quaglia. J'abandonnerai cette explication à la discrétion pleine et entière de mes lecteurs, leur laissant toute liberté de l'adopter ou de la condamner. Mais voici venir à la rescousse un savant membre de l'Institut; dès lors la question est plus grave. C'est M. Littré qui parle : "Caille, étymologie : de l'italien quaglia, du bas latin quaquila.» M. Littré et Ménage se donnent la main, mais non pour s'appuyer sur l'idiome primitif. Le mot quaille, employé dans les anciens fabliaux pour désigner la caille, vient fortifier l'étymologie précédemment énoncée. Mais enfin pourquoi, chez les Latins, a-t-on attribué à la caille le nom de quaquila? Papias nous en donne la raison : "Quaquila genus avis vulgo coturnix, a vocis sono. " La quaille, espèce d'oiseau, appelée ordinairement co"turnix, doit son nom au son de sa voix. " Selon de graves autorités, le mot quaquila était une onomatopée se présentant, comme tous les noms anciens de trois syllabes, sous la forme d'un dactyle imitatif du cri de l'oiseau. Ici se rencontre une nouvelle difficulté, celle de faire concorder le cri de l'oiseau avec le dactyle quaquila. Le mâle de la caille fait entendre un cri très-accentué, que de savants observateurs ont traduit par ces mots " ketkaya, ketkayac, " ou "piapaya, piapayac," ou "pet tabac, pet tabac, " et que les gens de la campagne redisent sous cette forme naïve : point de tabac, point de tabac. Quelques autres naturalistes ont cru pouvoir exprimer ainsi le chant de la caille : paye tes dettes! paye tes dettes! Conseil qu'il ne serait pas inutile de répéter souvent, à la campagne comme à la ville. 
Prisch assure que, du temps de Charlemagne, on donnait at la caille le nom de quacum, qui traduit encore d'une certaine manière le cri de l'oiseau.

Ce cri est précédle d'une espèce de sompir étouffé ou de miaulement, "mia ouan, ouan, ouin, ouin. " La femolle répond par cette simple stllabe "cri, cri, cri... " ou "crui, crui. " J'indique les variations de ces différents chants; car, comme pour les textes difficiles, les traductions sont multipliées.

La mâle accentues sun cri avec une telle force et une si littigante continuití, qu'il se fiit entendre it plusieurs kilomètres de distance, et, sous ce rapport, il est bien le gallinacé par excellence, surtout si l'on compare la puissance du cri au volume de l'oiseatu. Tout en répétant son chant, il parcourt de grandes distances avec une excessive rapidité ; cette remarque nous servira plus tard pour l'étymologie du mot. ontrgs.

Dans aes crurses ratabondes et irrifléchies, le mâle se précipite en véritable ítourdi et même en fou dans tous les piéces qu'on lui tend. C'est pour représenter ce eri répéti d’une façon irritante et cette folle étourderie tue l'on a furmi l'expression française cailleter, «parler et agir comme une caille. ")

Certains írulits pensent que caillette, cailleter, aurait pour véritable origine caillach, qui, dans le celtique. signifiait fomme; et dès lor's cailleter voulait dire "bevarder, parler comme une femme." C'aille aurait la môme étymologie, et la caille, à cause de son chant fatigant et continu, aurait étr assimilée ì la femme, à une personne bavarde.

C'est pour la mème raisun qu'on a donné an fou de François ler le nom de Guillette. Bans les anciens temps: te la monarehie, les rois so laisaient accompagner d'un prersonnage remplissint le ròle de fou privilégié, diflomé, afin qur ses filles evfravagances fissent oublier 
celles qui, pour paraître moins étranges, étaient cepenlar.t plus compromettantes; c'était agir un peu comme Alcibiade qui coupait le queue de son magnifique chien, afin que l'on s'occupât de l'animal et que l'on oubliât le inaître. Dans notre siècle de progrès, on a supprimé le fou titré, peut-être parce que son rôle devenait trop difficile : n'aurait-il pas trop de confrères sans titre, à éclipser?

Je m'arrête et reviens à mes étymologies. Avant de passer à la dénomination grecque de la caille et à tous les souvenirs qui s'y rattachent, je succombe à la tentation d'exprimer un sincère regret, celui de ne pouvoir donner au mot caille, oiseau, le même principe qu'à caille employé dans un autre sens, à savoir, de caille de sang, caille de lait, etc.

Dans cette acception, caille dérive de coagulare, conglare, coailler, cailler; cette formation est régulière, et caille signifierait alors " oiseau dont la chair serait coagulée et grasse par excellence : " interprétation qui serait parfaitement fundée, car c'est à cet engraissement extraordinaire des cailles qu'on attribue la brièveté de leur vie, considération que doivent méditer ceux qui travaillent trop volontiers à développer leur embonpoint. Mais, dans les cailles, l'embonpoint a du moins cet avantage, qu'il est la cause de l'extrême chaleur que communiquent ces oiseaux aux personnes qui les touchent et les pressent. Aussi les Chinois se servent-ils de cailles, comme de manchons, pour se préserver du froid pendant l'hiver. Malgré l'efficacité constatée du procédé, je n'oserais le recommander qu'aux habitants du CélesteEmpire; car, pour en ressentir la bénigne influence, il faut avoir obtenu le driit de porter le bouton d'un degré supérieur.

Je me rappelle qu'accompagnant un soir un trappeur émérite, je fus chargé de tenir captive dans ma main une 
caille qui était venue, comme une fulle, perdre sat libertí au pirge suspendu dans un sillon de blé. Tandis que mon vinérable guide démêlait la prison de fil qui derait réunir mon captif à ses infurtunés frères, je ressentais très-vivement, aux soubresauts communiqués à mes mains, les aspirations qui faisaient battre pour la liberté le cour de la caille. Dìs lor's, comme un bon prince pensant à ses sujets, je me disais à moi-même: La presser trop, e'est m'exposer à l'étouffer; lui laisser trop de liberté, e'est hélas! perdre le fruit de longs efforts. P'endant que je cherchais le moyen terme usité par les Chinois, la caille m’échappa : je fus réprimandé par mon chef de file; mais je me consolai facilement de ses reproches, en entendant la caille s'arrêter non loin de nous ct cilébrer son triomphe par un chant encore plus prononcé qu'à l'ordinaire; je crus même y saisir un accent de reconnaissance. En tout cas, j'avais fait un heureus et conquis un ami.

Non-seulement l'embonpoint que la caille acquiert. muit à sa longévité, mais il cause encore souvent sa perte. Ciet oiseau, avant les récoltes, peut se dérober assez ficilement ì la poursuite de ses ennemis par une course ratpide qui l'avait fait surnommer courre-rite. "Currit satis velociter, undè currelium vulgo dicimus. " [Buffon, éd. in-4", vol. II, pag. 449.) Mais après la moisson, il devient tellement pesant que, comme un víritable sybarite, couché le ventre au soleil, une patte étendue en l'air, il laisse le chien approcher tout près de lui, et ne se décide à prendre la fuite que lorsqu'il n'est plus temps. Très-souvent il paie de sa vie l'indolence qu'a engendrée en lui son excessif embonpoint. C'est la même incommodite qui, chaque année, obliqe un certain nombre de eailles à ne pas partir avec leurs congénères, et ì attendre que leur poids ait diminuć avant de participer aux migrations régulières de leur famille. Preuse évidente 
des résultats fâcheux ‘iu'entraìne l'embonpoint pour ceux qui se livrent à la nécessité ou à la douceur des voyages!

Un second motif qui contribue beaucoup à abréger la vie des cailles, c'est leur caractère difficile et batailleur. Non-seulement au printemps, mais à toutes les époques de l'année, les cailles se livrent des combats acharnés. Pour quelques grains de nourriture ou quelques insectes convoités, un duel à mort s'engage immédiatement. Cette tendance à une irritation excessive et permanente fatigue tellement les cailles, que leur vie se prolonge rarement au delà de quatre à cinq ans.

Les Grecs et les Romains avaient remarque cette disposition de la caille, et ils en avaient profité pour se créer un nouveau divertissement et établir des combats de cailles. Ces combats étaient de deux espèces : l'un, de caille à caille; l'autre, de caille à homme.

Dans le premier cas, on jetait sur le milieu d'une table quelques graines en petite quantité, puis on plaçait une caille à chaque extrémité, et on les lâchait ì un signal donné ; bientôt elles se rencontraient, et le désir de profiter seule du repas préparé excitait chaque caille à repousser sa rivale. La querelle s'envenimait rapidement, et l'un des deux combattants restait sur le terrain ou se retirait couvert de blessures. Le vainqueur mangeait les quelques grains de chènevis ou de froment, mais d'un appétit qui devait être assaisonné d'angoisses et de douleur; car il me semble qu'il est difficile de se livrer aux joies d'un festin près du sang d'un ami ou d'un membre même de sa famille.

Iais les cailles comprennent mieux que moi le soidisant point d'honneur, et, comme les ferrailleurs émérites, elles sont toujours disposées à batailler, même pour une mouche ou pour un atome. Dans ces tournois, certaines cailles acquéraient une réputation considérable, et leur nom était inserit parmi ceux des illustrations de 


\section{$-508-$}

leur époque. Ponr comprende jusqu'à quel excès de folic les anciens ponssaient la vénération à l'égard des cailles cólebres, il suffit de lire le lait rapporté par Ildrovande, tom. II, fas. 161. Cet auteur alfirme qu'Auguste fit punir de mort un préfet d'Egypte qui, par raffinenent de sensualité ou d'orgueil peut-être, arait osé faire acheler et ensuite servir sur sa table une caille illustrée dans maintes rencontres.

Le deuxième genre de combat (Jul. Pollux., de Ludis, ch. $\mathrm{x}$ ) avait lieu entre un homme et une caille. Celle-ci se trouvait renfermée dans une grande boìte découverte, sur le fond de laquelle était tracée une circonférence n'occupant qu'une partie du fond de la boîte. L'homme se servait d'un de ses doigts pour attaquer la caille, en pesant sur la tête ou sur le dos de l'viseau. Celui-ci, bien entendu, arait toute liberté pour se défendre : s’il soutenait l'attaque sans sortir de la circonférence, il était déclaré vainqueur, comme un preux ne reculant jamais d'un pas; si, an contraire, la caille, fatiguée des coups de doigt, se réfugiait en dehor's de la ligne courlıe, elle était déclarée lâche et vaincue.

Les Grees avaient nommé la caille ortris, dont lit racine est onxwir. Ce verbe a, selon Alexandre, plusieurs sens. IIomère lui donne la signification "d'exciter une tempète, un combat, ") et l'humeur batailleuse, (querelleuse de la caille justifie cette acception. De plus, il est mmployé dans le sens de "réveiller, mettre en mouvement, ) et il signifierait alors, " oiseau qui réveille, qui met en mouvement " ou " qui se met en mouvement." La caille, comme le eoq, véritable type et chef des gallinacés, chante de très-bonne heure, et son chant trèssonore et très-ribrant est un réveille-matin qui appelle les villageois et les engage a se mettre au travail. La raille de l'ìle de Java est appelée par les naturels "le réveille-matin. " Dans la trusieme aeception, qui est 
encore mieux fondée que les deux premières, ontrus représenterait parfaitement l'oiseau " qui se met en monvement » et qui se livre à des pérégrinations régulières. Cette explication serait d'autant plus juste, que les Grecs devaient chercher à caractériser la caille par une dénomination indiquant le point de vue le plus important pour eux, celui qui leur procurait chaque année d'immenses ressources. La caille, en effet, entreprend, deux fois par an, des voyages, non pas en zigzag comme le jaseur de Bohême, mais d'une manière régulière. Chaque année des multitudes de cailles, dont le nombre s'élève ì plusieurs millions, abandonnent les déserts de l'Afrique, dans le mois d'avril, pour se diriger vers les différentes contrées de l'Europe. Elles entreprennent ce voyage le soir ou de grand matin, afin d'éviter plus facilement la serre des oiseaux de proie; elles avancent ou retardent le moment du départ selon les variations du vent. Le vol de la caille est lourd et peu soutenu; aussi cet oíseau ne saurait-il parcourir une assez longue distance qu'autant qu' il est secondé par un vent favorable. Les anciens n'ayant jamais pu, à cause du moment où s'effectuent les migrations des cailles, constater leur départ, pensaient, avec quelques modernes, que ces oiseaux passaient l'hiver dans des grottes sous l'influence d'un sommeil prolongé. Cette erreur cependant n'était pas générale ; car plusieur's auteurs ont donné sur le voyage des cailles de curieur renseignements. Ainsi Pline, cité par Buffon (vol. II, édit. in-4º p. 2:3\%), dit que les cailles, surprises et fatiguées par les vents contraires, se reposaient en si grand nombre sur les navires qu'elies rencontraient, que ceux-ci coulaient à fond sous le poids de leur nouvelle cargaison. Pline a oublié de constater quel était le tonnage de ces navires; peut-être appartenaient-ils à la flotte alcyonnienne. Etait-ce pour éviter ce malheur commun que les cailles, selon Aldrovande (t. II, p. 13̈6), avaient recours 
it une préeaution ingenieuse? Chacune d'elles, dans le dirsert du Sahara, wu il y en a des millions, se muni--ait d'une petite planche bien préparée; ce qui suppose qu iil levait exister d immenses depots de ces planches. Comment la caille tenait-elle cette planche? Je lignore. P’uis, $\therefore$ elle desait etre une planche de salut sur la mer, no: devenait-elle pas un sérieux enbarras pour acomplir un wrathe prolongé? Isrel, laissons de cóté ces petites diffirultí, et suivons le récit d'Aldrovande. (Juand les caillese trouvaient fatigues et qu elles ne rencontraient pad iles ou de vaisseaux puur se reposer, chacune dielles - laissait tomber a la mer en tenant la planche sous ses pattes. Cette planche devenait alors, pour chaque caille. une esprece de radeau sur leruel elle se rejosait. "si non ¿े veru, è bene trovato : si ce n'est vrai, c'est bien trouvé. " A près quelque tenus de repos, les cailles re[renaient leur essor; emportaient-elles une seconde fois leur petite planche? - Aldrovande ne le dit pas d'une maniere pusitive; rependant cette upinion me semble. dícumler naturellement de son récit, puisque cet auteur assure que les cailles se délassent de temps en temps, en voguant sur les flots, de la fatigue quelles iprouveraient de naviguer dans l'air. Pline (liv. IV, ch. xxul) fretend que chargue caille, afin de se soutenir cuntre le rent, avait soin de prendre dans son bee, tuut juste, trois petites pierres, yrovision plus facile it faire datns les -ables de l'Afrique que ne le serait la rencontre dune petite planche. Je pense que ers pierres etaient destinies it servir d'un lest analogue à celui dunt se munisornt les aripunates, et que le joids en devait varier avec celui desailles. Appien dunne une autre explication de lusage 1. cos purres : il prótend qu elles ne servaient aux cailleyue funr savuir sil était temp̧s su non do se reposer. f.Il diantres termes, que pour ètre averties si elles

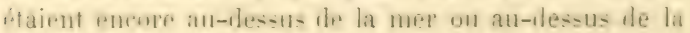


terre. Voici l'explication que cet auteur ajoute. Il paraît, selon lui, que la caille a l'ouïe bien plus perçante que lit vue (ce qui se comprend très-facilement pendant un voyage de nuit). Lorsque la bande voyageuse doutait encore qu'elle fût au-dessus des flots, chaque caille, prohablement à un signal donné, laissait tomber une des précieuses pierres, et, selon la nature du bruit qu'elles produisaient en touchant l'élément liquide ou la terre, lis troupe savait s'il fallait s'arrêter ou continuer son voyage. L'expérience ne pouvait être faite que trois fois; dès lors les cailles ne devaient pas la commencer trop tôt.

Continuons nos excursions dans le pays des fables. Un certain nombre d'oiseaux d'espèces différentes se joignent nux cailles pour effectuer ensemble leurs pérégrinations; ils s'aident ainsi mutuellement à vaincre la résistance du vent et à triompher, par leur multitude et par leurs cris dirers, des attaques de leurs ennemis.

Il est bien clair que les oiseaux qui s'unissent ainsi sont doués à peu près de la même puissance de vol. C'est pour cette raison que les râles de genêt accompagnent ordinairement les cailles. Plus forts que ces dernières, ils occupent, à ce qu'il paraît, les premières places, et semblent les chefs de file.

Mais, quand la troupe voyageuse s'abat sur les rivages curopéens, les individus qui la composent sont tellement. fatigués que, pendant les premières heures de leur arrivée, il est facile de les prendre à la main. Les viseaux de proie peuvent, sans effort, en faire d'immenses hécittombes, et les râles, comme étant au premier rang, fournissent plus de victimes que les cailles. L'imaginattion des anciens s'est emparée de ces faits bien simples, ret les a dénaturés en les embellissant. Le râle de genêt. a été nommé par eux ortsgoutras, de ortsigs, "caille, " et Mìtı́k, " mère, " c'est-it-ilire " mère des cailles, " rt. on a supposé ì celte prétendue mère un tel dévonement 
pour son innombrable progeniture, quelle writ so mettre au premicr rang pour sauver ses enfants en se laissant immoler. D iatres l'appelaient "roi des cailles; " et prétendiaient que, comme Decius Mus, il se sacrifiait pour le salut de la patrie, et que, comme dans la fimille de cet illustre consul romain, le dévouement à la patrie, chez les râles conducteurs, était véritablement híréditaire. Pour le coup, dans notre siecle de progrès, on voit bien qu'un pareil sacrifice ne doit citre qu'une fiction.

Passons maintenant aux réalitís. Dans le mois d'arril, des troupes innombrables de cailles quiltent les plage: re l'. Ifrique, et profitent d'un vent favorable jour ste diriger ver's les cuntrées méridionales de l'Europe. Si lr vent change de direction, les cailles s'alualtent dans lit mer où alles trourent promptement la murt. Si quel ju. navire se prísente aux royagenses, elles sempressent de renir se reposer sur les mâts, sur les cordiages et mème sur le pont, et lia, elles se laissent puende lacilement à la main.

Elles montrent en cela du bon sens; du moment qu'elles sont condamnées à une mort inévitable, elles font bien de préférer celle qui, du moins, ne sera jas sans fruit pour l'homme. En effet, les répuipages trourent ainsiune ample et délicate provision; car ils ne partagent pas les préjugés des anciens qui, d'après l'line (lix. X, cap. xxur), avaient de la répugnance pour la chair des cailles, parce qu'elles mangeaient de la gzraine d'ellibure, ot qu'on les soupconnail d'etre sujettes an mal carue. si les vents, an contraire, ont favorisé le vol des cailles, celles-ci viement se reposer sur les plages de l'Wurope móridionale et surtout dans les îles, où elles font une halte avant de gagner la terre lerme. Jes lieux de leurs stations citant commus, ainsi que les vents qui dirigent lour wol et le temps de leur départ, il s'mstuit que les

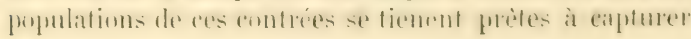


les pauvres voyageuses. La chasse en est très-facile. Les cailles, tant elles sont fatiguées, se laissent prendre ì la main, ou couvrir avec d'immenses filets étendus sur le bord de la mer. L'île de Délos, l'une des Cyclades, si célèbre dans les annales de la mythologie, a été de tout temps un lieu de repos privilégié pour les cailles, qui s'y arrêtaient en grand nombre, à ce point que les anciens l'avaient nommée Ortyggia, du mot ortygs, "caille. " Pour se faire une idée approximative de la quantité des cailles capturées, il suffit de constater, d'après Buffon, que dans les environs de Nettuo, près de Naples, plus de cent mille ont été prises en un seul jour. L'érêque dans le diocèse duquel se trouve l'île de Caprée, célèbre par le séjour et les crimes du sombre et cruel Tibère, est appelé l'évêque aux cailles, parce qu'il prélève une dîme sur celles qui sont prises dans l'île de Caprée. C'e revenu est estimé de 23 à $2 \%, 000$ fr. par an, ce qui suppose un nombre incalculable de cailles. En effet, un de mes honorables amis, M. de Joannis, m'a dit que, lorsqu'il allait en qualité de lieutenant de vaisseau et de commandant en second du Luxor, chercher en Égypte l'obélisque destiné à embellir la place de la Concorde à Paris, il avait vu vendre, à Alexandrie et dans les autres villes de ce pays, la cagée de cailles pour 10 fr. Chaque cagée renferme cinq cents cailles, ce qui fixe le prix de chaque caille à deux centimes. On peut, d'après cette donnée certaine, calculer le nombre de cailles que doivent capturer les habitants de Caprée, pour que la dîme prélevée

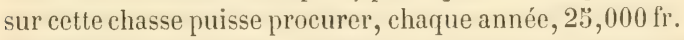
à l'évêque de ce diocèse. J'ajoute ici quelques détails sur les précautions que prennent les cailles pour effectuer leur retour en Afrique, et sur les moyens employés par les Arabes pour s'en emparer. Je dois ces notes à la bienveillance de $\mathbf{~}$. de Joannis, et je me borme à les transerire. 
"Dieu a donné à la caille un instinct merreilleux, qui "lui sert à se diriger vers la mer, sans avoir besoin de "boussole et en suivant la ligne la plus courte. Tuns "les navigateurs qui rencontrent les cailles, lorsqu elles "effectuent leur seconde migration, savent que ces " viseaux tendent directement vers le sud. Les cailles "sont rarement seules dans ce voyage, mais ordinaire"ment sept à huit ensemble. Leur vol très-rapide effleure " la surface de la mer, et, lorsqu'en route elles trouvent " du gros temps qu'elles n'avaient pas prévu, elles sui"vent l'ondulation des grandes lames, rasant toujours " la surface de l'eau. Cette méthode est admirablement " combinée; car, sans cesse dans le ereux des lames, " elles sont toujours déventées par la haute montagne " d'eau qui est devant elles, et c'est ainsi qu'elles jouis"sent d'une plus grande ficilité pour vaincre le grand " courant aérien ù̀ elles se trouvent engagées. Ce qu il " $\mathrm{y}$ a de plus admirable dans ces migrations, aprés la "faculté qu'ont les riseaux de se diriger sans boussole, "cest la force que manifestent les cailles pour entre"prendre un vol non interrompu de six ì huit heures; " car elles ne peurent guère parcourir plus de cent vingt " kilomètres à l'heure, et, selon qu'elles partent d'un "point plus ou moins éloigné de la côte d'Áfrique, elles "se trouvent entrainées à effectuer une tratersée plus " ou moins considirable. (Muand les cailles sont contra" rices dans leur vol par des brises contraires et violen"tes, elles tombent de fatigue et se noient; ou, si elles "rencontrent sur leur route un bâtiment, elles s'en"pressent d'y chercher un peu de repos et n'y trouvent "qu'un autre senre de mort. IIorriblement fatiguis, " ces paurres viseaur nont pas la force de s'envoler, et "sont facilement capturís par les hommes de l'íquipage " qui savent très-bien qu il ne faut pas chercher ì saisir "les cailles au moment où elles viennent de se poser sur 
"le pont ou sur les cordages, mais attendre quelques "minutes, afin que, refroidies, elles ne puissent pas re" prendre facilement leur essor. C'ette migration des cailles "donne lieu à un grand commerce, dans lequel les "Arabes réalisent d’assez beaux bénéfices. Voici la ma" nière dont ils capturent les cailles sur les immenses "plages de sable, qui se déroulent dans les environs "d'Alexandrie. Deux Arabes s'unissent pour la chasse " aux cailles; l'un d'eux porte sur son bras un petit filet " fin et noir, dont les mailles ont à peu près trois cen" timètres carrés, représentant une simple nappe de " soixante-dix centimètres carrés, aux deux extrémités " de laquelle est fixée une corde légère en poil de cha" meau et longue d'environ dix mètres. Mlunis de ce " filet, les deux Arabes regardent autour d'eux en se " tournant le dos, afin d'embrasser l'horizon tout entier. "Sitôt qu'une caille vient se reposer sur le sable, les " chasseurs se dirigent de manière à se mettre sous le "vent; arrivés à une trentaine de pas, ils déploient leur " filet, et, prenant chacun le bout d'une des ficelles, ils "s'éloignent l'un de l'autre, pour tenir trèz-tendue la "petite nappe du filet. Celle-ci, soulevée par la brise ou "par la rapidité des deux $\Lambda$ rabes, se tient à peu près "horizontalement à un mètre du sable, puis, aussitôt "que la nappe se trouve au-dessus de la caille, les chas" seurs la laissent tomber sur leur proie. L'un des deux " se dirige vers la caille pour la saisir avec la main. C'est " alors que le pauvre oiseau, épuisé par la latigue d'un " voyage pénible et très-long, fait un dernier effort pour "s'échapper; mais soudain il se trouve enlacé dans le "filet : l'Arabe le prend alors, lui coupe une aile, le "renferme dans une cage, et, lorsque celle-ci sera " pleine, c'est-ì-dire quand elle en contiendra cinq cents, " elle sera vendue sur le marché d'Alexandrie $10 \mathrm{fr}$., " c'est-à-dire deux centimes pièce. Le prix si minime de 
" ces cailles prouve que les Arabes réussissent parfaite" ment dans cette chasse, et ils doivent leurs succès ì "leur vue très-perçante, car la couleur de la caille se "marie tellement avre celle du sable qu'elle échappe " aux regards des Europúens. Celles des cailles qui ne " sont pas capturées par les Arabes pénètrent à plus de " quatre cents kilomètres vers le sud, el c'est dans les " champs de lentilles de la haute Egypte qu'elles fixent "leur séjour privilégié. "

Cette chasse pratiquée par les Arabes a-t-elle eté importíe en Europe, ou bien sont-ce les habitants du dísert qui nous ont imités? Je l'ignore. Tout ce rque je sais, c'est que, dans ma jeunesse, je me suis livré sout la direction d'un trappeur émérite, dont j’ai dijjà parlí, it une chasse qui n'itait autre chose que celle qui est exécutée par les Arabes, arec des modifications nécessitées par la nature du terrain sur lequel elle arait lien. Cette chasse était-elle une faute, un délit? S’il y a eu faute, j'espère en avoir le repentir; s'il y a eu délit, je me rassure, car il doit être bien preserit. Done, il y a plus de trente ans, mon vénérable chef de file me conduisait, vers le suir, dans les terrains ensemencés de blé; puis il faisait retentir avec une grande perfection le cri de son appeau, et, quand il croyait avoir recomnu l'endroit où se trouvait la caille qui avait répondu à sa vois de chanterelle, il déroulait un filet semblable à celui qu'emploient les Arabes, et nous cuurions en le laissant voltiger au-dessus des blés. Le bruit qu'il faisait en flottant sur les moissons déterminait la caille à s'envuler, et souvent elle se trouvait enlacie dans le filet. D'autres fois, il avait recours à un chien couchant, l'envoyait à la recherche, et, quand il l'apercevait en arrêt, nous nous empressions de suspendre le filet au-dessus et un peu au-devant de la tête du chien, puis il donnait au fidèle animal l'ordre de s'avancer, et à ce moment la caille, en 
s'envolant pour échapper à son ennemi, se jetait dans le filet qui devenait sa prison.

Le passage des cailles dure près de deux mois; ce sont les plus vieilles qui partent les premières, par la raison toute simple que très-souvent, au moment de ces départs, les jeunes ne sont pas encore parvenues à leur développement complet. Dans le cours de ces deux mois, les habitants des principaux lieux où viennent aborder les cailles sont occupés à les capturer, à les plumer, à en extraire la graisse, puis à les saler et à les entasser dans des barils que l'on expédie dans tout le Levant. Pendant leur séjour dans notre pays, les cailles conservent les mœurs des habitants des pays chauds; comme les Napolitains ou les Espagnols, elles circulent et mangent le matin et le soir, puis le reste du jour, elles sont étendues nonchalamment le ventre au soleil, une patte allongée, savourant, en quelque sorte, les bienfaisantes émanations de cet astre, et s'abandonnant aux douceurs du sommeil. Les cailles ne se perchent jamais, si ce n'est sur les vergues des navires qu'elles rencontrent dans leurs migrations; elles se plaisent à courir dans les herbes des prairies ou dans les sillons de blé; là, elles se nourrissent d'insectes et de graines. Aussi quittent-elles notre pays vers la fin de septembre ou vers les premiers jours d'octobre, époque à laquelle insectes et graines commencent à leur manquer, ainsi que la vivifiante influence de la chaleur. Leur retour en Afrique n'est done pas un caprice, mais le résultat d'une nécessité. La preuve évidente de la justesse de cette assertion, c'est qu'un certain nombre de cailles séjournent toute l'année dans le midi de l'Espagne et de l'Italie, où elles trouvent, en tout temps, insectes et chaleur.

Avant de donner quelques détails sur la nidification des eailles et pour terminer cette longue digression, il me reste à expliquer le not colurnix, nom savant de la 
malle. Pour résoudre cette difficulté, j'anrai recours it Idolphe Pictet. (tum. I"r, p. 4!16), lui laissant bien volontiers la respousabilité de la dícision. D'après cet inteur, coturnix serait un ancien nom arien, composé probablement du sauscrit liutu, "îpre, âtre, perçant, " et de rana, " cri, " dérivant lui-même de "ran," sonare, "crier, " etc., et coturnix serait pour coturanix, comme corves pour coravus. Ainsi, en m'inclinant profondément devant l'autorité de l'ictet, f'admets facilement que le mot scientifique, ainsi que le mot vulgaire, est londé sur le chant ou plutòt sur le cri sonore et retentissant de la caille.

Ma tiche s'avance, et je l'achère par quelques renseignements sur les mours de la caille. Dans cette espèce, les mâles sont beaucoup plus nombreux que les femelles; aussi, en capturer une assez grande quantité au moyen de l'appeau serait rendre service à la propagation de l'espèce, en facilitant des unions légitimes, unions trep souvent combattues par des prétendants malheurenx qui, pour se venger de n'avoir pas de famille, troublent celle des autres, brisent les œuf's et maltraitent les femelles. Mais, si nous retrouvons dans les cailles mâles l'ardeur de certains guerroyeurs des siecles passés, frappant d'estoc et de taille tous ceux qu'ils rencontraient, nous ne retrouvons pas, parmi les niseaux de cette espèce, les chevaliers protecteurs de lat veuve et de l'orphelin. Les pritendus chefs d'une famille qui n'existe pas ricllement ne s'oecupent ni de protéger, ni de nutrir la mère et les petits. La paurre femelle est obligie de pourvoir it sa nourriture et de couver ses œufs. Aussi s'efforce-t-elle de compenser, par' la chaleur excessive qu'clle leur communique, le temps pendant lequel clle a été obligie de les abandonner pour chercher quelques insectes ou fueleques grains : elle parvient ainsi ì un tel degre de surexcitation, qu'elle n'apergoit et ne eraint aucun dan- 


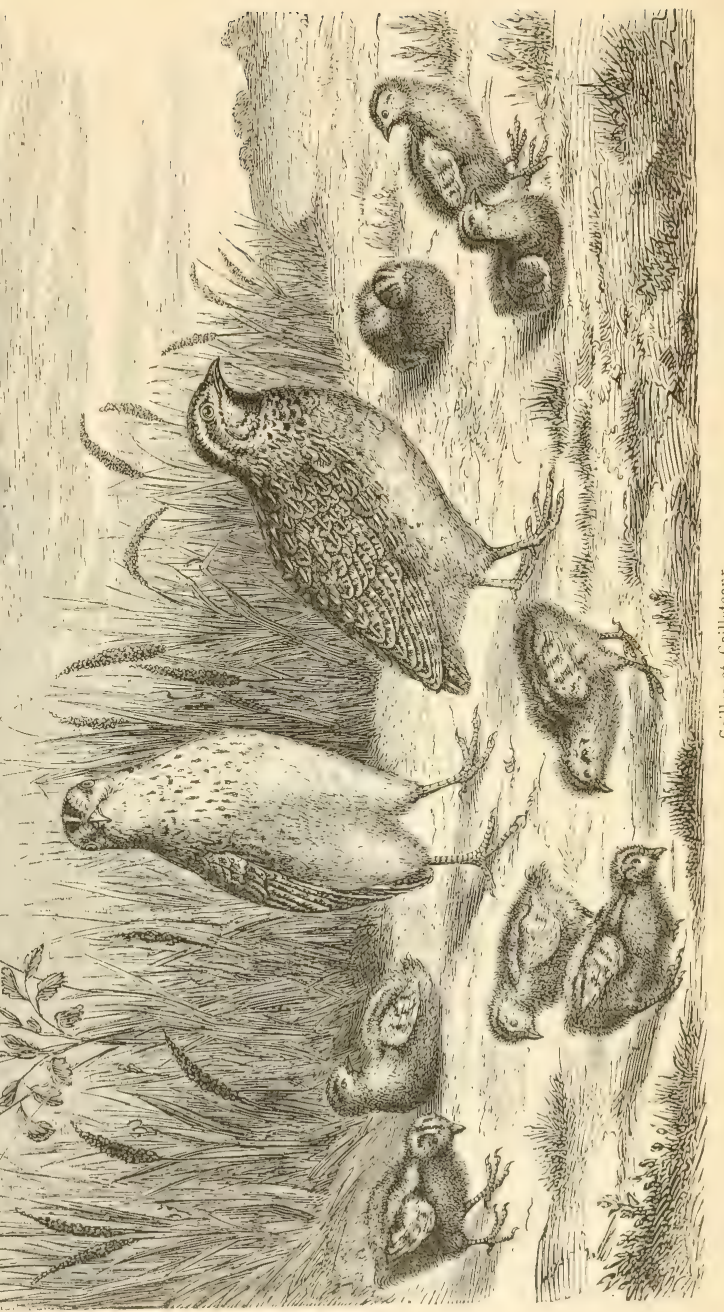



ger, et, dans cet état, elle se laisse prendre à la main ou faucher sur son nid.

Celui-ci est composé de brins d'herbe, tapissant une petite excavation circulaire que la femelle a creusée avec ses pattes. Les œufs, au nombre de dix à seize, diffèrent beaucoup de forme, de grosseur et de couleur; ils sont presque tous ventrus; leur grand diamètre varie de $0^{\mathrm{m}}, 026$ à $0^{\mathrm{m}}, 029$, et le petit de $0^{\mathrm{m}}, 022$ à $0^{\mathrm{m}}, 023$. La coquille de ces œufs est ordinairement d'un blanc jaunâtre plus ou moins prononcé; les uns sont parsemés uniformément de petits points noirâtres; d'autres sont couverts de taches d'un brun foncé et dont les proportions sont bien différentes. Je possède dans ma collection huit œufs de caille trouvés à Villevêque, et dont la couleur jaunâtre est presque entièrement recouverte par trois ou quatre larges taches noirâtres.

Quand la mère s'éloigne de son nid, elle a l'habitude de couvrir ses œufs avec une épaisse couche d'herbe, soit pour les empêcher de se refroidir, soit pour les dérober à la vue de ses ennemis ou même à celle des mâles. Lorsque les petits sont éclos, la femelle s'occupe d'eux avec beaucoup de soin, du moins pendant quelques jour's; car les cailleteaux peuvent, de très-bonne heure, se suffire à eux-mêmes et ne sont pas de caractère à subir longtemps une tutelle ou ì suivre une direction. Le soir, la mère les appelle, les réunit et les cache sous ses ailes. La disposition à une vie insubordonnée est tellement évidente chez les petits cailleteaux, que les anciens auteurs, et Aristophane entre autres, comparent les écoliers querelleurs, mutins, à de petites cailles renfermées en cage. Dans la comédie de la Paix, v. 788 et seq., Aristophane appelle crilleteaux, des jeunes gens criailleur's, indisciplinés, difficiles à tenir, comme sont les cailles captives. En effet, dans la cage où on la retient, encore plus que dans les plaines, la caille manifeste son ca- 
ractire batailleur ef ses aspirations ardentes pour une liherté sans contrainte. Sians exise en momement, elle fuit loute société ou ne l'accepte un moment que pours: baltre avec les autres captifs. Si l'on n'avait pras la précaution d'étendre une toile bien mobile pour former le dessus de la cage, la caille se briserait la tele contre les barreaux sujurieurs de sa prison. (Quelques naturalistes ont affirmé que, lès que les petits railleteaus pouvaicnt se passer de leur mère, celle-ci faisait une seconde convás. Uautres pensent que cette seconde couvie n'a lieu que pour les cailles dont les ceufs ont été brisés par la fureur des màles rípudiés par les femelles. Je crois que la première opinion aurait de la peine à être défendue, si l'on pense aux époques de l'arrivée et du départ des cailles. Il serait difficile l'admettre que le séjour des cailles dans nos pays pût être suffisant à l'éducation de deux couvées, et surtout pour que les cailleteaux de la dernière couvée fussent assez forts au moment d'entreprendre leur royage d'outremer. Les deux couvées ne pourraient être admises réellement que pour les cailles arrivées les premières, et cette opinion ne serait alors qu'une exception, mais nun la règle générale.

Le mâle se distingue facilement de la femelle par la tache noire qu'il porte sur la gorge, et dont la couleur se prononce ì mesure que les dimensions croissent avec l'ìge de l'oiseau. Quelques ornithologistes ont voulu re.comnaître dans la caille deux races différentes, la petite et la grande. Cette distinction n'existe pis réellement: chez les cailles, comme chez tous les autres oiseaux, il y a des sujets plus ou moins liorts, selon leurs dispositions naturelles, lit nourriture qu! ils trourent et les lieus qu'ils fréquentent.

Je terminerai cette petite étude sur la caille par une simple remarque : e'est que dans cette espèce il n'existe ni famille, ni esprit de lamille, comme chez tous ceux 
dont le caractère est difficile, batailleur, opposé ì toute idée de soumission, et qui, enclins à une vie de sensualité, ne se laissent diriger que par le plus méprisable do tous les instincts, celui d’un grossier égoïsme.

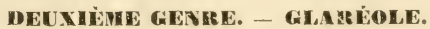

\section{GLARÉOLE A COLLIER. - GLAREOLA TORQUATA.}

Les pages que je vais consacrer à la glaréole seront peu nombreuses. Elles comprendront la solution de ees trois problèmes : la glaréole vient-elle en Anjou? sa place la plus naturelle est-elle parmi les gallinacés? enfin, quelles sont les étymologies des dénominations données i cet oiseau par les savants ou par le vulgaire?

Pour répondre à la première question d'une manière affirmative, je n'ai d'autre autorité que celle de plusieurs amateurs et chasseurs qui prétendent avoir tué, à différentes fois, des glaréoles dans les limites de notre département. Je n'avais aucune raison personnelle d'admettre cet oiseau dans la Faune de Maine-et-Loire; car, en lui donnant le droit de cité parmi nous, c'était augmenter encore un travail qui me semble déjà assez étendu.

Quant à la seconde question, elle est beaucoup moins facile à résoudre. La glaréole a été et est encore un des oiseaux les plus difficiles à classer; selon qu'on la considère à un point de vue ou à un autre, on la range dans telle ou telle catégorie. Les naturalistes, qui ont été frappés de ses ailes longues, de sa queue fourchue, de son vol rapide et ondulé, accompagné d'un petit cri plaintif, l'ont placée naturellement parmi les hirondelles sous le nom d'hirundo pratincola, "hisondelle qui fréquente les prairies, les lieux humides. ") Ceux qui n'ont considéré que la longueur de ses tarses et sa manière de 
courir sur les sables et mème sur les grandes routes, sans se préoccuper des passants, et en agitant sa queue comme le traquet, ont rangé les glaréoles parmi les ́́chassiers et les pluviers. D'autres enfin et en plus granrl nombre, faisant simplement attention à la forme du bec de la glaréole et à son habitude de courir, l'ont rapprochée des gallinacés en la désignant sous le nom de perdrix è collier, perdrix de mer, etc. Ces derniers auteurs ont-ils été mieux inspirés? J'en donte. Leur classification est-elle la plus rationnelle? Je ne le pense pats. C'est pour cela que je la placerai là où les savants le jugeront à propos, dès que j’aurai pu parcourir toute la Faune de Maine-et-Loire. En attendant la fin de ce rude labeur, la glaréole restera parmi les gallinacés, sans que je puisse encourir de graves reproches.

D'où lui vient le nom de glaréole à collier, qui n'est que la traduction littérale de la dénomination savante glarenla torquata? La glaréole se plaît sur les bords des vastes marais, des étangs, des cours d'eau et même des mor's intérieures. Elle fréquente très-peu les plages des grands océans; elle court avec une agilité remarquable sur les sables et sur les graviers répandus dans ses lieux de prédilection : cette habitude lui a fait donner le nom de glitéole, dérivé de glaren, "gravier, gros sable. ") (In la trouve en grand nombre sur les bords des marais salís de la IIongrie. Là, comme dans tuutes les contríes qu'clle habite, elle vit de ver's arquatiques, de mouches et d'insectes auxquels elle donne la chasee dans les rorseaux avec une grande rapidité et une estrême adresse. Souvent les glaréoles voyagent par petites bandes. C.elle'sci sont-elles formies d'une seule famille ou bien d'une runion d'amis? Je ne puis l'affirmer; ce qui cist bien démontré, c'est le sentiment de vive amitié qui lie entre eur tous les nembres de cette petite suciéti. Quand l'un d'eus est atteint par le plomb meurtrier, ses compa- 
gnons de voyage s'empressent auprès de lui, et plutôt que de l'abandonner, ils subissent presque tous le même sort, tant le chasseur est impitoyable et comprend peu un sentiment si généreux et si bien fait pour émouvoir, puisqu'il est si rare de nos jours!

Dans le midi de la France, la glaréole apparaît et niche d'une manière régulière, et là où l'on peut étudier plus facilement et en détail les habitudes caractéristiques de cet oiseau, les gens de la campagne, bons observateurs, l'ont désigné par ces mots piquo-ën-terra, pique-en-terre. Cette expression représente d'une manière bien naïve et bien expressive une habitude caractíristique de la glaréole : dans sa course très-rapide à la recherche des insectes, elle donne de fréquents coups de bec sans ralentir sa chasse, et, tout en saisissant arec une très-grande adresse la proie qu'elle rencontre, elle paraît frapper, piquer la terre. Quant à l'ípithète torquata, à coliier, elle sert à distinguer cette espèce de quelques autres, en faisont connaître une particularité remarquable de son plumage. Une jolie ligne noire se dessine agréablement sur la couleur jaunâtre de la gorge de l'oiseau, et représente assez bien un feston suspendı en forme de collier. Toutefois elle ne doit pas ce surnom ¿̀ une victoire, comme le célèbre romain Torquatus, qui fut ainsi désigné pour avoir enlevé à un Gaulvis, qu’il avait vaincu dans un combat singulier, le riche collier d'or dont celui-ci avait orné sa poitrine.

La glaréole niche ordinairement sur le bord des lacs salés, qu'elle recherche de préférence à tous les autres lieux. Le nid ne demande pas beaucoup de travail au mâle ni à la femelle; car ceux-ci choisissent de concert une petite excavation, soit naturelle, soit formée par le pied d'un cheval ou d'un bœuf; ils y réunissent quelques brins d'herbe, et c'est sur cette couche simple ef grossière que la femelle dépose deux ou trois œufs, rare- 
ment quatre. C'es œufs sont ventrus, d'une couleur d'un faune d'ocre sale, quelquelois un peu grisîtte ou même verdatre. Ils sont parsemés de taches irrégulières et asse\% nombreuses, les unes brunes, les autres d'un brun noir qui semble velunté. Le grand diamètre varie de $0^{\mathrm{m}}, 0: 30$ à $0^{\mathrm{m}}, 032$, et le petit de $0^{\mathrm{m}}, 020$ à $0^{\mathrm{m}}, 022$.

Ici je terminerai, ami lecteur, la tàche que je m'étais d'abord proposé de remplir : jaai parcouru en entier, it travers des difficultés de toute nature, les cinq premiers Ordres de la Faune de Maine-et-Loire.

Deux Ordres restent encore à expliquer : celui des Echassiers et celui des Palmipèdes. Plus tard, si Dieu me prôte vie, j'essaierai d'aborder ce nouveau labeur; mais, en attendant ce complément de mes Lssais étymologiques, puisse la bienveillance du lecteur trouver, du moins on partie, dans le travail qui lui est soumis en ce moment, lit rúalisation de la devise que jai adeptée :

Benedicite, omnes volucres cali, Domino!

Vous tous, oiseaux du ciel, bénissez le Seigneur!

(DANIEL, cant. 3). 


\section{TABLE MÉTHODIQUE}

DES MATIERES CONTENIES DANS CE VOIIME.

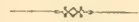

Pagez,

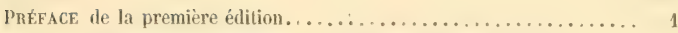

- de la deuxieme édition. ... .................... 3

- de la troisième édition........ ............... 11

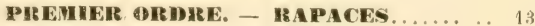

Familles. Gienres. $\quad$ Espèces.

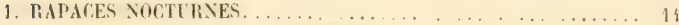

1. Cholette. ............. 16

1. Iulotte...... 16

2. Chevèche...... 22

3. Etiraie ....... 24

4. Brachyote...... 28

5. Grand-duc..... 29

6. Moyen-duc. ..... 31

7. Petit-duc...... 32

2. RAPACES DIURNES. ...................... 37

1. Vautour....................... 38

8. Catharte perenopt. 38

2. FAucon ................... 49

9. Pèlerin ........ 57

10. Hobereau ...... 58

11. Emerillon. ..... 59

12. Kobez........6 61

13. Crécerelle..... 62

3. Aigle .................. 64

14. Bonelli. .... 68

15. Criart........ 70

16. Botté......... 72

17. Pygargue...... 72 
Pamilles.

lienres.

Espices.

18. Balluzard ..... is

19. Jean-le-blanc. . is

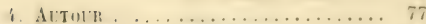

20). Antour. ....... 77

21. H.mpin....... 79

э. M $11 \ldots \ldots \ldots \ldots \ldots \ldots \ldots \ldots \ldots$

29. linval. . . . . \$ 81

23. Noir......... si

6. BUSE , . . . . . . . .

24. Bondrée. ..... \$ \$6

25. Commune.... ss

26. Pattue........ si

7 Bisin.................

27. Jes marais.. ... 93

28. Saint-Martin.... 94

29. Montagu .... 9. 95

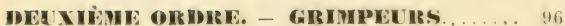

1. CUCULIDES ............................ 96

1. Cotcou ...................

30. (iris........ 97

31. Houx........ I11

9. PRORIOLSES..... . . . . . . . 10:3

1. Төнсн1................. 104

32. Torwol......... 104

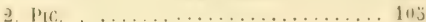

33. Vert ......... 110

3น. Cindre...... 115

35. Epeiche.... . 117

36. Haw......... $11 !$

37. Epeichette. . . 1:20

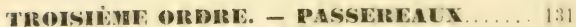

1. I.ATIROSTRES......................... 132

1. Exgoulevent ... . . . . . . . . . 133

38. Orelinaire ..... 133

2. Martinet ................. 136

39. be muraille.... 136

3. HIRUNIEI.I. . . . . . . . . . . . 111

40. De cheminée.... 1 1

41. De croisic...... 1:1

42. De rivage ...... I is

43. be rutier ..... 1601

4. (iont-Mutcuts . . . . . . . . . 161

14. liris ...... 162 
Familles. Gienres. Espèces.

2. DENTIROSTRES

45. A collier blanc... 162

46. Bec-figue. ..... 163

\#................................. 163

47. Grise........ 166

48. A poitrine rose... 167

49. Kousse........ 168

50. Ecorcheur...... 169

2. Merle................... 170

51. Draine. ...... 170

52. Litorne....... 174

53. Grive........ 175

54. Mauvis..., 177

55. A plastron. ..... 178

56. Noir.......... 179

3. Grand-Jaseur $\ldots \ldots \ldots \ldots \ldots \ldots \ldots, 180$

57. De Bohême..... 180

4. LoRIOT .................. 183

58. Ordinaire...... 183

5. Trapuet.................... 186

59. Motteux....... 186

60. Tarier........ 187

61. Pâtre........ 188

62. Oreillard...... 190

6. Fauvette................... 191

63. Rousserolle..... 192

64. Effarvatte.... 194

65. Verderolle ...... 196

66. Phragmite...... 197

67. Aquatique...... 198

68. Locustelle...... 199

69. Pit-chou...... 200

70. Rouge-gorge....202

71. Gorge-bleue .... 206

72. Rouge-queue. ... 207

73. De muraille..... 208

74. Rossignol.....2 209

75. Philomèle ....2 211

76. Orphée....... 212

77. A tête noire.....214

78. Des jardins .... 216

79. Grisette.......216

80. Babillarde...... 218

81. $\Lambda$ poitrine jaune.. 219

82. Mélanocéphale. . 222

83. A lunettes...... 222

84. Passerinette..... 223

7. Pullllot. ................... 224

85. Siffleur. ..... 225 


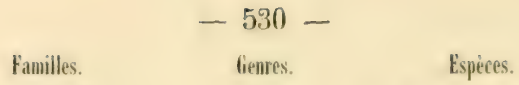

86. Filis........ 226

87. Véloce....... 228

88. Natterer.......2930

8. Acentrur.................230

89. Pégot........2 230

90. Mouchet........ 231

9. Roitelet. .................. 232

91. Huppé.........2 232

92. A triple bandeau.. 23 i

10. TROGLODTTE............... $23 \%$

93. D'Europe....... 234

11 Bergeronnette.................. 238

94. Grise....... 240

95. Lugubre. . . . . 240

96. Jaune........ 241

97. Printanière... . 242

12. Piमit .................

98. Richard........ 243

99. Spioncelle...... 2ik

100. Rousseline...... 2 2

101. Farlouse.......2 2 i7

102. Des arlures...... 249

103. Obscur. ........ 2:0

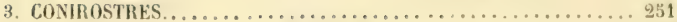

1. Alovette................... 259

104. Cocheris...... 273

105. Des champs...... 275

106. Lulu.......... 276

107. Calandrelle..... 277

2. MÉSANGE.................. 982

108. Charhomniere. ... 289

109. Petite charlonniere 290

110. Bleue.........291

111. Nonnette....... 293

112. Huppée. ....... 295

113. A longue queue.. 296

114. Moustache...... 298

3. Bruaxt..................... 299

115. Jaune.......... 307

116. Zizi.......... 309

117. Des roseaux ..... 311

118. Des marais..... 316

119. Ortolan....... 317

120. Prover. ...... 318

121. De pré ou fou. . 322

122. De neige ...... 323

4. Fringille................ 325

123. Chardonneret... 328

124. Tarin......... 331 
Familles.

Gienres.

Espèces.

125. Linotte......... 333

126. Sizerin........ 336

127. Pinson........ 340

128. Pinson d'Ardennes. 346

129. Moineau. ...... 348

130. Friquet. ...... 360

131. Soulcie....... 363

132. Verdier........ 364

133. Gros-bee....... 366

134. Cini .......... 368

5. Bouvreull. ................ 372

135. Gros-bec-bourreuil. 372

6. BEC CROTSÉ................. 375

136. Bec croisé des sa-

pins.......... 375

7. Etourneau,................... 378

137. Etourneau vulgaire 378

8. Martin...................... 384

138. Martin roselin... 38

9. Corbeau. ................... 394

139. Noir.......... 397

140. Corneille......400

141. Freux........ 406

142. Hantele . . . . 115

143. Choucas ..... 416

144. Chouc....... 417

10. FiE. ...................

145. Commune..... 422

11. GeAI.................... $\$ 31$

146. Commun...... 431

147. A calotte noire... 437

12. RotLlER.................. 438

148. Ordinaire...... 438

13. CASSE-No1X ............... 440

149. Casse-noix..... \$il

14. Sitelle. .................. 145

150. Sitelle torchepot. $4 \$ 5$

4. TÉNUIROSTRES

150. Sitelle torchepot.. tis

1. HuppE .............. $\$ 46$

151. Ordinaire. ... . \$46

2. Grimipereat .............. 449

152. D'Europe....... 449

3. TrCHOLROME,.............. 453

153. Tychodrome éche-

lette......... 453

5. SYNDACTYLES ........................ 455

1. Martin-pècheun ............. 456

154. Alcyon........ 456 
$-532-$

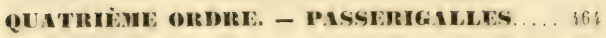

Fanilles. fienres. Espèces.

1. ColombINS............................ 482

1. Colomif.................... 469

155. Hamier....... 469

156. Colombin......4.473

157. Hivet. ........ 176

158. Tourterelle..... 477

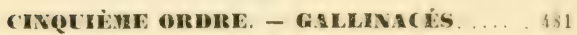

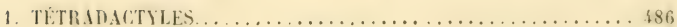

1. Perdrix ...................... 488

159. Houge........ $\$ 88$

160. Grise........ 496

161. Caille......... 500

2. Gilamb́ote. ................ 523

162. A collier...... 523 


\title{
TABLE ALPHABETIQUE
}

\author{
DES MATIERES CONTENUES DANS CE VOLLME.
}

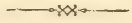

Pages. - mouchet (Accentor modularis) ............. 231

- pégot (A. alpinus)....... 230 Accipitrins ou Diurnes (Famille des) ............ 13

Aigle (Falco) ............ 64

- balbusard (Faleo haliætus). 74 .

- Bonelli (F. Bonelli)..... . 68

- botté (F. pennatus)...... 72

- Jean le Blanc (F.brachydactylus $\ldots \ldots \ldots \ldots \ldots \ldots .76$

- pygargue (F. albicilla).... 72

- tacheté ou criard(F.nœvius) 70

AlLEU (Allodium) .......... 265

Alouette (Alauda)........... 252

- calandrelle (A. brachydactyla).............. 277

- cochevis (A. cristata).... 273

- des champs ( 1 . arvensis). . 275

- lulu (A. arborea)........ 276

Autoun ordinaire (Falco palumbarius).......... 77

BEC-CRoIsé des sapins (Loxia curvirostra)......... 375

Bergeronnette (Motacilla).... 238

-- flavéole (M. flaveola)...... 243

- grise (M. alba)......... 240

- jaune (MI. boarula) ...... 241

- lugubre (M, lugubris!... . 240

- printanière (M. flava), ... 212

- Yarrell (M. Yarrelli)...... 240
Bouvreuil commun (Pyrrhula vulgaris) .......... 379

- ponceau ( $\mathrm{P}$. coccinea).... . 374

Bruant (Emberiza). . . . . . . . 299

— des marais (E. palustris). . 316

- de neige (E. nivalis) ..... 323

— de pré (E. cia) ........ 322

- de roseaux (E. Schæniclus). 311

- jaune (E. citrinella) .... . 307

- ortolan (E. hortulanus)... 317

- proyer (E. miliarius)..... 318

- zizi (E. cirlus)......... 309

Busard (Falco)............ 99

- de marais ou harpage (F. rufus $) . \ldots \ldots \ldots \ldots \ldots, 93$

- Montagu (F. cineraceus) .. 95

- Saint-Martin (F. cyaneus). 94

Buse (Falco) ............. 85

- bundrée (F. apivorus) . ... 86

- commune (F. Juteo)...... 88

- pattue (F. lagopus)...... 89

Cartharte percnoptere (cathartes percnopterus) . ...... 38

CASse-Norx (Nucifraga caryoca tactes) .......... 440

Colomerins (Famille des). . . . . 466

Colombe biset (Columba livia). . 476

- colombin (C. xnas)...... 475

- ramier (C. palumbus). ... 469

- tourterelle (C. turtur) .... 477

Chouette (Strix) . ........ 17

- chevêche (S. passerina) ... 22 
Chovette eftraie S. llammea).. 23 - hulotte (S. aluco) ....... 16 Conirostres (Famille des) . ... 251 Coucou (Cuculus) .... . . . . . 97 - gris (C. canorus)........ 97

- roux (hepaticus) ....... 101

Corrbeau (corvus) . . . . . . . . 39.5

- corneille (corone) ....... 400

- choucas (Monedula)...... 417

- choue (spermologus)...... $\$ 16$

- freux (frugilegus)....... 406

- mantelé (cornix) ....... 结

- noir (corax)........... . 397

Cuculines (Famille des). . . . . 97

DÉfEnsE des Buses.... . . . . . 123

- des Chouettes... ....... 123

- des Moineaux .......... 354

- ders l'ies. . . . . . . . . . . . 121

Dentirostres (Famille des) . .. 163

Exgouleveyt ordinaire (Caprimulgus Europzeus)..... 133

Epervier commun (Falco nisus), 79

Etourneau vulgaire (Sturnus vulgaris $) \ldots \ldots \ldots \ldots 378$

Faucon (Faleo) . . . . . . . . . 49

- à pieds rouges ou kobez ( $F$. rufipes) .......... 61

- crécerelle F. tinnunculus). 62

- émerillon (F. xsalon).... 59

- hobereau (F. subbuteo).... 58

- pèlerin ( $\mathrm{F}$. peregrinus).... 57

Fautette (Sylvia) . . . . . . . 191

_. aquatique (S. aquatica).... 198

- a lunettes (S. conspicillata) 222

- à poitrine jaune (S. hippolais) .............. 219

- à tète noire (S. atricapilla). 214

- babillarde (S. curruca).... 218

- des jardins (S. hortensis). 216

- de muraille 'S. phanicura!. 208

- ellarvate (S. arundinacea).. 19.4

- gorge bleue (S. suecica)... 206

- grisette (S. cinerea). .... 216

- locustelle (S. locustella) ... 199

- mélanocéphale (S. melanocephala)............. 222

- Orphee S. Orphea).... . 212

- passerinette (S. passerina). 223

- Philomile (S. Philomela). 211

- pit-chou (S. provincialis).. 200
Fuevetre phragnite (S. phragmitis ............... 197

- rossignol (S. luscinia).... . 209

- rouge-zorge (S. rubecula). 202

- rouge-queue (S. tithys)... 207

- rousserolle (S. turdoides).. 192

- verderolle (S. palustris)... 196

Fringille (Fringilla)........ 325

- chardomeret (F. carduelis) 328

- d'Ardennes (F. montifrin. gilla ) ........... 3 i 6

- friquet (I. montana) .... 360

- gros-bec (F. coceathraustes) 366

- gros-bec cini (F. serinus). . 368

- linotte (F. cannabina). ... 333

- moineau (F. domestica) ... 348

- pinson ( $F$. coelebs) ...... 341

- tarin (F. spinus)........ 331

- $\operatorname{sizerin}(\mathbf{F}$. linaria) .... 336

- soulcie (F. petronia)..... . 363

- verdier (F. chloris) ..... 364

Gallinacés............ 481

Glaréole a collier Glareola torquata).......... n00

GEAI commun (Garrulus glandarius $\ldots \ldots \ldots \ldots \ldots \ldots, 431$

- à calotte noire (G. melanocephalus).......... 437

Gobe-Movches (Mluscicapre) .... 161

- à collier (M. albicollis) .... 162

- bec-figues ( 11 , luctuosa) . . 163

- gris (M. grisola)......... 169

Girmpeuns (Ordre des)........ 96

Grimpereau ordinaire Certhia familiaris) ........ $\$ 49$

Hibou (Strix). ............ 28

- brachyote (S. brachyotos) 28

- grand-duc (S. bubo)... .. 29

- moyen-due (S. otus)...... 31

- petit-duc ou scops(\$. scops). $\quad 32$

HiRoxdelLE (Hirundo)....... 141

- de cheminée (H. rustica) . 141

- de fenetre (II. urbica)..... 151

- de rivage (II. riparia) ... $\mathbf{1 5 8}$

- de rocher (II. rupestris). . 160

Huppe ordinaire (Upupa epops). $\$ 46$ JASEuR (Grand) (Bombyeilla garrula)........... 180

Latinostres (Famille des) . . 132

LÉGENDE sur les alouettes..... 259 
LÉGENDE sur la fauvette du Cal-

vaire............. 230

— sur le pic vert ......... 112

LoRIot d'Europe(Oriolus galbula) 183

Martinet de muraille (Cypselus

murarius) ........ 136

Martin roselin (Pastor roseus). 384

MARTIN-PÊCHEUR (Alcedo ispida) 456

Merle (Turdus) ........... 170

- à plastron (T. torquatus). . 178

_ draine (T. viscivorus)..... 172

— grive (T. musicus) . .... 175

- litorne (T. pilaris)....... 174

- mauvis (T. iliacus) . . . . . 177

- noir (T. merula)........ 179

MÉSANGE (Parus)............ 282

- à longue queue (P. caudata) 296

- moustache (P. Biarmicus).. 298

- bleue (P. cæruleus)....... 291

- charbonnière (P. major)... 289

- petite charbonnière ( $P$. ater) 290

- huppée (P. cristatus)...... 295

- nonnette (P. palustris) .... 293

Milax (Falco milvus) ........ 81

- noir (F. ater).......... 84

- royal (F. milvus) ....... 81

OEgoliens (Famille des) ou NocTURNES............ 14

OEufs de Paques (Origine des). 46

Passereaux (Ordre des) ...... 131

Passerigalles .......... 464

Perurix (Perdix) .......... 483

— rouge (P. rubra) ....... 483

- grise (P. cinerea) ....... 496

— caille (P. coturnix)....... 501

PICs................ 105

PIC épeiche (Picus major)..... 117

— epeichette (P. minor)..... 120

- mar (P. medius) ........ 119

- vert (P. viridis).........110

PIE commune (Garrulus picus) 422

PIE-Grièche (Lanius) . . . . . . 164

- à poitrine rose (L. minor). 167

- écorcheur (L. collurio).... 169

- grise (L. excubitor)....... 166
Pie-grièche rousse (L. rutilus). 168

PIPIT (Anthus) .......... 243

— des arbres (A. arboreus) . 249

- farlouse (A. pratensis) ... 2 2 77

- obscur (A. obscurus) .... . 250

- Richard (A. Richardi).... 243

— rousseline (A. rufescens) . 2 2 7

- spioncelle (A. aquaticus) .. 24k.

Povillot (Sylvia).......... 22i

- à ventre jaune (S. flaviven-

tris) ............. 223

— fitis (S. trochila)........ 226

- natterer (S. Nattereri)..... 230

- véloce (S. rufa) ......... 228

- siflleur (S. sibilatrix) ..... 225

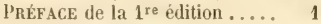

- de la 2 édition......... 3

- de la $3^{\mathrm{e}}$ édition......... 11

Proglosses (Famille des)...... 103

RAPACES (Rapaces)......... 13

- diurnes ............ 37

- nocturnes........... 14

RoITELET ordinaire ou huppé

(kegulus cristatus).... 232

- à triple bandeau (R. igni-

capillus)...........23t

RoLlien ordinaire (Coracias garrula).......... 438

SITELLE torchepot (Sitta europasa)............ 4 43

Syndactules (Famille des).... 450

Tenuirostres , Famille des) ... i if

Tétradact yles (Famille des).. i8z

Ticuodrome echelette (Tichodroma phœenicoptera)... 453

Toncul ordinaire ( I unx torquilla) ........... 10 i

Traquet (Saxicola) ........ 186

- motteux (S. cenanthe)..... 186

- oreillari (S. aurita)...... 190

— pàtre (S. rubicola).... . 188

- tarier (S. rubetra) ....... 187

Troglodyte d'Europe (Troglo.

dites vulgaris $) . . . \ldots . .234$

VAutour (Vultur),......... 39 



\title{
TABLE ANALYTIQUE
}

\author{
DES MATIÉRES CONTENUES DANS CET OUVRAGE.
}

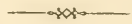

A Messieurs les membres de la Société linnéenne. - Objet de l'ouvrage . . . . . . . . . . . . . . . . . .

A mes Lecteurs. - Réponse à quelques objections, à propos de la méthode émise par l'auteur. - Étymologie du mot cirlus, employé pour désigner le bruant. - Trois sortes d'étymologies. - Encouragements adressés à l'auteur....

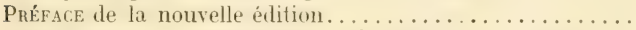

Premier ordre. - RAPACES. - Étymologie du mot rapace. - Division . . . . . . . . . . . . . . . . . . . . . . .

Rapaces nocturnes ou Egoliens. - Rapprochement entre les chouettes et les chèvres. - Le chat-huant ou chonette hulotte. - Son nom et ses mours. - Un nid pétrifié. Pourquoi les œufs des rapaces nocturnes sont de couleur blanche. - Observation à propos des taches qui se trouvent sur la plupart des œufs. - La chouette chevêche. La chouette effraie. - Légendes, erreurs et préjugés.....

Les hiboux. - Le brachyote. - Le grand-duc, le moyenduc, le petit-duc. - Mcurs des rapaces nocturnes. - Plaidoyer en faveur de ces oiseaux. - Comment chasse une chomette..............................

Rapaces diurnes ou Accipitrins. - Le catharthe alimoche. Ce qu'il faut entendre par oiseau sédentaire, et oiseau de passage accidentel ou régulier. - Voracité des vautours et des cathartes. - Un témoignage de Jules Gérard. Dissertation sur les mots vautour et vultur. - L'origine des œufs de Páques. - Une cérémonie de la fète de Pâques à la cathédrale d'Angers... . . . . . . . . . . . . . . . 37 
Les faucons. - Leur courage et leur ardeur it la chasse. Un épisode du siége de Sébastopol. - Un faucon contre une armée. - Singularité physiologique du faucon. - La faucon pèlerin; le hobereau; l'émerillon. - L'émerillon d'llenri II. - Le kobez; la crécerelle. - L'éducation d'une

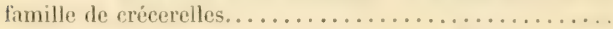

Les Aigles. - Comment mourut Eschyle. - Histoire des armoiries de la nation polonaise. - Mours des aigles. - Le Benelli; le rriard; le botte; le pygargue; le halbuzand; lo Je:m-le-Blanr . ....................... tif

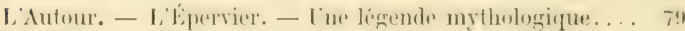

Les Milans. — Milan royal; milan noir............. 83

Jes Buses. - La luse bondrien, commune, pattue. - La chasse aux buses. - Une variété de buse qui pourrait être

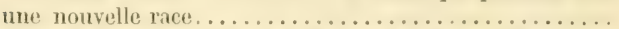

Le Busart des marais ; Saint-Martin; Montagu. - Équilibre entre les divers ordres d'oiseaux.............. .

Detixìne ondre, - GRIMPEURS ............. 96

Les Concous. - Intelligence et ruse de la femelle du concou. - Le coucou roux n’est pas une variété. - Discussion et preuves à l'appui. - Explication d'un proverbe popu-

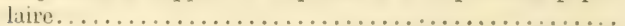

Le Torcol ou l'oiseau mystérieux................ 10 f

Les Pur.s. - Description anatomique. - Son rible et ses travaux. - Un pic enfermé dans un arbre et délivré à coups de bec. - Le Pic-Vert. - Histoire du roi Picus changé en oiseau. - Légende norwégienne de la mère Gertrude. — Commentehasse le pic-vert. - Le pic cendré. L'épeiche. Un épeiche apprivoisé. Le pic mar. L'épeichette. - Le procès des pics, des chouettes et des buses. Histoire d'un chène abattu. Une accusation mal fondée. Il faut compter les services avec le salaire. Dévouement du prèteur Tubéo. Une maison envahie par les fourmis. Conclusion en faveur des pies................................. 105

Troisième ondRE. - PASSEREAUX .............. 131

I. Fingoulevent. Comment il fait du bruit en volant. Th mot de Pline............................ 133

Le Martinet. La rapiditi de son vol. Particularités de son édueation. Hypothèse sur l'étymologie du mot martinet. .....

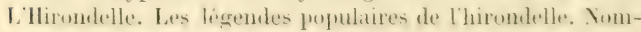
breuses élymologies. La philosophie du mot domestique. Les meurs honnètes de l'hirondelle. Sa tendresse maternelle. In lemoignage du vorageur Bernier. Laemple de 
tidelite eonjugale dans l'hirondelle. - Hirondelle de croisée. Comment se fait un nid. Le départ des hirondelles. L'hirondelle de rivage; de rocher. - Caractères distinctifs des quatre espèces d'hirondelles................ 141

Les Gobe-mouches: gris; à collier blanc; bec-figues...... 161

Dentirostres. Pie-grièche. Son caractère insociable. - Piegrièche grise; à poitrine rose; rousse; écorcheur. . . . . . 164

Le Merle. Discussion sur l'étymologie du mot. - Le merle draine; litorne; grive; mauvis; à plastron; noir. - Le chant du merle........................ 171

Le Jaseur de Bohème. Détails inérlits sur la niditication et sur les $a u f s$ du jaseur . . . . . . . . . . . . . . . . . 180

Le Loriot ou oiseau doré. Le nid du loriot. . . . . . . . . . 183

Le Traquet motteux; tarier; pàtre; oreillard. Moeurs immocentes et gaies du traquet.................. 186

Les Fauvettes. Leur mission. La rousserolle ou paisse des marais. Précaution d'une rousserolle contre l'inondation. - L'effarvate. Son chef-d'œuvre au milieu des roseaux. La verderolle; la phragmite; l'aquatique; la locustelle. Explication du mot calamoherpes. - Le pit-chou. Le rougegorge. Il est l'ami, le compagnon du bûcheron. Une légende bretonne mise en vers. Le rouge-gorge conduit les voyageurs. - La gorge bleue; le rouge-queue; la fauvette de muraille; le rossignol. - La fauvette Philomèle. Histoire de la fille de Pandion. Une famille métamorphosée en oiseaux. La fauvette Orphée. Encore un récit fabuleux. Les inconvénients de la curiosité. La fauvette à tête noire; des jardins; grisette; babillarde; à poitrine jaume; la plus babillarde des fauvettes; mélanocéphale; à lunettes; passerinette. Différentes opinions sur la présence en Anjou de certaines fauvettes. Difficultés d'étudier les habitudes de ces viseatux. . . . . . . . . . . . . . . . . . . .

Les Pouillots. - Quatre pouillots sont vus en Anjou : pouillot siffleur; pouillot fitis; pouillot véloce; pouillot natterer ou honelli .......................... 224

Les Accenteurs. - L'accenteur pégot; accenteur mouchet . . 230

Les Roitelets. - Le roitelet huppé; roitelet à triple bandeau. 232

Le Troglodyte d'Europe. Ses différents noms : berrichot, robertaud, mussot, etc. Courage de ce petit oiseau. Un troglodyte annonce la mort de César. L’aigle défié et vaincu par le troglodyte. I. chant du troglorlyle ef erlui du russignol. Nid remarquable du troglodvte. . . . . . . . . 23'

La Bergeromette. - Bergeronnette grise; bergeronuette lu- 


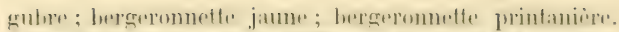

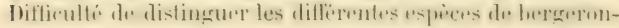
nettes. La bergeronnette lugubre et la bergeronnette Yarrell. Étymologie du mot boarula..............

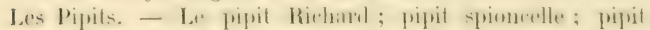
rousseline; pipit farlouse; pipit des arbres; pipit obscur. - Les métamorphoses du pipit spioncelle. Deux vers de Martial expliqués et appliqués par les campagnards. Pourquoi cet oiseau est appelé aussi spipolette. Une délicatesse des gastronomes romains. Portrait du pipit farlouse.

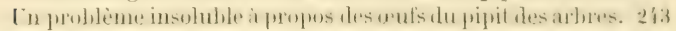

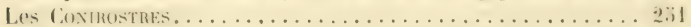

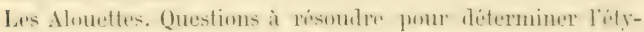

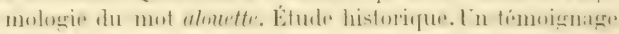
de Cicéron en faveur des Gaulois. Origine celtigue du mot

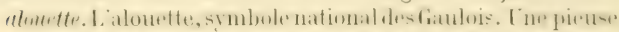

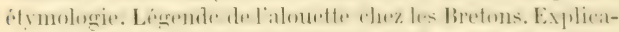

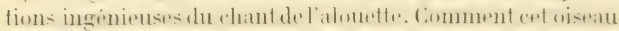
se laisse prendre aux miroirs. L'alouette et l'épervier. Histoire de Nisus et de sa fille Scylla. Détail anatomique. Les ennemis de l'alouette. Services que cet oiseau rend à l'agriculture. Rapprochement entre les mots alouette et alleu. Dissertation à ce sujet. Dire et placer, louer et partager. Conclusion. L'alouette est l'oiseau joyeux. . . . . . . . . 233

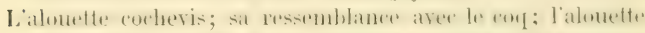

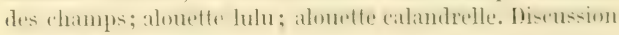
sur le mot calandre ...................... 273

Les Misanges. Leur aractere eruel at violent. Differentes hrymlhises sur le mot mismege. Ine explieation singulire d'un texte latin. Étymologie probable du mot parus, nom latin de la mésange. - La mésange charbonnière; mésange petite charbonnière; mésange bleue; nésange nonnette; étymologie du mot nome; mésange huppée; mésange a longue queue; un nid en forme de four; niesange

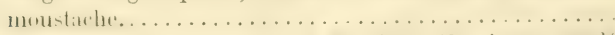

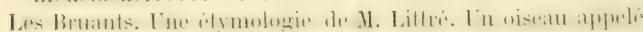
verdier, paree qu'il est jume. Une étude de mours pour expliquer un mot. Discussion de plusieurs hypotheses sur Jes noms du bruant. - Le bruant jaune; bruant des haies ou zizi; le mot cirlus expliqué; bruant des roseaux ou coqueluche. Qu'est-ce que la coqueluche? Le coucher des bruants. Deux expressions de la langue populaire. Bruant des marais; bruant ortolan; bruant proyer. Habitudes sin- 
gulières du proyer. Un chasseur en peine. Bruant de pré ou bruant fou; bruant de neige. Les plectrophanes....... 299

Les Fringilles ou les oiseaux briseurs. Le chardonneret. La victime d'un caprice. Le tarin. La linotte. Un conseiller général dans l'embarras. Pourquoi l'on dit « léger comme une tête de linotte. ") Le sizerin ou linotte des vignes.... . 325

Le pinson ou l'oiseau célibataire. Concours de chant pour une éfrouse. Les vaincus faciles à consoler. Un cruel abus de la gaieté du pinson. Dicton lorrain. Les ruses du pinson pour défendre ses petits. - Pinson d'Ardennes. - Le moineau. Son audace effrontée. Histoire d'un neveu et d'une troupe de moineaux. Des petits pois pour un héritage. Des moineaux qui ne respectent rien. Un nid dans un shako. Le moineau franc. Moine et moineaux. Un récit de Plıtarque. Ce qu'un moineau peut manger de chenilles dans un an. Les cerises du grand Frédéric. - Le friquet. Le soulcie. - Le verdier. - Le gros-bee ou l'oiseau pinceur. - Le serin ou cini. Étymologie du mot syrène.... 3 3

Le Bouvreuil, petit hœuf, ou perroquet de France........ 372

Le Bec-croisé des sapins..................... 376

L'Etourneau vulgaire ou sansonnet. Une opinion des anciens sur la langue des étourneaux. Explications diverses du dicton populaire : "étourdi comme un étoumeau. » Babil incohérent des étourneaux. Trop parler nuit. Un service rendu sans le savoir...................... 378

Le Martin-Roselin, ou le chasseur de sauterelles. Une invasion de sauterelles en Afrique, récit de M. de Joannis. Les martins expulsés, puis rappelés. Une exagération de Pline le naturaliste. Comment chassent les martins-roselins. Le respect qu'ils impriment aux Tartares. Chant remarquable du martin-roselin. . . . . . . . . . . . . . . . . . . 384

Le Corbeau, on lonseau mir. Hétamorphose de corones. Le ròle du corbeau dans l'histoire. Sa facilité pour apprendre à parler. - Le corbeau noir ; son excessive voracité ; une erreur de Lafontaine. - Corbeau corneille; l'oiseau solitaire; ce qu'il ne faut pas reprocher à la corneille et ce qu'il faut lui reprocher; qu'est-ce qre buyer aux comeilles? - Corbeau freux, le mangeur de blé; une colonie de freux en grand émoi; les dénicheurs intrépides; mœurs sociales des freux; ce qu'on peut dire en leur faveur; gastronomie anglaise. - Corbeau mantelé; corbeau chouc; corbeau choucas. Mythologie du choucas; le choucas au collége; 


\section{$-542$}

temdresse du rhumeas pom se's petits; 110 drame de famille ¿̀ la porte d'une cage.... . . . . . . . . . . . . . 394

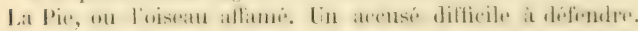
Insolence des neuf filles de Piérius. Caractère batailleur de la pie. Un nid fortement défendu. Décourerte extraordinaire dans une toufle de roseaux. Babil, inquiétude, intelligence de la pie...................... 422

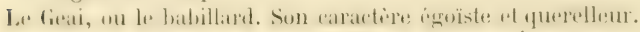
Le geai imite la voix de tous les animaux. Étymologie. Maru's et habitudes. - Le Geai a calotte noire......... 131

Le Rollier, ou geai d'Afrique................. 4.38

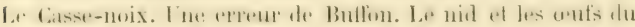

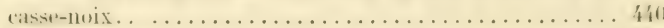

La Silello-turchepot. Explication de ce singulier nom ... . . 443

Les Ténumostres........................ Áti

La Huppe, ou coq puant................... fiti

L. Girmpresu d'Europe. Gripper, yrimper, yriffer........ fi!

Le Tichodrome échelette, ou papillon des montagnes....... \{.i...

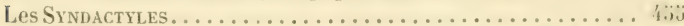

Le Martin-pechem aleson. Tondresse eonjugrale d'Alerm,

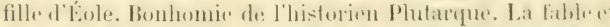

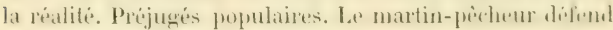
sa propriete. Chasse liem gardier..............

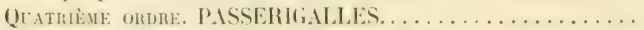

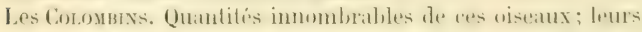
ravages; le commerce auquel ils donnent lieu en Amérique. Nceurs des colombins. La rapidité de leur vol. Les oiseaux messigers . . . . . . . . . . . . . . . . . .

Les Columbes. Le Pigeon ramiur. Simplicité du la columlu. Hypothèses très-contestables. Lutte de dérouement entre un père et une mère. Les ennemis des colombes. - Colombe colombin; biset. - Pigeon tourterelle. Un nid bien caché, mais non sauvé. Pourquoi les colombes étaient regardées, chez les Juifs, comme des oiseaux purs. Opinion

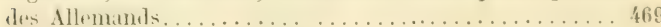

Cinquième ordre. - GALLINACÉS. . . . . . . . . . . 481

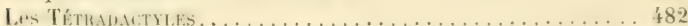

Les Perdrix. - La perdrix rouge; histoire merveilleuse du eri de la perdrix; moeurs singulières, insouciance, ruse de la perdrix. Le bartavelle ou perdrix des Cyclades ; elle est plus rusée encore que les antres perdrix. Moeurs différentes de la perdrix grise et de la perdrix rouge. Une espèce particulière à l'Anjou: la perdrix noire-rouge. - La per- 


\section{$-543$}

drix grise; pourquoi l'espèce tend à disparaître; causes multiples..............................

La Caille. Etymologie très-difficile à déterminer. Hypothèse de Huet, de Ménage, de M. Littré, de Papias; le nom grec. Caillette, le fou de Francois $1^{\mathrm{er}}$. Un désir de l'auteur. Usage que les Chinois font de la caille. Les combats de cailles chez les Romains. Récits extraordinaires de Pline et d'Aldrovande sur les migrations des cailles. Objection de l'auteur. Récit véridique d'un officier de marine. Le nom latin de la caille, mours domestiques de cet oiseau; son caractère turbulent et insociable...................... 501

La Glaréole à collier, hirondelle des prés, perdrix de mer. Classification difficile. L'oiseau pique-en-terre......... 523

Conclusion de l'auteur....................... 526 


\section{E R R A T A.}

Note, pag. 279, lisez: se relevant et retombant au lieu de: se relevait et retombait.

Page. 341, dans le vers de Purse, lises: pinsit an lian de prosit. 


1449 
SMITHSONIAN INSTITUTION LIBRARIES 